\title{
Product-Service System Design for Sustainability
}

\section{可持续产品服务系统设计}

卡洛・维佐里、辛迪・科塔拉、安穆利特・斯里尼瓦桑

$\mathrm{J} \cdot \mathrm{C} \cdot$ 迪尔、萨姆皮特 - 莫伊 $\cdot$ 福萨克勒、刘新、迪帕・萨迪斯
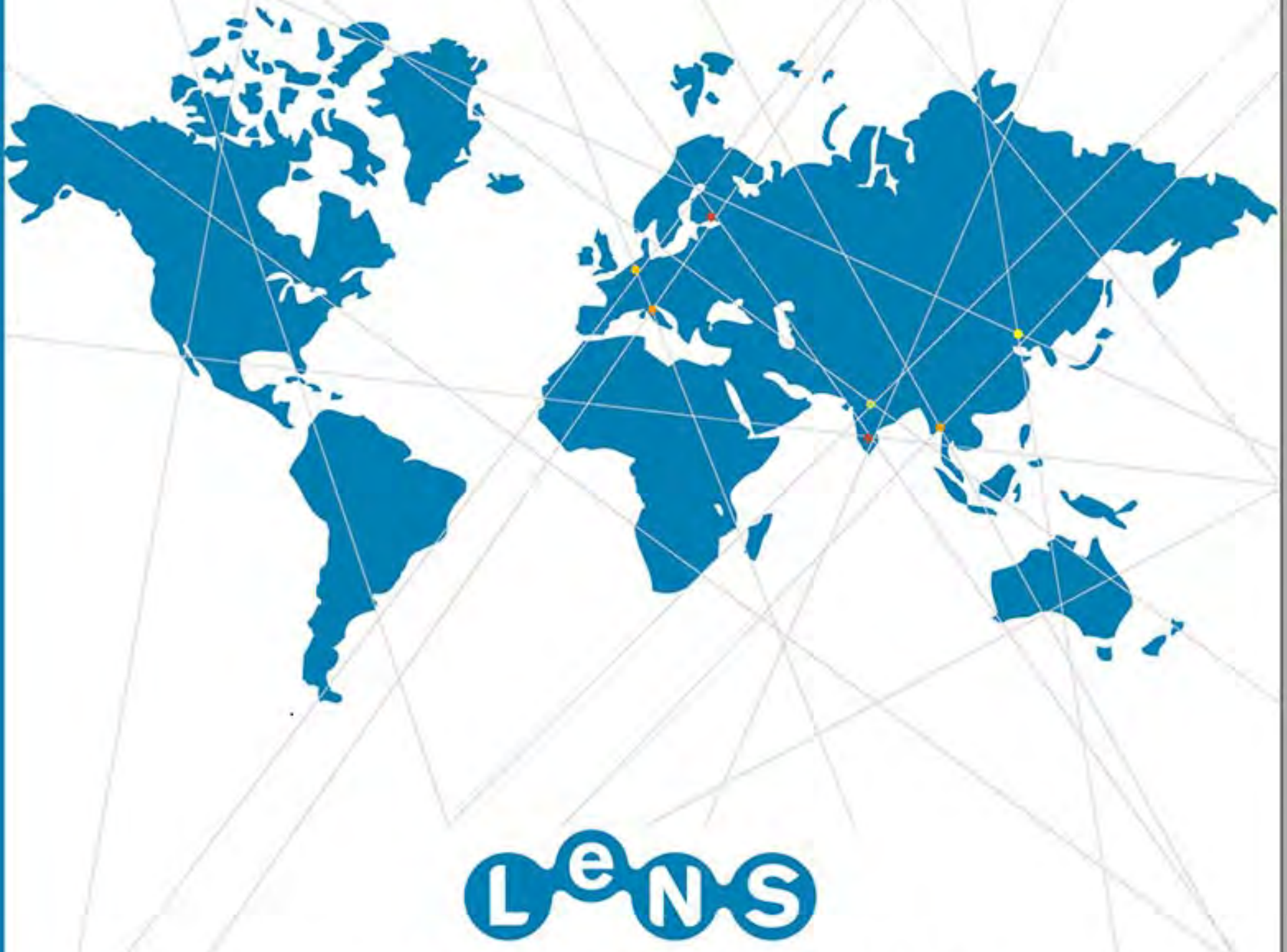

Learning Network on Sustainability 中国可持续设计学习网络 翻译 
可持续产品服务系统设计 


\section{可持续产品服务系统设计}

\section{卡洛 - 维佐里 (Carlo Vezzoli)，辛迪・科塔拉 (Cindy Kohtala) 、安穆利特 - 斯里尼瓦桑 (Amrit Srinivasan)}

$\mathrm{J} \cdot \mathrm{C} \cdot$ 迪尔 (J.C.Diehl) 、萨姆皮特 $\cdot$ 莫伊 · 福萨克勒 (Sompit Moi Fusakul)、刘新、迪帕·萨迪斯（Deepta Sateesh）

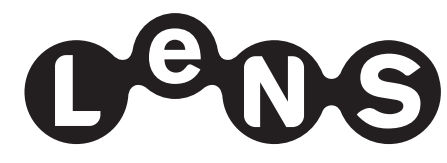

Learning Network on Sustainability

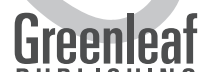

PUBLISHING 
科学委员会和编辑小组名单:

卡洛·维佐里 (Carlo Vezzoli) 、辛迪・科塔拉 (Cindy Kohtala)、安穆利特·斯里尼瓦桑 (Amrit Srinivasan)、J・C · 迪尔(J.C.Diehl)、萨姆皮特 - 莫伊 ·福萨克勒 (Sompit Moi Fusakul)、刘 新、迪帕·萨迪斯 (Deepta Sateesh)

Creative Commons: Attribution-NonCommercial-ShareAlike (CC BY-NC-SA)

\section{(c) (1) 89}

(C) 2014 Greenleaf Publishing Limited

Published by Greenleaf Publishing Limited

Aizlewood's Mill

Nursery Street

Sheffield S3 8GG

UK

www.greenleaf-publishing.com

Cover design by LaliAbril.com

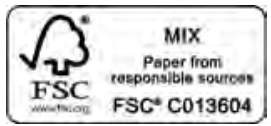

British Library Cataloguing in Publication Data:

A catalogue record for this book is available from the British Library.

ISBN-13: 978-1-906093-67-9 [hardback]

ISBN-13: 978-1-909493-69-8 [PDF ebook]

ISBN-13: 978-1-78353-079-3 [ePub ebook] 


\section{鸣谢:}

本书是LeNS项目（可持续性学习网络）所有作者和编辑们合作的结晶。本书主要 作者如下：卡洛 - 维佐里 ${ }^{1}$ (Carlo Vezzoli) 负责撰写引言和第一卷的1至4章, 主 要编辑人员包括辛迪 - 科塔拉 ${ }^{2}$ (Cindy Kohtala) 、安穆利特 - 斯里尼瓦桑 ${ }^{3}$ (Amrit Srinivasan)、萨姆皮特·莫伊 - 福萨克勒 ${ }^{4}$ (Sompit Moi Fusakul)、J C C 迪尔 (J.C.Diehl) 5 和刘新 6 。另外, 由刘新执笔第3.5.1章, 萨姆皮特·莫伊 - 福萨克勒 (Sompit Moi Fusakul) 负责第3.5.2章, 安穆利特 · 斯里尼瓦桑 (Amrit Srinivasan) 撰写第3.5.3章, 而第4.3.13章至4.3.15章则由玛丽莎·盖勒帕蒂1 (Marisa Galbiati), 玛丽安娜 · 辛希亚 1 (Mariana Ciancia) 和弗朗西斯卡 · 彼瑞达 ${ }^{1}$ (Francesca Piredda) 三位共同撰写。帕瑞恩纽治·安 · 斯瑞迪治 ${ }^{4}$ (Praoranuj Ann Siridej) 和 萨姆皮特·莫伊 $\cdot$ 福萨克勒4 (Sompit Moi Fusakul) 负责撰写第4.2.2章节。

在第二部分里, 每章的开始均列出了本章作者和特邀作者的姓名。我们向 参与第二部分写作的编辑: 卡洛·维佐里 ${ }^{1}$ (Carlo Vezzoli) 、辛迪·科塔拉 ${ }^{2}$

(Cindy Kohtala)、安穆利特·斯里尼瓦桑 3 (Amrit Srinivasan)、 J C C · 迪尔 5 (J.C.Diehl)、刘新 ${ }^{6}$ 、萨姆皮特·莫伊 · 福萨克勒 ${ }^{4}$ (Sompit Moi Fusakul)、迪 帕·萨迪斯 ${ }^{7}$ (Deepta Sateesh) 致以最诚挚的谢意, 借此机会向支持并帮助本书 出版的人士：法布里齐奥・ 山士恩8 (Fabrizio Ceschin)、拉迪卡·罗翰（Radhika Ralhan）和帕瑞恩纽治·安·斯瑞迪治4（Praoranuj Ann Siridej）表示感谢。

1 意大利米兰理工大学设计学院设计系

2 芬兰阿尔托大学艺术、设计与建筑学院设计系

3 印度德里理工学院

4 泰国先皇技术学院建筑学院设计系

5 荷兰代尔夫特理工大学工业设计学院

6 中国清华大学美术学院

7 印度斯瑞施蒂 (Srishti) 艺术设计与技术学院

8 英国布鲁奈尔大学工程与设计学院设计系 


\section{本书版权}

本书符合《知识共享许可协议》的规定; 尤其是《署名-一非商业性使用- - 相同 方式共享》的规定。

\section{(c) (1) $(\Theta \Theta$}

可以从LeNS项目（可持续性学习网络）网站www.lens.polimi.it免费下载本书的电子 版。

本书是LeNS项目（可持续性学习网络）研究成果之一。可持续性学习网络, 由亚洲 连接计划、欧洲援助合作办公室和欧盟委员会共同出资赞助，主要从事可持续产品 服务系统设计的创新性研究, 旨在将研究成果应用于世界各国的高等教育机构的课 程编制和教学推广中。

本书由 “联合国可持续发展教育十年” 项目赞助出版（2005-2014，可持续发展教育 十年项目）。

2002年12月, 联合国第57届大会通过了第254号决议，将2005年～2014年确定为“ 可持续发展教育十年”, 并指定联合国教科文组织 (UNESCO) 为该教育十年计划 的领导机构。“可持续发展教育十年” 项目的目标是：把可持续发展的原则、观念 和实践贯穿到学习和教育的各个方面，以解决 21 世纪人类面临的社会、经济、文化 和环境问题。在这十年中, 可持续发展教育能够帮助人们做好准备, 更好地迎接当 前和未来所面临的挑战; 使决策者尽职尽责, 致力于建设一个富有生命力的世界。 
因此，“联合国可持续发展十年教育计划” 对以下5种基础知识的学习提供支持, 以 提升素质教育水平并推进可持续发展：学会认知，学会做人，学会共同生活，学会 改变自己和社会。

(www.unesco.org/education/desd --- esddecade@unesco.org)

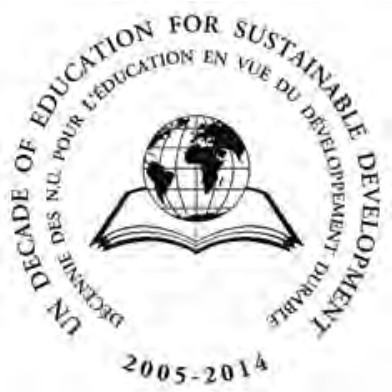




\section{目录}

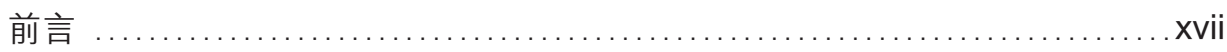

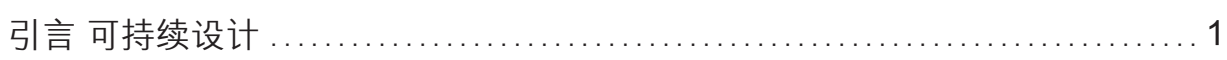

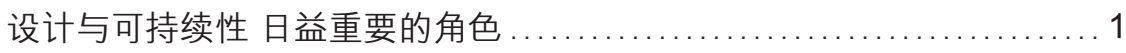

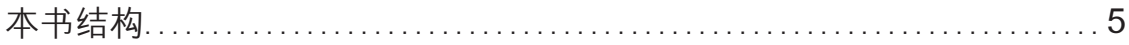

\section{第1卷 可持续产品服务系统设计的基本知识和专门技能 …........ 7}

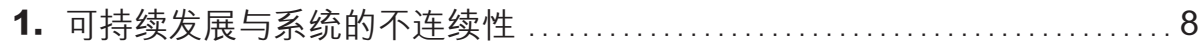

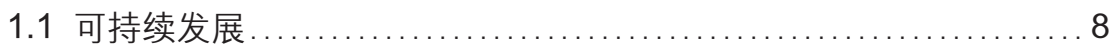

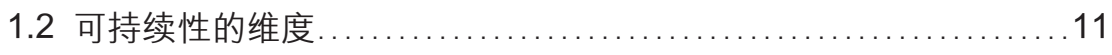

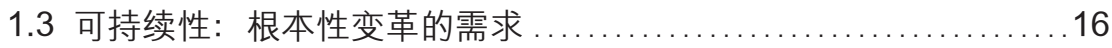

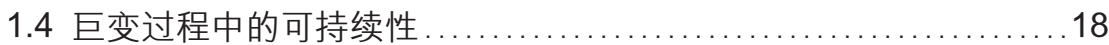

1.5 实现可持续发展的多元化路径 ............................... 19

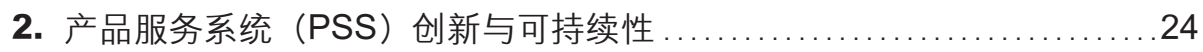

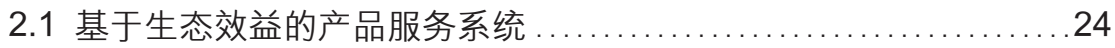

2.2 新兴经济体和低收入国家和地区的产品服务系统 .................36

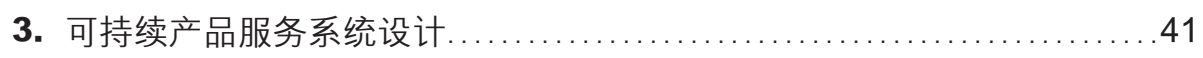

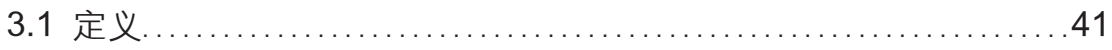

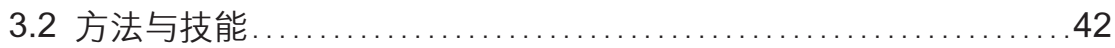


x 可持续产品服务系统设计

3.3 系统生态效益设计标准及范例 ............................. 45

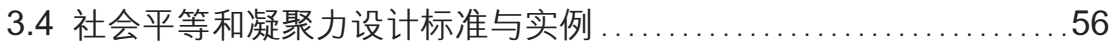

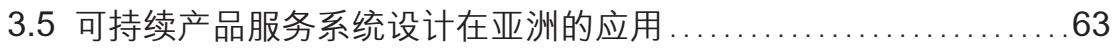

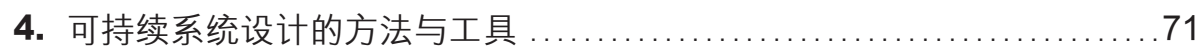

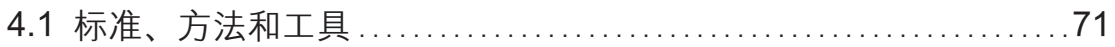

4.2 MSDS: 可持续系统设计的模块化方法 ........................73

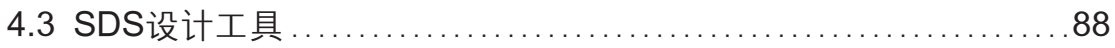

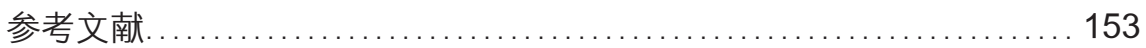

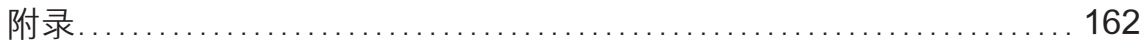

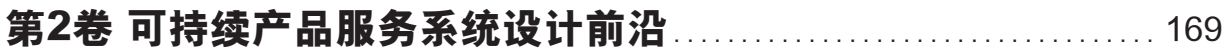

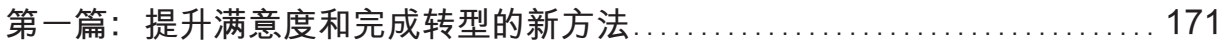

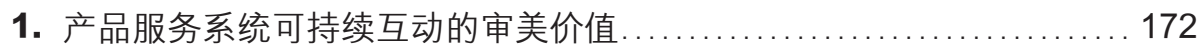

1.1 生态效益型产品服务系统的传播局限性 ....................... 172

1.2 生态效益型产品服务系统 (PSS)：

用户接受产品服务系统所面临的障碍 ............................. 173

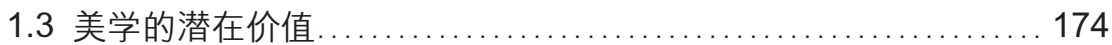

1.4 PSS的符号学、审美和生态效益方面的含义 ................ 179

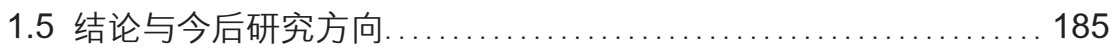

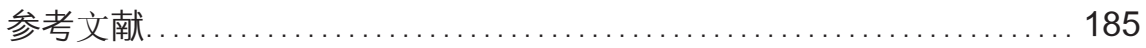

2. 以服装业为例分析可持续的消费者满意系统 $\ldots \ldots \ldots \ldots \ldots \ldots \ldots \ldots \ldots \ldots \ldots$

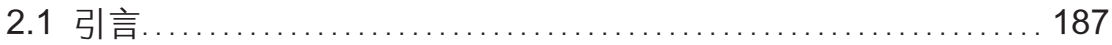

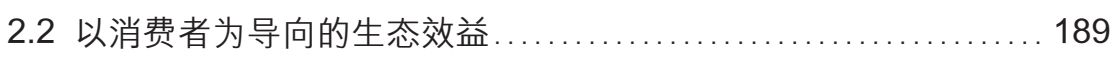

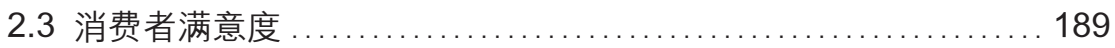

2.4 通过设计策略和产品服务系统来提高满意度 .................... 194

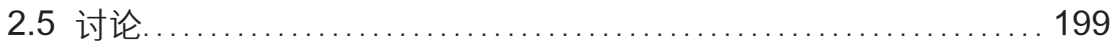

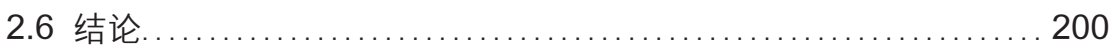

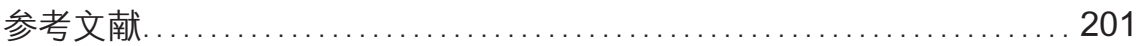




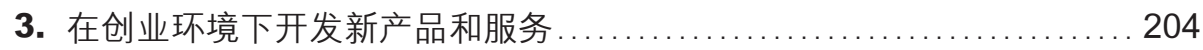

3.1 引言.................................................. 204

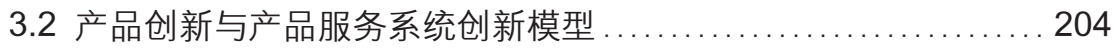

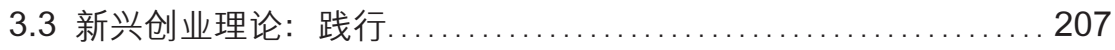

3.4 在践行过程中的产品服务系统 (PSS) 创新 ..................... 209

3.5 可持续舞蹈俱乐部 (SDC: Sustainable Dance Club )

(SDC) 案例 .......................................... 210

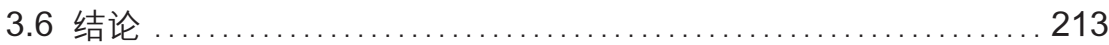

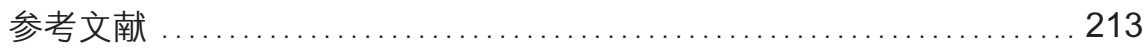

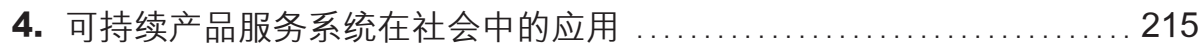

4.1 生态效益型产品服务系统在应用与推广中存在的问题 ........... 215

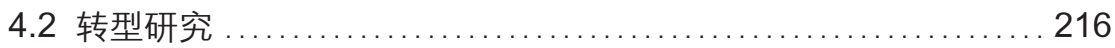

4.3 实施和推广生态效益型产品服务系统 (PSS) 的理论框架 .......2219

4.4 设计的含义：战略设计在可持续发展中扮演的全新角色 ..........22 224

4.5 设计与实施生态高效产品服务系统的新方法 .................... 230

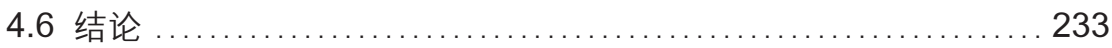

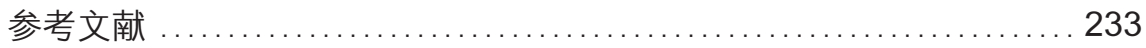

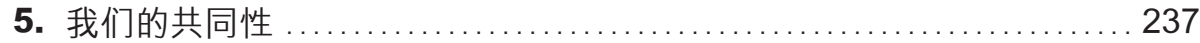

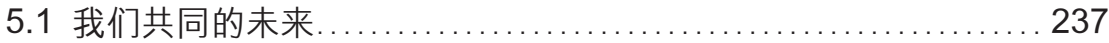

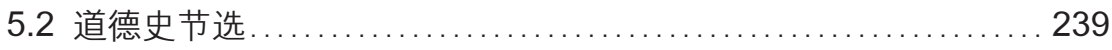

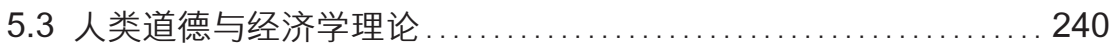

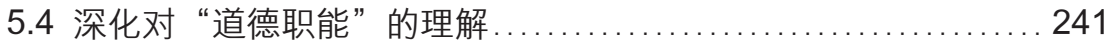

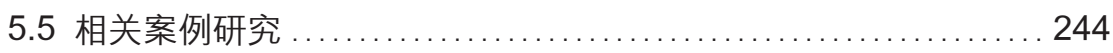

5.6 可持续设计 “道德职能” 的深层含义及其潜在作用 ..............2247

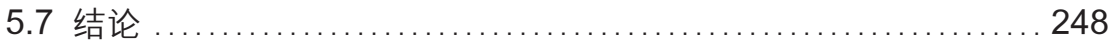

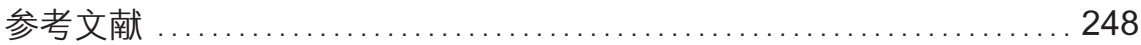


xii 可持续产品服务系统设计

第二篇：在低收入和新兴经济体背景下审视产品服务系统 (PSS)

的新视角

6. 垃圾处理行业中的产品服务系统：印度非正式经济的经验教训 ........ 252

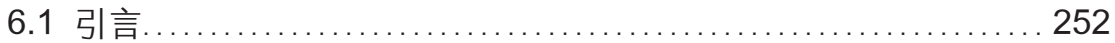

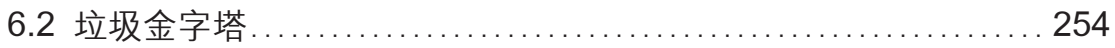

6.3 垃圾处理产品服务系统设计中的社会公平问题 ............... 255

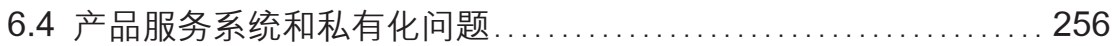

6.5 产品服务系统与垃圾回收和再利用中的政治经济学 ............257

6.6 产品服务系统的提升和垃圾处理的文化感知 ................. 257

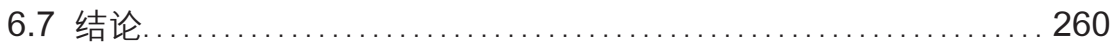

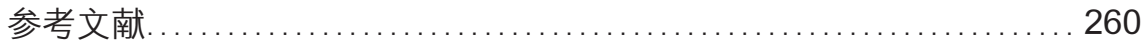

7. 贫困城市背景下非正式经济中的可持续产品服务系统 ................ 262

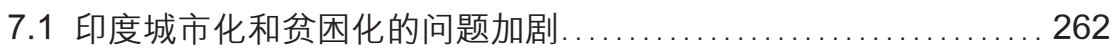

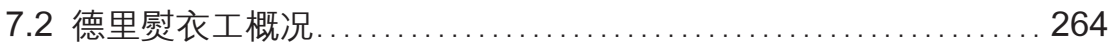

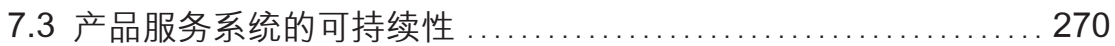

7.4 结论与未来产品服务系统的介入 ........................ 272

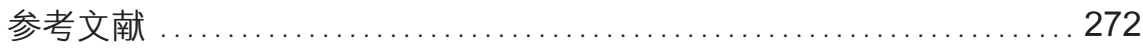

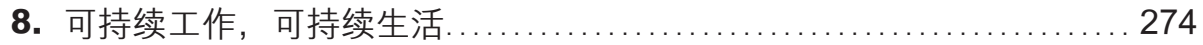

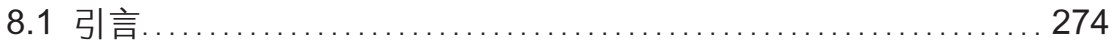

8.2 通过 “能力方法” (capabilities approach) 来了解人类需求 .......276

8.3 城市Spinning ....................................... 277

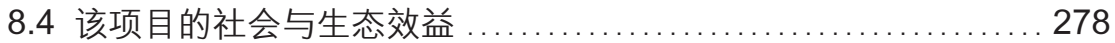

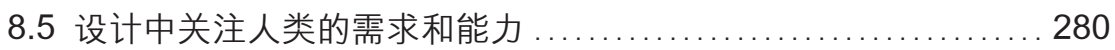

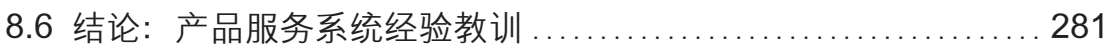

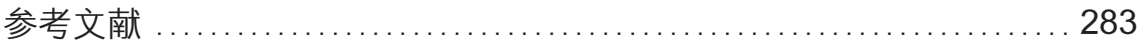




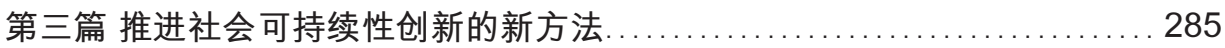

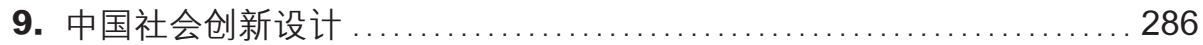

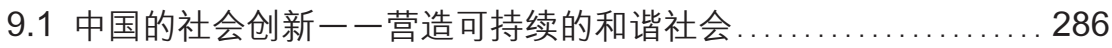

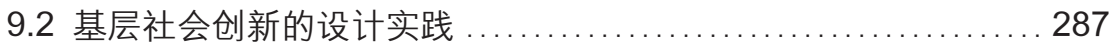

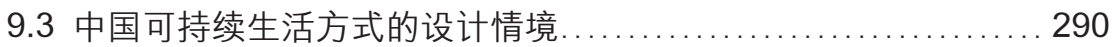

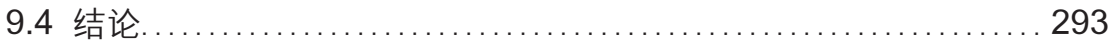

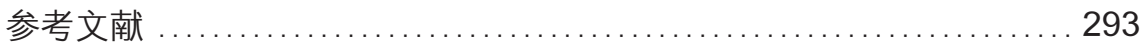

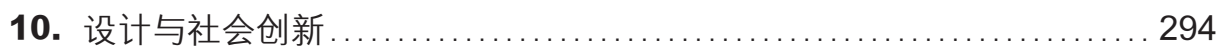

10.1 引言............................................... 294

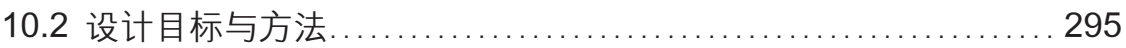

10.3 案例分析：传统社区中的社会创新举措 ......................297

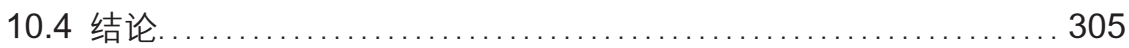

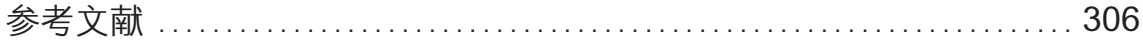

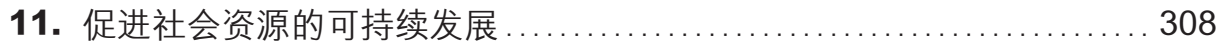

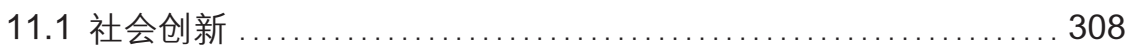

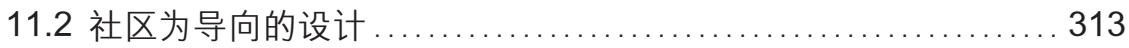

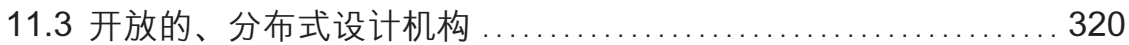

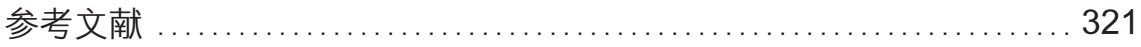

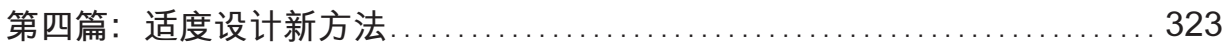

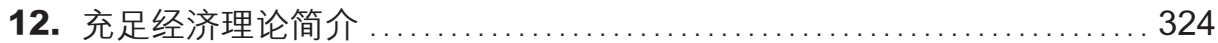

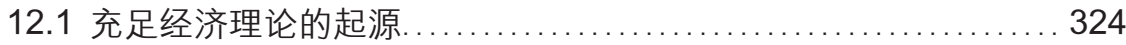

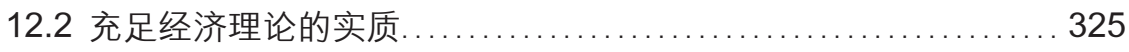

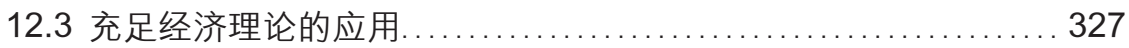

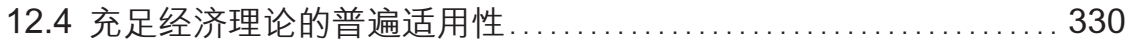

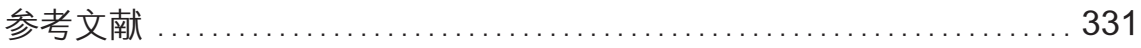


xiv 可持续产品服务系统设计

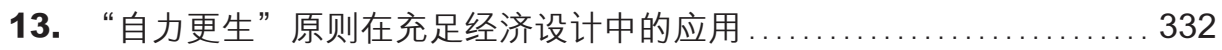

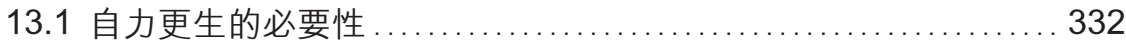

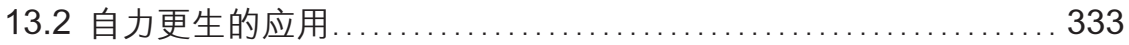

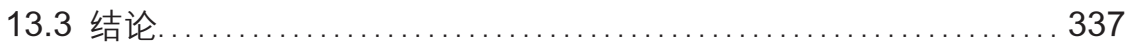

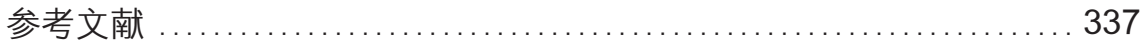

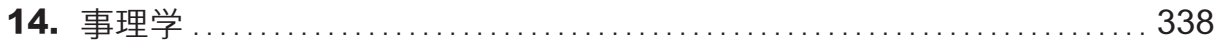

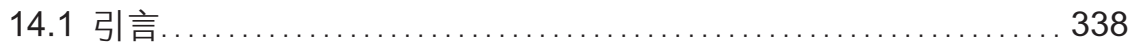

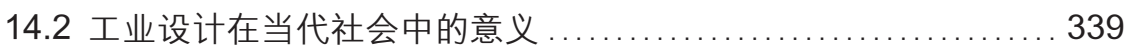

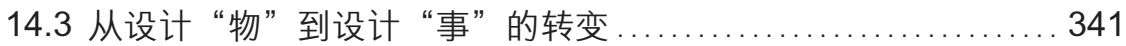

14.4 “设计事理学” 是知识经济时代设计的方法论 .................... 342

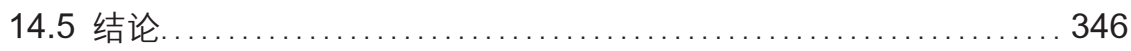

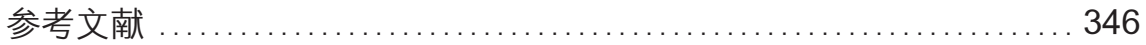

15. 中国传统的生态文明观与现代服务设计系统 ....................... 348

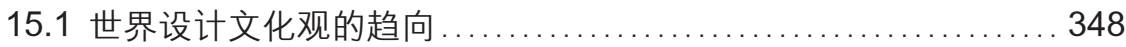

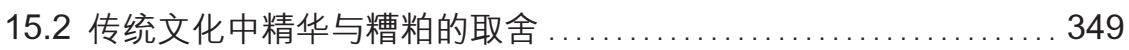

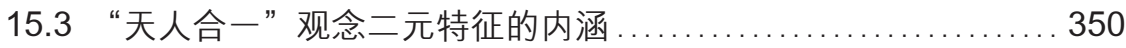

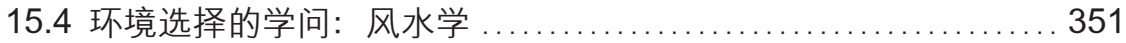

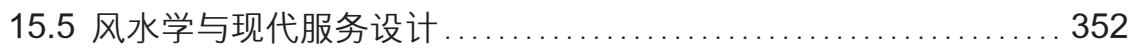

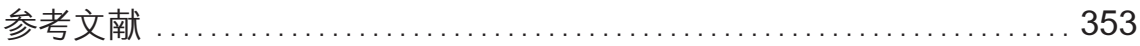

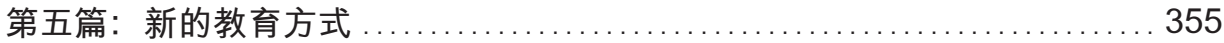

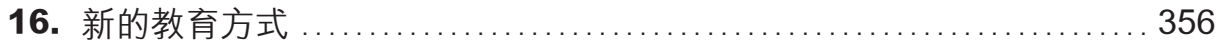

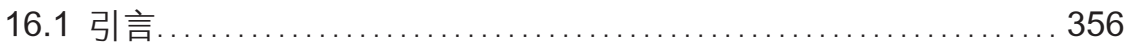

16.2 印度艺术与设计专业本科学生的认识论信念..................... 357

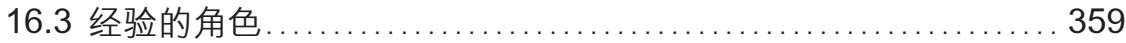

16.4 第一次教学法尝试：公共环境中的恐惧与性别 ..................360

16.5 第二步教学法尝试: 公共场所和教学法 ....................... 362

16.6 第三步教学法尝试：抗议美学 .................................... 364 


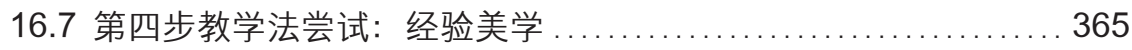

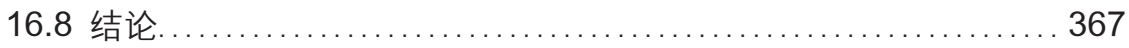

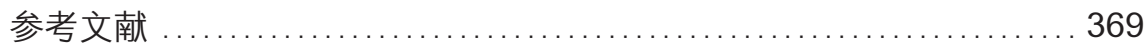

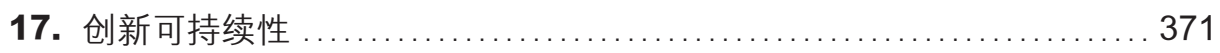

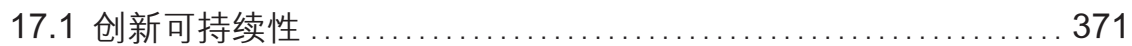

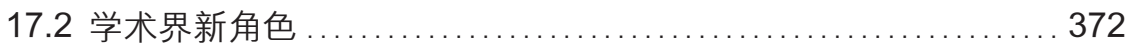

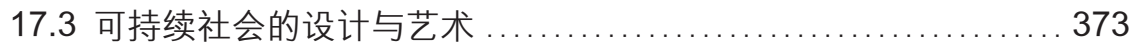

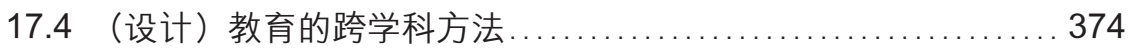

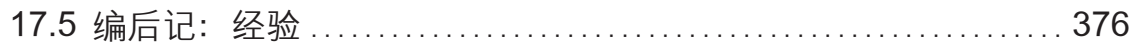

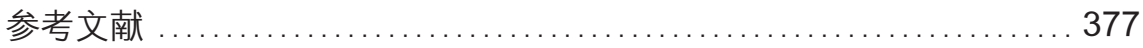

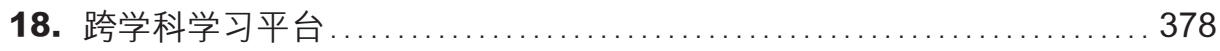

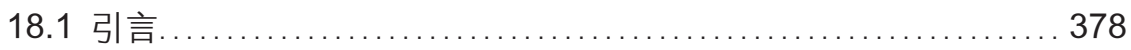

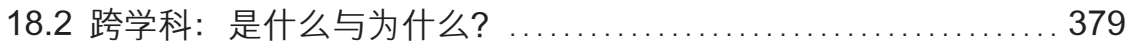

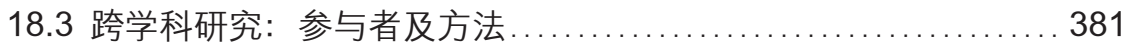

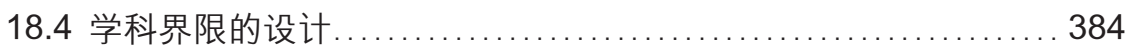

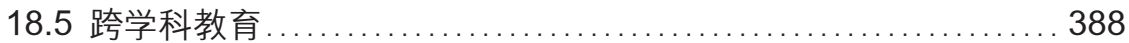

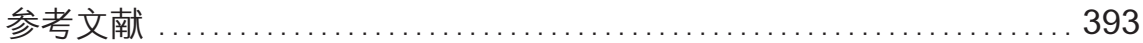

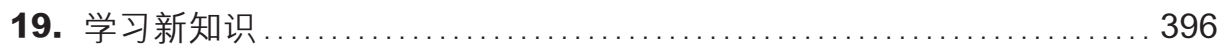

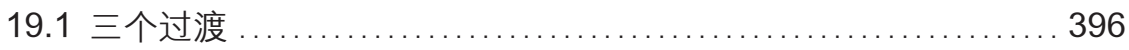

19.2 可持续设计（DfS）的兴起及在中国的发展 ...................... 397

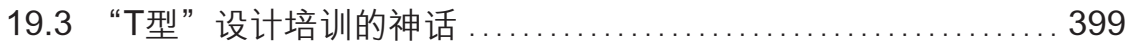

19.4 可持续设计与 “传统” 学科混淆的风险 ...................4 400

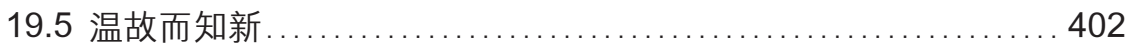

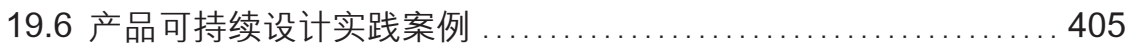

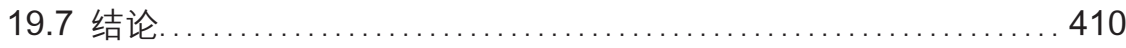

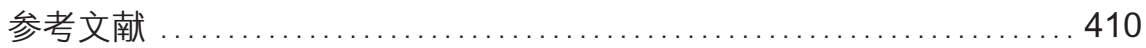


$x v i$ 可持续产品服务系统设计

20. 在可持续产品服务系统 (PSS) 设计过程中引入改进的生命 周期评估 (LCA)

20.1 引言. 412

20.2 生命周期评估与产品服务系统设计 413

20.3 理解产品服务系统 (PSS) 中的系统. 415

20.4 LeNS项目学生设计竞赛中的生命周期 417 20.5 产品服务系统 (PSS) 方法的意义 418 20.6 结论. 423

参考文献 423

术语对照表 425 


\section{前言}

拜拉维提斯 (Arturo Dell’ Acqua Bellavitis)

意大利米兰理工大学设计学院院长

\section{西尔维娅 (Silvia Piardi)}

米兰理工大学设计系主任

纵观过去几十年的设计文化与实践历史, 与可持续性相关的设计问题已经从个别产 品的设计演变成关于消费与生产的系统的设计, 从单纯的环境问题转化为包含社会 伦理、环境和经济各领域在内的综合性问题。

事实上, 设计在可持续发展中能够扮演十分重要的角色, 并可以成为解决方案 的一部分, 换言之, 设计能够为可持续发展提供动力。设计之所以能够扮演这样的 角色, 是因为它本身可以提高我们的生活质量: 通过对大多数设计师的设计动机进 行的深入调查, 我们可以在设计中发现伦理文化的因素, 尽管它们表现得并不明显。

同时, 设计能有效推动可持续发展的原因在于其扮演的重要的社会角色，从本 质上说，设计处理人类与人工制品及其功能之间的关系。也就是说，设计必须找到 问题的核心: 人类的生存方式正朝可持续的方向转变。

在前方我们还有很长的路要走, 我相信这本书在设计界的快速转型过程中将会 起到一定的推动作用, 并有助于我们更好地迎接新的挑战。 


\section{海伦蛁 (Helena Hyvönen)}

芬兰赫尔辛基阿尔托大学艺术与设计学院院长

\section{辛迪・科塔拉（Cindy Kohtala）}

LeNS项目团队 设计部

\section{缇娜 - 拉瑞拉（Tiina Laurila）}

创新性可持续发展学硕士课程主管

约翰・卡拉 (John Thackara) 曾提出“无论富国、穷国或处于两者之间的国家和 地区, 都是新兴经济体” 的观点。今天, “进步”与 “发展”的理念常常与现有的 文化习俗或者社会资本相冲突。在全球化步伐不断加快以及不确定性因素逐渐增加 的背景下, 这种理念是有用的, 甚至是必要的。因为任何国家和地区都无法确保其 未来在全球的地位、就业状况和资源不会发生变化, 甚至其食品安全也无法得到保 障; 我们建立的全球化网络迫使我们必须共同承担保护地球的责任。

以芬兰为例, 这个国家在摆脱了战争和落后的农业经济的阴影之后, 一举成 为一个拥有先进教育体系的国家。在这里, “设计推动者”们提出平等、合作的理 念, 并要求人们对大自然怀有深深的敬意。即便如此, 目前的芬兰仍然面临着与其 他北方国家相同的挑战：即如何应对就业机会的减少、全球经济形势的瞬息万变、 贫富差距的不断增大以及人口的大量流动。当我们进入后工业时代时, 我们应该如 何定义“进步”与 “成功” ? 或者更准确的说一一我们应该怎样做呢? 最重要的 是, 究竟该由谁来定义我们使用的这些概念呢?

这些复杂的全球及地区挑战使高等教育与研究成为社会可持续发展的核心推动 力量, 必须将环境、经济、社会文化等各种因素与教育有机地结合起来。

阿尔托大学应对这一挑战的具体举措是于2010年秋开设创新性可持续发展学 (CS) 国际硕士课程, 该课程在建筑、城市规划、景观规划、房地产、商业和设计 领域开展跨学科教学。创新性可持续发展学 (CS) 课程将学生们聚集到一起, 以 跨学科小组的形式提高他们对不同课程的理解并鼓励他们为社区、城市、工业和商 业环境的可持续发展设计新方案。在不久的将来, 越来越多的机构将把可持续发展 转型工作提升到战略高度; 因此, 这些组织将需要更多的全面掌握可持续发展技能 的专业人士作为它们的跨学科专家。在未来的职业能力要求中, 有创意的设计是关 键一一创造性解决问题的能力, 即以设计的手段来定义问题, 提供具体的创意方案 并进行实施。

基于这些原因, 我们认为, 这本书的出版是非常及时的, 因为单纯地依靠设计 学院的师生及研究人员, 仅在其小范围内, 用他们的学科专业语言就可持续设计系 统进行交流是不够的, 他们必须能够与其他学科的专家进行沟通。我们认识到, 作 为新兴经济体, 我们在这方面需要不断地进行学习, 共同分享成功经验, 汲取失败 教训。我们都需要识别、废除并重建那些不可持续的模式, 同时对于那些符合可持 续发展原则的模式，应加大支持和鼓励的力度。这是一个对全人类的“发展”进行 重新定义的过程。 


\section{辛格（S.N. Singh）}

印度新德里, 印度技术研究所工业研究与发展院 (IRD) 院长

我很荣幸能为 《可持续产品服务系统设计》这本书作序, 这是近期由欧盟委员会亚 洲连接计划中的LeNS项目全新推出的创新型教材。LeNS项目是欧共体授予印度德 里研究所的少数精选项目之一。自2007年冬开展以来, 该项目就一直由印度德里理 工学院 (IIT) 的工业研究与发展部 (IRD) 负责。我在此向意大利米兰理工大学, 维佐里 (Carlo Vezzoli) 教授, 以及印度德里理工学院 (IIT) 首席研究员斯里尼瓦 桑 (Amrit Srinivasan) 教授表示祝贺, 祝贺他们高瞻远瞩, 适时地推出了这本有 关可持续发展的教育与研究出版物。这本书有效地体现了在项目运行期间, 合作机 构、LeNS项目参与国-一意大利、荷兰、芬兰、印度、中国以及泰国之间的学术交 流精神。同时, 为推广LeNS项目, 本书提供免费的印刷版本和可下载的电子版本。

我向本书的编辑以及撰稿人致以真挚的祝贺, 他们在设计教育学这一领域为研 究者们开辟了一条崭新的道路, 为构建可持续发展的社会做出了巨大贡献。

\section{郑曙旸（Zheng Shuyang）}

中国清华大学美术学院院长

人类的延续和文化的进步一直以来都受到设计发展的影响。

可持续设计从本质上来讲是宏观的战略概念。“环境与发展”的均衡, 是国家 可持续发展战略的核心，也是“人与自然”之间取得平衡的基本标识。可持续设计 因此成为其中关键的制衡要素。

体现人类理想的生存环境的最佳状态是：生态系统的良性循环; 社会制度的文 明进步; 自然资源的合理配置; 生存空间的科学建设。可持续设计就是这种最佳状 态一一可持续发展总体战略下的实施系统。

在地球村的背景下, 要实现生态文明的可持续设计理想, 仅靠一个城市、一个 地区乃至一个国家, 已经不可能办到。寄希望于世界范围的合作与国际间的综合协 调, 这就是可持续设计的全球概念。

中国经济持续高速增长的势头、人口基数庞大并在不断膨胀的现实、自然资源 的大量消耗、区域发展不平衡等, 均对 21 世纪中国的环境与发展造成巨大的压力。 同时又对世界产生负面的影响。中国处在一个既不能走世界发达国家“先污染、后 治理”的老路, 又不能不把“发展”置于优先位置的“两难”境地之中。

面对可持续发展的全球性挑战和机遇，中国专业的设计者与设计教育者，肩负 着更大的责任。如何解决 “环境与发展” 的矛盾, 如何在二者之间寻求合理的均衡 点, 成为面向未来的严峻任务。可持续的产品服务系统设计因此成为走出这一困境 的重要途径。 


\section{萨姆皮特 - 莫伊 - 福萨克勒（Sompit Moi Fusakul）}

泰国先皇技术学院建筑学系, 建筑学硕士, 工业设计课程主任

在LeNS项目伊始，我们发现“产品服务系统 (PSS) ”非常具有挑战性, 然而, 我 们坚信，我们过去的艰苦努力将会取得有价值的回报：我们找到了一种更好的教育 方式来帮助年轻的设计师们适应这个环境日益恶化的世界。LeNS项目提供了探索产 品服务系统 (PSS) 与可持续设计 (DFS) , 以及与一直支持和鼓励我们的合作伙 伴们分享知识的机会。

我们还将另一主要议题加入其中, 以此作为产品服务系统的补充性研究：探讨 设计如何推动“充足经济 (Sufficiency Economy)” 的发展-一这是我们尊敬的泰 国国王普密蓬·阿杜德 (King Bhumibol Adulyadej) 提出的一个独特的哲学概念。 在探索产品服务系统与充足经济之间的联系的过程中，我们分析了两者之间的异同 点。随着我们研究的深入, 我们逐渐认识到, 产品服务系统的理念早已扎根于泰国文 化中, 只是人们不一定总是用“产品服务系统 (PSS) ”这一术语来表达这一概念。

其他可持续发展研究人员和专家的研究成果为我们对 “充足经济设计 (DSEP) ” 的诠释工作奠定了基础。本书不仅包括那些能够帮助设计教育工作者开设产品服务系 统课程的实用信息, 还包括有关充足经济设计 (DSEP) 为帮助人们获得更加自力更 生且平衡的生活方式而撰写的简短报告; 同时本书还提倡人与自然和社会和谐相处; 并要求在保存人类尊严以及文化价值观的前提下, 推进现代化进程, 以便追随全球 化的发展步伐。充足经济设计 (DSEP) 仍然处于发展的初始阶段, 因此整个探索过 程仍在 “进行中”。我们仍然处在探索过程中, 许多事情有待进行讨论与总结。即便 在LeNS项目完成之后, 有关充足经济设计 (DSEP) 方面的研究也必须继续进行下 去, 因为只有充分研究，才可以更好地实现全球的可持续发展。

例如：在烈日炎炎的夏天, 沙滩上的大多数人都选择在太阳伞下遮阳乘凉, 然 而他们真正需要的不是太阳伞, 而是伞下的阴凉。对于我们而言, 充足经济与可持 续发展正恰好能提供这片“阴凉”。尽管两者在本质上并不相同，它们却有着一个 相同的功能一一为世界上的人们提供更舒适的生活环境。这些“伞”的应用应该得 到推广和鼓励，这样全世界的人们将会生活的更美好。

\section{罕・布力扎特（Han Brezet）}

荷兰代尔夫特理工大学工业设计学院研究项目主管, 可持续性设计研究项目组组长

随着时间的推移, 设计已经逐步融入到可持续性问题的教学和实践中, 并在应对挑 战的过程中发挥着越来越大的作用。生态设计理念兴起于 20 世纪 90 年代, 旨在以环 保为视角对现有产品进行全新的设计, 通过将社会方面纳入其中直接催生可持续设 计方法的问世, 从而推动该领域进入一个全新的阶段。随后, 这些着眼于可持续设 计的方法超越了产品本身，并直接促进了更为激进方法的出现，如可持续产品服务 与可持续系统创新。

尽管更多影响深远的可持续性的相关研究成果相继出炉, 但我们发现, 这些方 法的来源和关注点都略显狭險：很大程度上, 这些方法都是按照西方的模式照搬过 
来的。从这个角度看, LeNS项目的独特之处在于它一开始便将欧亚的学者、教育家 和学生们召集在一起, 大家共同探索、讨论, 推出一部以可持续设计和可持续产品 服务系统为主题的教材。从而, 它在该领域催生了一个独特的知识库。另外, 该计 划与其他许多项目的不同之处在于, 它将集体研究的成果免费奉献, 由此全世界的 教育工作者们和学生们都可以通过互联网共享相关的知识、方法和实例, 为自己今 后的课程或项目的研究工作奠定一个良好的基础。我们认为, 现在年轻的设计师们 思想开放, 具有独特的批判性思维, 善于深入思考问题, 同时他们大多掌握多种学 科的相关技能，这些对将来社会的可持续发展都有着极大的推动作用。

这本书可谓是该领域的集成之作, 它全面概述了全球设计和可持续的最新进 展, 所涵盖的内容涉及欧亚两大洲, 从生态设计到可持续制度创新, 从对该领域学 术和教育方法的探讨延伸到对相关案例的分析。

我们同样希望本书也能对您有所启发!

\section{吉萨 - 纳拉亚南 (Geetha Narayanan)}

印度班加罗尔斯瑞施蒂 (Srishti) 艺术、设计与科技学院, 创始人兼董事

出于对环境问题的深切忧虑和对采取应对行动的勇气, 我为LeNS项目的出版物《可 持续产品服务系统设计》写下了这篇序。这本书的出版标志着这三年来, 各顶级设 计学院之间的合作教学和交流达到了顶峰, 也促成了2010年9月底由班加罗尔艺术设 计与科技学院举办的国际研讨会的成功召开。

忧虑, 是因为大自然对目前人类的发展方式提出了严肃的质疑, 并以自然灾害 的方式对人类提出了警告, 其规模之大前所未有, 始料末及。而人类受传统观念的 禁锢、政治和经济意识形态所限, 对此浑然不觉。人们习惯于采用先进的工程设计 概念构建很多大型基础设施，而对环境与可持续发展问题却漠不关心。

勇气，则是因为我们必须用信念和希望来面对日益增长的焦虑、应对挑战并武 装我们的设计师、工程师、社会科学家、教育家, 而最重要的是培养德才兼备的年 轻一代, 以满足当下及将来的需求, 并建立一种非歧视的新哲学。LeNS项目、研讨 会, 以及这部（通过利用新兴的跨学科知识）侧重于记录人类社会的可持续发展历 程、人类的物质与精神成果的作品, 都对该领域的发展作出了重要贡献。显然, 探 索产品服务系统设计的过程和实践, 及其 “演变”（如果可以这样说的话）的根由 是非常必要的, 而到目前为止, 西方的独有方式在这方面占据主导地位。但其彻底 转变必须建立在兼容并蓄的全球模式的基础上，因此，未来的创新应考虑到可持续 的理解、概念形成、设计和实施的全过程, 使我们所在的这个星球及其居民作为一 个 “整体”，而非 “部分” 受益。我们现在必须理解, 在大自然眼中人无分贵贱, 然而, 大自然对人类提出了严厉的警告, 人类追求 “能动设计 (enactive design)” 的过程应当是相互协作, 并能够促进发展的过程, 并按照有同情心、公正、公平的 原则, 满足所有人的需要。

本书对这一领域的总体情况进行了概述。 


\section{引言 可持续设计}

\section{设计与可持续性 日益重要的角色}

从历史上看, 尤其是从上个世纪 50 年代开始，人类应对环境恶化问题的方式从早期 的事后处理方式逐渐地转变为以预防为主的方式。这实际上意味着, 环境污染的研 究方向和处理方式, 已经从以前仅仅关注清除系统的污染转变成以减少污染源为主。 换句话说, 这种转变体现在以下几个方面:

- 污染之后进行干预（例如, 治理被污染的湖泊）

- 转变为在污染过程中进行干预（例如, 使用清洁技术避免污染湖泊）

- 再转变到对相关产品与服务的干预（例如, 设计新型的产品和服务, 避免相 关流程污染湖水)

- 最后转变到对消费模式进行调整 (例如, 可以改进消费模式中那些可能会污 染湖泊的产品流程, 以减少甚至杜绝污染的产生)

上述特征表明, 设计的作用随着时间的推移而日益明显。这主要是由于其角色发生 了下列变化:

- 从仅在事后采取治理和补救措施转移到以预防和杜绝为主的行动上来

- 从只关注产品的局部生命周期 (仅生产) 转移到着眼于产品整个生命周期

- 关注点更进一步深入到社会文化维度, 设计师应成为连接全球生产、消费以 及创新的社会/社区环境之间的“枢纽”

- 人类应该能够以一种可替代、可持续的方式生活, 而且这一方式应不断得到推 广 
以上述目标为框架, “可持续设计”作为一门学科已经建立, 从广义上, 该学科的 定义是: “以推进可持续发展理念为目的, 通过某种方式开展的设计实践、教育与 研究活动” 1。

随着时间的推移，很多研究人员开始注意到，“可持续设计”所涉及的 范围和领域正在不断扩大（卡尔松 (Karlsson) 和卢措普 (Luttrop) 2006; 罗基 (Rocchi) 2005; 维佐里 (Vezzoli) 和曼齐尼 (Manzini) 2008a; 莱恩

(Ryan) 2004；查特（Charter）和蒂什纳（Tischner）2001）。关注点已从环保资 源的选择扩展到产品生命周期或生态设计，再到产品服务系统的生态效益型设计， 最后到推进社会公平和凝聚力的设计。

上述情况可被理解为一个拓宽设计对象范围的过程。实现可持续性设计的定义 及其四种方法: 1 选择对环境影响较小的原材料; 2 设计对环境影响较小的产品; 3 设计具有生态效益的产品服务系统； 4 设计体现社会公平性和凝聚力的产品。 以上四种方法并不是按时间顺序进行排列的，各种方法之间也并未划定明确的界 限, 这是因为每个案例的具体情况有所不同。然而, 这四种方法有助于我们初步了 解可持续设计。本书将会对这些方法进行更进一步地阐述。

\section{选择低环境影响的资源}

众多理论家和学者一直以来始终坚持的一个基本标准是选择对环境影响较低的资源:

这里首先要研究的是一个关于有毒及有害物质处理的问题。除了能够胜任传统 的实用功能之外, 还要求设计师对相关领域有所涉猎, 并采用一般的预防原则。

另一个与环境影响问题密切相关的主题是垃圾处理, 尤其是垃圾回收、材料的 循环使用以及通过焚烧而获得蕴藏在垃圾内部的能量。随着时间的推移, 人们认识 到, 若要实现再循环式设计及二次使用式设计, 仅考虑材料的可回收性是远远不够 的, 还要对整个过程的经济和技术可行性进行评估。再循环设计和再使用设计及其 指标必须包括以下所有步骤: 采集, 运输, 拆卸, 最终清理, 鉴别以及生产二次原 材料, 并鉴别再次应用的机会。

一个焦点话题就是生物降解性。人们在环境质量问题方面存在很多误解。资源 材料能否在自然生态系统中得到降解对环境的影响至关重要。然而, 许多可降解材 料可能存在保质期过短的问题, 而更换和丢弃这些保质期过短的材料又将引发新一 轮产品生产和分配过程。

最后一点也非常重要, 就是使用可再生资源（不论是能源还是材料）问题，以 及对替代能源（如太阳能、风能、水利、氢能以及生物质发电等）的研究和开发, 并将它们纳入（能源消耗型）产品系统。资源的可再生性与资源的可回收速度和使

1 一些专家还针对 “可持续设计” 提出了更为严格的定义：如, 蒂什纳 (Tischner, 2010) 认为, “可持续设计” 方案应不仅有利于社会和我们身边的社区（对穷人和弱势群体也同样 适用），还可使（全球特别是当地）的自然环境和经济体制受益。 
用者的消耗速度紧密相关。更准确地说, 只有当自然资源的再生速度大于或等于人 类的消耗速度时，这种资源才叫做可再生资源。

\section{产品生命周期设计或生态设计}

从20世纪90年代开始, 人们越来越关注产品标准, 如低环境影响的产品设计 通常被称为产品生命周期设计、生态设计或环境设计（克雷恩 (Keoleian) 和 曼纳瑞 (Menerey) 1993; 布力扎特 (Brezet) 和赫梅尔 (Hemel) 1997; 曼 奇尼 (Manzini) 和维佐里 (Vezzoli) 1998; 蒂什纳 (Tischner) 2000; 赫梅 尔 (Hemel) 2001; 海斯基宁 (Heiskanen) 2002; 莱恩 (Ryan) 2003; 孙

(Sun) 2003; ISO 140062 2002; 内斯（Nes）克莱默 (Cramer) 2006)。那 些年, 环境问题主要归处于产品的生产、使用和废品处置过程, 而对这些过程的评 估已经变得越来越容易。目前已经开发出了新的产品环境影响（技术层面、地理层 面和生物层面的输入和输出）评估方法, 其中最易被人接受的还是生命周期评估 (LCA)。下面将介绍两种主要评估方法:

第一种: 生命周期评估方式一一包括从设计一件产品到设计这件产品的生命周 期各阶段之间的全部过程。例如, 从生产材料到制造产品、分配产品、使用产品, 最后到处置废品等一系列的活动。

第二种: 功能性方式-一从环境的观点出发得到的概念。例如, 为了设计并 评价一件产品的环境可持续性, 应以它的功能而非物理实体本身为出发点。众所周 知, 对特定产品进行环境评估, 包括设计, 也必须参考该产品的功能。设计应当更 加重视产品所能够提供的“服务效果/满意度” 而非产品本身。

\section{具有生态效益的产品服务系统设计}

在 20 世纪 90 年代末期, 人们对可持续性提出了更为严格的定义。在这个定义中, 可持续性产品的生产和消费模式发生了根本性的改变, 设计师不再仅仅关注产品本 身, 而逐渐将注意力转向具有生态效益的产品服务系统（斯坦赫 (Stahel) 1997; 霍克茨 (Hockerts) 1998; 歌德库 (Goedkoop) 等1999; 林赫斯特

(Lindhqvist) 2000; 库普 (Cooper) 和西恩 (Sian) 2000; 布力扎特 (Brezet) 等2001; 查特 (Charter) 和蒂什纳 (Tischner) 2001; 曼齐尼 (Manzini) 和 维佐里 (Vezzoli) 2001; 比玛 (Bijma) 2001; 扎林 (Zaring) 2001; 蒙特

(Mont) 2002; 联合国环境规划署（UNEP） 2002; 肖勒（Scholl）2006）。其 中, 联合国环境署（UNEP 2002）给出了如下定义：产品服务系统 (PSS) 是 “一 种将工作的重心由仅仅为设计和销售实体产品转移到能够满足用户特定需求的产品 与服务系统的创新型战略成果”。

在这种背景下，随着设计范围从针对单一产品的设计向满足用户特定需求和欲 望 (比如满意) 方面转变, 有些学者 (维佐里 (Vezzoli) 2003a) 认为, 设计理念 已从关注单纯的功能实现转变为以客户满意度为导向。

这种方式是本书的核心, 将在以下章节中进行详细阐述。 


\section{社会公平性和凝聚力的设计}

最后, 设计研究还对社会公平和凝聚力设计可能发挥的作用进行了讨论。

琳 (Margolin) 2002; 拉佐特 (Razeto) 2002; 曼西 (Mance) 2001; 曼齐尼 (Manzini) 耶由 (Jégou) 2003; 克鲁 (Crul) 2003; 瓜达奴齐 (Guadagnucci) 和伽万利 (Gavelli) 2004; 罗基 (Rocchi) 2005; 佩宁 (Penin) 2006; 蒂 什纳 (Tischner) 和维尔库基 (Verkuijl) 2006; 维佐里 (Vezzoli) 2003a; 梁 (Leong) 2006; 马埃斯 (Maase) 和多斯特 (Dorst) 2006; EMUDE 2006; 康 尼亚托（Carniatto）等 2006; 康尼亚托 (Carniatto) 和奇亚拉 (Chiara) 2006; 魏德玛（Weidema）2005; 克鲁 (Crul) 和迪尔 (Diehl) 2006; 桑托斯 (dos Santos）2008）。这种设计的潜在作用将直接体现在以下几个方面一一“使社会更 加公平; 保障基本的人权; 尊重文化多样性, 创造同等机会; 与各种形式的歧视作 斗争”（欧盟（EU）2006）。此外, 一些学者和研究人员强烈要求开展构建和谐社 会活动（设计的一个关键作用），其目标不再仅仅局限于公平和正义，而是鼓励人 们更友善, 更具同情心, 更能够设身处地地为他人着想（福萨克勒（Fusakul）2010; 里夫金 (Rifkin) 2010)。

我们观察到, 一些新的设计研究关注点已经开始往这方面转移, 尽管还是零 散的, 但已经开始尝试对一些问题进行界定并试图理解其中的含义。这是一个涉 及范围极广而且极复杂的问题, 因此, 很少有人研究其对设计的影响。对这个问 题进行研究的同时, 还遇到了来自道德方面的考验。一些学者 (克鲁 (Crul) 迪尔

(Diehl) 2006; 桑托斯（dos Santos）等 2009; 坎达查（Kandachar）2010) 认为, 在低收入的环境下, 可持续性产品设计需要引入更直接的技术支持; 例 如, 提议引入金字塔基础设计 (BoP) 。关于社会影响, 还有一些学者（魏德玛

(Weidema）2005）正在致力于将产品生命周期评估的范围由单纯的对环境影响评 估扩展到对社会影响的评估, 这将更接近产品的创新标准。

另一些学者（苏米特里 (Soumitri) 和维佐里 (Vezzoli) 2002; 坎达查

(Kandachar) 2010) 认为, 一个有发展前景的产品服务系统设计应该具有社会公 平和凝聚力的特征, 或者更通俗地说, 是一种可持续设计。此外, 还有人（福萨克 勒 (Fusakul) 和斯瑞迪治 (Siridej) 2010) 2 进一步提出, 将充足经济哲学融入 到产品服务设计当中，使其在技术、社会文化、组织和基础设施方面给人们的生活 和工作提供支持。社会公平性和凝聚力的产品服务系统设计将在以下章节进行扩展 讨论。

回顾那些在消费领域为设计文化做出理论贡献的学者, 我们发现, 很早就有人 在这方面进行了探索 ${ }^{3}$, 如托马斯 · 马尔多纳多 (Tomas Maldonado) 所倡导的新 “设计希望”（马尔多纳多 (Maldonado) 1970)，早在20世纪70年代初期, 他就 认识到设计师应当肩负起社会责任。维克多 - 帕帕内克 (Victor Papanek) 在 “消费

2 参看第1部分第4章。

3 早在 20 世纪60年代末, 意大利设计界就曾对当时的消费模式提出过批判, 设计文化界的几 位领军人物曾为新型的消费模式做过代言人。尽管方式不同, 也并未特别提及消费模式对 环境的影响, 但当时的做法对当今的设计理念具有借鉴意义。 
的作用” 方面表达了相似的观点：“设计可以也必须成为年轻人参与、改变社会的 一种手段”（帕帕内克 (Papanek) 1971)。这些理念在 20 世纪 80 年代末期, 在 可持续发展概念被引进之前就已经出现了。

\section{可持续设计：现状}

为了全面掌握可持续设计现状, 我们可以从两个维度对上述四个方面进行考量。 学科整合水平（来自设计研究的成果）; 其次, 设计教育与实践中的水平和传播 情况 ${ }^{4}$ 。学科整合水平 (来自设计研究的成果); 其次, 设计教育与实践的水平和传 播情况。最新研究表明, 至今尚未对可持续设计的教学与研究进行全面的整合与推 广, 或者整合与推广的程度很低, 而我们希望能够在更高的水平上对设计教学与实 践进行整合与推广。

在工业化经济背景下, 尤其以欧洲国家为代表, 选择对环境影响低的材料/能源 及产品的生命周期设计 (LCD) 或生态设计已经处于一个很高的整合水平（维佐里

(Vezzoli) 和曼齐尼 (Manzini) 2008a), 而其在向设计教育与实践活动的渗透方 面并没有达到相应的高度。

目前, 很少有设计研究者对社会公平和凝聚力开展前瞻性研究。这是一个新的 研究前沿, 在理论上很难找到可供参考的资料; 在实际操作上, 几乎很少有现成的 方法和工具 5 。同时, 这方面的课程也很少。

让我们看一下新兴国家或地区的情况, 它们在可持续性景观设计的研究和教育 方面有很大的区别: 桑托斯 (dos Santos 2008) 认为, 在巴西, 产品设计在社会道 德层面的可持续性比在环境方面的可持续性更早引起人们的关注。另一方面, 在泰 国, 虽然生命周期设计 (Life Cycle Design) /生态设计 (Eco-Design) 教学在课程 设置中有较长的历史, 但在高等教育机构中, 利用可持续充足经济设计和社会企业 设计的方法和工具的相关课程是最近才设立的。这表明, 在泰国, 社会公平和社会 凝聚力以及充足经济学理论已成社会关注的焦点。可持续设计研究由此以独特的方 式获得了提升并实现了拓展, 它强调与适当的生活方式相配套的设计, 培养公共意 识, 或通过公众的消费选择或消费活动来实现社会公平并增强社会凝聚力。

一些学者认为, 工业化经济体与新兴低收入经济体背景下的可持续设计研究存 在巨大的差异, 这是由各自的工业需求和不同的创新环境造成的。尤其是在工业化 经济最不发达的地区, 其经济和劳工市场主要是由中小型企业 (MSMEs) 组成, 公 司的产品开发过程通常都很不规范, 只是根据实际经验或参照市场现有的类似产品 进行开发。其员工的受教育水平较低, 其运营部门的技术含量较低, 如, 食品加工 或金属加工等。因此, 工业化经济体与低收入或新兴经济体的可持续设计实践与研 究的动力是完全不同的。例如, 在欧洲, 外部动力如法规、消费者、供应商需求占 据主导地位, 而在新兴经济体背景下, 情况却有所不同。在工业化程度较低的经济

4 值得注意的是, 联合国已经启动了联合国可持续发展教育十年规划(2005-2014), 在融合 可持续发展的原则、价值观和实践的范围内, 发展教育与学习的各个方面。这意味着每个 开设设计专业的高校有责任设置可持续设计课程。

5 参看第 1 部分第 4 章。 
体中, 可持续设计的动力主要来自内部的驱动, 如成本效益、竞争力和新市场（克 鲁 (Crul) 和迪尔 (Diehl) 2008, 2006)。

在本部分, 为了促进这种设计方法在工业化国家、新兴国家和低收入国家的传 播, 我们将关注那些具有环保、社会道德和经济可持续特性的产品服务系统的设计。

\section{本书结构}

本书的范围是介绍并阐述可持续产品服务系统设计的理论及实践。

本书分为两卷:

第一卷是基础课程, 主要介绍了可持续性产品服务系统设计的基本知识和专门 技能。这部分主要为满足本科生 (水平) 的学习需要而设置。

第二卷是高级课程, 主要介绍可持续性产品服务系统的最新前沿设计。这部分 主要为满足研究生 (水平) 的学习需要而设置。

第一卷的结构如下:

- 第一章介绍了可持续发展的概念框架、含义及其影响：即, 根本性变革的需 要

- 第二章介绍了产品服务系统 (PSS) 创新的概念: 解释产品服务系统创新为 什么在可持续性方面具有长远的发展前景: 例如, 在不降低用户满意度的前 提下, 产品服务系统 (PSS) 可以大大降低当前资源的消耗量。创新的性质 和特点, 如何区分不同类型的产品服务系统 (PSS), 及其相关的利益、驱 动力和障碍。可持续性产品服务系统创新的例子将在以后章节进行阐述

- 第三章将阐述可持续性产品服务系统 (PSS) 设计的作用、方法、技术和标 准

- 第四章将会展示产品服务系统 (PSS) 可持续性设计的方法及所使用的相关 工具, 并在LeNS项目中进行检验。

本书第二卷展示了关于产品服务系统 (PSS) 可持续设计最具发展前景的研究 方向和假设。它是由主题部分及其相关章节组成的。

- 保证满意度的新方式, 促进其向新的方式转变

- 低收入和新兴经济体背景下产品服务系统 (PSS) 的新视角

- 影响社会创新的可持续性新方法

- 适度设计新方案

- 教育新方案

本书的补充阅读材料包括：学习教育资源（如幻灯片、录像教学片等），以及免 费的开源性可用设计工具, LeNS 项目网站上具有公共版权的材料 (www.lens.polimi. it)。 


\section{第1卷: 可持续产品服务系统设计的 基本知识和 专门技能}




\section{1 \\ 可持续发展与系统的不连续性}

\section{1 可持续发展}

最近几十年, 可持续发展的理念已经登上国际政治舞台。这个术语是指在全球和地 区范围内社会和经济发展的系统条件。

1. 在环境承载力的限度内 ${ }^{1}$, 能够承受人类活动所造成的影响, 而不会造成环境 不可逆转的恶化。

2. 不牺牲子孙后代赖以生存的资源, 即保障人类后代的生存方式和自然资本 ${ }^{2}$ 。

3. 在保障每个人的生存环境和生存空间的前提下, 对资源重新进行平均分配 3 , 例如, 同等获取地球自然资源的机会。

让我们考察一下这些概念是如何产生并进行传播的。

生产消费系统影响生态平衡的环境问题最早是上世纪60年代后期在工业化不断 加速和扩展的背景下提出来的, 而关于这些问题的科学论著最早在上世纪 70 年代开 始出版。工业发展导致生态环境的退化和自然资源的枯竭逐渐成为国际上研究和争 论的焦点问题。由于地球上的自然资源十分有限, 技术和生产力的失控发展以及地 球人口的不断增加, 导致自然环境和自然资源对人类的的制约日益明显。

1 承受能力是生态系统所具备的特殊能力, 用来克服某些干扰, 防止其本身不可逆转地丧失 其保持均衡的条件。这个概念放之四海而皆准, 提出人类活动的存在已使地球生态圈的承 载力逼近极限, 倘若突破了这一界限, 出现的当是不可逆转的恶化现象。

2 自然资本是非可再生资源和可再生资源环境承载力的总和。但它同时也可用来指自然多样 性, 地球上生物物种的数量。

3 环境空间是指能够以可持续方式开发利用的能源、土地和主要非可再生资源量。它指的 是, 在环境承载范围内, 适宜世界各地的人们生活、生产和消费的环境。 
上世纪80年代, 有关环境问题的国际争论日益广泛、愈加激烈。来自公共與论 的压力促使公共机构制定了一系列生态标准和政策来监督生产活动, 并制定了“污 染者付费” 的原则。联合国环境规划署和其他机构提出了“清洁生产”的概念，这 一概念被定义为 “对工业过程和产品进行持续不断的重新设计, 以防止人类造成环 境污染和资源浪费。

1987年, 联合国世界环境与发展委员会发起了一项重要的研究, 旨在为人类的 未来制定指标。该报告的标题为 “我们共同的未来” , 并首次对可持续发展进行了 定义, “既满足当代人的需求, 又不会对后代人满足其自身需求构成危害”。

上世纪90年代, 环境问题进入了成熟期。对地球的关爱：1991年, 世界自然保 护同盟（IUCN）、联合国环境规划署（UNEP）和世界野生生物基金会（WWF） 共同发表了《保护地球- - 可持续生存战略》 (Caring for the Earth: A Strategy for Sustainable Living）, 将可持续发展定义为：“在不超出生态系统承受能力的情况 下, 改善人类的生活品质”。该报告强调了既改善人类生活水平又保护地球自然资 源再生能力的可能性4。在同时考虑了上述两种定义后, 可持续发展被视为是一种可 以使人类和生态系统均受益的做法。

那段时期内发生的另一项历史性事件就是1992年在里约热内卢举行的联合国环 境与发展大会 (UNCED) 。此次会议与其他一些举措不断地对可持续发展这一概念 进行整合, 然后将其纳入国际组织的所有文件之中, 作为对社会与生产发展进行重 新定位的模板。自1994年以来, 可持续发展与环境可持续性已经在欧洲委员会第五 届环境行动计划中形成了基本标准。

从21世纪开始（即约翰内斯堡会议后, 里约热内卢大会十年之后）, 在生产一 消费领域, 公众的参与意识与积极性已经有了很大提高。2000年5月, 联合国环境规 划署 (UNEP) 设立了可持续消费部门, 这一举措尤为重要。该部门认为 “尽管过去 十年期间工业和企业取得了明显的进步，但消费能力明显超过自然界的资源承受力 和处理废弃物的能力，且这一问题变得日益严峻”（Geyer-Allely 2002）。

2006年6月, 欧洲理事会对成员国不断发展壮大的欧盟制定了一项雄心勃勃的综 合可持续发展战略（SDS）5。该战略是以2001年的“哥特堡战略”为基础，同时它 也是在2004年开展的广泛调查成果的基础上制定的。为应对可持续发展的挑战, 新 的欧盟可持续发展战略（EU SDS）是为有效实现其承诺而制定的一项总体战略。该 战略认识到, 必须逐步改变现有的不可持续的消费与生产模式, 并建立一种更具综 合性的政策指令; 同时再次肯定在全球范围内加强团结的必要性, 并意识到加强与 欧盟以外的合作伙伴之间工作的重要性, 包括那些对全球可持续发展有着重要影响 的高速发展的国家。

根据《里斯本条约》（Lisbon Treaty），2009年11月，欧洲理事会确定“可持 续发展仍是欧盟的根本目标”。欧盟主席在2009年对欧盟可持续发展战略所做的评 论中指出, 该战略将继续成为欧盟的长期战略, 并为所有欧盟国家的政策和战略提 供总体的政策框架。各国应当紧急行动起来, 扭转那些不可持续的发展局面 6 。

4 参见http://gcmd.nasa.gov/records/GCMD_IUCN_CARING.html.

5 欧盟, 可持续发展新战略, 欧盟委员会第10117/06号决议, 布鲁塞尔, 2006

6 参见http://ec.europa.eu/environment/eussd. 
除了欧盟可持续发展战略, 亚洲国家也开始制定各种相关战略, 以期实现与 自然的和谐共处。例如, 由泰国国王普密蓬·阿杜德陛下主导的许多皇家事业均根 据 “充足经济” 的理论原理, 关注自然资源的可再生性, 强调保存文化遗产、优 化人类发展环境, 并改善人们生活的重要性。2006年5月, 联合国秘书长安南向普 密蓬国王颁发了联合国开发计划署 (UNDP) “人类发展终身成就奖” (Human Development Lifetime Achievement Award），以表彰他登基60年来为改善泰国人民 生活所做出的贡献。

从全球来看, 联合国已经将总体政策框架分解成地区和国家议程。这个项目本 身就是《21世纪议程》的一个案例（《21世纪地方议程》在当地制定）, 还有一个 案例就是 “可持续性消费与生产 (SCP) ”。联合国环境规划署 (UNEP) 与联合国 经济社会事务部 (UNDESA) 联合发起的 “马哈喀什进程” (Marrakech Process) 促进并支持地区和国家的各种举措, 以推动向可持续消费与生产 (SCP) 模式转 变。其中一项举措就是建立国家圆桌会议交流机制, 在国家和地区范围内进行协 商, 同时, 还成立任务小组, 该小组负责 “在地区和国家层面实施具体项目和计 划, 并负责开发完善SCP工具和方法”。

这些举措带来的成果是出台了一项有关可持续消费与生产 (SCP) 10年项目框 架草案, 该草案在2011年第19届联合国可持续发展会议上交由各成员国讨论。

联合国的这项议程旨在提醒各成员国, 应认识到每个国家的经济和社会体系 的多样性, 尤其要考虑工业化、新兴经济体和低收入国家各自产生的环境影响的差 异, 同时要认识到社会融合的迫切需要及其相关基本需求。可持续发展和可持续消 费与生产 (SCP) 已经成为欧盟指令和政策制定过程中所必须考虑的重要参数。 必须强调的是, 向可持续发展转变对新兴和低收入国家而言, 应当是一个机遇而不 是一个负担。这就要求, 新兴经济体在向可持续消费和生产模式的转变过程中, 应 当采取跨越式发展的模式, 而不应重蹈西方国家的覆辙; 对低收入国家来说, 制 定专门的解决方案是可持续发展的基础（塔克（Tukker），斯塔（Stø）和维佐里

(Vezzoli) 2008a）。而总的指导方针对于我们理解自己在全局中的位置十分重 要, 只有当这些指导方针落实到具体的地区或国家的行动时, 我们才能够真正认识 到其具有的潜力和所面临的困难。

从教育层面上来说, 我们要重点指出的是, 联合国教科文组织 (UNESCO) 已 经启动《联合国可持续发展十年教育规划》 (UN DESD 2005年-2014年) 7。十年教 育规划的目标是将可持续发展所蕴含的价值观融入教学的各个方面, 以改变人们的 行为方式, 建设一个更有活力的公平社会。在这十年期间, 可持续发展教育将有助 于公民更好地面对现在和未来的挑战, 并能够帮助决策者在创造一个更有活力世界 的过程中表现得更具责任感。

7 参见www.unesco.org/education/desd. 


\section{2 可持续性的维度}

为了更好地了解可持续性及其含义, 通常的做法就是用三维坐标的方式加以说明, 三个坐标分别代表环境（地球）、社会道德层面（人类）和经济层面（利益）:

- 环境层面 (地球) : 在生物圈一一陆界的 “恢复能力” 范围内, 也就是说, 地球能够吸收人类的各种对环境的负面影响而不会引起任何不可逆的退化现 象, 如全球变暖、臭氧层损耗、海水酸化、水体富营养化等

- 社会道德层面 (人) : 我们的后代有能力满足他们自己的需求, 实现社会公 平并增强社会凝聚力, 而问题的关键是在坚持人人享有获取资源的权利的基 础上, 平等地对资源进行再分配

- 经济层面（利益）：在规范性的市场上执行经济可行性解决方案

这三个方面均有着各自明显而典型的特征，下面我们将逐一介绍这些特征。

\subsection{1 环境层面 (地球)}

在20世纪60年代, 工业国家的消费与生产系统迅猛发展, 但是很快又意识到这种快 速发展所带来的并非只有好处。

在那些年中北美发生了五大湖污染事件; 20世纪50年代末期伦敦的冬季烟雾污 染导致数千人死亡; 油轮货舱清洗物倒入海洋引起生态灾难等。

1972年发表的《增长的极限》一书, 首次用计算机模型对不断发展的生产与消 费系统对环境的影响进行了研究, 第一次对全球生态系统面临崩溃的可能性进行了 科学的预测。因此, 人们在那些年开始对环境极限（不可逆的有害影响）进行了探 索。直到今天我们仍然面临这些危害。城市中的悬浮微粒物质 (SPM) 引起的烟雾 每年危害着成千上万的人; 臭氧层消耗造成日光浴越来越危险; 而全球变暖使得气 候现象越来越恶劣, 受害者人数与日俱增。

如果我们考察这些环境影响的准确含义, 我们发现每个环境影响都建立在自然/ 环境与生产和消费系统之间的交换物质的基础之上 8 。

这些影响主要表现在以下两个方面:

- 输入, 即从环境中获取物质。

- 输出, 即向环境中排放物质。

那么有哪些影响涉及环境需求呢?

在输入（获取资源）方面, 最有害的影响就是资源的枯竭, 所造成的社会和经 济后果就是人类后代赖以生存的资源严重匮乏。

8 当然, 就破坏程度来说, 各类影响也并非都具有同样的危害。向环境中排放1公斤水, 与同 样排放1公斤高浓度石棉的影响显然有着显著的差异。 
12 可持续产品服务系统设计

与此相关的是改变生态系统平衡问题。例如, 建筑（各种类型的人工制品）或 供暖行业的木材需求可能导致滥砍滥伐, 这使得土壤随时间推移愈来愈容易受到侵 蚀, 并已经导致了许多物种灭绝。

最后, 还存在一些与获取过程有关的有害影响, 如开采和运输过程中油的泄

漏。这些问题将在下面与输出方面的问题一起进行进一步讨论。

在输出（排放资源）方面, 主要环境影响及其产生的效应列表如下。

\section{表1.1：环境效应的主要影响}

\begin{tabular}{|c|c|}
\hline 环境影响 & 环境效应 \\
\hline 全球变暖（温室效应） & $\begin{array}{l}\text { 极地冰层融化、海平面上升、淹没低地 } \\
\text { 土地沙漠化 } \\
\text { 病原体迁移 }\end{array}$ \\
\hline 臭氧层消耗 & $\begin{array}{l}\text { 破坏动植物 } \\
\text { 患皮肤肿瘤的风险升高 } \\
\text { 免疫系统功能降低 }\end{array}$ \\
\hline 富营养化 & $\begin{array}{l}\text { 氧气耗竭造成水生物减少 } \\
\text { 地下水和湖泊受到污染, 导致水不可饮用 } \\
\text { 游泳障碍 }\end{array}$ \\
\hline 酸化 & $\begin{array}{l}\text { 再生森林受到限制 } \\
\text { 城市区域树木再生受限 } \\
\text { 遗迹与建筑物受到腐蚀 } \\
\text { 地下水受到污染 } \\
\text { 水生物减少 } \\
\text { 健康风险 (呼吸问题) }\end{array}$ \\
\hline 烟雾 & $\begin{array}{l}\text { 一些有机化合物（如乙醛）导致眼睛流泪并对呼吸产生影响 } \\
\text { 一些化合物（如PAN）毒害植物 }\end{array}$ \\
\hline 有毒物质排放 & $\begin{array}{l}\text { 二氧六环 (TCDD) 引起氯痤疮（皮肤病）并导致软组织癌症 } \\
\text { 吸入嵌二萗和苯并芘将高度致癌 } \\
\text { 铅中毒 (铅毒) 可导致永久性神经损伤 }\end{array}$ \\
\hline 垃圾 & $\begin{array}{l}\text { 垃圾的出现 } \\
\text { 降低垃圾处理厂的可用性 } \\
\text { 污染土壤和地下水 } \\
\text { 造成垃圾掩埋场内嗅神经污染和爆炸危害 } \\
\text { 垃圾运输 } \\
\text { 消耗燃料 } \\
\text { 噪音和空气污染 }\end{array}$ \\
\hline 其它 & $\begin{array}{l}\text { 嗅神经污染 } \\
\text { 噪音污染 } \\
\text { 电磁污染 } \\
\text { 景观破坏 }\end{array}$ \\
\hline
\end{tabular}


观察人类世界与自然界之间的关系之后, 我们可以区分出以下两种基本行为。

- 从自然中获取资源时, 我们必须节约资源, 尽量减少资源的使用, 或使用可 再生资源。

- 向自然中输出物质时, 我们必须防止污染（资源）, 减少排放, 提高生物相 容性。

这些行为可以进一步细分为三种情形。

第一种情形是生物相容性。在这种情形下, 产品与服务生产的资源流动与自 然系统能够相互兼容: 使用可再生资源, 处理生物可降解和可相容的排放物及废弃 物。在工业化经济体中, 这一情形存在若干局限性。

第二种情况是不干预情形。在这种情形下, 资源不再从大自然算取, 而是以回 收的方式（如果是原材料）进行或在级联中使用（如果是能源）。

这种情形同样具有局限性, 至少在热力学定律中, 在任何转化过程中都会引起 熵的增加。

最后一种情形是非物质化, 我们如何满足人类需要（即 “需求满足的非物 质化”），在这种情况下，我们可以减少为满足一定社会需求和欲望而消耗的资源量。

很明显, 基于不同背景下的各种条件, 上述三种情形相辅相成, 以实现向可持 续发展的过渡。

\section{2 .2 社会道德层面（人）}

促进社会道德的可持续发展需要考虑（根据对可持续发展概念的假设）所谓的“公 平原则”（联合国2002）。在该原则下, 每个人都有权利获得公平的资源分配, 拥 有相同的“环境空间”。换言之, 人类对全球的自然资源有相同的使用权, 通过不 同的方式可以获得相同的满意度。当从消费的可持续性过渡到社会道德的可持续性 时, 可持续性的含义及所肩负的责任也扩大到了以下方面：民主的原则和规则；人 类的权利和自由; 和平与安全的保障; 减少贫穷与不公正; 改进信息获取方法; 培 训与就业; 尊重文化差异、区域特征和自然生物的多样性（联合国 2002）。

当谈到可持续发展的社会道德层面时, 一个引人关注的问题是：“我们应当如 何消除贫困?"

2006年, 世界银行和联合国人口活动基金会（UNFPA）给出了令人吃惊的贫困 数据统计报告 9 :

- 13.7 亿人每天的生活费不超过1.25美元 ${ }^{10}$ 。

- 25.6 亿人（世界总人口的 $40 \%$ ）每天的生活费不超过2美元。

- 10 亿儿童（世界儿童总数的一半）生活在贫困状态中。

9 参见http://www.heartsandminds.org/poverty/hungerfacts.htm

10 世界银行将 “极度贫困” 定义为每天的花费不足1美元的人群（购买力平价）, 而中度贫困 的标准则是每天消费不足 2 美元。 
14 可持续产品服务系统设计

- 每年约1000万儿童在15周岁之前死去。

- 每年约 1800 万人（占死亡总数的 $1 / 3$ ) 死于贫穷。

- 800 万人死于缺少食物和营养。

- 11 亿人缺少安全饮用水。

- 2.6 亿人缺少基础的卫生措施。

- 8 亿人每天饿着肚子睡觉。

- 6.4 亿人居无定所。

- 2.7 亿人无法获得医疗服务。

1996年, 联合国粮食和农业组织召集的首脑峰会在罗马召开, 185个国家就“全 世界营养不良的人数减少一半” 的承诺达成了协议。四年后, 即 2000 年 9 月 8 日, 在 联合国总部召开了为期三天的“世界领导人千年首脑会议”，大会通过了由191个成 员国签署的“千年宣言”。11会议的宣言承诺:

在2015年之前根除贫穷。a) 从1990到2015年，将生活在极度贫困状态下的 人数减少一半； b ) 给所有人（包括妇女和年轻人）提供全职的就业机会和 有尊严工作岗位；c）从1990到2015年, 将营养不良的人数占总人数的百 分比减少一半。

据联合国粮食与农业组织（FAO）提供的“2012世界粮食不安全状况 (SOFI)” 的报告估计, 按照膳食能量供给指标 ${ }^{12}$, 全球营养不良人口的数量和比 例已经回到了1990年的水平；2010-2012年，全球接近8.75亿人长期营养不良，而 处于饥饿状态的人数始终出奇的高。这些人中的绝大多数都生活在低收入和发展中 国家, 据估计, 在这些国家, 有大约 8.5 亿人, 或略低于15\%的全球总人口目前处于 营养不良状态。如图1.1所示, 在2007-2008年期间，在这方面取得了一些明显的进 展。但从那以后, 在减少饥饿人口数量方面, 全球的进展缓慢。

11 全文请见http://www.undemocracy.com/A-RES-55-2.pdf

12 http://www.fao.org/docrep/016/i3027e/i3027e.pdf 


\section{图1.1 低收入和发展中国家中的营养不良人口情况}

来源：联合国粮食与农业组织（FAO）、世界粮食计划署 (WFP) 和国际农业开发基金会 (IFAD) 发布的“2012 世界粮食不安全状况 (SOFI) ”指出, 经济增长是必须的, 但更迫切的工作是减少饥饿与营养不良人口（Www. fao.org/docrep/016/i3027e/i3027e.pdf）。（未经同意不得复制。）
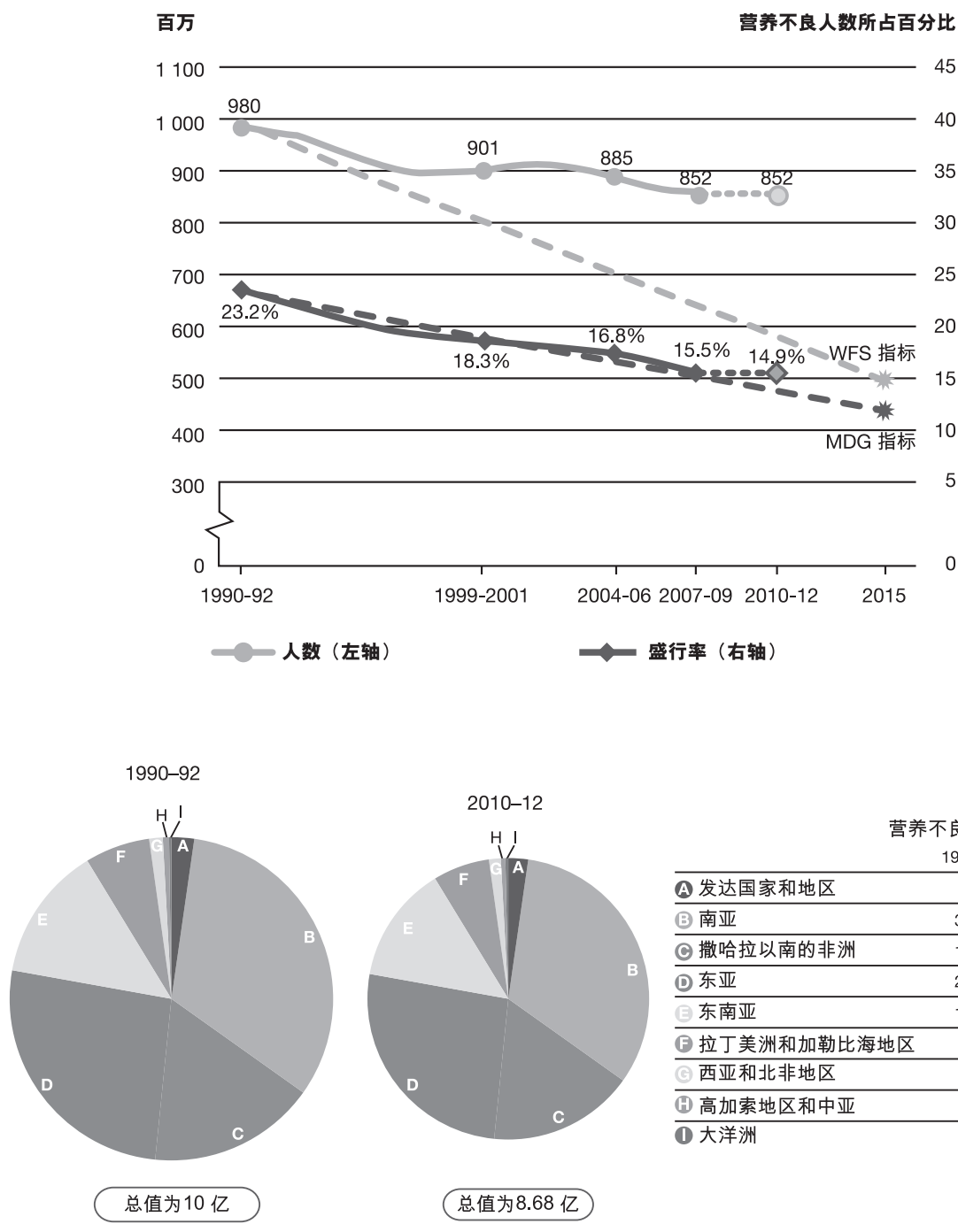

\begin{tabular}{|c|c|c|}
\hline & $\begin{array}{r}\text { 不良人数 } \\
1990-92\end{array}$ & $\begin{array}{l}\text { (百万) } \\
\text { 2010-12 }\end{array}$ \\
\hline (A 发达国家和地区 & 20 & 16 \\
\hline (B) 南亚 & 327 & 304 \\
\hline ○ 撒哈拉以南的非洲 & 170 & 234 \\
\hline D东亚 & 262 & 167 \\
\hline 东南亚 & 134 & 65 \\
\hline @ 拉丁美洲和加勒比海地区 & 65 & 49 \\
\hline () 西亚和北非地区 & 13 & 25 \\
\hline (1) 高加索地区和中亚 & 9 & 6 \\
\hline (1) 大洋洲 & 1 & 1 \\
\hline
\end{tabular}

然而, 需要注意的是, 社会公平性不仅仅是要消除贫穷, 还需要生活环境的改 善和生活质量的提高，如“推进民主，增强社会的包容性、凝聚力，尊重公民的基 本权利, 打造能够创造同等机会的多样性文化, 建立健康、安全与公平的社会, 并 与各种形式的歧视作斗争”（EU 2006）。 


\section{2 .3 经济层面 (从利益角度来看)}

在经济的可持续性方面, 一个重要的原则就是：环境和社会道德层面上具有可持续 性的生产和消费必须在经济上具有可行性。这方面, 主要包括三种策略：成本内在 化, 寻求可持续的解决方案, 促进有前景的利基市场经济模式的建立。

我们发现, 在工业化背景下, 许多自然资源的成本与它的实际使用的成本不相 匹配。砍伐热带森林里的木材, 可能会导致土壤遭受侵蚀, 降低生物的多样性, 并 产生其他负面效应; 这些本来应该是其社会成本的一部分, 却没有包含在购买价格 中。而使用汽油产生的 $\mathrm{CO}_{2}$ 排放物也会加剧全球变暖。这些非直接成本来自于产品 在其生命周期内的环境成本和经济成本。汽车生产商和使用者仅支付很少的间接成 本, 像人们因为空气污染而感染肺病, 而进行治疗所需要花费的健康成本等

成本内化使得直接成本和间接成本都能体现出来, 从而鼓励人们尽量减小对环 境的影响。换句话说, 我们应该努力寻求一种适当的计算资源成本的（或内化的） 方法, 而这主要涉及政治和法律方面的问题。

另一个策略是向可持续的解决方案进行转变, 即, 向互联、全球化和本地化 （合称全球本地化）、信息、服务等（一个简单的例子是，相对于传统的邮政系 统, 开发出诸如信息通信技术 (ICT) 和电子邮件系统等非物质产品的潜力) 的转 变。事实上, 重新定位比试图让时光倒流回到从前的生产一一消费模式上来, 可能 会带来更好的效果。

最后, 作为上述策略的补充, 促进并提高有发展前景的经济模式（即使这些经 济模式目前只在某些细分市场上有效）也可能是一件非常有效的措施。

本文研究了一些具有环境可持续性和社会道德可持续性的的经济模式, 如分布 式经济 (DE) 和产品服务系统 (PSS)，而后者是本文研究的重点。

\section{3 可持续性：根本性变革的需求}

\subsection{1 变革的规模}

在上世纪 90 年代后期, 通过一系列的研究和分析, 人们对实现高效和全球可持续发 展而进行社会变革的必要性有了更加清醒的认识。然而, 与成熟工业化社会的资源 消耗相比, 发展中经济体只有通过大幅度降低其环境资源消耗, 才能实现社会的可 持续发展。

有些研究, 通过对不发达国家和地区人口的不断增长和当地人民追求小康生活 的迫切需求等因素的分析, 获得了令人意想不到的结果: 在过去的50年中, 只有 当生产一一消费系统的生态效益增加十倍时, 可持续性条件才能体现出来。换句话 说, 只有当社会一一技术体系下每个满意/服务单元所消耗的环境资源低于成熟工业 化社会条件下所消耗的 $90 \%$ 时，这个体系才被认为具有可持续性 ${ }^{13}$ 。

13 在这个问题上可参见德国乌珀塔尔研究所 (Wuppertal Institut) 福尔·克利马所撰写的 能源著作以及自然环境研究咨询委员会 (Advisory Council for Research on Nature and 
大多数学者都认为, 如果 20 世纪 70 年代的目标是在达到极限之前减缓资源消 耗的速度, 那么, 现在的目标就是在没有任何战争、尚未对地球造成严重破坏的 前提下返回到极限之内。例如, 如果过度捕鱼和污染继续加剧的话, 所有的海洋 生物将会在 2048 年遭受灭绝之灾, 而在 21 世纪中期, 将会有 60 个国家的 70 亿人口 面临缺水的困境。科学家认为, 人类和自然界一直处在相互冲突的状态 (梅多斯

(Meadows) 等2006)，全球社会应该控制对资源的消耗速度，而不是放任自流。

\subsection{2 变革的质量}

这些评估（当前科学讨论）已经向我们表明了变革应该达到的程度：对发展模式进 行彻底的、根本性的变革迫在眉睫, 可持续社会的生产和消费模式与我们一直以来 想当然的生产和消费模式截然不同。换句话说, 可持续性变革需要我们在生产、消 费甚至生活方式上均发生根本性的转变。可持续发展带来的光明前景是我们讨论发 展该模式的根本原因。

在未来的几十年里, 以生产和物质的消费速度作为衡量国民幸福指数和经济健 康指数的指标的观念, 应该转变成为: 经济增长不再是最终目标, 就像森 (Sen) 认 为的那样 (森 (Sen) 1999), 自由是以提高生活质量为目的的原始动力; 自由保 证了我们是命运的主人, 而不只是发展规划中的被动受益者。

目前仍很难预见这种转变将会如何实现。然而, 要转向可持续的发展模式, 就 必须对现有的体系进行彻底的变革。换句话说, 考虑到变革的性质和范围, 向可持 续性（尤其是可持续性的生活方式）的转变过程, 实际上就是一种广泛的社会学习 过程, 是对过去的某些模式进行脱胎换骨的改造。事实上, 如本文前面所述, 关于 可持续性消费模式的辩论已经列入了各国政府机构的主要议程中（比如：联合国在 2000年5月建立了 “可持续消费单位” )。

这项复杂的辩论主题可总结如下: 如何建立一个新的质量标准, 既能够满足社 会幸福需求又不以资源消耗的增加为代价（成熟的工业社会的主要特点）?

\subsection{3 可持续发展的制度创新}

需要注意的是, 各种不同的背景之间有着巨大差别。如果我们认真考虑可持续社会的 概念, 就要经历一个宽泛的社会学习过程, 正是这个过程导致了系统的不连续性。因 此, 当涉及到实施层面时, 系统创新方式就出现了, 其目的是促进向可持续性转变。

系统创新主要涉及各组件层面和技术结构层面（亨德森 (Henderson) 和克拉 克（Clark）1990），以及社会与制度结构层面的变革，如协调机制（法规、管理）, 或者来自供应商和用户方面的创新。在体系创新方面, 对产品、服务和生产体系进行 了优化; 在现存制度框架内, 寻找到满足消费者需求的新方式; 开发并实施新的基

Environment) 的相关书籍（尤其是：“将生态容量作为技术发展的挑战”，一项由荷兰政 府各部门资助的研究; 世界可持续发展工商理事会组织的生态效益工作小组的研究项目）, 具体参见最终报告 “生态效益领导” (WBCSD 1996)。 
础设施、空间规划和激励体系，从而推动了更具有可持续性的生活方式的发展（塔克 (Tukker) 和蒂什纳 (Tischner)，2006）。

体制创新主要指的是在 “社会一一技术体制” 14领域的转变, 以及社会功能实现 方式的变革。社会、经济、技术和政策等领域的变革是一个长期而复杂的过程（瑞普

(Rip) 和肯普 (Kemp) 1998; 吉尔斯 (Geels) 2002；吉尔斯（Geels）2004)。

在怎样进行系统创新的广泛讨论中（安德森（Andersen），2006），产品服务 系统 (PSS) 前景广阔, 它可以在创造价值的同时减少对资源的消耗。以下章节将 会对创新的类型进行阐述。然而, 在此之前, 重要的是应当深刻理解我们当今所面 临的的生活环境。

\section{4 巨变过程中的可持续性}

如今, 我们不能再用那些孤立的、僵化的、缺乏相互联系的方法来解释目前的一些 社会现实，如世界、国家和社区等概念，它们具有以下特征：

- 信息与通信技术的出现（作为生产力、竞争力和实力基础的技术和知识）

- 互联性 (人员、思想、影像、物品和资金在较大范围内流动)

- 网络化社会 (不再是隔绝的孤立的国家和社区)

- 网络化企业（团队合作、网络化、外包、分包和非本地化等）

在当代，个人和思想比以往任何时期都具有更强的流动性。我们生活在全球化 的背景下, 世界联系在不断加强并呈现出多元化的趋势。越来越多的个人和团体参 与到全球化（现代化）进程中, 并由此创造了一个全新的、现代主体（由阿帕杜莱

(Appadurai) 提出)。大众电子通讯和人口大规模迁移等互联效应对集体和社会各 个方面均产生了重大影响（阿帕杜莱（Appadurai）1996)。在这个时代，国家所面 临的危机是显而易见的。我们不能理所当然地认为有效的公共领域仅仅是指国家层 面。在这个复杂的交互系统里, 国家很难从长远角度来把握全球化和现代化的关系 (阿帕杜莱 (Appadurai) 1996)。我们不妨引用鲍曼（Bauman）的引人深思的比 喻：当今时代体现出一种 “流动的现代性” 的特征。越来越多的东西正在变成转瞬 即逝、可更改的和可试验的（鲍曼（Bauman）2000）。

虽然每个人都在特定的地方活动, 但我们清楚地知道, 各个不同的地理区域是 由物质、人员和信息的不断流通并通过不同方式而被联系到一起的。这已经改变并 将继续改变人与人之间的关系模式、观念以及对近/远、本地/外来、可能/不可能、内 部/外部、排他/非排他等概念的认知。我们已经进入了一个真正的、具有多元文化、 且相互依赖的世界。只有从多元化的视角出发, 把文化认同、全球网络和多维政策 结合起来, 我们才能够理解和改变世界。

14 社会技术机制可被定义为创新、生产、分配、消费的主导方式。它是由社会经济领域中各 利益相关方、习俗、通用规则以及某一具体领域的行事方式所组成（交通、能源等）。 
根据科斯特（Castells 1996）的研究, 在全球资本、管理和信息的网络化基 础上, 新型工业化经济已经形成, 以生产力和竞争力作为立脚点, 这些经济体能够 获得技术方面的专门知识。尽管我们每天都面临技术上的问题, 并且这些问题在背 景和内容方面都有所不同, 但是交互式计算机系统已经被广泛地应用于开放的网络 上。信息技术范例突破了单纯的计算机之间的联系，创造了新型合作关系，这就摆 脱了交互各方因地理位置而受到的束缚。

在网络作为新的全球经济竞争基本形式（伴随着新信息技术）出现的同时，各 种组织模式应运而生。网络化企业（科斯特（Castells）1996）。这些企业（包括越 来越多的组织和机构）是指分布在世界各地、通过网络组织起来的企业。网络的存 在, 使公司规模的大小变得不再重要。网络化企业通过连通性（能够促进交流而不影 响各个组成部分的结构) 和一致性（网络目标和具体组成部分目标之间利益共享）来 提供服务。这是一个全新的工作分工, 以工作人员的特长和能力而非其在组织中的工 作角色为基础。工作将越来越依靠团队合作、网络、外包和分包等形式而展开。

根据科斯特的理论(科斯特 (Castells) 1996), 当今社会日益朝着网络（全球 化) 和自我（特性）的两极化的方向发展。在大多数人看来, 网络化社会似乎导致 了巨大的社会混乱（meta-social mess），但建立一个巨大的网络有助于减少大量不 必要的中间环节, 不必要的功能机构, 以及毫无价值的地区投入。

互联和多元文化是关键的背景要素, 一些人把它们解读为环境在恶化（为自己 开脱），一些人认为这是必须面临的挑战（新起点），而另外一些人把它们看成是 实现可持续创新的机遇和动力（待开发利用）。

最后, 我们还认识到, 服务（而不是产品）在欧洲国内生产总值中占50\%（在 德国占 $70 \%$ ），在美国占 $76 \%$; 在亚洲, 服务在中国、日本和泰国的国内生产总值 中分别占 $40 \%$ 、69\%、45\%。我们还必须认识到，（在写这部书的时候）我们正处 在结构性的经济危机中, 甚至是社会危机中。这场危机是从2008年的金融危机开始 的。因此, 我们目前面临着双重危机, 既包括社会经济方面的危机, 又包括环境方 面的危机。在这种背景下, 许多人开始分析这些危机, 并为解决危机出谋划策。同 时, 我们还应该探讨其中的机遇。设计的本质是把机遇纳入考虑范围之内, 并且设 法开发、利用这些机遇。

\section{5 实现可持续发展的多元化路径}

\subsection{1 工业化、新兴经济体和低收入国家和地区背景介绍}

实现可持续发展对工业化、新兴经济体和低收入国家和地区都是一个极大的挑战 15 。 然而, 在不同的背景下, 应通过不同的途径来实现这一目标 (哈特 (Hart) 和米尔斯 坦（Milstein）1999）。在成熟的工业化国家或地区，有必要降低获得每“单位满意

15 使用了下列术语: “低收入”这个术语要优于“发展中”这个术语, “工业化”这个术语 要优于 “发达” 这个术语, 前者将事物的特征以更为客观的形式表现出来, 同时又涵盖了 相对较少的价值判断成分。同时还应说明的一点是, 工业化国家的生产和消费模式远没 
度” 所消耗的资源（同时提高生活质量）; 新兴经济体国家或地区的目标在于如何 引导社会建立一个可持续的生产和消费系统。而在低收入国家或地区, 当前, 最迫 切需要解决的问题是使其生产和消费系统能够满足人们的基本需求, 进而为可持续 发展创造条件。

当衡量一个社会的可持续发展水平时, 我们必须考虑人们的生活满意度与地球 的承载能力之间的关系。例如, 快乐星球指数（The Happy Planet Index）16就是结 合环境影响与人类福利, 以及各个国家的人均寿命和生活满意度来评估环境效应。 根据该指数所进行的评估表明，在中美洲，获得高分的国家并非工业化程度高的国 家，而是快速发展的新兴国家。众所周知，当今世界 $80 \%$ 的人口仅占有 $20 \%$ 的资 源, 而绝大部分的资源却为 $20 \%$ 的人口所消耗。在此背景下, 我们必须强调社会公 平和社会凝聚力。因此, 尽管人们对生活的满意度与资源消耗没有必然联系, 我们 也有必要对资源进行再分配。另外, 还需要强调的是, 正如上文所述, 可持续性并 非只是一个资源再分配的问题，而是一个更为广泛的社会伦理与社会责任问题。

在以下章节中, 我们将简要介绍欧洲和亚洲可持续发展议程中所描述的实现可 持续发展的路径。

\subsection{2 欧洲可持续发展议程}

目前，欧盟成员国执行的关于可持续发展的规范、惯例和政策多是由欧洲委员会制 定的。这里所说的可持续发展被视为跨领域的问题, 反映出各部门不同的政策取 向, 也反映了公私各个部门的做法和实践, 并使得欧洲委员会的指令在当地得到贯 彻执行。

因此, 在一定程度上, 意大利、芬兰以及荷兰这三个欧洲国家的LeNS项目在实 现可持续发展过程中的做法非常相似。当然, 各国根据自己的消费和生产系统的具 体情况, 都建立并实施了各自的可持续发展规划。

欧洲理事会于2006年6月通过了修订后的欧盟可持续发展战略, 并由此提出了以 下四个方面的发展目标:

\section{环境保护}

保护地球的承载能力, 保护生物多样性, 重视地球自然资源的短缺问题, 加强环境 保护并提高环境质量。预防并减少环境污染, 促进可持续消费与生产, 减少经济增 长对环境造成的破坏。

有达到发达的程度, 事实上其所应用的模式对环境几乎都是有害的。

“背景”这个概念优 于“国家”这个概念，不同国家可能会表现出不同的社会经济背景。

16 “快乐星球指数” 在事实上说明至今全球没有任何一个国家已成功达到了那三项标准：生 活满意度高、人口预期寿命长和 “一个地球生活”。(http://www.happyplanetindex.org) 


\section{社会公平与凝聚力}

促进建设一个民主、具有包容性、和谐、健康、安全、公正的社会, 保障公民基本 权利, 尊重文化多样性, 为每个人创造平等的机会, 消除一切形式的歧视。

\section{经济繁荣}

促进建立一个繁荣、创新、知识丰富、充满竞争活力、生态高效的经济体系, 在整 个欧盟范围内提供较高的生活水平与高质量的就业环境。

\section{我们的国际责任}

鼓励世界各国建立和平、安全与自由的民主体制, 并维护其稳定。积极促进世界范 围内的可持续发展, 并确保欧盟对内及对外政策都与全球可持续发展及其国际承诺 相一致。

我们发现，欧盟成员国的居民所关心的问题很大程度上都与健康和幸福有关。 生产部门的绿色生产问题不再像过去几十年那样，成为可持续发展政策中的主要关 注点。这是因为西欧国家意识到他们已经处于后工业时代, 其经济已经从以制造业 为主演变为以服务业为主。可持续消费和生产, 作为一个关键性的挑战在此提出并 非偶然, 按顺序排列, 消费排在生产之前。这一创新理念在欧洲委员会的可持续消 费研究交流网络 (SCORE) 项目中得到阐释17, 具体如下: “消费是被作为产品服 务系统的一部分, 同时它也受到该系统的驱动, 它不仅要满足人们的物质需求, 而 且与象征性价值和文化价值相关。”18此外, 在当今经济全球化的背景下, 欧盟委 员会在制定反映全球商业动态的工业生产与农业方面的相关法规中起到决定性的作 用, 从而对全球经济产生影响。

欧洲可持续消费和生产政策 (European Sustainable Consumption and Production Policies) 重点强调了两个问题。其一是将 “在发展经济的同时兼顾保护 环境” 作为可持续消费和生产 (SCP) 的一项整体战略, 从而引导我们建立一个由人 类福利、社会经济乃至社会制度组成的新模式。其二是我们必须理解, 为了实现可持 续消费和生产 (SCP) , 我们必须要改变 “我们设计、制造、使用及处理产品和服务 的方式”。

从这个意义上说, 不仅要执行具体的产品政策（例如, 通过欧盟生态设计政策 和整合性产品政策（IPP）），与此同时，还需要将 “系统性方法” 转化为行动，正 如可持续消费研究交流 (SCORE) 项目中的描述:

17 可持续消费研究交流由欧盟第六项框架规划支持赞助。该网络项目是欧盟为配合联合国可 持续消费和生产(SCP)10年规划框架而构建的其中一个骨干项目。

18 在欧盟2006年的可持续发展战略中也有所提及。可持续消费和生产设计的范围 “几乎涵盖 了完整的 “人” (社会)的系统和（经济）支撑子系统” (塔克 (Tukker) 和查特 (Charter) 等2008b), 以应对环境、社会和经济等各方面的问题。 
只有通过那些了解商业开发、(可持续) 解决方案设计、消费者行为以及 (政策) 手段实施效果的专家们通力合作，才能创建一个可持续的消费和 生产模式; 并且, 这应该与相关各方（相关行业、消费者团体、生态组 织）在消费领域实际生活中的经验相关。

在这个以知识为本的社会中, 欧盟作为倡导者, 在有关经济竞争力的研究和创新中 扮演者越来越重要的角色，但是与此同时，欧盟也是向世界各国推行可持续发展知 识、方法以及应用工具的重要力量。欧盟在促进可持续发展的研究上比世界其它任 何国家都做出了更多的投入。

欧洲委员会通过社区研究与信息服务开发 (CORDIS)，每5年就为科技信息的 研究开发建立一个全新的框架计划, 该计划作为一个金融工具对几乎所有科学领域 的研究和开发活动提供支持。社区研究与开发信息服务 (CORDIS) 框架计划以及其 他对外合作项目（如欧洲援助合作办事处（EuropeAid））－直以来在欧洲内部和外 部都是促进可持续发展的重要机构。在世界范围内, 通过可持续消费研究交流网络

(SCORE) 等活动, 欧盟已经成为打造可持续发展以及可持续消费和生产 (SCP) 模式的重要力量。联合国一直在加强其在这方面的协同效应。

\subsection{3 亚洲可持续发展议程}

亚洲经济的蓬勃发展导致人们对商品和服务的需求不断增加（至少一部分人口是这 样）; 而另一方面, 也导致了环境压力的持续增长, 包括城市基础设施建设的压力 以及随之而来的宜居问题。同时, 社会差距特别是城乡差距显著增大。而人们最为 关心的是, 经济发展从长远来看将会对全球环境造成怎样的影响。

\footnotetext{
“随着中国和印度逐渐成为世界经济大国, 它们也开始逐渐向工业化国家 的方向发展。在此过程中, 它们还成为主要的资源消费大国和当地及全球 生态系统的污染者。这种发展方式造成了非常严重的后果, 中国和印度不 得不自食苦果，与此同时，这种后果对全球的影响也是显而易见的。”

(弗莱文 (Flavin) 和加纳德 (Gardner) 2006)
}

需要指出的是, 尽管环境影响日益升级, 中国人均环境影响仍远低于工业化 国家。从这方面看, 像中国这样的国家对生态的影响还远低于欧洲国家或者美国。 印度已经通过长期以来形成的传统文化消费模式，尤其在食物消费与垃圾回收等领 域, 成功地解决了这一问题。尽管有大量农村人口向城市迁移, 但在像印度和中国 这样的国家，农村人口仍占很大比例。即便是这样，建立在资源密集型经济和个人 主义价值观之上的西方化、物质化的思维方式，正在逐渐取代传统的、农村的生活 方式。然而, 这未必能给大多数人带来福祉。

由于城市发展日新月异, 并处在一个转型期, 人们可以轻易感受到飞速发展的 经济给社会环境带来的压力。根据世界观察研究所的研究, 世界20个污染最严重的 城市中有16个分布在中国。到2015年, 世界人口最多的六个城市（人口超过2000 万）将会出现在新兴经济体国家，有一半以上在亚洲国家。而城市中空气污染、交 通系统、食物及水的供应等问题将面临前所未有的压力。 
在政策层面, 联合国已经采取行动鼓励各国政府就可持续消费和生产 (SCP) 问题展开讨论，而一些国家政府也已经就应对环境退化问题做出了回应。不同于实 施LeNS项目的三个欧洲国家（它们都共享许多可持续发展议程），泰国、中国与印 度这三个亚洲LeNS项目的参与国的可持续发展议程的工作重点与政策有很大的不 同。以中国为例, 新的五年经济计划（正在制定中）强调保护自然资源的重要性, 同时中国还将绿色GDP指数作为经济增长的一个指标, 该指数将环境影响以及资源 消耗的成本纳入其考虑范围之内。

威尼斯建筑大学 (IUAV) 及意大利卡美日诺大学 (Camerino) 最近的研究结果 表明 19 , 从20世纪80年代初期到现在, 中国的环境保护政策正在从终端治理模式逐 渐转向更加注重清洁生产, 并关注产品的整个生命周期对环境带来的不同影响。然 而, 这种与环境问题、生活质量改善以及企业创新相联系的模式, 如产品服务系统 (PSS)，尚未进入政策层面，目前只是作为一个科研领域出现在人们的视野中。

泰国对可持续发展非常重视, 并对其进行了专门的规划: 泰国国王提出了充足 经济理念 (SEP) 。充足经济理念 (SEP) 将人类的发展置于首位, 并将人类的福 祉视为发展的中心。因而, 充足经济理念 (SEP) 可以指导社会各阶层人民如何得 体地生活。从而使实施者（包括农民、商人、政治家、政府官员以及教育者）能够 面对全球性的挑战。充足经济理念 (SEP) 旨在引导一条复兴之路, 使泰国成为一 个更具活力, 可持续发展的经济体。这是一种普遍适用并可扩展的方式，从家庭、 社区层面以及民族的发展和管理层面出发, 加快其现代化进程, 从而与全球化的力 量保持一致。它由三个组成部分（合理、适度和自身免疫力）以及两个条件（知识 和道德) 20 。

19 研究由梅达多 · 齐雅波利 (Medardo Chiapponi) 和劳拉 · 巴达卢科 (Laura Badalucco) (威尼斯建筑大学 (IUAV University Venice, Dadi department) )和露西娅·派多里(卡美日诺 大学Camerino University ProCAm Department)负责, 研究项目 “Made in Italy for China”。 内部文件（中国环境可持续发展：总体框架与视角）, 威尼斯建筑大学, 2006年10月。 20 充足经济学理论详见第2部分第4章 


\section{产品服务系统（PSS）创新与可 持续性}

如第1章所述, 产品服务系统是一种更具战略性和更加系统化的发展模式。其基本 特征是, 在创造价值的同时不以增加资源消耗和环境破坏为代价, 这种模式首先出 现在工业化国家（主要是欧洲）。就其起源而言, 自1999年以来, 这种系统的学 者多数来自斯堪的纳维亚（特别是瑞典）、荷兰或者意大利（贝恩斯（Baines） 等, 2007)。一些亚洲的学者也发表了若干关于产品服务系统 (PSS) 的文章, 尽 管其中许多相关的研究并未提及“产品服务系统 (PSS) ”这个术语。

在本章中, 我们将首先分析为什么产品服务系统 (PSS) 被工业化国家视为提 高生态效益的机会, 以及这个系统为什么在新兴经济体和低收入国家和地区具有发 展前景及如何实现这一目标, 也就是说, 如何才能在环境、社会和经济等领域实现 全面可持续发展。

\section{1 基于生态效益的产品服务系统}

\subsection{1 什么是产品服务系统?}

如引言中所述, 近年来, 一些设计研究中心对环境的可持续性给出了更为严格的定 义（要求在生产过程中降低资源的消耗）, 并以系统创新为切入点, 开始重新讨论 可持续性设计问题。事实上, 一些学者已经发现, 在传统的产品销售模式中, 产 品生命周期设计或生态设计的实施遇到了一些障碍。（斯坦赫 (Stahel) 2001; 库普 (Cooper) 和西恩 (Sian) 2000; 林赫斯特 (Lindhqvist) 2000; 歌德库

(Goedkoop) 等, 1999; 曼齐尼 (Manzini) 和维佐里 (Vezzoli) 1998) 
这些学者认为, 在更大的范围内实现可持续消费并彻底改变传统的消费模式, 关键在产品以外实现更多的创新; 在本文中, 我们将其称为产品服务系统（PSS）。

表2.1是产品服务系统定义列表。

表2.1 产品服务系统的定义

\begin{tabular}{|c|c|c|}
\hline 作者 & 年份 & 定义 \\
\hline $\begin{array}{l}\text { 歌德库 } \\
\text { (Goedkoop), } \\
\text { 范·哈伦 (van } \\
\text { Halen), 里乐 } \\
\text { (te Riele), 洛蒙 } \\
\text { (Rommens) }\end{array}$ & 1999 & $\begin{array}{l}\text { 产品服务系统（或产品和服务的组合）是由一套适销的产品 } \\
\text { 和服务组成, 二者共同协作以满足顾客的某种需求。该系统 } \\
\text { 具有一种创新的商业模式, 更利于环境保护。 }\end{array}$ \\
\hline 蒙特（Mont） & 2002 & 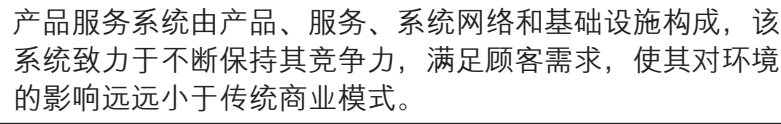 \\
\hline $\begin{array}{l}\text { 联合国环境规 } \\
\text { 划署: 曼齐尼 } \\
\text { (Manzini) 和 维佐 } \\
\text { 里 (Vezzoli) }\end{array}$ & 2002 & $\begin{array}{l}\text { 产品服务系统是战略创新的成果。它的创新之处在于: 将战 } \\
\text { 略中心从商业设计和 (有形) 产品销售转移到一种能够同时 } \\
\text { 提供产品与服务, 且能满足消费者特定需求的系统上。 }\end{array}$ \\
\hline $\begin{array}{l}\text { 布兰斯道特 } \\
\text { (Brandstotter) }\end{array}$ & 2003 & $\begin{array}{l}\text { 产品服务系统是指有形产品和无形服务的组合, 通过将二者 } \\
\text { 结合来满足客户的特定需求。此外, 产品服务系统也有利于 } \\
\text { 实现可持续发展目标。 }\end{array}$ \\
\hline $\begin{array}{l}\text { 欧盟, MEPPS, } \\
\text { 范·哈伦 (Van } \\
\text { Halen) 等 }\end{array}$ & 2005 & $\begin{array}{l}\text { 产品服务系统是战略创新的成果, 主要是指产品和服务系统 } \\
\text { 的设计和推广, 通过产品与服务的组合来共同满足消费者的 } \\
\text { 特定需求。 }\end{array}$ \\
\hline $\begin{array}{l}\text { 贝恩斯（Baines） } \\
\text { 等人 }\end{array}$ & 2007 & $\begin{array}{l}\text { 产品服务系统不仅提供产品, 还提供有价值的服务。该系 } \\
\text { 统改变了过去以消耗大量资源为代价的经济发展模式, 减少 } \\
\text { 了经济活动对环境的负面影响。 }\end{array}$ \\
\hline $\begin{array}{l}\text { 联合国环境规 } \\
\text { 划署: 蒂什纳 } \\
\text { (Tischner) } \\
\text { 维佐里 (Vezzoli) }\end{array}$ & 2009 & $\begin{array}{l}\text { 与仅提供产品本身的传统商业模式相比, 产品和服务 (基础 } \\
\text { 设施) 系统能够更高效地满足消费者的需求和需要, 并为企 } \\
\text { 业和消费者提供更多的价值。 } \\
\text { 产品服务系统改变了依靠消耗物质或能源来创造价值的传统 } \\
\text { 生产方式, 从而降低了传统的产品生产体系在其生命周期中 } \\
\text { 对环境产生的影响。 }\end{array}$ \\
\hline
\end{tabular}

为了理解这个概念, 我们不妨来看一个例子 (联合国环境规划署 (UNEP) 2002）：要提供一项令人满意的洗衣服务, 我们不仅需要一台洗衣机, 还需要洗涤 剂、水、电（这些材料和能源）, 以及相应的保养、维修和回收服务。当我们谈及 产品服务系统创新时, 它指的是在这个满意保证系统中所有的社会经济利益相关方 取得的创新：这些利益相关方包括洗衣机和洗涤剂的生产商、水电供应商、用户以 及负责保养和回收的机构。

此外, 如上所述, 理想的产品服务系统创新是指 “保持持续的竞争力, 不断满 足顾客需求, 对环境的影响比传统的商业模式更小”（蒙特（Mont）2002），“是 利益相关方之间进行创新互动及其所带来的经济利益相互趋同的结果”（联合国环 
境规划署（UNEP） 2002）。因此，具有生态效益的产品服务系统，其创新源于不 同利益相关方之间新的利益趋同：不仅是指产品（或半成品）层面的创新, 最重要 的是在同一个特定的价值创造体系里的不同利益相关方之间所建立起来的一种新型 互动/伙伴关系。（波特 (Porter) 和克拉默 (Kramer) 2006)。

换句话说, 该创新模式的研究价值在于：它能够通过利益相关方之间的创新互 动, 提高系统的生态效益。

LeNS项目对基于生态效益的产品服务系统的定义如下：

\section{通过价值创造体系（满意保证体系）的利益相关方之间进行创新互动，提 供一种能够满足客户特定需求的产品与服务的模式，在这种模式下，经济 利益和竞争利益促使供应商不断地寻求能够同时带来环境和社会效益的新 的解决方案。}

基于生态效益的产品服务系统创新的主要特点:

- 它们都是以客户满意为宗旨的经济模式, 即每一个产品或服务方案都要达到 一定的客户满意度。

- 它们基于利益相关方之间的创新互动, 比技术革新更具有突破性：各利益相 关方在一个达到特定满意度的产业链中建立一种新型的合作伙伴关系。

- 它们具有提高生态效益的内在需求, 比如公司为了提高经济效益和企业竞争 力进行创新, 从而降低对环境造成的影响, 能够在创造价值的同时不增加对 资源的消耗。

事实上, 《产品生命周期设计》的基础准则部分对产品服务体系 (PSS) 创新进行 了解释。然而, 当我们进行这种产品服务体系创新时, 我们就会更加清楚地认识到 （作为基本假设），产品服务体系创新是对系统的重建，也是可持续发展的起点。

\section{1 .2 传统产品销售/设计方式的局限性}

为了理解为什么产品服务系统创新和利益相关方之间的互动比传统产品销售/设计更 具生态效益, 我们再次以洗衣服务的满意系统为例对这一问题进行说明。要给顾客 提供满意的洗衣服务, 我们不仅需要一台洗衣机, 还需要洗涤剂、水、电（这些材 料和供应）, 以及保养、维修和回收服务。

在传统的产品销售/设计模式中, 洗衣机生产商（还有洗涤剂生产商以及水电供 应商）力求在生产阶段减少材料和能源的消耗。而这些生产商和供应商并不会关心 消费者在使用过程中的能源消耗，也不会对降低垃圾处理对环境的影响及导致的浪 费感兴趣。有时候, 生产商为了缩短顾客再次购买产品的时间间隔, 他们甚至更愿 意销售生命周期较短的产品。

对于与某一特定产品生命周期相关的其他（全部）利益相关方（包括生产前、 生产过程中、分配过程、使用过程和废弃过程中的利益相关方）来说，它们的观点 可能相似。简而言之, 传统产品销售或设计背后的经济利益促使各利益相关方, 在 他们能够直接控制的过程中, 努力减少对资源的消耗：即经济利益导致了不同环节 的资源优化（图2.1）。换句话说，一旦与某个单一的利益相关方（例如, 洗衣机的 
生产商）相关时，这些过程中最大的问题并不仅仅出现在某个特定的阶段。从生态 效率的角度来说, 在销售和处理产品（半成品）的过程中发现的问题最多。在这些 环节中, 人们缺乏减少资源消耗的意识, 而更糟的是, 更倾向于消耗更多的资源。 例如, 塑料生产商想要扩大其材料销售（导致资源消耗增加）。

\section{图2.1 产品生命周期中的利益相关方：离散与系统的资源优化}

来源：来自联合国环境规划署2002年的统计

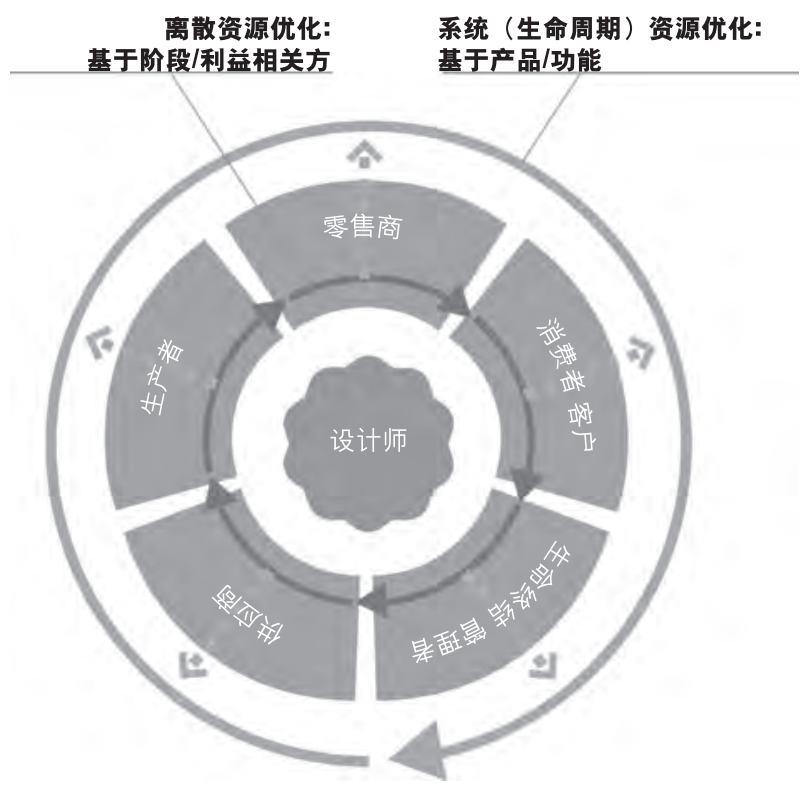

总之, 由于满意保证系统中利益相关方之间缺乏互动, 在传统的销售/设计模式 中（仅关注产品的销售）应用产品生命周期设计方法难免会受到某些限制。

最后, 我们会发现, 产品生命周期各个阶段（工业化国家的传统经济框架）的 利益相关方的分散性意味着这个生命周期系统的生态效益与单个利益相关方之间并 没有共同的经济利益。

\section{1 .3 具有系统生态效益的产品服务系统}

从生态效益角度出发, 考虑到经济/竞争和环境利益的趋同性, 我们有必要列出利益 相关方之间的所有创新互动以及他们之间的相互关系。从经济角度上看, 这能够带 来基于产品功能的资源优化。

勾画出整个产品服务系统中的创新交互和相互关系将更加富有成效。这些产品 和服务通常能够满足特定需求, 提供满意服务, 并能够打造一个基于资源优化的满 意服务系统。在我们所举的例子（图2.2）中，利益相关方包括洗衣机和洗涤剂生产 商、水电的供应商、保养维护人员、用户以及废弃产品处理机构。 
迄今为止, 人们一直以来不断争论的问题是, 公司提高系统生态效益的动力是 什么? 有没有一种经济模式能使公司在经济层面和竞争中获益的同时, 还能够降低 资源的消耗，或者从更广泛意义上，减轻对环境的危害?

让我们在利益相关方之间的互动和结构的创新中寻求创新元素。

利益相关方之间的互动和这种互动的延伸在这两种情况下都产生了积极的作用。

A）利益相关方的整合包括控制范围的延伸，可概括为以下两方面:

- 垂直层面：单个利益相关方负责产品整个生命周期的各个阶段，例如，洗衣 机生产商也是洗衣机的回收者;

- 水平层面：单个利益相关方负责满意保证系统中不同的产品和服务, 例如, 一个洗衣机和洗衣粉生产商, 同时也负责其产品废弃物的最终处理。

在深入探讨这一主题之前，不得不指出，垂直和水平层面的整合都有各自的局 限性，因为当两者不能同时发生时，将会产生炭断风险及低效率问题。

但是加强控制并不是调整互动的唯一办法。

B）互动和伙伴关系的时间上的延伸意味着利益相关方之间的关系不会随着（单个） 产品的交易和销售的完成而结束:

- 垂直层面：更多的利益相关方（包括最终用户）在一个特定的产品生命周期 内延伸这种互动关系。

- 水平层面：更多的利益相关方（包括最终用户）在一个特定的满意保证系统 中延伸他们之间的互动。

图2.2 满意保证系统中利益相关方之间的趋同计划：致力于实现系统的可持续性 来源：来自联合国环境规划署2002年的统计

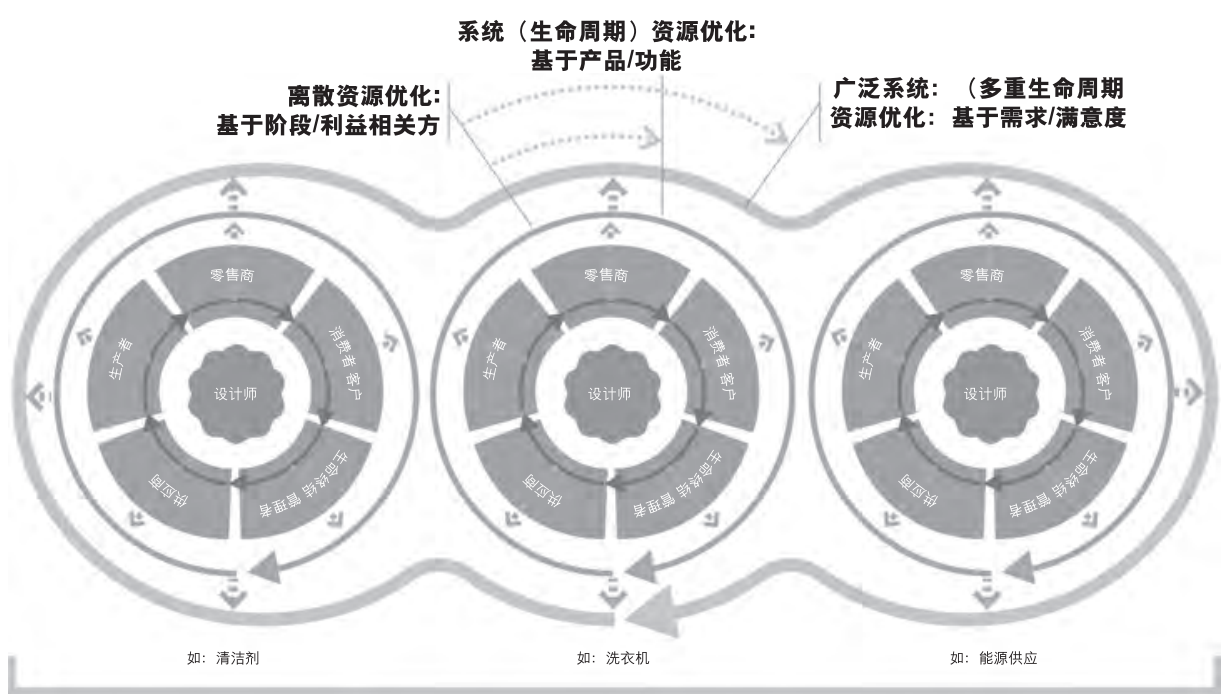

如: 满意度=有干净的衣服 
在以下章节中, 我们将探讨：利益相关方之间哪种类型的互动能够产生具有生 态效益的系统创新。

\section{1 .4 具有生态效益的产品服务系统的创新类型}

我们研究了三种主要的促进系统创新的商业模式, 并将其列为有益于提高生态效 益的商业模式（联合国环境规划署 (UNEP) 2002; 联合国环境规划署 (UNEP) 2009):

1. 以产品为导向的产品服务系统：为产品生命周期提供附加价值的服务;

2. 以结果为导向的产品服务系统: 为顾客提供最终结果的服务;

3. 以使用为导向的产品服务系统：为顾客提供支持平台的服务。

以产品为导向的产品服务系统：为产品生命周期提供附加价值（第1种类 型）

的服务具有生态效益的系统创新为什么能够为产品生命周期带来附加价值, 让我们 看下面的例子。

\section{克鲁勃润滑油及其服务}

克鲁勃已经从最初只销售润滑油，发展到同时向顾客提供产品增值服务。克鲁勃 通过一项称为萨特克鲁勃 (S.A.T.E.) 的服务, 来分析气溶胶处理设施和污水处 理的效率。为此, 克鲁勃设计了一个可移动的化学实验室, 即一个能够直接监控 客户端的工业设备的检测车, 以确定润滑剂的使用情况及其对环境造成的影响。 它还能够控制噪音、振动、烟雾及其它由工业生产所带来的负面环境影响。克鲁 勃向顾客提供的增值服务使得设备在效率、功能和耐用性、环境保护方面都得到 了提升。

克鲁勃打破了企业经营的传统做法。它不仅关注润滑油的销售量, 同时还 重视服务。事实上, 每单位服务所消耗的润滑油的总量在减少, 因此, 它能够 减少污染物的排放量。加强对各种机器性能的监测, 还带来了其它益处, 因此 避免了任何意外污染。顾客意识到他们从这项增值服务中受益, 使他们不用再 担心由于设备监控和检查所带来的成本及其他问题。润滑油带来的高效率, 使 得生产流程更加通畅, 机器寿命也得到了延长, 从而降低了生产成本, 带来了 经济效益。

总而言之, 能够为产品生命周期带来附加价值的以产品为导向的产品服务系统 创新的定义如下:

\section{一个能够为客户提供额外服务以确保产品在生命周期内性能的公司（公司 联盟）。}


标准服务合同包括在一定时期内的产品的保养、维修、更新、替换和最终回收等 服务。

这减轻了用户在使用和处理产品成品或半成品时所需承担的责任。公司和客户 之间在不断寻求环境效益的新方案时的创新互动提升了公司效益, 同时也提升了公 司的竞争力。经济利益不再仅由销售量来衡量。

以结果为导向的产品服务系统: 向用户提供最终服务结果（第2种类型）

下面是一个为客户提供最终服务结果的生态效益系统创新的例子。

\section{太阳能供热服务按单位热水量计费}

太阳能供热服务提供全方位的供热服务，包括将热水作为最终产品进行销售。这 种服务主要是通过一种新设备, 同时利用太阳能、电能和沼气产生热水, 这种方 式既经济又节能。所设计的太阳能发电设备力求最大限度地利用太阳能。热水的 供应量是通过特定的热量表进行测量。为了实现对运行的实时监控, 并达到《太 阳能供热保障协议》中设备供应商事先承诺所要达到的效率, 整个系统都通过监 控设备进行监控。在意大利的巴勒莫 (Palermo) 的一个网球俱乐部里, 这种设 施被应用于为俱乐部更衣室提供热水, AMG公司对这项服务进行了测试。这种 产品服务系统 (PSS) 的创新之处在于, AMG并不以用户使用的沼气量等所消 耗的能源为单位向用户收费，而是将热水作为一项整体服务出售给用户。AMG 以热量为单位进行出售, 并计算客户消费的热千瓦数。AMG公司的客户是在为 一个综合服务支付费用, 包括安装、热能计量, 以及甲烷输送至锅炉的一条龙服 务。整个服务也包含设备维护。客户购买的是整个最终产品。

新的产品服务组合即是将分散的服务整合成一个完整的服务之后再售出，这非 常有利于环境保护。为了最大程度地节约能源, 公司开始积极致力于创新。于是, 按整体服务而非所消耗能源为单位向用户收费的方式出现了。按这种计费方式：甲 烷使用量越少（太阳能使用越多，系统效率越高），AMG的收入就越高。

为客户提供最终结果的产品服务系统 (PSS) 创新的定义是:

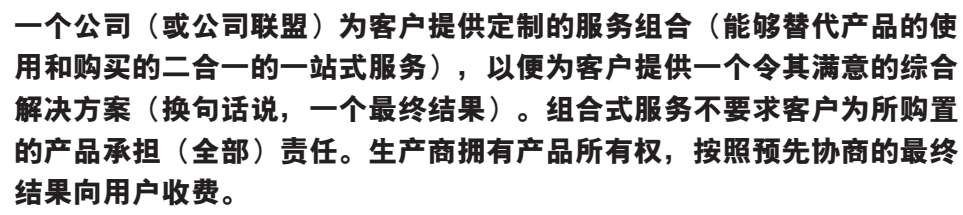

客户不拥有产品的所有权, 也不必亲自操作或运行该系统, 客户只需付费给提供商 就可得到预先协商好的产品或服务。客户也无需再操心产品或设备在运送、使用和 维修等方面的费用问题。公司和客户之间的这种创新性互动, 促使公司不断寻求更 
为环保的新的解决方案, 如开发生命周期长、可循环、可回收的产品, 以增强公司 的经济实力和竞争力。

以使用为导向的产品服务系统：为客户提供可用平台（第3种类型）

以下章节描述了一个将生态效益系统创新作为客户支持平台的例子。

\section{汽车共享- -Th!nk微型电动车}

与很多其他汽车共享系统一样, Move About是一种产品（车）服务平台。这是 一个汽车共享系统, 它为奥斯陆（挪威首都）的市民提供汽车共享服务; 该系统 的车队共有 40 辆电动车, 它们都是由挪威的制造商Th!nk生产。使用者每月需缴 纳会员费另加按小时计算的使用费（包括从保险到汽车耗能等所有费用）。对于 汽车使用者来说, 使用汽车共享系统的车, 比开传统的租车代理机构的车更为方 便, 价格也更为低廉。当地政府制定了多种刺激方案, 例如, 免费停车, 免收过 路费, 允许在公共汽车专用道上行驶等。1 汽车共享系统从根本上提高了汽车的 使用率, 这意味着在特定的交通需求情况下, 出行车辆的数目将会减少。

总结：一个以使用为导向的为客户提供最终结果的产品服务系统(PSS)被定义为:

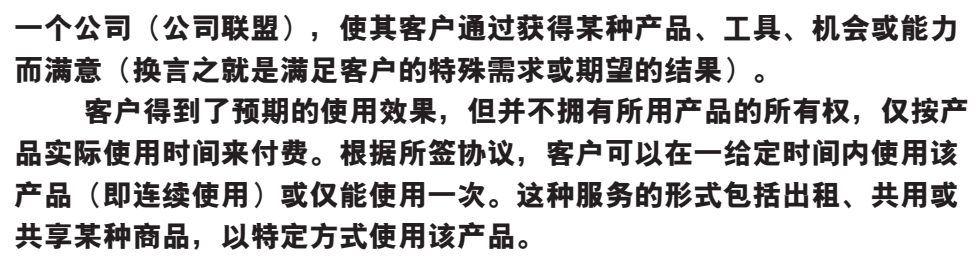

客户不拥有产品的所有权, 也不必亲自操作或运行该系统, 客户只需付费给提供商 就可得到预先协商好的产品或服务。公司和客户之间的这种创新性互动，促使公司 不断寻求更为环保的新解决方案, 如开发生命周期长、可循环、可回收的产品, 以 增强公司的经济实力和竞争力。

\section{1 .5 具有生态效益的产品服务系统的潜力}

本文对具有生态效益的产品服务系统 (PSS) 的三种创新类型（增加产品生命周 期内的价值, 为用户提供最终服务结果, 为客户提供可用的平台）进行了分析, 这 些创新对环境保护和经济发展都十分有利。事实上, 很多例子都表明, 客户和生产 商之间, 或客户与其它体系生产链的利益相关方之间进行创新互动可以实现互利共 赢, 从而在实现经济利益的同时降低对环境的影响。 
与传统的生产方式相比, 通过减少资源消耗/增大服务在产品服务组合中的比 重, 一家公司至少在满足客户相同需求的情况下可以获得更多盈利。在产品的使用 及处理过程中, 通过减少原材料的使用, 降低管理成本及相应的产品维护成本, 制 造商/服务提供商均可节省他们的成本。当然, 这些潜在的成本缩减会被服务费、运 输费、废弃产品处理费以及垃圾回收成本的增加所抵消。事实上, 在工业化国家, 劳动力成本的居高不下是实现产品服务系统 (PSS) 的最大障碍。

在产品服务系统的使用阶段, 企业的利润取决于提供给用户的每单位服务成 本, 因此生产商为了获取更大的经济利益就必须减少所消耗的资源。另外, 由于生 产商始终是产品的“所有者”, 或至少在产品的生命周期内有维护责任, 在经济利 益的刺激下, 生产商就会想方设法延长产品的寿命。实质上, 这种做法降低了生产 商的旧产品处置成本与新产品的制造成本。

在产品生命周期结束时, 出于经济利益考虑, 生产商会将废弃产品的组件进行 重新使用或重新制造, 以便在垃圾填埋场及新产品制造过程中节约资源。此外, 该 系统将会激励生产商想方设法研究出延长材料生命周期的其他方法, 例如, 垃圾回 收, 能源回收以及堆肥等。

系统创新的潜在生态效益依赖于利益相关方所关注的以下几方面的经济利益：

- 产品生命周期的最大化, 致力于扩大产品（及其组件）的生命周期, 增强产 品（及其组件）的使用。

- 材料生命周期的延长, 力图从废弃的产品中最大限度地获取价值。例如, 不 把废弃物当成垃圾填埋, 而是把它们重新加工成二次再生原材料或进行焚烧 来获取能量。

- 资源消耗的最小化, 设计旨在减少生产特定产品（或更准确的说, 由某种产 品所提供的特定服务) 所需原料和能源的消耗。

系统生态效益的提高还与以下因素有关:

- 容易采用的技术（如高新技术），因为服务提供商会避免较高的初始投资。

- 加快利用具有生态效益的新产品代替废弃过时产品的步伐。

\subsection{6 产品服务系统为生产商/制造商及客户带来的利益}

在本部分中, 我们主要介绍产品服务系统为客户和生产商/供应商带来的主要利益。

对客户来说, 产品服务系统 (PSS) 的价值体现在

更加个性化的服务和更高的服务质量方面。产品服务系统

(PSS) 的服务构成非常灵活, 其新功能更能满足客户

的需求，它把产品管理和监督的责任从客户转移到制造商(贝恩斯 (Baines) 等2007)。 企业对企业 (Business-to-business ) 客户常常把次要业务外包出去, 这样它们就可 以集中精力打造其核心竞争力（迈耶（Meier）等2010）。同时这样也减轻了个体消 费者需要承担的责任, 他们不再需要考虑那些与他们需求（例如, 洗净衣服) 不相 干的问题。 
由于更好地利用了产品的性能, 并延长了产品的使用寿命, 客户方也相应地提 高了他们的生产率。在多数情况下, 产品服务系统 (PSS) 都是以最接近客户需求 的形式实现其价值的; 也可能以创新的形式实现其价值, 这里提供了实际生活中几 个例子。

产品服务系统 (PSS) 能为公司带来好处是由于其全新的战略定位（联合国环 境规划署 (UNEP) 2002)，能够与客户所认知的潜在附加价值紧密相关。产品服 务组合将焦点放在了产品的实用效果上, 而使客户不必再考虑设备和产品在获得、 使用、维护和处理等方面的成本及其它问题。

具体而言, 以下几种方式可以提高公司的战略定位:

- 开发新市场, 即相对于单纯提供产品而言, 提供一种能够满足不同需求的并 为消费者带来附加值的新型产品组合; 这种产品服务在工业化经济体中屡见 不鲜。

- 提升灵活性, 由于建立了新型的外包关系, 使公司能够对不断变化的消费市 场做出更快的反应。

- 建立长期的客户关系, 使得公司与客户之间的关系更为牢固, 从而更好地维 护客户。

- 提升企业形象, 通过展示环境效益和社会效益, 使公司符合负责任且公开透 明的要求。

- 改进市场和战略定位, 因为当今和未来的环境立法都有许多要求和限制。例 如：生产者责任延伸制度、资源税、环保绩效等。

\section{1 .7 具有生态效益的产品服务系统的限制和局限性 并非所有的产品服务系统 (PSS) 都具有生态效益}

我们必须强调一点, 并非所有的产品服务系统都能产生环境效益: 产品服务系统

(PSS) 若想取得较高的生态效益, 就必须经过专门的设计、开发和实施。例如, 在产品使用期间, 产品的借出和返还会产生运输费用（同时还消耗燃料, 并排放污 染物）。在某些特定情况下, 燃料成本的增加和对环境产生的不利影响使得产品服 务系统不具备长期可行性。

此外, 即使经过良好的设计, 产品服务系统的一些变化仍可能会产生负面影 响, 这通常被称为反弹效应。社会作为一个整体, 是一套复杂且相互关联的体系, 很难对这个体系有一个全面清晰的理解。因此, 有些潜在的环保方案却在实际实施 时反而增加了全球环境资源的消耗。产品服务系统对消费行为的影响就是一个很好 的例子。例如, 外包服务, 而不是直接拥有产品, 可能导致不注重生态效益的行为。

然而, 从总体上看, 产品服务系统的发展呈现出巨大的潜力, 可以在提高利润 的同时改善环境, 实现双赢。该系统有潜力提供一些必要的条件（即使不充分）来 大力促进社会和经济系统向资源节约型（更低的资源消耗）转变。 


\section{4 可持续产品服务系统设计}

最后, 我们必须具有能够帮助我们实现可持续发展和可持续目标的敏感性、概 念语汇和运行工具, 并且最好避免一些可有可无的研究, 这些研究武断地认为无需 上述工具就可以实现环境友好的解决方案。这也意味着在操作上, 我们需要用一定 的标准、方法和工具对系统中生态效益方面利益相关方之间的互动及相互关系进行 定位设计。

\section{实施具有生态效益的产品服务系统所面临的障碍}

大多数产品都会涉及服务, 反之亦然; 而向服务型经济的转变已经持续了数十年。 换句话说, 产品服务系统也不再是一个新概念。然而, 为什么具有生态效益的产品 服务系统仍然没有得到普及呢?

在工业化国家, 基于生态效益的产品 服务系统的主要实施障碍在于用户文化价值 观念的转变, 即要以可持续的方式满足自己的 “需求” , 而并非是产品 “所有权”。 这种观念的转变说起来容易, 而让消费者或中间零售商 (作为客户) 理解它却并不 是件容易的事。王 (Wong, 2004) 认为, 一个产品服务系统的解决方案若想在消费 市场获得成功, 就必须对其所要实施地区的文化有敏锐的感悟能力。他指出, 斯堪 的纳维亚、荷兰和瑞士的社区已经欣然接受产品服务系统 (PSS) 解决方案。

企业在产品服务系统的设计、开发和实施过程中会遇到一些困难。为了将自己 打造成系统化创新型服务企业, 企业必须转变其公司文化和组织结构, 而企业在这 一转变过程中也会遇到一些障碍。在这方面, 在一些成熟行业中, 有些公司将其视 为企业生存的机会, 而有些公司将其视为进入新领域的契机。

企业要面对的另一个阻碍就是，在向公司内外的利益相关方或战略合作伙伴宣 传推广一些创新时, 很难从经济和环境方面对产品服务系统所节省下来的成本进行 量化。企业面对的障碍还包括在以下方面知识和经验的不足:

- 服务设计的方法和工具;

- 企业用来定位、评估和实施生态效益产品服务系统的新工具;

- 服务管理系统;

- 精通开发和提供服务的企业员工;

- 产品生命周期的成本计算方法。

此外, 企业也可能会遇到一些风险, 包括:

- 与现有内部程序和工具之间的冲突，如会计核算与报告方法;

- 一项服务很容易被竞争对手复制（比有形的产品更容易被复制）;

- 与合作伙伴以及企业间的相互依存会减少企业对核心竞争力的控制, 降低企 业决策的影响力。 
最后, 企业还要面对的问题是外部基础设施和技术的缺乏, 如产品的收集、再生产 和回收。

对每一个利益相关方来说, 生态效益产品服务系统在工业化国家传播的障碍可 总结为如下几点（山士恩 (Ceschin) 2010)：

- 对企业来说, 采用产品服务系统之后, 其管理要比现有的单纯的产品销 售的管理方式更加复杂。因此，企业必须对其文化和组织结构做出一些调 整，以支持企业向更加系统化的创新型服务企业转变（联合国环境规划署 (UNEP) 2002）；而企业在产品销售以外扩展其服务肯定会遇到一些阻碍 （斯托顿 (Stoughton) 等1998; 蒙特（Mont）2002）。要扩展服务就需要 一些设计和管理方面的新知识和新方法。同时, 由于需要中长期的投资, 所 以扩展服务可能存在现金流动不确定的风险（蒙特（Mont）2004）。企业要 面对的另一个阻碍就是, 在向公司内外的利益相关方或战略合作伙伴宣传推 广一些创新时, 很难从经济和环境方面对产品服务系统所节省下来的成本进 行量化。最后, 由于会给生产者的盈利带来巨大的不确定性, 使得他们不愿 意引入这类新概念, 其中的原因有两个方面：一是提供一项产品或服务时, 在定价方面缺乏经验; 二是担心引入这类概念会带来客户所担心的一些风险

（贝恩斯（Baines）等, 2007)

- 对消费者/用户来说, 主要障碍在于用户文化价值观念的转变, 即要以 可持续的方式满足自己的需求, 而不仅仅是拥有产品所有权 (歌德库

(Goedkoop) 等, 1999; 曼齐尼 (Manzini)，维佐里 (Vezzoli) 和克拉克 (Clark) 2001; 蒙特 (Mont) 2002; 联合国环境规划署（UNEP） 2002）。 以服务的获取和共享为基础的解决方案与占主导地位的传统的规范相抵触

（勃莱特（Behrendt）等，2003）；这一点在商对客（B2C）市场中表现得 尤为显著, 而生态效益产品服务系统在B2B领域却得到了广泛的认可（斯坦 赫（Stahel）1997）。产品的所有权不仅为个人用户提供产品的各种功能, 它还是用户地位的象征、形象的体现，并可以满足用户的控制欲（詹姆斯

(James) 和 霍普金森（Hopkinson）2002）。另一个阻碍就是对产品生命 周期成本缺乏理解（怀特 (White) 等, 1999) 这也会导致用户很难理解那 些无所有权方案的经济优势。

- 对政府来说, 在监管方面, 现有法律也许并不支持基于产品服务系统的解决 方案。由于环境对公司本身并不会直接产生回报, 因此公司一般不会重视环 境方面的创新 (蒙特 (Mont) 和林赫斯特 (Lindhqvist) 2003)。此外, 为 了使公司能够促进并推广这种创新，政府会制定一些政策，而这些政策在执 行过程中也会遇到一些困难（蒙特 (Mont) 和林赫斯特 (Lindhqvist) 2003 ; 山士恩 (Ceschin) 和维佐里 (Vezzoli) 2010)。

如果从一个更广阔的视角来看, 我们观察到, 固有习惯的不断扩散会限制基于生态 效益的产品服务系统的推广。也就是说, 产品服务系统不仅仅是一个跨越式的企业 
战略: 通常需要有一个过渡的过程 2 。此外, 最重要的一点是人们缺乏较高生态效益 的产品服务系统设计方面的知识: 我们需要一批能够应对复杂的系统研究和系统创 新的设计师（和设计教育工作者）以及其他专业人士。

\section{2 新兴经济体和低收入国家和地区的产品服务系统}

\subsection{1 产品服务系统在新兴经济体和低收入国家和地区会有发展前 景吗?}

2000年, 联合国环境规划署 (UNEP) 成立了一个国际研究小组 ${ }^{3}$, 向世界宣传产品 服务系统创新理念, 并开始探索该系统的发展潜力, 具体归纳为以下几个方面。

\section{产品服务系统（PSS）创新在新兴经济体和低收入国家和地区是否同样适用?}

提出这个问题是因为当前关于可持续产品服务系统的研究和开发并没有涉及到 可持续发展的社会道德层面, 也没有考虑到新兴经济体和低收入国家和地区的特殊 背景（已在联合国环境规划署的规划考虑范围内）。

而这个问题也是解决下一问题的前提。

（如果第一个问题的答案是肯定的）那么在这些背景下，产品服务系统（PSS）创 新方法对社会公平、社会凝聚力以及生态效益会有所帮助吗?

\section{如果有帮助的话, 它又具有什么特点呢?}

联合国环境规划署的国际专家组对前面两个问题的回应是基于如下假设：

“作为一个商业机遇, 产品服务系统 (系统创新) 能够促进新兴经济体和 低收入国家和地区加快社会经济的发展进程, 跳过产品的个人消费/产品所 有权阶段, 转向以消费者满意为基础、资源消耗程度较低的先进的服务经 济”（联合国环境规划署2002）。

为了明确这一假设, 我们可以研究一些新兴经济体和低收入国家和地区产品服务系 统创新的例子。4

2 参见第2部分，第1节。

3 该研究小组（包括作者）拥有来自工业化、新兴经济体以及低收入国家和地区的研究人 员; 它成立于 2000 年, 并于2002年解散, 其主要成就是以联合国环境规划署 (2002) 的名 义出版的“产品服务系统: 产品可持续发展的机遇”

4本章中提及的案例出自前面提到的2002年联合国环境规划署出版的那部书和小册子以及世 界可持续发展委员会数据库, 两者在各自的网站上都可免费下载：http://www.unep.fr/scp/ publications/details.asp?id=WEB/0081/PA 和 http://www.wbcsd.ch/publications-and-tools. aspx 


\section{全套式服务一一分布式太阳能和电气设备, 巴西}

2011年, 法比奥 ·罗萨 (Fabio Rosa) 开始探索一种新的商业模式，为巴西农 村地区的人们提供他们所需要的服务：包括各种能源服务, 而不仅限于太阳能。 罗萨 (Rosa) 创立了一个营利性公司一一农村电气化适用技术公司 (STA) 和一个非营利性组织- - 自然能源开发和可持续性研究所 (IDEAAS)。为 此, TSSFA开发了一种租用服务系统, 即消费者只需支付安装费和每月10美元 的租赁费, 就可以使用具有成本效益的太阳能服务套装- - - 种普通的家用光伏 太阳能系统。这不仅符合人们购买能源的传统支付方式，也为消费者节省了50\% 的销售税。TSSFA所说的家用太阳能套装不仅包括发电所需的全部硬件设备安 装服务, 还包括依靠太阳能系统发电的产品, 如照明设备和电源插座。STA保留 这些有形产品的所有权，仅仅把利用这些设备所提供的服务租赁给消费者。

以上案例说明, 产品服务系统创新在新兴经济体和低收入国家与地区是适用 的。得出这个结论的主要理由如下（联合国环境规划署 (UNEP)，2002）5: 首 先, 如果产品服务系统 (PSS) 在体系层面上具有生态效益, 说明上述案例所描述 的产品服务, 可以为经济发展潜力小的国家提供机会, 使其更容易利用较低的成本 来满足社会需求。

其次, 产品服务系统 (PSS) 更注重产品使用的背景, 原因是商家并不仅仅是 在销售产品：他们还要与终端用户建立（长期）良好的关系。正因如此, 在新兴经 济体和低收入国家与地区增加服务会吸引更多的当地有能力的利益相关方, 从而促 进当地经济的繁荣发展。

再次, 既然产品服务系统是属于劳动和关系密集型的, 它的发展就会增加当地 的就业机会, 也会促进技术在当地的传播。

最后，由于产品服务系统的开发是建立在系统相互关系以及伙伴关系构建的基 础之上, 所以在由下至上的第二次全球化进程中, 产品服务系统与当地网络企业的 发展是密切相关的。下一章节将阐述上文中提到的最后一个问题, 并详细介绍分布 式经济的发展模式。

\subsection{2 分布式经济: 一个具有生态效益、社会公平和凝聚力、具有 良好发展前景的经济模式}

我们假定产品服务系统 (PSS) 适用于新兴经济体和低收入的国家和地区, 那么在 这里, 我们提出下列问题供大家探讨:

\section{产品服务系统（PSS）需要具备什么样的特点, 才能将社会公平、凝聚力以及生态 效益在新兴经济体和低收入国家与地区中体现出来?}

\footnotetext{
5 该假设经一系列案例研究证实, 由联合国环境规划署专人负责。
} 
我们的答案就是将产品服务系统 (PSS) 和分布式经济这两种模式结合起来。 与产品服务系统 (PSS) 类似, 一些专家认为分布式经济是一种有益的经济模式, 它能将社会道德和环保层面的可持续性有机地结合起来。（曼西 (Mance) 2003; 里夫金 (Rifkin) 2002; 约翰逊 (Johansson) 等2005; 维佐里 (Vezzoli) 和曼齐 尼 (Manzini) 2006; 克鲁 (Crul) 和迪尔 (Diehl) 2006; 里夫金 (Rifkin) 2010) 。以研究经济学和可持续性而闻名的国际工业环境经济学院 (IIIEE), 将分布式经 济定义为：生产的不同单元分布在各个地区, 在这些地区以一些小规模的、组织灵 活、彼此互相联系的单元为单位开展生产活动 (约翰逊 (Johansson) 等2005)

工业化背景下以集中的方式和大规模的生产单元为特征的主流经济模式，无论 从环境保护层面还是社会道德层面, 都是破坏可持续发展的罪魁祸首。这主要体现 在:

1. 由于原料和成品需要长途运输, 这就需要降低单位运输成本;

2. 产地和客户所在地之间的距离越远, 隐性的环境成本和社会成本就越高(达尔 贝里 (Dahlberg) 和扬松 (Jansson) 等1998);

3. 削弱了本地参与者对当地经济环境的掌握和控制能力;

4. 扭曲并破坏了文化认同感;

5. 限制了区域经济活动的多样性（约翰逊（Johansson）等2005）。

除了以上不利因素外, 主流经济模式的大规模和集中式结构也使得生产商不能 对瞬息万变的市场需求迅速地做出反应。近几十年来, “分布式” 6这个词愈来愈频 繁地出现在与社会经济体系相关的地方。如: 信息技术与分布式运算; 能源系统和 分布式能源生产; 生产和分布式制造可能性; 变动过程和分布式创新, 分布式创造 力及分布式知识等。在整个社会技术体系中, 该术语用于表示一种新的分布式经济 模式。

二十年前, 这些概念非常流行（如, “经典的” 分布式运算）。有些概念在 国际上有很大影响（例如分布式能源生产和分布式制造等概念）。一些概念以前出 现过, 一些则在近几年内出现（如：分布式创新、分布式创造及分布式智能等）。 它们受到了广泛关注, 而且关注的人群还在不断增加。在以上这些例子中, “分布 式” 的实质就是由相互联系而又各自独立的元素组成的网络, 即这些元素既相互独 立, 同时又与体系中其他元素有着紧密联系

下面, 我们从经济学和社会道德角度来分析一下化石燃料的资源模式。受到本 地化、矿物的开采及运输条件等复杂因素的影响, 化石燃料资源具有生产高度集中 和设施分布广泛的特点, 而这对获取资源尤其是能源和电能十分不利。因此, 有人 认为化石燃料能源本身的特点导致了贫富差距的加大（里夫金（Rifkin）2002）。

作为化石燃料的替代品, 使用可再生的本地资源, 如太阳能、风能和氢能等冊 庸置疑是非常环保的, 因为它们有效地降低了温室效应（及其所带来的不良影响）

6 分布：将某件事物分成不同的部分并进行分配（源自Wiktionary词典, 基于wiki的公开词 典）。 
, 具有可再生性, 而在环境影响方面, 与化石燃料相比, 它们在开发、运输和分配 等一系列环节中对环境所造成的影响要小很多。它们可以在小规模的经济单元中, 在独立的居民区, 甚至个人家庭中安装使用。如果太阳能、风能和氢能得到充分开 发, 人类将获得更多的能源, 而资源管理机制也会朝着民主化的方向发展。由可再 生资源提供能源的分散式设施, 通常称为分布式能源生产, 一方面减少了对环境的 影响, 另一方面促进了资源和能源生产管理的民主化, 使得个人、社区和国家在保 持其独立性的同时，还要承担相互间的责任（自给充足和相互依存）。

尽管可再生能源资源对环境影响较小, 是一种兼具分散性和民主性的生产体 系, 但这些优势不会自动发挥出来。

无论是在工业化、新兴经济体还是低收入国家或地区，为了更好地控制并掌握 自己的命运, 采用充足的、分散的、自下而上的体制将尽可能多的生产商和使用者 纳入到这些网络中来是非常重要的。例如, 在低收入地区, 通常会有农村合作社与 小型信贷银行进行互利合作 7 。

从更广泛的意义上说, 我们认识到, 在一个相互联系相互作用的社会背景下, 将环境问题和社会道德联系在一起, 需要坚持如下原则:

\section{主要使用当地传统的、可再生资源（即当地的可再生资源），引入分散式 系统网络用于开发、生产及使用这些资源。}

据观察（沙克斯（Sachs）等2002；沙克斯（Sachs）和桑塔留斯（Santarius） 2007），一旦当地利益相关方参与到资源的开发、输送和销售中来, 他们将更加重 视资源的可再生性。其根本原因是他们的经济命脉不仅依赖于这些资源短期内的可 获得性，更依赖于长期不断的资源供应。因此他们并不赞成过快地消耗资源。

该主题与那些基于合作、集体主义和协作观念的替代经济或替代企业研究的 一些观点相呼应(所谓C因子, 拉佐特 (Razeto) 2002)。尤其是它还融合了对合 作网络和创新社区的研究（佛罗里达 (Florida) 2002; 曼齐尼 (Manzini) 和耶由

(Jegou）2003），创新社区的居民都是有见识, 有批判精神, 有上进心的, 他们自 发组建或大或小的网络, 并建立了团结互助的经济社区。换句话说, 它是可持续社 会的一种创新形式，即一种自下而上的社会参与的组织形式，它提高了社会素质并 减少了对环境的破坏。

欧克利德斯 - 曼西（Euclides Mance）将这一问题放在共济经济 (Solidarity econom) 背景下进行讨论。曼西将“共济合作网络” (solidarity cooperative networks）（曼西（Mance）2001）称之为“在一个团结协作的背景下, 一个自给 的、能够自动传播的生产与消费单元所组成的网络”。

7 就全球层面来说, 合作社是最好的组织形式, 无需借助大型跨国公司的力量, 便能促进各 国本地资源实现有效的获取和应用。合作社是以地域构成为基础构建起来的, 将单个生产 者和消费者联系在一起, 是参与性的非盈利机构。根据国际合作社联盟的规定, 合作社的 组建原则如下：会员资格审批的统一标准、民主参与、资源平等分配、自治、培训、合作 社与社区服务间的配合。单一消费者（和生产者）的聚集使他们以更强大的实力来处理他 们与供应商之间的关系（集体谈判）。 
40 可持续产品服务系统设计

适用于分布式经济网络的模式有以下两个主要特点:

- 它们以本地为主。即企业或项目均是基于可持续的本地资源和本地需求, 但 也可以向外部或全球范围扩展。

- 它们都是网络结构企业或项目。比如, 它们通过网络连接可以获得各种资源 和市场。

最后, 为了回答本部分开头所提出的问题, 这里提出以下假设, 该假设的前提 是产品服务系统 (PSS) 能在新兴经济体和低收入国家或地区获得应用。

产品服务系统创新 (PSS) 为新兴经济体和低收入国家或地区的社会经济 的发展提供了商业机会一一它无需个人拥有对产品的所有权, 直接跨越到 一个基于 “满意度”和低资源消耗的先进的服务性经济，这种经济的特征 是, 它是以本地资源为基础并具有网络化结构的企业和项目, 是一个致力 于资源、产品和服务自主化的可持续的第二次全球化进程。

在这个框架下, LeNS项目提出的可持续产品服务系统的定义如下:

价值创造体系（满意体系）的利益相关方之间进行创新互动, 提供一种能 够满足客户特定需求的产品与服务的模式（提供一个 “满意单元”），在 这种模式下, 经济利益和竞争利益促使供应商不断地寻求能够同时带来环 境和社会效益的新的解决方案。 


\section{可持续产品服务系统设计}

\section{1 可持续产品服务系统设计：定义}

在理解了由产品服务系统为产品与服务开发所提供的机遇之后, 我们开始讨论设计 师的角色。

让我们从（工业）设计的定义开始, 国际工业设计协会联合会 (ICSID) 1 将其 定义为:

设计是一种创造性活动, 旨在整个生命周期中建立目标、过程、服务及系 统等多方面的属性特征。设计旨在发现并评估一个系统的结构、组织、功 能、表现方式和经济关系等各种属性和特征，其任务是:

- 促进全球可持续性和环保事业（普遍伦理）;

- 为整个人类社会、个体和集体带来利益和自由;

- 最终用户、生产者和市场参与者（社会伦理）;

- 在全球化的背景下支持文化的多样性（文化伦理）;

- 赋予产品、服务和系统一定的形式, 这种形式是这些产品、服务和系统的复 杂性一种表达（符号），并与其复杂性保持一致（美感）。

尤其值得一提的是，与过去的定义有所不同，设计不仅仅考虑产品和过程，而且在 设计范围内考虑整个系统。此外, 该定义提倡这样一种理念, 即考虑“整个生命周 期”的设计理念, 并将环境问题纳入考量范围。

该定义与来自同一机构的托马斯 · 马尔多纳多 (Tomàs Maldonado) 在 40 年前 所给出的定义有所不同：工业设计，我们通常是指对工业化生产对象进行设计。

1自2005年以来的定义, 参见http://www.icsid.org. 
此外, 新的定义包括一个可持续产品服务系统方法, 主要是拓展产品之外的创 新可能性，尤其是那些具有下列特征的创新：

- 与客户特定 “满意度” 相关的开发、设计和交付

- 激进式创新, 不局限于技术层面, 作为某一具体生产链的利益相关方之间的 新型互动/合作关系

- 能够减少环境影响（系统生态效益）并有助于公司经济利益和竞争力方面的 创新

通过上述解释，可持续产品服务系统设计可以被定义为：

\footnotetext{
一种基于利益相关方（直接并间接与 “满意” 系统相链接）的创新互动设 计, 并能够共同满足特定客户需求（实现 “满意单元”）的产品和服务系 统的设计。在这种设计中, 设计方案提供者在经济利益和竞争利益的驱动 下, 不断寻求能够带来环境与社会伦理效益的新的解决方案。
}

\section{2 可持续产品服务系统设计：方法与技能}

至此, 将可持续产品服务系统创新概念纳入到设计中使设计研究人员能够在更加具 有战略意义的层面上对新技能进行定义，通过利益的战略趋同，实现系统的可持续 性, 而这些方法是与满意为导向的方式一致的。“战略”在这里也指的是对社会结 构中特有的文化背景、特定的机遇和障碍的必要认识。例如, 在亚洲背景下的设计 研究, 必须考虑那些对社会已经产生了上千年影响的传统和价值观体系 ${ }^{2}$ 。

总之, 本书中所关注的可持续产品服务系统设计的方法和技能包括:

- 满意一一系统方法, 即满足一项特定需求（满意单元）的设计和所有相关的 产品和服务

- 一种利益相关方配置方法, 即具体满意体系的利益相关方的互动设计

- 系统可持续方法, 即此类利益相关方之间的互动设计（提供模式），不断寻 求新的、具有生态效益、社会公平、当地的、具有凝聚力的解决方案

将在以下章节进一步探讨这些关键的要素。

\subsection{1 具体满意度设计}

以满意度为导向的方法, 其首要关键点在于, 关注的焦点已经不再集中在一个单一 的产品上了。因此, 仅对单一产品进行设计和评估是不够的, 我们应对那些与满足 特定需求相关的每项产品和服务的整个过程进行考量。

为了弄清这一概念, 我们可以回顾一下之前的例子(联合国环境规划署 (UNEP) 2002), 客户想得到的（满意单元）是 “拥有干净的衣服”。在这个单元中, 我们需 
要有洗衣机、清洁剂、水、电（服务中包括提供这些要素）, 并提供保养、维修和回 收服务。“满意”这一术语是强调将设计范围从一个单一的产品扩展到能够同时满 足特定需求和欲望的产品服务系统（及利益相关方）, 实际上, 就是满足特定需求。

其他学者也对这一术语的使用予以支持。例如, 梅多斯 (Meadows) （梅多斯 (Meadows)，梅多斯 (Meadows) 和兰德斯（Randers）2006), 在一个公式中使 用了“满意” 这一术语3 来评估增长的极限, 在由罗马俱乐部 (Club of Rome) 推出 的举世闻名的《增长的极限》一书的30年更新版本中, 作者描述了快速增长的全球 人口与有限的资源供应之间的矛盾所带来的严重后果。

马克斯 (Marks) 等人 (2006) 认为, 在向可持续过渡的框架下衡量个人福祉 的各种指标中, 更倾向于采用“满意度”这一指标。

最后, 在为产品生命周期设计引入功能单元（参见引言）这一概念的同时, 可 以引入一个满意度单元的概念。以汽车为例, 我们将下列功能单元定义为: 每公里 运送一位乘客 (可能是用车) 作为一个单元。如果我们考虑一辆车能够带来的满意 度, 我们实际上可以识别出若干满意单元, 例如:

- 满意单元1: 个人上下班的交通方式（每年）

- 满意单元2: 个人文件快递服务（每年）

满意单元的概念由此要求一种方法同时能够:

- 广义（需要考虑更多产品、服务和利益相关方）

- 狭义（只看一个客户的最终满意度）

根据埃伦费尔德 (Ehrenfeld) (2008), 设计中获得满意的方式 “更多的是考虑客户 的状态 (满意) 而不是拥有（满意的产品）”。

\subsection{2 利益相关方互动的设计}

第二项关键的任务是, 引入利益相关方配置方法。如果我们想要设计利益相关方之 间互动, 系统设计方法应当设计并推广社会经济利益相关方之间的创新互动与合作 的类型, 同时能够满足特定社会的需求。

为了更进一步阐明这种方式，我们可以再次回顾一下洗衣服务的例子，而在这 一满意体系中, 创新涉及到所有不同的社会经济利益相关方。这些利益相关方包括 洗衣机和洗涤剂的生产商、水电供应商、用户以及负责保养和回收的机构。

为了使这种模式更形象化, 我们有必要将其与传统设计师通常关注的设计问题 进行对照, 传统设计师在设计过程中往往会说明产品组件的技术特征、性能和美学 特征。通过对比, 我们便能够掌握那些与产品的构成材料（具有特殊效能）及其构 成方式 (结合要素) 无关的产品要素的配置。这样, 可持续系统的设计师就必须想 象并倡导一种能满足具体社会需求的系统适当要素（社会经济利益相关方）之间的

3 《增长的极限》: 30 年的变化（梅多斯 (Meadows) , 梅多斯 (Meadows) 和兰德斯 (Randers) 2006)，应用了以下公式：资源和能源/年 $=$ \#每人 $\times($ 满意度/人 - 年 $) \times$ 资源 和能源/每项满意度指标)。 
创新型连接（合作/互动）。换句话说, 满意系统组件就是使经济和社会活动中利益 相关方之间（通过他们的技能和能力）形成良好的合作互动关系（合伙关系, 或通 常所谓的互动关系）。因此，系统结构的设计要求我们弄清楚谁是最佳利益相关方

(组件)，以及什么是最合理的相互联系方式（连接）。

图3.1显示的是一个产品服务系统的设计工具, 又叫利益相关方系统构成图。它 可以被看作是一个设计和可视化工具, 其功能是辅助利益相关方的结构设计。

\section{图3.1 利益相关方系统构成图, 该图展示了一个大学校园餐厅饮食满意系 统的例子。}

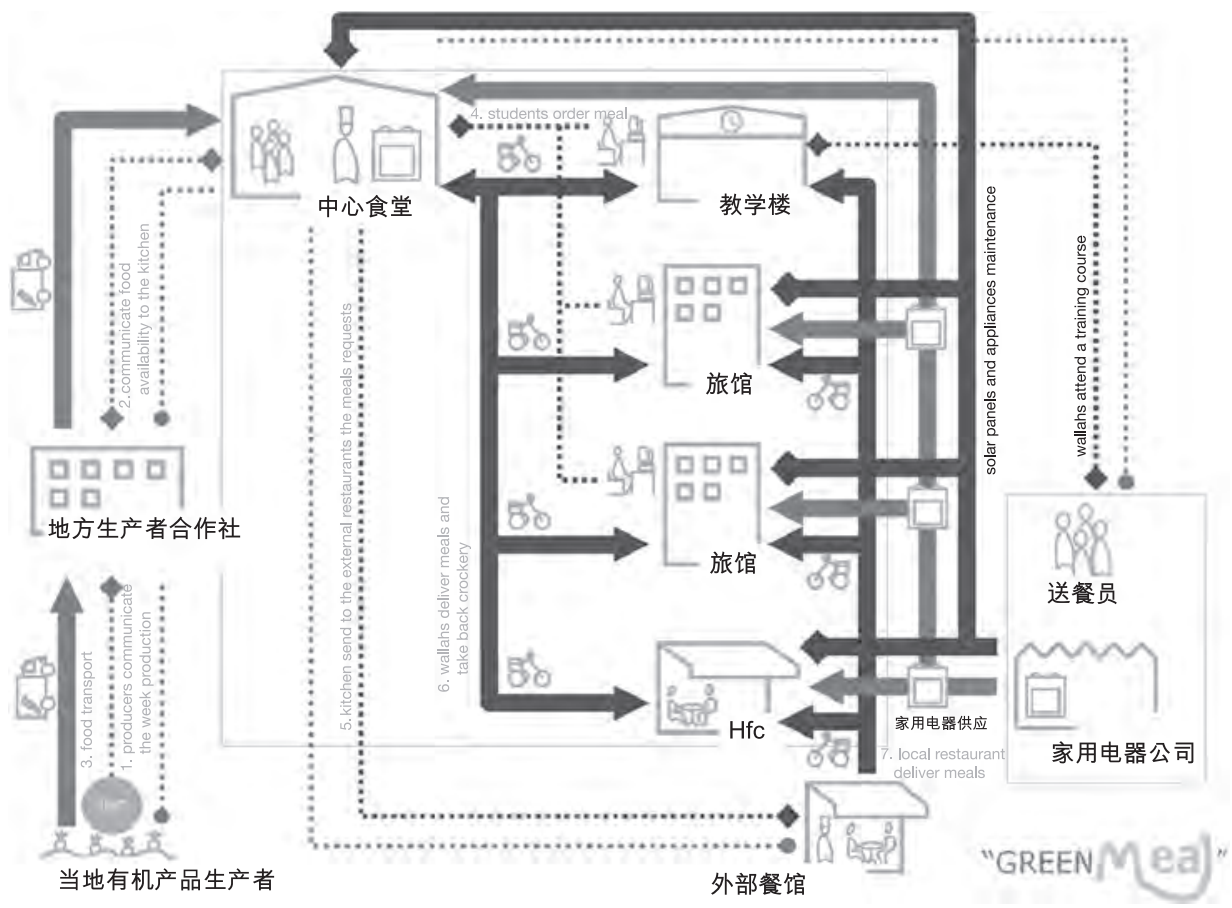

\subsection{3 可持续利益相关方交互系统设计}

必须再次强调, 正如上一章所述, 不是所有的系统创新都具有促进生态效益、社会 平等和团结的功能。为了避免那种认为 “可实现的产品服务系统自然而然就具备可 持续发展的潜力”的直观假设, 我们必须以挑剔和反思的态度来进行分析。

因此, 就开发新系统而言, 我们有必要采取适当的尺度和标准。这就要求我们 在管理和定位产品设计的过程中要非常重视研究各种案例、方法和工具, 以此促进 利益相关方之间形成可持续的互动关系。

以洗衣服为例, 新的利益相关方系统构成包括, 洗衣服务按次付费系统 (单 位满意度），洗衣机送货上门（不拥有），水电供应（不直接支付），洗涤剂供应 （不直接支付），维护、升级以及使用周期结束后的回收。公司和客户之间这种创 
新型互动激发了公司进行设计的兴趣, 促使它们设计并提供更高效（节能、节水、 清洁）、更持久、能重复使用以及可以回收利用的新型洗衣机。

如此方式所需求的技能对于设计师来是比较生疏的, 但之前我们已经提到, 这些技能与一个称为战略设计的领域相关(例如: 曼齐尼 (Manzini), 科利纳

(Collina) 和埃文斯（Evans）2004), 而这个领域有自己的理论、方法和工具。

因此，可持续战略设计这个术语开始被人使用（曼齐尼（Manzini）和维佐里 (Vezzoli) 2001)。由于这种考虑导致了可持续性产品服务系统设计与战略设计 和产品生命周期设计相聚合, 因此有人主张(布力扎特 (Brezet) 等2001; 曼齐尼

(Manzini) 和维佐里 (Vezzoli) 2001), 环境可持续设计必须使用并整合战略设计 的方法和工具（反之亦然）。

从设计角度，所有社会经济利益相关方都被纳入了考虑范围，设计师也必须用 必备技能, 在参与式设计背景（例如各类企业、机构、非政府组织, 协会和服务系 统）下推动系统的开发（包括提供产品和服务）。

就设计实践而言, 凭借一系列欧盟资助的研究项目, 早在本世纪初就开发出了 第一批设计方法和工具, 例如, 为开发可持续设计导向情景的工具; 为促进各利益 相关方战略合作的工具; 为了互动设计所提供的工具; 为了创造高度可持续发展理 念的工具。在亚洲背景下, 教育学家们一直在致力于开发和测试适合本土条件和文 化习惯的工具和框架。

本书第四章将讨论所开发的方法论以及相关工具。

\section{3 系统生态效益设计标准及范例}

事实上, 并不是每个系统创新都具有生态效益。因此, 当设计一个新系统时, 采取 适当的标准和指导方针并使用正确的方法和工具来进行系统创新至关重要, 这样做 才能设计出可持续解决方案。在此, 我们提出若干系统生态效益设计标准。

首先, 根据欧盟研究项目MEPSS 的定义, 这里列出六条以生态效益为导向的标 准。

1. 优化系统生命 (以下的3.3.1节)

2. 降低运输和分销量 (3.3.2)

3. 节约资源 (3.3.3)

4. 减少浪费/增值 (3.3.4)

5. 生态保护/生物多样性 (3.3.5)

6. 减少有毒物质排放 (3.3.6)

在LeNs项目框架内制定了一系列指导方针 ${ }^{5}$, 附件中列出了各种标准。

4 一项被命名为MEPSS的欧洲研究项目, 产品服务系统的发展方法, 由欧盟赞助, 5FP, 增长。

5 LeNS项目还就其他工具和指导方针进行了研发和测试, 特别针对当地的特质和文化价值观 进行了研究。相关方法在本卷第2部分有详细的论述。 
对于一个具体的满意单元而言，（如前面提到的洗衣服务），某些标准（及其 相关的指导方针）比其他标准对减少环境影响更具相关性（例如, 减少资源消耗和减 少有毒物质排放比其他标准具有更高的优先性）。因此, 在决策过程中（即设计）, 识别设计优先性 (生态效益) 至关重要。也就是说, 最有可能满足这些标准的是那 些与现有产品和服务组合最为相关的, 能够实现特定满意度, 并能够促进创新利益 相关方互动的产品服务组合 6 。以下章节将结合一些例子来阐述这些标准。

\subsection{1 系统生命优化}

系统生命优化是指设计一个利益相关方互动系统, 以满足某一具体需求, 延长产 品寿命, 并提高产品利用率。

通常, 一个产品使用寿命越长, 对环境影响就越小。图3.2 所示是一个拥有更 长使用寿命的产品 (系统) 所具有的生态优势一个使用寿命短的产品不仅会过早产 生垃圾（而其他产品还可以正常使用）而且由于需要对其进行替换, 会对环境带来 进一步影响（参见图3.2）。新产品的研发、生产和分销, 不仅包括旧产品所有的功 能, 而且会增加资源消耗和污染物排放指标。图3.2所示的是对两个具有相同功能但 具有不同生命周期的产品进行的比较, 并具体显示了在哪一个阶段能够避免环境影 响。换言之, 与寿命较短的产品相比, 寿命较长的产品能减少很多由于产品研发、 生产、销售和处理所造成的不良影响（如图3.2上半部分所示）

\section{图3.2 所示是一个拥有更长使用寿命的产品（系统）所具有的生态优势}

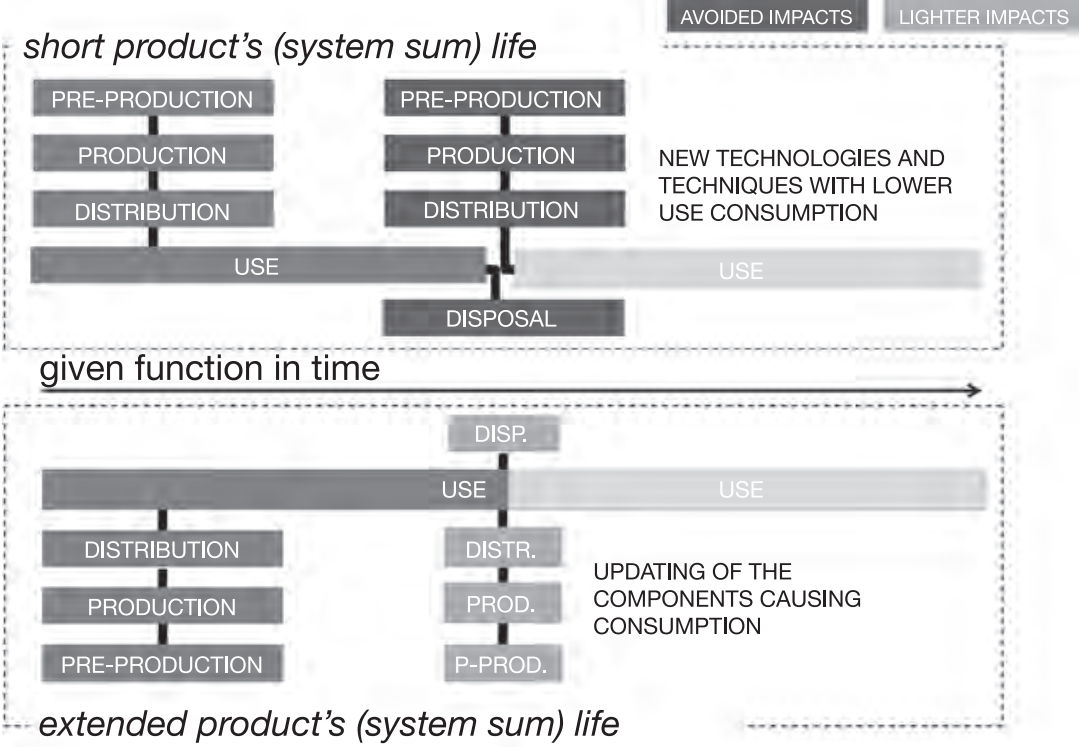

6 参见第1部分第四章的第4.3.1节SDO工具 
在使用阶段, 延长产品寿命并不一定能从总体上减少环境影响; 相反, 如果新 产品更具环境效益, 延长产品寿命可能会给环境带来更大的影响。换句话说, 在使 用阶段, 对于环境有很大影响的某些产品, 拥有最佳的使用寿命才是最好的结果。 在提供相同服务时, 技术的进步还能为人们提供更加环保的新产品（节能减排）。 今后, 有可能会出现这种情况：产品的研发、生产和分配（废品处理）阶段给环境 带来的不良影响将被新产品更优质的性能所抵消。

因此, 产品的使用寿命通常会有一个上限, 也就是一个临界点。从这个临界点 开始, 用新产品（提供相同服务）取代旧产品会降低产品对全球环境的影响。更确 切地说, 就是生产和分配新产品以及处理旧产品所造成的环境影响要低于因为新产 品性能的提高而降低的环境影响。只有那些在利用过程中消耗较少资源（能源和材 料) 的产品才有必要拥有较长的使用寿命。

让我们来看一个更典型的案例, 这些产品在使用和维护的过程中消耗大量的资 源, 例如摩托车和家电。在这些案例中, 可以采用一种相关策略, 即采用资源消耗 较低的新组件替换那些资源消耗较大的组件。这样, 便无需研发、生产、分配和处 理整个产品, 而只需关注那些能全面降低环境影响的部分（图3.2)

最后, 从系统角度出发（不限于一件产品），我们必须考虑在整个产品或辅助 产品（整个系统）的使用寿命期间对环境造成的各种交互影响，并找出方法避免产 生这些影响。

优化环境系统生命可以通过强化产品的使用功能来实现。

在特定的时间和地点, 任何产品如果比同类产品使用强度高, 在满足其性能的 条件下, 对这种产品的需求数量便会减少。这样也能够减少对环境的影响。下面我 们要利用一些图表来说明这个概念。

图3.3假设产品的实际使用与寿命无关，我们来设想（参见上面“使用时间”的 箭头）在 $A 1 、 A 2 、 A 3$ 时段, B1、B2、B3 时段, C1、C2、C3 时段, 该产品分别由 安德鲁 (Andrew) 、伯纳德 (Bernard) 以及查理 (Charlie) 高强度使用。

现在我们来设想另外一种情形（参见下方的“使用时间” 箭头），每位参与者 在相同时段（假设相同的功能）拥有并使用自己的产品。从图表可以看出, 主要影 响是由额外产品在研发、生产和处理阶段带来的。这种情况只有在当产品的使用寿 命不受控于实际使用时间时才成立，例如，由于产品过时。

换句话说, 产品的使用强度越大, 寿命就越短, 这样就不会使全球产品总量和 产品处理量增加。因此, 在满足同等需求的前提下, 产品正常使用的频率越高, 产 品越陈旧（技术或审美方面）, 额外产品的数量就越会减少。事实上, 通常使用强 度越大就越会缩短绝对寿命（从购买到处置），但是，另一方面，会延长产品有效 使用期（减少对过时产品的处理）。

产品寿命与其实际使用时间成反比, 这就意味着较大的使用强度会有效缩短产 品使用寿命。让我们回顾一下之前的图表, 并延长其时间轴。假设功能相同（在这 两种情形下安德鲁 (Andrew) , 伯纳德 (Bernard) 和查理 (Charlie) 都是在同一 时段使用产品），我们一定能找到高强度使用产品的替代品（参见图3.4, 我们假设 在 “使用时间” 线的顶部有两个替代品）。然而, 在这种情形下, 环境优势仅是源 于技术的进步（提高产品在研发、生产、使用和处理各阶段的效益）。 
48 可持续产品服务系统设计

\section{图3.3 加大产品系统使用强度带来的生态效益（预计使用寿命与实际使用时 间无关）}

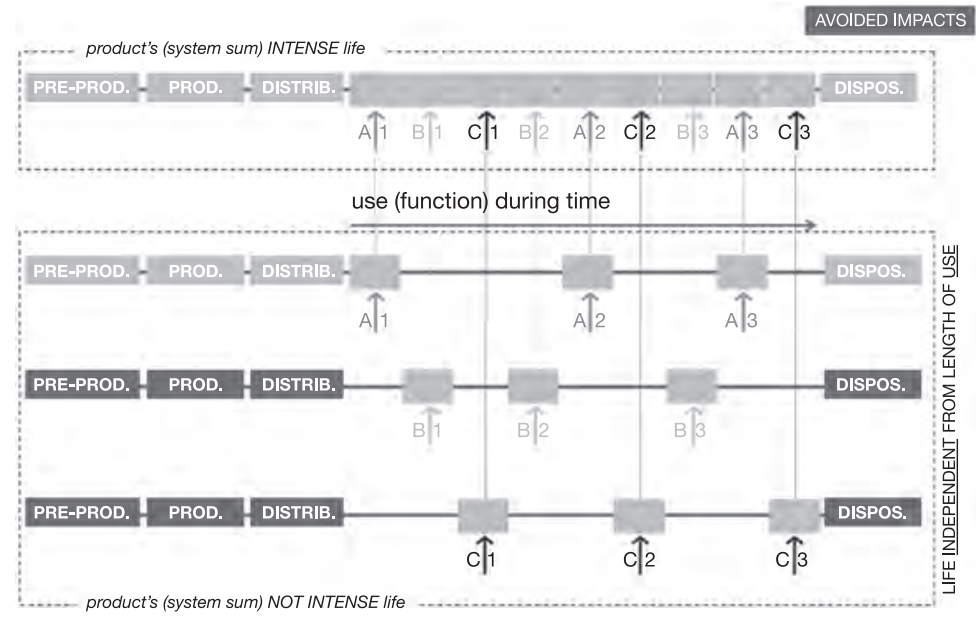

因此，只有替代技术的出现才能在满足同等需求的前提下（降低影响的可能 性），不增加额外产品的数量，从而提高生态效益。

此外，我们可以适当把使用强度与生产出来但并没有销售出去的产品的数量结 合起来考虑。换句话说，额外产品数量越少，我们对某组产品的使用强度就越大。

\section{图3.4 加大产品使用强度带来的生态效益（使用寿命取决于使用时间）}

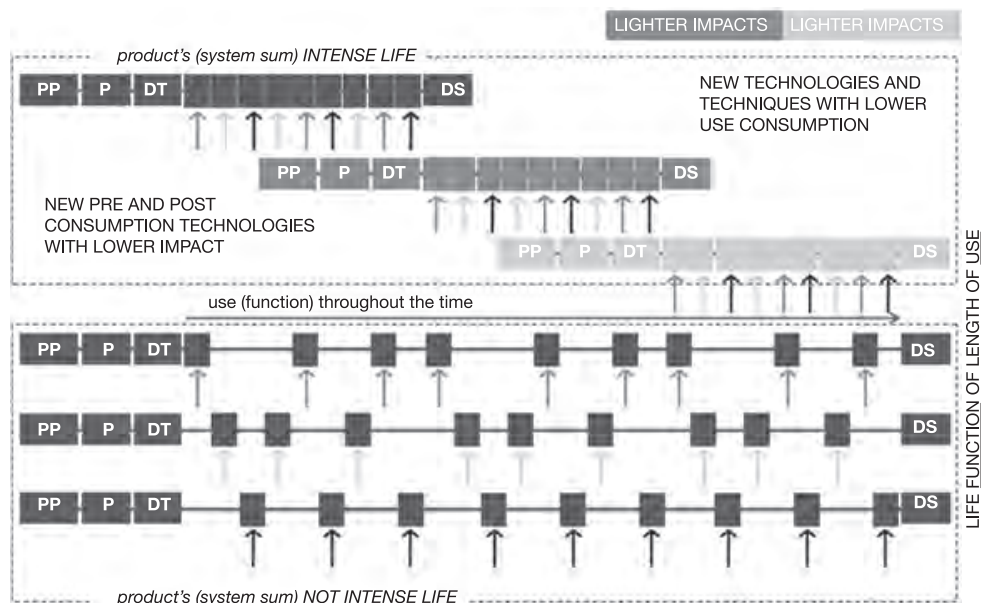


就性质而言, 在优化产品使用寿命方面, 当前系统存在下列问题:

- 使用一次性产品或一次性辅助产品

- 使用一次性包装

- 在技术层面, 系统的某些部件过时

- 系统的某些部件较之其它部件更易磨损。

\section{优化系统生命的产品服务系统范例}

\section{EGO, Ecologico Guardaroba Organizzato(组织生态服装)}

EGO是一家意大利公司, 在布雷西亚和米兰有两家连锁店。该公司建立了一个 为少数女性提供共享服装的系统。

用户在注册后可以（从样本册中）选择14套衣服（这些衣服将被放置在 共享衣柜” 中。目前, 衣柜里有120款衣物, 被分成八种风格）。用户每周可以 去一次连锁店, 挑选并带走7件衣服, 同时必须归还前一周拿走的衣服。会员要 支付年费170欧元, 然后每月再支付130欧元用于清洗和维护衣物。EGO公司不 仅提供服务而且进行服装设计和生产（由外国公司进行生产）。

这种服装共享系统带来的主要生态效益就是提高了衣服的使用率, 这意味着 在一个既定的有服装需求的范围内, 对新服装生产的需求减少了（通过加大产品 使用强度来优化系统生命周期）; 另外, 因为制造商或提供者是服装的所有者, 出于经济利益的考虑, 他们当然愿意延长产品使用寿命, 以达到减少产品维护和 处理成本及新产品制造成本的目的。这种优化系统生命的结果是减少衣服在生 产、运输和处理过程中对资源和能源的消耗。另外, 该公司使用高效节能的洗 衣机洗衣服 (EGO的这种举措减少了每次洗涤的费用, 也减少了能耗和洗涤剂 的用量）。另一方面, 我们必须强调, 与传统方式相比, EGO系统洗衣次数很 多, 因为衣服穿过一次后就必须清洗一次, 而传统情况是-一用户穿的是属于自 己的衣服, 自己负责清洗工作, 洗衣次数相对较少。

\subsection{2 减少运输或分配量}

减少运输或分配量是指利益相关方互动系统的设计会减少运输量和包装量。例如我 们可以通过创造合伙关系使这类创新成为可能：远程活动（使用、维护、修理）, 使用当地资源（信息/数据传递），现场组装/生产（信息/数据传递）, 以及产品维修 保养的远程控制。

就性质而言, 现存系统存在下列与运输和分配相关的一些问题:

- 过多的货物运输

- 过多的半成品或副产品运输 
- 过量的人员运输

- 现有的运输方式没有得到充分利用

\section{减少运输量/分配量的产品可持续系统的例子}

\section{Lampi di Stampaー一按需出书}

在意大利, 通过采用一种堪比平版印刷术的数字化处理模式, Lampi di Stampa 公司提供一种 “按需出书” 的服务。这种创新意味着印刷行业可以由传统的平版 印刷向按需印刷（例如数字化）过渡。平版印刷术包括书籍制作、运输和储存等 环节。另一方面, 实际上数字印刷术只需进行一项操作, 即在预售期或销售当时 直接把文件里的书印刷出来, 这样就省去了若干生产和物流阶段。运输量和印刷 环节的减少，以及书籍制作环节的大幅度减少都优化了生态效益。从经济学角度 看来, 按需印刷可以根据订单数量印制满足市场需求量的书, 避免库存费用, 降 低修订成本; 这就意味着作者出版书籍更容易了。读者可以低价买到书, 找到珍 贵书籍或各种版本的书, 而且可以根据喜好让书籍更加个性化。

\subsection{3 降低资源消耗}

降低资源消耗是指系统利益相关方互动设计降低了系统中所有产品和服务所用资源 的总量。

尽管不同产品对材料和能源的使用强度不同，但是各种产品在整个生命周期都 需要使用它们。因此, 我们的设计必须减少各个阶段, 包括设计和管理过程中的资 源消耗。很明显, 资源使用量的减少可以降低对环境的影响。减少材料的使用就减 少了对环境的影响, 这不仅仅是因为制造出来的产品数量少了, 而且还避免了原材 料加工、运输和处理过程中对环境造成的影响。同理, 由于能源使用量和运输量的 降低, 其对环境的影响也会相应减小。

最后, 从系统角度出发, 我们必须考虑到为了满足某种需求的整个产品类别或 辅助产品所消耗的材料。

就性质而言, 在一些与资源数量相关的问题上, 当前系统存在以下问题:

- 系统消耗大量能源

- 系统消耗大量的自然资源或消耗品

- 产品、包装或辅助产品消耗大量材料 


\section{降低资源消耗的产品服务系统的案例}

\section{清洁布料租货服务一MEWA Textil-管理}

MEWA的综合服务项目包括向工业公司、印刷厂和维修厂提供可重复使用的棉 质百洁布。这项管理系统允许公司回收客户用脏的百洁布。服务流程包括交付、 回收、清洗、替换擦洗布料。按照与客户协商好的使用周期, 公司的服务人员定 期用干净的百洁布回收客户用脏的百洁布。在交付过程中这些布料集中放置在专 门的安全容器内。在MEWA公司采用最新技术配置的洗衣间进行洗涤之后, 这 些百洁布再次交付给客户使用。每件百洁布的循环使用寿命高达50次。尽管市 场上还销售更便宜的一次性擦洗布, 但是不断增长的一次性旧擦洗布的处理成 本使得MEWA公司的该项服务成为备受瞩目的选择。事实上, 在德国百洁布行 业, MEWA公司已经成为了市场的领导者。此外, 该公司不仅提高了租赁服务 水平, 而且能将用过的材料回收再造。残留在布料里的洗涤剂被再次回收利用于 清洗过程中。在整个清洗和甩干过程中水和能源都被反复利用, 而污水中的油则 被回收用于MEWA工厂的能源生产。污水经MEWA工厂处理后已经足够清洁, 达到了城市污水处理厂的接收标准。

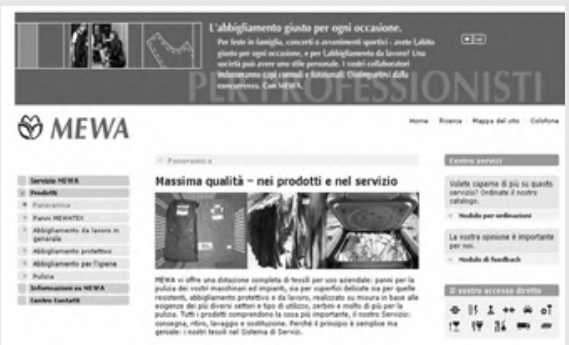

\subsection{4 减少废弃物/废物利用}

减少废弃物/废物利用要求系统的利益相关方开展互动, 增加资源回收利用的总量并 减少资源浪费。

这里的“回收”是指二级原材料被用来生产新的工业产品或堆肥。另外，垃圾 可以重新进入生产环节, 循环使用, 创造价值。例如, 在设计的过程中可以将垃圾 价值评估纳入考虑范围。

在所有这些情况下, 我们都可以收获双重生态效益（见图3.5）。首先, 我们不 在垃圾填埋场进行垃圾处理以避免对环境造成影响。其次, 将回收的资源或能源用 于生产, 以减少提取和处理自然资源中的材料和能源, 避免产生环境影响。这些措 施在实施过程中对环境产生的影响可以被认为是间接的生态效益。

最后, 就系统整体而言, 我们必须站在宏观的角度, 全面考虑如何避免为满足 某一需求而制造的所有产品和辅助产品对环境造成的影响。 


\section{图3.5 延长系统需求下的所有产品和辅助产品的使用寿命, 就是延长生态效益}

\section{AVOIDED IMPACTS}

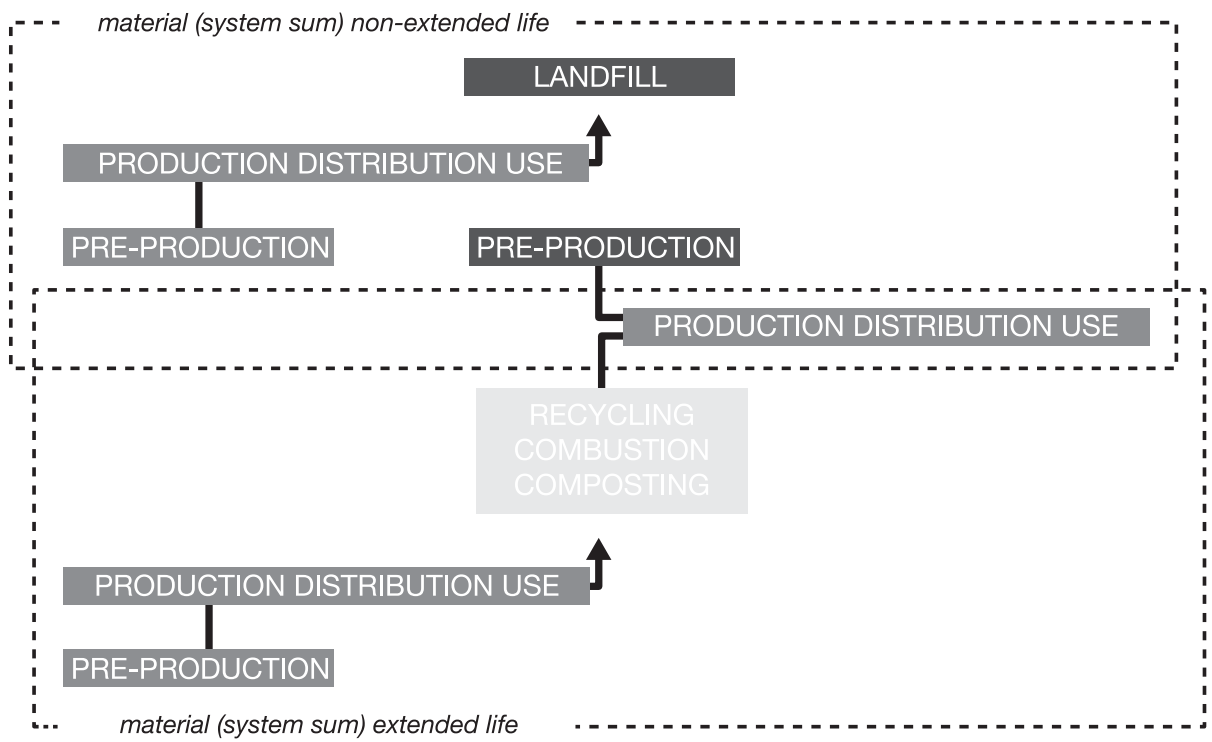

对材料的可回收性进行必要说明：我们经常会听到某种材料是百分之百可回收 的说法, 而这些说法通常没有任何意义。事实上, 从某种程度上讲几乎所有的材料 都是可以回收的。这是由它们本身具有的特性决定的, 也就是说, 这是由材料本身 具有的可回收性能和相对回收成本决定的：例如，在循环利用中，与塑料相比，金 属可以更好地恢复其性能。

然而, 这种可回收性也与材料制作成产品的方式有关。如果此种材料可以较容 易地被分离出来，则其可回收性较强：其容易回收的程度与产品的构造有关。有的 材料可恢复性较强, 但是不易与其他材料分离, 那么它们就不能叫作可回收材料。

同样, 可回收性与回收的各个阶段都有关, 从收集和运输开始。如果某种材料 回收后能继续发挥其性能, 也容易与其他材料分离, 但是回收和运输到回收地点的 成本过高, 那么它也不属于可回收材料。

就性质而言, 在减少废弃物和增加材料使用价值方面, 当前系统存在下列问 题:

- 系统的产品在使用寿命结束时会产生大量的填埋场垃圾

- 产品包装和配套产品会产生大量的垃 


\section{减少垃圾和利用废军物的产品服务系统案例}

\section{一揽子协议 (Pay Per Page Green) - 一日本理光（Ricoh）}

理光 (Ricoh) 提出了一个一揽子协议 (Pay per Page Green), 包括安装、维护 并收集报废的打印机和复印机（顾客无所有权）; 顾客按照页数支付打印和复印 费。公司与客户之间的这种新型互动关系激发了公司提供或设计持久、可回收利 用的复印机的兴趣, 期待以此获得经济利益。

所有元件先经过检测, 有用的元件可重新被加工利用或直接用来制造新的复印 机, 对破损的元件直接进行回收。Ricoh旗下的产品, 其元件具有兼容性, 可适 用于不同型号的产品, 这些做法促进了整个再利用或再生产过程。
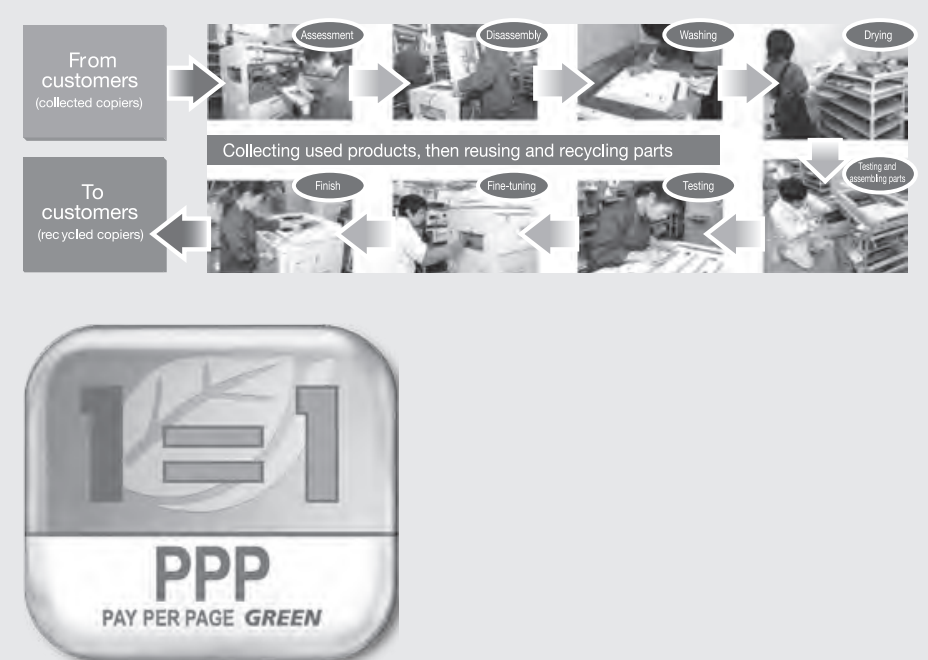

\subsection{5 生态保护/生物相容性}

系统利益相关方互动设计遵循了生态保护和生物相容性的原则, 加大了资源保护力 度或增强了资源的可再生性。

这里需要解释一下 “资源可再生性” 这个概念。众所周知, 木材是一种可再生 资源, 我们可以从两个不同地区获得同类木材。假设其中一个地区对木材进行了合 理规划并控制开采量, 另一个地区未进行合理规划, 结果导致了乱采乱伐。那么对 于同一种材料来说, 前者可以被看做是可再生的, 后者却不是。总之, 可再生能力 与再生长速度和采伐频率相关。因此我们可以这样定义:

\section{只有当消耗的速度小于自然生长速度时, 这种资源是可再生的}

最后, 从系统角度出发, 我们必须从宏观的、相互联系层面, 考虑所有能够满 足某种需求的材料、产品或配套产品的可再生能力。 
就性质而言, 在生态保护和生物相容性的问题上, 当前系统存在以下问题:

- 所有的能源生产都是在不断地消耗资源（例如, 化石燃料)

- 该系统利用正在枯竭的或不可再生的材料来生产产品、配套产品、包装和基 础设施。

\section{生态保护或生物相容性的产品服务系统案例}

\section{Qurrent, 荷兰}

Qurrent的宗旨是打造一个能源平衡的社会。由此，Qurrent促进了公平、清洁的当 地能源消费。其目的在于改变消费者的行为。随着时间的推移, 人们越来越觉得 需要建立独立、开放的分散性能源社区。Qurrent为人们提供了自我选择的机会, 他们可以自己生产能源, 并消耗更少的能源。因此, 消费者变得更加独立自主。

改变消费者行为从知晓他们的实际能源消费和理解家庭平均能源消费标准开 始。“Mijn Energie” 提供了每日、每周、每月和每年的消费标准。Qbox还对太 阳能电池板的效能进行了登记。这些数据都通过Qbox进行收集。

为了降低消费者的能源消耗量, Qurrent还向他们提供太阳能电池板、保温 材料和节能产品, 如LED灯。Qurrent公司大力提倡独立自主, 而Qbox安装起来 非常方便，各能源公司均使用Qbox。

Qbox的优点:

- 可节省高达 $10 \%$ 的能源费用。

- 自己安装, 非常方便

- 与你的能源供应商的系统兼容

- 深刻理解你的太阳能电池板的效能

- 与其它家庭进行比较

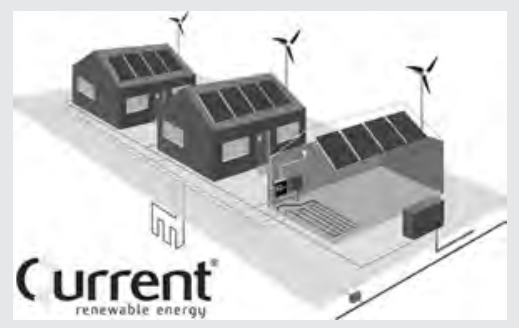




\subsection{6 减少有毒物排放}

减少毒气毒物排放涉及系统利益相关方互动设计, 这种设计减少或避免资源利用或 排放过程中产生的有毒和有害物质总量。

依据上述标准, 重要的是, 一条真正有效的途径一定是与某一满意系统中的所有产 品以及配套产品的整个生命周期和并行过程相关。这就意味着, 我们有必要将各种材料 加工和处理（具有同等效力的材料, 有些可能会排放毒物或毒气, 有些则不会) 技术, 与对环境污染最少的分配系统，以及低能耗的产品设计等几个方面综合起来进行考量。 最后, 我们必须要以处理过程中的最少排放量（和添加剂）为原则来选择材料。

为了说明材料对环境的影响, 我们必须了解, 除了有毒材料（如, 必须避免的 石棉）之外，环境影响取决于：

- 材料的具体特征

- 产品的具体特征

我们来看一个复合材料的例子, 例如, 这是一个填装着纤维的聚合物尽管它是制造 一次性餐盘的材料, 但是对环境却有极坏的影响。因为在处理阶段该材料会引发很 多问题, 而且它属于资源密集型生产。

另一方面, 如果用同样的复合材料来替代那些可能会消耗运输燃料、对环境 产生更大影响的材料, 那么它就是环保产品。而且, 与其他材料相比, 这种材料很 可能比较轻, 这样就减轻了整个产品的重量, 相应地, 降低了运输过程中的燃料消 耗。因此, 这种复合材料对环境是有益的或至少是比其他材料要有益。

从这个原因来看, 单纯地以不同材料对环境的影响程度进行分级是不合理的。

最后, 从系统角度出发, 我们必须站在宏观的角度, 全面考虑为满足某种需求 而产生的所有材料、过程以及所有产品或配套产品的毒性。

就性质而言, 在关于有毒或有害资源的问题上, 当前系统存在下列问题:

- 加工过的原料可能有毒, 或可能会导致工人中毒

- 加工过的原料有毒, 或分配过程中可能产生毒性

- 加工过的原料有毒, 或可能导致使用者中毒

- 产品、配套产品、包装或基础设施有毒或可能在售后服务过程中产生毒性

\section{减少有毒物质的产品服务系统案例}

\section{化学品分销：陶氏化学}

这个 “安全容器系统” 是一个闭环输送系统, 运用专业的垃圾管理和处理技术供 应新鲜的氯化溶剂- -三氯乙烯、全氯乙烯、二氯甲烷, 同时收集使用过的溶 剂。该 “安全容器系统” 采用双层容器进行保护, 避免溶剂和废弃物在运输、搬 运、储藏和使用过程中因容器受损而泄露。这种容器就像是放在钢制容器里的一 
种装置, 配备有特殊的防泄漏机制, 防止其在使用期间溢出、泄漏或挥发排放。 这种容器分为两种类型：一种是装新鲜溶剂的 “安全容器”，专门用来装运相同 产品和同等级的原始溶剂, 以确保产品质量上乘; 另一种是用来装从清洁器中回 收的的被消费者使用过的溶剂，以防止出现与前者意外混合使用的现象。陶氏

（Dow）将大量的原始溶剂运送到通常设在经销商处的补给站，将其放在储罐 中或容器中。分销商将装有新鲜溶剂的容器和装有二手溶剂的容器同时送到客户 手中。客户通过特殊的连接方式把容器连接到清洁设备上（去油机或干洗机）。 顾客将二手溶剂抽洜入指定容器里, 容器装满以后由分销商回收。从容器中抽取 废弃物，将其回收并送到回收站进行专业化处理。例如，二手溶剂的循环利用和 蒸馏污泥的处理。回收的材料基本可以恢复其原有的性能, 并重新返回市场上 销售, 其价格低于原始溶剂。陶氏德国的子公司SafeChem在欧洲使用 “安全容 器” 产品来管理氯化溶剂的运送、收集和循环再利用的业务。除了采用“安全容 器” 系统外, SafeChem还为员工提供了学习培训的机会, 让他们了解如何更有 效地使用氯化溶剂, 并学习正确的搬运和回收溶剂的方法。SafeChem对 “安全 容器” 系统的管理才是系统创新的关键。引进 “安全容器” 系统可以满足顾客需 要, 实际上也消除了对环境的污染。在德国, 由于环境立法和氯化溶剂使用量下 降等原因, 陶氏化学德国子公司 (Dow Chemicals Germany) 与一家回收公司 $\mathrm{RCN}$ ，组建了一家新的合资公司，SafeChem公司。这个 “安全容器”系统就是 针对SafeChem公司设计的, 帮助该公司在清洗金属表面的过程中安全地使用氯 化溶剂, 既能充分利用溶剂, 又能达到保护环境的目的。采用这个系统, 用户可 以更安全有效地使用氯化溶剂, 减少浪费。

\section{4 社会平等和凝聚力设计标准与实例}

如前所述7, 产品服务系统 (PSS) 将生态效益与社会公平和团结相结合。然而, 并 不是所有的系统创新都符合社会伦理道德, 也并非都具有可持续性。因此, 学习案 例、标准、指导方针、方法和工具, 并将它们运用到符合社会伦理标准的可持续设 计当中去, 这才是至关重要的。

对此, 我们针对设计师制定了一系列标准, 以确保产品设计在社会伦理道德方 面具有可持续性 8 :

\section{1. 改善就业/工作环境（参见以下的3.4.1部分）}

2. 改善与利益相关方有关的公平公正问题(3.4.2)

\section{3. 实现负责任/可持续性消费 (3.4.3)}

4. 更重视或兼顾弱势和边缘群体的利益 (3.4.4)

5. 加强社会凝聚力 (3.4.5)

6. 激发地方经济活力 (3.4.6) 
针对每项标准我们都制定了一系列指导方针（可参见附录）。

就某个特定满意系统而言, 一些标准（和与之相关的指导方针）比另一些标准 更具相关性。因此, 在决策过程中（例如, 设计）, 我们有必要通过识别每个系统 类型的每项设计标准的相关度或匹配度, 也就是找到最具有发展前景的利益相关方 的互动方式，来制定更利于社会道德建设的设计方案。9

下面的章节将通过一些具体例子来说明这些标准 ${ }^{10}$ 。

\subsection{1 改善雇佣/工作条件}

雇佣/工作条件是指系统的设计要体现改善工作条件的意愿（不仅是企业内部的还 包括供应商的工作条件）。例如，工作保障、职工健康与安全、安排合理的工作时 间、支付合理的薪水、员工的动机与参与度等。

设计师在下述情形中处于边缘化的地位：公司的目标和要求决定了雇用和工作 条件。但是, 设计师必须意识到所有相关问题, 并积极参与改进工作。例如, 通过 各种沟通方式，建立公平的雇用关系，并改善工作条件。

就性质而言, 在雇用和工作环境方面, 当前系统存在下列问题:

- 强迫劳动和雇用童工现象

- 关于职业健康和安全的问题

- 关于工作场所歧视问题

- 关于超负荷工作或工资不足问题

- 关于自由联盟和集体协商的问题

\section{改善雇佣/工作条件的产品服务系统的范例}

\section{可持续发展责任SA8000认证}

“社会责任国际” (Social Accountability International)建立了 世界闻名的社会标准- - 体面工作SA8000标准, 这是一项执 行国际劳工标准的工具, 该工具已经帮助超过一百万工人改 善了他们的生活。SA8000要求雇主考虑每项工作的重要性, 并承认供应链中所涉及每个人的同等地位, 无论是工人、零 售商还是消费者。SA8000标准充分利用企业和消费者的力 量, 购买的产品均产自能够改善人们生活的工作场所。 给工人、工会以及非政府组织带来的利益:

- 增加了组织工会和集体谈判的机会

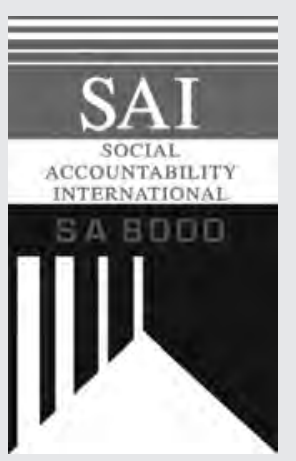

- 帮助工人了解他们应享有的主要劳动权利

9 参见第1部分第4章的第4.3.1节SDO工具

10 从欧洲研究项目新兴用户对可持续方案的需求 (EMUDE) 所收集的相关案例中, 我们获得 了很多有价值的信息。 
- 提供直接处理劳动者权利问题的机会

- 提高公众意识的一种方式, 告知公众该公司致力于建立人性化工作环境 给商家带来的利益包括:

- 提高公司及其品牌的声誉

- 改善企业员工招聘工作, 确保留住人才, 提高劳动生产力

- 支持更有效的供应链管理和绩效模式

给消费者和投资者带来的好处包括:

- 确保顾客购买的是经过认证的产品

- 证明产品的制造和公司的经营符合社会伦理道德和可持续发展的要求

- 覆盖了广泛的产品种类和产地

\subsection{2 改善与利益相关方有关的公平、公正问题}

与利益相关方有关的公平、公正问题是指设计要促进各利益相关方之间建立公平和 公正的关系; (企业外部) 同样要在合作伙伴、上游行业及下游行业之间和社区内 建立公平和公正的关系。具体包括促进建立合作伙伴之间公平、公正的关系; 与供 应商、分包商和下一级供应商之间形成平等、公平的关系; 与客户/最终用户之间形 成平等和公平的关系; 在相关社区之间建立平等和公平关系; 与地方机构/经销商之 间建立平等和公平的关系。

从利益相关方之间平等和公平关系的角度来看, 当前系统存在下列问题:

- 利益相关方对供应系统有不满

- 客户或最终消费者对供应系统有不满

- 合作伙伴之间不公平的关系

- 供应商、分包商和下一级供应商之间不公平的关系

\section{促进建立利益相关方之间公平、公正关系的产品服务系统的范例}

\section{CTM，一家促进公平贸易的Altromercato联盟}

Altromercato联盟建于1988年，是一家位于米兰的全球第二大公平交易促进机 构。该联盟由118家非盈利合作协会组成, 负责管理意大利的 300 家全球连锁商铺

(Botteghe Altromercato)。Botteghe Altromercato是提供产品公平交易的场所, 该场所还提供相关的信息和教育服务。公平贸易是基于向制造商支付 “公平”价 
格, 并建立在以民主方式组建的制造商联盟与CTM Altromercato采购中心之间形 成平等关系的基础上。Altromercato联盟是一家在世界公平贸易组织 (World Fair Trade Organization) 注册的机构。目前, 该机构与全球50个国家的170家机构开 展协作, 包括当地工匠和农场主等。该项目致力于保护制造商的权利并促进与新 兴国家的贸易。Altromercato联盟确保产品根据其实际生产成本和工资进行定价, 促进商业活动中的持续合作, 促进有机产品的生产, 同时促进那些致力于环境保 护和社会进步的项目的展开。Altromercato联盟的产品包括那些在超市、当地商 店、酒吧、药草商等其它商店中常见的手工艺品、服装、食品、化妆品等。2010 年, Altromercat联盟推出了一个新品牌Solidale Italiano Altromercato, 致力于促 进意大利国内的公平交易。Altromercato很快将推出在线商店。
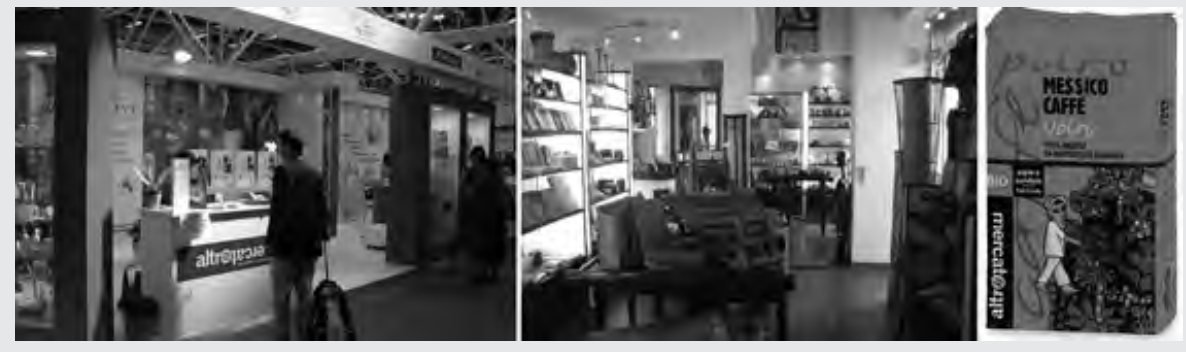

\subsection{3 实现负责任的可持续性消费}

负责任的可持续性消费是指我们的设计要强化客户的可持续消费观念或使最终消费 者的选择和言行更有利于可持续发展。例如, 使所有的利益相关方实现可持续发 展, 为客户或最终用户提供关于负责任/可持续行为的信息或学习经验, 将客户或最 终用户纳入设计和决策过程、生产和分配过程, 为客户定制可持续的产品服务系统。

在负责任的可持续性消费方面，当前系统存在下列问题：

- 客户/最终用户无法清楚地识别整个价值生产链附带而来的社会（非）可持续性

- 客户/最终用户无法理解供应系统中的负责任/可持续行为

\section{负责任的可持续产品服务系统的范例}

\section{Tattle集团的自建太阳能电池板课程}

Tattle集团在意大利开设制作太阳能电池板的课程。在课程结束时, 学生可以 设计自己的太阳能发电设备并且可以要求Tattle订购所需材料。为了降低运 费, Tattle集团要求供货商-一澳大利亚AEE合作仓库一一在订单累计达到一定 数量时再将物品一次性运送到有同样需求的一批用户手中。学生在课堂上, 可以 获得一本由同一家AEE合作机构编辑的包含有设备设计软件等内容的手册。这些 机构旨在使太阳能技术被更多人掌握, 同时将设备成本降低了 $50 \%$ 以上, 平均价 格在 2,600 欧元。与此同时, 培养自给自足的用户, 使他们在设计、建造和维 护过程中节省成本, 并传播生态意识。 


\subsection{4 重视/兼顾弱势和边缘群体的利益}

当谈到重视/兼顾弱势和边缘群体的利益问题时, 我们指的是系统设计要更重视和兼 顾这些人的利益，例如，小孩、老人、伤残人士、失业者、文盲或其他的少数民族 或被社会边缘化群体。具体内容包括：改善弱势和边缘群体的生活条件, 帮助引进 国外人士，开拓向所有社会阶层提供产品和服务的途径，开发共享系统或产品和服 务交换系统以扩大受益群体范围，并开发更便于（公司）取得信用的系统。

在弱势和边缘群体方面，当前系统存在下述问题:

- 供应系统设置了障碍或限制条件, 将弱势群体排除在外（例如，孩子、老人、 伤残人士等)

- 提供系统不对低收入者开放

- 提供系统在某种程度上支持边缘化现象

\section{重视/兼顾弱势和边缘群体利益的产品服务系统的范例}

\section{向55岁以上老人提供合住房一ーAquarius，艾恩德霍芬 (Eindhoven) 住房社团}

Aquarius是荷兰一个由年龄在 45 岁左右的人群组成的社团, 他们比邻而居, 力所 能及地帮助其他人。这个街区总共有30幢带有花园的两层楼, 一间宽敞的带有公 用厨房的公共休息室, 还有一个很大的公园。Aquarius社团除了行使基本职责之 外, 还负责寻找潜在使用者来进行第一轮篮选。优先考虑那些年龄在55到65岁之 间的、积极活跃且有自理能力的人。生活在这样一个社区可促进邻里之间的社会 交往; 为居住者提供一种安全感, 使他们自己和家庭受益; 同时, 减轻了公共部 门原已很沉重的照顾负担。
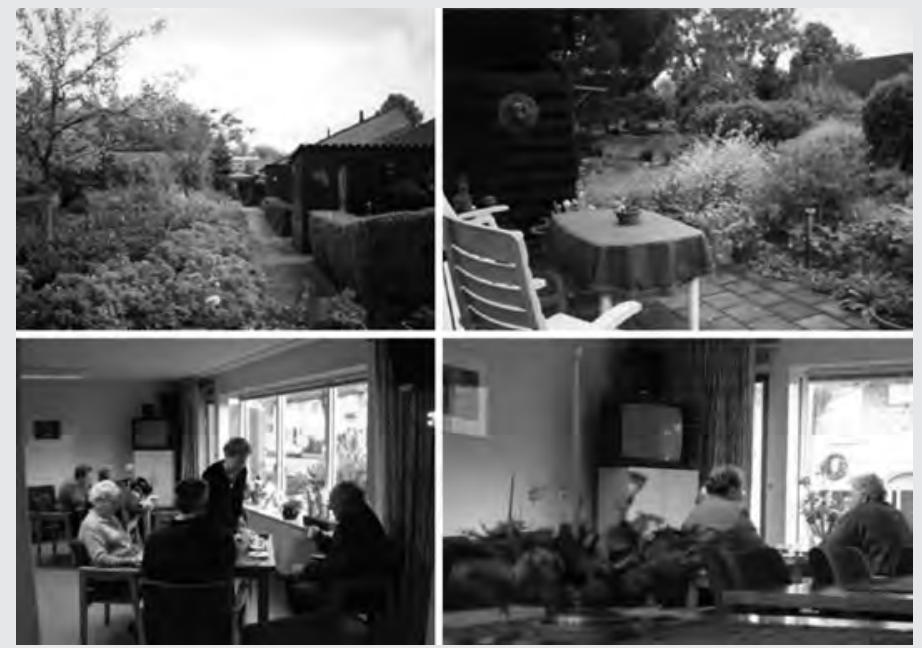

EMUDE图片一可持续解决方案_ECFP6不断增长的用户需求 


\subsection{5 加强社会凝聚力}

加强社会凝聚力, 在这里是指我们的设计要使系统更有利于促进社会团结: 有助于 邻里之间、隔代人之间、两性之间以及不同文化间的团结互助。具体举措是, 推动 建立邻里间物品和维修共享系统、合住房系统、合伙办公系统。

就社会凝聚力而言, 当前系统存在下列问题:

- 提供系统造成了同性之间、同一种文化内或者同代人之间的边缘化趋势。

- 系统容易滋生歧视现象, 例如, 宗教、文化和性别。

\section{加强社会凝聚力产品服务系统的范例}

\section{领取养老金者与学生共享公寓一一自我管理与合作服务协会 (Associazione Auser Como），意大利，科摩（Como）}

该项目既满足了学生的需求（住房价格适中且位于大学附近），同时也满足了退 休老人在陪伴、安全、协助家务等方面的需求。同时, 这个方案有助于隔代人之 间进行交流。该项目以低廉的价格向居住在意大利科摩的退休人员以及外地的学 生提供住房。“Abitare insieme” 方案为促进社区团结提供了重要机遇, 同时这 也是一个很经济的合住方案。该项目也成为老年人和年轻人之间交流的纽带。

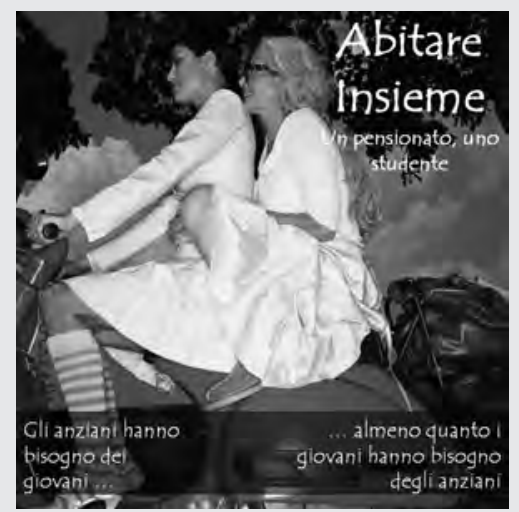

\subsection{6 改善当地资源}

改善当地资源是指我们的设计要推动建立能够激发地方经济活力的系统。具体内容 包括: 尊重并加强地方文化特色, 开发能够促进地方经济的系统, 开发并改善那些 几近失传的当地手工艺, 利用当地可再生资源系统, 促进当地和基于网络的企业和 项目的发展。

就地方资源而言, 当前系统存在下列问题: 
- 当前参照系统导致当地文化价值和文化认同感的丧失。

- 当前系统为所有的地域和文化只提供一种解决方法, 缺乏灵活性。

- 当前系统对当地社区的福利造成了消极的影响。

- 当前系统使地方经济丧失了活力。

- 当前系统一直在消耗当地的不可再生资源。

\section{激发当地经济活力/改善当地资源的产品服务系统范例}

\section{有机食品送货上门服务：当地食品链货车组（Van Group）}

当地食品货车链（Local Food Van Link）与其他的组织联合起来, 通过在当地 社区分销农产品的方式，帮助苏格兰斯开岛(Skye，Scotland)增加食品产量。 斯开岛和洛哈尔什食品链（Skye and Lochalsh Food Link）是一个由当地生产 商、酒店业、零售商和消费者共同自发组建的社团，致力于推动当地生产的新鲜 食品的销售。共享货车链接成一个网络并且将当地的产品输送到该岛屿的每个角 落。该组织成立于 2000 年4月, 最初由当地的一些生产商组成。这些生产商决定 改变过去自产自销的模式，于是使用一辆货车，每星期两次按规定的路线，从制 造商那里接收订单, 并把它们的产品送到顾客手中。这个举措不仅可以减少汽油 的消耗, 同时可以确保把当地的产品输送到全岛各个角落, 以便打造更可持续的 社区。另外, 这个举措通过分销确保了当地食品生产商的未来业务的发展, 促进 了当地社区经济和环境的改善, 同时通过种植当地的新鲜食物, 促进了社区居 民的健康。据说斯开岛能够生产一些无污染、无公害的高质量转基因产品。很 明显, 40个农场主共用一辆货车的方案可大大缓解道路拥堵情况和空气污染程 度。促进当地小规模生产, 推动在岛上建立健康的公共生活模式, 避免了传统农 业给环境带来的不良影响。人们购买新鲜的当季食物, 减少了食物冷却和冷冻对 能源的消耗。

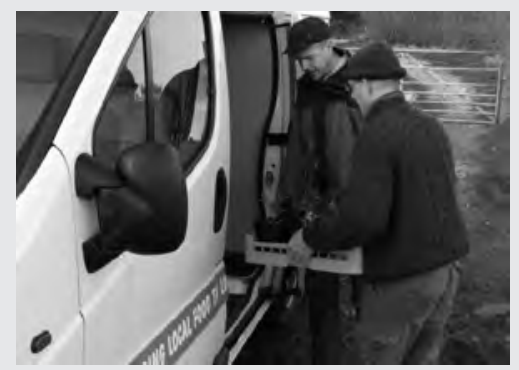

EMUDE图片一可持续解决方案_EC FP6不断增长的用户需求 


\section{5 可持续产品服务系统设计在亚洲的应用}

\subsection{1 可持续产品服务系统设计在亚洲的应用}

未来中国要实现可持续发展就必须彻底转变当前的发展模式。中国已经为过去30 年的快速发展付出了沉重的代价, 当前比较突出的是生态危机和社会公平问题。越 来越多的人认识到, 如果不改变当今这种过度物质化的产品设计、生产、消耗的经 济发展模式，中国的未来将不可避免地遇到“玻璃天花板效应”，而到达增长的极 限。总之, 这个民族正面临一个巨大的危机, 汉语的 “危机” 中既包含了“威胁” 同时又存在着 “机会”。

应对危机, 讨论固然重要, 但行动更重要; 而方向比行动还要重要。引导 我们行动的价值观是关系到人类兴衰的重要因素（谢里（Sheri）2010）。

在这个转型阶段，基于可持续发展理念的设计创新扮演着极其重要的角色。一个关 键性的问题就在于如何建立一种基于中国传统文化并适应当前中国实际的理论, 用 这一理论来有效指导创新系统的设计研究, 并培养下一代人的生活理念和智慧。

在中国, “可持续发展” 这个概念本身在某种程度上甚至可以说是一个从外部 引入的概念, 它是指一种对当代西方社会非可持续的经济发展模式的反思和修正: 从根本上说, 这种思维模式的本质是一种主客观二元论。其背后的逻辑是, 既然人 类造成了大自然的污染, 那么人类就有责任重新治理和保护大自然。然而, 按照中 国古代 “天人合一”的思维模式，人与自然并非保护与被保护的关系：人本身是自 然的一个组成部分。中国的传统哲学一贯认为: 人与自然是一种共生的、融为一体 的和谐整体，人类若自诩为自然的主人，必将毁灭人类自己。

在中国古代, 可持续性是一个系统的概念, 它的核心是生态环境, 而将人类和 自然的和谐发展作为一种愿景。因此, 中国传统 “设计” 的核心思想可以总结为: 敬天惜物、乐道尚和、适可而止。上天是指一种 “超自然”存在; 敬畏上天是指“ 设计”应该遵循自然规律, 充分利用自然资源, 避免不必要的浪费。“道”在中国 古代是指一种强大的自然法则, 万物都受其支配。因此, 人们只有通过领会和追 随 “道”义才能拥有智慧, 发现真理, 最终到达一个自由王国。“和谐”强调的是 人类活动的社会属性, 是中国传统价值观和幸福观的根本性原则。“适可而止”代 表一种消费理念, 其鼓励一种知足常乐的生活方式, 这源于中国人不喜欢奢侈浪费 的传统。基于这种思想的整体性设计方法确实是有利于人类的福祉和长远发展。

中国当前的设计理论, 例如, “设计事理学” 11 就深深植根于中国的传统哲学, 将设计教学的重点从以往仅仅针对 “物” 的设计, 转到了关注整个系统, 即 “事” 的思考和创新中（参见刘新2010; 刘新和刘吉昆2011）。其核心思想与可持续设计 的 “产品服务系统” (PSS) 的设计理念不谋而合。因此, 可持续设计的本质应该 是 “重建知识结构和产业链, 以达到资源整合和机制创新的目的, 并引导人类社会 走上一条健康、理性的可持续发展的道路”（广州2009；广州2006）。 
人类的可持续发展、地球上有限的资源和“极端个人主义”理念的局限性等, 所有这些都迫使我们深刻理解为什么要求我们的评价标准必须 “合理”且 “适度”。 换句话说, 这正是中国古代哲学所提出的“适可而止”的观点。“危机”意识是任 何转变的先决条件。为了应付危机和实现转变, 中国的设计必须从古代智慧中汲取 灵感。

\subsection{2 产品服务系统的可持续设计在泰国的应用}

充足经济理论 (SEP) 的概念最初由泰国国王普密蓬·阿杜德 (Bhumibol

Adulyadej）于1974年提出 ${ }^{12}$ 。这个充足经济理论（SEP）最初旨在通过向大多数民 众提供生活保障, 提出一个可以避免泰国像其他国家那样由于各种不平衡而引发危 机的方案, 以此来巩固泰国的经济基础。这是一个适用于所有领域的方案：从日常 生活到农业, 从企业到国家政策。这个理念证明了充足经济可以指导一切行为, 从 动机到标准, 到行为, 直至系统, 并可以解决动态环境下的一切问题。因此, 这个 理念也应该可以被应用到设计领域。然而, 相对而言, 充足经济理论 (SEP) 在设 计领域的应用还不是很广泛。

在各种可持续设计方式中, 产品服务系统的设计理念和充足经济理论的整体观 念有异曲同工之妙一一在某种意义上, 两种途径都与保护环境有关; 两者都更重视 系统的整体性发展而不只是关注单个产品或服务的设计; 两者都优先考虑利益相关 方之间的互动关系。很明显, 环境保护是我们必须追求的目标, 但也不能忽视社会 和经济效益。

\section{充足经济设计的独特性}

充足经济 (DSE) 的设计方案与现有的可持续设计 (DfS) 方案有一些相似之处, 但也有自身的特点。设计师的双重身份便是特点之一。首先, 充足经济设计通过评 价用户的行为, 来判断当前的行为是否遵循了充足经济理论的原则。然后, 一旦设 计师观察并确认了用户的需求, 他们会依据充足经济原则来考虑这些需求的优先顺 序。例如, 他们开始进行利益相关方互动和新系统支持组件的设计过程。换句话 讲, 充足经济设计师的首要任务是评估 “当前我们的用户是如何将充足经济理论运 用到他们的生活中”。设计师的另外一个角色是站在公司的角度，去探索作为公司 或服务提供者, “如何通过为用户提供一系列产品、服务或系统来鼓励他们实现充 足的生活目标”。同时, 他们会问, “在这么做的同时, 我们如何才能从整体上达 到资源整合的目的, 并且符合社会可持续发展的要求? ”通过采用充足经济设计的 方法、工具和指导方针, 设计师就可以扮演好自己的多重角色 ${ }^{13}$ 。

\section{2 见第二卷第四章}

13 这些指导方针由来自泰国先皇技术学院建筑学院设计系 (KMITL) 的研究小组在 LeNS项目 实施期间开发的。该小组由项目经理Sompit Moi 福萨克勒（Fusakul）助教及其同事斯瑞迪 治 (Praoranuj Ann Siridej) 和普温 (Pwinn Rujikietkhumjron) 共同组织实施。本书第2部 的第四节详细描述了有关充足经济哲学和充足经济设计的概念。 
挑战

以“策略为导向”的充足经济理论是一种手段, 而不是目的。通过研究充足经济设 计 (DSE) , 探索如何使充足经济理论与设计理念相辅相成, 并如何以更加可持续 的方式满足人们的需求。因此, 充足经济设计的方法论旨在引导设计师设计一个可 以鼓励用户选择符合充足经济理论思想的生活方式的系统。同时，设计师可以用该 方法论提供的工具和图表来实现该目标 14 。该方法论已经过检测, 且在学术界和研究 领域得到了进一步推广, 但在专业实践中尚未得到广泛的应用。

目前, 充足经济理论在设计中的应用遇到了一些障碍。阐释和误解是最棘手的 问题。许多人将充足经济理论看做是一种关于 “生活方式” 的抽象理论, 因此他们 无法理解该理念如何能应用到产品或服务的设计中。此外, 充足经济理论被误认为 是一种指导乡村生活的哲学, 所以不适合用于城市生活和企业部门的设计。还有人 错误地认为, 如果一个人在他的生活中采用了该哲学, 那么他或她必须回到最基本 的生活方式中, 回到原始的行为模式。比如自己种稻谷和棉花, 自己纺纱织布。这 样的误解导致人们认为充足的生活方式和现代文明的生活方式是相互冲突的。

事实上, 充足经济理论强调的是一条中间路线, 可以将之看作是指导各阶层民 众行为的最重要原则。它创造了一种环境, 使得人们品行变得更加诚实, 而人们在 生活中能够展现他们坚持不懈、善良友爱、慷慨大方的品格。该理论是鼓励实施者 在行动中表现得更加理智和温和, 同时培养一种富有弹性的免疫力来保持一种平衡 状态, 以确保应对快速而巨大的变化。这种对所有行为都有益的思维方式不仅可以 应用在设计方面，而是适用于所有地域、时代、文化、环境等。

因此, 实施者在充足经济理论的指导下应对全球化带来的挑战和危机, 即使遇 到了失败, 他们也能找到复兴之路, 最后走出一条更有生机与活力的可持续的经济 发展道路。尤其在经济波动、文化贬值、环境恶化、资源贵乏、政治动荡的大背景 下, 充足经济理论显得尤为重要。充足经济设计是对充足经济在设计领域应用的一 个新的诠释, 而且它将帮我们实现我们的福祉。

\subsection{3 产品服务系统在印度的应用}

印度在产品服务系统（PSS）理念上的贡献是源自历史上为反抗英帝国工业体制及 其社会经济压迫而产生的本土知识创新。知识创新运动具有多重性, 主要是反对殖 民统治者给印度带来的生态和政治层面不可持续的资本主义生产模式。作为非暴力 不合作运动的领导者, 甘地 (M.K. Gandhi) 认为发展当地产业以满足最贫穷民众的 需求才是获得自由的途径。当时的社会, 人们为国外或城市市场提供产品和服务, 而自身却食不果腹、衣不蔽体, 这种现象在甘地看来是不道德的, 无法接受的。卡 迪手织粗布 (Khadi) - - - 种以家庭种植的棉花为原料, 手工纺纱, 手工编织而成 的粗布一一对甘地来说自然成为了斯瓦代希运动（Swadeshi）或自力更生运动的焦 点。运动的主题便是自力更生, 自给充足, 抵制侵入印度市场的来自工厂的棉布的

14 详细有关充足经济设计的方法论, 参见第1部分。在LeNS工具数据库中可下载电子表单和 使用指南 (www.lens.polimi.it）。 
生产、分配和消费。不仅是实践, 产品服务系统的理念也成为了纺车革命 (Spinning Wheel revolution) 的核心 (Brown2010)。

印度土布 (khadi) 运动作为一次政治变革取得成功的先决条件是它的实践具有 可持续性, 否则难以成功。这项运动不仅是对英国帝国主义的抗议, 同时也对隐藏 在工业制造背后的整个产品设计理念提出了质疑。卡迪当地体系处理社会变革的方 法不是将“设计”和产品的设计定位在实验室而是定位在社区中。这就需要通过“ 合适的” 或 “过渡性” 技术工具、方法和过程, 对工业专家或工业研究者进行重新 审视和定义, 正如人们后来所认识到的那样, 这是向全世界发出了一个强烈的信 号, 尤其是对那些新加入现代化进程的非西方国家（Prasad 2010）。

卡迪运动所展现的这种内生性创新模式, 不仅把知识看作是公共财产, 而且是 社会广泛参与的生产活动。复兴艺术和提倡手工艺、乡镇企业合作机制、参与技术 创新、本土资源使用, 所有这些都是卡迪运动的有机组成部分, 也是当代产品服务 系统理念的先导。最近, 在印度宣扬甘地思想的人们提出了一个关于可替代科技的 宣言, 这个宣言可以看作是产品服务系统的衍生物 ${ }^{15}$ 。

这个宣言提出：我们的科学、技术和产业政策的设计需要建立在公正（包括认 知公正）、多元化和可持续这三个目标上-一所有这些目标也是产品服务系统的目 标 (普瑞赛德 (Prasad) 2010)。最重要的是, 我们应该记住, 甘地的变革方案并 没有将商业或财富的创造排除在外。

很明显, 卡迪只是本地知识系统中经久不衰的传统之一, 它以 “发展”为主 题, 通过引进现代技术的方式来达到与时俱进的目的。然而, 考虑到我们当前所面 临的复杂的气候变化所带来的挑战, 以及将来可能出现的灾难, 人类的生存正是要 从这些 “过时的” 知识体系中汲取思想并看到希望。因此, 西方孕育出的产品服务 系统可以通过与 “被其打败的” 的亚洲进行知识和思想的相互交流来重新看待设 计。以下内容包含在卡迪概念产品服务系统理念的各个方面, 而卡迪概念在今天仍 对设计理论具有重要意义。

\section{农业模式}

甘地大力推崇卡迪手织粗布, 并不是为了与英国工业展开竞争, 而是提倡一种更接 近农业的生产模式, 这是产品服务系统理念的最初表现形式。卡迪与乡村有着千丝 万缕的联系, 而乡村不仅种植棉花, 还为穷人提供了生活必需品, 使他们有能力为 国效力, 这一点在甘地看来是实现印度强盛并从英国统治者那里获得经济自由的最 重要途径。我们不应该忘记印度早期是英国的销售市场和贸易伙伴, 而英国是第一 个走向工业化的国家, 因此, 资本主义初期的产品-一纺织品-一市场便成为卡迪 可持续生产模式必须要争取争夺的市场。卡迪以满足村民需求为目标一举取得了成 功, 甘地要把农业和乡村作为印度产业发展的重中之重。

他将纺丝列入生计劳动（Bread Labour）的范畴的想法与此观念一脉相承。 体力劳动” 虽与农业的关系是最为密切的, 可当时社会的人们往往不愿从事此类劳 
动, 而更倾向于其他类型的劳动, 他们心中永远都会有更理想的劳作方式。他坦诚 自己对于生计劳动的了解是源于俄罗斯作家列夫•托尔斯泰（Leo Tolstoy）（而托 尔斯泰本人又受益于农民作家邦德瑞福（T.M.Bondaref））和英国经济学家约翰・拉 斯金 (John Ruskin) 。这在当时历史背景下对英国-一印度关系具有重要意义, 并 揭露了西方发达经济体如何通过工业资本主义缓慢但又无情地消灭传统农业的过程 （甘地（Gandhi）1960a）。传统劳动和手工业绝不会因现代教育而终结。现代专 业化的行业分工也同样, 不可能出现脑力劳动完全取代体力劳动的情况。体力劳动 的存在仍有其必然性，对于构建一种服务于他人的价值观有着十分重要的意义，同 时它确实有助于我们摒弃纯粹自私的生计关注。而在印度, 在甘地的领导下, 上述 那些前瞻性的、反直觉的现代观点却取得了令人瞩目的成功。甘地希望以非暴力的 方式，使这个国家从英国的统治下获得政治自由。

正是对服务的重视将卡迪变成一种更接近农业可持续理念的模式。早在1932 年, 在英国人的监狱里, 甘地向自己提出了这样的问题:

当前印度的广大同胞最需要哪种服务? 这种既可以被所有人理解和接受, 又比较容易实施, 还能满足许多半饥饿农民的生存需求的服务是什么?

他给了自己和世界一个答案就是卡迪, 或者 “纺车普及化”（1932：37）（重点强 调）。

按照当代的说法, 产品服务系统并不认为只有制造业和产品生产才是经济的原 动力。对服务的重视正是它区别于主流产业设计理念的地方。甘地对生计劳动的重 视只是预言了欧洲人终会意识到要从过去的农业生产模式中发现可持续发展的道路。

\section{托管的经营理念}

有趣的是, 甘地关于可持续性的思考同样也为自由印度的商业发展和财富创造留下 了空间。甘地认为, 富人不是真正地拥有自己的财富而只是财富的托管者, 这意味 着富人必须为了社会的福利经营业务并获取利润。这样, 甘地就将资本和资本家放 在了他的政治和经济变革方案的中心位置 (1960b)。很明显, 托管概念的背后最根 本的观点便是平等和可持续发展, 而不是简单的慈善或博爱精神。因此, 这个观念 面临的挑战或实施困难便是由此引起的根本性社会变革。

不平等和等级差异不仅仅是源于富人和穷人所占物质财富的差异, 而且还源 于一种根深蒂固的观念, 这便是富人可以不劳而获, 可以依靠他人的服务为生。因 此, 放弃财富是一件困难的事情, 因为这意味着要他们放弃自己的整个生活方式。 于是甘地劝告富人应该自主地转变思维观念, 接受生产的义务, 例如, 生计劳动。 他说, 即使是一位百万富翁也不能完全不劳动, 因为他们需要靠运动来消化食物。 那么, 为什么富人就不能在一天中的某段时间和大多数民众一样参与劳动, 这样不 就能消除社会中最基本的潜在的不平等性吗?

劳资矛盾无处不在, 穷人总是姤妒富人。如果所有人都自食其力, 那么等 级差别就会消失; 富人群体仍在, 但是他们会把自己看作是财产的托管者 而且将财产主要用在公共福利上 (1932: 22)。 
从这个角度看, 托管模式是企业社会责任 (CSR) 的先驱。当前, 在管理领 域, CSR强调重组社会和企业结构, 以使个人在充分享受权利的同时, 为公众谋福 利。在印度独立后, 这种模式被认为是理想主义的, 是以不合理的自我牺牲原则为 基础的，结果遭到了人们的摒弃。而今，在经济和金融体系不稳定以及失去价值的 背景下, 托管模式再次出现, 成为企业的使命, 被用来应对挑战。简单来说, 托管 模式要求人们改变对富人和拥有财富的认识（观念）。它并不否认财富和金钱在建 立可持续机制中扮演的较色, 而是强调, 在满足个人需求之后, 人们应当将剩余的 财富或收益用于造福大众。不管是资本家还是穷苦农民都必须首先保证自己留有足 够的食物和棉花, 然后将剩余的食物和棉花出售给别人。很明显, 如果没有这样的 前提，卡迪运动不会深入到广大的农民生活之中，成为一个群众性运动。

在历史上, 甚至是像企业社会责任 (CSR) 这样的托管模式并不意味着要通过 福利和慈善来重新分配物品, 而是要通过提高经济价值的方式来变革资本主义的行 业和企业的结构, 来提高社会意识。最近, 由许多发达经济体签署的公平贸易协定 就是一个典型的例子。同样, 托管模式的作用在 2000 年《全球契约》16中表现得很 明显。这个契约是在联合国秘书长科菲 - 安南 (Kofi Annan) 的倡议下提出的。它提 议：衡量企业的价值不仅仅在于其利润的多少, 而且要将非金融因素考虑进来一一 经济学家和政策制定者在管理和衡量发展时多了一个新的衡量尺度。正如, 甘地之 前提出的一个类似的观点-一 “真正的经济学是支持社会公平的, 它会为所有的人 带来利益, 包括最弱势群体, 让他们过上体面的生活”。

如果将公平分配财富看作是衡量经济成功与否的尺度, 而不是遵循现行的鼓 励扩大收入差距的尺度, 那么托管模式将企业社会责任融入到私营部门的企业价 值中, 这时财富的分配就不仅仅具有慈善的特性而且具有可持续的特征。在保障 了人类的基本尊严后, 企业不应该仅仅被看作是与社会无关, 只是充当生产和分 配的参与方。甚至创新也应当被看作是以用户为主导的社会化进程（希佩尔（von Hippel) 2005)

为了调和资本主义的利已主义和社会意识或责任之间众所周知的矛盾, 托管 的经营理念已经完全从过去的产品获取转向今天的提供服务- - 这便是产品服务系 统理念的基本原则。固有的托管经营理念是应对 21 世纪许多挑战的产品服务体系

(PSS) 解决方案（拉纳 (Rana) 2010) :

1. 仅按照自己的需要进行消费, 并且不忽视其他人的需求

2. 将自己看做是自然资源的保管人, 确保从自然中获取的一切可以得到很好的 保护, 为后代谋福利

3. 公平分配产品和服务, 以确保产业和社会工作者的权益受到全面保护

4. 通过使民众满意并为他们提供福祉来获得人类尊严并促进经济增长, 而不是 采取资本积累的方式 


\section{瓦尔纳刷摩（Varnashrama）的印度教理论}

最后, 甘地对现代社会工业化的干预主要是为了阐明印度教中的瓦尔纳刷摩概念背 后的理论原则, 进而提醒人们经济背后的社会属性（Granovetter 1985）。他强烈反 对种姓制度带来的 “赘生物”, 比如, 基于脑力和体力劳动所划分的贱民身份。在 甘地看来, 瓦尔纳刷摩作为一种模式, 坚持了生态、道德和社会可持续发展的原则

（甘地2009）。

当今的社会学家和环境学家开始重新审视印度教的种姓制度, 不再将其看作 是对家庭工作传统的恪守和对他人行为或思想的禁忌, 而是看作是一种自我克制的 体系, 它剥夺了人对自然资源和人类资源的使用权, 有利于保护地方生态系统。例 如，马德哈夫贾 ·加吉尔 (Madhav Gadgil) 记录了不同群体中间存在的 “节俭的” 生态系统。一个注重生态保护的社会实行限制资源开发利用的措施，尽管这些措施 的实施放弃了一些当前利益, 但从长远看来, 却大幅度增加了未来可以开发利用的 资源量 (1985a：190)。

在个人能力范围内, 在不剥夺他人生计的前提下, 将服务当地社区并将邻居放 在优先位置, 这就是斯瓦代希 (Swadeshi) 或充足原则的核心内容, 同样也成为 了卡迪运动的主导原则。这个原则过去曾为穷人提供过保护, 但如今穷人们却失去 了这种保护。那些城市中受过教育的人群已经接替城市未受过教育的人群从事体力 劳动和服务, 如洗衣服、管理垃圾、捡拾垃圾、理发、个人装扮等服务工作。这种 职业多样化分工的结果是导致大量的未受过教育的人无事可做。甚至像医生、建筑 师、木匠和艺术家等技术型、高收入的传统工作职位也被那些接受过英式教育的上 等阶层占据着。早期禁止上等阶层从事这些工作的理由是这些工作与体力和物质基 础密切相关, 如今, 上等阶层成为了当代印度社会服务行业的精英。

穷人和社会地位低下者在现代经济发展过程中已经输了两次。早些时候, 正如 里区 (Leach) 在《在系统层面》一书中指出, 种姓制度蕴含的社会逻辑颠倒了西方 历史上盛行的等级划分制（里区（Leach）1960）。欧洲的封建主义是以一个由财 富地位和权势构成的金字塔为基础的, 金字塔的最上层是少数贵族（只有极少数 人），而印度与欧洲的情况有所不同，这个国家的瓦尔纳制度允许最底层民众旡断 服务行业, 以至于在公共生活中, 其他人不能再将这些服务当作谋生手段。乡村文 化将经济活动中的材料和技术的使用控制在比较低的水平, 远远低于当前消费至上 的DIY文化。

蒙特 (Mont) 和普莱皮斯 (Plepys) 坚定地反对电动工具, 电动工具在这里 很少使用, 而对于西方的中产阶级家庭而言, 电动工具已经是家庭车库或工棚中不 可或缺的一部分 (2004）。工业方面, 设计陈旧也会导致由于这种弃用“隐藏” 内 容所带来的资源浪费问题。甚至, 许多产品在投入使用前就被丢弃在了设计实验室 里。当前这个时期摆在货架上的产品被新产品取代的速度越来越快。换句话说, 产 品更新换代的速度越来越快, 这对地球上有限的资源造成了灾难性的影响。

印度教的种姓制社会主要是以乡村经济为基础发展而来的, 它具有高度 自主性, 曾被英国管理当局定义为一个 “小共和国” (巴顿 - 帕沃 (Baden Powell）1957）。人们将每个家庭提供的服务汇集起来供大家分享, 这样就满足了 村民的日常所需和举行仪式的需要。因此, 技术和工具没有得到广泛传播, 而仅仅 
是由那些为他人提供服务的家庭成员所掌握。我们无需对大自然赐予的一切进行优 化, 这是人与自然一种固有的交换, 人们已经可以从中获得满足而无需所谓的人造 产品。人们用香蕉叶子包饭, 在稻草席上睡觉, 没有餐具和陶器, 穿着未缝合的衣 服, 这就是当地的生活方式, 这不仅具有浓重乡土气息, 而且对资源和技术的消耗 也是极少的。

一篇著名的论文 (1958年) 这样写道: 印度独立后, 两位设计型思考者查理 (Charles) 和雷 ·伊姆斯（Ray Eames）推动了国家设计学院 (NID) 在艾哈迈达 巴德 (Ahmedabad) 的成立。他们发现 “印度圆水壶”代表了一种极简主义文化。 这种水壶是由大量不同的材料做成的, 有多种多样的用途。正因为在举行宗教仪式、 烹饪和沐浴的时候, 人们发现用这种水壸装运、储藏以及倒水都非常方便, 所以, 该 水壶被公认为具有环保、经济、实用和美观的特点, 深受人们喜爱。他们认为现代印 度应该支持这些传统设计, 反对那些早期从西方文化和英式教育中引进到印度社会的 设计方法，进而反对将拥有和使用物品看作是社会或精神文明进步的标志。

下面我们将分析这种引进的思维模式。通神论者莱德彼特

(C.W.Leadbeater) “发现” 哲学家J ·克里希那穆提（J. Krishnamurthy）以一个 男孩的模样出现在沙滩上, 并且和哥哥一块游泳。于是他给另一个通神论者安妮 .

贝费特 (Annie Besant) 以及印度国会工作者写信说道: 我收到了上天的启示来拯救 这些男孩子。

他们一直生活在地狱; 要向他们展示天堂的样子......教会他们使用刀叉, 指甲刷以及牙刷, 告诉他们要轻松地坐在椅子上而不是蹲在地上, 要安心 地睡在床上，而不是像小狗一样蜷缩在一个角落（詹金斯2000：84）。

培训使男孩们认可了西方社会的生活标准。在 $\mathrm{J}$ ·克里希那穆提 ( $\mathrm{J}$. Krishnamurthy）看来，提供这样的培训是作为救世主首先应该为世人做的事。他从 南非回到了印度, 并将公共服务作为自己的职业。那时他提出了“半裸” 的口号, 没有比这个更能证明他和甘地对“自我进步”的理解是多么的大相径庭。

这里我们要说明的是, 如果产品交换是以人与人、人群与人群面对面的方式展 开, 而不是直接在市场上进行, 这些东西的传播速度注定要受到影响。而这些生活 方式在资本主义的殖民统治时期彻底改变了, 是甘地让我们意识到了隐藏其后的原 理。今天，产品服务系统的理念正是以同样的方式提出了可持续发展的概念。 


\section{4}

\section{可持续系统设计的方法与工具}

\section{1 标准、方法和工具}

在介绍和描述具体的方法和工具之前, 让我们先对目前已知的几个主要问题进行总 结。有人认为, 可持续设计潜在地促进并推动了系统创新, 进而使一批有利于环境 保护、经济增长和社会公平（有凝聚力）的企业（项目）能够在网络平台上或在本 地同时提供产品和服务。

对利益相关方的结构进行设计是我们关注的第一要点。该设计旨在根据特定的 社会需求, 在社会经济利益相关方之间建立创新型互动与合作关系。因此, 设计师 必须掌握一些新的技能:

- 设计师必须能够根据特定的需求, 同时设计出产品和服务, 例如一个满意单元。

- 设计师必须能够发现、促进并推动不同利益相关方（企业家、用户、非政府 组织、机构等）形成创新互动关系（即互动/合作），即能够根据特定需求构 建令人满意的体系单元。

- 设计师必须能够促使/促进企业家、用户、非政府组织、机构等多方参与设计 程序, 从而实现可持续的解决方案。

鉴于并非所有的系统创新都能够带来生态效益并有利于促进社会平等和团结, 第二 个关键点是, 我们的设计过程应始终以实现可持续解决方案为目标。因此, 设计师 还需要掌握以下技能:

- 使系统设计创造生态效益的能力1。

- 使系统设计创造社会效益的能力 ${ }^{2}$ 。

1 包括环境和经济可持续发展。

2 包括社会伦理和经济的可持续发展。 
为了学会利用这些方法和工具来实现可持续的设计解决方案, 我们有必要将产品、 服务或系统在开发阶段的简化方案当作基准，并在这些阶段就能够对系统概念与系 统细节进行设计, 并最终完成相关的系统工程。

\section{图4.1 产品-服务系统设计过程的总体行动方案。该方案将所有以可持续为导向 的工具均纳入到设计过程的各个阶段中}

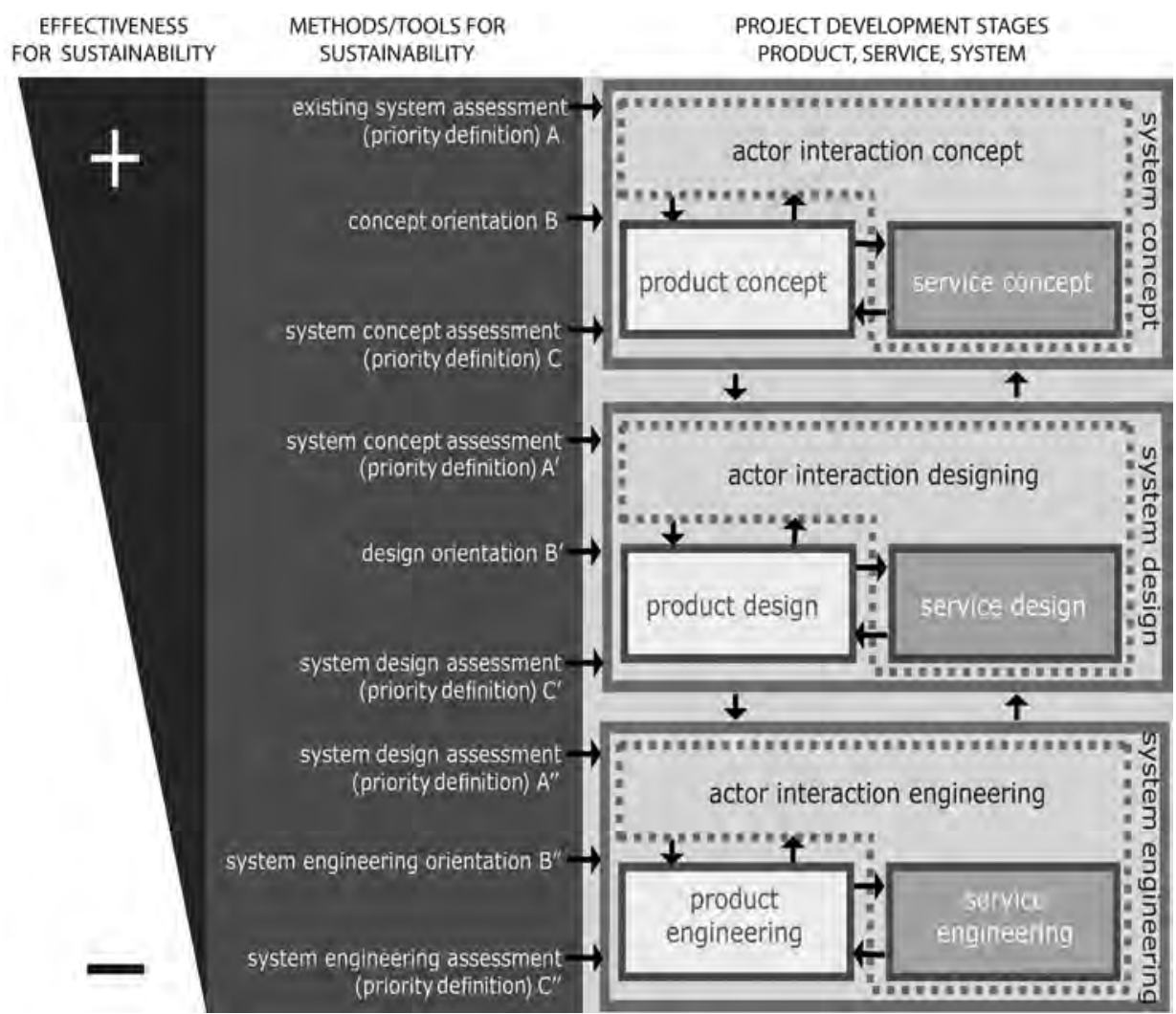

就系统开发而言, 在概念设计阶段, 我们就应该对该系统中参与者之间的配置 编排，或者说他们之间相互关系的设定进行定义。很明显，在发展的第一阶段，将 各种能带来可持续结果的要素, 如合适的方法和工具, 进行整合, 将使开发过程更 加高效。这一章我们将向大家描述一系列已经开发的工具, 它们可以用于开发的不 同阶段。除去各自具有的特点之外，这些工具均有助于设计师完成三个具体目标：

1. 确定可持续发展的优先顺序（现有系统评估）

2. 形成一个以可持续为导向的理念（创新型系统开发）

3. 审视/展示可持续性改善/恶化的状况（对现有系统与创新系统之间进行比较） 
在过去的几年里, 致力于开发、测试系统设计的方法与工具, 欧盟资助了许 多不同的研究项目, 联合国环境署也出资为一个项目提供基金 ${ }^{3}$ 。它们中主要采取 的系统设计方法、工具包括: 可持续家庭计划 (SusHouse) 4、产品服务共同设 计计划 (ProSecCo) 5, 高度定制化解决方案 (HiCS) 6、产品服务系统开发方案 (MEPSS) 7 以及可持续产品和服务共同设计网 (SusProNet) 8 。

本章对可持续系统设计方法(MSDS)及其可持续系统设计所使用的工具进行了描 述。这是可持续学习网络项目 (LeNS) 的成果, 它整合并更新了上述项目的成果和 在可持续系统设计（例如：充足经济哲学的设计）中运用到的工具。这些研究方法 和工具已经在一些LeNS项目的试点课程和一些公司的咨询项目中得到了检验。后者 包括减少废弃物排放项目（减少废物排放Less waste）：“另辟蹊径的行事方式” 是一个由ASM布雷西亚公司 (ASM Brescia) 委托实施的项目, 该项目通过拟定情形 和制定系统概念, 防止在食物和纸张生产链上产生垃圾 9 ; 一个由芬兰通力电梯公司 (KONE) 委托实施的项目, 则旨在制定具有生态效益的系统概念 ${ }^{10}$; 此外, 由利乐 (Tetra Pak）（食品包装）公司委托实施的项目也与其有着相似的目标。

强调实验在应用研究和教学 (LeNS)中的基础作用是至关重要的, 当前如此, 将 来也是如此。只有这样, 我们的方法和工具才能够得到评估、修改和完善。

\section{2 可持续系统设计方法（MSDS）：可持续系统设计的 模块化方法}

可持续系统设计方法旨在支持并引导整个系统创新过程朝着可持续方向发展。它不 仅适用于设计师和企业, 同样也适用于公共机构和非政府组织; 不仅适用于设计师

3 可持续设计 (D4S) 循序渐进的方法 (由联合国环境规划署资助, 2005-2009) (参见 蒂什纳 (Tischner) 和 维佐里(Vezzoli) 2009)。

4 SusHouse: 可持续家庭战略(欧盟资助，1998-2000) (参见 维格雷特(Vergragt) 2002)。

5 ProSecCo: 产品-一服务合作设计(欧盟资助, 2002-2004)。

6 HiCS: 高度定制化解决方案(欧盟资助, 2001-2004) (参见曼吉尼(Manzini), 柯琳娜

(Collina) 和埃文斯 (Evans) 2004)。

7 MEPSS: 产品服务系统开发方法论(欧盟资助, 2002-2005) (参见凡·海伦 (Van Halen), 维佐理 (Vezzoli) 和维默尔 (Wimmer) 2005)。

8 SusProNet: 可持续产品-一服务共同设计网络 (欧盟资助, 2002-2005) (参见塔克

(Tukker) 和蒂什那 (Tischner) 2006)。

9 有关项目实施方法的更多信息, 参见山士恩 (Ceschin) 和维佐理 (Vezzoli) (2007)和维 佐理 (Vezzoli) 和山士恩 (Ceschin) (2009)。

10 参见库尔特斯 (Cortesi), 维佐理 (Vezzoli) 和东吉 (Donghi) (2010)。 
74 可持续产品服务系统设计

个人, 也适用于设计团队。任何情况下, 设计方法都会特别关注组织内部（有不同 学科背景的个体之间）和组织外部的共同设计过程, 使那些具有各种不同社会经济 背景的参与者和终端用户都参与到设计过程中。

这个方法包含多个阶段、过程和子过程, 其特色是模块结构灵活。经过调 整, 它可以轻松地满足设计师或公司的特殊要求, 在多样化的设计背景和条件下也 可使用。该模块结构有以下几个方面值得关注:

- 程序阶段: 根据项目的具体要求, 我们既可以采用该模块的所有阶段, 也可 以选择某些特定的阶段加以应用。

- 使用工具：该方法附带一系列工具（上述提到的欧洲和联合国环境署的研究 项目中都充分运用了这些工具）。在设计过程中, 我们可以挑选出有用的工 具。

- 可持续性的几个维度：该方法充分考虑到了可持续性的三个维度（环境、社 会伦理和经济）。我们可以选择适合的维度开展工作。

- 与其他工具和活动的整合：该方法允许我们对那些并非为该方法专门开发的 设计工具进行整合。我们也可以根据设计项目的特殊要求对当前活动进行修 改或者增加。

可持续系统设计方法的基本结构包含四个主要阶段:

- 战略分析

- 发现机遇

- 设计系统概念

- 设计（构建）一个系统

我们也可以跨越其他阶段, 增加一个新的阶段, 如起草文件以报告设计方案的可持 续性特征。

- 交流

下表显示各阶段的目标和过程。 
表4.1 可持续系统设计方法各阶段的相关目标与过程。以可持续性为导向的过程 皆以粗体呈现；充足经济设计过程以粗斜体呈现。

\begin{tabular}{|c|c|c|}
\hline \multicolumn{3}{|c|}{ 可持续系统设计方法 } \\
\hline 阶段 & 目标 & 流程 \\
\hline \multirow[t]{6}{*}{ 战略分析 } & \multirow{6}{*}{$\begin{array}{l}\text { 获取所需信息, 促进可持续系统创新 } \\
\text { 观点的形成 }\end{array}$} & 分析项目申请人并概述干预的背景 \\
\hline & & 分析参照环境 \\
\hline & & 分析系统的承载结构 \\
\hline & & 分析最佳可持续实践的案例 \\
\hline & & $\begin{array}{l}\text { 分析现存系统的可持续性, } \\
\text { 并根据可持续性的要求确定设计 } \\
\text { 干预的优先顺序 }\end{array}$ \\
\hline & & 充足需求评价 \\
\hline \multirow[t]{3}{*}{ 发现机遇 } & \multirow{3}{*}{$\begin{array}{l}\text { 对所有具有发展前途的战略可能性、 } \\
\text { 单个以设计为导向的可持续设计场景 } \\
\text { 或一套可行的可持续系统设计理念进 } \\
\text { 行编目收录 }\end{array}$} & $\begin{array}{l}\text { 产生以可持续为导向的 } \\
\text { 理念 }\end{array}$ \\
\hline & & 充足机会探索 \\
\hline & & 勾画以设计为导向的可持续场景 \\
\hline \multirow[t]{4}{*}{ 设计系统概念 } & \multirow{4}{*}{$\begin{array}{l}\text { 确定一个或多个以可持续性为导向的 } \\
\text { 系统概念 }\end{array}$} & 选择创意集群和单个创意 \\
\hline & & 开发系统概念 \\
\hline & & 环境、社会伦理和经济评估 \\
\hline & & 充足系统设计 \\
\hline \multirow{4}{*}{$\begin{array}{l}\text { 设计（构建） } \\
\text { 系统细节 }\end{array}$} & \multirow{4}{*}{$\begin{array}{l}\text { 为了顺利实施, 将最有前景的系统概 } \\
\text { 念进行细化 }\end{array}$} & 具体系统设计 \\
\hline & & 系统实施的充足性开发 \\
\hline & & 环境、社会伦理和经济评估 \\
\hline & & 充足设计评估 \\
\hline \multirow[t]{2}{*}{ 交流 } & \multirow{2}{*}{$\begin{array}{l}\text { 通过报告展现可持续系统设计总体和 } \\
\text { 最主要的特征 }\end{array}$} & 记录可持续性交流 \\
\hline & & 充足设计交流 \\
\hline
\end{tabular}

以下章节将描述各阶段的具体流程, 其中应当特别关注以可持续性为导向的过程。

\subsection{1 战略分析}

该方法第一部分的目标是收集和处理所有背景信息，以便生成一系列潜在的可持续 理念。这个目标具有双重性: 一方面, 我们要了解当前形势, 找出更多关于项目申 请人的信息, 了解他们的社会经济背景, 并找出影响此背景形成的动因（社会经 济、技术和文化宏观趋势）; 另一方面, 我们要在引导设计过程通向有发展前景的 解决方案的基础上进行信息处理。以下是所有过程的概述。 
定义干预背景, 并分析项目申请人的情况

鉴于项目申请人可能是公司、公共机构、非政府组织、研究中心或上述机构的组 合, 这项活动的首要目的应该是界定设计干预的范围, 更准确地说是满足福利需求

（例如：拥有舒适便利的交通或干净的衣服）。在这一点上, 应该对项目申请人的 特点进行仔细地调查, 例如: 在干预范围内的 “任务”、主要的专业域、优势和 劣势、机遇和挑战。尤其当申请人是一家公司时, 我们就必须对其价值链进行分 析, 以便弄清楚它的结构、参与者以及可能遇到的（环境、社会道德以及经济） 问题。

关键问题:

- 需要满足申请人哪些需求?

- 项目申请人的专业领域是什么?

- 他们主要的优势和劣势是什么?

- 谁是主要的参与者? 他们之间是什么关系?

- 与价值链相关的主要环境、社会伦理以及经济问题有哪些?

- 客户或终端用户的价值观是什么?

\section{参照环境分析}

该活动的目的是分析背景, 或更准确地说, 是分析社会技术机制, 而未来创新成果 必将融入其中。首先, 要对生产和消费系统（干预范围）的结构进行分析：参与者 有哪些(公司、机构、非政府组织、消费者等）? 他们之间有什么联系? 另外，系统 有哪些具体动态特征（技术、文化、经济和管理）? 我们还应该特别关注当前和潜 在的竞争者（分析他们的特点和产品）, 同时也应关注客户或终端用户（分析他们 的需求)。

关键问题:

- 生产和消费链的结构与干预范围有何联系? 主要的参与者有哪些（公共部门 和私营部门），他们各自的利益又是什么?

- 影响或潜在影响生产和消费链特点的技术、文化和规章制度方面的动因是什 么?

- 谁是主要的竞争者? 他们的产品（或服务）是什么? 这些产品（或服务）与 项目申请人的产品（或服务）有什么不同?

- 潜在客户和终端用户有哪些? 他们的需求是什么? 他们的需求得到满足了 吗? 


\section{分析系统的承载结构}

这项活动的目的是确定并分析隐藏在相关背景下的（社会、经济和技术的）宏观趋 势。这有利于理解对背景（或社会技术机制）形成潜在影响、并最终造成干预的因 素。

关键问题:

- 主要的社会、经济和技术发展的宏观趋势是什么? 这些趋势是如何影响相关 背景以及最终的设计选择的?

\section{分析优秀的可持续发展案例（最佳范例）}

此项活动的目标是具体分析一些可以刺激创意构思的优秀范例（不一定与干预域相 关）。其结果将会以文档的形式呈现，总结各优秀案例所提供的产品、与用户所开 展的互动、产品生产商或提供商, 及其可持续性特征等。支持工具包括用于分析可 持续特征的SDO工具包、用于描述案例基本特征的系统图和互动表。

关键问题:

- 产品和服务的内容是什么? 用户如何与产品服务进行互动?

- 产品和服务系统的参与者有哪些? 他们的目的什么?

- 环境、社会伦理和经济方面的优势是什么?

分析现存系统的可持续性, 并根据可持续性的要求来确定设计干预的优 先顺序。

该活动的目的是从环境、社会伦理以及经济角度来分析当前背景, 以便确定设计的 优先顺序（换句话说, 找到干预最重要的影响因素, 以便最大程度降低对环境、社 会伦理和经济的影响）。这项活动在设计过程中起着根本性的作用, 它引导设计朝 着最具有可持续性的目标进行。活动的结果将以文档的形式分析总结环境、社会伦 理和经济情况，并确定设计的优先顺序。这个过程的支持 “工具”之一是SDO工具 包（检查清单, 现有系统）。

关键问题:

- 当前的环境、社会伦理和经济的可持续发展形势如何?

- 可持续性不同维度间的设计优先顺序是什么? 


\section{充足需求评价}

此项活动的目的是对充足经济哲学的三大组成部分（分别是合理性、适度性和自身 免疫力）的当前形势进行全面的评价。合理性、适度性和自身免疫力。充足经济设 计(DSE)方法的第一个阶段：规划/设计和实施过程以帮助个人、社区和社会实现充 足生活和可持续福利发展的目标 11 。评估当前形势将获得大量的有用信息：该系统内 的利益相关方有哪些; 他们的行为和相互关系是什么; 现有系统是如何运行的。能 够察觉到所有可能影响未来发展趋势的当前变动也是至关重要的。我们面临的最重 要任务是确定在当前形势下，（用户和产品或服务提供者的）行为方式是否符合充 足经济哲学的原则。最终结果将以文档形式阐述当前的充足水平, 并阐述现有系统 在人类、地球、利益以及技术这四个维度上是否达到了平衡, 不平衡意味着系统中 存在待解决的薄弱环节。这一步骤所需的工具包括任务分析、充足经济设计检查清 单（第一部分）以及充足水平评估（第二部分）。

\section{表4.2 战略分析：流程、子流程、结果、工具。以下内容中, 具体描述的可持续} 系统设计工具用黑体字显示

\begin{tabular}{|c|c|c|c|c|}
\hline & 流程 & 子流程 & 结果 & 工具 \\
\hline \multirow[b]{2}{*}{ 齿 } & $\begin{array}{l}\text { 对项目申请人进行分 } \\
\text { 析, 并对干预背景加 }\end{array}$ & 确定设计干预的范围 & $\begin{array}{l}\text { 以文档形式规定干预 } \\
\text { 范围和设计概要 }\end{array}$ & \\
\hline & & 项目申请人分析 & $\begin{array}{l}\text { 项目申请人分析总结 } \\
\text { 任务 } \\
\text { 主要技能 } \\
\text { SWOT分析 } \\
\text { 价值链 } \\
\text { (参与者、结构等) }\end{array}$ & 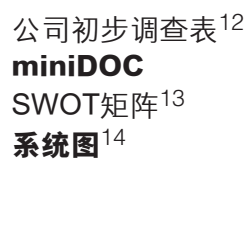 \\
\hline
\end{tabular}

11 更多有关充足经济哲学和充足经济的信息, 参见第一部分, 3.5.2节, 和第二部分, 第 4 节。

12 该项目创建于产品服务系统开发方案 (MEPSS) 研究项目期间 (http://www.mepss.nl/index .php?p=tool\& $14=$ W02)

13 SWOT分析的例子参见MEPSS 项目期间创建的工具包 (http://www.mepss.nl/index. php?p=tool\& $14=$ W05)。

14 一个与系统图类似用途的工具就是参与者网络图。详细信息, 参见Morelli (2006a)。 


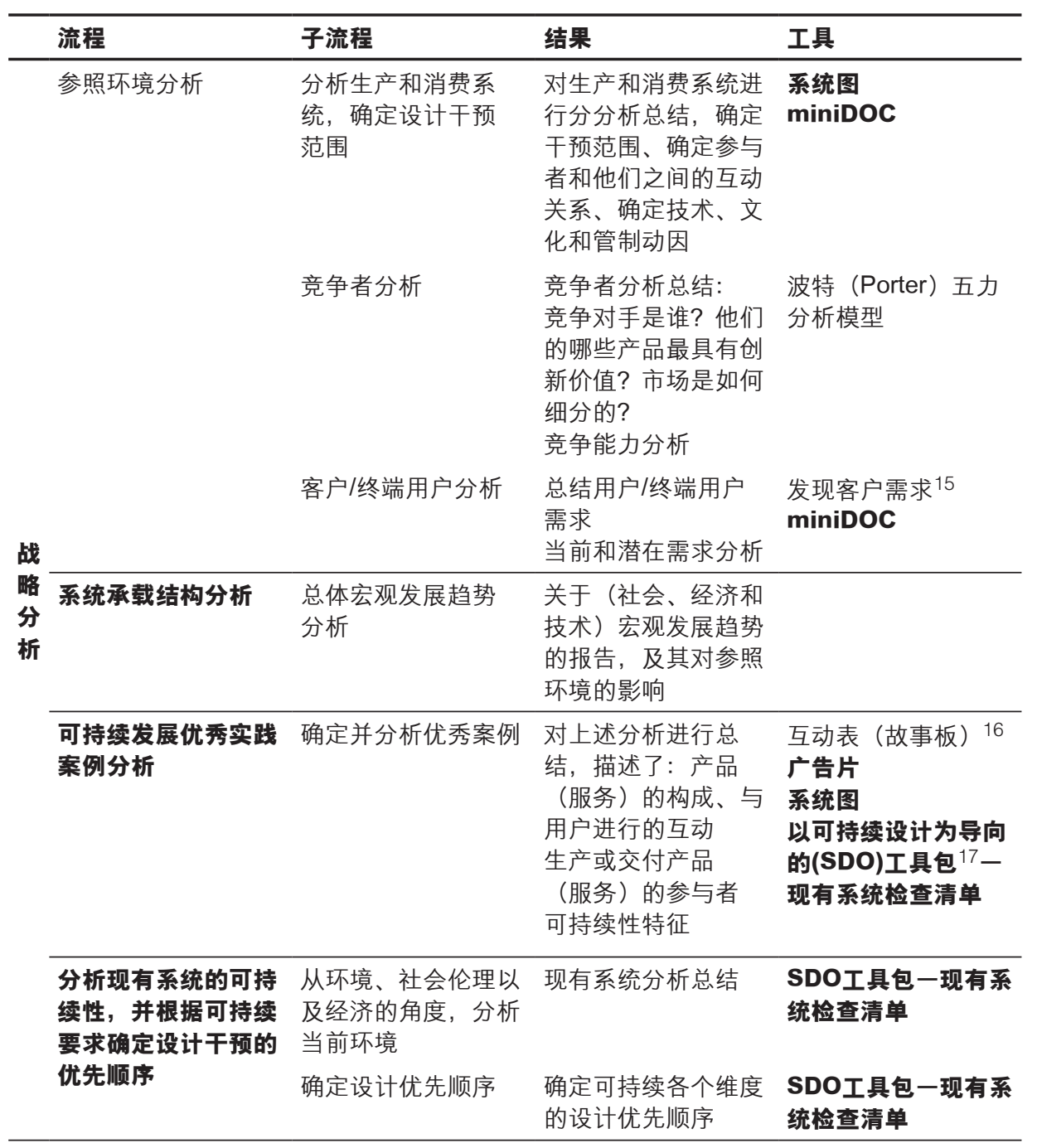

15 创建于产品服务系统开发方案（MEPSS）项目期间 (http://www.mepss.nl/index.php?p= tool $\& \mid 4=W 17)$ 。

16 与互动表类似的工具是 “使用案例”。详细信息, 参见莫瑞丽 (Morelli (2006b))。

17 可用于产品服务系统可持续特征分析的另一个工具是 “改进新服务” (Improving New Services, INES），这是一个在由奥地利交通、创新与技术部资助的“生态效益产品服务 系统”研究期间创建的工具。 


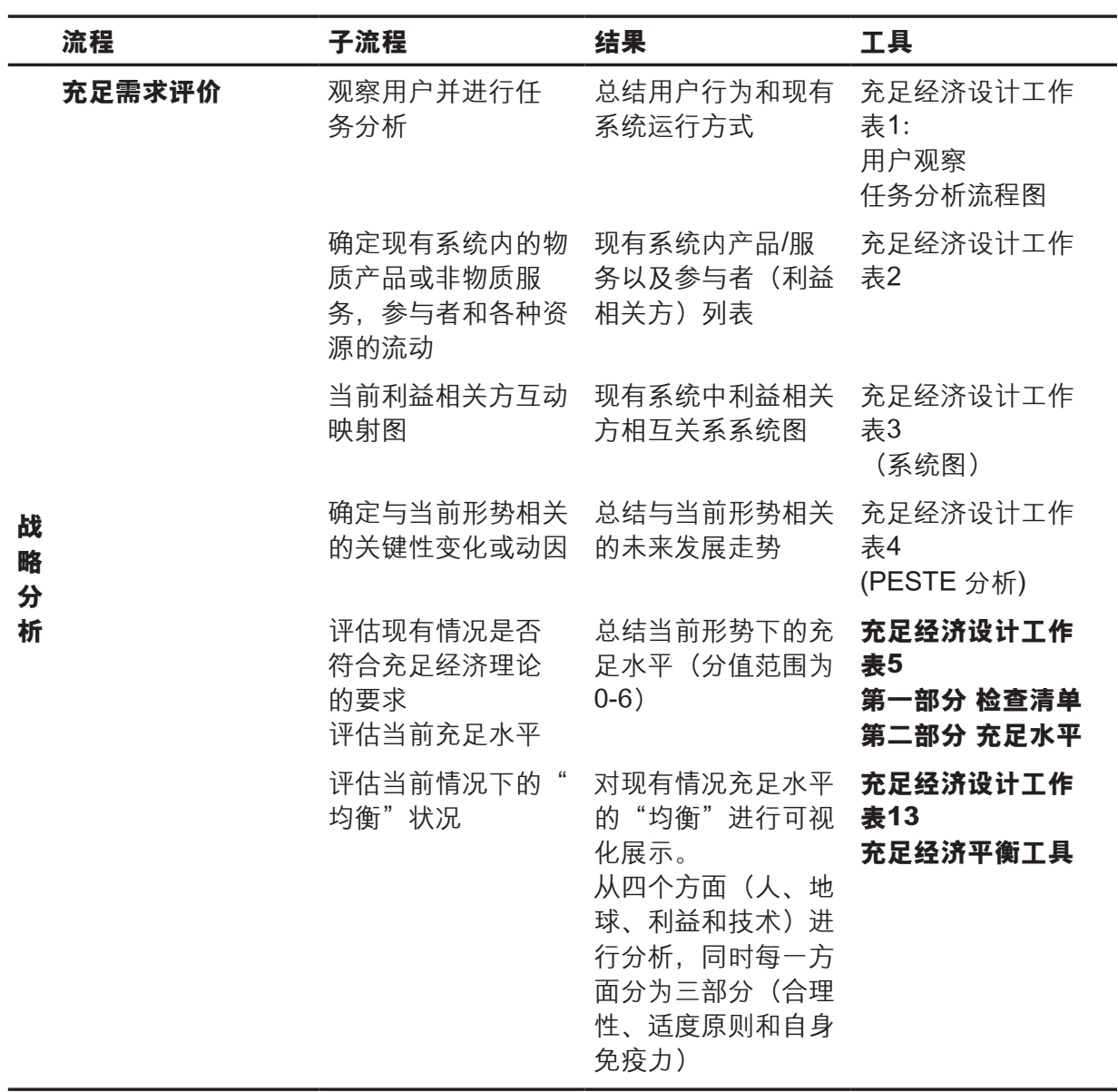

\subsection{2 发现机遇}

第二阶段的目标是为有前景系统确立可能的发展方向。创意需要各方参与者集思广 益才能实现。

必须强调的是, 这个产生创意的过程, 不是为了产品或服务层面上的逐步改 善, 而是为了获得系统层面的创新。这种创新的特点是使环境、社会伦理和经济的 各个方面, 获得根本性的改善。同时, 充足经济设计鼓励循序渐进式的发展, 并认 为只有在 “适当” 的情况下, 才能开展 “根本性” 的创新或变化。为了达到这一目 的, 应用经过深思熟虑的知识就变得至关重要。

因此，具体的目标就是：利用前期搜集和加工过的信息，勾勒出有发展前景的 战略可行性的一个 “目录” , 也就是可持续设计导向情景(SDOS), 这其中包括可持 续导向设想和创新理念。这个带有设想和理念的情景模式构成了今后可持续系统创 新开发和实施的基础。三个发现机会的过程概述如下。 
产生以可持续为导向的创意

在之前获得的信息基础上，通过集思会的形式，产生一系列潜在的可持续理念。 首先, 我们要对有待通过设计满足特定需求的满意单元进行定义。我们必须清楚 认识到产生的创意必须满足具体的福利需求（例如：干净的衣服）。从这个意义 上, 必须特别注意系统层面的创意, 例如: 关于以下方面的创意：1)构成提供物的产 品和服务；2）生产/提供这些产品和服务的参与者构成。我们起草了一套专门的设计 指导方针用于指导创意构思过程朝着可持续系统解决方案的方向发展（例如：由可 持续设计导向工具包软件生成的的创意构思表格）。收集能够刺激灵感的优秀实践 案例, 制作有潜能成为满意度系统组成部分的参与者地图也都是很有用的方法 ${ }^{18}$ 。这 个过程的结果将以文档形式呈现。其中包括满意度单元和满意度子单元, 以及具有 环境、社会伦理和经济可持续特点的一系列系统层面的创意。

关键问题:

- 有待通过设计满足的满意单元是什么?

- 谁将有可能参与满意度系统设计?

- 什么样的产品和服务系统能够带来（从环境、社会伦理和经济角度）根本性 的 改善? 什么样的参与者系统能够生产并提供这些产品和服务?

\section{拟定以可持续设计为导向的情景（带有设想和创意集群）。}

这个过程的目标是利用专门设计的极化图对应先前产生的创意19。该图及其所对应 的创意, 构成了所谓的以设计为导向的可持续设计导向情景, 也就是, 当某些动因

（经济、管理和社会文化）遭到改变或某些设计选项被调整时, 预计环境将如何发 生变化的一套设想。因此, 该情景模式概述了一系列设想, 或更好、更具前景的设 计导向。反过来, 每个设想都呈现于一系列的单独创意或创意集群中（具有共同 基本要素的一系列创意）。这些设想、单独创意和创意集群共同构成了讨论的基 础, 这场讨论确定了系统创新最具前景的发展方向。

\section{充足机会探索}

在充足经济设计 (DSE) 过程中, 本阶段的目标是使设计师能够分析公司或者系统 提供者的优势、劣势、机会和威胁 (SWOT) , 并确定项目的驱动力、目标和目的。 在分析了项目能力后, 充足经济设计 (DSE) 指导方针 (工作表单8) 和SWOT搜索 域矩阵技术 (Search Field Matrix techniques) (Crul and Diehl 2006：36-37)将在以 下四个层面产生创意: 人、地球、利益和技术。

18 该工具被称为满意度系统图; 详见第4.3.7节-一满意度系统图。

19 该工具描述, 详见第4.3.10节- - 极化图。它是一幅具有两个极性轴的图表。（例如, 用 户参与式提供物与全面服务提供物; 组织系统：集中系统与分散系统）, 可以对创意进行 定义和分类。 
表4.3 探索机遇: 流程、子流程、结果、工具。以下内容所具体描述的可持续系 统设计工具用黑体字显示。

\begin{tabular}{|c|c|c|c|c|}
\hline & 流程 & 子流程 & 结果 & 工具 \\
\hline & \multirow[t]{2}{*}{$\begin{array}{l}\text { 产生以可持续性为导 } \\
\text { 向的创意 }\end{array}$} & 定义满意单元 & $\begin{array}{l}\text { 对满意单元与满意子 } \\
\text { 单元进行详细说明 } \\
\text { 的文件 }\end{array}$ & \\
\hline & & $\begin{array}{l}\text { 举办为可持续系统征 } \\
\text { 集创意的集思研讨会 }\end{array}$ & $\begin{array}{l}\text { 具有环境、社会伦理 } \\
\text { 和经济可持续特征的 } \\
\text { 一系列系统创意 }\end{array}$ & $\begin{array}{l}\text { 创意工具: } \\
\text { SDO工具包一可持续 } \\
\text { 创意表 } \\
\text { 满意度系统图 } \\
\text { PSS创新矩阵 }\end{array}$ \\
\hline & $\begin{array}{l}\text { 概述一个以设计为导 } \\
\text { 向的可持续情形景 }\end{array}$ & $\begin{array}{l}\text { 定义单个创意和创意 } \\
\text { 集群, 确定有前景 } \\
\text { 的极化图、极化创 } \\
\text { 意, 确定设想 }\end{array}$ & $\begin{array}{l}\text { 带有极化创意的极 } \\
\text { 化图 } \\
\text { 带有设想的极化图 } \\
\text { 带有创意集群的极 } \\
\text { 化图 } \\
\text { 对创意集群和单个创 } \\
\text { 意描述 } \\
\text { 将概念与结果直观化 } \\
\text { 并有助于集体讨论的 } \\
\text { 影音文件 }\end{array}$ & $\begin{array}{l}\text { 极化图 } \\
\text { 产品和服务（提供 } \\
\text { 物）图 } \\
\text { 广告片 } \\
\text { 系统概念 } \\
\text { 影音文件 }\end{array}$ \\
\hline \multirow[t]{4}{*}{ 黙 } & 充足机会探索 & $\begin{array}{l}\text { 分析当前的优势和弱 } \\
\text { 点, 以及今后的机遇 } \\
\text { 和威胁 } \\
\text { 按照充足经济的原 } \\
\text { 则对公司进行SWOT } \\
\text { 分析 }\end{array}$ & $\begin{array}{l}\text { SWOT分析 } \\
\text { 充足经济哲学 } \\
\text { SWOT分析 }\end{array}$ & $\begin{array}{l}\text { 充足经济设计工作表 } \\
6 \text { (SWOT 矩阵) } \\
\text { 充足经济设计工作 } \\
\text { 表9 } \\
\text { (SWOT充足经济相 } \\
\text { 关分析) }\end{array}$ \\
\hline & & $\begin{array}{l}\text { 确定公司的驱动力、 } \\
\text { 设计目标和目的 }\end{array}$ & $\begin{array}{l}\text { 确定设计动因的文件 } \\
\text { 确定设计目标和目的 } \\
\text { (作为一家公司或一 } \\
\text { 个系统提供商) 的文 } \\
\text { 件 }\end{array}$ & $\begin{array}{l}\text { DSE 工作表单 } 7 \\
\text { (公司动因、目标和 } \\
\text { 目的) }\end{array}$ \\
\hline & & $\begin{array}{l}\text { 产生以知识和道德为 } \\
\text { 导向的系统 } \\
\text { 创意 }\end{array}$ & $\begin{array}{l}\text { 描述知识与道德前景 } \\
\text { 的创意列表 }\end{array}$ & $\begin{array}{l}\text { 工作表单 } 8 \text { (指导方 } \\
\text { 针 知识与道德) }\end{array}$ \\
\hline & & $\begin{array}{l}\text { 产生有充足发展前景 } \\
\text { 的系统创意 } \\
\text { 对有充足发展前景的 } \\
\text { 系统创意进行可视 } \\
\text { 化展示 }\end{array}$ & $\begin{array}{l}\text { 所产生创意和示意 } \\
\text { 图文件 }\end{array}$ & $\begin{array}{l}\text { 充足经济设计工作 } \\
\text { 表10 } \\
\text { (搜索域矩阵) } \\
\text { 充足经济设计工作 } \\
\text { 表11 } \\
\text { (新充足经济学产品 } \\
\text { 服务系 } \\
\text { 统示意图) }\end{array}$ \\
\hline
\end{tabular}




\subsection{3 设计系统概念}

从之前所详述的方案（包括设想、创意集群和单个创意）开始, 这个阶段的目标是 通过一个参与程序挑选最有发展前景的创意集群和单个创意, 此过程要求参与者们 各抒己见。将创意集群和单个创意分为不同的组, 每组均代表一个系统概念维形。 这些创意组将进一步得到完善, 并对产品和服务的构成, 以及相关生产和配送参与 者系统进行定义, 并对可能出现的环境、社会伦理和经济调整进行评估。下面将论 述系统概念的设计过程。

\section{选择创意集群/单个创意}

在进行程序篮选并组合最具发展前景的创意的过程中, 可能会使用到专门设计的工 具(参见表4.4)。每套创意组合将被开发成一个系统概念。

关键问题:

- 哪些是最具经济前景的创意? 哪些是技术上最可行的创意? 而哪些又是最容 易被用户接受的创意?

- 哪些是在环境和社会伦理方面最具发展前景的创意?

\section{开发系统概念}

上述的创意组合中将会产生一个或多个系统概念。这些系统概念对以下要素进行 定义：构成提供物的产品和服务, 及其能够实现的功能; 生产和配送参与者系统

（初级和次级）; 用户/客户和提供物系统之间的互动。在对这些要素进行设计和可 视化表达过程中将用到以下工具（参见表4.4）。

关键问题:

- 什么产品和服务构成了提供物? 它能够实现哪些功能? 对用户而言有什么价 值? 客户/终端用户如何与提供物系统进行互动?

- 在生产、提供产品和服务时, 如何构建社会经济参与者系统（以及他们之间 的互动）? 主要参与者和次要参与者分别是谁?

\section{充足系统设计}

充足经济设计阶段的目标是对在 “机遇探索” 阶段产生的创意进行精炼细化, 并在 此过程中遵循系统、全面、以人为本和崇尚自然的原则。利用基本的草图绘制技术 将在先前阶段产生的创意进行视觉化展示。对相关创意进行组合, 从而打造新的充 足产品服务系统概念。采用各种工具, 对系统要素的设计和视觉化展示提供支持。 
84 可持续产品服务系统设计

表4.4 设计概念的策划: 流程、子流程、结果、工具。以下内容中具体描述的可 持续系统设计工具用黑体字显示。

\begin{tabular}{|c|c|c|c|c|}
\hline & 流程 & 子流程 & 结果 & 工具 \\
\hline & $\begin{array}{l}\text { 选择创意集群和单 } \\
\text { 个创意 }\end{array}$ & $\begin{array}{l}\text { (从经济、技术、可 } \\
\text { 行性和用户可接受性 } \\
\text { 的角度) 选择最具前 } \\
\text { 景的创意集群和创意 }\end{array}$ & $\begin{array}{l}\text { 为选择的创意和创意 } \\
\text { 集群制作极化图 } \\
\text { 对选择过程进行说明 } \\
\text { 的文件 }\end{array}$ & $\begin{array}{l}\text { 极化图 } \\
\text { 组合图 } \\
\text { 选择/不选择的评估 } \\
\text { 标准 } 20\end{array}$ \\
\hline \multirow{6}{*}{ 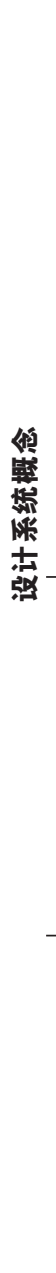 } & 开发系统概念 & $\begin{array}{l}\text { 定义参与者与新系统 } \\
\text { 之间的互动 }\end{array}$ & $\begin{array}{l}\text { 新系统中的参与者 } \\
\text { 以及他们之间的互动 } \\
\text { (物质、信息和资金 } \\
\text { 流) 图 }\end{array}$ & 系统图 \\
\hline & & $\begin{array}{l}\text { 定义那些构成提供物 } \\
\text { 的产品和服务概念 } 21\end{array}$ & $\begin{array}{l}\text { 通过图像和文字总 } \\
\text { 结向用户提供的主 } \\
\text { 要功能 }\end{array}$ & $\begin{array}{l}\text { 提供物力表 } \\
\text { AD海报 }\end{array}$ \\
\hline & & $\begin{array}{l}\text { 描述用户与系统之间 } \\
\text { 的活动, 提供产品 } \\
\text { (服务) 过程中其他 } \\
\text { 参与者之间的互动 }\end{array}$ & $\begin{array}{l}\text { 生产和交付过程中 } \\
\text { 的互动顺序（图像+ } \\
\text { 文字） } \\
\text { 诠释新观点的影音 } \\
\text { 文件 } \\
\text { 展示行动顺序的影 } \\
\text { 音文件 }\end{array}$ & $\begin{array}{l}\text { 互动表样片, 表现系 } \\
\text { 统概念的影音文件 }\end{array}$ \\
\hline & 充足系统设计 & $\begin{array}{l}\text { 选择相关创意并将其 } \\
\text { 与主题结合起来设计 } \\
\text { 概念 } \\
\text { 利用与系统设计 } \\
\text { (例如: 系统图) 相 } \\
\text { 关的工具, 选择最有 } \\
\text { 发展前景的主题并推 } \\
\text { 进其进一步 } \\
\text { 的发展 }\end{array}$ & $\begin{array}{l}\text { 将新充足产品系统可 } \\
\text { 持续 (SE-PSS) } \\
\text { 的创意绘制成草图和 } \\
\text { 系统图等 }\end{array}$ & $\begin{array}{l}\text { 充足经济设计 } \\
\text { 工作表11 } \\
\text { (分析前期开发的新 } \\
\text { 充足产品服务系统 } \\
\text { 草图) } \\
\text { 系统图（例如上） }\end{array}$ \\
\hline & $\begin{array}{l}\text { 环境、社会伦理和 } \\
\text { 经济评估 }\end{array}$ & $\begin{array}{l}\text { 评估系统概念对环 } \\
\text { 境、社会伦理和经济 } \\
\text { 域所具有的改进潜力 }\end{array}$ & $\begin{array}{l}\text { 对每个维度、每项标 } \\
\text { 准所带来的改进潜力 } \\
\text { 进行描述 }\end{array}$ & $\begin{array}{l}\text { SDO工具包一清单列 } \\
\text { 表概念 }\end{array}$ \\
\hline & & $\begin{array}{l}\text { 将环境、社会伦理、 } \\
\text { 经济方面的改进结果 } \\
\text { 进行可视化表达 }\end{array}$ & $\begin{array}{l}\text { 显示环境、社会伦 } \\
\text { 理、经济域改进效果 } \\
\text { 的雷达图 } \\
\text { 支持可持续改进的可 } \\
\text { 视化互动 }\end{array}$ & $\begin{array}{l}\text { SDO I } \\
\text { 具包 - 雷达 } \\
\text { 可持续互动故事会 }\end{array}$ \\
\hline
\end{tabular}

20 欧洲研究项目“产品-一服务可持续协同设计网络” (SusProNet) 所开发的工具

(2002-2005，第五个框架计划）。

21 产品概念创意的例子参见产品设计系统运作方法 (MPDS) 和维佐里(Vezzoli), 山士恩

(Ceschin) 和库尔特斯(Cortesi) (2009a) Metodi e strumenti per il 设计的生命周期中所描 述的具体工具。 


\section{环境、社会伦理和经济评估}

该过程目标是评估系统概念可能带来的在环境、社会伦理和经济（地球、人和利 益) 方面的改进。为了确定是否还存在未解决的关键问题, 这个过程非常重要, 另 外, 如果同时提出了多个概念, 还需要确定哪一个概念更具发展前景。收获是: 对 每个概念进行详细阐述, 描述潜在的改进方案（根据各可持续性不同维度上的各项 标准）; 用可视化雷达图表现改进结果; 用可视化表达技术显示改进过程的互动作 用。有助于完成前两项目标的工具包括SDO工具包（检查清单和雷达部分）, 以及 辅助完成第三项目标的可持续互动故事会 (Sustainability interaction story-spot)。 关键问题:

- 该系统概念对环境、社会伦理和经济方面产生的潜在的改进有哪些?

- 该系统概念在环境、社会伦理和经济方面有需要重视的关键点吗? 其要素是 否需要重新设计?

\subsection{4 设计（构建）一个系统}

这个阶段的任务是详细列出系统概念的具体要求, 以便进行具体实施。

以下描述了本阶段的操作流程。

\section{具体系统设计}

这项活动旨在深入剖析系统概念, 并对以下方面进行定义：构成提供物的产品和服 务系列; 系统的所有参与者（首要和次要）, 其角色分工和互动; 终端用户/客户和 参与者之间在交付时的互动; 交付提供物所需的全部要素（物质的和非物质的）以 及设计/生产/交付这些要素的对象。辅助设计并实现这些要素可视化表达的可能用到 的各种工具（参见表4.5）。

关键问题:

- 该系统的产品和服务构成是什么? 该系统发挥的主要和次要功能分别是什 么? 对用户而言有什么价值? 客户/终端用户如何与提供物系统进行交互?

- 谁是系统的（主要和次要）参与者? 他们之间的相互关系是什么（合伙、协 议）? 在交付提供物的过程中，他们各自扮演的角色是什么? 他们之间的关 系如何?

- 为了交付提供物, 需要什么样的物质和非物质要素? 谁将设计/生产/交付这些 要素?

\section{充足系统的实施}

充足经济设计 (DSE) 阶段的目标是对新型充足产品服务系统概念, 就其运行步 骤、系统提供者和用户的角色以及运营中所需的解决方案重新进行详细定义, 并确 定何种成分对新系统的每个运行步骤提供支持, 成分共分为五类：工具、互动规 则、所需能力、提供的信息和背景。 
环境、社会伦理和经济评估

这项活动的目的是更准确地评估系统创新一旦实施所带来的环境、社会伦理和经济 方面的改进。评估的结果就是对潜在的改进（每个可持续维度的各项标准）进行更 为详细的描述; 通过一个雷达图对这些改进进行可视化表达。适当工具, 如上所 述，包括有助于完成前两项目标的SDO工具包（检查清单概念和雷达）以及辅助完 成第三项目标的可持续互动故事会（Sustainability interaction story-spot）。

关键问题:

- 通过实施所设计的系统创新, 可以在环境、社会伦理和经济方面获得哪些改进?

充足设计评估

这个充足经济设计（DSE）阶段的任务是从两个方面评估新设计的系统：新的充足 产品服务系统的 “改进” 及其充足改进的 “均衡”。要实现这一目标，第一步就是 对新产品服务系统的充足水平的 “均衡” 性进行可视化表达。人、地球、利益和技 术（分别采用四个条形图）。设计师就充足性的三个方面：适度性、合理性和自身 免疫力, 将新设计的系统同当前情形进行比较以观察是否有所改善。第二步是评估 新的充足产品服务系统是否改进了系统中每个利益相关方的行为, 且所有方面的改 善是否达到均衡（仅仅使用一个总的条形图）。支持这项评估的工具是充足经济平 衡工具 (Sufficiency Economy Balance Tool)。

表4.5 系统设计和工程：流程、子流程、结果、工具。以下内容所具体描述的 可持续系统设计工具用黑体字显示。

\begin{tabular}{|c|c|c|c|}
\hline 流程 & 子流程 & 结果 & 工具 \\
\hline \multirow{5}{*}{ 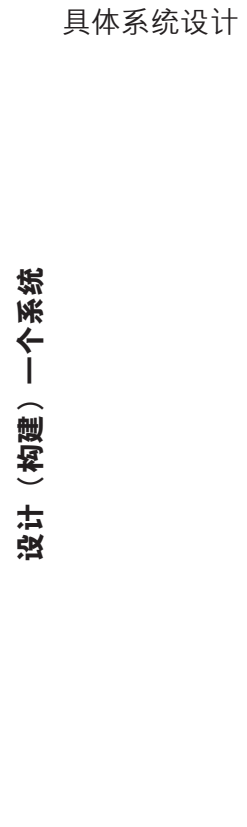 } & $\begin{array}{l}\text { 对新系统中（主要和 } \\
\text { 次要）参与者之间 } \\
\text { 互动的具体细节进 } \\
\text { 行定义 }\end{array}$ & $\begin{array}{l}\text { 主要和次要参与者及 } \\
\text { 其相互关系（物质、 } \\
\text { 信息和资金流）的详 } \\
\text { 细图示 }\end{array}$ & 系统图 \\
\hline & $\begin{array}{l}\text { 定义构成提供物 } \\
\text { （主要和次要功 } \\
\text { 能）的产品和服务集 } \\
\text { 合的细节 }\end{array}$ & $\begin{array}{l}\text { 交付给用户的、显示 } \\
\text { 主要和次要功能的图 } \\
\text { 像和文字 }\end{array}$ & 提供物图表 \\
\hline & $\begin{array}{l}\text { 定义为用户提供的具 } \\
\text { 体服务, 在交付提供 } \\
\text { 物时其他参与者间 } \\
\text { 的互动 }\end{array}$ & $\begin{array}{l}\text { 在提供物生产和交付 } \\
\text { 过程中, 对所发生的 } \\
\text { 互动顺序进行描述 }\end{array}$ & $\begin{array}{l}\text { 互动故事板样片, } \\
\text { 表现系统概念的影 } \\
\text { 音文件 }\end{array}$ \\
\hline & $\begin{array}{l}\text { 对每位参与者的角 } \\
\text { 色、贡献和动机进 } \\
\text { 行说明 }\end{array}$ & $\begin{array}{l}\text { 对每位参与者在合作 } \\
\text { 中的贡献、预期利益 } \\
\text { 和潜在冲突进行说明 } \\
\text { 的矩阵 }\end{array}$ & 动机矩阵 \\
\hline & $\begin{array}{c}\text { 定义交付提供物所需 } \\
\text { 的物质和非物质要素 } \\
\text { (确定谁将设计/生 } \\
\text { 产/交付提供物) }\end{array}$ & $\begin{array}{l}\text { 对系统所需要素和参 } \\
\text { 与者在设计、生产和 } \\
\text { 交付过程中所扮演角 } \\
\text { 色进行阐述的图示 }\end{array}$ & 方案要素概述 \\
\hline
\end{tabular}




\begin{tabular}{|c|c|c|c|c|}
\hline & 流程 & 子流程 & 结果 & 工具 \\
\hline & \multirow[t]{2}{*}{ 充足系统实施 } & $\begin{array}{l}\text { 制定一个完整的运 } \\
\text { 行计划 }\end{array}$ & $\begin{array}{l}\text { 文件和故事板, 用于 } \\
\text { 详细描述新充足产品 } \\
\text { 服务系统中运营、角 } \\
\text { 色、方案, 以及每个 } \\
\text { 运营步骤所需的组件 }\end{array}$ & 互动故事板（同上） \\
\hline & & 定义并设计组件 & $\begin{array}{l}\text { 在以下五个类别中列 } \\
\text { 出并设计支持新充足 } \\
\text { 产品系统服务的组 } \\
\text { 件: 工具、互动规 } \\
\text { 则、所需能力、提供 } \\
\text { 的信息和背景 }\end{array}$ & $\begin{array}{l}\text { 充足经济设计工作 } \\
\text { 表12 } \\
\text { (组件列表) }\end{array}$ \\
\hline 紫 & $\begin{array}{l}\text { 环境、社会伦理和经 } \\
\text { 济评估 }\end{array}$ & $\begin{array}{l}\text { 通过系统实施可以获 } \\
\text { 得的环境、社会伦理 } \\
\text { 和经济方面的改进 }\end{array}$ & $\begin{array}{l}\text { 确定不同可持续维 } \\
\text { 度中各个标准的改 } \\
\text { 进潜力 }\end{array}$ & $\begin{array}{l}\text { SDO工具包－清单列 } \\
\text { 表概念 }\end{array}$ \\
\hline \multirow{3}{*}{ 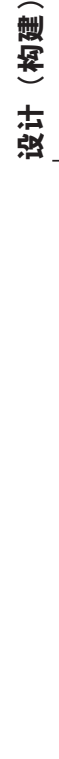 } & & 可视化结果 & $\begin{array}{l}\text { 改进的雷达图 } \\
\text { 互动的可视化 }\end{array}$ & $\begin{array}{l}\text { SDO 工具包 - 雷达 } \\
\text { 可持续互动故事会 }\end{array}$ \\
\hline & 充足设计评估 & $\begin{array}{l}\text { 评估新产品服务系统 } \\
\text { 的充足性 }\end{array}$ & $\begin{array}{l}\text { 将新充足产品服务系 } \\
\text { 统与现有系统进行比 } \\
\text { 较, 并在0-6的分值 } \\
\text { 范围上对所得到的改 } \\
\text { 进进行可视化表达 }\end{array}$ & $\begin{array}{l}\text { 充足经济设计工作 } \\
\text { 表5 } \\
\text { 第1部分：DSE 检 } \\
\text { 查清单 } \\
\text { 第2部分：定义充足 } \\
\text { 水平 } \\
\text { 第2部分：评估充足 } \\
\text { 性改进 }\end{array}$ \\
\hline & & $\begin{array}{l}\text { 就 “平衡” 方面以及 } \\
\text { 与现有系统（每个组 } \\
\text { 件和4个维度的总体 } \\
\text { 平衡）进行两方面比 } \\
\text { 较, 评估充足性程度 }\end{array}$ & $\begin{array}{l}\text { 就四个维度 (人、地 } \\
\text { 球、利益、技术) 以 } \\
\text { 及与现有系统进行两 } \\
\text { 方面比较, 对新充足 } \\
\text { 产品服务系统达到 } \\
\text { 的 “平衡” 进行可视 } \\
\text { 化表达 }\end{array}$ & $\begin{array}{l}\text { 充足经济设计工作 } \\
\text { 表13 } \\
\text { 充足经济平衡工具 }\end{array}$ \\
\hline
\end{tabular}

\subsection{5交流}

“交流”阶段就设计方案的总体特点以及上述可持续性等, 与外界进行交流沟通并 作用于其他所有阶段。前些阶段应用于设计和可视化解决方案中各要素的一些工具 在本阶段中也将得到应用, 对交流提供支持。

基本目标是提供一个文件以表明: 
- 可持续解决方案的设计优先顺序。每个可持续维度优先顺序的确定都有特定 的标准（就现有系统而言）, 用以引导设计过程朝向可持续的解决方案发展。

- 产品服务系统的总体特点。对构成系统创新的要素进行描述：即提供物所包 括的产品和服务; 系统的（首要和次要）参与者, 他们各自的角色和相互间 的互动; 参与者与客户/终端用户之间的互动。

- 产品服务系统的可持续特点。显示了通过实施解决方案所获得的潜在改善空 间（经济、社会伦理和经济角度），同时系统要素也表现出改善过的迹象。

- 充足设计交流。这个步骤在充足经济设计过程中至关重要, 因为产品服务系 统和充足经济设计的概念对于多数设计师而言还很陌生。因此, 不仅需要就新 系统如何运作与客户和利益相关方进行交流, 而且还需要说服客户/服务提供 商接受新设计的充足产品服务系统。有效工具包括交互故事板和现场故事会。

表4.6 交流: 流程、子流程、结果、工具。以下内容所具体描述的可持续系统设 计工具用黑体字显示

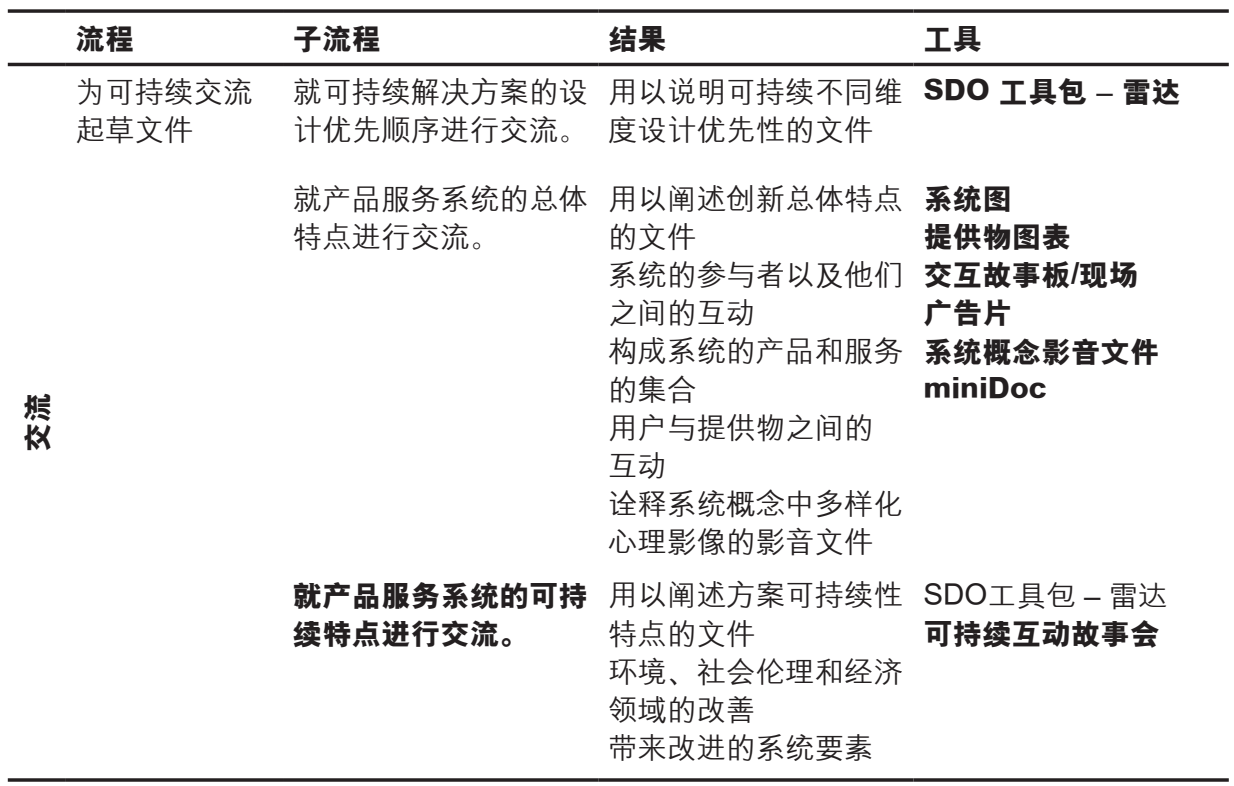

\subsection{SDS设计工具}

本节描述了用于支持可持续系统设计方法 (MSDS) 各阶段的若干工具。可将这些工 具分为两大基本类型:

- 可持续系统设计导向工具

- 创意刺激、辅助工具和系统设计战略 
第一组, 可持续系统设计导向工具 22 由一系列将系统过程导向环境、社会伦理、经济 领域可持续解决方案的工具组成。

这些工具旨在:

- 帮助确定设计的优先顺序: 可持续设计导向(SDO)工具包- - “设置优先顺 序” 部分

- 引导创意向可持续解决方案发展：SDO工具包-—“定向概念”部分

- 确定实施解决方案所带来的潜在改善空间（环境、社会伦理和经济方 面）：SDO工具包一一“检查概念”与“雷达”

- 对系统创新的可持续特点进行可视化表达：可持续互动故事会

需要强调的是, 如果其目的是为了确定可持续解决方案, 那么在设计过程的最初阶 段, 整合这些工具将会使目的的实施更加有效。

第二组工具包括: 一方面, 支持并促进系统层面创意形成的工具; 另一方 面, 促进它们组织和沟通的工具。在这些工具中, 我们尤其要强调极化图和满意度 系统图的作用。

系统设计战略工具23已被开发用于促进（产品-一服务）系统创新中各要素的合 作生产和可视化表达。更具体地说, 这些工具用于设计和可视化表达:

- 构成提供物的一系列产品和服务所具备的功能：提供物图表

- 生产和交付提供物所需的系统结构（参与者及其互动）：系统图

- 客户/终端用户与系统之间在交付提供物时的互动, 以及在生产和配送期间系 统各参与者之间的互动：交互表、交互故事板、表现系统概念的影音文件

- 系统中各参与者之间的相互关系: 利益相关方的动机矩阵图

- 在设计/生产/输送各系统构成要素（物质和非物质）过程中, 不同参与者的角 色: 方案要素概述

除了支持各系统要素的可视化表达和设计, 这些工具也被开发用于促进各行动方共 同参与设计的过程中。

我们将从以下方面对设计工具进行描述:

- 工具的作用

- 与可持续系统设计过程的整合

- 如何使用

22 除了此处已列出的工具外, 还有其他类似用途的工具。本书因篇幅有限, 不一一详述。全 文可在www.lens.polimi.it的“工具” 部分中找到。

23 除了此处已列出的工具外, 还有其他类似用途的工具。本书因篇幅有限, 不一一详述。全 文可在www.lens.polimi.it的“工具” 部分中找到。 
90 可持续产品服务系统设计

- 结果

- 可用性和所需资源

这些工具将按下列顺序逐一展示说明。

首先, 引导设计过程向可持续系统创新发展的工具:

- 可持续设计导向工具包 (SDO)

- 可持续互动故事会

- 充足经济检查清单

- 充足经济指导方针

- 充足经济平衡工具

接下来是在系统创新中进行总体设计要涉及的其他工具:

- 利益相关方系统图

- 满意度系统图

- 互动表（故事板）

- 提供物图表

- 极化图

- 方案要素概述

- 利益相关方动机矩阵图

- MiniDOC

- 表现系统概念的影音文件

- 广告片

\subsection{1 可持续设计导向工具包 (SDO) 24 目标}

该工具旨在引导设计过程向可持续系统方案的方向发展。该工具具有以下多种功能 以支持设计师们实现这一目标：确定可持续优先顺序；分析最佳实践；使用可持续 设计导向指导方针; 在现有参照系统的基础上对照检验并采用可视化技术展示相关 的潜在改善空间。

24 产品服务系统发展理论（MEPSS）, 属于欧盟第5 FP增长计划, 它由卡洛·维佐里

(Carlo Vezzoli) 和蒂什纳 (Ursula Tischner) 研发。该工具先后为为联合国环境计划署 相关计划和欧盟赞助的LeNS（可持续性学习网络）项目进行过更新。 
这是一个能够提供不同功能的工具, 并具备模块化结构。设计师们可以根据各 设计项目的具体需求和情况, 选择全部或部分使用该工具。

该工具旨在:

- 为所有三个可持续维度确定设计优先顺序 (例如: 在环境维度方面, 确定究 竟是优化系统寿命还是减少资源更重要, 等等)。该功能通过利用检查列表 对现有系统进行分析(SDO部分：“设置优先顺序”)得以实现。

- 激发潜在的可持续系统的创意构思。该功能通过利用可持续方案的设计标准 和指导方针得以实现(SDO部分：“导向概念” ):

- 在同现有系统相比较的基础上，对三大可持续维度的潜在改进或退化进行 评估。该功能通过 “检查列表” 将设计方案与现有系统进行比较, 并且通 过“雷达图”对分析结果进行可视化表达(SDO部分：“检查概念”和“雷 达”)得以实现。

需要强调的是, 该工具所具备的三方面的基本功能, 适用于可持续的三个维度, 并 与设计过程中不同阶段进行愈发具体细致的整合。

现在, 让我们回顾一下该工具是如何构建的。SDO结构的关键要素是在多维度 结构中建立而成的标准和指导方针。如图4.2所示, 可持续的三个维度：环境、社会 伦理和经济均被纳入考虑范围, 每个维度有六项标准。每个标准都被用于评估给定 的系统和指导实际设计过程, 而反过来每一个标准又构成一系列指导方针。

\section{图4.2 SDO结构：可持续维度、标准和指导方针}

\begin{tabular}{|c|c|c|c|}
\hline $\begin{array}{l}\text { 可持续性 } \\
\text { 原则 }\end{array}$ & $\begin{array}{l}\text { 维度 } \\
\text { 重要领域 }\end{array}$ & $\begin{array}{l}\text { 标准 } \\
\text { 设计师-桥梁-分析师 }\end{array}$ & $\begin{array}{l}\text { 指导方针（２ 个层面） } \\
\text { 潜在的改进 }\end{array}$ \\
\hline $\begin{array}{l}\text { 环境恶化 } \\
\text { 环境恶化 }\end{array}$ & 环境 & $\begin{array}{l}\text { 标准1 } \\
\text { (例如: 运输量减少) }\end{array}$ & $\begin{array}{l}\text { - 指导方针 } \\
\text { (例如: 现场生产 } \\
\text { 组装) } \\
\text { - 指 方 针 } \\
\text { ( 例如: 使用当地资源) } \\
\text {-...... }\end{array}$ \\
\hline \multirow[t]{2}{*}{ 后代 } & & $\begin{array}{l}\text { 标准2 } \\
\text { (例如：系统生命优化) }\end{array}$ & - ....... \\
\hline & & ……标准 3-6 & $\bullet \ldots \ldots$ \\
\hline \multirow[t]{2}{*}{ 公平 } & 社会-伦理 & 标准 1-6 & \\
\hline & 经济 & ......标准 1-6 & • ....... \\
\hline
\end{tabular}


92 可持续产品服务系统设计

环境维度的标准:

- 系统生命优化

- 运输/分配量减少

- 资源消耗下降

- 资源消耗的最小化与资源价值的保持

- 资源保护 / 生物多样化

- 无毒

社会伦理维度的标准：

- 工作条件

- 利益相关方的公平与正义

- 负责任且可持续的消费

- 对弱势和边缘化群体的帮助与整合

- 社会凝聚力的加强

- 当地资源的强化 / 保护

经济维度的标准:

- 市场地位与竞争力

- 企业盈利能力 / 增值

- 为客户带来的附加值

- 企业长期发展

- 合伙 / 合作关系

- 宏观经济效益

这个工具成为了一座 “桥梁” , 连接了可持续评估的语言、数据、工具和设计师两 个不同的“世界”。这实质上是适用于复杂系统的定性工具。

将工具整合到可持续系统设计方法 (MSDS) 的设计过程中 SDO工具可用于该方法论的所有阶段:

- 在战略分析过程中, SDO可被用于:

A: 确定可持续性维度的设计优先顺序

B: 从环境、社会伦理和经济角度分析优秀案例

- 在发现机遇过程中, SDO可被用于: 
C 产生以可持续为导向的创意 (系统层面)

- 在设计系统概念过程中, SDO可被用于:

C' 产生以可持续为导向的创意（产品和服务层面）

D: 检查并可视化表达潜在的改善空间

D' : 如有需要, 重新确定设计优先顺序

- 在系统设计和构建过程中, SDO可以被用于:

D"：检查并可视化表达潜在的改善空间

\section{图4.3 将SDO整合到MSDS设计过程中}

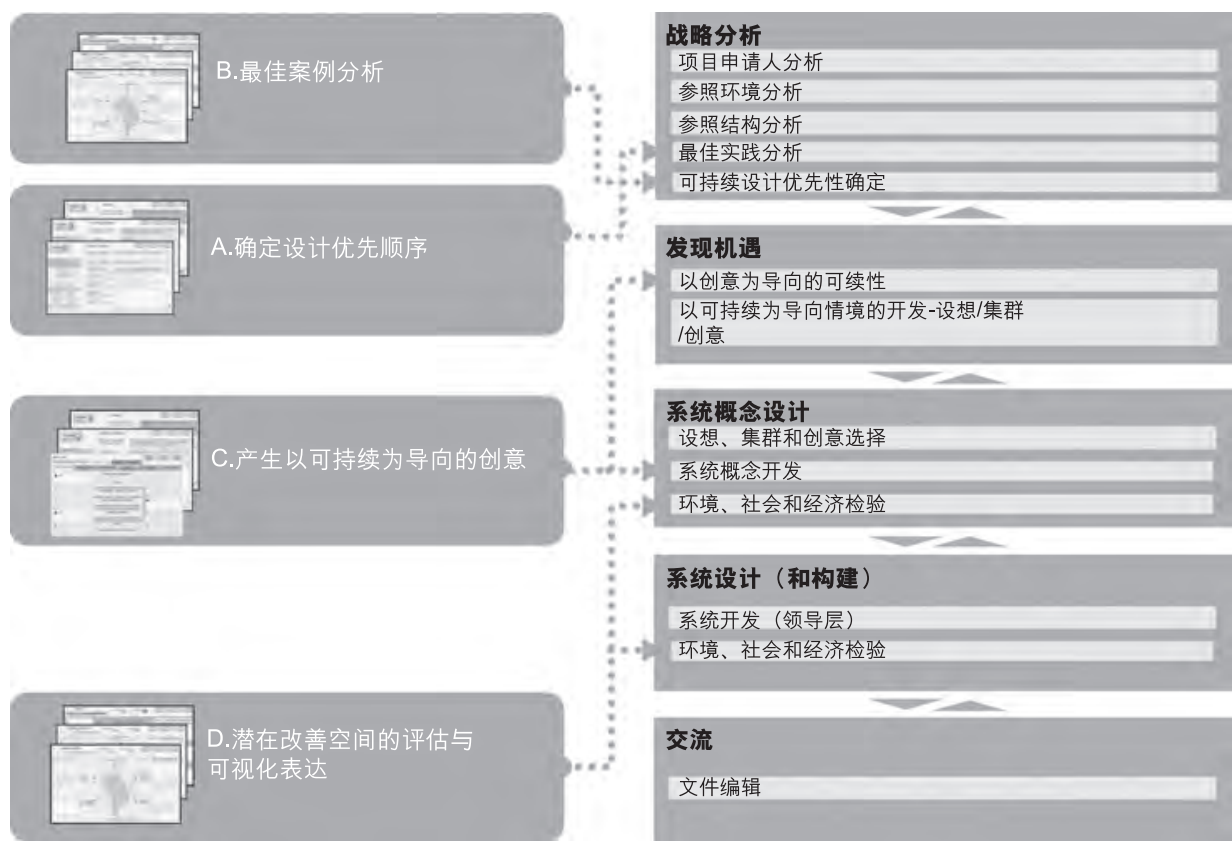

如何使用该工具

以下部分描述了如何参照MSDS各阶段的方法论来使用这一工具。

\section{启动}

点击开始界面屏幕中 ‘新建” 按钮, 输入名称, 点击 “确定” , 创建一个新项目。 (选择 “加载” 选项, 输入项目名称, 点击 “确定” , 可再次进入该项目)。出现一个 名称为 “项目记录” 的页面时, 可以在此页面输入关于该项目的基本资料, 标出满 意单元 (例如: 有待满足的福利需求) 和参照环境（或现有系统）。 
94 可持续产品服务系统设计

\section{图4.4 SDO工具包: 开始界面}

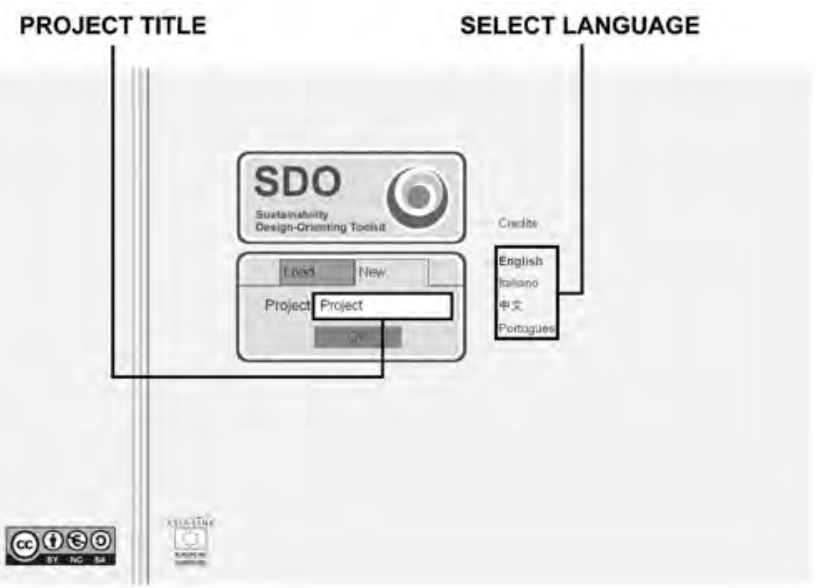

图4.5 SDO工具包: 输入起始数据

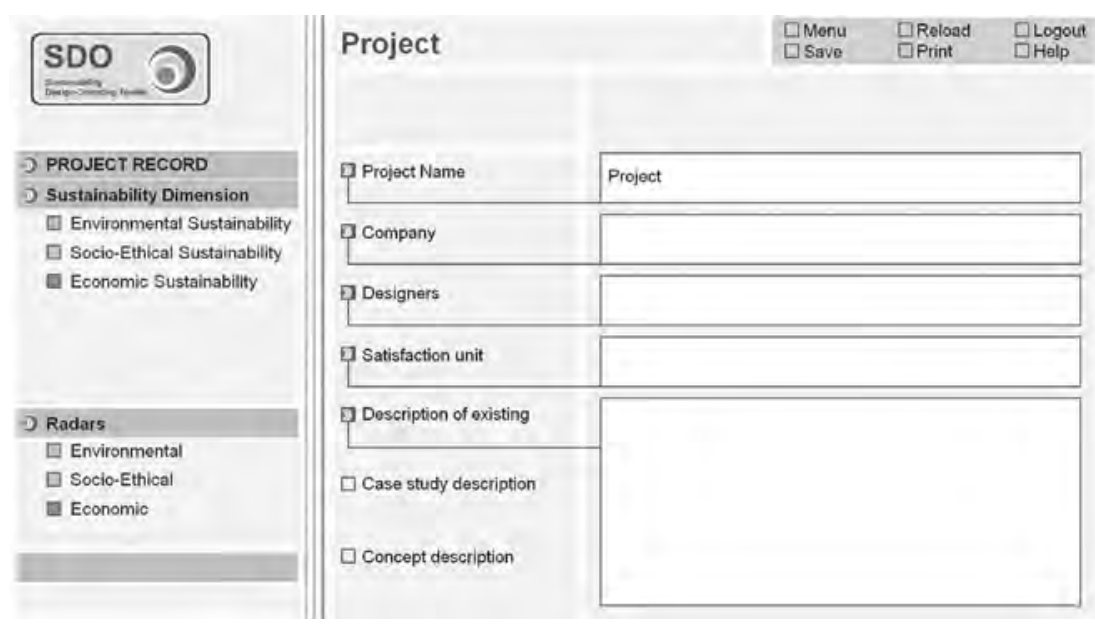

1. 战略分析

\section{A. 确定设计优先顺序}

本阶段旨在根据可持续的三个维度要求, 分析现有系统以确定设计优先顺序。这些 优先顺序为引导设计决策朝可持续解决方案方向发展奠定了基础。

通过回答6个不同标准下的一系列清单问题, 对可持续维度下的各个系统进行评 估。为此，您必须选择一个维度（例如：环境）并点击设置优先顺序：这时出现6个 
相应的标准, 每个标准与一系列检查清单相对应; 您可以在每个检查清单所对应的 区域输入答案和评论。

回答完各个检查清单中的问题后, 可以通过选择 ' $\mathrm{H}^{\prime}$ (= 高), ' $\mathrm{M}$ ' (=中), ' $L '$ ' (= 低)或 ' $N$ ' (= 不) 等优先等级, 来确定每个标准的设计优先顺序。

图4.6 SDO 工具包: 分析现有系统并确定设计优先顺序

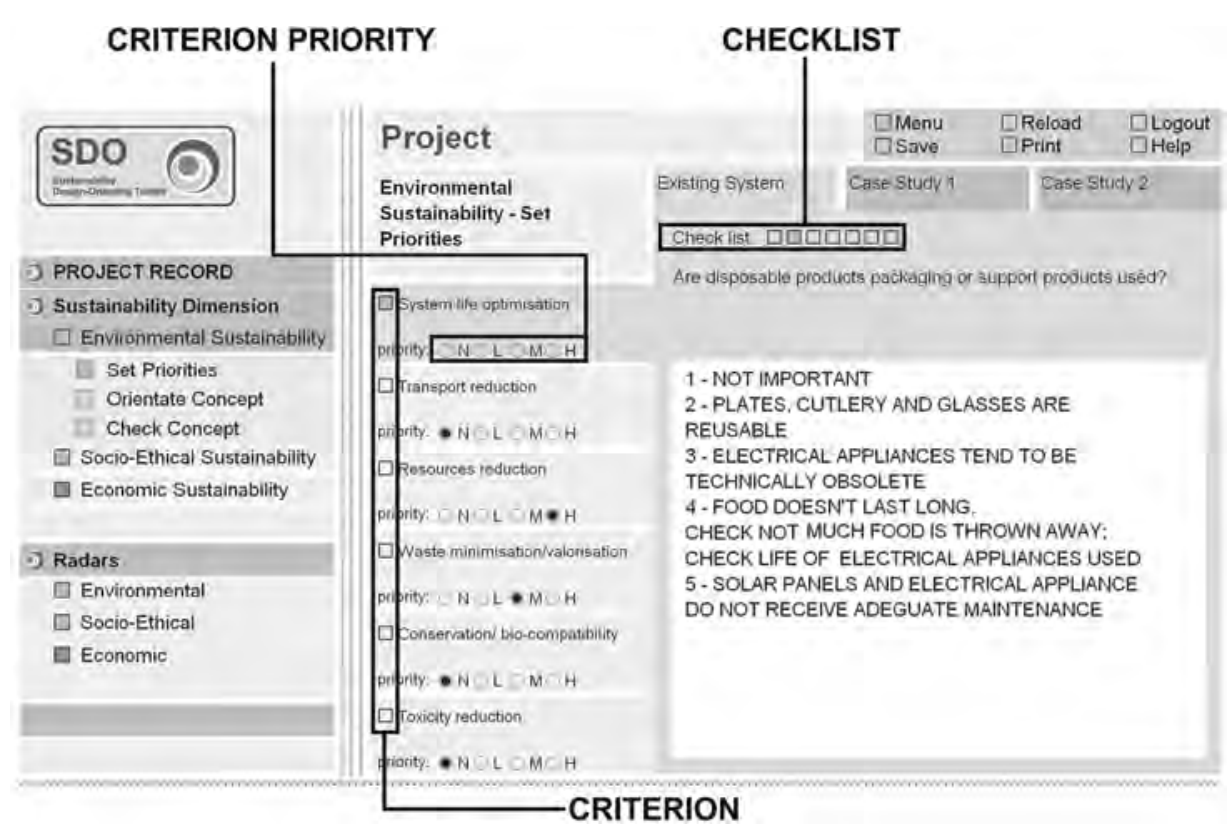

点击 “环境” 雷达, 可以对该过程的图形结果进行可视化方式显示。雷达图显示了 每个标准的设计优先顺序。此外, 还可以在与每项标准所对应的空白区域内填入现 有系统中最关键的要素; 可视化可被用作一个简要报告, 对随后的创意步骤提供支 持。

我们必须再次强调, 设计优先顺序的重要性在于：它能够识别实践设计过程中 至关重要的设计标准。

\section{B. 具有可持续特征的优秀案例分析}

为了使设计过程拥有持续的信息输入和内在洞察, 应当对现有的可持续方案进行审 查。SDO工具有助于我们将这些解决方案与现有系统进行比较, 以便确定其环境、 社会伦理和经济属性。 


\section{图4.7 SDO工具包：可视化设计优先顺序}

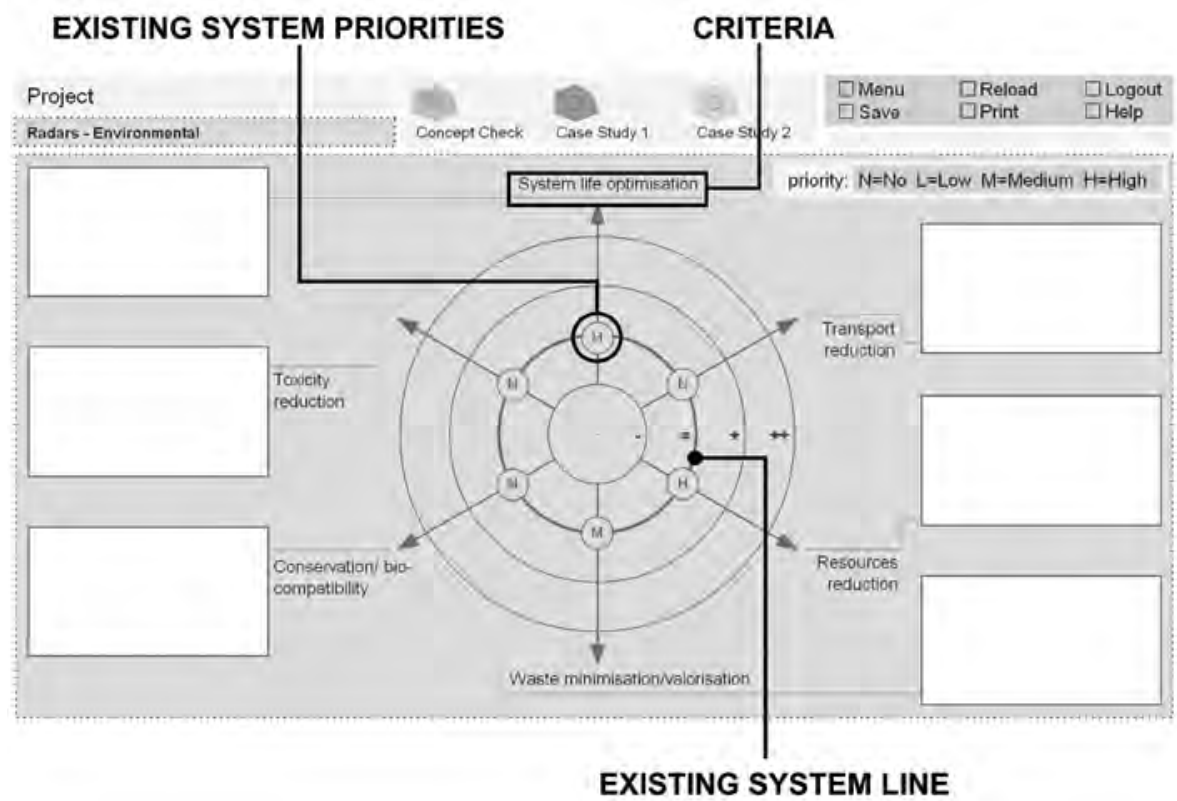

评估过程与A点所描述的过程类似。先选择一个维度并点击 “设置优先顺 序”, 然后点击 “案例研究”, 将出现6个相应的标准, 每个标准对应一系列检查清 单; 可在每个检查清单所对应的区域输入答案和评论。

对各种检查清单做出回应之后, 通过在下列选项中进行选择, 显示当前情况下 对每个标准所做的改进: 根本性改进 $(++)$, 渐进性改进 $(+)$, 无明显改进 $(=)$, 情况恶 化(-)。

通过点击 “雷达” 并选择与案例研究相对应的雷达区域, 可以对每个标准的改 进情况进行可视化表达。在这种情况下, 也可以在文字框内输入解决方案的关键要 素; 可视化结果有利于下阶段激发创意。

SDO工具包允许输入两个优秀案例。 


\section{图4.8 SDO工具包: 优秀案例显示的关于现有系统的可视化改进}

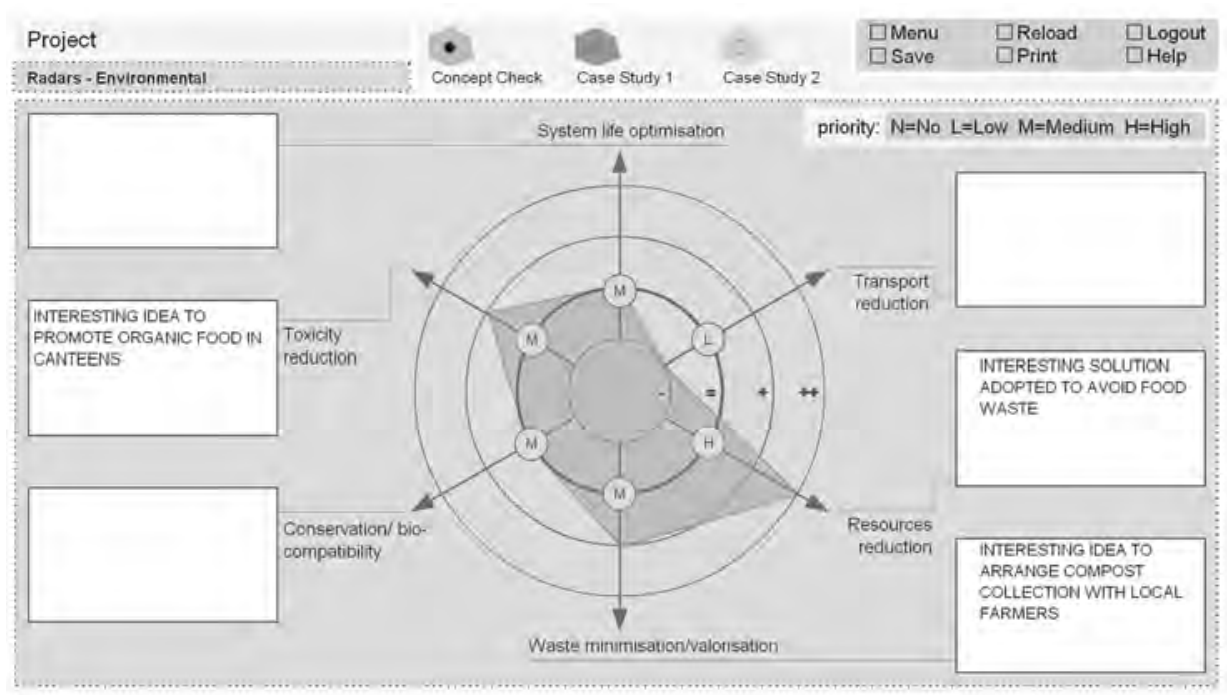

\section{2. 发现机遇}

\section{C. 产生以可持续发展为导向的创意}

本阶段旨在促进以可持续发展为导向的创意构思。为了达到这一目的, 我们可以为 每项标准制定一系列指导方针, 辅助并激励其实施。

在SDO工具包的菜单左侧, 选择可持续维度（例如环境）并点击 “导向概 念” ; 在顶部, 选择 “系统”。6个设计标准将再次出现在顶部, 点击这些标准, 可 以查看先前设定的优先顺序, 以及一系列相应的指导方针。这些指导方针将促进创 意构思，所产生的创意可以用屏幕两侧的虚拟 “便利贴”进行标注。

很明显, 如上所述, 创意生成需主要关注处于最高优先级别的标准。例如: 若资源消耗为优先项, 您就应当从与该标准相关的创意表开始, 从相关的指导方针 中获得灵感。同时, 如果 “运输/分配量减少” 的优先性最低, 您应给予次要关注 （如果优先顺序为零, 则不予关注）。 
图4.9 SOD工作包（系统层面）环境维度的创意构思表

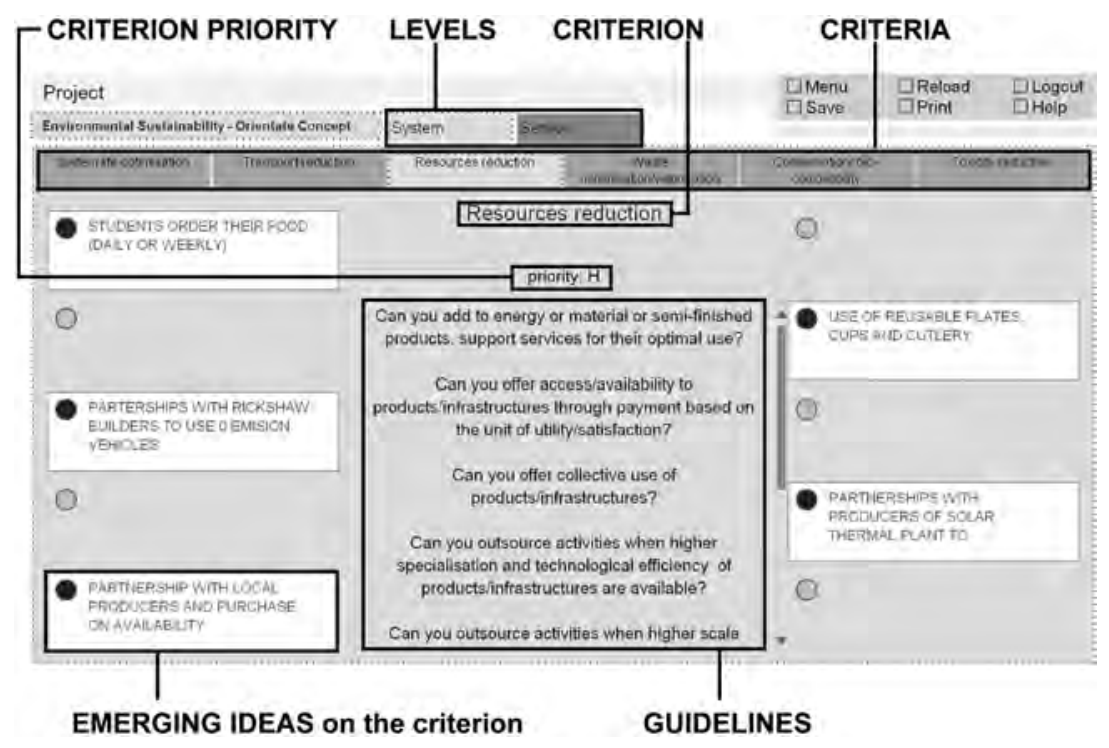

3. 设计系统概念

\section{C' . 产生以可持续发展为导向的创意}

本阶段旨在在产品和服务层面刺激产生以可持续发展为导向的创意。

在左侧菜单中，选择可持续维度，并点击“导向概念”；在顶部，选择“服务”。 系统层面的创意构思, 可以选择不同的设计标准, 对指定的优先顺序和相关的指导 方针进行可视化表达。指导方针对创意构思提供支持，所产生的创意可以通过屏幕 两侧的虚拟“便利贴”进行标注。

\section{D. 对已经开发的系统概念的潜在改进成果进行检查和可视化表达}

本阶段旨在分析系统概念，确定现有系统的潜在改进效果。

选择可持续维度（例如环境）并点击 “检查概念”。在顶部，点击 “概念描 述” 并在所对应的文字区域中输入系统概念的概述。回答检查列表列举的问题有助 于确定设计方案对现有系统所做的改进。每项标准均可选择：根本性改进 (++), 渐 进性改进 (+), 无明显改进(=), 情况恶化(-)。

检查清单可以帮助我们对照最佳案例，确认设计系统所带来的改进程度，以及 如何进行改进。

点击“雷达”并选择 “概念检查” 雷达区域, 您可以在初始系统或案例研究 中, 对每个标准中潜在的待改进要素进行可视化表达, 也可以将每个方案的关键要 素写在文字框内。 
图4.10 SOD工作包：潜在产品服务系统雷达图

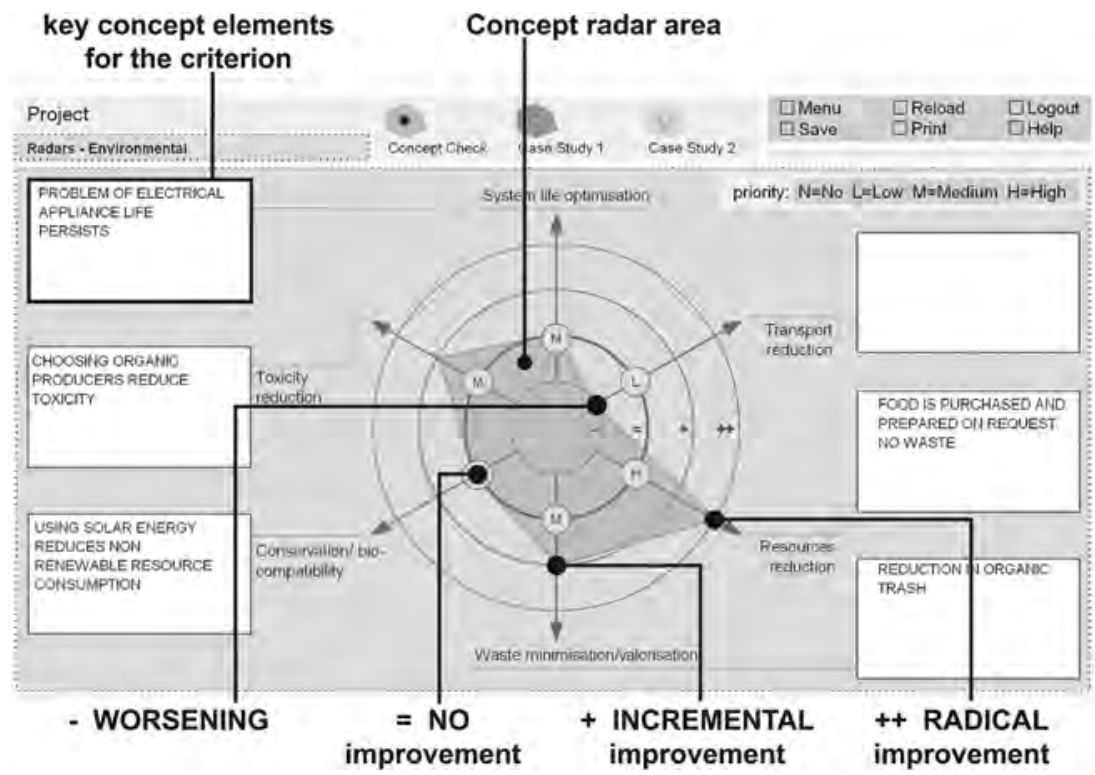

\section{C. 以可持续发展为导向的服务创意构思（指导方针2级）}

在“菜单”的“可持续维度” 中, 选择一个维度, 进入 “导向概念”; 选择顶部 的 “服务”。这些标准, 以及您所确定的相关优先性和一系列相关指导方针都通过 可视化的方式进行表达呈现（2级-服务）。从具有最高优先性 (参照现有系统) 和最 差改进效果 (系统概念) 的标准开始进行头脑风暴。在“便利贴”中写下自己的创 意灵感（点击左右两边的圆圈）。

\section{图4.11 创意表格图/指导方针2级一写在 “便利贴” 框中的一些带有创意的服务}

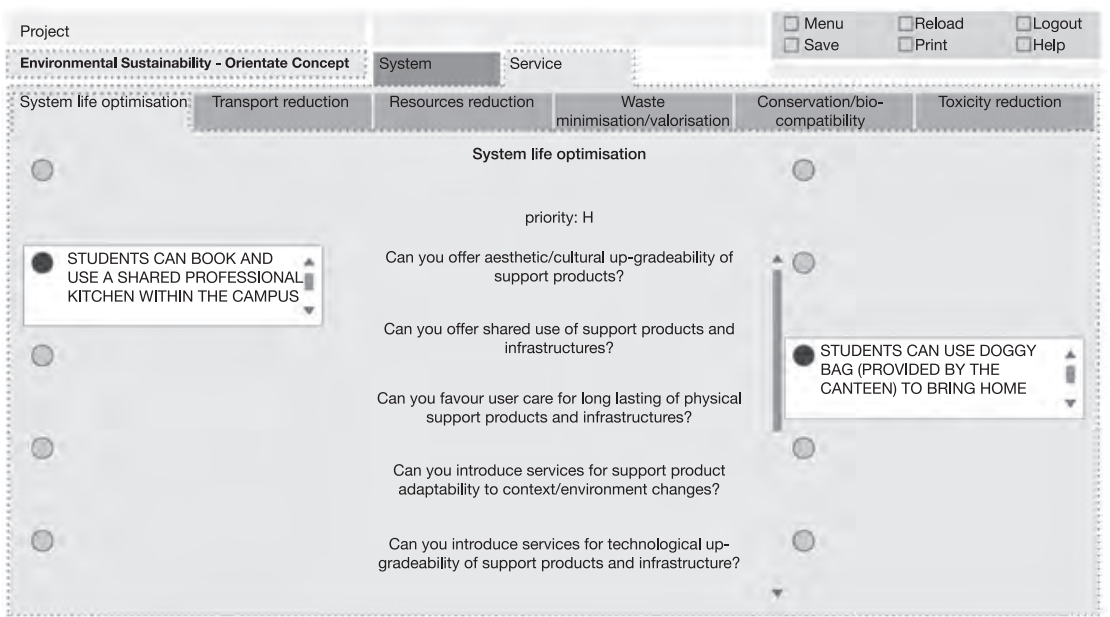




\section{D. 对所开发的产品服务系统概念的改进情况进行检查和可视化表达}

在“菜单”的“可持续维度”中, 选择一个维度，并进入“检查概念”。在文字框 中输入所开发的系统概念的综述（如果所写的系统内容有更新）。点击每个可持续 层面的“检查概念” 按钮, 进入检查列表（每个列表对应一个维度），它将帮助您 确定(如果所写的系统概念有更新)现有系统的改进。

对改进进行标记: 情况恶化(-), 无变化 $(=)$, 渐进式改进 $(+)$, 根本性改进 $(++)$ 。

通过检查清单, 您可以了解系统概念被改进和变更的情况; 点击 “概念描

述”，修改概念描述并更新之前的概念定义。

进入 “雷达” 页面, 您可以汶览改进后的效果图。选择您感兴趣的概念和可持 续维度, 雷达图能够对系统概念与现有系统 (粗体圆圈) 或案例研究的改进情况进 行可视化表达, 其结果显示为一个区域（形状如船帆）。

\section{4. 设计和构建系统}

\section{D' ' . 对产品服务系统所提供的潜在改进情况进行检查和可视化表达}

就 $\mathrm{D}$ 点而言, 每个标准都需要回答检查列表所列举的问题并标注改进程度: 根本性改 进 $(++)$, 渐进性改进 $(+)$, 无明显改进 $(=)$, 情况恶化 $(-)$ 。

点击 “雷达”，您可以汶览改进后的效果图。

结果

$\mathrm{SDO}$ 的不同功能将带来以下结果:

- 对现有系统的设计优先顺序进行确定（从环境、社会伦理和经济维度）

- 对以可持续发展为导向（系统、服务和产品）的不同理念的集合进行定义

- 来自设计方案的现有系统的可视化雷达图

- 雷达图能对构成优秀案例的潜在环境、社会伦理和经济改进方面的特征进行 可视化表达

\section{所需工具和必备资源}

SDO工具包是开源、公共版权的软件, 可在线使用 (www.sdo-lens.polimi.it25) 或在 局域网中下载安装使用（从www.lens.polimi.it 中的“工具”一栏中下载）26。

该工具虽更适合应用于多学科的团队中, 然而也可以由设计师单独使用。同时 也建议将各系统参与者、客户和终端用户纳入该工具中。

25 已有意大利语、英语、葡萄牙语及中文版本。

26 本地的可安装版本是开源的, 它可根据项目需要转换为其他语言并进行修改。 
该工具至少要求:

- 30 分钟确定设计优先顺序（每个可持续维度）

- 30 分钟进行创意构思 (每个维度)

- 60分钟对改进结果（设计方案和优秀案例）进行评估

\subsection{2 可持续互动故事会 27}

目的

可持续互动故事会是一个共同设计工具, 主要用于可视化。其作用在于简洁有效地 描述特定目标下产品服务系统的显著要素（例如：设计方案如何达到特定的环境和 社会伦理目标要求? ) 。

这主要由关注特定互动的互动表格来完成。结果将在单个屏幕/页面上进行展 示, 其中包括以下关键要素:

- 客户/终端用户与系统所提供的提供物之间的关键互动

- 提供物生产与交付过程中, 不同参与者之间的关键互动

- 设计的解决方案是如何实现特定目标的（例如：解决方案是如何实现所需环 境和社会伦理改进的）

当需要将系统概念的潜在功能进行可视化表达并与参与者进行交流时, 这个工具非 常有用。在这种情况下, 对各系统概念的关键要素进行合成并交流, 效果则会变得 更好。

将工具整合到可持续系统的设计过程中

可持续互动故事会可在以下情况下使用:

- 在系统概念设计和系统设计（构建）中:

简洁有效地对所设计的产品服务系统的关键要素进行可视化表达, 并突出强调它所 提供的环境、社会伦理和经济方面的改进情况。

27 该工具由可持续发展研究的设计和系统更新组织研发(Dipartimento INDACO, Politecnico di Milano)。更多信息请参见Vezzoli (2010)。 


\section{图4.12 将可持续互动故事会整合到MSDS设计过程中}

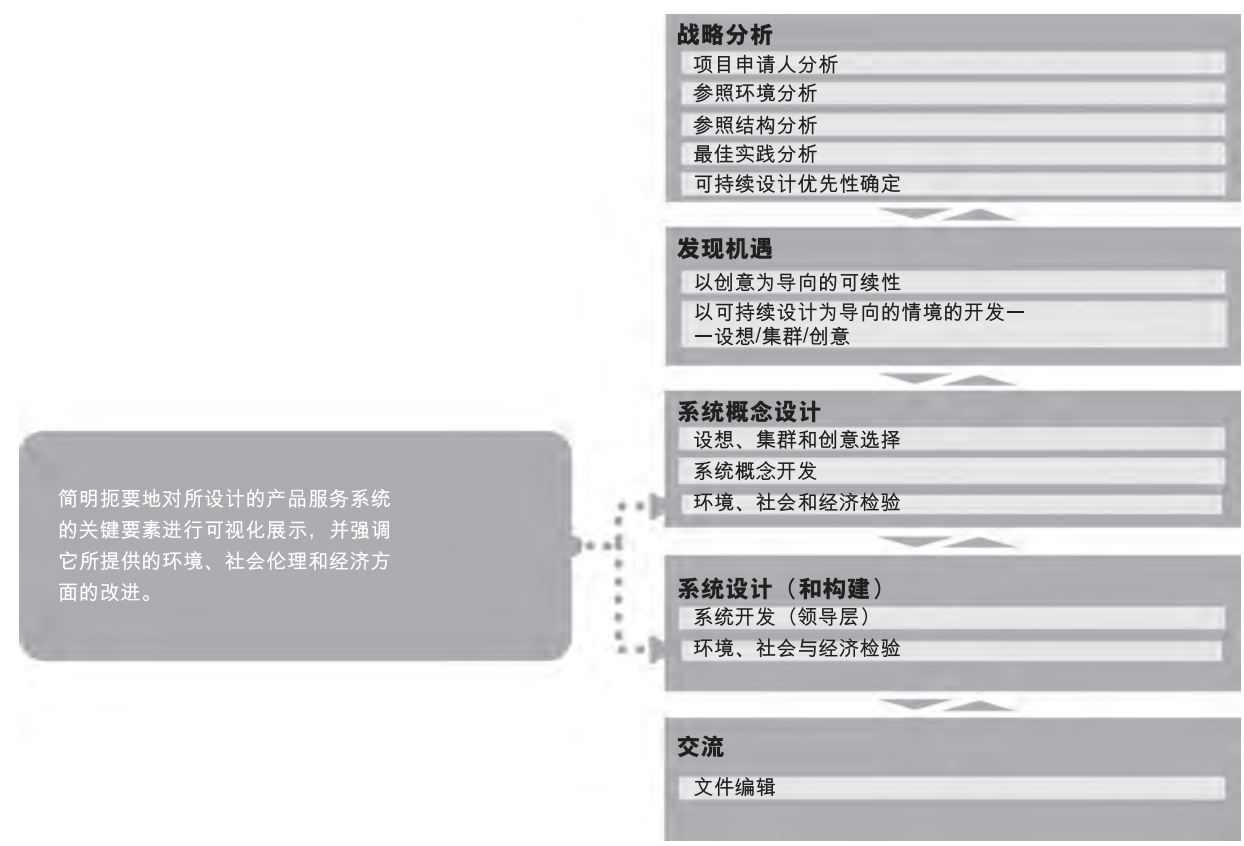

如何使用该工具

该工具需要使用图形图像处理软件和幻灯片软件(例如: 用微软办公系统的幻灯片软 件或Open Office中的类似软件)进行可视化处理 28 。

所形成的作品将展示在一个屏幕上, 其中展现了两类互动情况：一类关注 用户而另一类关注交付提供物的参与者; 这两类互动通过不同背景颜色进行区分

（图4.13）。每个互动均包括（图4.14）:

- 参与者颜色与背景颜色相匹配的图像 (有关如何处理图像的建议, 请参见有 关互动表的专门章节)

- 简要说明

在可视化操作页面的底部, 可以输入注释并与相应的互动建立链接（图4.15）。

28 用户可从www.lens.polimi.it下载互动故事会的基本版, 在 “工具” 栏中附有其详细使用说 明。 
图4.13 两类互动将显示在可持续互动故事会上: 前台和后台。两类互动将通过 不同背景颜色加以区分

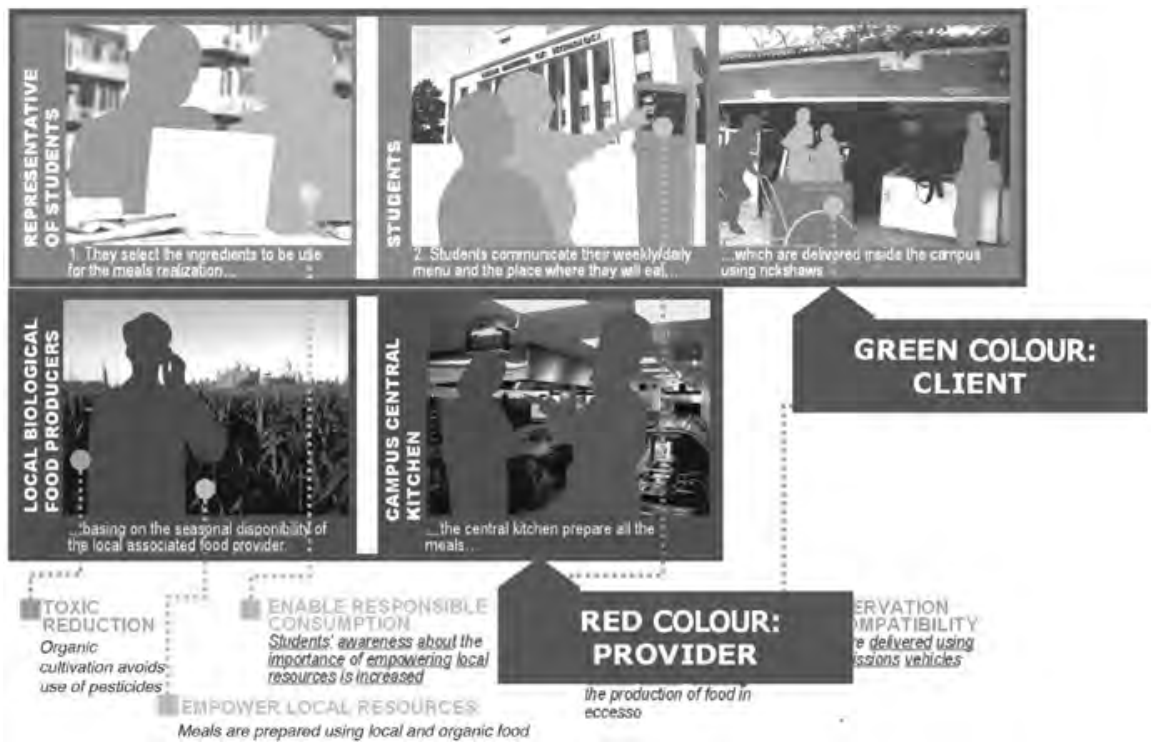

(†)

图4.14 在可持续活动故事会中构成单个互动要素的是图像、背景颜色、描述性 文字和具体描述

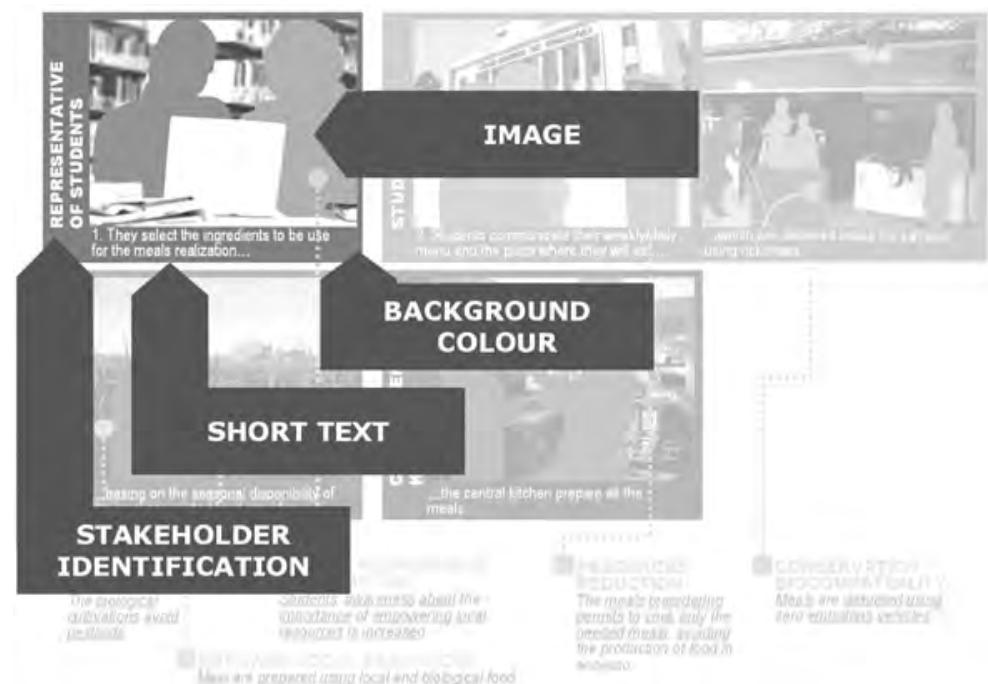




\section{图4.15 可持续互动故事会页面的底部是链接到相应互动的说明}
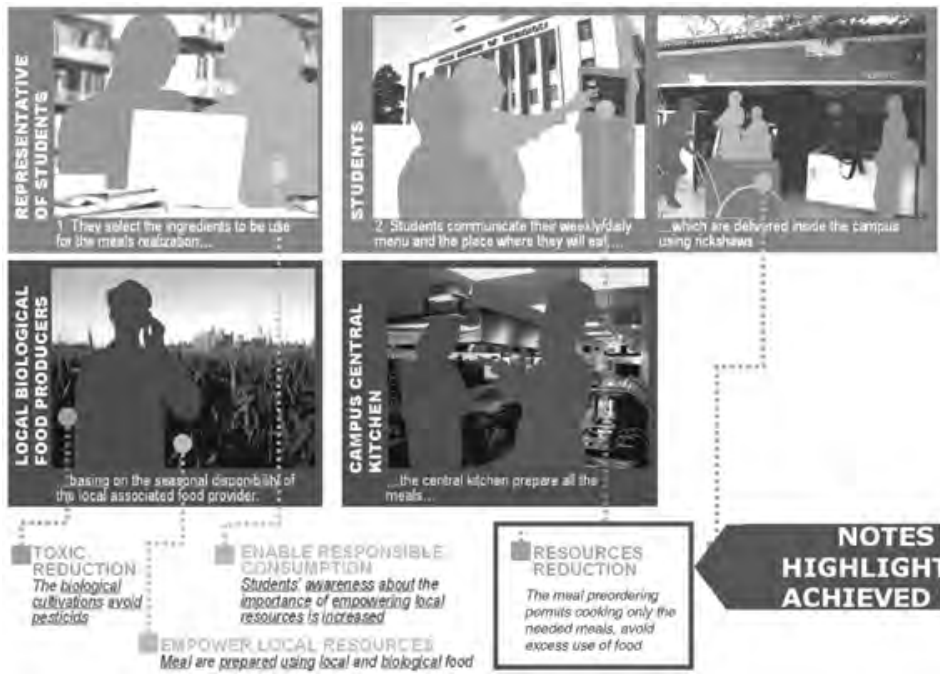

NOTES TO

HIGHLIGHT MAIN

ACHIEVED GOALS

结果

其结果是简洁有效地对关键要素进行可视化表达, 将其与特定目标相关联（例如： 对环境或社会伦理的改进等）。

\section{所需工具和必备资源}

可持续互动故事会需要使用图形图像处理软件和幻灯片软件。或者, 如果已创建互 动表（参见4.3.8）, 则可在此基础上, 使用电子数据表软件选择关键互动完成创 建。

就工具的使用而言, 创建图像需要有基本的图像操作技巧（图像编辑软件的 使用）。可持续互动故事会可以由设计团队成员使用幻灯播放软件（电子制表软 件）进行管理。

创建可持续互动故事会所需的最短技术时间约为：

- 从零开始创建需4小时

- 从现有的互动表格开始创建需30分钟 


\section{3 .3 充足经济检查清单}

目的

当处于不同生活水平的人们朝着中间路径（即充足水平）发展时, 充足经济清单有 利于对人们的生活方式/行为进行评估。该清单也可用于确定现有系统的充足水平。 清单覆盖四个维度（人、地球、利益、技术）, 并包含充足经济哲学的三个核心内 容（适度性、合理性和自身免疫力）。

充足经济设计 (DSE) 体现了可持续发展定义中的三个共同维度, 人（社会伦 理）、地球（环境）、利益（经济），并且也对科技给予了适当的关注。显然，选 择适当的技术能够有效防止系统的不平衡。这是从过去不适当的投资、技术推动及 其产生的负面影响中吸取到的教训。

将工具整合到可持续系统的设计过程中

充足经济清单可在下述情况中使用:

- 针对下述方面进行策略分析：

评估现有系统的充足水平（分析用户或系统提供方的行为是否与充足经济哲学 (SEP) 的原则相符, 以及是如何相符的）。

如何使用该工具

该清单的使用, 可分为两个步骤。

\section{步骤一：使用充足经济清单分析充足水平}

设计师对照工作表单 5 的第一部分, 分析清单里的四个维度, 在相应要点旁的选项框 里打钩。人、地球、利益和技术（参见图4.16）。

\section{步骤二：对现有系统的充足水平进行定义}

设计师评估现有系统的充足水平，在评估框中确定充足水平，分值范围从0至6 （工作表单5第二部分）。

\section{充足水平等级:}

$0=$ 无法生存/维持生活

$1=$ 家庭层面的勉强充足

$2=$ 家庭层面的充足

$3=$ 社区层面的勉强充足

$4=$ 社区层面的充足

$5=$ 国家层面的勉强充足

$6=$ 国家层面的充足 
显著问题将被记录在 “注释”框中。图4.16是清单和评估的部分实例。

\section{图4.16 充足水平的定义}

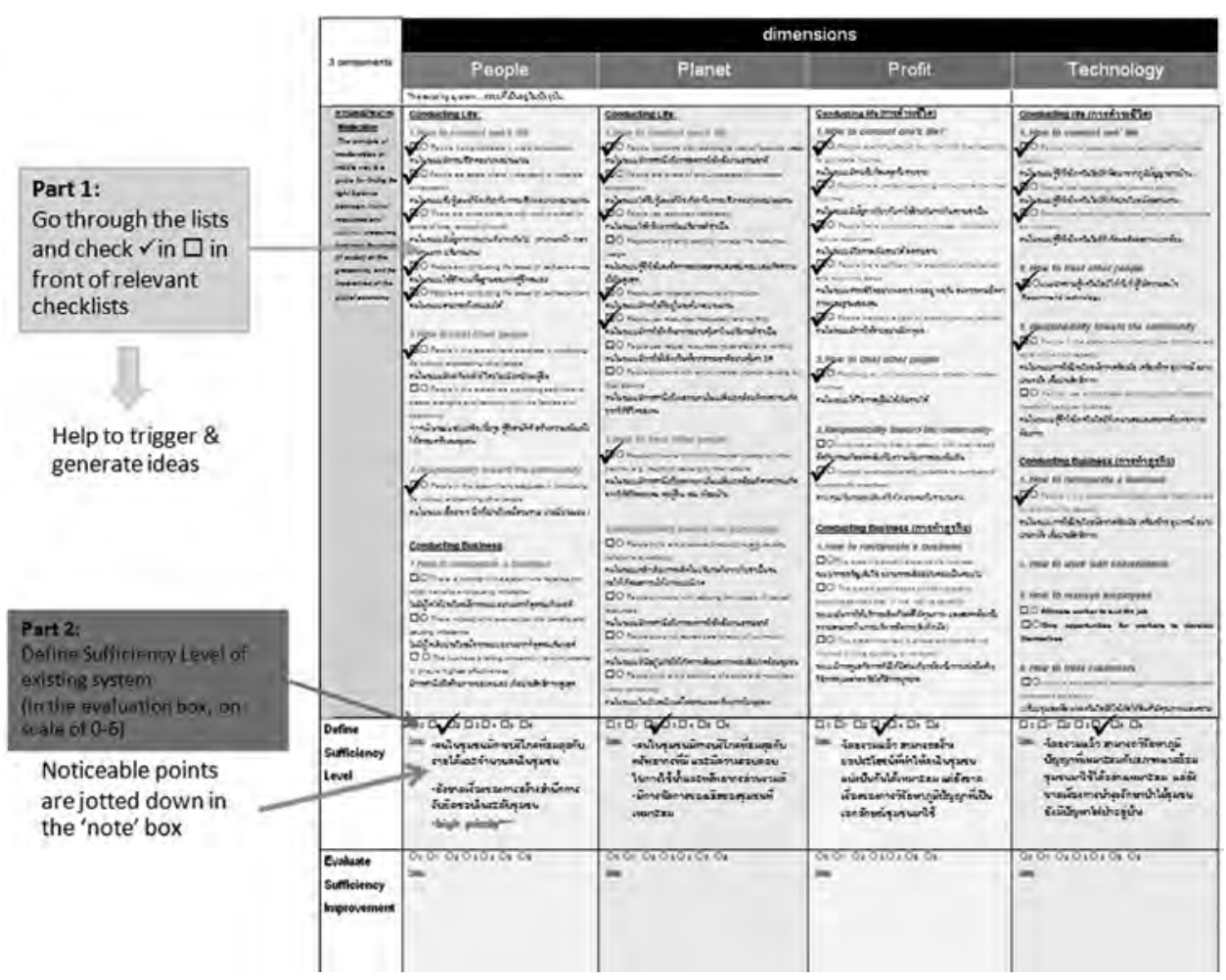

结果

清单从两个方面对充足水平进行评估：用户的生活方式和系统提供者的工作方式。

\section{生活方式方面:}

如何安排个人生活

如何对待他人

如何尽到应尽的社区责任

\section{工作方式方面:}

如何经营/管理企业

如何与股东合作

如何管理员工

如何对待客户 
如何与合伙人/联盟成员/竞争者展开合作

如何处理与股东之间的问题

如何为社区做贡献

在该过程中产生的创意可记录下来并于随后阶段中使用。

\section{所需工具和必备资源}

充足经济工作表单设计可从网上下载(www.lens.polimi.it中的 '工具' 部分)。工作表单 的运行需使用电子制表软件（例如：Microsoft Excel，或Open Office 中的类似软件）。

\subsection{4 充足经济指导方针}

目的

充足经济指导方针引导设计师形成基于充足经济哲学 (SEP) 的思维框架或模式。 指导方针能帮助设计师为具体情况设计合适的策略以及为新系统提供潜在思路和思 维方向。通过分析 “公司” 或组织的能力, 根据充足经济哲学 (SEP) 的两项条件 寻找设计充足产品服务系统的机遇。

条件一：知识（智慧）, 包括积累和洞察信息的能力, 以便更好地理解和 运用信息。

条件二: “道德”至关重要, 包括美德、道德行为、诚实、宽容和不损 人利已的坚守。

因此，指导方针的作用是协助设计师创造一个有关产品/服务/系统的整体概 念, 在关注适度和满足的同时也强调明智审慎地运用知识。此外, 他们也在寻求和 探索用户和公司在打造价值观，如诚实、勤勉、善良、共享等方面的潜力。

充足经济指导方针协助设计师在充足经济的三个阶段分别探索出构建充足生活 方式的新思路：在家庭、社区和国家层面的自给充足水平。本书在撰写时, 能够提 供社区层面指导方针的工具已完成开发工作 29 。

将工具整合到可持续系统设计方法的过程中

充足经济清单可在下述情况中使用:

- 探索新机遇以便:

生成以充足经济哲学 (SEP) 的知识和道德条件为导向的新想法

\section{如何使用该工具}

利用与充足经济清单同样的方式, 设计团队便可完成工作表单（工作表单8）。

图4.17和图4.18展示了家庭和社区层面指导方针的部分实例。

29 国家层面上的指导方针需要众多政府部门的参与, 故至今尚未最后确定。 


\section{图4.17 充足经济指导方针 知识条件（家庭层面）}

\begin{tabular}{|c|c|c|c|c|}
\hline \multirow{3}{*}{ 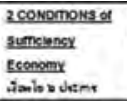 } & \multicolumn{4}{|c|}{ Components } \\
\hline & People & $\overline{\text { Plantet }}$ & Profit: & Techinolosy \\
\hline & 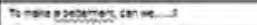 & & & \\
\hline \multirow{3}{*}{ 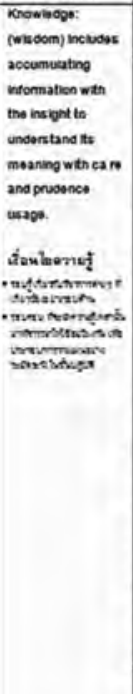 } & \multicolumn{4}{|c|}{ At household level } \\
\hline & 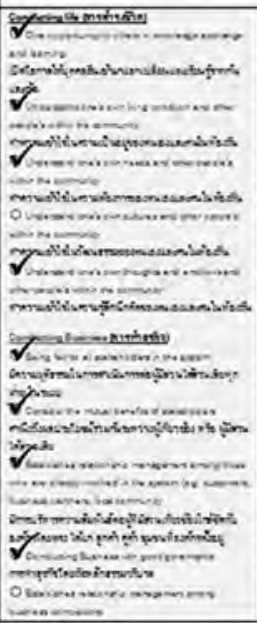 & 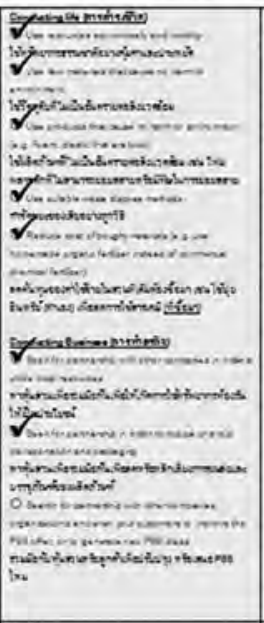 & 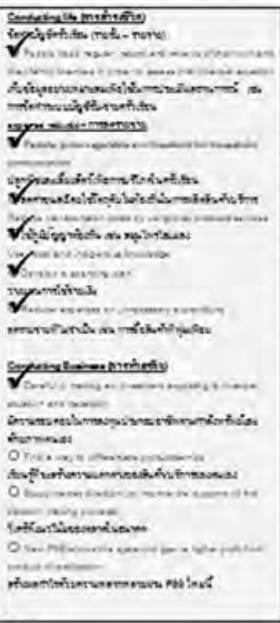 & 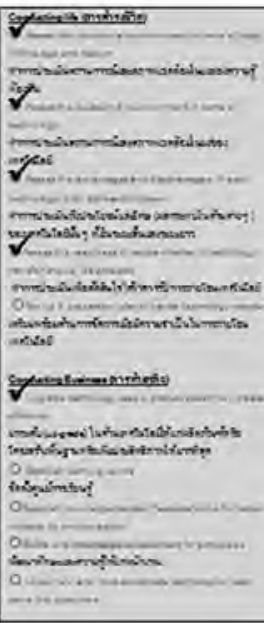 \\
\hline & $\operatorname{sen}$ & $\sin$ & $\operatorname{sen}$ & \\
\hline
\end{tabular}

\section{图4.18 充足经济指导方针 知识条件（社区层面）}

\begin{tabular}{|c|c|c|c|c|}
\hline \multirow{3}{*}{ 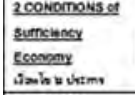 } & \multicolumn{4}{|c|}{ Components } \\
\hline & People & Planet & Protit & Tectinotogy \\
\hline & 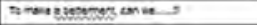 & & & \\
\hline \multirow{3}{*}{ 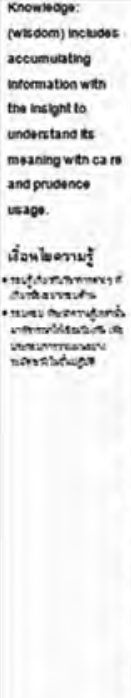 } & \multicolumn{4}{|c|}{ At community level } \\
\hline & 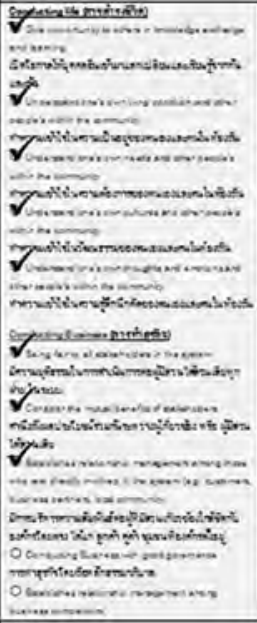 & 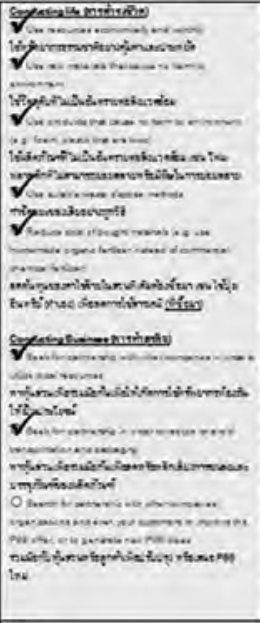 & 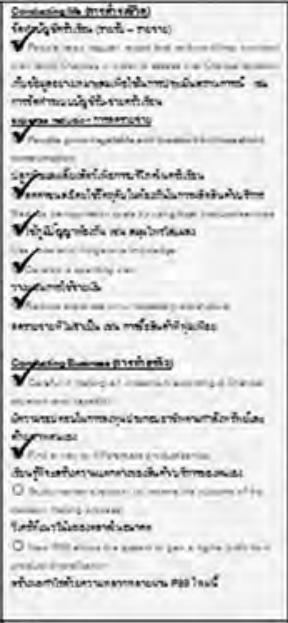 & 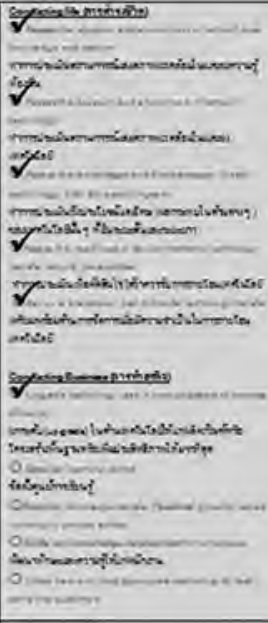 \\
\hline & $x$ cest & comsens & sats & \\
\hline
\end{tabular}


结果

结果表明, 工作表单记录下了讨论指导方针后所产生、激发的一系列创意。于是, 设计团队便就此对系统概念和组件进行设计。

所需工具和必备资源

充足经济工作表单设计可从网上下载(www.lens.polimi.it, 中的 '工具' 部分)。工作表单 的运行需使用电子制表软件（例如：Microsoft Excel，或Open Office 中的类似软件）。

\subsection{5 充足经济平衡工具}

目的

充足经济哲学的最终目标是实现平衡和可持续。因此当评估结果的成效时, 强调的 重点则是在以下四个维度间保持平衡：人、地球、利益和技术。

充足经济设计指导方针被用于引导新的思想形式, 以设计出更加充足的系 统, 而充足经济平衡工具被设计用于对该进程的平衡性进行评估和可视化表达。充 足经济平衡工具可用于该方法论的以下阶段:

- 在战略分析阶段, 充足经济平衡工具可用于评估

- 以对现有系统的充足水平 “平衡” 进行可视化表达（就人、地球、利益和 技术四个维度以及每个层面中的三个组件：适度性、合理性和自身免疫力）

- 在系统设计和构建阶段, 平衡工具可用于:

- 对新充足产品服务系统的充足水平 “平衡” 进行可视化表达（从四个维 度：人、地球、利益和技术）。

- 对比现有系统, 评估新充足产品服务系统中的提供物是否获得了改进, 且 在所有层面的改进是否达到平衡。

如何使用该工具

在设计过程中, 该工作表单的使用可分为两个步骤:

- A.需求评估：对系统当前的充足性进行可视化表达

- B.设计评估：从两方面对新充足产品服务系统的发展进行可视化表达

第一方面是评估充足水平的改进, 为此, 设计师须:

- 再次完成工作表单5第一部分中的充足经济设计检查清单, 但这次, 在已实现 的选项上打红色的勾。需在方框中记下关键说明

- 对新充足产品系统可持续 (SE-PSS)的充足性改进（工作表单5的第三部 分）进行评估, 分值范围从0至6（图4.19）。通过分析将揭示出新系统比现 有系统相比是变得更好还是更差。 
- 将对 “现有系统” 和 “新充足系统” 充足性水平进行分析（分值范围从 0-6）并将分值输入到数据表单中（工作表单13）（利用微软OFFIC Excel或 Open Office中的类似电子指标程序）。见图4.20

\section{图4.19 评估充足改进情况}

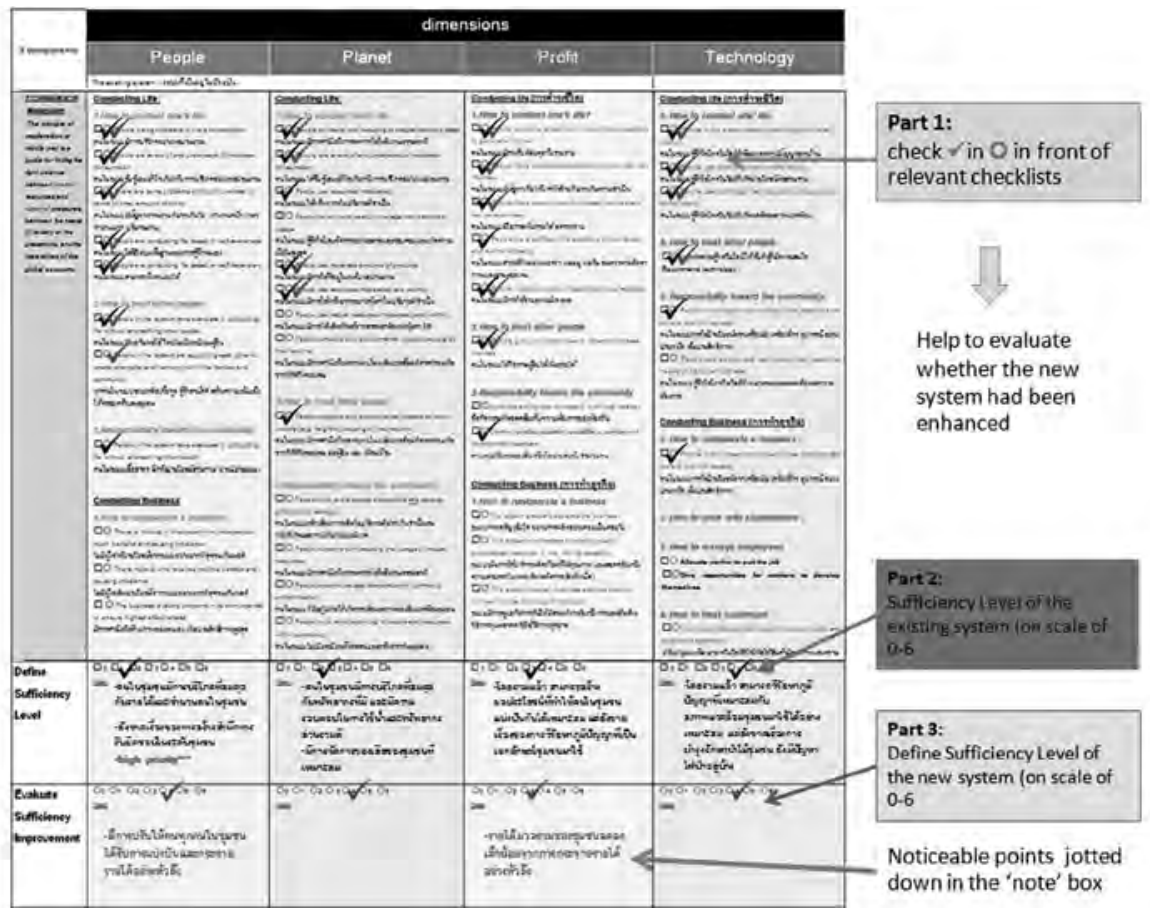

- 根据上述分值创建的柱状图将包括三个双向条形, 每个条形分别表示三个组 件的充足性水平（适度性、合理性和自身免疫力）。条形的左侧表示现有系 统, 而右侧表示新的充足系统。图4.21显示四个图, 分别显示四个维度充足 水平的改进情况

- 根据每个组件的效益 “改进”，对现有系统与新系统的 “持续性水平” 结果 进行比较, 见图4.22。

\section{图4.20 将分值输入数据表单中}

\begin{tabular}{|c|c|c|}
\hline 1.人的层面 & 现有系统 & 新自足产品服务系统 \\
\hline 适度 & 2 & 4 \\
\hline 合理 & 1 & 4 \\
\hline 自我免疫 & 3 & 4 \\
\hline 普通人 & 2.0 & 4.0 \\
\hline
\end{tabular}


图4.21 各维度的充足水平

\section{Evaluate improvement of sufficiency level ....People}

\begin{tabular}{|l|c|c|}
\hline & $\begin{array}{c}\text { Eusting } \\
\text { System }\end{array}$ & $\begin{array}{c}\text { New } \\
\text { Sulficiency } \\
\text { PSS }\end{array}$ \\
\hline Moderation & $n$ & + \\
\hline Reasonablentss & $t$ & + \\
\hline Sudrage Anogle & 4 & + \\
\hline
\end{tabular}

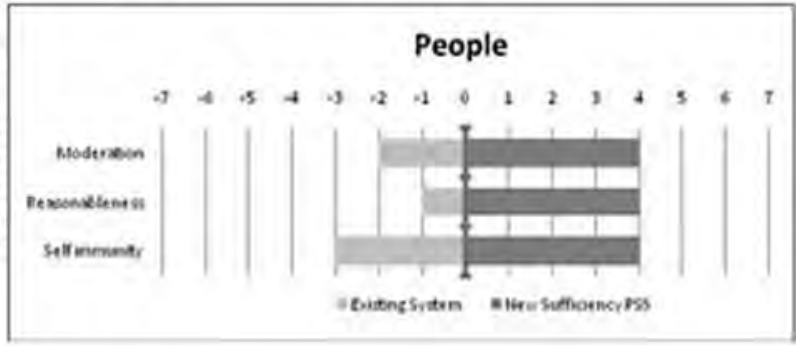

Evaluate improvement of sufficiency level ....Planet

\begin{tabular}{|l|c|c|}
\hline & $\begin{array}{c}\text { Existing } \\
\text { System }\end{array}$ & $\begin{array}{c}\text { New } \\
\text { Sufficiency } \\
\text { PSS }\end{array}$ \\
\hline Moderation & $t$ & + \\
\hline Reasonableness & 4 & + \\
\hline Sell immunity & 4 & 3 \\
\hline Average Paner & 10 & 11 \\
\hline
\end{tabular}

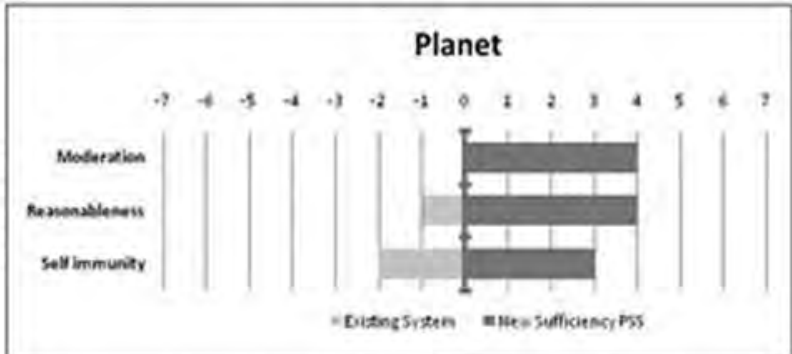

Evaluate improvement of sufficiency level ....Profit

\begin{tabular}{|l|c|c|}
\hline & $\begin{array}{c}\text { Evisting } \\
\text { System }\end{array}$ & $\begin{array}{c}\text { New } \\
\text { Sufficiency } \\
\text { PSS } \\
\text { iv }\end{array}$ \\
\hline Moderabion & 11 & 4 \\
\hline Reasonableness & 3 & 1 \\
\hline Sel immunity & 3 & 1 \\
\hline
\end{tabular}

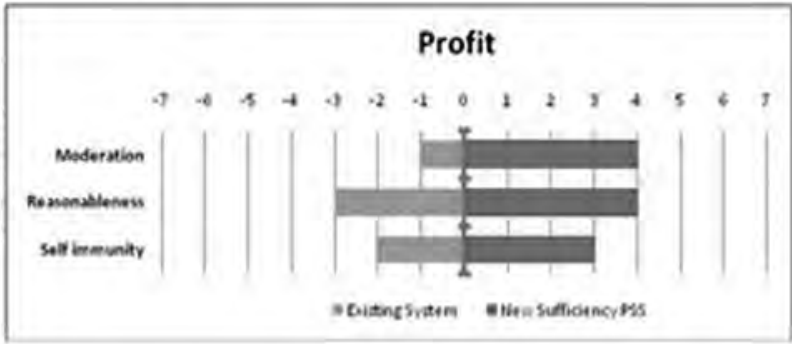

\section{Evaluate improvement of sufficiency level .....Technology}

\begin{tabular}{|c|c|c|}
\hline & $\begin{array}{c}\text { Evisting } \\
\text { System } \\
\text { 14 }\end{array}$ & $\begin{array}{c}\text { New } \\
\text { Sufficiency } \\
\text { PSS } \\
\text { (v) }\end{array}$ \\
\hline Moderation & 4 & 3 \\
\hline Reasonableness & + & 3 \\
\hline Self immunity & 3 & 3 \\
\hline Average Technolagy & $\Delta t$ & 11 \\
\hline
\end{tabular}

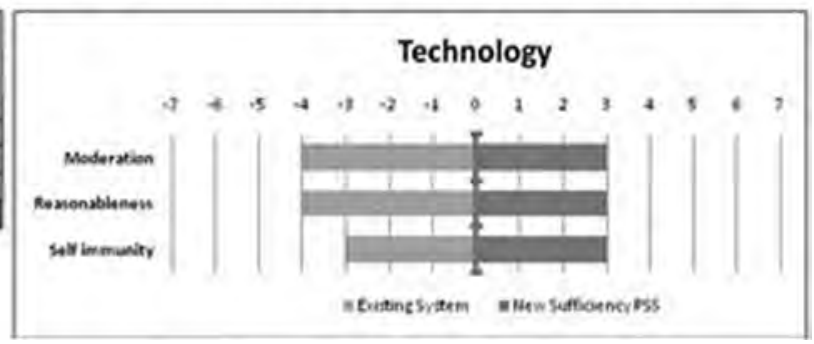




\section{图4.22 充足水平的改进情况（“人” 的维度）}

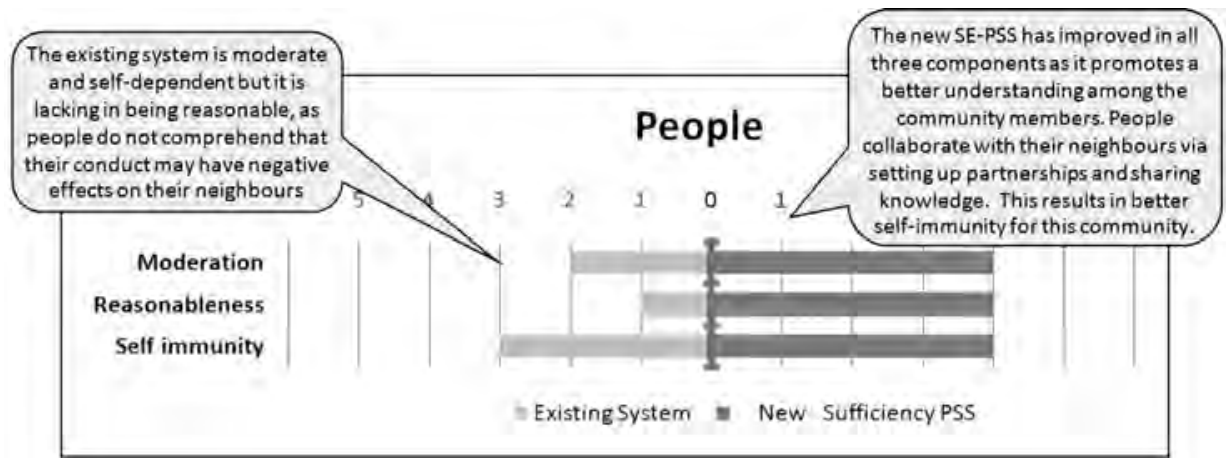

第二方面是对整体系统的 “充足水平平衡性” 进行评估。为此, 设计师须:

- 通过分析将 “现有系统” 和 “新充足系统” 充足性水平分值（分值范围从 0-6）输入到数据表单中（利用微软OFFIC Excel或其他开源软件的图表生成 工具）。输入到数据表单中的分值是每个组件的平均值。根据图4.20中的例 子, 这一步骤的平均值为 $2.0[(2+1+3) / 3]$

- 一个柱状图中将显示四个条形; 每个条形代表一个维度的充足水平。检查“ 现有系统充足性条形的平衡”, 将其与 “新充足系统的平衡” 进行比较。见 图4.23中的例子

- 根据四个维度的效益 “改进” 和 “平衡” , 将现有系统和新系统的 “充足水 平”结果进行比较, 见图4.24

\section{图4.23 充足水平的总体平衡（所有四个维度）}

Evaluate the Improvement of Sufficiency Levels and the Overall Balance

\begin{tabular}{|l|c|c|}
\hline \multicolumn{1}{|c|}{ Balance } & $\begin{array}{c}\text { Existing } \\
\text { System }\end{array}$ & $\begin{array}{c}\text { New } \\
\text { Sufficiency } \\
\text { PSS }\end{array}$ \\
\hline Average People & 2.0 & 4.0 \\
\hline Average Planet & 13 & 3.7 \\
\hline Average Profit & & $\mathbf{3}$ \\
\hline Average Technology & & $\mathbf{2 . 0}$ \\
\hline
\end{tabular}

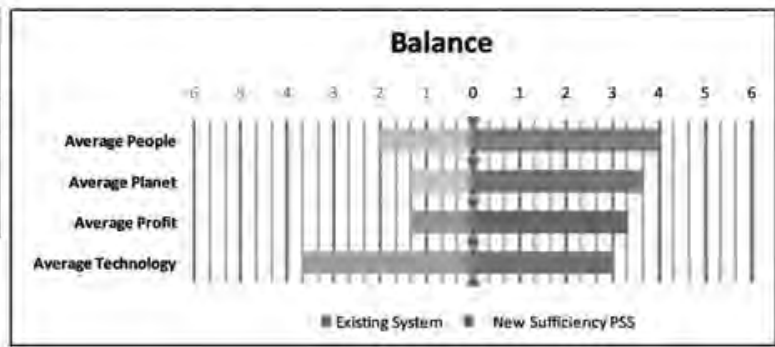




\section{图4.24 比较总体平衡的结果}

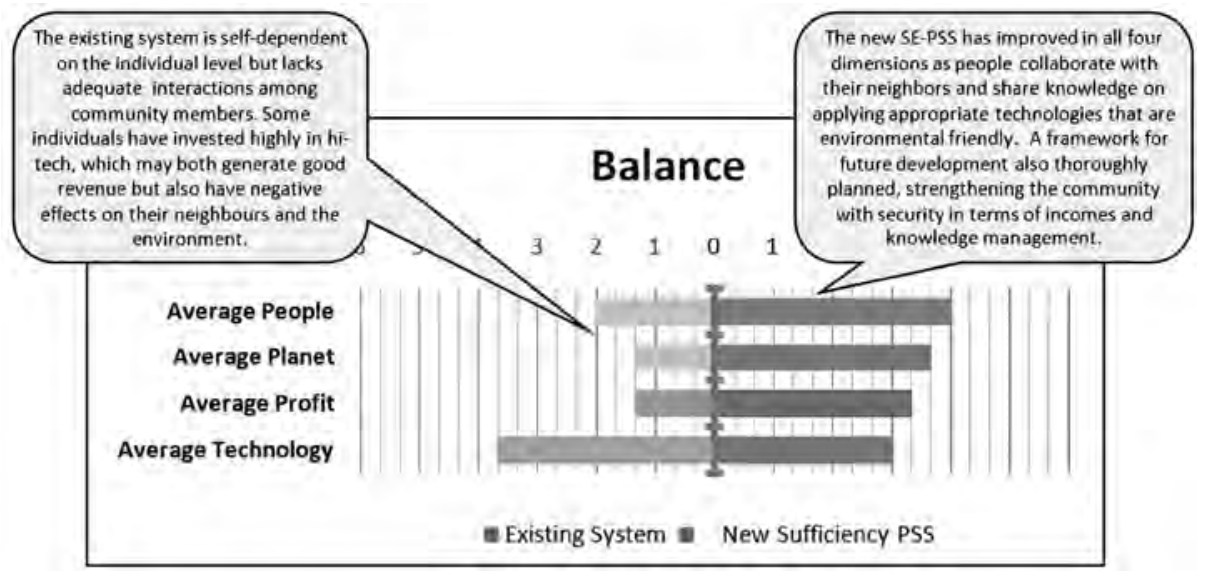

结果

该工具以柱状图的形式显示充足经济哲学内在的重要元素, 有助于加深对当前系统 和新系统的理解。该工具尤其关注相比于现有系统, 新系统有何改进。鼓励对每一 维度的效益进行改进（参见图4.21）。然而, 充足经济设计在实践中的成功, 不是 根据各维度改进了多少缺陷或增加了多少价值, 使得用户的产品和服务增多来衡量 的, 而是以四个维度中所生成效益的总体平衡程度来评价所有充足系统成功的大 小。因此，无需在每个层面都执意追求某一程度的改进。

因此, 充足系统需要能够同时提供四个维度上的效益改进和四个维度间的效益 平衡。例如：在经过综合考虑之后, 为了能够从整体上保持系统的平衡, 并使用户 与大自然和社会和谐相处（或者, 作为交换, 可获得其他社会利益），应当舍弃现 有系统的某些积极部分（例如：较高的经济利益）。

\section{所需工具和必备资源}

充足经济平衡工具及指导方针可以从网上下载(www.lens.polimi.it中的“工具”部 分)。工作表单需要使用电子制表软件（例如：Microsoft Excel, 或Open Office 中的 类似软件）。

\subsection{6（利益相关方）系统图30}

\section{目的}

系统图的作用是为系统结构的共同设计和可视化提供支持，显示出参与者及其之间 的互动。

30 该工具由HiCS研究项目组的Francois Jégou开发, 这是是高度定制化方案, 是基于解决方 案的设计、生产和交付方案（欧洲研究, 成长计划/欧洲第五框架 (European Research, 
基本上, 它用图形来展示:

- 系统中（主要和次要）社会经济参与者

- 不同参与者间之间的互动：物质/产品流动、信息、资金和工作 系统图是一个独具代表性的工具, 成文且先进。

它是一个正式化的成文体系。从某种意义上说, 它是一张参与者系统的工程 图, 以可再生和比较的方式来表现替代系统。从这个意义上看, 它包括固定的表现形式

(图), 开放式的图像要素程序库（图标、箭头等)和一系列规则（布局、句法等）。

它又是具有先进性的, 该参与者方案图纸始终处于“准正规化”阶段, 随着 不断地发展演变能够绘制出日益准确的项目蓝图。从这个意义上说, 在各设计过程 中, 参与者系统的细节都将能够逐渐得以明确。

因此, 它是一个支持工具, 用于:

- 设计, 表达法是构架想法, 便于解决方案产生的有效方法。

- 共同设计, 使用了标准语言, 所有设计团队成员或不同参与者可以共用此标 准 语言, 使他们之间进行战略对话已成为可能。

- 交流, 这使设计解决方案（及其演变）得到清晰的可视化表达

\section{将工具整合到可持续系统设计方法的研究过程中}

系统图被用于设计过程的许多不同步骤中。特别在:

- 战略分析过程中, 可用于描述:

- 设计干预范围内的生产和消费系统

- 项目所涉及企业的价值链（现有系统）

- 优秀案例中系统 (参与者和角色) 的组织体制

- 设计概念系统中, 可用于:

- 使初始系统的理念构思形式化(图4.26)

- 详细列明理念构思过程, 识别主要和次要参与者以及他们之间的交互流程 (图4.27)

- 设计和构建概念中, 可用于:

- 详细列明系统构造, 定义所有的参与者及他们之间的互动过程（图4.28）

GROWTH Programme / European 5th Framework)）。更多信息请参见耶由 (Jégou), 曼奇尼 (Manzini) 和梅罗尼 (Meroni) (2004); 凡·海伦 (van Halen), 维佐理 (Vezzoli) 和维默尔 (Wimmer) (2005) 以及http://www.mepss.nl/index.php?p= tool\& $14=\mathrm{W} 21$ 。 


\section{图4.25 将系统图整合到MSDS设计过程中}

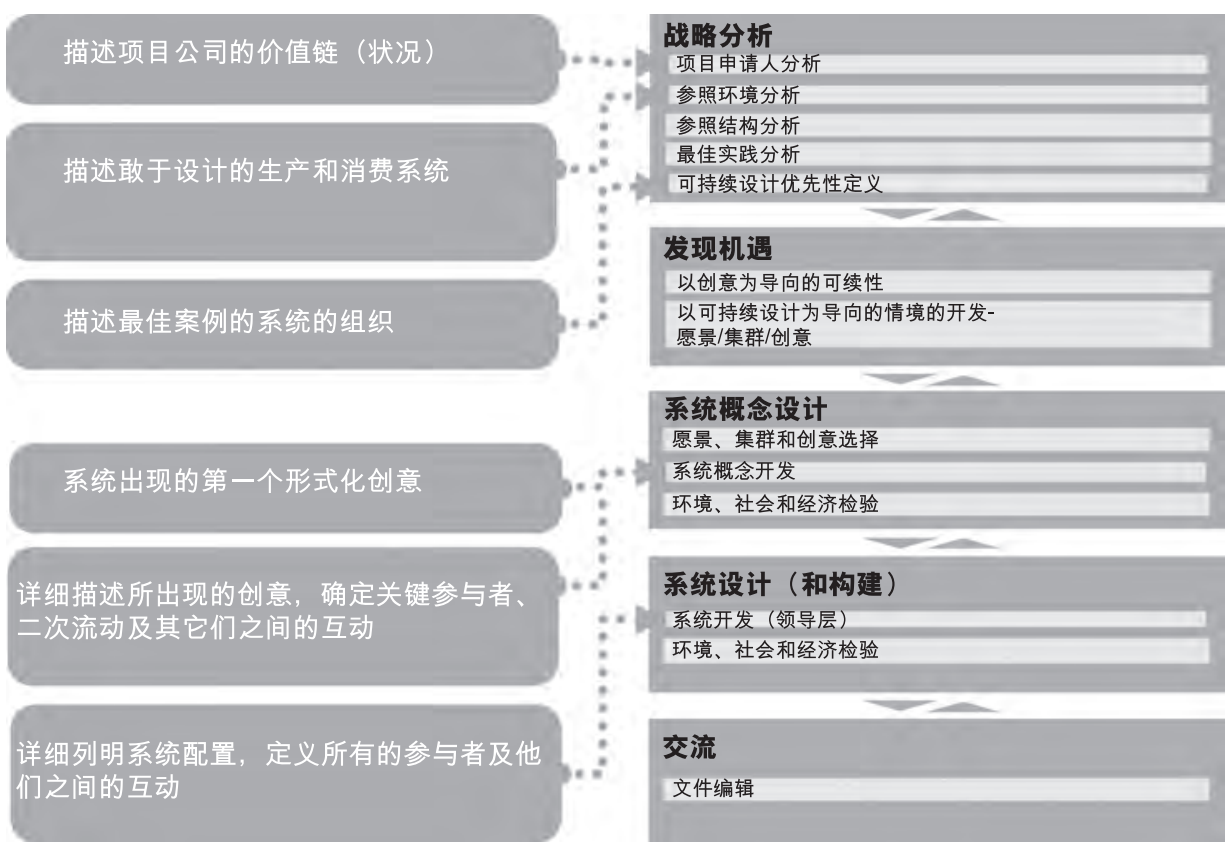

图4.26 当设计系统概念时, 初始想法（源自先前得出的设想和创意集群）被形 式化: 在这个层次上, 仅显示主要参与者和主要流动的开展

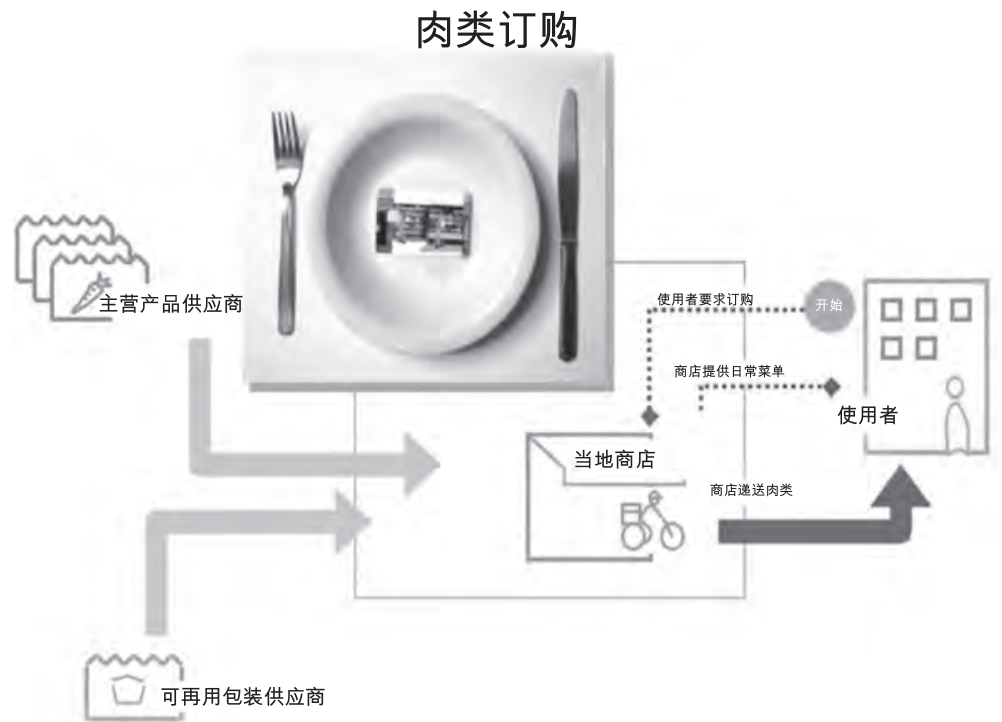


图4.27 详细描述先前勾画的初始系统想法: 在这个层面, 只显示主要和次要参 与者, 以及他们之间的互动

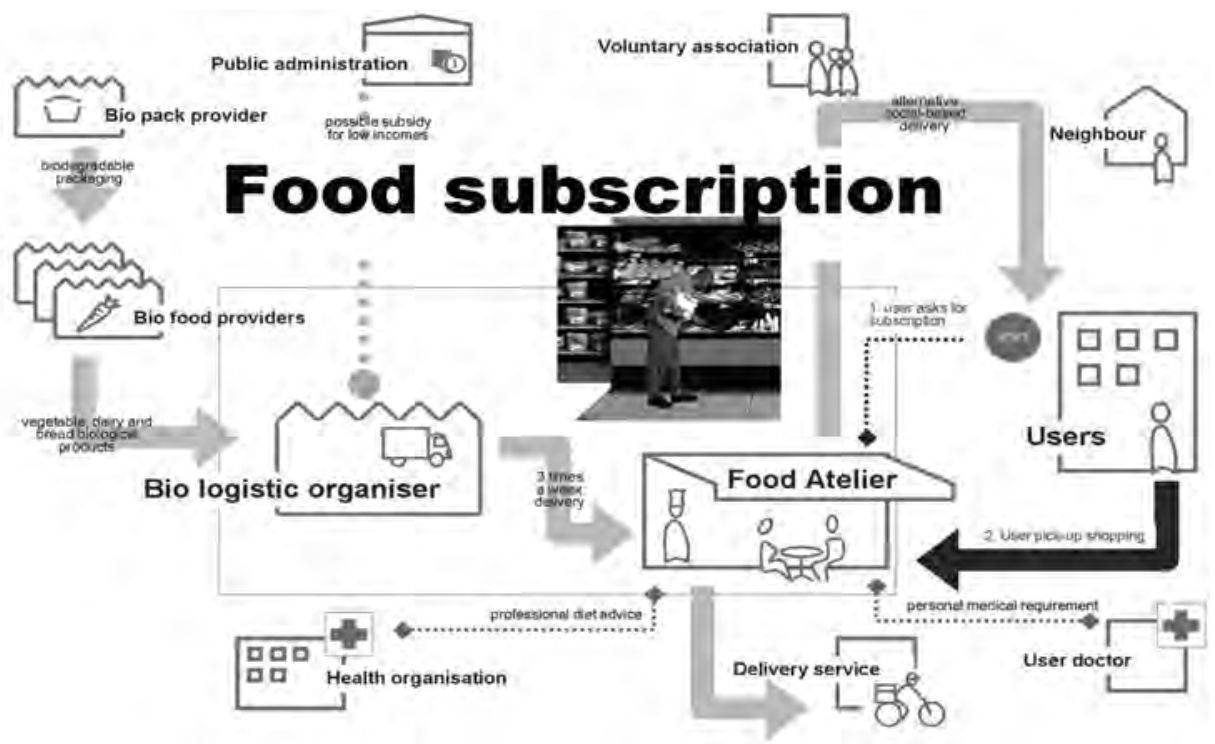

图4.28 在设计（构建）系统的同时, 详细勾画系统图, 具体说明所有主要和次 要参与者及其交互流程。进一步详细列明系统图的关键部分。食品工作 室（Food Atelier）中的典型样本（图4.27中系统图的其中一个关键部 件），具体说明了组件的子元件

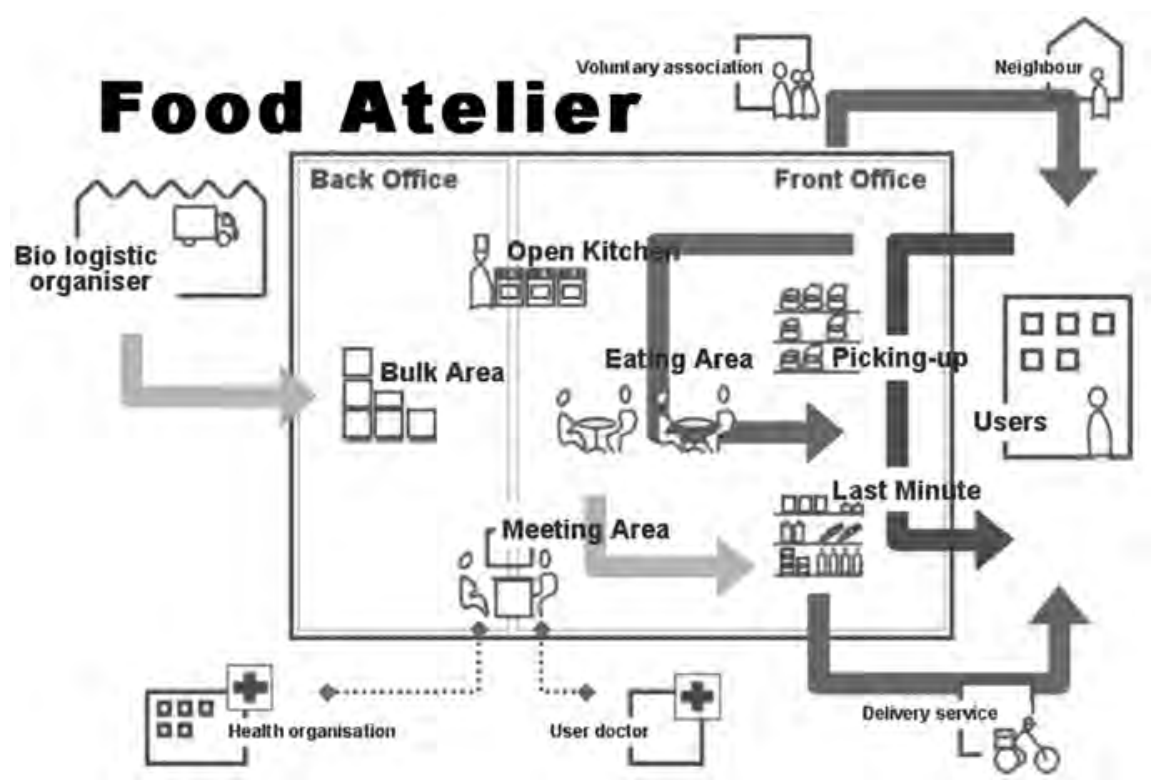




\section{如何使用该工具}

该工具要求使用幻灯播放软件 (例如: Microsoft PowerPoint, 或Open Office中的类 似软件）。凭借这款软件中的一系列标准化设计图标, 来（参见图4.3至图4.32）确 定并修改参与者图 ${ }^{31}$ 。

使用该工具的基础是广泛且方便软件的利用; 它将促进项目所有参与者在设计 过程中的参与并加快方案演化过程中各种步骤的交换、修改和展示。

以下文字描述了格式、图形要素库以及用于展现参与者图的一系列规则。

系统图建立在一张单独的幻灯片上（图4.29）。通常, 幻灯片的边界也就是 系统的边界, 而幻灯片上的矩形显示的则是系统平台的边界: 实施系统的核心参与 者在矩形内部而次要参与者在外部。后者是根据系统生命周期进行定位的：从左 （开始）到右（结束）。

\section{图4.29 系统布局和平台轮廊}

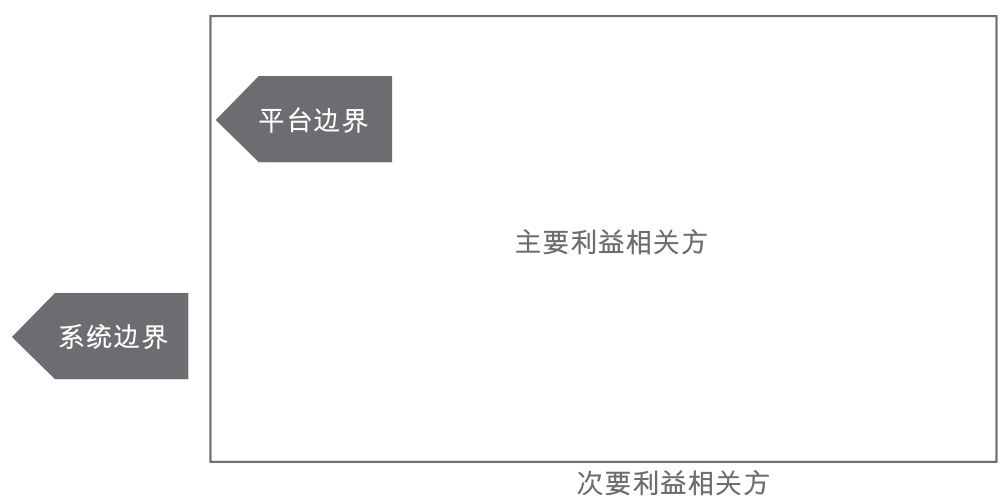

每个参与者由一个图标表示, 由三个要素构成:

- 结构, 显示参与者类型例如：公司、公共机构、家庭等。（图4.30和图 4.31)

- 特性, 定义参与者活动 例如：食品生产者、运输者等（图4.32）

- 标语, 详细说明参与者活动, 有机食品生产商、物流服务供应商等。

31 用户可以从www.lens.polimi.it网站上下载一个包含各种图标和用户指南的基本版。 
118 可持续产品服务系统设计

图4.30 结构显示参与者类型
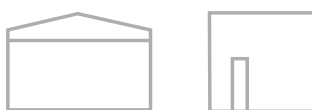

当地协会

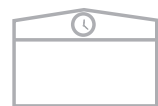

学校

公共机构或协会

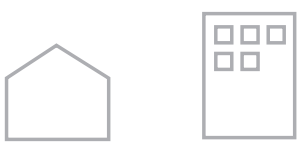

独立房屋

集合住宅
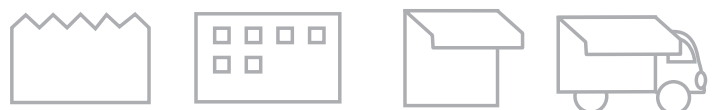

工业公司

服务公司

当地商店

移动售货车

\section{公司和商店}

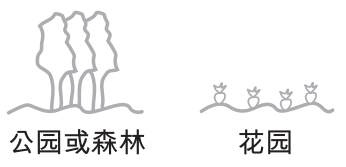

绿化区

图4.31 结构的大小表明的是主要参与者或次要参与者
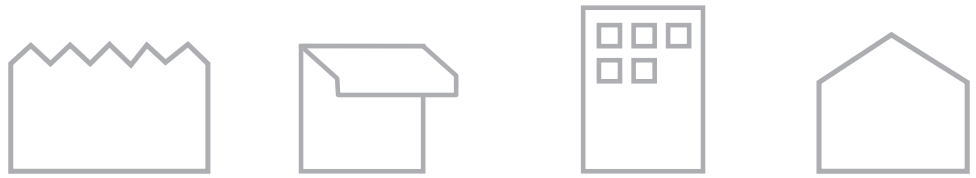

主要利益相关方
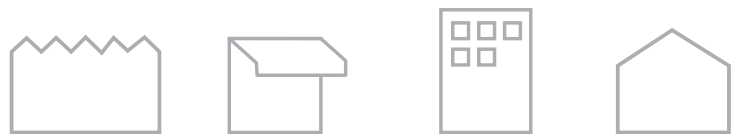

次要利益相关方 
图4.32 一系列图形符号用以表示参与者活动
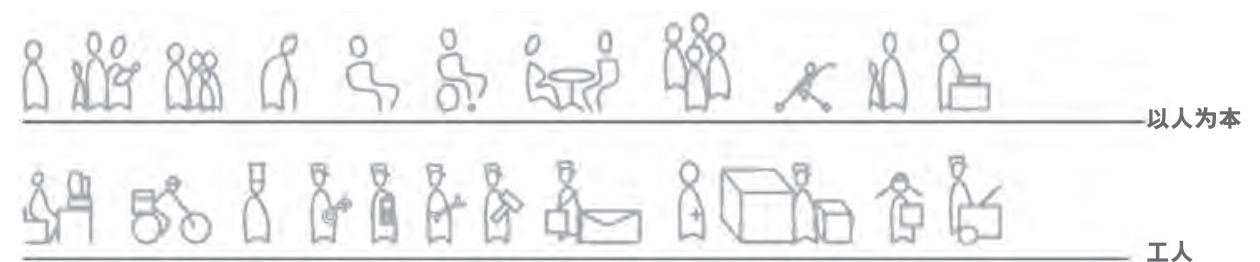

エ人
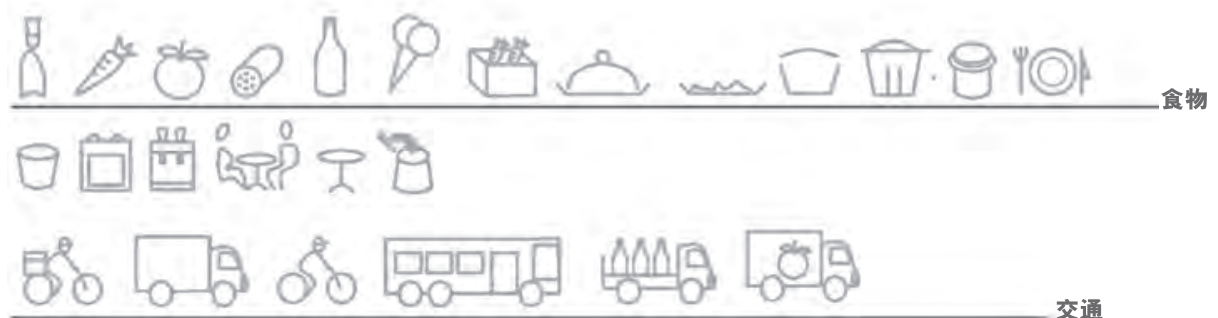

通过对三个标准化要素进行整合而获得的图标能够对参与者进行详细说明, 并 在系统图中, 将他们与其他参与者进行区分（图4.33）。

图4.33 构造图标 基本结构+图形符号+标语

结构

+

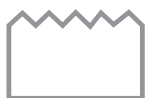

$+$<smiles>[CH]1CC2CCC1O2</smiles>

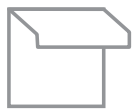

$+$
$+$

后勤服务供应商 =

口号:

+ 当地快递公司 $=$

特点

+ 有机食品提供者 $=$
图标
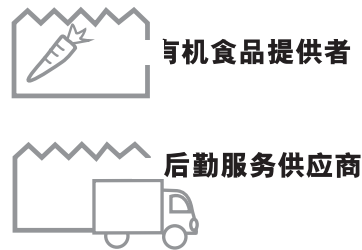

当地快递公司

不同参与者之间的流动将会用不同箭头进行标注（图4.34）:

- 完整的粗箭头表示材料流动（组件、产品等）

- 方块点状的细箭头表示信息流动

- 圆点状的细箭头表示资金流动

- 顶部为菱形的完整粗箭头表示工作流动

也可以对单向或双向流动进行区分。此外, 箭头的颜色区分的是主要流动

(深灰) 和次要流动（浅灰）。 
120 可持续产品服务系统设计

图4.34 不同的流动类型 物质、信息、资金和工作流动

物质流

信息流

资金流

募动力表现

核心产品服务系统性能
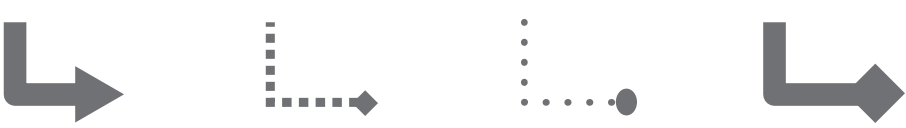

供替代的产

品服务系统性能,

后台流动的实施

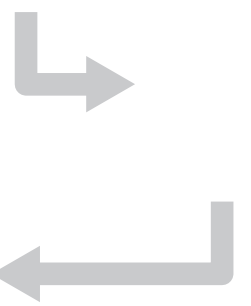

流动的时机与描述

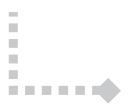

单向流动

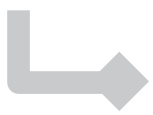

交换

系统图的构建过程, 对参与者和各种流动进行了定位。为了使得系统组织更易 于理解, 必须对各种流动进行详细说明, 并通过标明起始点和对各类型的流动进程 进行编号来确定阅读顺序（图4.35）。通常, 只会对主要流动进行编号。

\section{图4.35 构建系统图确定参与者和各流动类型的位置; 对流动进行描述, 对主要 流动进行编号}

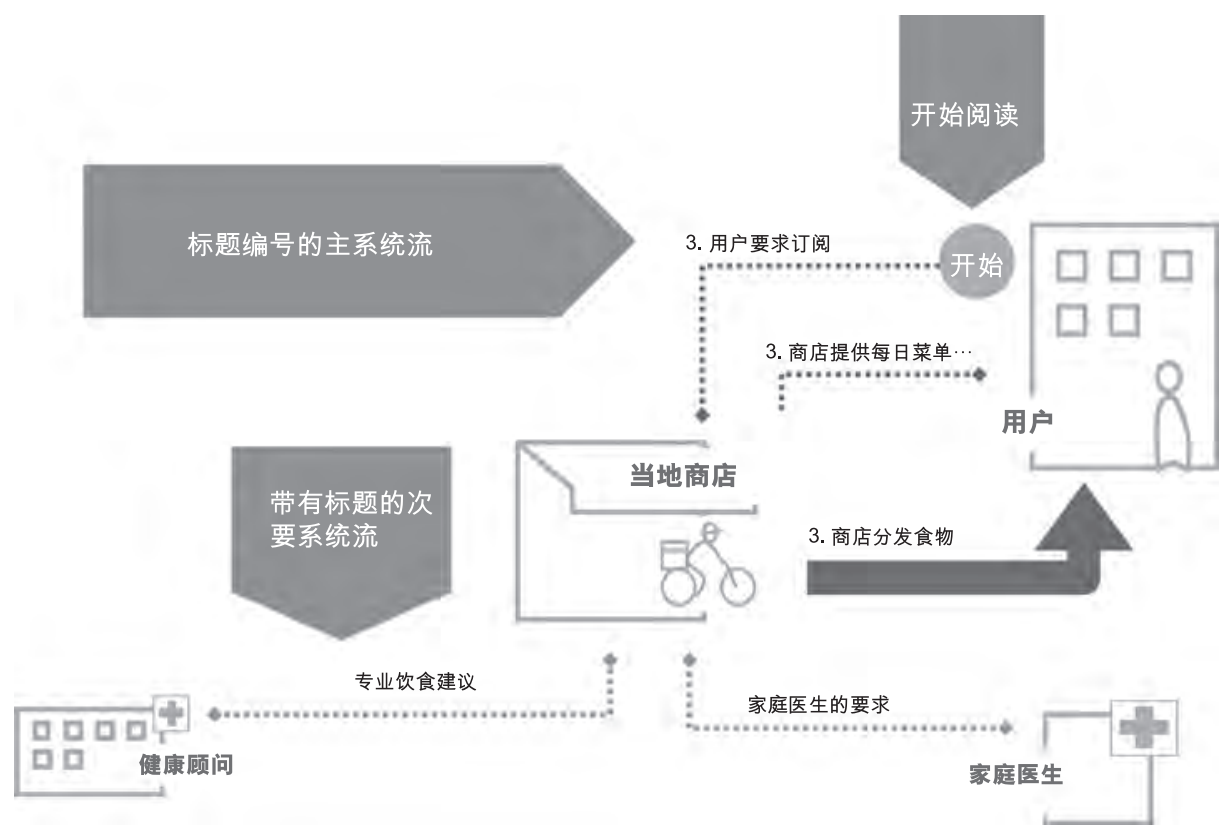




\section{结果}

结果是一张显示构成系统各部分不同社会经济参与者及其互动（物质、信息、资金 和工作流动）的图。该系统图将随着项目的推进而变得越来越详细。

\section{所需工具和必备资源}

该工具基于一套可在幻灯软件上使用的标准化图标和构图版式（(例如: Microsoft PowerPoint, 或Open Office中的类似软件)。在这个基础上它可用于修改各种图 标, 也可添加新图标。

由于不需要任何特殊作图技能，该工具适用于设计团队中的任何成员。

制定系统图所需的技术时间约为 30 分钟。

\subsection{7 满意度系统图32}

目的

满意度系统图能够辅助系统进行创意构思。

该工具的用途在于识别并对能够满足特定福利需求的潜在社会经济参与者进行 可视化表达。在创意过程中, 可视化将用于了解哪些参与者有可能加入到满意度系 统中。

换句话说, 该图将刺激新思想和方案的产生, 使其能够在不同的社会经济条件 下, 满足特定的福利需求。

该可视化过程包含以下关键要素:

- 设计中满意单元目标的展现（例如拥有衣物）

- 构成基本满意的次级满意要素的展现（例如: 拥有干净的家用衣物, 拥有干 净的特殊场合穿戴的衣物）

- 参照环境的展现（例如：家庭, 邻近服务中心等）

- 有可能成为各次级满意要素的参与者

32 这一工具由可持续发展研究的设计和系统更新组织（意大利米兰理工大学 (Politecnico di Milano）, INDACO) 研发。 
122 可持续产品服务系统设计

\section{图4.36 构成满意度系统图的要素}

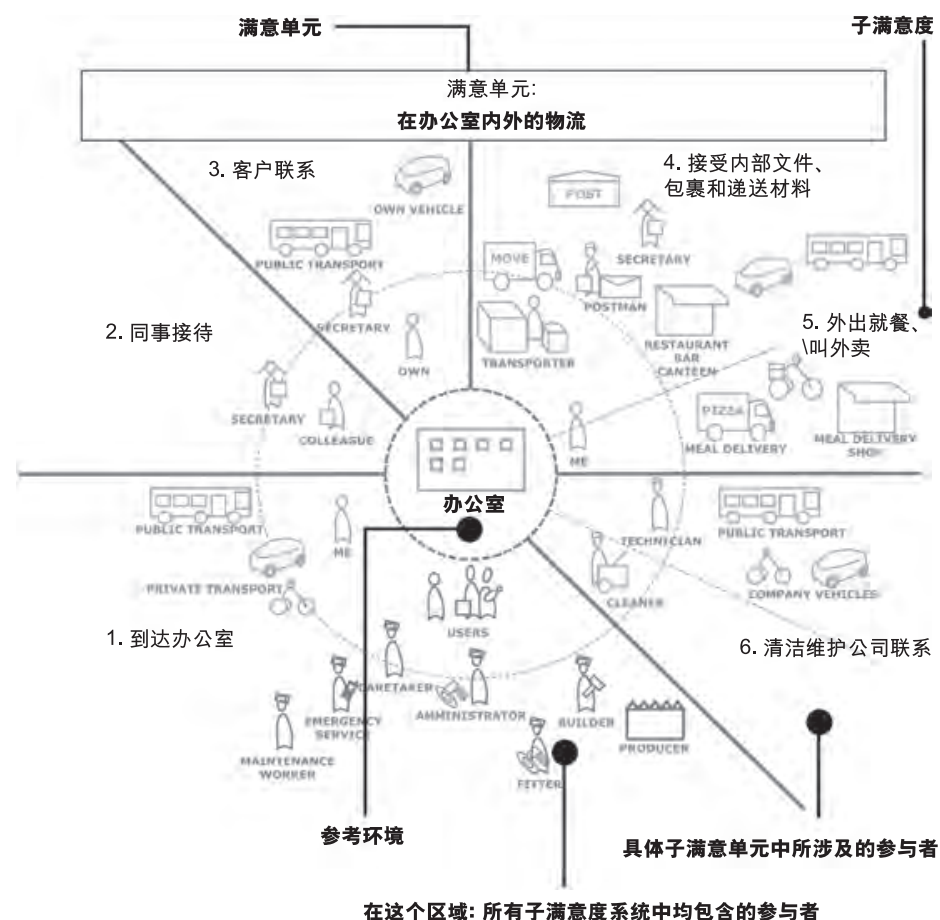

将工具整合到可持续系统设计方法的设计过程中

满意度系统图可用于以下情况:

- 在探索与下述机遇相关的情况下:

- 对可能促进满足福利需求的潜在参与者进行简洁的可视化表达, 并以此激 发创意的产生。 


\section{图4.37 将满意度系统图整合到MSDS设计过程中}

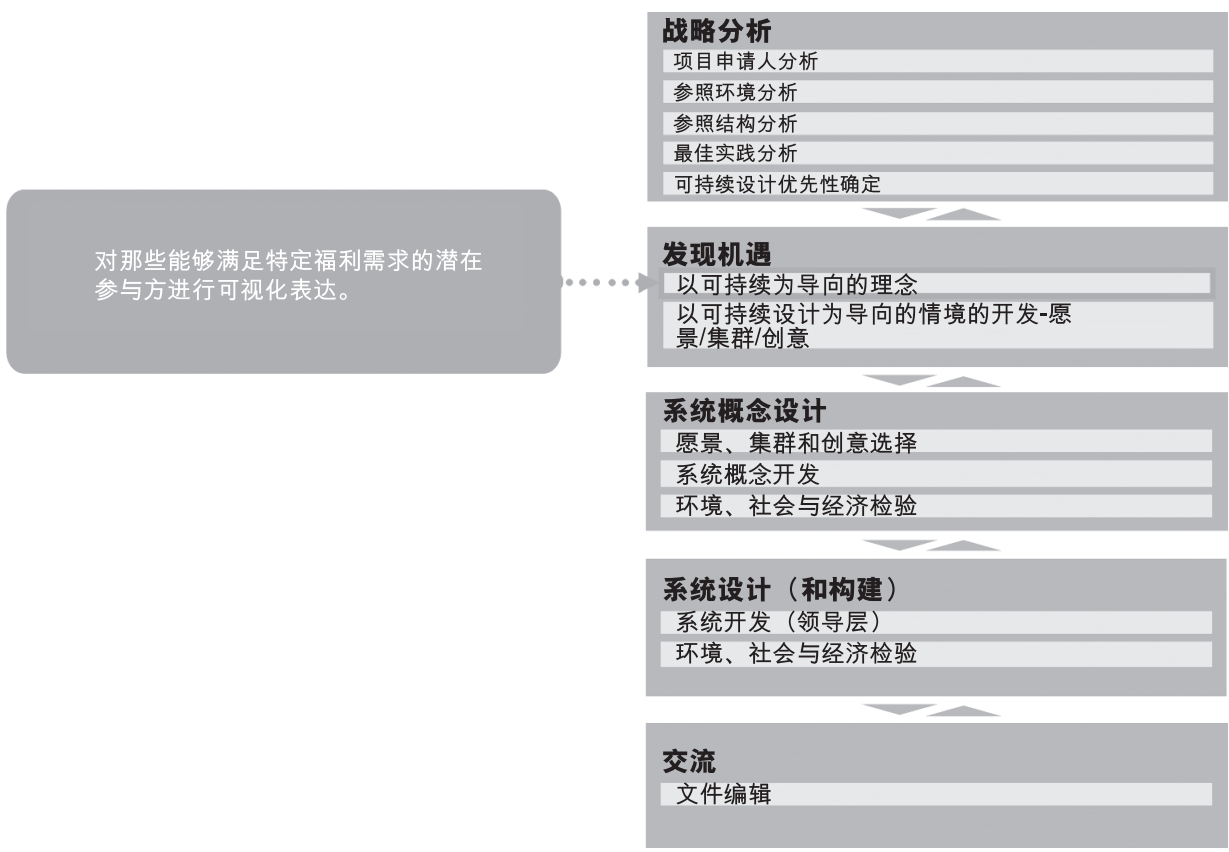

如何使用该工具

该工具无需使用任何软件; 然而, 为了增进管理和改进, 仍然建议使用幻灯片播放 软件（例如：微软的PowerPoint软件或者Open Office中的类似软件）33。

基本上是一个可在单个页面/屏幕显示的示意图。示意图顶部显示的是项目预计 完成的满意单元（在如图示例中, 为 “在办公室内外的物流” ${ }^{34}$ ) ; 中部显示的是参 照环境（在示例中为办公室）; 而各种次级满意度则以放射状的形式显示（到达办 公室, 同事接待, 接收内部文件等）。次级满意度旁边显示的是能够促进满足特定 民生需求的潜在参与者; 在示意图中, 参与者的位置由内向外分布, 以表示重要程 度。位于底部的是参与了所有次级满意要素的参与者。建议使用与系统图中相一致 的图标。

33 用户可以下载一个包含用户指南的基本版, 在www.lens.polimi.it的网站 “工具” 栏中草拟 一份 “满意度” 系统图。

34 这里举的 “满意度系统图” 的例子, 是米兰工业大学的 “DIS研究部” 为通力电梯 (KONE Elevator) 设计的一个项目, 该项目旨在通过通力电梯这个案例, 对生态高效产品服务系统 进行定义。 
结果

其结果为, 一个显示能满足特定需求的潜在参与者的示意图。

\section{所需工具和必备资源}

满意度系统图无需使用任何软件, 可直接在纸上绘制。然而, 为了促进管理和方便 改进，仍然建议使用幻灯片播放软件。

该工具的建立无任何特别制图技能要求，设计团队中的任何成员均可完成。在 集体讨论过程中, 建议由引导者先进行展示, 对显示图中的显著要素进行强调, 以 激发设计创作的进行。

制定满意度系统图所需技术时间约为：

- 2小时用于标明次级满意要素

- 2小时用于定位参与者

\subsection{8 互动表和互动故事板 ${ }^{35}$}

\section{目的}

互动表的目标在于完成对用户和产品服务系统之间一系列互动的（共同）设计和 可视化表达。该工具展示的是发生在“前台”层面（用户与服务提供系统间的互 动）和 “后台” 层面（在提供物生产和交付过程中各参与者的互动）的一系列互动。 准确地说, 该工具的目的是（随着项目的发展, 会变得更具体）：

- 对用户与提供系统间的主要互动进行描述和可视化表达

- 对各参与者（提供物生产和交付过程中的参与者）和用户之间的互动和角色 进行描述和可视化表达

- 对各参与者（提供物生产和交付过程中的参与者）和用户之间的一系列互动 和角色进行详尽的描述和可视化表达

基本而言, 该工具中的图表显示了:

- 一系列显示生产和服务交付过程中各种（系统中用户和其它参与者）互动的 图像（附有简要描述）。

- 各互动中其他信息的显示：例如：有哪些参与者、它们的角色以及完成项目 所需的要素（物质和非物质的）

35 这一工具是丹妮拉圣乔治（Daniela Sangiorgi）在产品服务系统方法 (MEPSS) 欧 洲研究项目成长计划/欧洲第五框架 (European Research, GROWTH Programme I European 5th Framework)的实施过程中研发的。详情请见Sangiorgi, Manzini 和 Meroni (2004); Sangiorgi (2005)和http://www.mepss.nl/index.php?p=tool\& $14=W 22$ 。 
当我们的目标在于流畅描述功能系统时, 互动表则不是最有效的工具。在此情况 下, 建议使用叙事故事板。

互动故事板由一个展示性图表构成，其中将单行显示一系列图像及文字，代表 着不同利益相关方之间的（按时间顺序排列的）主要互动; 本质而言, 它是互动表 的一个梗概。

\section{将工具整合到MSDS（可持续系统设计方法）的设计过程中}

在设计过程中, 互动表（故事板）将发展得越来越具体:

- 在战略分析阶段, 互动表（故事板）可用于:

- 对案例分析进行描述, 对用户与提供系统间的互动进行可视化表达 (图4.39)

- 在系统概念设计阶段, 互动表（故事板）可用于:

- 描叙或部分描述用户应该如何与产品服务系统的最初构思展开互动。该展 示是简明扼要的（由带有简要说明的图像序列组成），只需对系统所提供 的核心功能和用户之间的互动进行可视化表达(图4.40)。

- 详细列明参与提供物生产和交付过程的用户和参与者之间的互动。随着对 各参与者角色和所需 (物质的与非物质的) 要素说明的不断具体化, 该展 示也变得更加详尽充实。各种可视化方法可被使用：单线显示互动过程

（图4.41）；双线显示互动过程，一条表示用户的互动，另一条表示系统 参与者的互动（图4.42）; 或者多线显示互动过程, 每个参与者的互动均 用一条线来表示（图4.43）。

- 在系统概念设计（构建）阶段, 互动表（故事板）可用于:

- 详细描述用户和参与者在提供物生产和交付过程中的所有互动。与以往的 可视化表达有所不同, 为了处理解决方案所需的一切资料信息, 需要对每 一个互动过程都进行更为详细和深入的描述。每个互动在一系列互动步骤 中完成。各系统参与者的角色亦被详细列明; 在互动线条上（区分用户行 为和前台行为）加入了可视线条（区分用户可见的前台办公行为和后台办 公行为）和内部互动线条（区分后台办公行为和附属支持流程）；分别列 明了各互动步骤, 及各步骤所需的所有组件：工具（用于支持产品、标记 等），互动规则（用于指导互动的开展），专业技能（使用户和参与者能 够开展互动）和信息（互动过程中, 提供用户和其他参与者所需的信息）

这一类型的展示使设计团队能够在系统界面（用户与前台之间的互动）和系统本身 的机制下同时开展设计工作（图4.44）。 
126 可持续产品服务系统设计

\section{图4.38 将系统图整合到MSDS设计过程中}

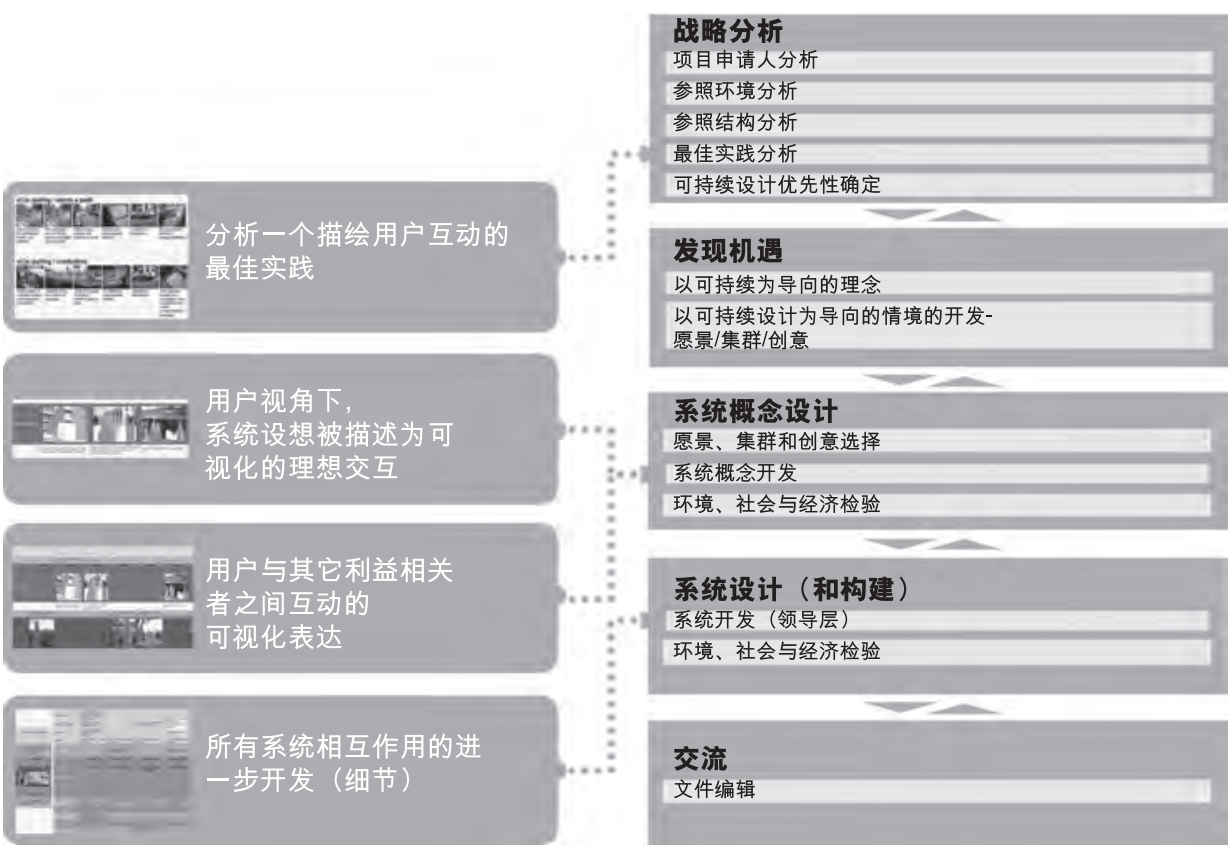

图4.39 在本实例中, 互动表从乘客与司机的角度描述用户体验

电子拼车/步行

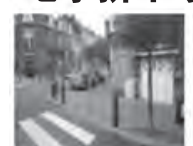

用户通过

手机告知

其目的

地, 手机

列出系统

的基本功

能及增值

功能

\section{电子拼车/司机}

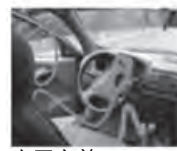

离开之前,

司机通过短

信告知其目

的地。

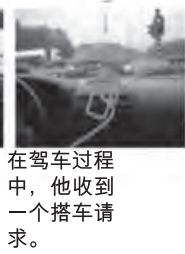

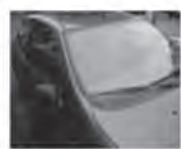

用户和司机

相互确认对

方身份

一辆蓝色菲

亚特车将在

5-8 分钟内

来接他

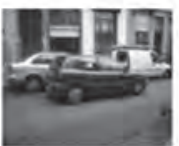

他们驾车驶 向目的地。

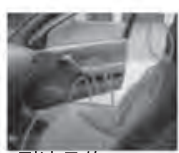

到达目的

地后, 用

户确认本

次搭载完

成。

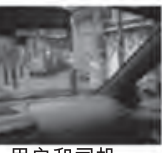

用户和司机 相互确认对 方身份。

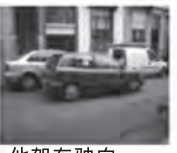

他驾车驶向 目的地。

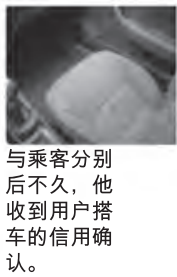


图4.40 用户与提供系统间互动的初步描述

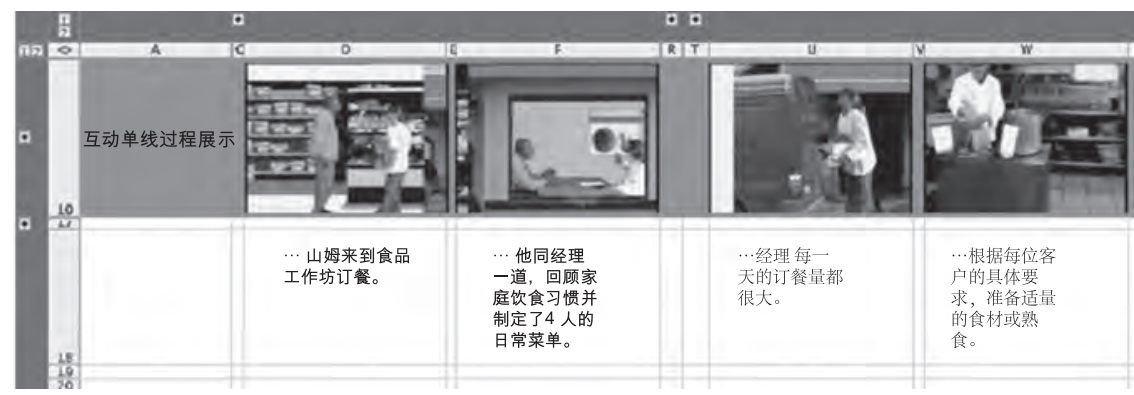

图4.41 提供物生产和交付过程中参与者和用户间互动的详细描述 单线展示互动 过程

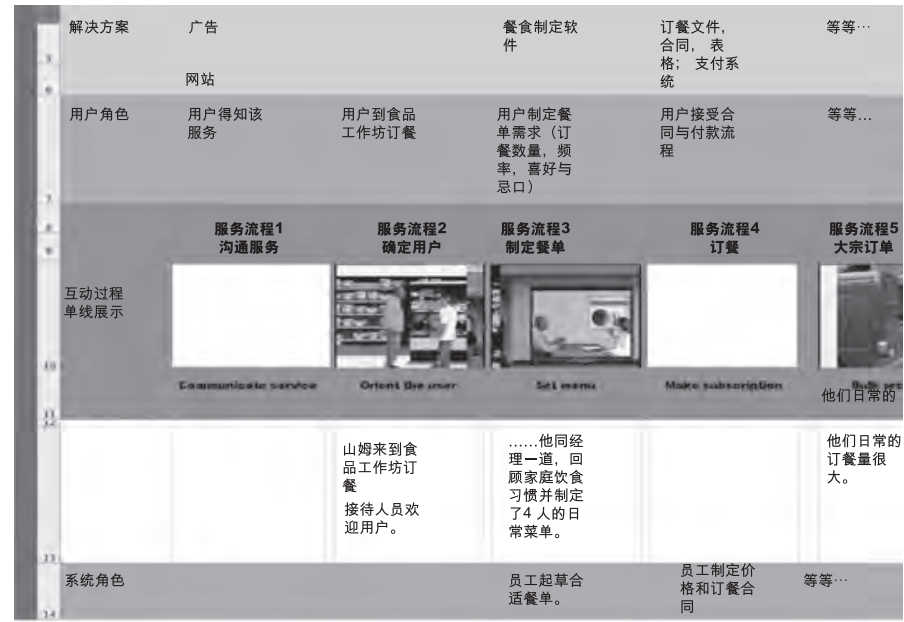

图4.42 提供物生产和交付过程中参与者和用户间互动的详细描述 双线展示互动 过程

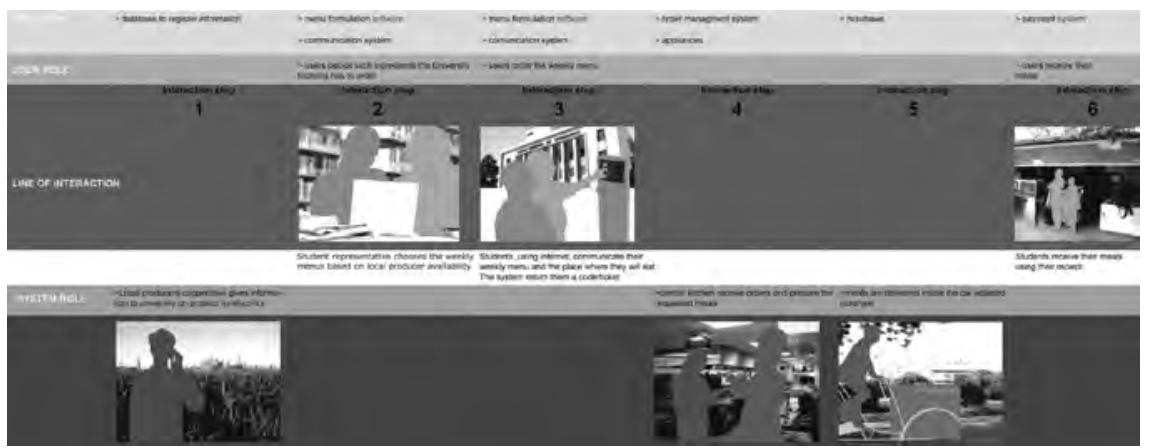


128 可持续产品服务系统设计

图4.43 提供物生产和交付过程中参与者和用户间互动的详细描述 多线展示互动 过程

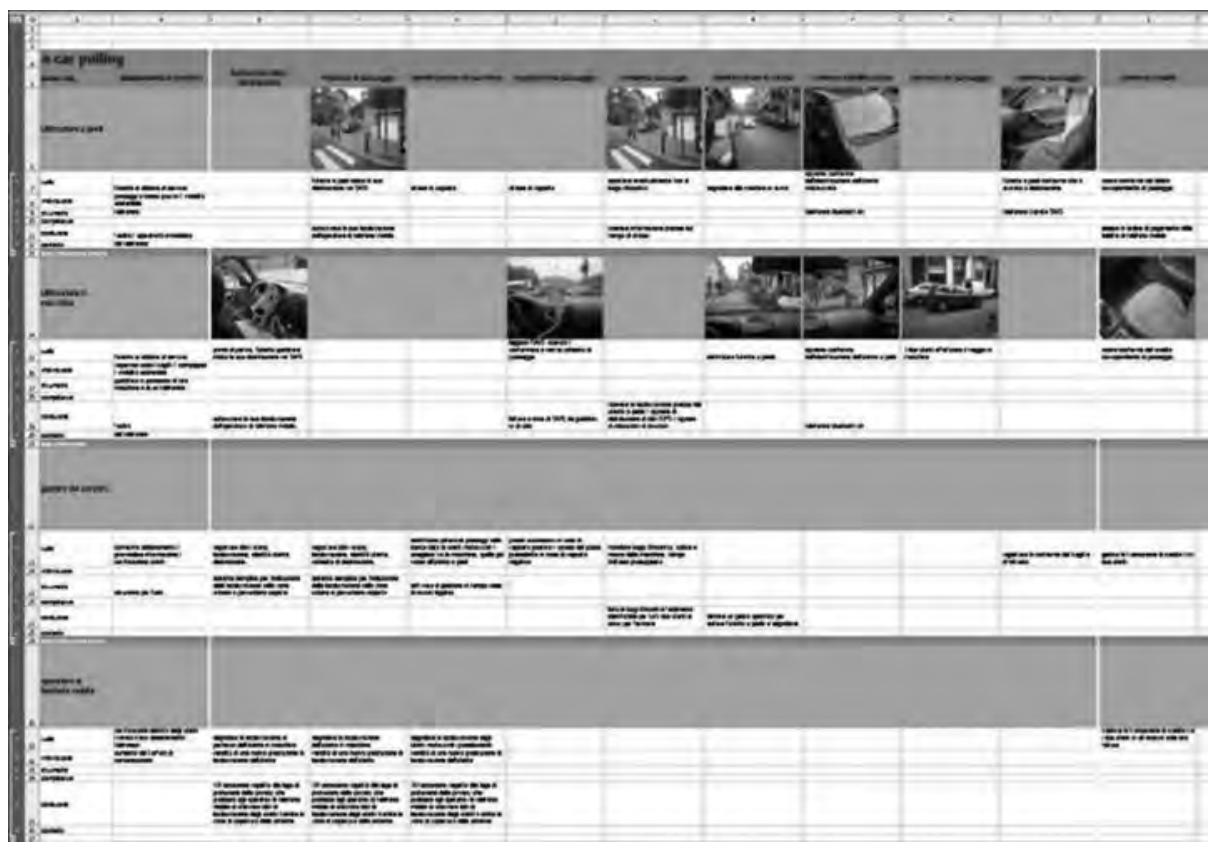

图4.44 带有方案实施详细说明互动表的最终版本 该图显示了构成互动3的各个 步骤
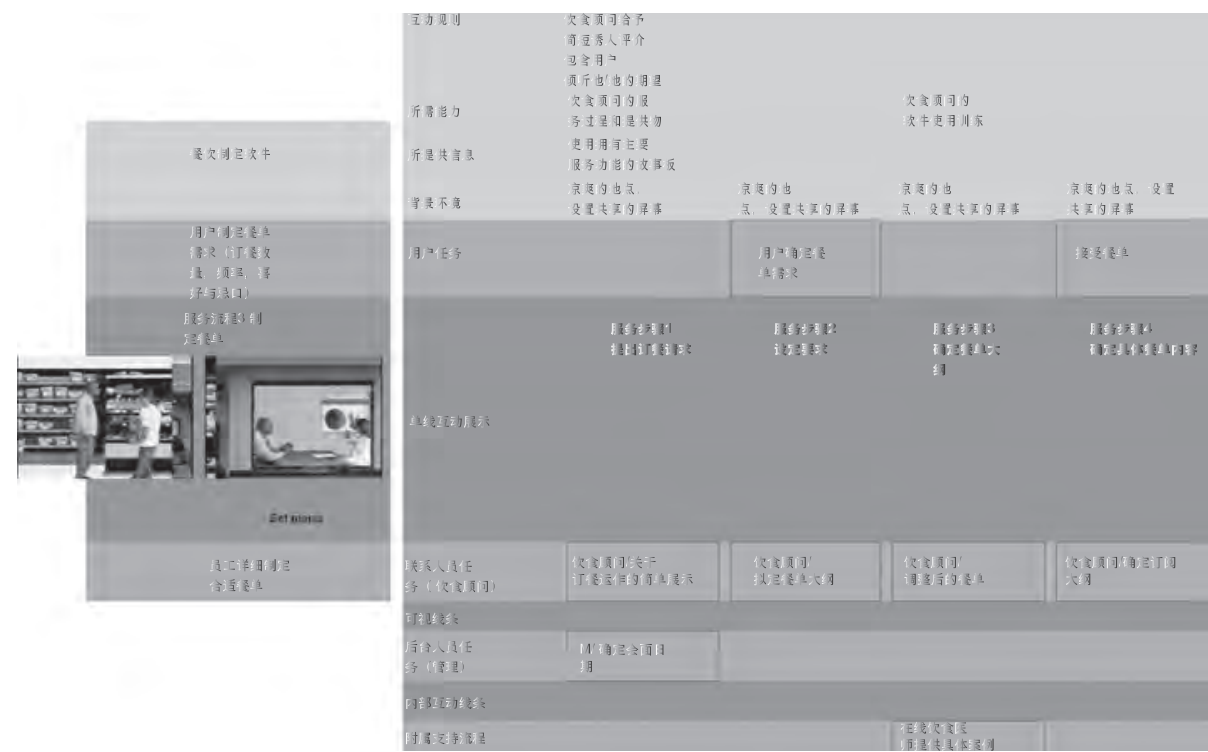


\section{如何使用该工具}

该工具需要使用电子制表软件（例如：微软的Excel软件或Open Office中的类似软 件 ${ }^{36}$ ) 。该工具要以常见且操作起来利于软件的使用为前提; 它将促进项目所有参与 者在设计过程中的参与并加快方案演化过程中各种步骤的交换、修改和展示。

数据表尤其有助于互动表的制作。可将图形要素（用以展现互动过程）和文本 要素（对互动和参与者角色的描述等）输入到特定的单元格中。可对不同单元格进 行涂色，以便例如：区分不同的互动线条。此外，软件还可以按您的意愿隐藏或显 示某一行或某一列的内容。

使用者还可以利用该软件在单元格中添加评论或注释, 以便开展团队工作, 并 创建阐述工作进度的相关文件, 使项目参与者能够在文件中留下建议或意见。

为了对互动进行可视化表达, 我们建议:

- 用图像背景充当行动开展的背景环境。

- 在图像背景中突出显示参与者。

- 图像应只包括必要要素, 以尽量减少语义上的混淆。

- 辅助文字（通常以第三人称叙述）简要描述参与者的行为。

- 图像的编排应保持节奏感和时间顺序。

- 在序列中只显示重要行动（仅在展示产品服务系统初始想法时）。

\section{结果}

最终得到的一种可视化的效果, 包括图像和文字要素, 显示系统各参与者与用户之 间在提供物生产和交付过程中的互动顺序。在整个设计过程中，这种可视化过程将 发展得越来越详细。

\section{所需工具和必备资源}

工作表单需依靠电子制表软件运行（例如：微软的Excel软件或Open Office 中的类似 软件)。

图像的制作需要掌握基本的图形处理技巧（需使用照片编辑软件）。然而, 设 计团队中的任何成员均可在电子制表软件中对互动表进行管理。

由于项目的复杂程度和所处设计阶段的情况不同，制作互动表所需的时间也不 同。因此很难对图表应用的所需时间进行准确预估; 我们只能进行预估, 其所需的 最短技术时间为:

- 用1小时制作简易的故事板, 只显示关键的互动过程（系统概念化设计阶段的 初始步骤） 
- 用8小时制作详细的互动表, 对各参与者的互动进行说明（系统概念设计阶段 的最终步骤)

- 用2小时将单个互动组合成完整的互动步骤（系统设计和系统构建）

\subsection{9 产品服务图37}

目的

产品服务图是系统功能的一种静态描述; 它可被用作设计和视觉化工具。该工具有 利于设计团队更加详细地对用户系统的功能进行定义。

它基本上是一种图像展示, 由图像和文字两种要素组成, 主要展示下列内容 （在设计过程中, 这种展示会越来越具体和详细）:

- 核心功能, 即提供物的标志性功能（例如定制的送餐服务）

- 基本功能, 即满足核心功能所需的功能（例如下订单, 付款等）

- 增值功能, 即与核心功能相关的、能够带来增值的功能 (例如饮食建议等)

- 子功能, 是指描述各项功能实现过程的功能(例如: “饮食建议” 功能可以被 细分为 “在线饮食建议”，“产品饮食信息”等)

\section{将工具整合到MSDS的设计过程中}

产品服务图将在整个设计过程中变得越来越详尽。

- 在探索机遇阶段产品提供图可用于:

- 描述构成特定情景的各种创意集群。这些创意可以与具体的核心功能相联 系。给这些理念配上标题, 简要地表述其要点, 并配上描述性图像。

- 在系统概念设计阶段, 产品提供图可用于:

- 从核心功能开始, 详细列举基本功能和增值功能。由于系统概念在此阶段 确定, 因此产品服务系统在此时应得以开发。从这个意义上说, 产品服务 图表既是一个辅助设计师对其产品服务系统进行细化的设计工具, 又是促 进团队和参与者之间进行沟通的一个可视化工具（图4.46）。

- 在系统概念设计（构建）阶段, 产品提供图可用于:

- 描述并列举实施设计方案所需的全部单一功能和相关子功能。这意味着必 须在子项目集群（该子项目集群描述并规定了这些功能如何实现）中详细 列出每项基本功能和增值功能（图4.47）

37 这一工具是由Francois J é gou在产品服务系统方法 (MEPSS) 欧洲研究项目成长计划/欧 洲第五框架 (European Research, GROWTH Programme / European 5th Framework) 的实施过程中研发的。详情请见凡·海伦 (van Halen), 维佐理 (Vezzoli) 和维默尔

(Wimmer) (2005)和http://www.mepss.nl/index.php?p=tool\&l4=W23。此处的描述性文本 来自 www.mepss.nl/index.php?p=tool\&14=W23 


\section{图4.45 将产品服务图表整合到MSDS设计过程中}

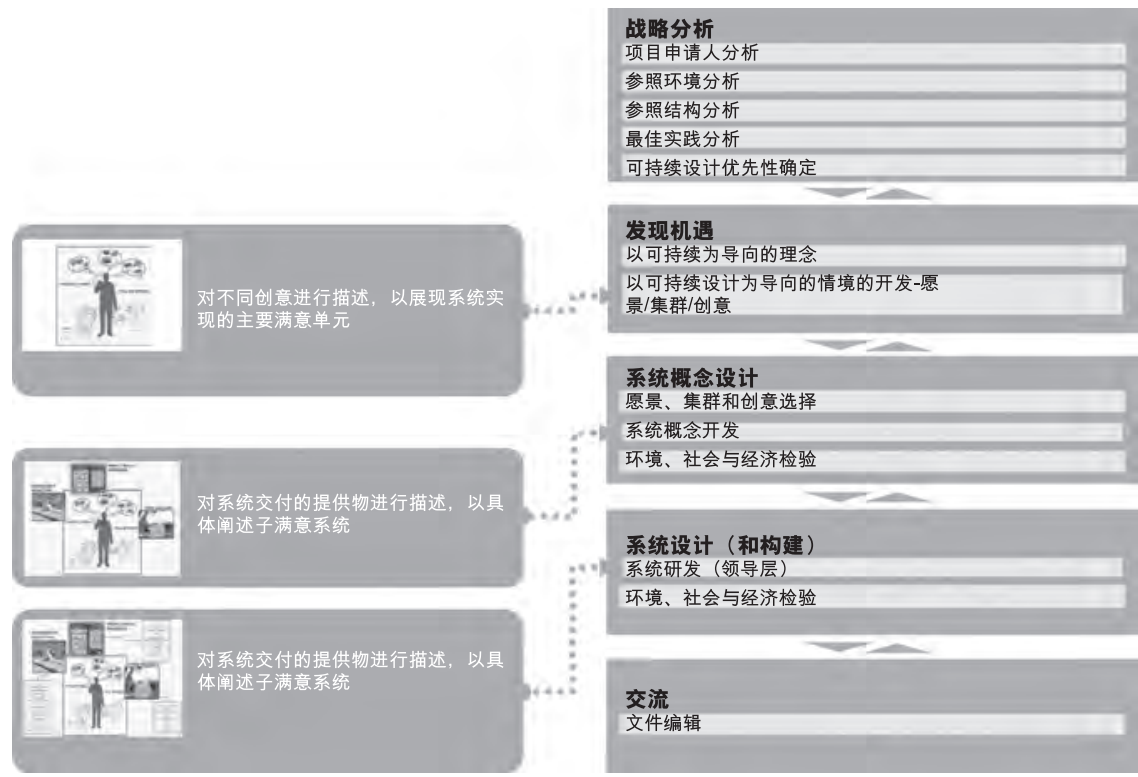

图4.46 在系统概念设计阶段, 产品服务图使得基本功能得以发展, 同时在主要 功能周边列出各项增值功能

来源：凡·海伦 (van Halen), 维佐理 (Vezzoli) 和维默尔 (Wimmer) (2005), 附带英文翻译

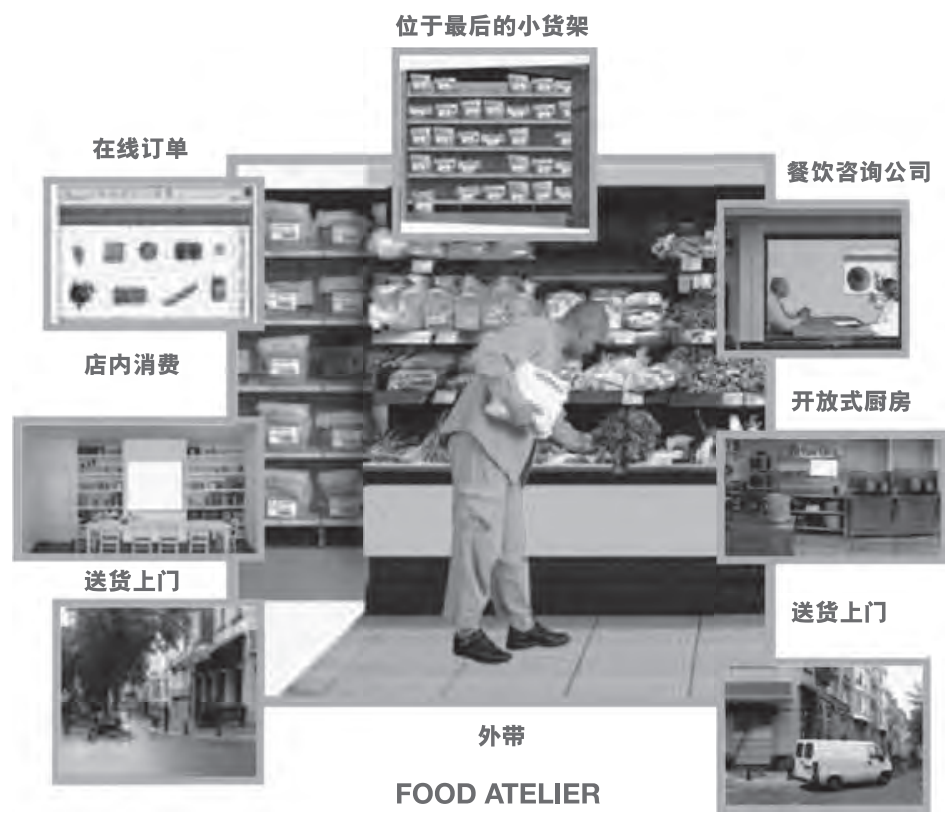


如何使用该工具

该工具并不要求使用任何特定软件; 产品服务图可直接在纸上绘制。然而，如果利 用该工具进行沟通交流，建议使用图形图像处理软件和幻灯片软件作图。

核心功能位于产品服务图表的中部（通过示意图、标题来显示, 可能附有说明文字）。 基本功能和增值功能位于核心功能周围; 也是通过附有说明性文字的图像来显 示。您也可以通过图像大小的差别来表示基本功能（较大图像）或增值功能（较小图 像）。

子功能位于其相关功能周围, 以文字的形式展现。

\section{图4.47 在系统设计阶段, 产品服务图进一步演化: 在每个次级功能中详细列出 每个单项功能}

来源: van Halen, Vezzoli和Wimmer (2005), 附带英文翻译

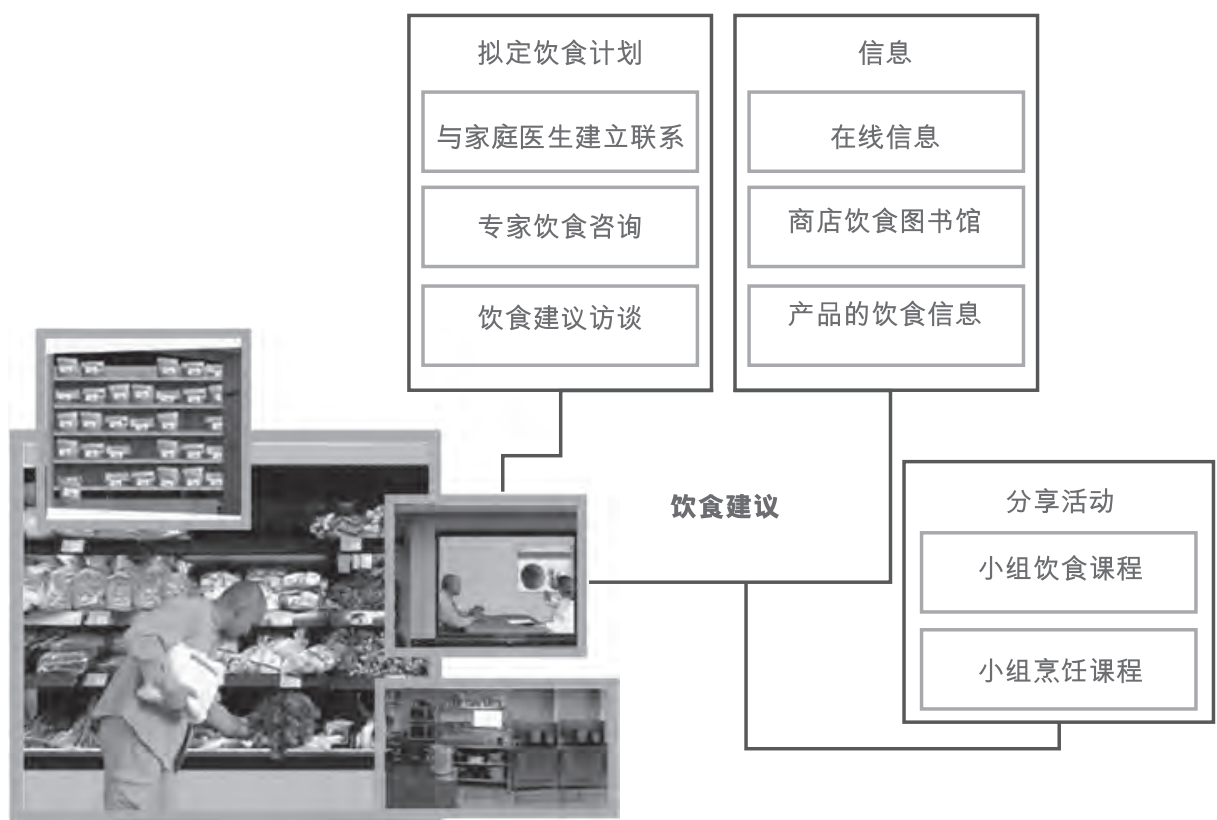

结果

最后得到的是一个展现了系统所具有的功能（核心、基本和增值功能）及其子功能 的图表。根据所开发的系统概念的不同，所生成的图表也各不相同。 


\section{所需工具和必备资源}

产品提供图可直接在纸上绘制。然而, 最好使用幻灯片软件和图像处理软件来绘制 图表。这样可使设计团队中各成员均能更容易地对图表进行修改。图像的制作需要 掌握基本的表格制作技巧（需使用照片编辑软件）。

创建产品服务图表所需时间因设计项目的复杂程度不同而各有不同。其中, 最 短技术时间约为:

- 1小时用于创建简易产品提供图，仅显示核心功能

- 2至3小时用于添加图表中的基本功能和增值功能

- 2至3小时用于添加子功能

\subsubsection{0 极化图38}

\section{目的}

极化图用于 “探索”现有系统今后发展的趋势和前景。换句话说，从具体的设计选 项开始, 它便是定义现有系统改造方式的辅助工具：它促进新创意的产生并支持创 意的组织和展现。特别地, 它应用于设计过程的开始阶段, 对我们所说的以可持续 设计为导向的情景, 即系统可能采取的有前景的结构变换进行诠释和可视化表达。

在实践中，它是一个建立在两极之上的图（图4.48）；每一极均显示产品服务 系统在相反的两个方向可能会出现的变体（例如：如果用户参与度比较低，那么我 们将提供全方位的服务产品, 若参与度高的话, 我们将考虑相应的解决方案）。

一方面，该工具能够在图表中对创意理念进行定位和组建；另一方面，它能进 一步刺激新创意的产生，例如，通过提问 “如果一个创意从一个象限移动到另一个 象限将会发生什么情况”。

38 这一工具是在产品服务系统的方法 (MEPSS) 欧洲研究项目成长计划/欧洲第五框架

(European Research, GROWTHProgramme/European5thFramework)的实施过程中研发 的, 目的是为构建场景提供支持。详情请见凡 · 海伦 (van Halen), 维佐理 (Vezzoli) 和 维默尔 (Wimmer) (2005)和http://www.mepss.nl/index.php?p=tool\&l4=W19. 


\section{图4.48 显示构成要素的极化图示例}

来源：图像由维佐理(Vezzoli)、奥比特格力(Orbetegli) 和山士恩 (Ceschin) (2006) 进行处理

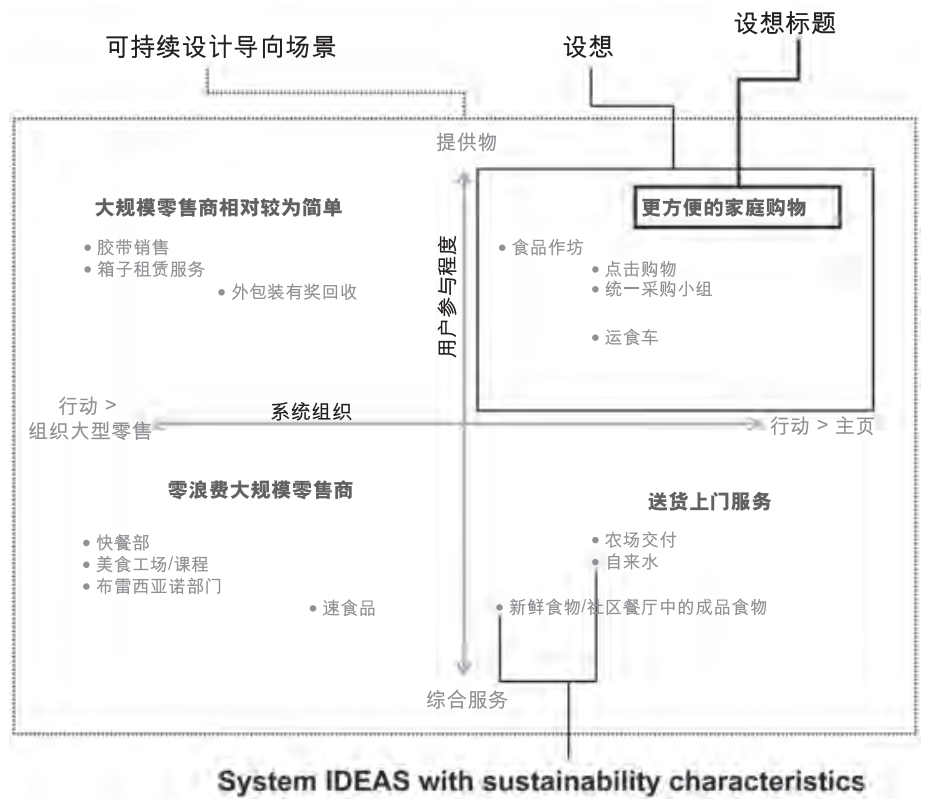

将工具整合到MSDS的设计过程中

极化图可用于:

- 在机会探索阶段, 支持可持续设计为导向的情景构建, 即新产品服务系统可 能采用的一系列构造。

该情景包括四个设想（每象限一个）以及图解性描叙, 关于采用特定设计选项 后, 背景环境将如何发展（图4.52）。相应象限内的一系列创意理念对每个设想都 进行了详尽的描述; 为了进行组织和沟通, 这些创意可以被重组成创意群, 每一组 拥有相似的基本特点（图4.53）。需要强调的是, 极化图是用于可持续系统设计方法 (MSDS) 中，对SDO工具包（参见4.3.1部分-SDO工具包）所产生的可持续创意 进行组织的。出于这个原因, 所产生的情景和设想被认为是以可持续为导向的情景 和设想。 


\section{图4.49 将产品服务图表整合到MSDS设计过程中}

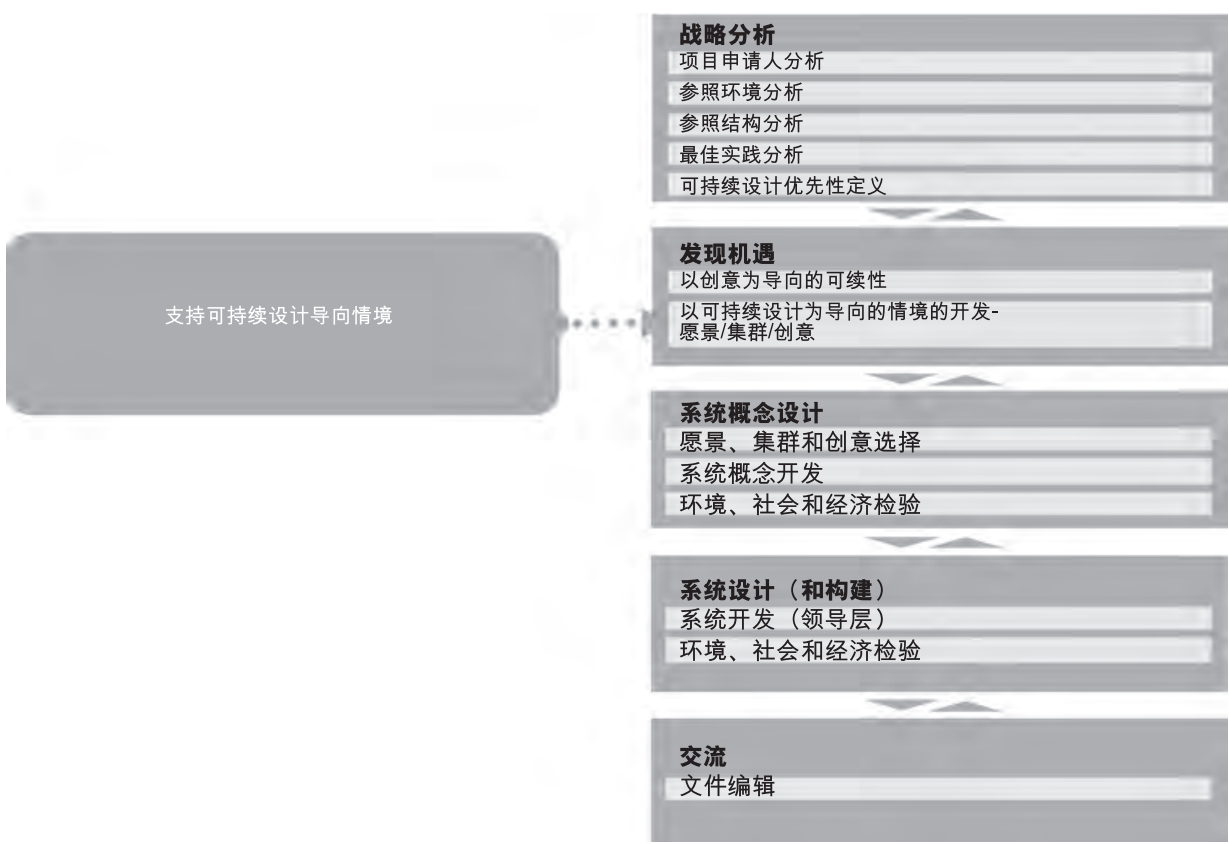

如何使用该工具

该工具无需使用任何特定软件; 它可以在纸上绘制或以数码形式(例如：使用幻灯片 软件)进行绘制 39 。具体过程分为以下四个步骤：进行创意构思、确定有发展前景的 极化图和极化创意、定义设想、定义创意集群。

\section{创意构思}

以可持续为导向的创意构思是在集体讨论会（头脑风暴）中进行的。在可持续系统 设计方法论 (MSDS) 中, 该过程得到以下工具的辅助, 如:

- 可持续创意构思图表（SDO工具包，见4.3.1中的SDO工具包）

- 满意度系统图, 即一种识别并对能满足特定福利需求的潜在社会经济参与者 进行可视化表达的图表（参见4.3.7一满意度系统图）

- 优秀案例分析

不同的创意可通过文字（标题、关键词、扩展描述）和视觉要素（图像、示意图 等）进行描述。

39 用户可以从www.lens.polimi.it的“工具”一栏中下载一个基本模型用于创建 “极化图” 及 用户指南。 


\section{识别有前景的极化图和极化创意}

在这一步骤中, 构造极化图需要将新形成的构思应用到不同象限中。

绘制极化图时, 可以：1）从各种已经定义的极性中进行选择2）根据项目的需 要再次对它们进行定义。

图4.50 可以用于绘制极化图的极性例子

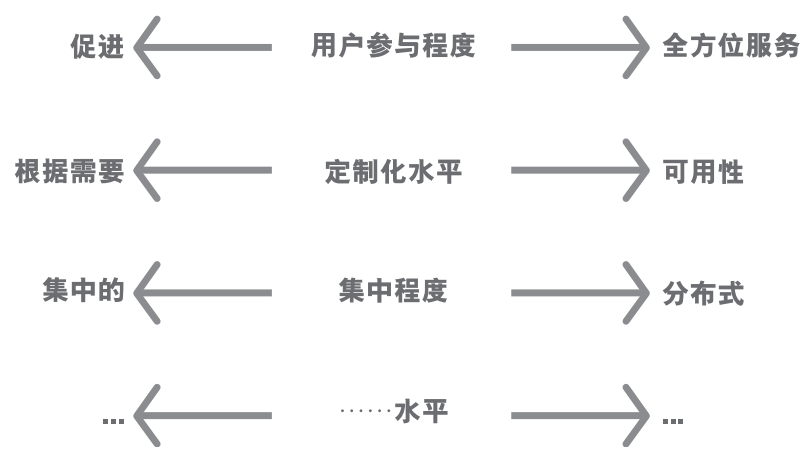

在这一点上, 可以在图上对创意进行定位。必须强调的是, 这种运行方式不仅在于 组织并展示创意理念, 同时也为了更进一步刺激新创意的产生。可以将创意从一个 象限转移到另一个象限, 以便潜在地产生新创意。

\section{图 4.51 极化图的构成, 创意的定位以及新创意的产生}

来源: 维佐理(Vezzoli)、奥比特格力(Orbetegli) 和山士恩 (Ceschin) 2006年的改进图

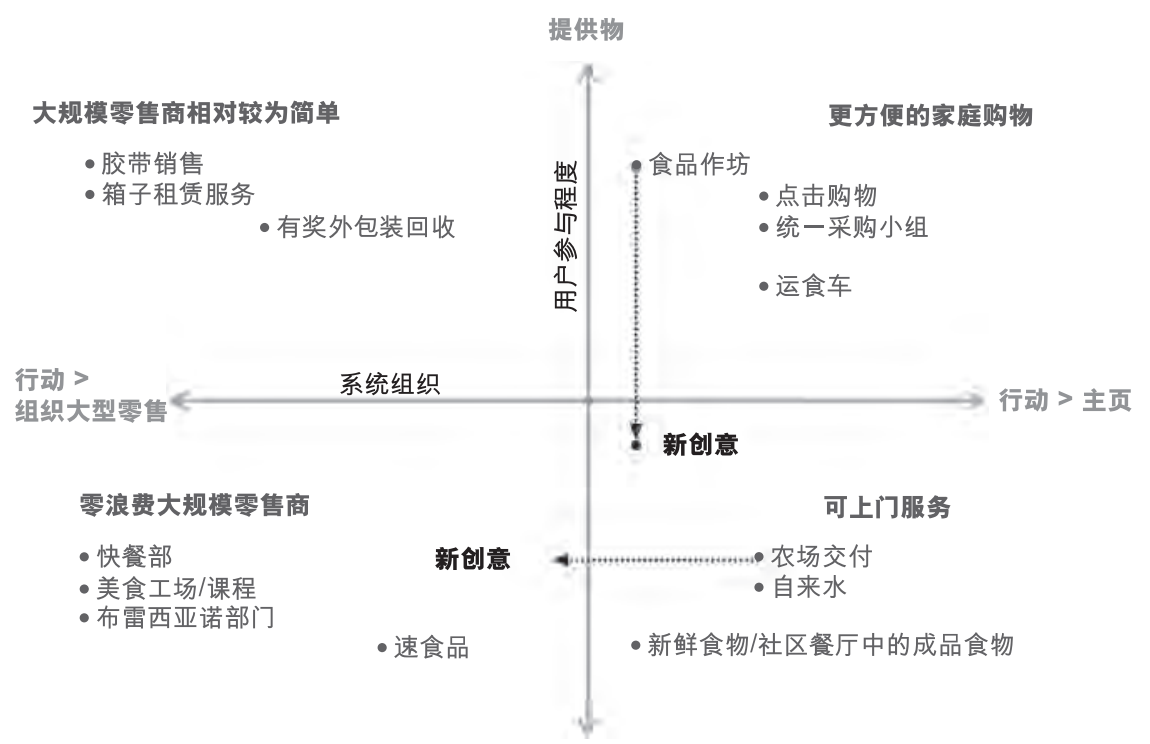

综合服务 


\section{定义设想}

一旦完成了对所有创意的定位, 就可以开始定位设想了, 像我们曾提过的, 这些 设想描述了特定的设计选项确定之后, 其环境是如何不断进行演进的。每种设想 (一个象限) 代表着系统演变的潜在发展方向。

通常每种视图都配有标题和详细叙述。

\section{创意集群的定义}

与设想的定义类似，创意集群的定义也可聚集新构思，也就是，对具有特征相似的 创意进行分组。当需要对大量的创意进行管理时, 尤其建议加强对构思的组织和 展示。

不同创意集群（来自不同象限）的融合成为了产生一个或多个系统概念的开端。

\section{图4.52 构成方案的各种设想的描述}

来源：维佐理(Vezzoli)、奥比特格力(Orbetegli) 和山士恩 (Ceschin) 2006年的改进图

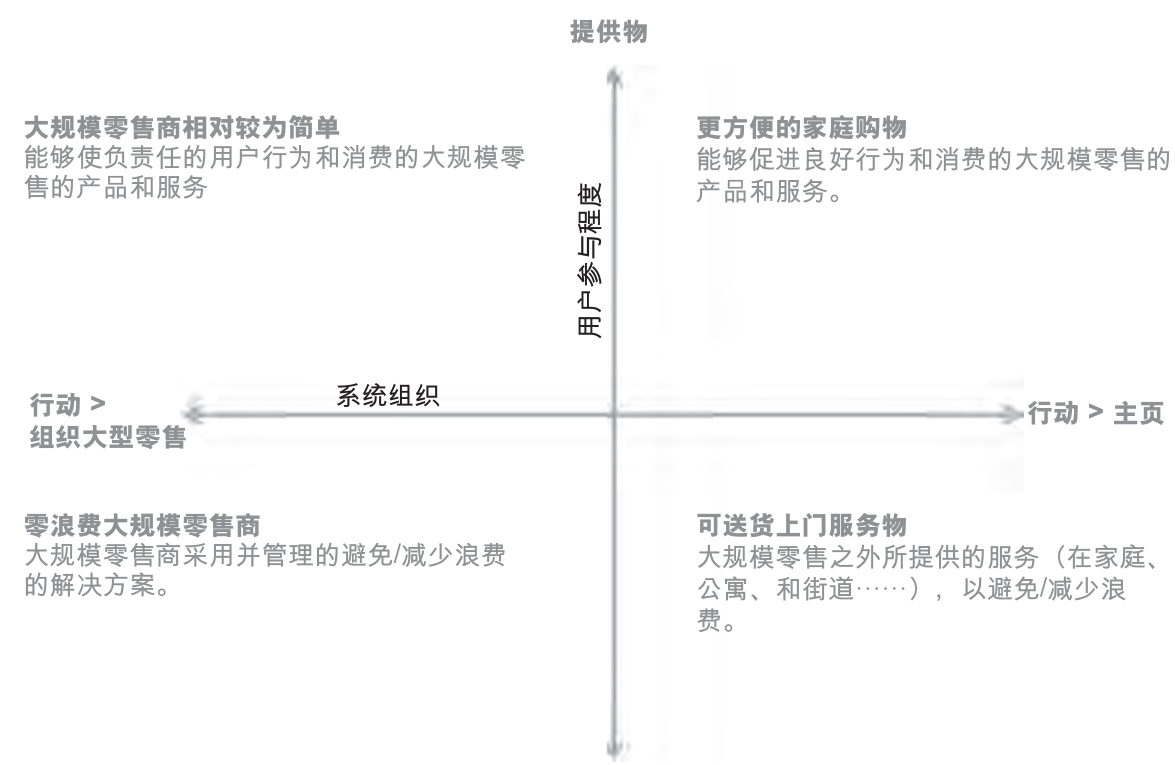

综合服务 


\section{图4.53 创意集群的定义}

来源: 维佐理(Vezzoli)、奥比特格力(Orbetegli) 和山士恩 (Ceschin) 2006年的改进图

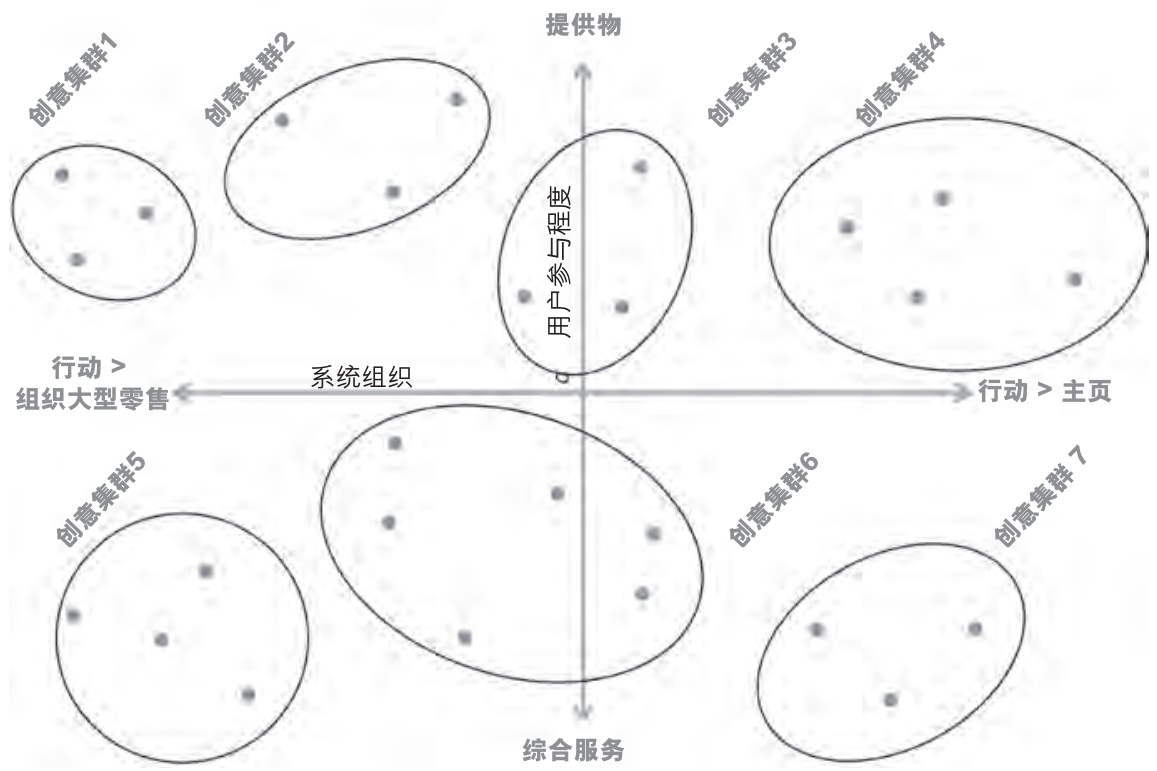

简而言之, 上述过程开始于创意构思, 最后形成了极化图以及相关设想的确定。事 实上, 该过程也可能朝着相反方向发展, 即:

- 定义极化图（从现有的极化图开始或另外进行设计）

- 通过描述四个新形成的象限确定设想

- 使用极化图和相关设想刺激新创意的产生

\section{结果}

得到一个对以可持续为导向的情景进行描述的示意图，包含了相应的设想和创意集群。

\section{所需工具和必备资源}

该图表可直接在纸上绘制。然而，仍然建议使用幻灯片软件，以便于管理和改进。

工具的使用无需特定图表制作技巧，所以设计团队中的任何成员都可完成这一工作。

极化图的使用包括对创意进行极性分组, 确定设想和创意集群。因此, 所需时 间因特定项目不同而各异。其中，所需最短技术时间约为：

- 30分钟用于定义极性和绘制图表

- 2小时用于定位创意并进一步产生新创意

- 2小时用于确定设想

- 2小时用于确定创意集群 


\subsubsection{1 解决方案要素简介40}

\section{目标}

“解决方案要素简介” 是一个（共同）设计和可视化工具。其目的在于对系统所需 的要素（物质或非物质的）和设计/生产/输送这些要素的系统参与者进行描述。这一 工具用于帮助在方案研发和交付过程中对单个参与者的角色进行定义。

这主要是一个图表展示, 由一个双向图表构成:

- 方案实施所需的物质 (产品, 设备等) 和非物质 (信息, 服务等) 要素都标 于水平轴上。这些要素主要由象形图进行表现。

- 系统内的参与者标于垂直轴上

- 要素与参与者相交所构成的图像显示了单一参与者在设计, 生产和交付各要 素过程中所做出的贡献。

\section{将工具整合到MDSDS的设计过程中}

“解决方案要素简介” 可用于:

- 在设计（和构建）系统阶段, 简洁有效地对单一要素的设计、生产和交付过 程中各参与者所做的贡献进行定义。

\section{图4.54 将“解决方案要素简介” 整合进可持续系统设计方法实施过程中}

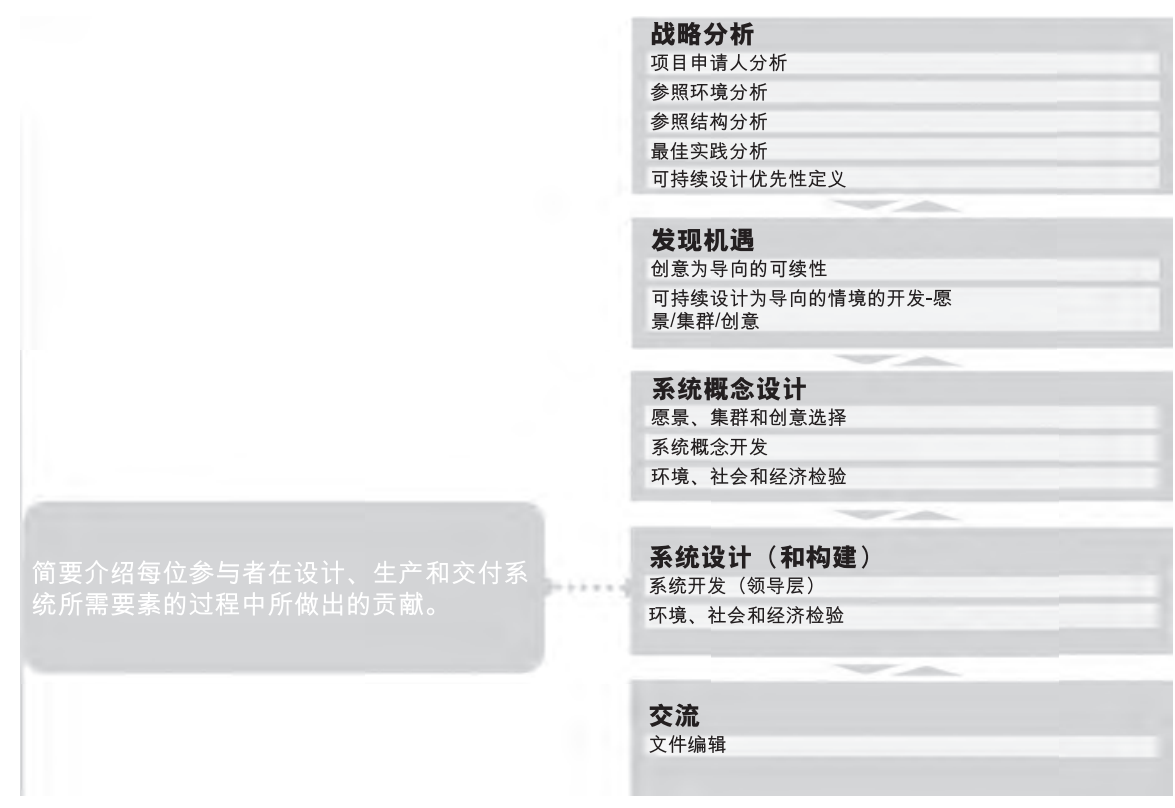

40 这一工具是在 HiCS 研究项目 “Highly Customerised Solutions, Solution-oriented design, production 和 delivery systems” 期间开发的（欧洲研究，成长项目/欧洲第五框 架）。详情请见：耶由（Jégou）, 曼奇尼（Manzini）和 梅罗尼（Meroni） (2004). 
如何使用该工具

该工具无需使用特定软件，然而，为了方便管理和改进，建议使用电子制表软件

(例如：微软的Excel软件或Open Office中的类似软件) 41 。

应用广泛, 操作方便的软件可以增加项目人员在设计过程的参与程度, 推进方 案发展过程中各步骤之间的交换，改进和展示。

可将不同图表和文本因素添加到电子数据表单元格中。

可视化表达由以下部分组成:

- 系统运行所应具备的功能

- 构成单一功能的要素 (可通过象形图, 或更简单通过说明性文字进行 展示）。

- 作为系统组成部分的参与者 (由jpg格式的系统图图标表示, 或者更简单地可 用它们的名称进行表示）。

- 不同参与者在设计、生产和输送各要素过程中所担当的角色（可用符号进行 表示, 如下图所示)。

图4.55 解决方案要素简介的示例 我们可以在顶部看到方案实施中所用到的必需 要素（单个要素在其中已经表现出来）。每个要素都与系统中的各参与 者密切相关: 十字型（加号）表明该参与者对特定要素的设计有影响; 方块表明该参与者会生产或交付这种要素; 十字型与方块的组合则表明 该参与者对设计、生产和交付都会产生影响。

来源：Ceschin(山士恩) 2006

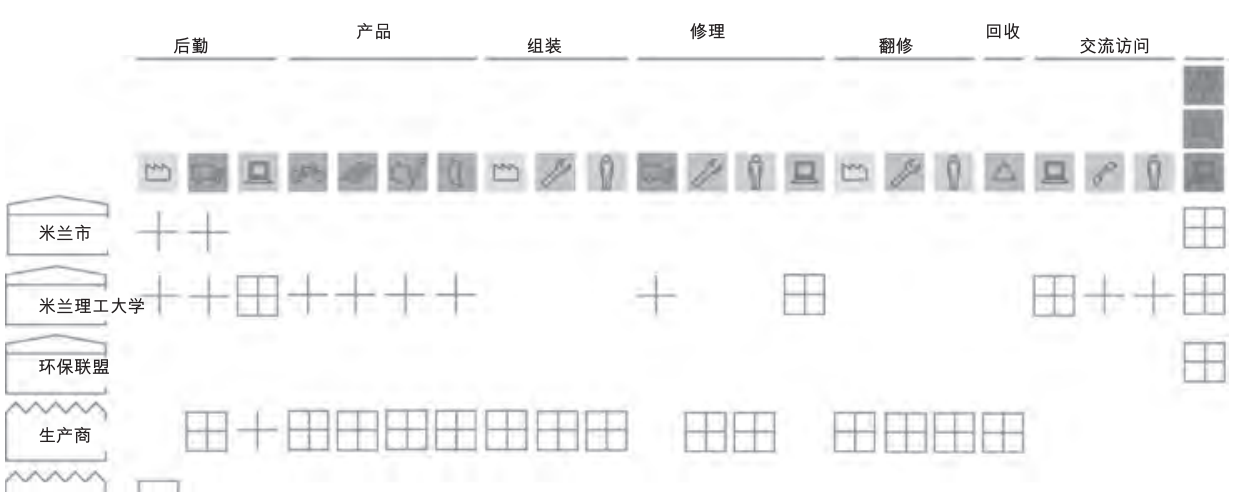

41 用户可以从www.lens.polimi.it的 “工具” 栏中下载一个基本模型用于创建一个 “方案元素 简介”，及用户指南。 


\section{结果}

最终得到一个双向图表, 表明系统实施所需要素（物质和非物质）以及各参与者在 设计、生产和交付等要素中所担当的角色。

\section{工具可用性和所需资源}

创建图标需要图像处理软件。建议在起草解决方案要素简介时使用电子制表软 件, 这样便于数据的整合和修改。

需要掌握制图所需的基本技能(图片编辑软件的使用)。然而, 电子制表软件中的 解决方案要素简介可以由设计小组中的任何一位成员负责管理。

该表制作所需的时间因各项目的复杂程度不同而有所不同。但我们预计大致的 最短时间为:

- 4个小时创建图标（为节省时间, 图标可由文字表述代替)

- 4 个小时来处理解决方案要素简介

\subsubsection{2 利益相关方动机矩阵42}

目的

利益相关方动机矩阵是一个（共同）设计和可视化工具。它旨在从单个参与者动机 的角度, 对系统方案进行表述。这是一项用于对每个参与者对整个合作伙伴关系及 其他参与者的角色和贡献进行定义的工具。

这是一幅双向图表, 各种影响因素置于两侧, 各种因素的交汇一目了然, 不同 因素在图表中:

- 加入系统的动机

- 整体上在合作过程中的作用, 特别是对于其他参与者的影响

- 收到的来自合作伙伴和其它单个利益相关方的贡献

- 收到的来自各参与者之间潜在的协作或冲突

42 这是由HiCS研究项目 (欧洲研究、成长项目/欧洲第五框架 (European Research, GROWTH Programme / European 5th Framework)) 中开发的一个工具。详见: 耶由 (Jégou），（Manzini）和梅罗尼 (Meroni) (2004)。这部分的描述引自： (Manzini) 和梅罗尼 (Meroni) (2004). 
将工具整合到可持续系统设计方法 (MSDS) 的设计过程中 利益相关方动机矩阵可以用于:

- 系统概念设计。在这种情况下, 项目提议者可以利用这一工具率先明确他们 参与该系统的动机、潜在贡献和预期收益。还可以用于识别和确定今后潜在 的合作伙伴（图 4.57）

- 设计 (构建) 一个系统。利益相关方动机矩阵随着设计过程的推进也会不断 完善：实际参与者逐渐取代潜在参与者（之前所确定的）; 可以重新定义并 列举他们的意图、贡献和预期收益; 可加强各参与者间的协同效应, 并可以 减少或解决冲突（图4.58）

\section{图4.56 将利益相关方动机矩阵整合到可持续系统设计方法实施过程中}

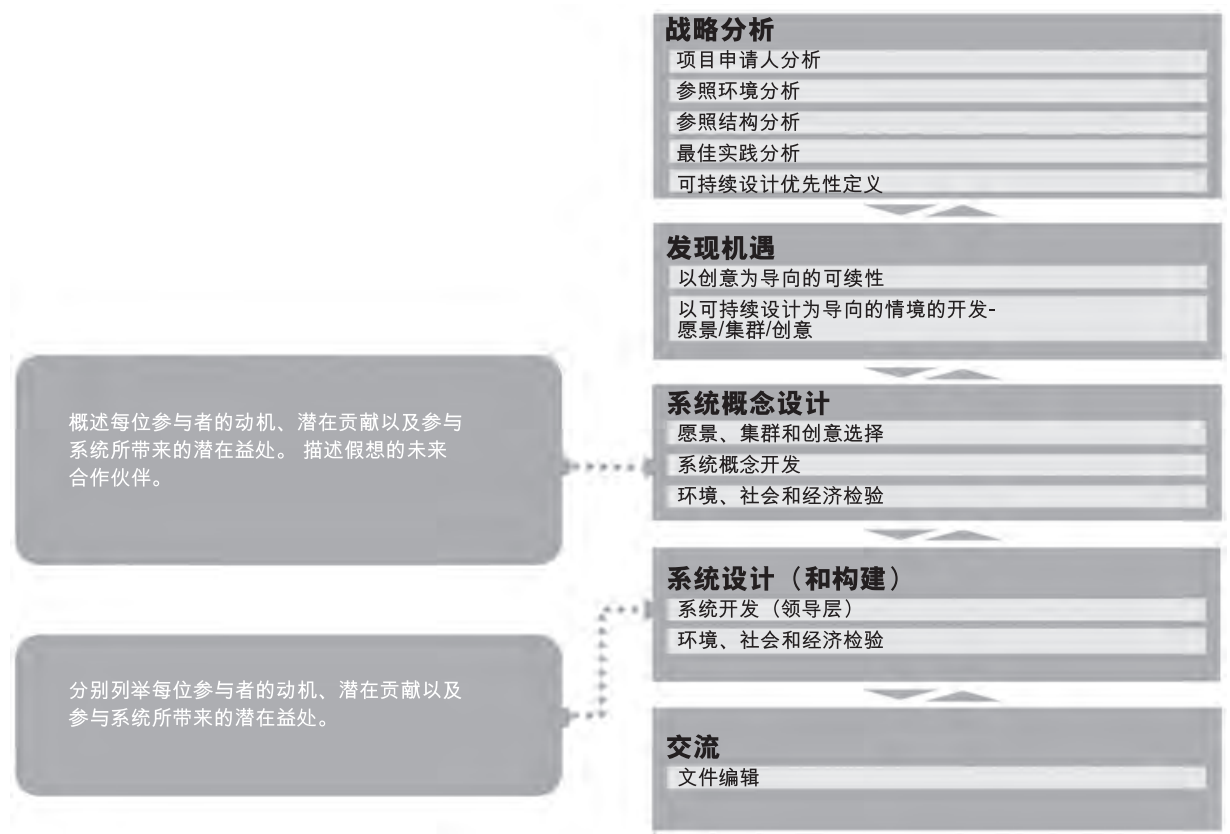




\section{图4.57 将该模型应用于系统概念设计阶段}

来源: 改编自山士恩 (Ceschin) 2006的图片

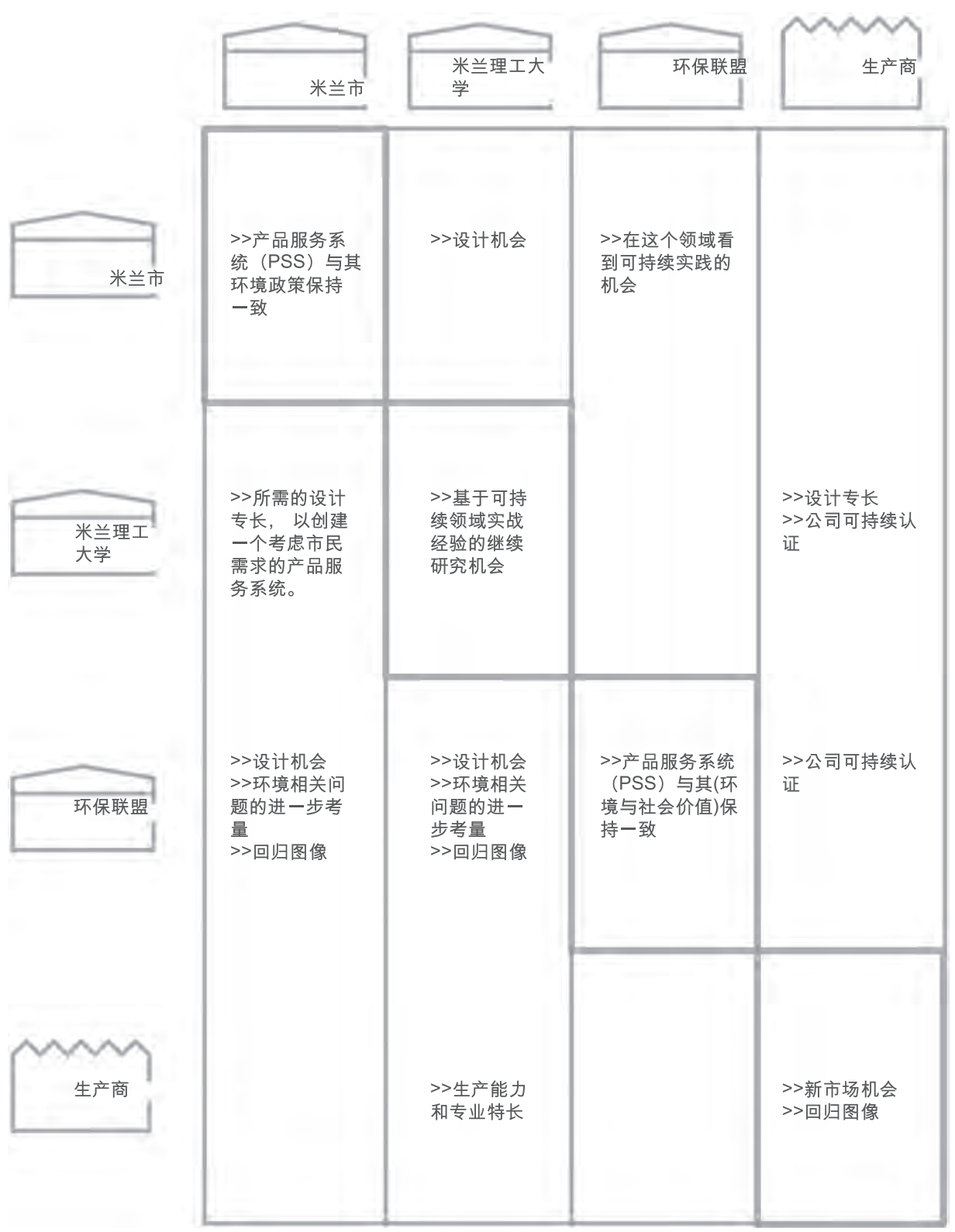


144 可持续产品服务系统设计

\section{图4.58 将该模型应用于系统设计和工程阶段}

来源: 改编自山士恩 (Ceschin) 2006的图片

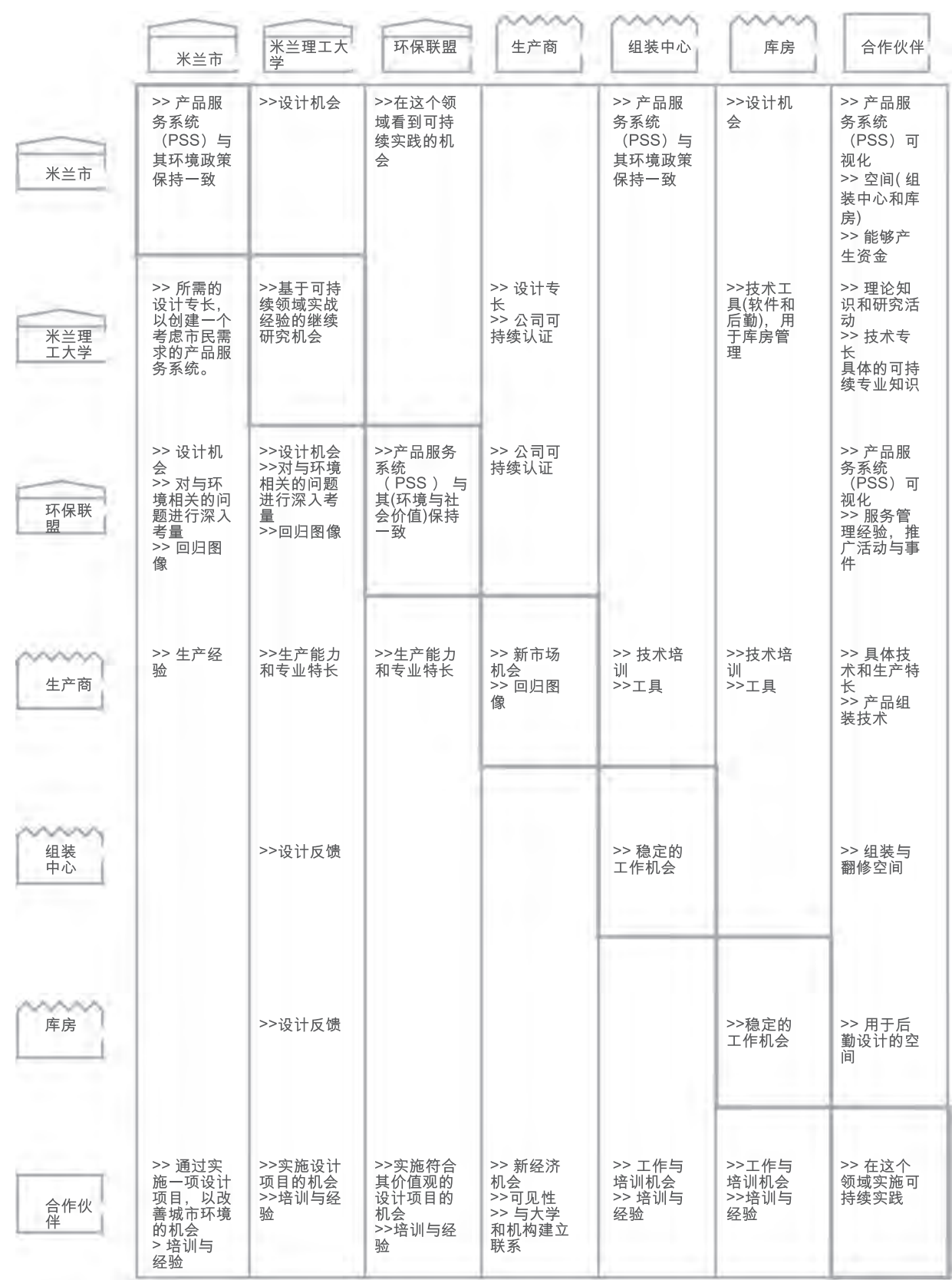




\section{如何使用该工具}

该工具不需要使用特定的软件, 然而, 为了对各种图像元素进行有效管理, 还是建 议使用电子制表软件（例如：微软Excel，或开源办公软件系统中的类似软件） 43 。

这些软件应用广泛, 使用便捷, 将促进项目所有参与者在设计过程中的参与并 加快方案演化过程中各种步骤的交换、修改和展示。

可以将各种图表和文本要素输入到电子数据表中。

可视化部分包括:

- 参与者, 位于双向图表的两侧（由系统图使用的图标创建的.jpg文件来表 示, 或只是用它们的名称来表示)

- 动机、贡献和预期收益, 由每对参与者输入

可将该表左侧各参与者同顶部各参与者结合起来进行解读。

\section{图4.59 构成利益相关方动机矩阵的各组成要素及其解读方法}

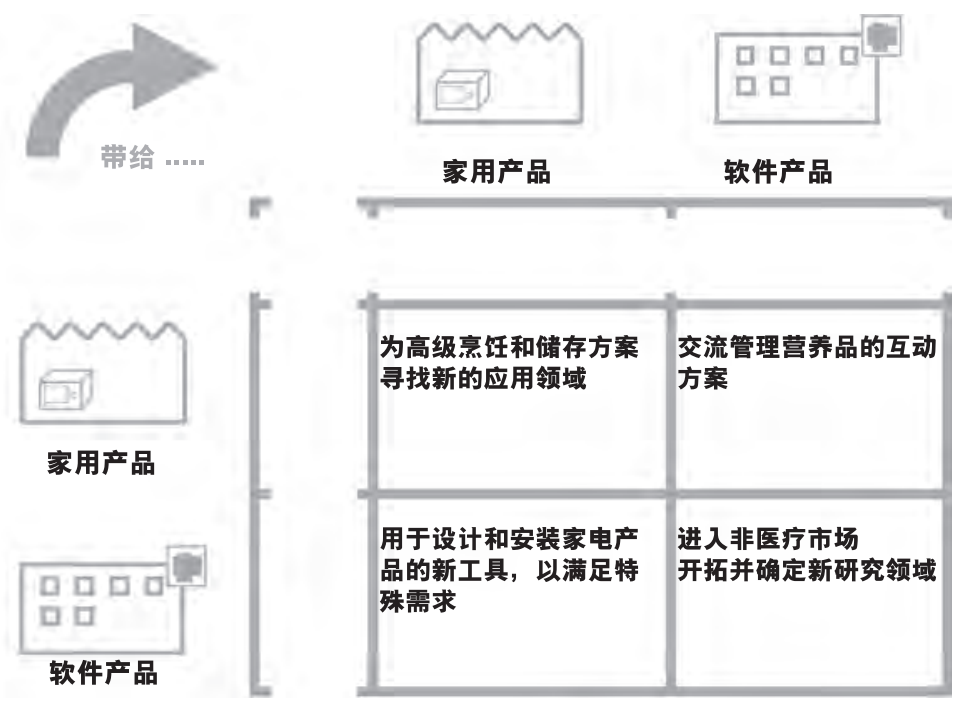

结果

得到的是一个可视化的双向图表, 系统中每个参与者的动机、贡献、预期收益、可 能出现的冲突或协同效应都可以被描述出来。

43 为创建一个 “利益相关方” 的动机矩阵, 用户可以从www.lens.polimi.it的 “工具” 栏中下 载一个基本模型和用户指南。 


\section{工具可用性和所需资源}

创建图标需要图片处理软件（图标可依据系统图中的那些来创建）。建议在起草利 益相关方动机矩阵时使用电子制表软件, 这样便于数据的整合和修改。

需要掌握制图所需的基本技能(利用图片编辑软件)。电子制表软件中的利益相关 方动机矩阵可以由设计小组中的任何一位成员负责管理。

制作利益相关方动机矩阵所需的时间因各项目的复杂程度不同而各有不同。但 我们预计大致的最短时间为：

- 2 小时绘制出该矩阵的初始版本（仅包括主要参与者）

- 2 个小时更新二级参与者矩阵。

\subsubsection{3 miniDOC44}

目的

影音工具以讲故事的形式推进对话的进程。MiniDOC是一套视听工具, 使决策制定 者们在系统共同设计过程中进行内部对话成为可能。

在短时间内（大约5分钟），该工具可以通过以下方式将分析后得出的重要成果 以可视化的形式表现出来:

- 确定案例分析和最佳实践方案

- 对利益相关方进行视频访谈

- 对历史及当代的图片资料进行研究，有助于记忆的重塑和想象的提升。

该工具的具体用途在于:

- 对环境进行研究和定位

- 在研究领域打造并促进新创意的产生。

- 促进不同利益相关方的对话

将工具整合到可持续系统设计方法 (MSDS) 的设计过程中 miniDOC在分析阶段可作为做音频和视频输出工具作用。

- 在战略分析过程中, miniDOC可以被用于:

- 描述在研究阶段发现的关键方面（优势和劣势）并对其进行形象化展示。对于 表格中内容、参与者和集群的确定十分有用, 为构建决策者之间的对话奠定了 基础，这也是充分发挥了影音材料易于获得、便于理解的特点（见 图4.60）。 
图4.60 对从miniDoc可视图中提取出的描述内容和框架等关键领域进行描述的 概念图表
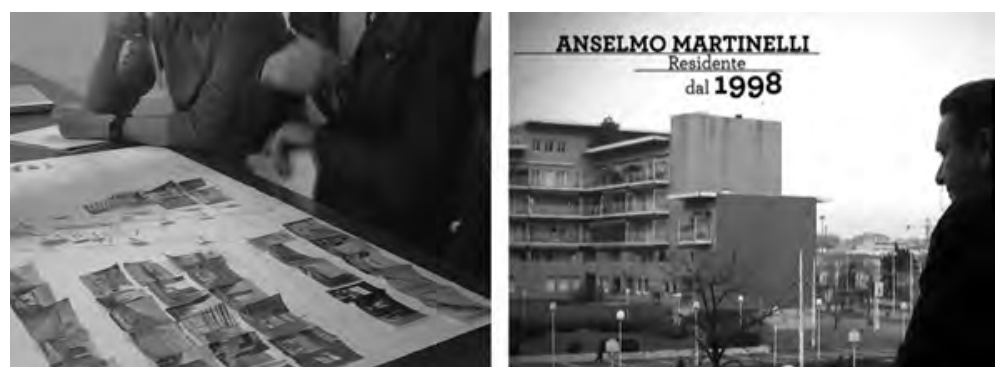

如何使用该工具

该工具需要使用编辑合成软件, 因此是基于一种叙事型结构的软件。

miniDOC不仅可以保证所有利益相关方都参与到材料收集的过程中来（图片资 料和视频访谈），同时它也给设计者提出了要求：关键元素需要被更好的收集和组 织起来, 形成叙事和审美集群。因此, 所研究的内容成为该项目开发过程中的灵感 来源之一。

材料可通过不同设备进行收集和编辑（摄像机、手机或相机），便于将信息的 复杂性表现出来。结合记录的物质、信息图表和音频文件, 设计师们可进行不同的 交互。将这些信息传到网上实现在线讨论也是可能的（例如：在线会议）。

\section{表4.7 miniDOC工具使用阶段}

\begin{tabular}{ll}
\hline 阶段 & 活动 \\
\hline 概念 & 听 \\
& 脚本 \\
& 故事板 \\
& 美学语言 \\
\hline 前期制作 & 历史和当代 \\
& 图像材料 \\
& 视频访谈 \\
\hline 制作 & 拍摄 \\
& 动画片 \\
\hline 后期制作 & 编辑 \\
& 合成 \\
\hline
\end{tabular}

结论

这是一套视听工具, 构建在叙事结构的基础上, 可以展现出研究领域的最新成果。

充分发挥视听故事的潜力, miniDOC能帮助利益相关方展开反思, 并使其成为 随后设计项目灵感的来源。 
工具可用性和所需资源

该工具的使用需要编辑合成软件（例如视频编辑软件Adobe Premiere、Final Cut或 其他；还有像After Effects一类的软件用于影片合成）。

良好的沟通和技术能力对于编辑和故事线索的构建都是十分重要的。

因此, 需要雇佣专门的通讯设计师, 主要负责在分析过程中应用可视化之外的 专业技能对收集到的信息进行转换。

构建miniDOC 所需的时间根据项目复杂程度不同而有所不同, 并且与产出质量 直接相关:

- 至少需要30天来完成一些基础性工作（符合要求的图像质量、编辑和故事线 索），这些可以由专人支配、通过一些工具来实现（例如：手机或免费编辑 软件等)。

- 需要40天或更长时间来获得良好的分析结果（良好的图像质量、编辑和故事 线索），这需要技术和讲故事的技能以及有计划的目标设置。

\subsubsection{4 表现系统概念的影音文件45}

目的

该系统概念可视化工具有助于刺激新创意的产生; 它使创意具体化, 从而促进设计 项目的开发。

该工具也如miniDOC一样有助于简化项目成果的生产过程, 并能对相应理念进 行可视化展示, 实现不同参与者之间的讨论。

尤其值得一提的是, 该工具使用的是短视频格式（通常3分钟左右）, 基于三幕 叙事结构:

- 第一部分显示背景环境

- 第二部分展望未来, 提出经典的设计问题 “假使...将会怎么样? ”

- 最后一部分提出可行性解决方案

目的是显示可能的概念, 并激发想象力以及不同参与者之间的对话。

系统概念影音材料是一种设计过程中会用到的有效工具, 可使相关概念在不同 的项目参与者之间实现分享。

将工具整合到可持续系统设计方法 (MSDS) 的设计过程中 在整个设计过程中, 系统概念影音材料将越来越详细。

45 系统概念影音通常被称为 “视听场景”：如需进一步信息, 参见Piredda 2008。 
- 当进行系统概念设计时, 系统概念影音材料可被用于:

- 将设计概念进行可视化表达, 有助于在不同的观点之间展开比较; 方便利 益相关方识别需求, 并与设计团队制定出共享的路径。

- 在沟通过程中, 系统概念影音材料可以被用于:

- 对设计理念进行可视化展示, 以便促进其交流与传播。使不同心理影像之 间建立连接, 共同参与到共享理念的构建中（参见图4.61）

\section{图4.61 系统概念影音材料如何与结果建立联系的例子}
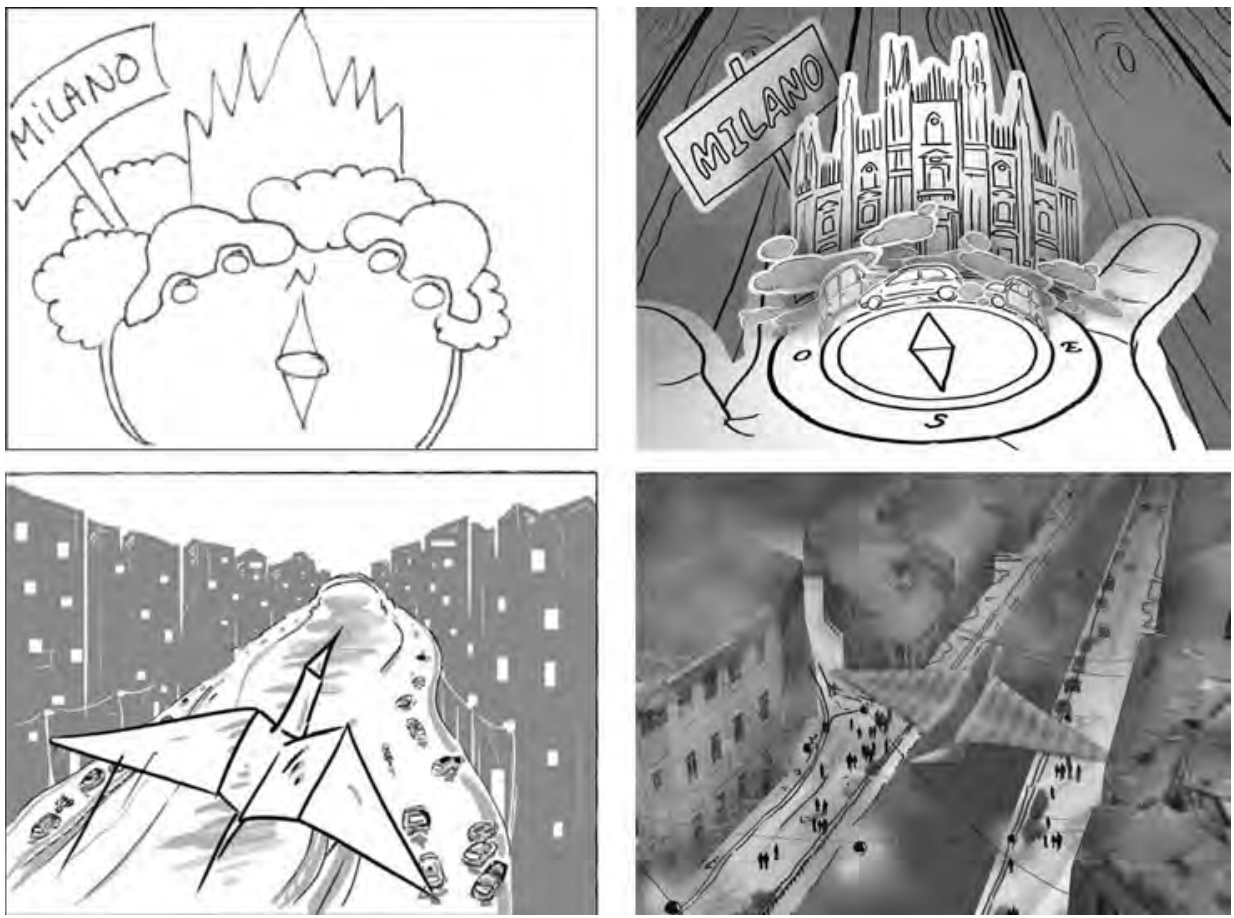

如何使用上述工具

为了实现最有效且最有创意的对话，建议设计师与设计团队的成员进行沟通以在下 列活动中展开协作:

- 倾听一将关键功能（优势和劣势）整合到叙事和审美集群中

- 脚本和故事板- - 故事线索和故事板的确定

- 可视化影音材料的制作 
在系统概念影音材料中, 利益相关方的主要职责是与设计团队合作确定他们的创 意: 通过其理念、知识和经验, 丰富图像的含义。

表4.8 系统概念影音材料工具使用阶段

\begin{tabular}{ll}
\hline 阶段 & 活动 \\
\hline 概念 & 听 \\
& 材料 \\
& 故事板 \\
& 美学语言 \\
\hline 前期制作 & 资料查找 (图像、 \\
& 照片、图画......) \\
\hline 制作 & 拍摄 \\
& 动画片 \\
\hline 后期制作 & 编辑 \\
& 合成 \\
\hline
\end{tabular}

结论

输出结果是视听文件, 可对设计过程中产生的创意进行可视化表达。因此, 传媒设 计能为将来提供认知和美学借鉴。

\section{所需工具和必备资源}

使用该工具需要具备良好的沟通能力、叙述故事的能力和专业技能。

在聆听阶段, 建议所有参与者都积极参加关键功能和创意的组织与整合工作。 在故事情节和故事板图片的创建过程中, 参与人员需具备良好的写作和绘图水

平，可直接在纸上作图或能够熟练使用照片处理软件。

在前期制作、制作和后期制作阶段，对编辑和合成技能都有较高要求。

由于可视化表达的复杂程度不同, 创建系统概念影音材料所需的时间也各有不 同。半成品即包含图像背景的草图和图纸，这种视听形式可以从时间和空间等不同 维度操控创意。因此, 它要求:

- 最少有 5 天的技术处理时间。此类系统概念影音材料对倾听的能力和叙述故事 的技巧有很高要求，专业技能关系到可视化审美素质。可应用先进技术对那 些使用新设备收集来的五花八门的材料进行整合、混搭。

- 制作该系统概念影音材料最少需要15天，对那些要求具有丰富图像文化和精 湛的专业技巧（例如表演或小说）的复杂创意和故事进行可视化表达。这种 类型的系统概念影音材料可用于系统概念设计的最终阶段和交流阶段。 


\subsubsection{5 动态脚本}

\section{目的}

动态脚本对共同设计过程提供支持。

它是一个以动画片形式呈现的交互故事板, 将图像、对话和声音编辑在一起。 设计团队可利用该视听工具对一系列过程的先后顺序进行详细的可视化表达, 以便 明确每一环节的行动时间。它可以在（静止）交互故事板的基础上或在其之后完成 创作，使相同的叙述变得更加生动。

事实上, 该工具是一个视听表达工具, 有助于:

- 对过程的详细顺序进行可视化表达

- 添加关于行动时间的信息

- 促进各参与者的集体对话

将工具整合到可持续系统设计方法 (MSDS) 的设计过程中

- 在发现机遇过程中, 动态脚本可以用于:

- 对一个新创意的不同阶段进行可视化表达使其通俗易懂, 并推进这一学习 过程。它是一个半成品, 以图解的方式展现了各个过程及其关系, 并能够 促进集体对话。

- 在系统概念设计过程中, 动态脚本可用于:

- 对概念进行初步描述, 从时间和空间的角度对行动顺序进行可视化表达。 设计团队可借助模拟过程搜集项目的各种观点（参见图4.62）。

\section{图4.62 运行中的动态脚本的例子, 带有对话和声音的简单视频拼接}

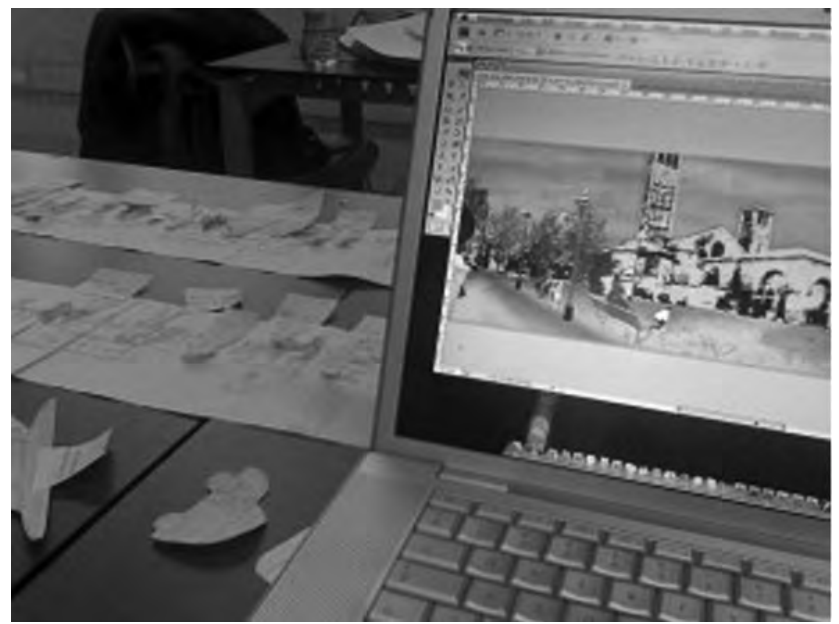


如何使用上述工具

动态脚本是一种内部交流和协同设计工具。这其实是视频的简单拼接，通过对来自 交互故事板的图画和图像进行线性编辑, 并将其与对话和声音合成在一起。建议使 用图形图像处理软件来制作图形要素。拟定故事情节，以便将收集到的材料进行整 合, 建议使用幻灯片软件（例如幻灯片(PowerPoint)软件, 或Open Office中的类似 产品）或者基本的编辑软件。

\section{表4.9 有声动画系列广告工具使用阶段}

\begin{tabular}{ll}
\hline 阶段 & 活动 \\
\hline 概念 & 材料 \\
& 故事板 \\
\hline 制作 & 资料查找 (图像、照 \\
& 片、图画......) \\
& 图像处理 \\
\hline 后期制作 & 线性 编辑 \\
\hline
\end{tabular}

结论

该工具是一个视听输出设备, 应用多种材料、多种设备。它超越一般的动画故事 板, 可将创意进行可视化表达, 促进利益相关方之间的对话和交流。在设计过程 中, 该动态脚本的功能将不断增加并逐渐细化, 其复杂程度逐渐能够达到与视听概 念材料工具相匹配的程度。

\section{所需工具和必备资源}

使用该工具需要具备良好的表格制作能力、叙述故事的技巧和专业技能。

创建动态脚本所需时间因可视化的复杂程度及叙述质量不同而各异。它大约需 要:

- 实现视频拼接的技术工作至少需要两天, 并通过交互故事板实现对图画 和图像的线性编辑, 并与对话和声音合成在一起（例如幻灯片或简单视 频）。该工具需要应用简单的表格制作技巧和基本的故事讲述技能，绘制图 片（素描、绘画或照片）。专业技能的高低关系到可视化美学效果的优劣。

\section{表4.10 使用有声动画系列广告制作的大体时间表}

\begin{tabular}{lll}
\hline 阶段 & 活动 & 时间 \\
\hline 概念 & 材料 & 一个简单的故事板需6小时完成 \\
& 故事板 & \\
\hline 制作 & $\begin{array}{l}\text { 资料查找（图像、照片、图画.......) } \\
\text { 录制对话和声音 }\end{array}$ & $\begin{array}{l}\text { 从故事板和其他材料中笁选图片需4个小时 } \\
\text { 录制对话和声音耗时5小时 }\end{array}$ \\
\hline 后期制作 & 线性 编辑 & 编辑收集好的材料需要8小时 \\
\hline
\end{tabular}


本书第二卷的相关章节将从一系列角度对产品服务系统进行探究：可持续产品 服务系统设计研究前沿。

\section{参考文献}

Andersen, M. (2006) 'System transition processes for realising sustainable consumption and production', Proceedings of Perspectives on Radical Changes to Sustainable Consumption and Production (SCP), Sustainable Consumption Research Exchange (SCORE!) Network (Copenhagen).

Appadurai, A. (1996) Modernity at Large: Cultural Dimensions of Globalization (Minneapolis: University of Minnesota Press).

Baden-Powell, B.H. (1957) The Indian Village Community (New Haven: HRAF Press).

Baines, T. S., H.W. Lightfoot, S. Evans, A. Neely, R. Greenough, J. Peppard, R. Roy, E. Shehab, A. Braganza, A. Tiwari, J.R. Alcock, J.P. Angus, M. Bastl, A. Cousens, P. Irving, M. Johnson, J. Kingston, H. Lockett, V. Martinez, P. Michele, D. Tranfield, I.M. Walton, H. Wilson (2007) State-of-the-art in product-service systems (Cranfield, UK: Innovative Manufacturing Research Centre, Cranfield University).

Bauman, Z. (2000) Liquid Modernity (Oxford: Polity Press Cambridge - Blackwell Publishers) (Italian translation 2002, Modernità liquida, Roma-Bari: Laterza).

Behrendt, S., C. Jasch, J. Kortman, G. Hrauda, R. Pfitzner, and D. Velte (2003) Eco-Service Development: Reinventing Supply and Demand in the European Union (Sheffield, UK: Greenleaf Publishing).

Bijma, A., M. Stuts and S. Silvester (2001) 'Developing Eco-efficient Product-Service Combinations', in Proceedings of the 6th International Conference 'Sustainable Services and Systems. Transition towards Sustainability?', The Surrey Institute of Art and Design, University College, Amsterdam, Netherlands, October 2001: 239- 245.

Bistagnino, L. (2009) Design sistemico. Progettare la sostenibilità produttiva e ambientale (Italy: Slow Food Publishing).

Brandstotter, M., Haberl, M., Knoth, R., Kopacek, B., and Kopacek, P. (2003) 'IT on demand towards an environmental conscious service system for Vienna (AT)', Third International Symposium on Environmentally Conscious Design and Inverse Manufacturing EcoDesign'03 (IEEE Cat. No.03EX895).

Brezet, H. and C. van Hemel (1997) Ecodesign: A promising approach to sustainable production and consumption (UNEP, Parigi).

Brezet, J.C., A.S. Bijma, J. Ehrenfeld and S. Silvester (2001) 'The Design of Eco-Efficient Services: Method, Tools and Review of the Case Study Based 'Designing Eco-Efficient Services" (Delft, the Netherlands: Dutch Ministries of Environment VROM \& Delft University of Technology).

Brown, R. (2010) Gandhi's Spinning Wheel and the Making of India (UK: Routledge).

Carniatto, V. and E. Chiara (2006) 'Design for a fair economy', in Proceedings of P\&D conference, Curitiba, Brazil.

Carniatto, V., F.V. Carneiro and D.M.P. Fernandes (2006) Design for sustainability: a model for design intervention in a Brazilian reality of local sustainable development, in Proceedings, international design conference, Dubrovnik, Croatia.

Castells, M. (1996, second edition, 2000) The Rise of the Network Society, The Information Age: Economy, Society and Culture Vol. I. (Cambridge, MA; Oxford, UK: Blackwell). 
Ceschin, F. (2006) Mobilità sostenibile per i trasporti leggeri. Progettazione di un sistema di prodotto-servizio per un quadri ciclo leggero a energia solare e muscolare. Master's degree thesis, Politecnico di Milano, Faculty of Design.

Ceschin, F. (2010) 'How to facilitate the implementation and diffusion of sustainable ProductService Systems? Looking for synergies between strategic design and innovation sciences' in Ceschin, F., Vezzoli, C. and Zhang, J. Sustainability in design: now! Challenges and opportunities for design research, education and practice in the XXI century. Proceedings of the Learning Network on Sustainability (LeNS) conference (vol. 1), Bangalore, India, 29 September - 1 October 2010 (Sheffield, UK: Greenleaf Publishing).

Ceschin, F., and C. Vezzoli (2007) 'Sustainable product-service systems development. Application and evaluation of the SDOS (Sustainability Design-orienting Scenario) methodology for the upstream waste reduction in the food and in the paper chains in the city of Brescia' in FHNW (School of Life Sciences - Institute for Ecopreneurship) 11th European Roundtable on Sustainable Consumption and Production (ERSCP 2007), Basel, Switzerland, 20-22 June 2007.

Ceschin, F., and C. Vezzoli (2010) 'The Role of Public Policy in Stimulating Radical Environmental Impact Reduction in the Automotive Sector: The Need to Focus on ProductService System Innovation', Int. J. Automotive Technology and Management 10.2/3: 321-341.

Charter, M. and U. Tischner (2001) Sustainable Solutions: Developing Products and Services for the Future (Sheffield, UK: Greenleaf Publishing).

Chiapponi, M. (1989) Ambiente: gestione e strategia. Un contributo alla teoria della progettazione ambientale (Feltrinelli, Milan).

Cooper, T. and E. Sian (2000) Products to Services (Friends of the Earth, Centre for Sustainable Consumption, Sheffield Hallam University).

Cortesi, S., C. Vezzoli and C. Donghi (2010) 'Case study of the design of Eco-Efficient ProductService-System for KONE Corporation, using the MSDS method and tools' in Ceschin, F., Vezzoli, C. and Zhang, J. (eds.) Sustainability in design: now! Challenges and opportunities for design research, education and practice in the XXI century. Proceedings of the Learning Network on Sustainability (LeNS) conference (vol. 2), Bangalore, India, 29 September - 1 October 2010 (Sheffield, UK: Greenleaf Publishing).

Crul, M. (2003) Ecodesign in Central America (Delft, the Netherlands: Delft University of Technology).

Crul, M. and J.C. Diehl (2006) Design for sustainability: A practical approach for developing economies (Paris: United Nations Environment Programme; TU Delft).

Crul, M. and J.C. Diehl (2008) 'Design for Sustainability (D4S): Manual and Tools for Developing Countries', in Proceedings, 7th Annual ASEE Global Colloquium on Engineering Education, Cape Town, South Africa, 19-23 October 2008.

Dahlberg, K. and A.M. Jansson (1998) 'Sustainable regional food supply: analysis of food consumption patterns, local production and external dependence from the perspective of wholesalers and retailers of food' in Dwyer, S., Ganslosser, U., and O'Conner, M. (eds.) Life Science Dimensions - Ecological Economics and Sustainable Use (Filander Verlag): 409-419.

Diehl, J.C. and J.C. Brezet (2003) 'Ecodesign methodology, tools and knowledge transfer', in Corte-Real, E., C.A.M. Duarte and F. Carvalho Rodrigues (eds.) Senses and sensibility in technology: linking tradition to innovation through design (Lisbon: Instituto de Artes Visuais Design e Marketing).

Eames, C. and R. Eames (1958) The India Report (Ahmedabad: NID).

Ehrenfeld, J.R. (2008) Sustainability by Design: A Subversive Strategy for Transforming Our Consumer Culture (Yale University Press).

EMUDE (2006) Emerging User Demands for Sustainable Solutions final report, 6th Framework Programme (priority 3-NMP), European Community. 
EU (2003) Directive 2005/32/CE, establishing a framework for the setting of ecodesign requirements for energy-using products and amending Council Directive 92/42/EEC and Directives 96/57/EC and 2000/55/EC of the European Parliament and of the Council, Official Journal of the European Union.

EU (2006) Renewed Sustainable Development Strategy, Council of the European Union. No. 10117/06, Brussels.

EU (2009) 2009 Review of the European Union Strategy for Sustainable Development, Brussels.

FAO, WFP and IFAD (2012) The State of Food Insecurity in the World 2012: Economic growth is necessary but not sufficient to accelerate reduction of hunger and malnutrition (Rome: Food and Agriculture Organization of the United Nations). Flavin, C., and Gardner G. (2006) State of the World 2006: China and India Hold World in Balance (Washington, DC: Worldwatch Institute).

Florida, R. (2002) The Rise of the Creative Class and How It is Transforming Work, Leisure, Community and Everyday Life (New York: Basic Books).

Fusakul, S.M. and P. Siridej (2010) 'DSEP: implementation of Sufficiency Economy Philosophy in design' in Ceschin, F., Vezzoli, C. and Zhang, J. (eds.) Sustainability in design: now! Challenges and opportunities for design research, education and practice in the XXI century. Proceedings of the Learning Network on Sustainability (LeNS) conference (vol. 1). Bangalore, India, 29 September - 1 October 2010 (Sheffield, UK: Greenleaf Publishing).

Gadgil, M. (1985a) 'Social Restraints on Resource Utilization: The Indian Experience', in J.A. McNeely and D. Pitt (eds.) Culture and Conservation: The Human Dimension in Environmental Planning (Dublin: Croom Helm).

Gadgil, M. (1985b) 'Cultural Evolution of Ecological Prudence'. Landscape Planning 12: 285-99.

Geels, F. (2002) Understanding the dynamics of technological transitions: a co-evolutionary and socio-technical analysis, The Netherlands: Phd University Twente (Enschede).

Geels, F.W. (2004) 'From sectoral systems of innovation to socio-technical systems: Insights about dynamics and change from sociology and institutional theory', Research Policy 33.6/7: 897-920.

Geyer-Allely, E. (2002) 'Sustainable consumption: an insurmountable challenge', in Industry and Environment Review (UNEP).

Gandhi, M. (1932) From Yeravada Mandir: Ashram Observances (V. G. Desai, Trans.) (Ahmedabad: Navjivan Publishing House).

Gandhi, M. (1960a) Bread Labour (The Gospel of Work) (Ahmedabad: Navjivan Publishing House).

Gandhi, M. (1960b) Trusteeship (Compilation by Ranindra Kalekar) (Ahmedabad: Navjivan Publishing House).

Gandhi, M. (2009) Essence of Hinduism (English Paperback edition) (Ahmedabad: Navjivan Publishing House).

Giudice, F., G. La Rosa and A. Risitano (2006) Product Design for the Environment. A Life Cycle Approach (USA: CRC Press, Taylor and Francis Group).

Goedkoop, M., C. van Halen, H. te Riele and P. Rommes (1999) Product Service Systems, Ecological and Economic Basics, report 1999/36 (the Hague: VROM).

Granovetter, M. (1985) 'Economic Action and Social Structure: The Problem of Embeddedness', American Journal of Sociology 91(3): 481-510.

GRI (2006) G3 Sustainability Reporting Guidelines, Global Reporting Initiative

Guadagnucci, L. and F. Gavelli (2004) La crisi di crescita. Le prospettive del commercio equo e solidale (Milan: Feltrinelli).

Guanzhong, L. (2006) Science of human affairs (Changsha, China: Central South University Press). 
Guanzhong, L. (2009) "Urgent need to re-understand the "origin" and "primacy": reflection from industry chain' (Beijing, China: Yishubaijia).

Hart, S.L. and M.B. Milstein (1999) 'Global sustainability and the creative destruction of industries', Sloan Management Review 41.1: 23-33.

Heiskanen, E. (2002) 'The institutional logic of life cycle thinking', Journal of Cleaner Production 10(5).

Hemel, C.G. van (2001) 'Design for environment in practice: three Dutch industrial approaches compared', in 4th NTVA industrial ecology seminar and workshop: industrial ecology methodology and practical challenges in industry.

Henderson, R.M. and K.B. Clark (1990) 'Architectural Innovation: The Reconfiguration of Existing Product Technologies and the Failure of Established Firms', Administrative Science Quarterly 35.1: 9-30.

Hockerts, K. (1998) 'Eco-Efficient Service Innovation: Increasing Business-Ecological Efficiency of Products and Services', in M. Charter (ed.) Greener Marketing: A Global Perspective on Greener Marketing Practice (Sheffield, UK: Greenleaf Publishing): 95-108.

ISO 14062 (2002) Environmental Management - Integrating Environmental Aspects into Product Design and Development, ISO/TR 14062:2002(E) (ISO, Geneva).

James, P., and P. Hopkinson (2002) Service innovation for sustainability. A new option for UK environmental policy? (Bradford: Bradford University).

Jégou, F., Manzini, E., and Meroni, A. (2004) 'Design plan. A design toolbox to facilitate solution oriented partnerships' in Manzini, E., Collina, L., and Evans, S. (eds.) Solution oriented partnership (Cranfield: Cranfield University).

Jenkins, P. (2000) Mystics and Messiahs: Cults and New Religions in American History (Oxford: Oxford University Press).

Johansson, A., Kisch, P. and M. Mirata (2005) 'Distributed economies: A new engine for innovation', Journal of Cleaner Production 13: 971-979.

Joore P. (2006) 'Guide Me: Translating a broad societal need into a concrete product service solution', Proceedings, Perspectives on Radical Changes to Sustainable Consumption and Production (SCP), Sustainable Consumption Research Exchange (SCORE!) Network, Copenhagen.

Kandachar, P. (2010) 'Designing for global sustainable solutions: challenges and opportunities' in Ceschin, F., Vezzoli, C. and Zhang, J. (eds.) Sustainability in design: now! Challenges and opportunities for design research, education and practice in the XXI century. Proceedings of the Learning Network on Sustainability (LeNS) conference (vol. 1). Bangalore, India, 29 September - 1 October 2010. (Sheffield, UK: Greenleaf Publishing).

Karlsson, R. and C. Luttrop (2006) 'EcoDesign: what is happening? An overview of the subject area of Eco Design', Journal of Cleaner Production 14 (15-16).

Keoleian, G.A. and D. Menerey (1993) Life Cycle Design Guidance Manual: Environmental requirements and the product system (USA: EPA).

Kohtala, C. and Vezzoli, C. (eds.) (2010) A World of Sustainable Ideas, LeNS Award Catalogue [Online], Available at http://www.lens.polimi.it.

Leach, E.R. (1960) 'Introduction: What Should We Mean by Caste?' In E. R. Leach (ed.) Aspects of Caste in South India, Ceylon and North West Pakistan (Cambridge: Cambridge University Press).

Leong, B. (2006) 'Is a Radical Systemic Shift toward Sustainability possible in China?', in Proceedings, Perspectives on Radical Changes to Sustainable Consumption and Production (SCP), Sustainable Consumption Research Exchange (SCORE!) Network, Copenhagen.

Lindhqvist, T. (2000) Extended Producer Responsibility in Cleaner Production, Doctoral dissertation, IIIEE Lund University, Lund. 
Maase, S. and K. Dorst (2006) 'Co-creation: A way to reach sustainable social innovation?', in Proceedings, Perspectives on Radical Changes to Sustainable Consumption and Production (SCP), Sustainable Consumption Research Exchange (SCORE!) Network, Copenhagen.

Maldonado, T. (1970) La speranza progettuale. Ambiente e società (Turin: Einaudi).

Mance, E. (2001) A revolução das redes. A colaboracão solidária como una alternativa póscapitalista à globalização atual (Petrópolis: II ed., Editora Vozes).

Manzini, E. and F. Jégou (2003) Sustainable Everyday: Scenarios of Urban Life (Milan: Edizioni Ambiente).

Manzini, E. and C. Vezzoli (1998) Lo sviluppo di prodotti sostenibili (Rimini: Maggioli editore).

Manzini, E. and C. Vezzoli (2001) 'Strategic design for sustainability', in TSPD proceedings, Amsterdam.

Manzini, E., C. Vezzoli and G. Clark (2001) 'Product-Service Systems: Using an Existing Concept as a New Approach to Sustainability', Journal of Design Research 1.

Manzini, E., L. Collina and S. Evans (eds.) (2004) Solution oriented partnership (Cranfield: Cranfield University).

Marchand, A. and S. Walker (2006) 'Designing alternatives', Proceedings, Perspectives on Radical Changes to Sustainable Consumption and Production (SCP), Sustainable Consumption Research Exchange (SCORE!) Network, Copenhagen.

Margolin, V. (2002) The Politics of the Artificial (Chicago: University of Chicago Press).

Marks, N., S. Abdallah, A. Simms and S. Thompson (2006) The (Un)Happy Planet: An Index of Human Well-Being and Environmental Impact (London, UK: New Economics Foundation and Friends of the Earth).

Meadows, D., D. Meadows and J. Randers (2006) Limits to Growth: The 30-year update (Chelsea Green, White River Junction, VT).

Meier, H., R. Roy, and G. Seliger (2010) Industrial Product-Service Systems - IPS2, Manufacturing Technology Journal.

Meroni, A. (ed.) (2007) Creative Communities: People Inventing Sustainable Ways of Living (Milan: Edizioni Polidesign).

Mont, O. (2002) Functional thinking: The role of functional sales and product service systems for a functional based society, research report for the Swedish EPA (Lund, Sweden: IIIEE Lund University).

Mont, O. (2004) Product-service systems: Panacea or myth? PhD Dissertation. IIIEE, University of Lund, Sweden.

Mont, O., and T. Lindhqvist (2003) 'The Role of Public Policy in Advancement of Product Service Systems', Journal of Cleaner Production 11.8: 905-914.

Mont, O. and Plepys, A. (2004) 'From ownership to service-based lifestyle: the case of joint use of power tools', The Society for Non-Traditional Technology (Japan: Tokyo).

Morelli, N. (2006a) 'Developing new product service systems (PSS): methodologies and operational tools', Journal of Cleaner Production, 14.

Morelli, N. (2006b) 'New representation techniques for designing in a systemic perspective' paper presented at the 'Engineering and product design education' conference, Salzburg University of Applied Sciences, Salzburg, Austria, 7-8 September 2006.

Nes, van N. and J. Cramer (2006) 'Product life time optimization: a challenging strategy towards more sustainable consumption patterns', Journal of Cleaner Production 14 (15-16).

Papanek, V. (1971) Design for the Real World (published in Italy by Arnaldo Mondatori Editore, Milan).

Penin, L. (2006) Strategic design for social sustainability in emerging contexts, PhD thesis, Politecnico di Milano, Milan.

Piredda (2008) 'Design e comunicazione delle pratiche sociali tra cinema, televisione e Web', Convergências 2. Retrieved from http://convergencias.esart.ipcb.pt/artigo/23. 
Porter, M.E. and M.R. Kramer (2006) 'Strategy and Society: The Link Between Competitive Advantage and Corporate Social Responsibility', Harvard Business Review, December.

Prasad, S. (2010) Farm Innovators (Delhi: ICAR).

Rana, N. (2010, October 28 Thursday) 'Trusteeship, Gandhi and Business in the 21st Century'. Retrieved from 'Living Principle' blog <http://www.livingprinciples.org/trustee ship-gandhi-and-business-in-the-21st-century>.

Razeto, L. (2002) Las empresas alternativas (Montevideo, Uruguay: Nordam).

Rifkin, J. (2000) The Age of Access: How to shift from ownership to access in transforming capitalism (London: Penguin Books).

Rifkin, J. (2002) The Hydrogen Economy: The creation of the worldwide energy web and the redistribution of power on earth (Los Angeles: Jeremy P. Tarcher).

Rifkin, J. (2010) The Empathic Civilization: The Race to Global Consciousness in a World in Crisis (New York: Jeremy P. Tarcher).

Rifkin, J. (2011) The Third Industrial Revolution (New York: Jeremy P. Tarcher).

Rip, A., and R. Kemp (1998) 'Technological Change', in S. Rayner and E.L. Malone (eds.) Human Choice and Climate Change, Vol. 2 (Columbus: Batelle Press): 327-399.

Rocchi S. (2005) Enhancing Sustainable Innovation by Design: An Approach to the Co-creation of Economic, Social and Environmental Value, Doctoral Dissertation (Erasmus University, Rotterdam).

Rocha C., Frazao R., Zackrisson M., Christianseb K. (2006) 'The use of communication tools and policy instruments to facilitate changes towards sustainability', Proceedings, Perspectives on Radical Changes to Sustainable Consumption and Production (SCP), Sustainable Consumption Research Exchange (SCORE!) Network, Copenhagen.

Ryan, C. (2003) 'Learning from a Decade (or So) of Eco-Design Experience' (part one), Journal of Industrial Ecology 7 (2).

Ryan, C. (2004) Digital Eco-Sense: Sustainability and ICT - a New Terrain for Innovation, (Melbourne: Lab 3000).

Sachs, W. and T. Santarius (2007) Per Un futuro Equo. Conflitti sulle risorse e giustizia globale. Un rapport del Wuppertal Institut (Milan: Feltrinelli).

Sachs, W., H. Acselrad, F. Akhter, A. Amon, T.B.G. Egziabher, H. French, P. Haavisto, P. Hawken, H. Henderson, A. Khosla, S. Larrain, R. Loske, A. Roddick, V. Taylor, C. von Weizsäcker, S. Zabelin (2002) The Jo'burg-Memo: Fairness in a Fragile World, Memorandum for the World Summit on Sustainable Development (Berlin: Heinrich Böll Foundation).

SAI, Social Accountability 8000, http://www.sa8000.info/sa8000doc/2001StdEnglish.pdf

Sangiorgi, D. (2005) Interaction story board, in van Halen, C., Vezzoli C., Wimmer R. (eds.), Methodology for Product Service System Innovation: How to develop clean, clever and competitive strategies in companies (Assen: Van Gorcum).

Santos dos, A. (2008) 'Strategies of Change Towards Sustainability: The South American Experience', in Cipolla, C. and Peruccio, P.P. (eds.) Changing the Change: Design, visions, proposals and tools Conference Proceedings, Turin, Italy, 10-12 July 2008 (Torino: Umberto Allemandi \& C.).

Santos dos, A., A. Krämer and C. Vezzoli (2009) 'Design Brings Innovation to the Base of the Pyramid', Design Management Institute Review 20(2).

Scholl, G. (2006) 'Product Service Systems', in Proceedings, Perspectives on Radical Changes to Sustainable Consumption and Production (SCP), Sustainable Consumption Research Exchange (SCORE!) Network, Copenhagen.

Sen, A. (1999) Development as freedom (Oxford: Oxford University Press).

Sheri, L. (2010) Look Around: Chats with Chinese and Foreign Philosophizers about Green Prescriptions (Beijing, China: Sunchime Film Library Audiovisual Press). 
Soumitri, V. and C. Vezzoli (2002) 'Product Service System Design: Sustainable opportunities for all. A design research working hypothesis. Clothing care System for Kumaon Hostel at IIT Delhi', in Proceedings, Ecodesign international conference, New Delhi.

Stahel, R.W. (1997) 'The Functional Economy: Cultural Change and Organizational Change', in Richards, D.J. The Industrial Green Game (Washington: National Academic Press).

Stahel, W. (2001) 'Sustainability and Services', in Charter, M. and U. Tischner (eds.) Sustainable Solutions - Developing products and services for the future (Sheffield, UK: Greenleaf Publishing).

Stiglitz J. (2002) Globalization and its discontents (USA: W.W. Norton \& Company).

Stoughton, M., Shapiro, K., Feng, L., and E. Reiskin (1998) The business case for EPR: a feasibility study for developing a decision-support tool (Boston, USA: Tellus Institute).

Sun, J., B. Han, S. Ekwaro-Osire, and H.-C. Zhang (2003) 'Design for Environment: Methodologies, tools, and implementation', Journal of Integrated Design and Process Science 7(1).

Tamborrini P. (2005) L'impegno dell'ecodesign per una società sostenibile, conference proceedings Formazione sviluppo sostenibile e Design, Politecnico di Milano.

Tischner, U. (2010) 'Design for Sustainability: where are we and where do we need to go?' in Ceschin, F., Vezzoli, C. and Zhang, J. (eds.) Sustainability in design: now! Challenges and opportunities for design research, education and practice in the XXI century. Proceedings of the Learning Network on Sustainability (LeNS) conference (vol. 1). Bangalore, India, 29 September - 1 October 2010 (Sheffield, UK: Greenleaf Publishing).

Tischner, U. and M. Verkuijl (2006) 'Design for (social) sustainability and radical change', in Proceedings, Perspectives on Radical Changes to Sustainable Consumption and Production (SCP), Sustainable Consumption Research Exchange (SCORE!) Network, Copenhagen.

Tischner, U. and C. Vezzoli (2009) 'Product-Service Systems: Tools and Cases', in M. Crul and J.C. Diehl (eds.) Design for Sustainability (D4S): A Step-By-Step Approach (United Nations Environment Programme UNEP).

Tischner, U., E. Schmincke and F. Rubik (2000) Was ist EcoDesign (Basel: Birkhauser Verlag).

Tischner, U., Ryan C., Vezzoli, C. (2009) Product- Service Systems. In Design for Sustainability a global guide. Modules. Crul M., Diehl J. C. (eds.), United Nations Environment Program (UNEP).

Tukker, A. and P. Eder (2000) Eco-design: European state of the art, ECSC-EEC-EAEC, Brussels.

Tukker, A. and U. Tischner (eds.) (2006) New Business for Old Europe: Product Services, Sustainability and Competitiveness (Sheffield, UK: Greenleaf Publishing).

Tukker, A., E. Stø and C. Vezzoli (eds.) (2008a) Journal of Cleaner Production, Special issue $16(11)$.

Tukker, A., M. Charter, E. Stø, M.M. Andersen and C. Vezzoli (eds.) (2008b) System Innovation for Sustainability 1. Perspectives on Radical Changes to Sustainable Consumption and Production (Sheffield, UK: Greenleaf Publishing).

UN (1992) Report of the United Nations conference on environment and development, Rio de Janeiro, 3-14 June 1992, Annex I, Rio declaration on environment and development (Rio de Janeiro: UN General Assembly).

UN (2000) 55/2. United Nations Millennium Declaration, at http://www.un.org/millennium/ declaration/ares552e.htm.

UN (2002) World summit on sustainable development: Draft political declaration, submitted by the president of the summit, Johannesburg.

UNEP (2000) Achieving Sustainable Consumption Patterns: The Role of the Industry (Paris: United Nations Environment Programme IE/IAC). 
UNEP (2002) Product-Service Systems and Sustainability: Opportunities for Sustainable Solutions (Paris: United Nations Environment Programme, Division of Technology Industry and Economics, Production and Consumption Branch).

UNEP (2009) Design for sustainability. A step-by-step approach (Paris, France: UNEP).

UNFPA (2006) State Of World Population 2006, United Nations Population Fund, Thoraya Ahmed Obaid, Executive Director.

van Halen, C., Vezzoli, C., and Wimmer, R. (eds.) (2005) Methodology for Product Service System. How to develop clean, clever and competitive strategies in companies (Assen, Netherlands: Van Gorcum).

Vergragt, P.J. (2002) Strategies towards the Sustainable Household. Final report (Delft: TBM, Delft University of Technology).

Vezzoli, C. (2003a) Systemic design for sustainability, in Proceedings, Cumulus working paper, UIAH, Helsinki.

Vezzoli, C. (2003b) 'A new generation of designer: perspective for education and training in the field of sustainable design. Experiences and projects at the Politecnico di Milano University', Journal of Cleaner Production 11: 1-9.

Vezzoli C. (2010) System design for sustainability: Theory, methods and tools for a sustainable 'satisfaction-system' design, 2nd edn (Milan, IT: Maggioli editore).

Vezzoli, C. (2011) 'System Design for Sustainability: The new research frontiers', In Z. Haoming, P. Korvenmaa and L. Xin (eds.) Tao of Sustainability: Strategies in a globalisation context, Proceedings, Academy of Arts and Design, Tsinghua University, Beijing, 27-29 October, 2011.

Vezzoli, C. and F. Ceschin (2009) 'Sustainable Scenarios for Upstream Waste Reduction in the Food Chain', in Hülsen and Ohnesorge Food Science Research and Technology (New York: Nova Publishers).

Vezzoli, C. and E. Manzini (2006) 'Design for sustainable consumption', in Proceedings, Perspectives on Radical Changes to Sustainable Consumption and Production (SCP), Sustainable Consumption Research Exchange (SCORE!) Network, Copenhagen.

Vezzoli, C. and E. Manzini (2008a) Design for Environmental Sustainability (London: Springer).

Vezzoli C. and E. Manzini (2008b) 'Review: design for sustainable consumption and production systems', in Tukker, A., Charter, M., Stø, E., Andersen, M.M. and C. Vezzoli (ed.) System Innovation for Sustainability 1. Perspectives on Radical Changes to Sustainable Consumption and Production (Sheffield, UK: Greenleaf Publishing).

Vezzoli, C. and D. Sciama (2006) 'Life Cycle Design: from general methods to product type specific guidelines and checklists: a method adopted to develop a set of guidelines/ checklist handbook for the eco-efficient design of NECTA vending machines' Journal of Cleaner Production 14 (15-16).

Vezzoli C., E. Manzini and G. Clark (2001) 'Product-Service Systems: Using an Existing Concept as a New Approach to Sustainability', Journal of Design Research 1.

Vezzoli, C., L. Orbetegli and F. Ceschin (2006) 'Meno rifiuti altri modi di fare. Scenari (SDOS) di riduzione a monte dei rifiuti' Research report for the project 'Less waste: other ways of doing!', Politecnico di Milano.

Vezzoli C., F. Ceschin and R. Kemp (2008) 'Designing transition paths for the diffusion of sustainable system innovations. A new potential role for design in transition management?' In C. Cipolla and P.P. Peruccio (eds.) Proceedings, Changing the Change: Design, visions, proposals and tools (Turin: Umberto Allemandi and C.).

Vezzoli, C., F. Ceschin and S. Cortesi (2009a) Metodi e strumenti per il Life Cycle Design. Come progettare prodotti a basso impatto ambientale (Rimini: Maggioli Editore).

Vezzoli, C., F. Ceschin and M. M'Rithaa (2009b) 'LeNS Africa: An African Learning Network on Sustainability for the development and diffusion of teaching materials and tools on Design for Sustainability in an open-source and copyleft ethos', 4th International Conference on Life Cycle Management, Cape Town, South Africa.

von Hippel, E. (2005) Democratizing Innovation (Cambridge, MA: MIT Press). 
WBCSD, Doing business with the poor. A field guide, World Business Council for Sustainable Development www.wbcsd.org/web/development.htm.

WBCSD (World Business Council for Sustainable Development) (1996) Eco-efficient Leadership for Improved Economic and Environmental Performance (Geneva: WBCSD).

Weidema, B.P. (2005) 'The integration of economic and social aspects in Life Cycle Impact Assessment', paper 2.-0 LCA consultants, Copenhagen, Denmark.

White, A.L., M. Stoughton and L. Feng (1999) Servicizing: The Quiet Transition to Extended Product Responsibility (Boston, USA: Tellus Institute).

Wong, M. (2004) Implementation of innovative product service-systems in the consumer goods industry. PhD Thesis, Cambridge University.

Xin, L. (2010) 'Current Situation and Practice of Design for Sustainability in China', in F. Ceschin, C. Vezzoli and J. Zhang (eds.) Sustainability in design: now! Challenges and opportunities for design research, education and practice in the XXI century. Proceedings of the Learning Network on Sustainability (LeNS) conference. Bangalore, India, 29 September - 1 October 2010 (Sheffield, UK: Greenleaf Publishing): 540-549.

Xin, L. and L. Jikun (2011) 'Possible Opportunity: the concept and practice of product service system design', Proceedings of the Dao of Sustainability Conference, Beijing, China (Wuhan, China: Huazhong University of Science \& Technology Press Co.): 27-30.

Zaring, O. (2001) Creating Eco-Efficient Producer Services (Goteborg: Goteborg Research Institute).

Zupi, M. (ed.) (2004) La globalizzazione vista dal sud del mondo (Rome: Laterza). 


\section{附录1 生态高效型系统的设计标准和指导方针}

此附录中, 重点阐述了上述章节中确定的6项环保标准, 以及具体的指导方针, 旨在 引导以生态效益型系统方案为导向的创意（例如：以可持续设计为导向 (SDO) 工 具软件中的创意表）。上述指导方针旨在对创意过程提供支持，其目的并非是实现 产品的渐进式改进, 而是从系统层面促进潜在的创新, 此类创新是就环境、社会伦 理和经济域来讲的重大改革。从这个角度来说, 该指导方针的主要关注点为系统层 面的创意, 也就是说，观念应该涉及：1）构成提供物的产品与服务；2）提供生产 与服务的参与者的构成。

\section{系统生命周期优化}

- 完善产品和基础设施, 对其提供维护、维修和更换服务

- 完善产品和基础设施, 提供技术升级服务

- 完善现有产品和基础设施, 提供能推进/促进美学和文化价值的升级服务

- 完善产品和基础设施, 提升其重新配置的能力（新地区的应用）

- 为产品或基础设施提供共享服务

- 为产品的共享/再利用/二手销售提供服务平台

\section{削减运输或分销量}

- 利用数字基础设施进行信息的传输/获取

- 寻找新的合作伙伴, 实现远距离合作（使用、维护和维修）

- 寻找新的合作伙伴, 优化并合理利用当地资源（信息、数据传输）

- 寻找新的合作伙伴, 实现现场生产（信息、数据传输）

- 对产品/基础设施交付进行整合，并提供现场装配服务

- 寻找新的合作伙伴, 降低产品或半成品运费和包装成本

- 整合产品/半成品输服务, 优化分销方案

- 鼓励客户对包装进行再利用, 并减少运输环节

- 为产品的维护/维修提供远程控制服务 


\section{资源节约}

- 利用配套服务, 优化能源/材料/半成品的使用

- 通过基于满意度单元的付费, 获取产品和基础设施（应用支持平台）

- 在一定时期内支付年费，获取产品和基础设施（应用支持平台）

- 基于满意单元进行收费, 为客户/最终用户提供全方位服务（最终结果）

- 提供资源节约型技术和方案, 更新现有设备, 用节约下来的资金进行投资

- 实现产品和基础设施的集体使用

- 当产品/基础设施的技术效率和专业化程度都得以提升时, 可采用外包方式

- 寻找新的合作伙伴, 对现有产品或基础设施进行利用/整合

- 当达到一定经济规模时, 可采取外包方式

- 为实现资源优化, 将适应性设计融入产品/基础设施中

- 通过设计服务, 使产品/基础设施在使用过程中能够适合各种资源要求。利用 适应性服务, 达到产品/基础设施的资源使用标准

- 提供可用的产品/半成品

- 根据预先制定的需求进行产品/半成品的生产

\section{将浪费降到最低/提高利用率}

- 利用回收性服务, 实现产品/基础设施的再利用与再加工

- 利用回收性服务, 实现产品/基础设施的循环使用

- 利用回收性服务改进产品/基础设施, 实现能源节约

- 增设产品召回服务, 制成堆肥

- 寻找本地盟友/合作伙伴, 利用共生/级联法, 实现资源的二次利用

\section{节约/生物相容性}

- 寻找合作伙伴, 实现化整为零的/可再生能源的利用

- 寻找合作伙伴, 推广当地可再生、可降解材料和产品的使用 
164 可持续产品服务系统设计

- 推广被动式能源资源在基础设施和产品功能中的使用

- 寻找合作伙伴, 促进当地可回收材料的使用

\section{毒性削减}

- 与其他生产商合作, 实现有毒有害物质的回收再利用

- 通过提供服务, 实现产品/基础设施/半成品在使用过程中有毒有害物质的最小 化排放

- 销售有毒有害物质须附带终极处理方案

- 以满意单元收费的方式, 为客户/最终用户提供有毒物质管理服务 


\section{附录2 社会公平和凝聚力设计标准和指导方针}

与附录 1 类似, 本附录重点强调了上述章节中确定的 6 项环保标准, 以及具体的指导 方针, 旨在引导以生态效益型系统方案为向导的创意（例如：以可持续设计为导向 (SDO) 工具软件中的创意表)。

\section{改善雇用条件或工作环境}

- 改善工作条件

- 避免/杜绝强制劳动和雇佣童工情况的出现

- 避免/杜绝工作过程中各种形式的歧视

- 保证员工的结社自由和享有集体协商的权利

- 采用相应的工具和标准对公司进行社会伦理责任认证

- 加强职业卫生安全工作的管理

一 提升员工健康水平, 确保安全生产

- 采用相应的工具和标准对公司进行社会伦理责任认证

- 保证工作时间充足以及薪酬公平

- 保证薪酬的公平和工作时间的充足（在整个价值链中）

- 保证足够的工作小时数

- 提升员工的满意度、积极性和参与度

- 根据员工的工作能力, 提供合适的工作岗位

- 保证员工有机会得到长期培养和培训

- 切勿忽视创造性工作

- 保证员工/雇员有参与决策的权利

- 营造良好的工作氛围, 重视员工的创造性提议

- 在整个价值链中, 与同事共同努力营造良好的工作环境 


\section{改善与利益相关方有关的公平公正问题}

- 推进平等和公平的合伙关系

- 支持合伙人参与到开发中来, 并为创意环境提供支持

- 支持合伙人参加社会活动

- 参加那些宣传社会平等的组织

- 鼓励合伙人之间相互学习、互通有无

- 向合伙人推广社会道德责任认证的标准和工具的定义或应用

- 为利益相关方提供充分的信息流

- 提高利益相关方的生产能力

- 促进供应商、分包商和次级供应商之间的公平和公正关系

- 加入公平交易活动系统/开展援助活动

- 在新兴市场促进合作项目

- 考虑利益相关方的预期和潜能, 为供应商和分包商提供他们所需或感兴趣 的信息

- 鼓励供应商、分包商和次级供应商参与到设计（决策）过程中

- 促进/要求参与到价值链中的其它企业确保工作条件符合要求

- 促进/要求参与到价值链中的其它企业保障相关人员的健康与安全

- 促进/要求供应商、分包商和次级供应商实施社会认证系统

- 为企业的社会伦理认证提供标准和工具

- 促进并提高与客户和终端用户之间的平等关系

- 向客户/终端用户提供能够保证其人员健康与安全的产品和服务

- 改进系统, 改善健康与安全条件, 减少歧视和边缘化现象

- 保障产品和服务工作的健康与安全

- 制定并采纳与终端用户相关的社会伦理责任的认证标准与工具

- 促进并提高社区（提供产品与服务所在社区）的公平与公正关系

- 验证提供物（产品或服务）不存在任何反弹效应

- 促进并提高普通商品的质量和可获得性

- 促进与当地机构/代理的平等公正关系

- 通过所提供的系统支持民主制度（例如：在发展中国家） 


\section{促进负责任/可持续性消费的发展}

- 增强透明度, 并鼓励所有利益相关方对社会发展的可持续性做出贡献

- 制定并实施标准, 以便提高供应过程的透明度, 强调社会发展的可持续性

- 为客户和终端用户提供信息或学习体验, 帮助他们提高社会责任感和可持续 发展的意识

- 开发那些能够促进客户/终端用户的社会责任感/参与社会可持续发展的产品或 服务

- 在生产/实施/定制化过程中, 开发那些能够促进客户/终端用户的社会责任感/ 参与社会可持续发展的产品或服务

- 鼓励客户/终端用户参与到他们自身产品服务系统的生产/实施/定制化过程, 促进产品服务系统向社会责任感和可持续方向发展

\section{重视/兼顾弱势和边缘群体的利益}

- 改善社会弱势群体的条件, 鼓励他们融入到系统中来

- 改善边缘化群体的条件, 鼓励他们融入到系统中来

- 改善边缘化群体 (例如失业者) 的状况, 为他们提供良好的、能够提高他 们能力的工作机会

- 鼓励外国人参与到社会活动与事务中

- 开发一个使所有社会阶层均能够获得产品与服务的系统

- 为低收入人群开发免费或低成本的产品或服务

一 提供多元化的产品和服务, 既满足高端客户同时又满足低端客户的需求

- 开发共享使用系统或产品服务交换系统，以增强其可获得性

- 开发经济财产共享系统

- 开发能够促进平等劳务服务的系统

- 开发一些关于产品共享并能够降低成本的系统（例如合作系统）

- 制定一些使（企业）容易获得信用的系统 


\section{提高社会凝聚力}

- 构建促进社区邻里相互融合的系统

- 促进社区大众产品共享和维护系统的构建

- 鼓励能够实现邻里互惠的协同设计系统的构建

- 促进住房共享系统的构建

- 促进联合办公系统的构建

- 促进有助于代际之间社会融合系统的构建

- 促进能使不同性别之间相互融合系统的构建

- 促进能够使不同文化之间社会融合系统的构建

\section{改善当地资源}

- 尊重/改善特有的当地文化特色

- 尊重各种文化并鼓励文化发展多元化

- 鼓励不同品味和审美倾向

- 制定能够刺激并促进当地经济发展的系统

- 加强当地经济在当地创造服务过程中的作用

- 鼓励能够增强当地经济活力的开发活动, 开展协作生产, 促进改善当地和 外部经济环境

- 工艺品改进和再利用

- 废弃工艺品（例如：让弱势参与）的翻新和再利用

- 工业、家庭和城市弃用产品和材料的翻新和再利用

- 适应/改进使用再生资源和当地资源的系统

- 促进当地网络化企业的发展

- 改进/依靠分布式的可再生能源生产网络

- 改进/依靠人群协作网络（开放式和点对点式）

- 改进/依靠工艺品协作网络（开放式和点对点式） 


\section{第2卷}

\section{可持续产品服务系统设计前沿}

( 


$$
\text { 第一篇 }
$$
提升满意度和完成转型的新方法 


\section{1 \\ 产品服务系统可持续互动的审美 价值}

法布里齐奥·山士恩 (Fabrizio Ceschin)

意大利米兰理工大学设计学院, 可持续设计与体系创新 (DIS) 项目 (Politecnico di Milano, Design Department, Design and system Innovation for Sustainability (DIS), Italy)

英国布鲁奈尔大学, 工程与设计学院, 设计系 (Brunel University, School of Engineering and

Design, Department of Design, UK)

卡洛·维佐里 (Carlo Vezzoli)

意大利米兰理工大学设计学院, 可持续设计与体系创新 (DIS) 项目 (Politecnico di Milano, Design Department, Design and system Innovation for Sustainability (DIS), Italy)

萨尔瓦多・津格尔 (Salvatore Zingale)

意大利米兰理工大学设计学院 传播设计 (D.COM) 项目 (Politecnico di Milano, Design Department, Communication Design (D.COM), Italy)

\section{1 生态效益型产品服务系统的传播局限性}

生态效益型产品服务系统（PSS）（这个系统中, 利益相关方的经济利益使环境资 源消耗方式得到不断优化）堪称是一种实现可持续发展的好办法。但尽管呈现出双 赢的潜在特点, 此概念的应用范围依然有限。其中, 一个关键的原因在于生态效益 型产品服务系统 (PSS) 的创新模式通常十分激进, 会遇到消费者现有的行为习惯 （文化壁垒）、公司的组织（企业壁垒）和规范框架（规范壁垒）等方面的挑战。

出于上述考虑, 本章首先探讨了导致生态效益型产品服务系统 (PSS) 及替 代品影响力受限和接受程度偏低的原因。随后讨论了关于生态效益型产品服务系统

(PSS) 审美价值, 就美学如何提升生态效益型产品服务系统 (PSS) 的内在品 质、如何促进其推广和传播进行了论述。通过案例分析, 并结合符号学原理, 本章 
其后将就美学元素是如何提升生态效益型产品服务系统的吸引力、用户认可度和满 意度提出几种研究性假设。

\section{2 生态效益型产品服务系统（PSS）：用户接受产品 服务系统所面临的障碍}

消费行为是每个人独特选择权的体现, 受社会规范和制度环境的影响。阻碍生态效 益型产品服务系统 (PSS) 传播的居主导地位的因素是当前的消费行为。让我们 总结一下那些 (在工业化的背景下) 影响传播的主要因素。之后, 我们遵循蒙特

(Mont, 2004) 的思想方法, 将它们划分为经济和社会心理因素。

从经济角度讲, 莱普克 (Røpke, 1999) 认为, 当今消费行为首先是受到了工 业化发展历史的影响。工业革命促进了生产力的发展, 使产品总量得以提升, 同时 造成了产品的相对价格水平下降, 这就决定了各国需要更多的市场来销售产品, 并 催生了更多新产品的出现。反过来, 也会使人工制品的市场需求增大, 因此要制定 相应策略来刺激消费。根据这一情况, 柯尔本 (Kilbourne, 2001) 等人提出：现今 的政治和经济体制让人们萌生了追求更高物质繁荣的念头。

经济活动的外部效应是造成物质消费水平提升的另一主要原因。尽管环境与社 会成本与产品本身密切相关, 但它们在产品的售价中却得不到体现, 这就使得生态 效益型产品服务系统 (PSS) 很难与工业制成品进行竞争 (蒙特 (Mont) 和林赫斯 特 (Lindhqvist) 2003; 山士恩 (Ceschin) 和维佐里 (Vezzoli) 2010)。另外, 劳 动密集型产品（生态效益型产品服务系统（PSS）常被归为这一类）的价格正呈不 断上升的趋势, 所以消费者会更倾向于购买廉价的产品（如洗衣机），而非产品服 务系统（如衣物护理服务）。

而且, 消费者对 “生命周期成本” 这一概念大都知之甚少（蒙特 (Mont, 2002））。所以，有时消费者难以觉察出产品服务系统（PSS）的潜在经济效益。 拥有产品的总成本（如使用、维护、修理和处理成本等）往往没有反映在产品销售 价格中, 这通常就会让很多最终用户认为单纯购买产品会相对便宜些, 而整套产品 服务系统的价格则一定高很多（其实有时并非如此）。

传统的经济学研究往往都会基于下述假设: 消费者都是理性的决策者, 其消 费目的是实现效用的最大化, 价格和收入水平则是影响他们选择的最主要因素。然 而，蒙特 (Mont) 和普莱皮斯（Plepys）（2008）则认为：消费行为不仅仅是对价 格做出理性的回应, 而是受多重影响因素的制约, 整个过程相当复杂, 分内部和外 部两方面，包括人类心理、社会规范和制度环境。

社会学研究强调的是习惯在消费行为中所发挥的作用, 认为消费选择受到先 前的消费模式的影响。而生态效益型产品服务系统 (PSS) 则与现行的产品所有权 的主流标准完全相反, 它是以共享和拥有使用权为基础（伯南特 (Behrendt) 等 2003），而消费者一般很难接受无所有权的解决方案。对某些特定的需求满足而言 就是如此（例如洗衣服, 我们不习惯使用放在自家却不属于我们的洗衣机）, 而无 所有权方案在另一些情况下却也得到了应用（例如使用公共交通工具）。 
妨碍无所有权方案推广的另一大因素, 在于人们一般都用产量的多少和 质量的高低作为衡量产品是否优秀的标志, 因为它是一种社会衡量指标 (蒙特

（Mont）2004）。此外, 郝奇亚（Halkier，1998）强调, 目前的消费趋势正朝个性 化发展, 因此扩大消费需求势在必行。如今一个人身份地位的高低不再像以前一样 由其社会背景决定, 而是取决于他/她拥有商品的档次（商品可以用来显示一个人的 社会地位）。此外, 出于对独立性、卫生和情感等方面的因素考虑, 消费者常常对 无所有权方案望而却步。

虽然有很多因素导致人们不愿选择无所有权方案（蒙特（Mont）2004）， 但我们仍然可以创造机会, 推广无所有权方案, 让更多的人接受并使用它。首 先, 传统经济学认为, 用户用实体产品来满足他们的需求, 而一些社会学家则认为

（如麦克斯·尼夫（Max Neef， 1991），物质和非物质 “满足物” 都可以满足人 们的需求。此外, 物质消费水平的高低并不能与幸福划等号; 实际上, 过分追求物 质享受的人并不一定比其他人幸福（波尔克（Belk）1985; 麦克斯 · 尼夫（Max Neef） 1995）。另外, 一些研究表明, 消费水平的提高往往意味着心理需求和社 会期望值的提高, 而并不代表物质需求有了提升（杰克逊（Jackson）和马克斯

(Marks) 1999)。同样, 哈克 (Hacker, 1967) 也认为, 购买同种品牌的商品可 以弥补已经丧失了的群体意识。此外, 如果拥有商品真的会成为衡量社会地位高低 的标准, 那么无所有权方案也可作为某种身份的表现形式。我们以乘出租车和受教 育或参加文化教育活动为例（蒙特 (Mont) 2004)。

我们可以看出, 用户层面的各种不同障碍, 会影响消费者对无所有权方案的接 受和满意程度。由此, 产生了几个关键性的问题。

- 怎样才能让用户接受与此类方案相关的（激进式）行为变革呢? 怎样才能使 这种嵌入过程融入用户的消费习惯呢?

- 在购买过程中, 我们该怎样引导消费者购买生态效益型产品服务系统

(PSS) 而非传统的以产品为主的方案呢?

- 在使用中, 我们怎样提升生态效益型的产品服务系统 (PSS) 的消费者 满意度? 换句话说, 怎样让消费者认为使用生态效益型的产品服务系统

(PSS) 会比传统产品获得更为舒适和便捷的感受呢?

\section{3 美学的潜在价值?}

我们都知道美学对产品设计十分重要, 也是反映消费者接受程度和满意程度的主要 考察标准。说到提升系统的创新水平, 主要问题在于: 如何确定生态效益型产品服 务系统 (PSS) 的审美价值? 我们在之前的论述中就已经看到, 生态效益型产品 服务系统 (PSS) 是个相当复杂的范畴, 由多种不同元素构成: 产品、通信、服 务（用户与生产商/供应商之间的互动）, 以及更为广泛的互动活动（产品服务系 统（PSS）价值生产系统中不同的社会经济利益相关方之间）。因此, 产品服务系 
统的吸引力、被接受程度和获得满意程度则取决于这个集产品、服务、沟通和互动 为一体的系统能否得到用户的认可了。因此, 我们认为, 对生态效益型产品服务系 统 (PSS) 不同组成元素的看法是评估该系统的基础。这里我们需要解释一下系统 美学 (system aesthetic) 的概念, 即一个描绘产品服务系统 (PSS) 中不同元素 的综合性审美系统：因此，该审美系统旨在实现产品、沟通、服务和互动中的审美 价值完美结合。那么, 怎样才能让生态效益型的产品服务系统发挥其美学特点, 更 有吸引力, 更好地赢得消费者的青睐呢? 若要勾勒出一个大体框架以便回答上述问 题, 我们就得从生态效益型产品服务系统 (PSS) 的相关案例入手, 分析、研究并 得出一些结论, 然后提出一些工作假设。

\subsection{1 案例分析结论}

洗衣吧

洗衣吧（Wash bar）（塔姆博瑞尼（Tamborrini，2009）是乐喜金星电子的一家洗 衣房, 于2005年在巴黎成立。这里既有洗衣机和甩干机, 也有酒吧和各种娱乐文化 服务设施, 如wi-fi无线上网、短片放映, 还可参与这里组织的多项活动。其室内景 观就像一家酒吧或游戏厅, 只是里面还多了洗衣机和甩干机。这种服务的环保效益 是显而易见的。那么洗衣吧和传统的洗衣房究竟有何不同之处呢? 首先, 洗衣吧成 立的初衷就是为了吸引更多的消费者前来享受这一服务。其策略很简单, 就是让人 们更好地享受洗衣机和甩干机工作时那段无聊的等待时间。该系统由多种元素组成

（家具、通信和服务）, 旨在宣传热情待客的服务理念, 让消费者感觉宾至如归: 消费者可以在洗衣吧中读书、上网、听音乐。

该方案的主要特点在于其社会意义。有形元素（沙发、扶手椅、桌子等及其布 局）与多种服务（酒吧、wi-fi等）完美地结合在了一起，方便消费者之间开展交流。 这种社会关系方面的考虑正是产品服务系统 (PSS) 的关键卖点。而恰恰是产品服 务系统 (PSS) 对社会质量这一概念的创新使得此项方案会比传统洗衣房（甚至是 国内的洗衣店）更能得到消费者的认可和满意。

\section{图1.1 洗衣吧：室内布局}

来源：塔姆博瑞尼（Tamborrini，2009）
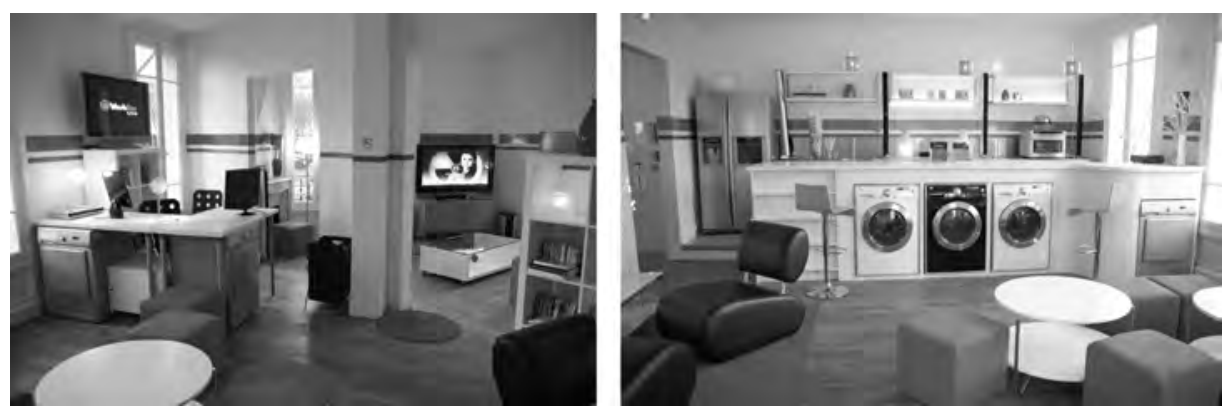


\section{汽车设计峰会 (Vehicle Design Summit) 项目中的汽车共享系统}

我们这里要提及的第二个实例是将拼车和搭车两个概念融为一体的城市交通系统, 它由劳瑞恩佐·达沃利 (Lorenzo Davoli) 在“汽车设计峰会 (Vehicle Design Summit) ”研究项目中以硕士学位论文的形式提出。1简单地讲, (维佐里

(Vezzoli) 和山士恩 (Ceschin) 2008)，凭借这一系统, 用户可以使用一批绿色 环保汽车并与他人拼车旅行。每位注册的用户都有一张智能卡, 可以用于乘坐电动 汽车或公共交通工具。车辆的预订可通过互联网或手机实现（可用车辆都停在市政 府指定的专用停车场内）。在车辆的使用过程中, GPS系统会为驾驶员指明最快 捷、最畅通的行驶路线, 服务按行驶里程收费。

该系统的特点是, 用户可以通过互联网创建并经营自己的关系网（朋友、同 事、亲戚、邻居等），制定并分享自己的旅行计划。此外，通过手机可以实时了解 朋友车辆所处的位置，以便随时联系他们搭顺风车（服务费用共同承担）。

\section{图1.2 汽车设计峰会（Vehicle Design Summit）项目中的拼车系统：能完成 用户互动的一种故事板}

来源: 维佐里 (Vezzoli) 和山士恩 (Ceschin) (2008)

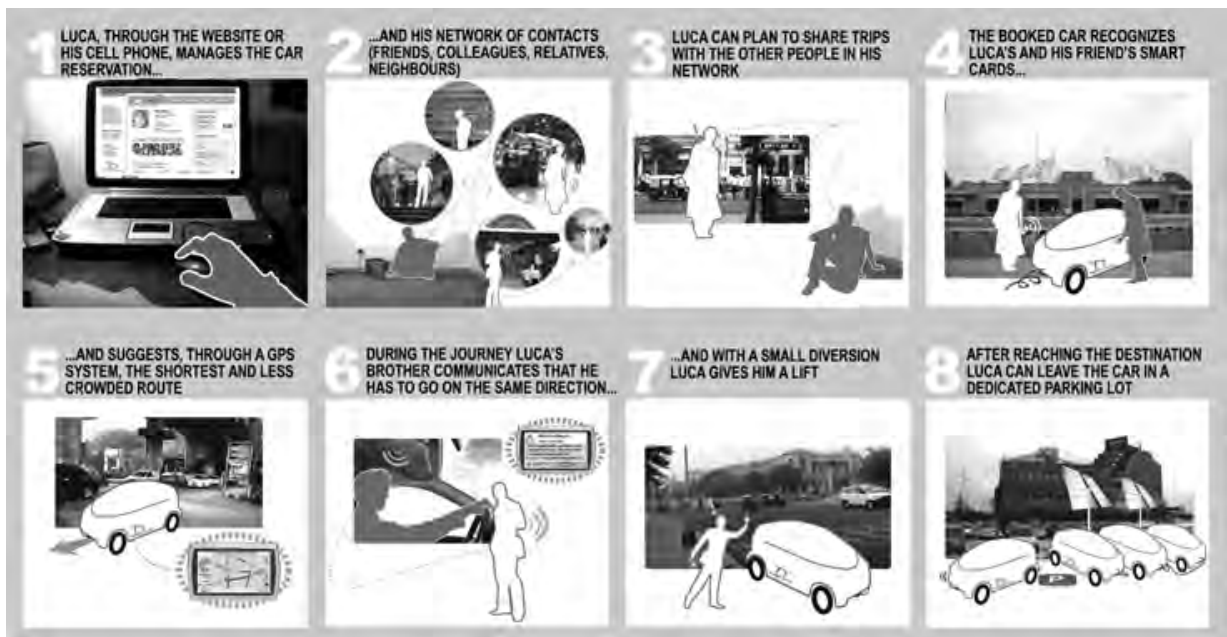

1 汽车设计峰会 (Vehicle Design Summit) 是由波士顿麻省理工学院 (MIT of Boston.) 主 持, 世界上27所大学组成的国际联盟。该联盟旨在完成一种新型汽车的设计, 既环保又 “ 开放”, 同时创造条件, 以创新和可持续交通为口号进行市场推广。米兰理工大学设计团 队（the Politecnico di Milano team（劳瑞恩佐・达沃利（Lorenzo Davoli），弗朗西斯卡・弗 欧凯 (Francesca Fiocchi和林君, 由卡洛. 维佐里 (Carlo Vezzoli) 和法布里奇奥・山士恩

(Fabrizio Ceschin) 出任组长) 旨在设计一种创新和有生态效益型的商业模式, 同时为引 进该模式和市场推广做准备。(参看达沃利（Davoli）、弗欧凯 (Fiocchi) 和林君2008)。 
与传统的私家车出行方式相比, 该系统的环保优势显而易见。那么两种方式究 竟有何不同之处呢? 我们可以看出, 上述例子的效果比传统的拼车系统和私家车出 行更让人满意。上述案例关注点在于拼车系统内在的社会关系因素, 即共乘联系网 络的创建和管理。这样, 用户的拼车旅行比以前更加方便快捷, 同时还可以不断发 展新的联系人, 感觉自己仿佛处在一个社区中。也正是这种服务基于社会层面的考 虑, 使用户的传统行为习惯发生了根本性的转变。

值得一提的是, 为了推进上述转变, 该系统旨在唤起大众的环保意识。该服务 一方面能为用户指明快捷畅通的行车路线（同时还能节约资源）, 另一方面, 也诠 释了该系统的环境效益。因此, 这个案例反映了这种解决方案在满足用户需求方面 的巨大潜力。

\subsection{2 设计研究工作假说}

由此产生了下述关键问题：生态效益型产品服务系统（PSS）的审美价值会对用户 产生怎样的影响呢?

首先, 生态效益型产品服务系统 (PSS) 是一项基于消费者满意度的服务方 案, 所以其设计的着眼点在于 “满意度” 而非实现满意度的 “产品” 2 。因此, 从这 一角度来讲:

- 该设计方案的终极和长远目标是审美价值的实现和认知价值的传播。具体来 说, 是满意度, 而非实现满意程度的各种方式。在这个意义上, 同类的审美 价值（如吸引力、接受程度和满意度）对用户来说会显得更真实可靠。

此外, 正如我们在前面所看到的那样, 生态效益型产品服务系统通常以（产品或最 终结果的）获取和（产品的）共享为基础, 所以, 如果我们希望制定优于传统产品 的方案, 就必须关注生态效益型产品服务系统 (PSS) 所具备的独特优点。特别是 生态效益型产品服务系统（PSS）具有的诸多潜在优势：产品服务系统 (PSS) 能 促进不同用户之间的交流。多人之间的产品共享有利于新型人际关系的构建（如以 上例子所述）。

- 在产品服务系统 (PSS) 的使用过程中, 人与人之间的直接接触能提升用户 在活动中的参与度, 并感觉自己是 “社区中的一份子”。比如：可以将用户 之间的关系设想为一个紧密联系的采购团体（有组织的一群人直接从当地农 民那里买食物）。

- 促进用户和产品服务系统 (PSS) 生产商/供应商之间的互动, 完成采购时二 者的关系并不会因此而终结（就如传统产品服务一样），而是一直持续到合 同/协议结束。

确切地说, 产品服务系统 (PSS) 用户之间以及用户和制造方/提供者之间能建立相 应的关系, 这些元素在传统的产品服务中是没有的。因此, 它们体现了生态效益型

2 例如, 出行尽量不自己开车; 不用锅炉和甲烷进行供热; 洗衣服时不用洗衣机和洗涤剂。 
的产品服务系统 (PSS) 方案的独特性。所以, 如果我们想提高产品的吸引力、消 费者的认可度和满意度, 就必须重视这些关系的建立。

这与前文所述一致。事实上, 如果物品采购能与满足社会需要联系起来 （杰克逊（Jackson）和马克斯（Marks）1999），并且有时可用来替代丧失的社区 意识（哈克 (Hacker) 1967, 产品服务系统 (PSS) 应该尤其着重强调这些社会过 程, 这样才能被认为是优于传统的以产品为导向的方案。

除了上述特点外, 生态效益型产品服务系统 (PSS) 以其固有的环境和经济 效益而著称。然而问题在于, 正如第一节所示, 绝大多数客户根本意识不到它的特 质。所以, 如果我们想提高此类产品的吸引力和认可度, 就必须对这些方面给予相 应的关注。特别是:

- 有必要让用户对生态效益型产品服务系统（PSS）的环境和经济效益有更清 晰的认识。

- 使用户意识到他们选用了一种既对自己负责任又可持续的方式, 这对于该产 品服务系统 (PSS) 方案的推广有着十分重要的作用, 因为用户可以向他人 推荐产品服务系统 (PSS) 并鼓励他人使用。

另外, 与传统的拥有所有权的产品所不同的是, 生态效益型产品服务系统 (PSS) 通常会给用户带来更多的收益, 比如:

- 可以有效避免因维护、修理和处理产品所产生的问题及开销。

因此, 应向用户着重强调这一点, 最好还能让他们亲身感受到这一好处。

最后, 生态效益型产品服务系统（PSS）不仅应在使用阶段提升消费者满意 度, 同时（与传统的拥有所有权的产品相比）在销售阶段也对消费者更具吸引力。 换句话说, 生态效益型的产品服务系统 (PSS) 应比以产品为主导的方案更能 “激 发”消费者的兴趣和购买欲望。

生态效益型产品服务系统（PSS）中的美学元素将如何帮助提升产品的吸引力 和消费者满意度和认可度呢? 以下列出了一些相应的工作假设（有待证实）：

- 在购买选择阶段, 生态效益型产品服务系统 (PSS) 的美学元素应能吸引消 费者, 提升他们的兴趣, 着重强调实体产品的非所有权特征。

- 在使用阶段, 生态效益型产品服务系统 (PSS) 的美学元素应当强调相互依 赖、相互作用的特征（加强消费者之间、消费者和产品生产商/供应商之间的 互动）。

- 在使用阶段, 生态效益型产品服务系统 (PSS) 的美学元素应让消费者充分 了解其在产品维护和处理方面不会有任何问题和成本。

- 在使用阶段, 生态效益型产品服务系统 (PSS) 的美学元素还应让消费者了 解并感受到其诸多的经济和环境收益。 


\subsection{PSS的符号学、审美和生态效益方面的含义}

\section{4 .1 关系意识}

此处的案例清楚地表明产品服务系统（PSS）对环境和用户的益处，因为它除了 能设计工艺品, 还能设计各种关系: 使用关系和社会关系。不同的人因其经历的不 同, 对同一事物的看法也各异, 因而同一事物对不同人的意义也是千差万别, 而我 们选择符号学作为我们研究分析这些关系的工具。从文本分析和产品、服务设计方 面来看, 存在着一种介乎于表达层面与内容层面之间的重要关系（参阅杰斯勒夫

(Hjelmslev) 1943）：表达层面涉及事物发生的方式一一它们所采用的形式、各部 分的组织架构以及材料的组成。表达指的是产品的逻辑结构以及显性表象; 而内容 层面则涵盖了产品所有的语义背景：范围包括它们的潜在含义及其存在的意义。

但当我们提及产品和服务时, 则要从实用主义的角度出发探讨其语义层面: 消 费者的态度、产品对消费行为的影响、能产生的满意度水平、用户本身的购买目的 以及使用某产品或服务的目的。产品绝不仅仅是 “说” , 还能“做”或 “让人做”。

\subsection{2 从“产品感” 到“效用感”}

对于消费者而言, 无论使用哪种产品, 其所能带来的满意度才是最重要的。不难 发现, 决定一件产品满意度的主要因素有：1）外在的感受性与内容的认知性之 间的关系；2）不同语义之间和交流意图之间的对话关系；3）设计中（设计师意 图）目标含义、（作为产品本身）产品意义以及（产品使用结果）产品效用之间的 关系（金吉尔 (Zingale) 2009）。

在乐喜金星电子洗衣房（LG Electronics）的例子中, 设计师/供应者的目标含义 是确保洗衣机能够减少能源消耗; 产品效用则是为用户创造轻松一刻, 将劳动时光 转变为轻松自由的时光。洗衣吧 “热情待客的服务理念” 能够让消费者感受到自己 与环境、空间和家具之间彼此相处融洽，从而也更能与其他消费者友好相处。

在这个案例中, 虽然产品和环保理念都是以实体形式表现出来的, 但服务的 构建大多展现出非物质性的特点, 并通过通讯工具、环境和社会交易等形式展现出 来。符号会对人们生活方式的选择及行为的表现产生影响。各种要素不再单纯是所 要拥有的产品, 还包括相应的行为。事实上, 生态效益型产品服务系统 (PSS) 的 表现形式、沟通方式和服务模式就是相互作用和相互影响的一系列要素。

这种相互影响催生了一种集审美和符号学意义为一身的全新设计方法。而在 探讨产品意义时却出现了问题, 就像对于一篇完整的文章而言, 所要考虑的因素不 仅仅包括其整体结构, 还要特别考虑到其可能带来的一系列影响。换句话说, 我们 不仅需要考虑到产品的形式, 还要留意它可能产生的效果 (参阅派瑞斯 (Peirce) 1878, CP 5.402)。

\section{4 .3 经验观察}

如果按照这种方式, 产品可以被认为是一篇界限明确的 “文章” , 语义表达一 致, 句法衔接紧密（参阅麦隆（Marrone）2009），那么, 产品服务则是一个 “符号 
文本”，界限不固定且结果不明确。此类文章存在偶然事件发生的可能，服务供应 商与用户之间的彼此互动具有决定性的影响。

如此看来, 针对符号学领域的研究将采用类似民族志学的观察法, 调查用户的 体验效果。此项观察分三阶段进行:

1. 项目展开之前, 以民族志学或民族志学与符号学相结合的方式 (参阅玛诗安 妮 (Marsciani) 2007) 观察现有社会实践。

2. 项目进行过程中, 对生态效益型产品服务系统 (PSS) 进行认证与检测。

3. 项目完成后, 对已经通过审核的生态效益型产品服务系统 (PSS) 进行案例 分析, 获得了一些积极成果。

特别值得一提的是，对用户体验效果的观察应该包括：

- 理解层次 用户们是如何理解他们所获得的服务的

- 预期收益 用户对自己能做什么或想要什么的诠释

- 态度 用户对产品有何看法, 采取何种行为

- 行动的选择 用户选择做什么? 为什么?

- 用户反响 在设计项目中, 用户是否关注行动顺序, 他们有何反应?

- 解释性合作 用户对服务形态有何意见和建议

- 解释性反馈 对享受到的服务所做出的反馈和评判

\subsection{4 从经验到设计}

这一流程可通过汽车设计峰会 (Vehicle Design Summit) 项目一一拼车这个案例得 到完美呈现。该设计项目的关键就在于从生态角度引导我们今后的日常生活习惯朝 健康的方向发展，而我们的日常习惯往往根深蒂固，对别人的批评也常充耳不闻。 尽管如此，我们必须学会观察，清楚我们要做的事情，熟悉我们做事的方式以及使 用的工具。

我们会发现, 用符号学的方式观察事物有助于把观察数据转化为社会实践, 转 化为设计方案, 尤其是创新性强、令人满意的高效方案。转化的难点主要在于提升产 品服务系统 (PSS) 的新颖程度, 满足摒弃固有行为模式的隐性需求。在产品的使用 上, 个人和社会偏好往往根深蒂固, 如上所述, 习惯和传统在这方面有重要的影响。 因此，创新型产品服务系统（PSS）要满足以下要求:

1. 认知转换, 转向未知的习惯和方案

2. 语义重组，对传统的产品价值观进行重新调整

\section{3. 产品服务系统 (PSS) 的清晰交流形式}

因此，以符号学为工具, 对可行性方案进行阐释, 它主要关注的是产品服务系统（PSS） 在设计人工制品新用途方面所采取的方式，显示了传统方式的区别。尤其是: 
- 用户必须形成新习惯

- 产品服务系统 (PSS) 的实现途径与传统的产品获取方式不同

- 产品服务系统 (PSS) 的分享原则, 或共享理念及主体间的所有权关系

- 新型使用模式的学习方式

- 源自产品服务系统 (PSS) 的满意度要素, 这是只有PSS才能提供的满意度

\section{4 .5 感知与满意度}

最后, 这个方面是讨论产品服务系统 (PSS) 方案中最为重要的的核心问题之一。 事实上, 如果产品服务系统 (PSS) 与传统产品的使用及消费形式是完全不同 的, 而这种不同旨在使产品的使用和消费形式变得更加可持续, 那么用户会把产品 服务系统 (PSS) 的哪些方面作为实际效益来源呢? 为此, 我们又回到一开始说的 与符号学有关的内容。在所有的沟通形式中, 表达发挥着战略性的作用。它既表现 内容, 又引导内容。

问题存在于表达层面和内容层面之间的关系。产品的感知方面和物质方面 如何才能将用户吸引到具体的内容中? 在产品服务系统 (PSS) 中, 相关内容 基本上可从以下两个语义层面搜集：关注领域（所提供的服务和益处、使用需求 等）和理想领域（生活方式改变、产品共享、消费控制等）。但是如果产品服务系 统（PSS）实用性不强, 它被关注的几率就很低。实用性关系到用户对产品的选 择，激发感性效应（我理解的、该做的、该选择的等）, 并进而得出产品的接受/拒 绝程度。

\section{4 .6 美学思考}

有些人可能会认为, 这第三感知层面的存在是设计的特点, 因此美学的任务是赋予 工业产品独一无二的价值。但是, 这里有所改变的是美学功能所扮演的角色以及我 们对它的理解方式。或许其作用仍然受到艺术模式的限制。设计不是艺术, 虽然两 个领域有许多共通之处, 但它们之间仍然存在许多不同点。混淆两种截然不同的模 式是“设计”领域中的重大失误。

如果我们假定美学的功能是刺激用户在认知和感官方面进一步留意产品, 那我 们必须说, 在总体的设计领域以及特殊的产品服务系统 (PSS) 中, 我们应该对美 学功能及其发展方向有如下认知:

- 充当吸引用户/接受者了解产品服务系统 (PSS) 全貌的桥梁

- 作为引导消费者接受新型创新性消费理念的一种形式

- 作为用户与产品之间保持持续沟通的一种战略

因此, 我们必须从这个前提出发, 即要理解, 生态效益型项目的深层价值主要 在于理解产品中的美学功能所扮演的角色。雅克伯森 (Jakobson, 1963) 认为, 在 沟通中, 美学功能与信息形式相关, 但是, 美学功能仅仅是沟通过程中的六种功能 
之一, 而不能将其视为唯一的功能。事实上, 其它五种功能都与沟通过程的固有因 素有关：表达功能与信息发送者的身份有关，意动功能与信息接收者的行为类型有 关, 元语言功能与传统沟通模式的性质有关, 指示功能与语义语境有关, 联络功能 （或交流功能）与交流渠道有关。

仔细观察后我们可以发现, 在雅克伯森 (Jakobson) 给出的方案中, “功能” 这个词的含义主要体现在数学方面: 一个变量 $(x)$ 变化时, 其它变量也会跟着变 化 ( $y, z, \ldots . .$.$) 。雅克伯森 (Jakobson) 还指出, 在任何言语活动中, 这六种$ 功能呈层级状出现, 但每次各个功能的比重和重要性可能不同。另外, 在某种程度 上, 经常存在的某一种功能可能发挥的是另一种功能的作用。例如: 设想一下, 正 确扫描的文字（美学功能）方便人们理解文字内容（意动功能此时充当的是指示功 能的作用）。

设计中, 美学功能主要与以下方面有关:

- 产品带来的感官反应类型（喜欢或排斥）就会超出品味或潮流的范畴, 如果 用户对产品的感官反应能够将其注意力转向产品的其它方面（对制造方身份 的认知、产品的易辨识性等）。

- 在设计过程中和预期标准下, 这些美学功能所强调的功能是否发挥了作用。

\subsection{7 功能运行}

为了更好地理解产品服务系统 (PSS) 的美学功能, 在这里我们把雅克伯森

(Jakobson) 的语言功能模型展示出来, 图形上略有改动, 希望能够表达清楚我们 所说的这个 “功能运行” :

\section{图1.3 雅克伯森（Jakobson）：沟通功能}

来源: 由作者改编

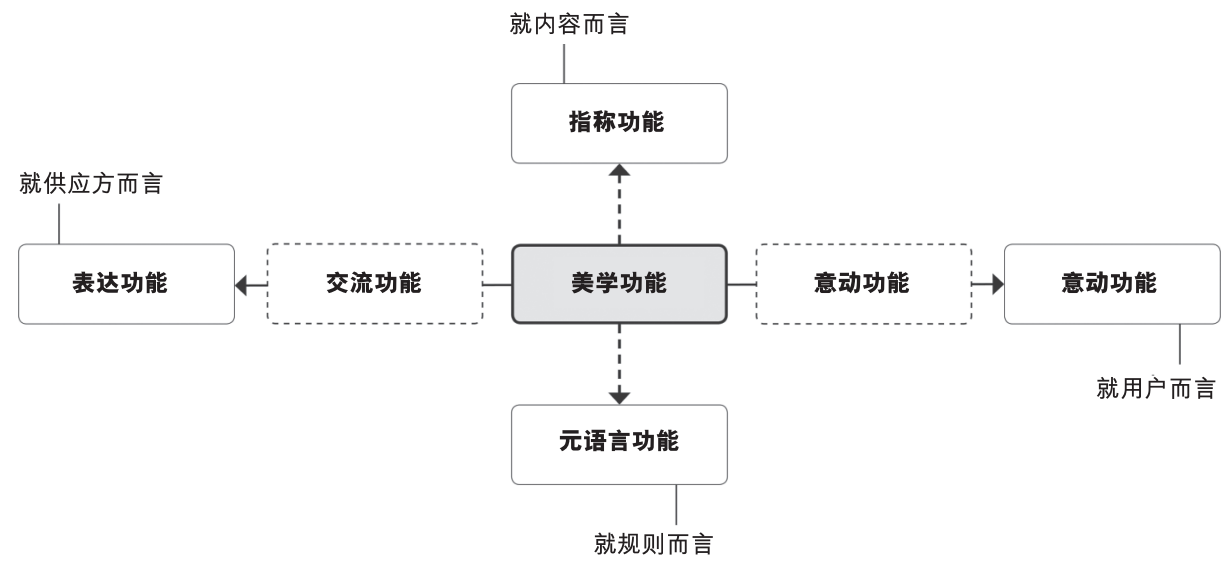


此模型图经过修改, 更清晰地表达出沟通过程中出现的两条不同的轴线。我们 将水平轴线称为 “对话轴”：凭借产品服务, 公司资产、服务供应方和使用方之间 的沟通得以确立。垂直轴线被称为 “认知轴”, 因为该轴线指的是对产品服务的全 面理解以及使用产品服务所必备的能力。

两条轴线的交叉点处所描绘的正是美学功能。这就意味着一切事物都与美学功能 有关联。每种功能以及用户的各种实际行为或心理活动, 都通过美学功能 “开启”。 因此, 可以假定, 美学功能和其它功能之间相互影响、相互作用。

那么, 让我们探讨一下该如何描述这个模型, 以及该模型的运行方式又是怎样 的呢?

表达功能（顾名思义, 它展现了一种思维或情感方式）的目标是表明产品服 务系统 (PSS) 产品提供者的来源和身份。该功能清楚阐明了符号学中表达主体 的概念, 在目前情况下即指消费者和 (或) 设计师。然而, 美学功能还能表现出产 品所处的文化环境, 所以它还可表明产品是出自哪些研究领域。在产品服务系统 (PSS) 中, 美学功能起着战略性作用, 并且在某种程度上说, 起着 “契约” 作 用。引导用户, 让他们知道提供的产品服务来自于哪个研究领域, 即：1）动员他们 应用创新型的消费方式、体验新型产品关系；2）让他们参与共同设计, 即参与到向 可持续设计过渡的项目中来。

如果表达功能较弱, 或者美学功能没有反映出表达功能, 用户很有可能就认为 产品服务系统 (PSS) 的价值不高。因为用户觉得自己并未在交涉和规划设计中扮 演重要的角色。

这与我们在对话轴上反方向看到的意动功能（来源：拉丁语conari，“拉 紧” ) 有关。意动功能指的是产品或产品服务对用户的所有显性或隐性行为的影 响, 使得用户实施其它功能和做出其它行为：了解方案性质、识别产品类型、明确 产品优势, 掌握产品使用方法等。而且, 意动功能还明显依赖于产品的美学功能: 产品的最后一项特性越 “完备”、越是 “设计精良”, 产品就越能够把用户带入到 生态可持续项目中。

尽管如此, 要实现这样的目标还少不了决策和后续行动。不应当纯粹地诱惑 和捕获用户, 而应该正确地引导他们。也正因为如此, 交际功能或联系功能也出现 在了水平轴线上。交际功能或联系功能不仅反映出产品和用户间的认知与物理关 系，而且能够在使用阶段引导客户更好地使用产品。

此外, 产品的联系和引导功能会因为产品的美学功能而得到加强或抑制。例 如：产品的材质、颜色和大小。一个物体, 太大或者太小, 都不好掌控。一个指示 牌, 太近或太远, 太亮或太暗, 都会看不清楚。这些相似的例子说明, 产品不仅外 形设计很重要, 设计过程也很重要, 在这个过程中需要考虑产品与用户之间的关 系。如果设计过程没有考虑到用户, 那么上述的所有功能, 虽然形式上存在, 但在 实际应用过程中是不起作用的。

纵轴上所体现出的各项功能应与横轴上的各项功能实现进行整合：也就是其美 学功能、指代功能与元语言功能三者实现合并, 指示功能赋予产品内涵和价值(具有 语义价值: 明确产品类型), 使用户在诸多产品中锁定其中意的那款。而元语言功能 
(具有说明价值, 诠释产品的使用方法)可提示用户在使用某种特定产品时, 所要具备 的各种知识、指导和程序。

而且, 垂直轴线上的一切内容都要通过美学功能来实现。将产品本身的语义 功能与其社会价值进行区分, 或相关知识的应用, 都少不了对符号语言的分析和掌 握, 从表现形式到实质内容, 由表及里, 深入挖掘。

\section{4 .8 美学功能的应用}

总而言之, 审美价值不仅只应用于描述材料的质量和物体的形状。这个问题有史可 寻, 在《大希比亚斯》中, 著名的柏拉图对话录里就曾讨论过。里面提到一种具有 普遍性的观点, 即 “美” 是视觉享受的主要来源。这一观点把 “美” 归结为与用户 及其行为之外的一种特性。从这个意义上说, “美” 是无法触碰, 且无法改变的。

而我们需要把握产品服务系统的核心。我们不仅要接触它, 还要根据自己的不 同喜好对其进行修正，重塑和调整。因此，在实际应用审美价值时，我们所需要考 虑的不仅涉及形式与句法, 还应包括如下两点:

1. 在设计领域, 美通常意味着赏心悦目, 能被大众接受, 即人们在使用产品的 过程中获得了相应的满足感。无论是何种情况, 心理感受不再是产生美感的 唯一来源, 取而代之的是使用过程当中的触觉（也会用到嗅觉和味觉）, 以 获得更直观的感受。接触使得产品和用户之间的互动成为了可能, 甚至能够 提供指导或服务; 另一方面, （凭借其外观、性能和吸引力）它也能更好地 激发用户的好奇心。设计师的心理认知如今表现为自身理想的实现, 以及实 际解决问题的惊喜, 正是这样的过程带给设计师无尽的满足和愉悦感。因 此, 我们不仅要关注产品的形式, 而且要关注产品与用户之间的互动。

2. 在产品服务系统中, 美学功能已经从反映客观事物扩展至表现各社会主体之 间的关系（服务提供商和用户之间，以及不同用户之间的关系）。

但是, “人际关系中的美学功能”的实现又意味着什么呢?

首先，它是指人与人之间的互动，因此其互动方式是我们所要关注的焦点。 比如说, 不同用户在使用某种产品的过程中会产生不同的看法, 也就是说该看法不 只是某个用户的看法, 而是一种集体共享的观点。事实上, 用户在使用任何一种产 品的过程中, 都会留下使用的痕迹。这些痕迹在集体共享的过程中也不会消失, 相 反, 它们会体现在产品的结构中, 它属于每个人并且为每个人所享有。因而, 产品 服务系统应该作为用户之间进行互动的虚拟平台, 不管这样的互动是直接的还是间 接的, 用户都将在这里找到归属感。在这里, 任何用户都没有特权, 因为他们所使 用的是同一个产品服务系统。

产品服务系统的美学功能具有通用性, 每个人都可以使用, 最重要的 是, 每个用户都通过该系统与其他用户进行交流。产品和用户之间不再是相互分离 的, 也不只是单纯的使用与被使用的关系，而是共享的，互动的关系。用户交替使 用产品, 将不同的感受汇聚到一起, 最终就会形成集体性的主观感受。 
产生这种集体性感受是设计的主要目的。因此, 产品服务系统的设计一定要合 理并且能够体现出这种这方面内容。

\section{5 结论与今后研究方向}

生态效益型产品服务系统 (PSS) 不仅为解决经济效益和物质及能源消耗的脱 钩问题提供了重要模型, 也消除了对环境产生的负面影响。然而, 大多数情况 下, 创新都是以剧烈变化的形式出现, 其传播都会受到来自文化、企业和管制方面 的阻碍。本章对生态效益型产品服务系统推广中遇到的阻碍进行论述, 并就美学的 实际作用进行分析：无论是在购买还是使用阶段, 美学设计是否能够让用户觉得产 品服务系统 (PSS) 方案比传统的“基于产品的” 方案更令人满意。这一章的关键 性研究主题是: 如何通过在生态效益型产品服务系统中应用美学设计, 使之更具有 吸引力, 被大众接受, 并得到认可。

事实上, 这个关键性的问题包括其他两个主要的问题。

第一个问题涉及到总体的设计研究。由于产品服务系统创新目前还处在初级阶 段, 由利益相关方参与的互动创新也刚刚起步, 因此, 需要建立一种面向服务型社 会的知识库, 来定义产品服务系统实践过程中所出现的新概念, 如各利益相关方的 互动美学, 以及与用户互动时的服务美学。

第二个问题与生态效益型产品服务系统创新的特性有关, 比如无所有权实体 产品。正如1.3.2一节中所提, 我们假设美学元素在用户购买（比如引起用户的兴 趣）和使用产品的阶段（比如凸显产品和服务的关系价值, 无所有权的优点, 以及 能带来的环境和经济利益）均起到各种不同的作用。

在本章中, 我们还探讨了将设计与符号学领域相结合的研究方面的最新进展。 我们之前提出的假设必须得到进一步证实。本书作者认为该领域很重要, 有待深入 研究。

非常有必要就美学在促进向可持续性设计转型的过程中可能发挥的和必然发挥 的作用展开研究。而仅仅进行可持续创新是远远不够的, 必须让用户看到这些创新 比现有的非可持续设计所具备的的优势。此外, 这种新进展意义重大, 它引发了一 场辩论，这场辩论不仅涉及可持续性，而且与设计本身的作用有关。

\section{参考文献}

Behrendt, S., C. Jasch, J. Kortman, G. Hrauda, R. Pfitzner and D. Velte (2003) Eco-Service Development: Reinventing Supply and Demand in the European Union (Sheffield, UK: Greenleaf Publishing).

Belk, R.W. (1985) 'Materialism: Trait Aspects of Living in the Material World', Journal of Consumer Research 12: 265-280. 
Ceschin, F., and C. Vezzoli (2010) 'The Role of Public Policy in Stimulating Radical Environmental Impact Reduction in the Automotive Sector: The Need to Focus on ProductService System Innovation', Int. J. Automotive Technology and Management 10.2/3: 321-341.

Davoli, L., Fiocchi, F., and J. Lin (2008) Vehicle Design Summit 2.0: introduction of sustainable mobility systems in emerging contexts. Master's degree thesis, Politecnico di Milano, Faculty of Design.

Hacker, A. (1967) 'A Defence (or at Least an Explanation) of American Materialism' Sales Management, March 1967: 31-33.

Halkier, B. (1998) Miljbhensyn i Forbrug. Erfaringer og Forhandlinger i Ambivalente Hverdagsliv (Roskilde: Institut for Miljb, Teknologi og Samfund, Roskilde Universitets).

Hjelmslev, L. (1943) Prolegomena to a Theory of Language (Madison, US: Wisconsin Univ. Press).

Jackson, T. and N. Marks (1999) 'Consumption, Sustainable Welfare and Human Needs - with Reference to UK Expenditure Patterns Between 1954 and 1994' Ecological Economics 28 (3): 421-441.

Jakobson, R. (1963) Essais de linguistique générale (Paris, FR: Minuit).

Kilbourne, W.E., Beckmann, S.C., and A. Lewis (2001) 'A multinational examination of the role of the dominant social paradigm in environmental attitudes of university students', Environment and Behavior 33 (2): 209-229.

Marrone, G. (2009) L'invenzione del testo (Bari-Roma, IT: Laterza).

Marsciani, F. (2007) Tracciati di etnosemiotica (Milan, IT: Franco Angeli).

Max-Neef, M. (1991) Human Scale Development: Conception, Application and Further Reflections (New York, US: The Apex Press).

Max-Neef, M. (1995) 'Economic growth and quality of life: a threshold hypothesis', Ecological Economics 15: 115-118.

Mont, O. (2002) 'Clarifying the concept of product-service system', Journal of Cleaner Production 10 (3): 237-245.

Mont, O. (2004) 'Institutionalisation of Sustainable Consumption Patterns Based on Shared Use', Ecological Economics 50 (1/2): 135-153.

Mont, O., and T. Lindhqvist (2003) 'The Role of Public Policy in Advancement of Product Service Systems', Journal of Cleaner Production 11 (8): 905-914.

Mont, O., and A. Plepys (2008) 'Sustainable Consumption Progress: Should We Be Proud or Alarmed?', Journal of Cleaner Production 16: 531-537.

Peirce, C. S. (1878) 'How to make our Ideas clear', in Writings, vol. III (Bloomington: Indiana Univ. Press, 1986).

Røpke, I. (1999) 'The Dynamics of Willingness to Consume' Ecological Economics 28: 399-420.

Tamborrini, P. (2009) Design sostenibile. Oggetti, sistemi e comportamenti (Milan, IT: Mondadori Electa).

Vezzoli, C. and F. Ceschin (2008) 'Modelli di business alternativi per l'industria automobilistica' Trasporti \& Cultura, Campanotto Editore 21: 46-57.

Zingale, S. (2009) Gioco, dialogo, design (Milano, Italy: AT ì). 


\section{以服装业为例分析可持续的消费 者满意系统}

齐尔希·尼恩伊玛姬（Kirsi Niinimäki）

芬兰阿尔托大学, 艺术与设计学院 (Aalto University School of Arts, Design and Architecture, Finland)

\section{1 引言}

近三十年来, 随着科技的进步, 工业制造过程中对环境的负面影响逐渐减小。然 而, 产量和消费量的同步增加使该趋势存在反弹的风险, 甚至将引起资源消费的 大幅增长（斯隆-赫斯特等, 2007)。赫特维克（2005）认为, 这是一种逆火效 应, 也就是说高生产率和低廉的价格会导致需求的增加。于是, 产品低劣的质量及 它低廉的价格对客户产生了诱惑, 非可持续性消费模式就产生了：即兴购买, 短期 使用, 然后随意丢弃。尽管从技术上来说, 生产经久耐用的产品是可实现的, 但是 在实践中，这种做法往往会被经济上的、制度上的、或者心理上的因素所阻碍。

当下，产品的快速更迭和限期报废（为增加销量故意制造不耐用商品）是经济 和工业体制的基础。因此, 产品的经久耐用已然不是生产目的, 而且旧产品修理也 成为一件不划算的事情。于是, 在欧洲, 大部分产品最后都被丢弃, 越来越多的产 品在没有达到它的最优使用寿命之前就被过早地被丢弃了。这不仅仅是由于产品破 旧了, 还因为消费者热衰于使用新奇的产品。然而, 可持续消费的前提是产品本身 耐用并且能实现长期使用。库普 (2005) 认为, 消费者往往将耐用与高质量相关 联，却没考虑到耐用本身还有利于保护环境，而在可持续发展方面，延长产品的使 用期限非常重要。 
如今, 限期报废现象在工业中很普遍, 在服装行业就是一个典型的例子。服 装的设计和生产总是紧随时尚元素和消费者短期内的需要而进行的。而这种非可持 续的生产模式在日用品行业也越来越常见。这种模式导致服装质量低劣, 使用周期 短, 频繁地舍旧换新, 导致源源不断纺织废料的产生, 这些都带来了严重的环境负 荷。2005至2010年, 英国的纺织和服装垃圾以惊人的速度增加, 如今每年的垃圾量 可达到150到200万吨（英国环境、食品和农业部（Defra）2008）。导致这个结果 的直接原因是1995年至2005年期间英国的纺织服装消费大幅上涨, 涨幅甚至超过了 30\%（英国环境、食品和农业部（Defra）2008）。据估计，现在英国市场上销售的 服装, $20 \%$ 是劣质的短期流行款, 而仅在1996年至2006年的10年里, 这类产品就增 加了一倍（英国环境、食品和农业部（Defra）2008）。

时尚和潮流加上有效的营销体系, 带给了消费者以新的诱惑, 激发了他们 的购买欲望。潮流的快速变化致使心理淘汰 (psychological obsolescence) 的出现, 根据伯恩斯的观点, 这种淘汰又可以分成审美淘汰和社会淘汰 ${ }^{1}$ 。伯恩斯

(Burns, 2010) 认为, 消费者购买的服装类产品都需要从审美和社交两个方面进行 评价。产品对于消费者而言是具有象征意义的, 能够引起消费者情绪上的回应并产 生心理上的满足感; 比如说, 消费者可以通过着装和追随时尚来赢得社会认可, 获 得珍贵友谊以及情感上的美学体验。

先前的研究表明，欧洲消费者之所以买服装，其原因按先后顺序，依次为： 时尚潮流的转变, 有吸引力的价格, 特殊场合的需要, 品牌力量, 购买习惯和以 旧换新。事实上, 除了实际需要或使用方面需求, 消费者也常常有许多无意识的 消费行为。因此, 减少消费量是一项极具挑战性的工作。然而, 必须通过可持续 性模式让消费者得到心理上的满足, 这就意味着我们需要学习如何让消费者产生 更深层次的心理满足感, 从而延长产品的使用时间。所以, 研究消费者在产品长 期使用过程中的满意度状况是极其重要的, 更重要的是要找出导致产品使用时间过 短的决定性因素, 也就是要知道人们为什么很快就把服装丢弃。在服装业, 为了引 导消费者接受可持续消费模式，人们也曾经尝试制定过几个方案，例如可持续家庭 (SusHouse) 项目 (维佐里 (Vezzoli) 2000)。

因此, 这一章探讨的是西方工业化进程之后, 服装行业的消费者满意度情况。 此外, 我们也从设计策略和产品服务系统思维的角度来分析消费者满意度, 并就如 何通过服务来提高消费者满意度并相应地促进可持续消费展开讨论。本章既从微 观视角, 又从宏观视角来分析满意度问题, 其实也就是一种点面结合的方法。首 先, 我们所谓的 “点” 就是要掌握服装行业消费者满意度最新研究结果, 然后, 在 探讨该问题的时候，把设计策略和服务两方面都考虑进来，即应用到“面”上去。 这样, 本章既对消费者满意度进行了深入的经验性分析, 同时也通过产品服务系统 (PSS) 思维, 就满意度展开了一场更为开放的理论探讨。 


\section{2 以消费者为导向的生态效益}

直到最近，消费者满意度才在服装行业和设计领域中得到广泛研究。因此，目前在 如何实现消费者对不同类别产品的可持续满意方面我们所掌握的知识还十分有限。 这种满意度研究方法的提出, 把设计的焦点从原来的单个产品扩展到了整个产品服 务系统, 甚至把不同的利益相关方也考虑了进来, 这样一个整合系统满足了消费者 的需求和愿望（维佐里 (Vezzoli) 2010)。

斯隆-赫斯特 (Throne-Holst) 等人 (2007) 认为, 在我们的消费模式向可持 续性模式转变的过程中, 人们需要更加深入地了解消费环节; 而可持续消费与生产

(Sustainable Consumption and Production, SCP) 模式也得出了相同的结论, 可 持续发展要求对生产和消费两个方面给予同等的关注。这种生态效益方法关注的仅 仅是生产, 一般来说, 就是 “用更少的材料生产更多的产品”，并通过发展科技和 改进系统, 减少资源消耗, 从而达到节约成本的效果。其中还运用了一种技术经济 与工程的方法, 来减少工业生产过程对环境的影响。自1990年以来, 由于行业利益 忽视了当今不可持续消费模式中人类需求的层面，行业的可持续发展受到了极大的 制约。总而言之, 尽管工业生产率越来越高, 但由于商品很廉价, 导致产品生产量 和消费量也大幅增加（麦克利斯（Michaelis）2001）。

帕克 (Park) 和塔哈勒 (Tahara2008) 认为, 生态效益只能作为设计领域的一 项评估内容, 而不能用来衡量产品的关键性可持续问题。他们建议把基于生产方的 生态效益与基于消费者的生态效益结合起来, 以便更好地识别生态设计中的重要问 题。在这个过程中, 不仅要对产品对环境的影响进行分析, 而且要对产品的质量和 消费者满意度进行评估。获得消费者满意度的最好方式是, 为消费者提供他们最关 注的产品方面的性能, 并提高产品的内在质量。这就要求我们必须非常了解消费者 真正想要的和重视的到底是什么, 要明白他们实际上购买的并不一定就是他们真正 想要的。

\section{3 消费者满意度}

先前关于产品依恋感的研究表明, 产品和用户之间的积极情绪、回忆、特殊意义和 反思等都能使用户对产品产生依恋（例如：西克森特麦哈伊埃 (Csikszentmihalyi) 和莱克伯格-浩顿（Rochberg-Halton）1981；麻吉（Mugge）等2005；尼尼麦基

(Niinimäki) 2010a)。产品依恋感是长时间形成的, 包括感觉、情绪、自我形象、 个人满足、回忆和认知等 (2005) 。因此, 情感依恋很个人化, 而且主要是与那些 不穿的旧服装有关（尼尼麦基（Niinimäki）2010a）。我们在拥有和使用产品的时 候, 对消费者和产品之间的关系还不够了解, 然而, 这个过程对于我们理解产品替 换又非常重要（麻吉 (Mugge) 等 2010)。

之前的几项研究表明：产品必须要经过更细致和深入的检验才能产生积极的体验。 积极的产品体验是指用户在使用过程中, 产品的物理因素、样式和实用性（弗罗利基 (Forlizzi) 等 2003) 以及在使用阶段的相关操作（玛高琳（Margolin）2002) 
和产品本身的固有特性（诗非斯坦 (Schifferstein) 和兹瓦特克里斯-派尔格里姆

(Zwartkruis-Pelgrim) 2008) 能够提供给用户愉悦感和满意度的过程。

\subsection{1 对服装的满意度}

有关产品满意度的研究都一直在关注(不)满意的确定规则, 对产品性能来说, 消费 者有自己的标准, 如果产品的性能没有达到他的预期, 那么他就会不满意（丘吉尔 (Churchill) 和修普瑞兰特 (Surprenant) 1982; 奥利佛 (Oliver) 1980)。奥利佛 (Oliver, 1980) 认为, 消费者对于产品的预期构成了一个参照系, 消费者就是在这 个参照系之下对产品做出自己的评价。这种参照系的定位与产品使用场合有关, 因 此, 产品与它使用场合的不同, 所对应的参照系也不同, 也就是说, 消费者的预期 是由产品的使用场合及其象征意义共同决定的。比如说, 工作服就有一定的着装要 求, 必须被社会认可, 符合社会规范, 体现职业素养。家居服装给人一种放松的感 觉, 质地柔软, 带给人安全感。而运动服最重要的特征就是舒服和耐穿。此外, 消 费者的个人因素也会影响该参照系的确定, 个人的满意标准在消费者评价产品的时 候显得极其重要。

斯旺 (Swan) 和康博斯 (Combs 1976) 认为, 服装性能分为使用性能和 表现性能; 服装的使用性能是指其物理特性, 能够保护我们的身体, 具有实用性 （凯瑟（Kaiser）1990），而其表现性能指的是消费者对那件服装的心理反应。 首先, 服装必须具备使用性能, 但是仅此还不能使消费者满意。因此, 要让消 费者完全满意, 服装还必须要满足消费者的情感需求（斯旺 (Swan) 和康博斯

（Combs）1976）。时装的出现标志着服装设计中已经融入了感情因素, 并通过各 种外在符号和状态来表现我们的内在个性（凯瑟（Kaiser）1990）。而审美体验对 服装的满意度也很重要, 它与服装的表现性能有关。我们通过多种感知方式考虑服装 的美学设计。服装的美不仅可以通过视觉感受到, 还可以通过触觉、嗅觉和运动体验 感受到, 例如舒服的感觉和服装的重量感觉等（尼尼麦基（Niinimäki）2010）。

为了获得服装长期满意度方面的更多信息, 2010年我们在芬兰展开了调查 ${ }^{2}$, 这 次的调查结果证实, 消费者的预期和现实之间的最大矛盾在于所提供的产品无法满 足消费者的预期。比如：我们都知道，现在西欧国家 $90 \%$ 的服装都是进口的（英国 环境、食品及农业部（Defra）），而这里44\%的消费者愿意买国产服装。在分析调 查问卷时, 我们发现, 人们在买服装的时候, 考虑环境效益是一回事, 但真正去实 践这种可持续的价值观又是另外一回事。3而对于那些不太坚定践行可持续发展的调 查对象来说, 上述因素就不会影响到他们的购买决定 ${ }^{4}$ 。此后, 本章节将会详细讨论 这些方面是如何影响消费者满意度的。

2 本问卷采用 “滚雪球抽样” 的方法, 调查对象共有 204 人。大多数的受访者年龄在 35 岁以 下, $70.4 \%$ 的受访者是女性。

$3 \mathrm{n}=37$

4 即他们对此项声明持完全或部分不同意态度, 或也许根本不知道这些方面是否会对他们的 购买行为产生影响 $(n=77)$ 。 
在调查问卷中, 调查对象需要对最近一次购买的服装作出评价。根据调查问卷 结果, 美观对消费者来说很重要, 然而, 就满意度而言, 服装的尺寸、颜色、质感 和审美体验更为重要。

另一方面，产品的使用期限是消费者考虑的一部分，以及产品信息，其中包括 生产地（在哪制造的），材料一致性和保养说明。尤其是生产地，在购买时，消费 者会根据产地衡量一种产品的质量, 它是消费者鉴定产品质量的一个重要的外部线 索（详见2.3.4一节）。服装满意度的根本是服装的质量。

\subsection{2 长期与短期用途}

在芬兰的调查中，当被问及服装的哪些方面让他们不放心时， $78 \%$ 的女性和 $68 \%$ 的 男性都担心服装的使用期限过短。当被问到他们服装的最长穿着年限时，74\%的男 性和 $66 \%$ 的女性的回答是 5 年以上。而最短使用时间，10\%的男性和 $22 \%$ 的女性回 答不超过一个月。此外, 消费者对社会道德和环境问题的态度也影响着服装的使用 时间：在践行可持续发展理念的消费者中，84\%的消费者的服装穿了5年多时间，只 有 $14 \%$ 的人说有些服装只穿了不到一个月。而对不太坚定执行可持续发展观念的调 查对象来说， $59 \%$ 的消费者的服装超过 5 年而 $22 \%$ 的消费者的服装消费时间不足一个 月。总之, 消费者对可持续发展这种价值观的态度会影响他们的服装的使用时间

在这次调查中, $51 \%$ 的人说买新服装是因为需要改变形象 5 。那些在购买服装 时身体力行可持续价值观的人（坚定奉行可持续发展理念的人），19\%的人说，他 们最近一次买服装是即兴购买, 而这个数据在不坚定奉行可持续发展理念的人中是 $31 \%$ 。

有些调查对象承认, 他们曾经一时激动就买了一件粗制监造的便宜货, 而他 们也没期待要穿很长时间。此外, 有些人在接受调查时说他们在购买便宜货的时 候，不会考虑那么多。在开放式问题的回答中，有人说即兴购买会导致做出错误的 购买决定。这些消费者后来发现, 那件服装不怎么合身, 颜色也很奇怪或完全不搭 配, 而且服装料子摸起来也不舒服, 或者和现有服装的风格完全不搭, 这些都说明 了服装的表达性能没有达到消费者的预期。他们可能永远不会再穿这些由于冲动而 错买的服装。因此, 消费者被便宜的价格诱惑而进行的即兴购买, 这样往往达不到 购买预期, 最后还是把这些服装弃之不用。

通常, 消费者把优质与高价联系在一起, 而把劣质与低价联系在一起。而 且, 价格越高, 消费者在买之前就会考虑得越多。参与调查的人们也给出了他们长 期使用的一些理由, 比如季节性服装或不会经常用到的节日服装（例如：冬季/夏季 服装, 节日盛装）。在接下来的部分, 我们将描述决定服装长期使用的三个决定因 素: 质量、美观和功能。

$577 \%$ 的受访者回答, 近期产生购买行为的主要原因是自己确实需要一件新衣服。 


\subsection{3 质量}

奥夫伊斯（Ophuis）和特雷普 (Trijp）（1995）提出了感知质量一说, 也就是说 产品的质量评估由用户自己来判断。两位作者认为, 感知质量是对四个方面所做的 综合评定, 即感知过程、个人因素、使用过程和产品的性能。他们还把质量分成 质量线索和质量属性两个方面。质量线索是在未使用或消费之前就可以观察到的 产品特征, 而质量属性是只能在使用过程中体会到的产品属性。此外, 奥夫伊斯

(Ophuis) 和特雷普（Trijp）还特别指出了之前提到的内在和外在层面的内容, 并 认为内在层次与产品的物理特性有关。外在特征也与产品有关, 但是并非与其物理 特性有关, 比如价格。

因此, 消费者可以根据使用经验来评价产品的质量属性, 然而, 信用质量 属性仍处于认知水平, 并不能直接依靠服装的外观和使用经验而确定（奥夫伊斯

(Ophuis) 和特雷普（Trijp）1995）。服装的信用质量属性包括某些价值观，比 如符合伦理的生产制造和低环境影响, 而它们的重要程度取决于消费者个人价值观

（奥夫伊斯 (Ophuis）和特雷普（Trijp）1995）。那些注重环境问题的消费者比其 他消费者更珍惜生态材料, 更重视符合伦理的生产制造, 而且他们服装的使用时间 比其他消费者更长（尼尼麦基（Niinimäki）2010c）。

消费者体验到的质量属性对长期使用的服装来说至关重要。芬兰的问卷调查 结果显示, 高品质是服装使用周期长的最重要因素。调查对象还进一步表示, 高品 质就意味着产品耐用、材料结实和较高的制造水平。在调查中, 有些值得评论的答 案表明了服装使用周期短的决定因素。其中，有些人认为服装使用周期短是因为服 装的质量不好。另外, 还有一些人回答说, 有些服装在第一次洗过之后, 就不再穿 了, 因为在那之后, 要么服装的大小尺寸变了, 要么服装的颜色和材质看起来就像 是旧了一样。很多消费者都有过这样的经历, 在第一次洗过之后, 服装就不再合身

（例如：服装缩水或者变形）或开始褪色。有些服装甚至在第一次洗之前或洗的过 程中, 就裂开了。因此, 服装的不耐用, 尤其是容易变形似乎是造成消费者不满意 的关键因素，从而导致服装的使用周期短。

\subsection{4 审美角度}

显而易见，消费者选择服装的时候需要有审美体验，而这种体验是与一定社会场合 下对服装的评价有关。当问卷中问及，最近一次买服装时考虑的需求是什么，38\% 的女性和 $8 \%$ 的男性说希望服装美观漂亮。而同样的问题中，13\%的男性和 $6 \%$ 的女 性说, 不同场合对服装的特定要求影响了他们最近的购买决定。当被问到最近一次 买服装时最看重那些因素时, 回答风格的人占 $69 \%$, 尺寸 $67 \%$, 和现有衣柜搭配 $51 \%$, 材质 $44 \%$, 颜色 $42 \%$, 这些都是很重要的因素。在买服装的时候, 所有这些 特点都是审美属性，甚至其中有些因素比价格（64\%的人选择）和质量（54\%的人 选择）更重要。

从服装满意度来看, 审美属性属于表达性能, 并与消费者对服装的心理反应 有关。调查对象也是以服装的使用周期长为出发点来考虑审美属性的。在开放式的 问题中, 他们提及了与服装使用周期长有关的几个因素：合身、私人定制、颜色 
漂亮、柔软舒适。服装的触感对穿的人来说非常重要, 甚至有人说某些材质在长 期使用过程中会感觉越来越舒服（如材质渐渐软化）。也有人指出服装使用周期 长也因为其款式和颜色都很经典, 即使时尚潮流已改变, 它们看上去也还是很不 错。其中还有一个人这么评价, “不随潮流”的服装其使用周期往往会更长。因此 很显然, 服装的使用周期短还有一个原因, 即过于追求外观时髦, 总害怕服装不够 前卫。这种心理上的害怕过时导致产品在还能使用的时候就被过早地丢弃。另一方 面, 某些调查对象也表示, 他们之所以保留一件服装是因为某种漂亮的颜色或特殊 的款式。在这种情况下, 表达性能已上升到了更高层次, 不仅达到了消费者满意 度, 也成为他们保留这件服装的理由。

若要确保一件令人满意的, 漂亮的服装不那么快就落伍, 那么它不仅要款式经 典, 品质优越, 所用材料还要耐用。有些面料短暂使用之后, 就变得老旧不堪, 如 起求的面料。还有些调查对象表示, 那些需要经常洗的服装比不需要经常洗的服装 看上去要旧, 并且更容易变旧。某些衣料的老化不但没有影响其美观反而变得更耐 看, 而另外一些衣料却并不如此。早期的研究表明, 高质量的羊毛衫的老化过程并 不明显, 而真皮服装老化后甚至变得更有韵味（尼尼麦基（2010a）。当被问及他 们穿的最久的服装是什么面料的时候, $83 \%$ 的人回答是纯棉, $68 \%$ 的人回答是羊毛 衫, $40 \%$ 的人说是真皮。聚酯纤维是全球产量最高的纤维材料 $(2009$ 年占 $62 \%$, 西 皮莱（ (2003），然而只有18\% 的受访者提到它。

\subsection{5 功能性}

当问卷提到, 哪种因素使你开始喜爱服装时, $84 \%$ 的人选择了这一说法: 服装很合 身, 并且适合情境需要, 我就会喜欢上它, 而且穿很长时间。在关于服装使用寿命 的开放性回答中, 实用性和功能性也被多次提到。对于特殊的服装, 如登山运动服 和帆船运动服装, 而最重要的是优秀的设计。运动服会经常使用, 因此服装材质要 耐用, 制造工艺也要更细致结实。由于运动服质量好, 经久耐用, 消费者甚至把它 当成日常必需品。一位调查对象说, 最好的服装是既耐用, 又实用, 消费者在穿着 过程中能够体会到设计的别具匠心，就像航海服和登山服那样的服装。

在关于服装使用寿命的开放性回答中, 易于保养这方面也被提及。那些不需要 经常清洗或通过蒸汽清洁的（如羊毛衫）服装很受消费者欢迎。细致的保养也是延 长服装使用时间的一个原因。好的保养是指轻柔地洗护它, 织补破损的地方, 甚至 还要进行适度的修整, 以延长它的使用时间。

\subsection{6 服装长期使用的总结}

调查对象重点强调是下列属性使得他们长时间使用某种服装：质量方

面, 包括耐用性; 功能方面, 如令人满意的使用体验; 审美属性, 如美观和质感。 优秀的服装设计应该涵盖所有这些方面。对于那些非常重视伦理问题和环境问题的 消费者来说, 以下的这些观念在他们选择服装时很重要, 并且与对服装的满意度有 关：采用本地生产或符合伦理的生产制造，使用生态材料，服装的耐用性。这些环 境因素与消费者的个人价值观有紧密联系, 因此它们属于信用质量属性的范畴。对 
这些消费者而言, 可持续性方面的属性已包含在其个人对产品的预期中, 在这样的 基础上, 他们再针对产品做出自己的评价。因而, 为了获得更高的产品满意度, 就 必须达到他们在服装可持续性方面的预期。消费者也表示, 如果在购买的时候就能 对这些属性进行衡量的话, 那么他们很愿意付高价买质量更好的、使用时间更长的 产品 6 。然而, 衡量这些特点有一定的难度。关于服装的质量和最佳使用时长, 目前 也还没有任何信息支持; 如果有, 这些信息将体现产品的质量, 这使得为那些高品 质, 耐用的和使用寿命长的产品定价成为可能（尼尼麦基2010b）。

\section{4 通过设计策略和产品服务系统来提高满意度}

到目前为止, 本章采用相对单一的方法, 并以消费者为中心, 讨论了服装行业中消 费者满意度的问题。接下来, 我们将会以更广阔的视角来分析满意度, 进而对设计 策略和产品服务系统领域展开探讨, 并分析在使用产品或获得服务的过程中, 它们 是否能够提高消费者满意度。这要求我们开展理论方面的探讨：如何通过不同的设 计策略, 来延长该行业产品的使用寿命或降低其对环境的影响。2.4.7一节将总结消 费者对这些策略的重视和接受程度。

\subsection{1 多重生命周期}

麦克唐纳 (McDonough) 和布劳恩加特 (Braungart) (2002) 建立了“从摇篮 到摇篮” 的原则, 这项原则考虑到产品的下一个生命周期。这么做的好处是在制造 过程中减少原材料和能源的消耗。斯坦尼齐普 (Steinhilper) (2006, 格雷和查特

(Charter) 引用 2007：14）认为，再制造过程比使用原材料进行制造节省约 $85 \%$ 的能源。同时也可以大幅减少二氧化碳排放量。例如: 日本天神节纤维有限公司

(Japanese Tenjin Fibers Ltd.) 的数据报告显示, 采用可回收的材料制造聚酯, 二 氧化碳排放量降低了 $77 \%$ 。在设计初期产品的时候, 需要对再制造概念进行仔细深 入的考量。要保证产品在首次使用之后, 便于拆卸, 而不应当包括不可回收利用的 零件或混合材料。目前, 服装的回收是个大问题, 因为大多数的服装都是由混合材 料制成, 并且各部分还不易分离。此外, 如今的服装质量低劣, 服装行业的回收利 用已不再有利可图。目前, 大约 $70 \%$ 的废弃服装最后都被填埋了, 剩下的或被重新 使用, 或被回收（弗莱彻（Fletcher）2008）。

再生产过程中最关键的问题是质量。回收后再利用, 材料的质量会变差, 产品 和材料的价值也就降低, 人们称之为降级回收（麦克唐纳 (McDonough) 和布劳恩 加特 (Braungart) 2002)。某些材料会很适合再生产循环使用（如涤纶、尼龙、丙 纶）, 然而, 其他材料在反复循环使用的过程中质量就会大大降低, 只能被循环使

6 调查中, $83 \%$ 的受访者对这种说法持完全同意或比较同意的态度。

7 www.teijinfiber.com/english/products/specifics/eco-circle.html 
用一次 (如纯棉)。无论如何, 我们要重视多次回收利用策略, 否则纺织业将不可 救药地朝着聚酯生产的方向发展, 越来越倚重不可再生资源, 如石油。

这种策略在实践中也有应用，如澳大利亚巴克豪森公司（Backhausen）

“回收” 特雷维拉新型阻燃面料 (CS) , 这种材料是可回收的, 而且其回收过 程也非常环保8。在第一次使用之后, 面料可被工厂回收。同样的, 瑞典胡迪尼

(Houdini) 运动装也在实施服装回收计划一一该活动在各大零售店放置一个回收 箱, 把回收的服装直接送回制造商那里 ${ }^{9}$ 。多次回收利用策略非常注重生态效益, 它 要求消费者在购买的时候预交部分定金，消费者送回使用过的产品给商店就可以取 回这笔定金（尼尼麦基（Niinimäki）和海希（Hassi）2010）；例如：瑞典攀山鼠

(Klättermusen) 服装公司就规定, 消费者返还服装，就退还其定金 ${ }^{10}$ 。

调查研究发现, 从那之后, 有 $61 \%$ 的调查对象在处理服装的时候会考虑到面 料对环境的影响; 另外 $76 \%$ 的人会担心服装的使用寿命过短, 而多次回收利用策略 能够给消费者带来价值, 这使消费者对自己的购买决定感到满意。回收利用的做法 本身并不能延长服装的使用时间，但是它提供了一个比现有体系更环保的新服装制 造模式。它为消费者提供了一条捷径来降低他们对环境造成的影响, 同时又不要求 他们的消费模式有很大的改变; 因此, 这种方法很容易被消费者和制造商接受。然 而, 这就要求我们找出新的适合回收的服装设计方法, 同时针对服装和纺织面料建 立有效的回收利用体系。

\section{4 .2 本土生产}

把原材料的生产和产品制造转移到离终端市场更近的地方, 可以减少运输过程中的 二氧化碳排放。本地生产也有多种纺织材料和生产模式可供选择。例如：芬兰可以 种植亚麻、菖麻和大麻。这些植物除了水, 只需少许甚至无需肥料和杀虫剂就可存 活。韧皮纤维 (亚麻, 大麻和黄麻) 植物可以种在适宜耕种粮食的地里（哈卡萨尔 米 (Härkäsalmi) 2008; 弗莱彻 (Fletcher) 2008)。韧皮纤维加工酶可用于避免 污染。酶类可作为生物催化剂, 它们可以在这些植物生长的不同阶段使用, 如亚麻 软化阶段。如果没有酶, 植物的生长就需要消耗更多的能量和化学制品（涅米宁

(Nieminen) 等 2007)。

最近, 很多小型设计公司开始注重向本地化生产方向发展, 它们注重生态问 题, 并使用生态材料组织生产, 并通过网络和在线的方式来销售它们的产品。例 如: 芬兰的莫鲁 (Muru) 公司使用的是印度生态棉, 这种棉首先在德国采用环保工 序进行染色, 然后再运到芬兰进行小规模的加工, 包括设计, 对材料进行工业编织 并缝制11。这种以设计为中心, 进行小规模生产并结合当代设计的方式受到了广大年 轻设计师的推崇, 这种设计方式以采用进口生态材料, 组织本地生产, 并结合在线 销售为特征。

8 www.returnity.at

9 www.houdinisportswear.com/en

10 www.klattermusen.se

11 www.muru.fi 
既然本地生产得到了大多数消费者的认可, 那么就很有必要采用这一选项。消 费者会根据生产地点来评估服装的质量及其生产过程对环境的影响, 因此, 对他们 而言, 这是一项信用质量属性。然而, 生产厂家经常不标注服装的产地信息, 服装 行业的消费者将此视为一种负面内容。也就是说, 消费者认为厂家忽视了他们的意 见和价值观。这意味着产品未能达到消费者的预期, 重要信息的缺失使消费者感到 不满。

\section{4 .3 慢/快}

考虑到环境因素, 既简单又行之有效的办法就是减少消费。然而, 大部分消费者都 不愿意那么做。这种现状是慢时尚和快时尚设计理念的来源, 它综合考虑了两种 不同消费群体的需要。根据产品的预期使用寿命, 选择最好的材料和最好的保养 方法, 这样就有可能把纺织衣物对环境的影响降到最低, 并以一种更可持续的方 式，来满足两个对立的消费群体的不同偏好。消费者信息中应该包含对产品使用寿 命预期的信息。

服装使用期限已经缩短。在这项研究中, 当问及我们的调查对象在他们穿过 的服装中, 最短的使用时间是多久时：18\%的调查对象回答说不到一个月，10\% 回答说一两个月, $29 \%$ 回答说三到六个月, 另外有 $27 \%$ 的人则是七到十二个月。 荷兰的一项研究表明, 一件衣服在衣柜里存留的平均时长是三年零五个月。期 间, 人们穿它的时间只有44天, 而且每洗一次会穿2.4到3.1天, (优伊特登博格尔德 (Uitdenbogerd) 等 1998, 弗莱彻 (Fletcher) 引用 2008)。

经常洗涤衣服对环境的影响最大, 优化这一过程将降低那些时尚的消费者们给 环境带来的负担, 保养维护阶段的能耗和环境负荷可能达到产品整个寿命周期所需 的三分之二。由于材料和产品本身的不同, 其使用阶段中的能耗可能比实际生产过 程多六倍（泰温玛（Talvenmaa）1998; 富兰克林联合公司 (Franklin Associates) 1993, 弗莱彻 (Fletcher) 引用 2008)。随着服装中使用的涤纶含量增加, 服装的洗 涤频率也增高。

慢时尚的设计旨在通过提高其耐用性和质量, 来延长产品的使用时间, 从而达 到延长产品寿命的目的。它采用的是一种伦理性设计, 例如: 小批量本地生产, 优 良的工作环境, 以生态材料为主要原料。通过这种方法设计出的产品有较长的生命 周期, 因为服装的风格和颜色都很经典, 选用的面料也很得当, 因此提升了服装的 审美价值（尼尼麦基（Niinimäki）2009a；弗莱彻（Fletcher） 2008）。德国赫斯自 然公司 (Hess Natur) 就是表现慢时尚理念的一个典型的例子。根据一项消费者调 查, 德国赫斯自然公司 (Hess Natur) 设计了一系列新服装, 它们的特点是: 所用材 料健康自然, 耐用且时尚美观, 品质高, 便于使用, 可更新, 可修补, 同时还附有 多重功能。他们设计的“耐用”系列服装确保服装能持久使用（如三年）, 并且这 个信息会添加到消费者信息中（勃利诗 (Paulitsch) 2001）。生命周期长的产品会 吸引那些注重可持续发展的消费者。高品质, 并承诺 “终生保障” 的产品满足了那 些注重环保观念的消费者的需求。

而快时尚概念会更适合那些紧跟潮流, 用外部时尚元素去定位自我的消费者 （尤其是年轻的消费群体）; 因而, 此类产品的使用寿命是短暂的。为了以较为可 
持续的方式满足这一消费群体的需求, 应对产品进行优化, 尽量延长产品的实际使 用寿命, 并把保养维护阶段的负面影响减到最低（如：在使用期间尽量免洗, 或少 洗）, 选用对环境影响小、可回收或能进行生物降解的材料。快时尚型的服装在穿 过几个月之后, 就会被返回到回收系统, 或者送回网络交易市场或商店, 如通过互 联网进行回收（尼尼麦基（Niinimäki）2009a，弗莱彻（Fletcher）2008）。

麻吉 (Mugge) 等人 (2005) 指出, 把不同的生态设计策略结合到一起, 共 同促进可持续性消费, 这是明智的做法。如把慢时尚和本地生产结合起来, 对服装 设计来说, 意味着产品的质量会更好, 可持续价值更高。此外, 把设计服务元素

（见下一节内容）整合到这种方式中, 能够取得长期的产品满意度, 并能够增强消 费者对产品的依恋感。另一方面, 我们也应把快时尚设计和多生命周期策略结合起 来, 这样才有利于消费者, 如逆向物流等。把这些服务应用到上文所述方案中, 如 网络服装交易体系, 可增加服装的使用频率并延长它的使用寿命, 从而降低年轻一 族消费选择的不稳定性对环境带来的负荷。

\section{4 .4 独特性与成就}

消费者通常是通过产品自身所具有的象征意义来传达自己的个性。诺曼（Norman 2005) 认为, 产品是我们表达自我的媒介, 它们可能是某些特征、独特性或者我们 认同的价值观的表现符号。格沃斯 (Govers) 和斯科曼斯 (Schoormans) (2005) 认为, 消费者更喜欢那些与他们自我形象和自身理念相一致的产品。查普曼

(Chapman 2009) 指出, 如果产品被设计得个性十足, 那么就有可能产生更深层次 的产品满意度和一种产品依恋感。总之, 这是延长产品寿命的一个很好的办法。

通过把设计的效果和消费者的个人需求和审美偏好紧密相连, 设计服务是一个 提升消费者满意度的机会。通过提供数字纺织技术, 我们可以实现具有独特性的设 计(尼尼麦基 (Niinimäki) 2009b)。大规模按定制化服务采用的是灵活的数码制造 技术, 为的是在分散的市场中满足制造方和个人用户两者的不同需求（潘恩1993; 李(Lee) 和陈 (Chen) 2000) 。此外, 与大规模生产的服装相比, 独特的设计和 “私人定制”服务能够更好地满足消费者的个人需求, 从而获得更高的产品满 意度。

诺曼（Norman2005）认为, 个人成就与积极的自我意识有很大关系。设计产 品时, “由我制造” 的情绪会让消费者产生积极的产品体验, 因为产品中含有他自 己的努力, 带给他成就感, 也给了他展示创新能力的机会。如果是用户自己生产的 产品, 他就会更了解这个产品, 并且当需要的时候, 他也能够修理自己生产的产品

（帕帕内克（Papanek）1995）。产品可以被设计成模块结构，这样消费者可以自 己缝制, 甚至创造出独特的新款式。

通过设计服务或 “自行制造” 的方式来激发独特性和成就感是提升消费者满意 度的一种可行的方式。通过提升满意度, 可以建立或加强产品与消费者之间的感情 联系, 反之, 这种深厚的依恋感也是延迟产品被丢弃的最好方法。当产品或其使用 过程对消费者而言具有特别意义的时候, 她会珍惜它并长时间使用它。 


\subsection{5 长时间高强度使用产品的维护}

正如本章之前所强调的，由于消费者的需求和偏好会随着时间而改变，如何消除消 费者对服装过时的心理感觉就会成为一个问题。延长产品寿命的关键在于让消费者 持续不断地对产品产生满意感。范・内斯 (Van Nes, 2003) 为延长产品寿命提出 了以下的设计策略: 可靠性和稳固性设计、可升级性设计、修理和维护设计、产品 依恋感设计和可变性设计。其中, 许多设计策略建立在产品质量好和耐用性高的基 础上。如果一件服装质地优良, 价格不菲, 那么就很有必要好好珍惜、保养、改装 它或甚至把它重新设计成一件新服装。此外, 优质产品也很适合共享和高强度的 使用, 例如: 租赁和出租服务。其他服务, 如更新和修改服务等, 也会对新产品 的生产有所启发, 并不一定仅仅依靠实体产品满足消费者的愿望和需求。查普曼

(Chapman，2009) 认为新的元素有助于消费者和产品间持续地进行互动。服装的 模块化设计使消费者可以自行设计服装。那些教授 “如何自己重新设计旧服装” 的 网页，也鼓励消费者延长服装的使用时间。而且，通过互联网进行的服装交换服务 可以对服装进行改造和创新设计，同时他们还提出了一些新的商业模式。

有些服务旨在延长产品寿命, 它们为当地市场（如租赁、更新）和国外市场 （如批量生产、在线交易、自己动手制作等概念）都创造了新的商机。网络经营模 式允许厂商直接与消费者接触, 更好地满足他们的愿望, 同时省去了分销商这一环 节（斯坦赫（Stahel）2001）。确保在每个服务单元为客户提供满意的服务, 不断 满足客户的需求。这种服务提供了使用上的灵活性, 但拥有所有权的模式并不具备 这种灵活性。因此, 如果可能, 尽量不要拥有某种产品, 我们应该更加关注服务、 功能的实现或需求的满足, 而不是产品本身。

\subsection{6 共同创造}

共同创造为包括终端用户的多个利益相关方提供了共同创造的机会, 即协同解决 问题的机会（福德・路克（Fuad-Luke）2009）。这个过程使设计产生更为满意 的效果, 因为消费者有机会参与设计或决策过程。当用户积极地参与到设计过程 中, 他更容易对产品产生依赖, 并通过参与这一过程获得情感上的满足。例如: 通过互联网, 制造商有机会让消费者直接参与设计, 并以投票或评分的方式听取他 们的意见。至今, 制造商已经把互联网作为主要的信息渠道, 发布有关服装行业的 企业社会责任和社会伦理等方面问题的信息。可充分利用互联网来开发新的产品服 务系统，如根据消费者的价值观和愿望而定制的各种生产系统，服装终生质保系 统, 消费者环境影响评估系统等。

一些有趣的互联网方案（如：客户定制）已经开发出来, 但它们主要是为了增 加产品销量, 而不是从根本上为消费者在可持续背景下做决策提供新的功能。美国 无线T恤公司（Threadless）是秉承“共同创造企业” 理念的典型：消费者把他们的 设计上传到网站, 然后整个客户群对其进行评价, 節选出最具情趣的设计理念, 然 后下订单, 一旦某款设计的买家数量达到了规定的要求, 它就会被印在服装上。因 此, 公司清楚地知道应该生产哪种款型的服装, 价格是多少12。 
而且, 开源时尚是最近才在网络上兴起的一种现象。时尚设计师仍然可通过设 计款式和结构来出售他们的设计，但是终端用户实现的是设计的最终效果。这种方 法改变了客户的角色, 从一个消极的用户转变为一个积极的制造者, 并为消费者提 供了更多的选择。也就是说, 它使得时装业变得更开放, 更大众化。

\subsection{7 产品服务系统中的消费者权益}

相对来说, 我们的研究几乎不涉及产品服务系统中的消费者权益问题。关于产品所 有权, 有些产品更适合租赁, 而消费者只关注使用方面的问题。就服装业而言, 一 些元素如亲切感, 个人定位和个人认同感的深层关系, 以及它是否合适在某一社交 场合穿着等因素, 都会让这类产品不太适合长期租赁。另一方面, 这些因素以及服 装的象征意义为服装的设计服务和个性设计提供了空间。

在芬兰进行的这项调查中, 我们也探讨了人们对于不同的服装设计策略和服务 的兴趣。结果显示, 女性比男性对这些问题更感兴趣, 但整体结果显示, 现在正是 在服装行业实验产品服务系统方法并采取这种商业模式的大好时机。男女客户均都 对修复服务、改造服务、升级服务、定制化服务很感兴趣。大多数消费者对短期租 借并不陌生, 例如节日盛装, 然而这种服务也可延伸到其他服务中。这就需要根本 性的创新和消费者角色的重大转变, 以便于他/她参与到整个创新过程中来。这更有 可能让全社会接受新产品服务系统的那些重大的创新设计。此外, 消费者对服装交 易系统的兴趣最大。而且, 消费者也对服装回收感兴趣, 并乐于接受这种理念, 因 为这对他们的消费习惯影响不大。

然而，消费者对延长服装的使用时间并不感兴趣，正如本章所述，有些服装的 使用时间非常短。延长服装的使用寿命将降低时尚达人们给环境带来的负荷。

那些非常注重伦理和环境问题的消费者对于服装和家庭纺织品的选择有着自 己独特的看法, 独特性修饰和设计服务比起其他方面更让消费者感兴趣（尼尼麦基

(Niinimäki) 2009b，2010c）。利用他们对可持续发展理念的兴趣, 能够推动这些 服务成为比传统的大规模工业制品更加可持续的发展选项。多数西方消费者担心目 前的工业生产体系对环境造成的影响，因此，以可持续的方式来获取消费者满意度 被认为是市场营销的优势, 而且它还提供了新的商业机会。

\section{5 讨论}

早期研究表明（如：尼尼麦基（Niinimäki）2010c），消费者个人的伦理观念影响 着服装的含义和购买服装的决定。对于那些注重伦理和环境利益的客户来说, 他们 优先考虑的是生态效益和伦理价值, 服装的长期使用和本土化生产等因素。在这次 的研究中, 在关注可持续发展的用户中, $70 \%$ 的用户在购买服装时会将生态因素作 为一个重要内容进行考量（不关注可持续发展的用户中只有 $7 \%$ 的人做出了同样的选 择）。如果消费者知道他/她的选择是有利于可持续发展的, 并与他/她的个人价值观 （环境问题）相关联, 这就会给他们带来情感上和思想上的满足。因此, 采用产品 服务系统方法的厂商应该向消费者强调环境效益, 并指出选择它比选择传统产品更 
好。创新型的产品服务系统方法带来的改变, 尽管更加可持续, 但如果消费者不接 受, 这些改变将无从谈起

目前，纺织品的设计和生产过程并没有考虑到消费者的意愿、价值观和环境利 益。要改变这种生产和消费模式, 我们应该让消费者更加深入地参与到产品服务系 统 (PSS) 的新的可持续价值创造方面来。因为, 人们往往是在一定的社会背景下 对服装和消费者的外表进行评价, 所以, 关于新的可持续价值观的讨论将有助于提 高消费者或整个服装业对产品服务系统（PSS）的关注度。在设计过程中把消费者 当成是利益相关方进行考量, 同时采用设计服务思维, 这样才有可能令消费者满意 不同的产品系列。根据不同消费群体的价值观，把产品服务和价值观结合起来，以 便更好地满足消费者的实用和心理需求; 例如向那些注重环境利益的消费者提供产 品长期使用保证, 或向不断追求新潮的时尚爱好者提供交换存货服务。以消费者为 导向的生态效益要求具备以消费者为中心的研究知识, 这样, 我们可以在不同的环 境中识别影响满意度的因素并有机会对满意度单元进行定义。

帕克（Park）和塔哈勒（Tahara）（2008）强调, 产品的价值不仅要体现在购 买的过程中, 而且还要体现在使用过程中。如果达到了这点要求, 价格就应该与质 量、耐用性以及产品使用过程紧密相连; 反之, 产品价值应该与消费者满意度和可 持续性方面的联系更为密切, 如产品及其使用过程对环境的影响。从这点出发, 产 品或服务价值可以以满意度为标尺进行评估。因此, 把设计的焦点由审美体验和产 品生产环节转移到产品的使用环节, 甚至是使用过程中产品带给消费者的满意度, 这是完全有可能实现的。在这个过程中, 把产品的可持续属性作为价值标准, 以 提高消费者满意度。消费者满意度会带来更多忠实的客户（雅克布斯（）2007）， 因此, 企业也应该把它看成是一种企业的价值观。这恰恰进一步证明关注消费者满 意度是开展可持续业务的必经之路。

\section{6 结论}

本章将以消费者为中心的知识应用到消费者满意度讨论中, 而且分析了延长服装使 用寿命的因素。识别那些使消费者能够对各类产品在不同使用背景下进行评估的层 面以及对消费者而言重要的产品属性是该方法的核心。因此, 通过设计产品服务策 略来放缓消费速度并延长产品的使用寿命是可能的, 这一策略与产品本身的耐用 性、适度维护、消费者满意度相关。

而且, 本章的分析表明, 通过服务, 我们有可能延长产品的使用时间, 或将 产品与消费者的身份紧密联系起来, 通过这些服务, 我们还能获得更高层次的消费 者满意度。通过提供新型服务, 如更新换代、修饰改造或存货交易服务等, 产品服 务系统设计能延迟消费者对服装的心理淘汰反应。这种产品服务系统思维引导制造 商更深入地考虑到产品的使用、功能和耐用性, 因为, 产品服务系统提供给消费者 的不是产品本身, 而是产品功能、意义和满意度。然而, 最重要的是要让消费者参 与到产品服务系统相关的可持续创新设计过程中。它的重要性体现在两个方面。首 
先, 要深刻分析影响消费者满意度的属性, 并理解此产品及其使用过程对消费者的 意义; 其次, 保证让消费者参与到产品创新过程中, 这将影响个体的消费习惯朝着 可持续方向改变, 并影响整个社会的接受程度。新的产品服务系统把产品质量与服 务相结合, 以延长产品的使用时间, 这种设计可带来消费者可持续的满意度, 并使 设计从精神上满足消费者的需求。

\section{参考文献}

Burns, B. (2010) 'Re-evaluating Obsolescence and Planning for It', in T. Cooper (ed.), Longer Lasting Products: Alternatives to the Throwaway Society (Farnham: Gower Publishing): 39-60.

Chapman, J. (2009) Emotionally Durable Design: Objects, Experiences \& Empathy (London: Earthscan Publications).

Churchill, G. and C. Surprenant (1982) 'An Investigation into the Determinants of Customer Satisfaction', Journal of Marketing Research 19 (4): 491-504.

Cooper, T. (2005) 'Slower Consumption: Reflections on Products' Life Spans and the "Throwaway Society"', Journal of Industrial Ecology 9 (1-2): 51-67.

Csikszentmihalyi, M. and E. Rochberg-Halton (1981) The Meaning of Things: Domestic Symbols and the Self (Cambridge: Cambridge University Press).

Defra (Department for Environment, Food and Rural Affairs) (2008) Sustainable clothing roadmap briefing note, December 2007 (updated March 2008). Available: http://www.defra.gov. uk/environment/business/products/roadmaps/clothing/documents/clothing-briefing-Dec07. pdf [1 October 2010].

Fletcher, K. (2008) Sustainable Fashion \& Textiles (London: Earthscan Publications).

Forlizzi, J., Disalvo, C. and B. Hanington (2003) 'On the relationship between emotion, experience and the design for new products', The Design Journal 6 (2): 29-38.

Franklin Associates (1993) Resource and Environmental Profile Analysis of a Manufacturing Apparel Product: Woman's knit polyester blouse (Washington, DC: American Fiber Manufacturers Association): 3-4.

Fuad-Luke, A. (2009) Design Activism: Beautiful Strangeness for a Sustainable World (London: Earthscan).

Govers, P. and J. Schoormans (2005) 'Product personality and its influence on consumer preference', Journal of Consumer Marketing 44 (4): 187-197.

Gray, C. and M. Charter (2007) Remanufacturing and Product Design. Designing for the 7th Generation (The Centre for Sustainable Design).

Härkäsalmi, T. (2008) Runkokuituja lyhytkuitumenetelmin: Kohti pellavan ja hampun ympäristömyötäistä tuotteistamista (Bast Fibres by short-fibre methods-Towards an environmentally conscious productization of flax and hemp) (Helsinki: University of Art and Design Helsinki, in Finnish).

Hertwich, E. (2005) 'Consumption and the Rebound Effect: An Industrial Ecology Perspective', Journal of Industrial Ecology 9 (1-2): 85-98.

Jacobs, D. (2007) Adding values. The cultural side of innovation. (Arnhem, Netherlands: ArtEZ Press).

Kaiser, S. (1990) The Social Psychology of Clothing: Symbolic Appearances in Context. 2nd edn (New York: Macmillan Publishers).

Lee, S. and J. Chen (2000) 'Mass-customization Methodology for an Apparel Industry with a Future', Journal of Industrial Ecology 16 (1): 2-8. 
McDonough, W. and M. Braungart (2002) Cradle to Cradle: Remaking the Way We Make Things (New York; North Point Press).

Margolin, V. (2002) The Politics of the Artificial: Essays on Design and Design Studies (Chicago: University of Chicago Press).

Michaelis, L. (2001) 'Sustainable Consumption and Production', in F. Dodds, T. Middleton (eds.) Earth Summit 2002: A New Deal, 2nd edn (London: Earthscan): 264-277.

Mont, O. (2008) 'Innovative approaches to optimising design and use of durable consumer goods', International Journal Product Development 6 (3/4): 227-250.

Mugge, R., Schoormans, J. and H. Schifferstein (2005) 'Design Strategies to postpone consumers' product replacement: The value of a strong person-product relationship', Design Journal 8 (2): 38-48.

Mugge, R., Schifferstein, H. and J. Schoormans (2010) 'Product attachment and satisfaction: understanding consumers' post-purchase behavior', Journal of Consumer Marketing 27 (3): 271-282.

Nieminen, E., Linke, M., Tobler, M. and B. Vander Beke (2007) 'EU COST Action 628: life cycle assessment (LCA) of textile products, eco-efficiency and definition of best available technology (BAT) of textile processing', Journal of Cleaner Production 15: 1259-1270.

Niinimäki, K. (2009a) 'Consumer Values and Eco-Fashion in the Future', in M. Koskela and M. Minnari (eds.) Future of the Consumer Society, Proceedings of the Conference Future of the Consumer Society, 28-29 May 2009, Tampere, Finland (Turku: Finland Futures Research Centre, Turku School of Economics): 125-134. Available: www.tse.fi/FI/yksikot/ erillislaitokset/tutu/Documents/publications/eBook_2009-7.pdf

Niinimäki, K. (2009b) 'Developing sustainable products by deepening consumers' product attachment through customizing', paper presented at the World Conference on Mass Customization \& Personalization MCPC2009, Helsinki, Finland, 5-6 October 2009.

Niinimäki, K. (2010a) 'Forming Sustainable Attachments to Clothes', paper presented at the 7th International Conference on Design \& Emotion, Chicago, USA, 4-7 October 2010.

Niinimäki, K. (2010b) 'Product Attachments and Longevity in Sustainable Design Strategies', Proceedings of the LeNS Conference Sustainable Design: NOW! 29 September-1 October 2010, Bangalore, India: 113-120.

Niinimäki, K. (2010c) 'Eco-clothing, Consumer Identity and Ideology', Journal of Sustainable Development 18 (3): 150-162.

Niinimäki, K. and Hassi, L. (2010) 'Emerging Design Strategies for Sustainable Production and Consumption of Textile and Clothing', Journal of Cleaner Production 19 (16): 1876-1883.

Norman, D. (2005) Emotional Design. Why We Love (or Hate) Everyday Things (New York: Basic Books).

Oliver, R.L. (1980) 'A cognitive model of the antecedents and consequences of satisfaction decisions', Journal of Marketing Research 17 (November): 460-469.

Ophuis, P. and H. Trijp (1995) 'Perceived quality: A Market Driven and Consumer Oriented Approach', Food Quality and Preference 6: 177-183.

Papanek, V. (1995) The Green Imperative: Ecology and Ethics in Design and Architecture (London: Thames and Hudson).

Park, P. and K. Tahara (2008) 'Quantifying producer and consumer-based eco-efficiencies for the identification of key ecodesign issues', Journal of Cleaner Production 16: 95-104.

Paulitsch, K. (2001) 'Hess Natur: Acting for the world of tomorrow', in M. Charter and U. Tischner (eds.), Sustainable Solutions: Developing products and services for the future (Sheffield: Greenleaf Publishing): 381-392.

Pine, J. (1993) Mass customization (Boston: Harvard Business School Press).

Schifferstein, H. and E. Zwartkruis-Pelgrim (2008) 'Consumer-Product Attachment: Measurement and Design Implications', International Journal of Design 2 (3): 1-13. 
Sipilä, A. (2003) Tilastotietoa Kitex-projektille (Statistics for the Kitex project), 22 October 2003, Available: http://www.redcross.fi/punainenristi/response/kierrattaja/fi_Fl/Tietoa_tekstiilikierratyksesta/ [1 March 2010].

Stahel,W.R. (2001) 'Sustainability and services',in M. Charter and U. Tischner (eds.) Sustainable Solutions: Developing products and services for the future (Sheffield: Greenleaf Publishing): 151-164.

Swan, E. and L. Combs (1976) 'Product Performance and Consumer Satisfaction: A New Concept', Journal of Marketing 40 (2, April): 25-33.

Talvenmaa, $P$ (1998) Tekstiilit ja ympäristö (Textiles and environment) (Tampere: Tekstiili- ja vaatetusteollisuus ry, Tekstiili- ja jalkinetoimittajat ry, Tekstilikauppiaitten liitto, in Finnish).

Throne-Holst, H., Stø, E. and P. Strandbakken (2007) 'The role of consumption and consumers in zero emission strategies', Journal of Cleaner Production 15: 1328-1336.

Uitdenbogerd, D.E., Brouwe, N.M. and J.P. Groot-Marcus (1998) Domestic Energy Saving Potentials for Food and Textiles: An Empirical Study (Wageningen, NL: Wageningen Agricultural University).

Van Nes, N. (2003) Replacement of Durables: Influencing product lifetime through product design (Rotterdam: Erasmus University).

Vezzoli, C. (2000) Clothing care function report (Delft, NL: Delft University of Technology).

Vezzoli, C. (2010) System design for sustainability: Theory, methods and tools for a sustainable 'satisfaction-system' design, 2nd edn (Milan, IT: Maggioli editore). 


\section{在创业环境下开发新产品和服务}

杜瑞格•凯斯肯（Duygu Keskin），瑞尼・威维（Renee Wever）和 J・C. ·布力 扎特 (J.C. Brezet)

荷兰代尔夫特理工大学, 工业设计学院 (Delft University of Technology, Faculty of Industrial Design

Engineering, The Netherlands)

\section{1 引言}

到目前为止, 针对可持续产品服务系统所开展的研究, 主要都是着眼于设计在可持 续性解决方案中所发挥的作用, 及其在解决社会问题时所扮演的角色; 并涉及在此 过程中设计师所使用的工具和方法。不过, 要把可持续理念融入到设计过程中并不 容易。正如约克 (York) 和维卡塔拉曼 (Venkataraman, 2010) 所说, “重大的环 境问题, 如人为因素导致的气候变化, 本身包含不确定因素。”与可持续设计有关 的问题的存在及其严重性是一个有争议的话题, 要找到相应的解决办法就显得难上 加难。这种挑战要求我们在“面临不确定情况下采取行动。”（约克 (York) 和维 卡塔拉曼（Venkataraman），2010）。

尽管建立完善的机构往往更倾向那些有清晰愿景和明确目标的设计空间, 但 不确定性是创业环境的固有属性。为了获得商机, 创业行动通常都是由不确定所驱 动。“未来是靠创造而获得, 而非靠预料得来的” (约克 (York) 和维卡塔拉曼 (Venkataraman），2010）。因此，本章旨在讨论新企业如何开发产品服务系统， 以满足可持续需求, 并探讨设计在此过程中的作用。

\section{2 产品创新与产品服务系统创新模型}

技术和市场上所呈现出的不确定性程度的不同使得创新过程以各种不同的方式展现 出来。正如海尔曼（Hellman，2007）指出, 在进行根本性创新时, 由于技术发展 
还不成熟（即，技术方面的不确定），也很难预测市场是否会接受这一创新，以及 何时会接受这个新产品（即市场的不确定性）。新颖性和不确定性的程度越高, 这 个过程就越复杂, 越无法控制（范德文（Van de Ven）等 1999）。以下段落回顾 了产品创新过程中的各种模型。理性模型（例如：卢森伯格（Roozenburg）和伊克 斯 (Eekels) 1995; 库普 (Cooper) 等2002) 主要是通过对那些有着明确经营目 标的知名公司的研究而获得的一种理论, 具有极强的分析逻辑性, 并以线性结构进 行可视化展示。另一方面, 非理性模型（例如：斯芒齐 (Thomke) 等1998; 里恩

(Lynn) 等1996)，是从根本性创新研究中得到的模型, 体现实验逻辑, 涉及一个 学习过程。

早期表述中的创新过程往往都是依次有序地进行（比斯（Buijs）2003）。设 计理论家布鲁斯 · 阿彻 (Bruce Archer, 1971) 设计了一个早期模型, 包含有六 个步骤, 即战略规划、调查研究、设计、开发、制造及行销和生产。而卢森伯格

(Roozenburg) 和伊克斯 (Eekels, 1995) 开发的代尔夫特 (Delft) 设计模型也包 含着类似的步骤, 由离散型和收敛型步骤构成, 包括: 政策制定、构想发现、严格 开发和方案实现。每一个步骤都包含分析、综合、模拟和评估这一系列的过程。整 个过程中, 先要对设计环境进行分析, 而后把多种可能的解决方案和模拟方案进行 综合比对, 以便于在原设计环境中对这些解决方案的效果进行评估。最后一步就是 评估设计方案。采用离散型的步骤是为了获得尽可能多的解决方案, 而收敛型步骤 则是为了选出其中最好且最有可能实现的方案。在代尔夫特理工大学工业设计工程 学院 (Faculty of Industrial Design Engineering at Delft University of Technology), 老师会教授各种设计工具的使用方法, 以便更好地实施这些步骤。例如: “头脑风 暴” 和 “形态盒子” 是离散型步骤阶段所采用的创新工具, 意在孕育新创意, 而 “需求程序” 是一种用于收敛的工具, 可对上一阶段中形成的新创意进行篎选 (比 斯（Buijs），2003）。在新产品开发 (NPD) 领域, 库普 (Cooper) 等人开发出一 个类似的模型, 我们经常称之为 “门径” (stage-gate) 的程序模型, 它以问题定义 为起点, 最终实现产品的商业化。

这些线性模型表明, 创新过程就是一系列以问题定义为起点, 最终实现 产品的商业化的过程（阿彻（Archer）1971; 卢森伯格（Roozenburg）和伊 克斯 (Eekels) 1995; 多斯特 (Dorst) 1997; 比斯 (Buijs) 和瓦尔肯伯格

(Valkenburg) 2000; 库普 (Cooper) 等2002; 比斯（Buijs）2003)。新产品开 发流程通常呈线性模式, 产品的设计过程循序渐进（卢森伯格（Roozenburg）和伊 克斯（Eekels），1995），因此，目标明确且能够对每一步进行可视化表达。

到目前为止, 产品服务系统创新过程也同样被设定成了一种线性模式。在卢森 伯格 (Roozenburg) 和伊克斯 (Eekels) 提出的产品开发流程的基础上, 布力扎特 (Brezet)等人新创了“生态效益设计服务” (DES) 方法论, 为服务和产品设计师在 生态效益 (ES) 服务设计时提供一个系统化的方法。

这个过程从探索阶段开始, 其中包含各种活动, 如由公司和合伙人组建一个项 目团队, 制定目标和愿景, 分析当前状况对环境的影响, 并发现潜在用户。这一阶 段的预期结果是建立起业务关系或开发新业务。探索阶段之后的步骤与上述产品创 新模型相类似, 即政策制定, 发现创意, 严格开发, 方案实施及评估。整个过程离 不开分析, 需要用到各种业务、设计和环境影响评估工具, 如市场调查、市场策略 
和营销策略工具（如SWOT分析：优势、劣势、机遇、威胁）、便捷的环境评估工 具（元矩阵：原材料, 能源, 有毒物质, 附加值）、标杆管理、反推法、生命周期 评估情境、利益相关方分析、生态成本/价值评估、拟定计划等其他工具（布力扎特 (Brezet) 等2001)。

整个过程将包含一个或多个子流程。例如：由于缺乏专业知识, 公司可能把一 部分开发计划甚至是整个产品开发项目外包出去。图3.1 所示的是生态效益型服务中 所含的一个子流程。

\section{图3.1 生态效益型服务设计方法}

来源：布力扎特（Brezet）等人, 2001

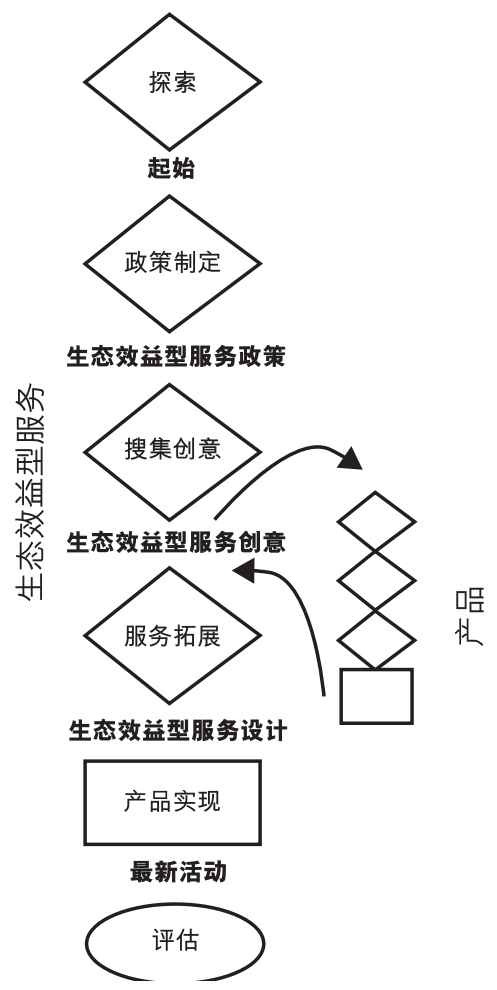

而在本书的第一卷第四章中提到的最新产品服务系统（PSS）方法, 即 “可持 续系统设计方法”也是由不同阶段、流程和子流程构成（见第一部分表4.1）。这个 方法整合了LeNS项目中用到的新方法和观点, 即 “以可持续性为导向的流程” 和 “充足经济流程设计”。可持续系统化设计方法的第一阶段包括对项目申请人、社 会技术体制、宏观趋势、最佳可持续案例、设计重点、充足性需求评估等进行分 析。接下来的步骤和上文提到过的方法很相似, 即寻找机会、选择最有发展前途的 构想（基于详细的环境、社会伦理和经济准则）、制定设计系统概念、设计并建立 系统, 以及沟通等。其中的每个步骤都需要用到不同的工具, 用于评估其可持续 
性, 分析利益相关方和未来发展趋势, 罗列清单并制定指导方针 (参见第一卷, 第 四章, 4.2章节) 。这种方法是以目标为导向来进行分析和评估, 旨在设计一套最具 可持续性的产品和服务。

尽管上述的分析逻辑和线性展示条理清晰, 在实际操作中, 创新过程也许会出 现混乱和非结构化特征（比斯 (Buijs) 2003)，可能需要采用一种实验性逻辑来解 决上述问题（海尔曼（Hellman），2007）。这对于根本性创新实践尤为必要; 正如 李 (2004) 等人指出, “实验是解决问题的基础, 这是由于结果具有不确定性, 而 所需的关键信息来源要么不存在, 要么不可用。”而且, 把可持续性考虑纳入到该 过程也使其变得更加复杂, 因为, 可持续性问题往往影响着将要做出的选择, 并要 求在缺乏具体数据的前提下采取行动, 尤其当考虑到创新过程给社会和环境带来的 影响时。因此, 从非理性的视角来看, 创新过程被视为带有中间产品的一个学习过程 （施容(Schön) 1967年; 里恩（Lynn）等1996年），而非新产品开发模型 (NPD) 中的单个产品。根本性创新过程中存在技术和市场的不确定因素, 所以 “创新过程本 身就包括具有高度不确定性的探索和学习过程, 并形成了包括技术开发、早期应用和 持续学习等多种并行活动的一个动态过程（海尔曼（Hellman）2007）。”为了减少 根本性创新的不确定性, 一些学者提出了不同的管理方法, 如“实验法”, “试错 法” 和 “探索学习法”（格鲁德 (Garud) 和范德文 (Van de Ven) 1992; 斯芒齐 (Thomke) 等1998; 里恩 (Lynn) 等 1996)。通常采用最终确定的“测试对象的 简化版本” 来进行实验（斯芒齐 (Thomke) 等人 1998)。实验以连续的方式进行, 该过程被称为 “试错法”（格鲁德 (Garud) 和范德文 (Van de Ven) 1992; 斯芒齐 (Thomke) 等人1998)。然而, 希尔博尔赞 (Silberzahn, 2011) 强调, 试错法在 实际学习进程中存在局限性, 因为, 这些实验都是在受控条件下创建相应模型而开展 的。因此, 这些模型本身是否具有现实性还有待商榷。

而另一方面, “探索性学习”把实验引入到真正的市场。这需要用尚未成熟的 产品版本来进行实验, 即在产品上市的早期引入尚未成熟的产品版本, 通过实验来 学习并再次进行探索, 然后再进行二次调查（里恩（Lynn）等人1996）。这个探索 过程就是学习技术并了解市场的一种方式。例如：通过这种探索可以揭示关于是否 需要加大技术投入的比例, 以及哪个细分市场对特定产品特征更感兴趣等方面的信 息（里恩（Lynn）等人1996）。“试错法”和 “探索性学习” 有着相似的特点, 如: 反复进行, 连续进行可负担的步骤; 然而, “探索法”比 “试错法” 能更加有 效地解决相关的不确定因素（希尔博尔赞 (Silberzahn) 2011）。

其实, 所有的这些做法都旨在应对一个难题, 那就是在不确定因素存在的情况 下, 凭借对有限信息的研究和分析, 做出理性的决定。因此, 有必要进行不同形式 的实验以降低技术方面和/或市场方面的不确定性, 同时降低创新过程中与可持续性 相关的不确定因素。但在资源有限的创业背景下应当如何行事呢?

\section{3 新兴创业理论：践行}

在创业领域, 近来通过一种叫做“践行” 新兴理论来应对“不确定性”这一概念。 根据奈特 (Knight, 1921) 对于 “风险”和“不确定性”的研究, 萨拉斯沃齐 
(Sarasvathy, 2001) 总结了优秀企业家们是如何通过让利益相关方作出一系列的 承诺, 来应对不确定性问题的。

奈特 (Knight, 1921) 把“风险”和“不确定性”分开而论, 在他看来, 风险 是一种可衡量的不确定性, 也就是说, 未来某种结果发生的可能性能够通过计算或 基于过去的经验推断得知。另一方面, 就不确定性而言, 由于情况的独特性, 我们 无法知晓未来的状态; 因此, 要预测结果的分布规律和发生率是不可能的。这就给 制定计划增添了难度, 并难以与其他方面相互联系起来（伯恩斯（Burns）和斯涛克 (Stalker) 1961) 。因此，萨拉斯沃齐（Sarasvathy，2001）提出了一种行之有效 的逻辑推理, 即在业务开发早期阶段就获得各利益相关方的承诺, 这将减少不确定 性。她声称, 这种逻辑推理针对一些特定领域非常有效, 尤其在那些传统的营销技 术不起作用的领域，如新产品引进和新市场服务方面（萨拉斯沃齐（Sarasvathy）, 2001)。

这种践行逻辑, 与因果逻辑恰好相反（即：预测性逻辑推理）, 主要是商学 院（萨拉斯沃齐（Sarasvathy），2001）并且经常是设计学院的授课内容（见前 文中的产品设计方法部分）。因果逻辑以目标为导向；所选用的方法是为了实现设 定的目标。相反，这里的“践行逻辑”从一开始就没有设定一个明确的目标。而 是在一系列的方法中生成了目标, 因此, 这个过程是以方法为导向。实际上, 企 业家最初考虑的只是, 他们用现有的方法能做些什么。他们会考虑三类方法：1) 他们是谁（他们的技能和能力）；2）他们所掌握的知识（他们所受教育和具备的 技能）；3）他们所认识的人（他们的职业和人际社交网络）。然后，开始设想并实 施他们所能创造的有价值的结果（萨拉斯沃齐（Sarasvathy），2001）。他们马上 就采取行动, 并与他人进行交流。愿意冒险的人会积极引进新的方法, 并设定新的 目标（如图表3.2 所示）。最终的结果就是, 方法不断多样化, 目标逐渐合并统一。 这就是共同创造未来市场的过程，而且这个过程的核心机制是不断增长的网络的利 益相关方对一项冒险的承诺（萨拉斯沃齐（Sarasvathy），2008）。

\section{图3.2 产品践行动态模型}

来源：萨拉斯沃齐 (Sarasvathy) 2008

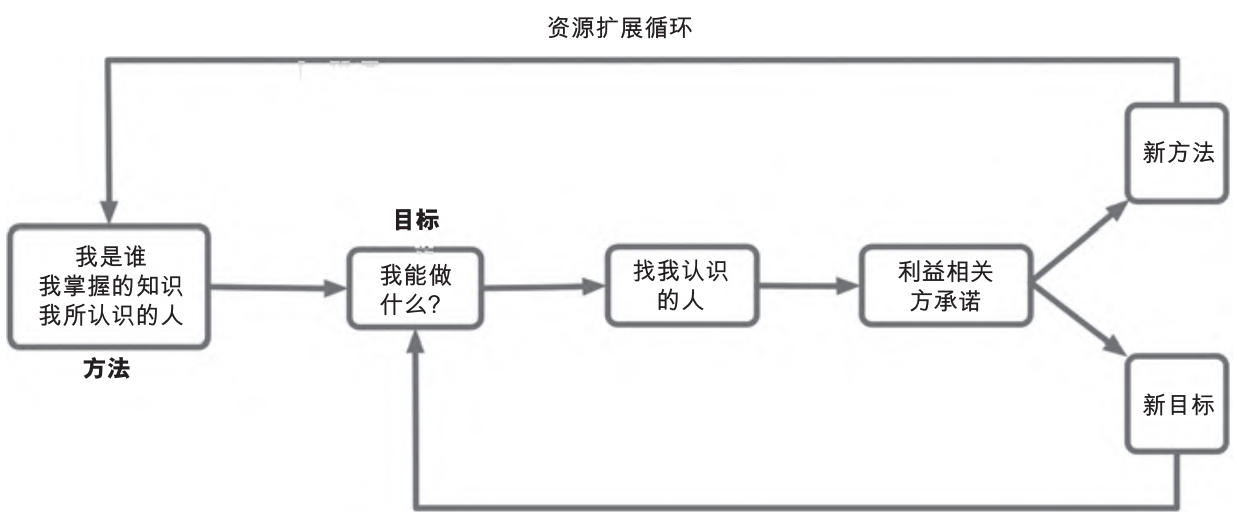

约束目标的收缩循环 
践行者将产品（创意/概念）看做可变的但绝不是完全预先确定好的。萨拉斯沃 齐 (Sarasvathy, 2008: 113) 认为, 在从搜寻和选择的过程中, 可替代方案的作用 是不同的。在探究和选择过程中, 可选方案是从一系列可能的结果中挑选出来的。 在这个过程中, 致力于某种产品的开发被看成是整个行动方案的最终目标, 而资源 在取得选定目标的可选方案之间进行分配。而在践行过程中则全然不同, 所选方案 只被看成是存在现实的可能转换形式。换句话说, 产品的实现过程只不过是某种产 品方案的实现过程, 这些方案或许会也或许不会, 创造出之前预想的产品（萨拉斯 沃齐 (Sarasvathy)，2008）。

换言之, 当已经选择了某种特定的预想效果, 如目标市场细分或产品特定功 能, 企业家就会根据预先设定效果去寻找利益相关方。而行动逻辑并不会设想到这 种预先存在的市场或产品。企业家拥有的人力资源决定了他们所能够创造的市场和 产品（萨拉斯沃齐（Sarasvathy），2001）。

\section{4 在践行过程中的产品服务系统（PSS）创新}

前文阐述了在不确定的环境下如何进行有效创业。这一节旨在说明设计迭代在产品 践行模型中的作用, 并研究设计为导向的践行能够成为开发产品服务系统创新的一 种可行方式。

在产品创新和产品服务系统创新的背景下, 要开发新的业务, 企业家不仅需要 与利益相关方进行互动, 还需要引入设计迭代环节。企业家要达成目标, 减少不确 定因素, 以及调整产品或产品服务系统, 不仅需要各利益相关方做出承诺, 也离不 开设计迭代环节。图表3.3展示了设计迭代是如何与萨拉斯沃齐 (Sarasvathy) 提 出的产品践行动态模型融为一体的。与利益相关方的互动环节代表了整个产品践行 模式, 并解释了企业家们在与他人的互动中如何产生并激发各种不同的灵感从而形 成他们所要达到的目标的。利益相关方的承诺是这个过程的核心机制（萨拉斯沃齐 (Sarasvathy)，2008)。

另一方面, 设计迭代过程是企业团队发展、提高自身能力的环节; 同时也是了 解技术限制和机遇的环节。设计迭代的最终成果可能是一张草图, 一个原型或一次 探索, 这些能让整个团队了解到它到底能实现什么样的功能。设计迭代的目的也许 是了解技术及其潜力, 也可能是为了验证各利益相关方承诺（即表明其原则）。

每个创新的过程都具有独特性, 没有一种固定的程式可以解释这些事件为什么 以这种方式发生, 以及如何发生。在创新过程中, 设计迭代以及与利益相关方的互 动可能同时存在, 也可能存在先后顺序。他们相继发生, 且反复进行。与各利益相 关方进行互动是设计迭代的原动力, 而反过来设计迭代的成果也可能促进与利益相 关方之间的互动。设计驱动的践行模式旨在展示它的独特性和多样性, 同时把设计 迭代作为一个重要的因素引入到企业的发展历程中。 


\section{图3.3 在创业背景下的产品服务系统创新}

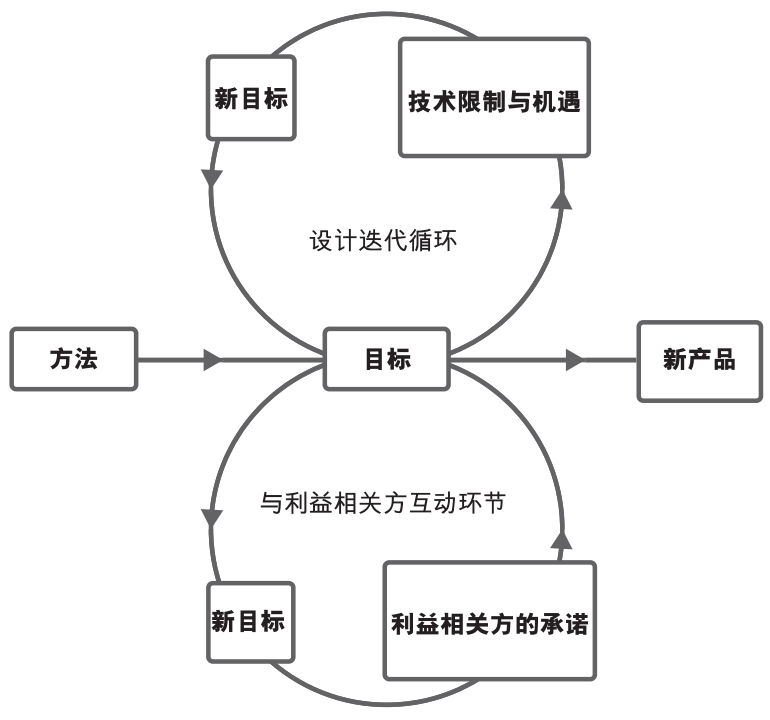

\section{5 可持续舞蹈俱乐部 (SDC: Sustainable Dance Club) (SDC) 案例}

这一节中, 我们用一个案例对该模型进行详细说明。2005年, 我们开办了一个可持 续舞蹈俱乐部（SDC：Sustainable Dance Club ）（SDC），这个项目由鹿特丹 Enviu网络集团 (Rotterdam-based network organisation Enviu) 和多利建筑公司

(Döll) 创建。创建这个项目的目的是：通过减少俱乐部对环境造成的影响并鼓励年 轻人践行可持续的生活方式，促进俱乐部发展的可持续性。

在初始阶段, 项目团队就俱乐部的能源、垃圾、原材料和水的利用与处理 提出了各种各样的建议。最初的商业想法是开发各类产品来减少俱乐部对环境的 影响, 同时还提供咨询服务, 以帮助俱乐部实现这一目标。可持续舞蹈俱乐部

(SDC: Sustainable Dance Club) (SDC) 于2006年正式成立, 当时最看好的产 品设计想法是建造一个能发电的舞池（图表3.4）。可持续舞池（SDF）把人们运动 转化为可持续的能源。将跳舞产生的动能转换成电能, 供地板上内置的LED灯使用。 因此, 这个舞池就会与舞者之间产生互动, 并带来更完美的娱乐体验。这样, 反馈 系统就成为最重要的方面之一: 在舞池跳舞的人必须清楚地明白, 是他们在给地板 充电, 所以, 只有当他们踩到地板上时, 地板灯才会发光。 


\section{图3.4 可持续舞池}

来源：可持续舞蹈俱乐部 (SDC: Sustainable Dance Club ) (SDC)

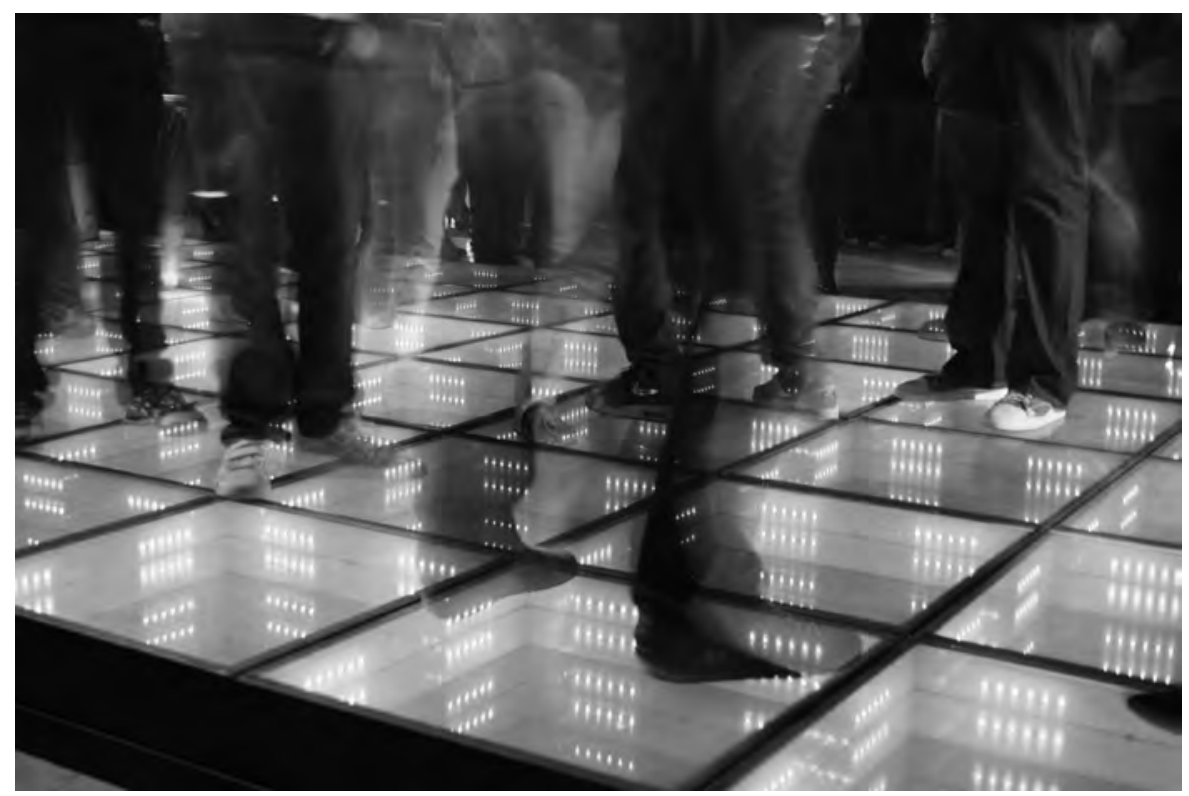

最初的经营构想是以出租的形式经营这个舞池, 即一种 “以使用为导向的产 品服务系统创新”（更多关于产品服务系统创新类型的内容, 见第1部分, 第2 章，2.1.4节）。同时，他们还创立了实现俱乐部可持续发展的“成功七步法”，并 且为该项目开拓了市场。这一方法包括：帮助客户树立雄心，分析他们当前的业务 状况，设定目标，成立工作小组来制定方案并付诸实施，完成共同目标。

该项目开发的初期阶段, 公司原本要打造一个能够为整个俱乐部提供足够电能 的舞池。2006年, 一位来自荷兰代尔夫特理工大学工业设计工程学院 (the Faculty of Industrial Design Engineering at Delft University of Technology）的设计专业的学 生, 用他自创的初步概念验证了该计划的可行性。第一个原型设计并不像预期的那 样奏效, 人们跳舞产生的动能转化成的电能没有达到预期的量。这时, 可持续舞蹈 俱乐部 (SDC: Sustainable Dance Club) (SDC) 开始就建立发电舞池 (SI1) 的 设计构想与其他俱乐部展开了交流, 并得知电费并不是俱乐部运营成本支出中所要 优先考虑的选项。实际上, 俱乐部的主要成本支出是饮料、人工服务费、通讯费和 演员出场费, 而电费支出只占整个支出的很小一部分。对于俱乐部而言, 重要的是 吸引消费者, 而不是省电。第二, 只有可持续方案投资不是很高的情况下, 俱乐部 雇主才会接受这个方案: 因为出售或出租地板的价格也不是很便宜。第三, 地板的 最大卖点就是它吸引消费者的发电机制, 就是说 “我们是一家可持续娱乐俱乐部, 而且我们所提供的是可持续娱乐享受”。但是, 与备选产品和服务相比, 可持续舞 池是否在吸引消费者方面具有最高性价比, 这一点还不明确。 
尽管第一个原型并没有达到预期效果, 各俱乐部也不愿意购买这种产品, 可持续 舞池依然在2006年至2007年期间的各种活动中得到使用, 展现在公众眼前。发电舞池 的创意也得到了国内乃至国际范围的媒体的广泛关注。尤其是企业、博物馆和举办活 动的那些机构, 它们迫不及待地想在公开场合中使用这种地板设计来展示其可持续性 特色。此外, 可持续舞池的创意也得到了参与测试的俱乐部会员的积极回应 $\left(\mathrm{SI}_{2}\right)$ 。

由于把人们跳舞的动能转化成供整个俱乐部使用的电能所产生的电量有限 $\left(\mathrm{DI}_{1}\right.$ 的测试结果)，且俱乐部不愿购买这种地板 $\left(\mathrm{SI}_{1}\right.$ 的结果），以及来自媒 体和俱乐部会员的大量积极的反馈 $\left(\mathrm{SI}_{2}\right.$ 的调查结果) 促使可持续舞蹈俱乐部

(SDC: Sustainable Dance Club) 调整其市场和业务重点。公司决定：努力将这 种地板打造成为最具吸引力的营销手段, 为那些想在公共活动中展示其可持续特性 理念的大型机构提供服务。这种发展方向将进一步强调地板的可持续性, 并以更有 效的方式把可持续理念传递给公众。目前, 可持续舞蹈俱乐部 (SDC: Sustainable Dance Club) 的主要业务是出租服务, 如有可能, 也可将其卖给那些从事大型活动 组织的机构和博物馆。同时, 公司还努力在成本和性能方面积极展开技术开发和优 化, 以期最终能达到俱乐部的实际要求 $\left(\mathrm{DI}_{2}\right)$ 。

发电舞池的创意不断地得到多家机构的关注(SI3)。它还激发了另一个创意的产 生, 即在人群集中的地方使用这项技术，如体育馆、飞机场、火车站、购物中心、 （公共）建筑和城市广场（来自SI3）；参见图3.5。自2010年起，可持续舞蹈俱乐 部 (SDC: Sustainable Dance Club) 就一直致力于研发可持续发电地板, 以便提供 成本效益更高、规模更大的应用服务 (DI3)。可持续发电地板所产生的电力被输入到 公共电网中, 或者用于当地电力系统中, 如 (LED) 街灯或信号指示系统。少量的电 能也反馈给用户，如部分地板模块的照明。

\section{图3.5 一家购物中心展示的可持续发电地板}

来源：可持续舞蹈俱乐部 (SDC: Sustainable Dance Club)

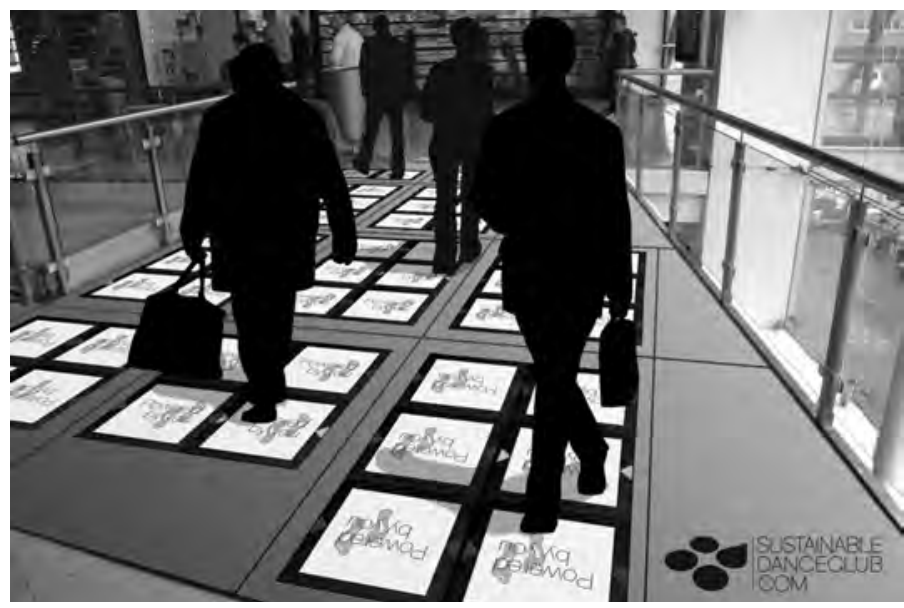




\section{6 结论}

早期设计和开发可持续产品和服务的方法有助于理解设计在可持续社会构建过程中 所发挥的作用。然而, 到目前为止, 开发的工具和方法往往都是概念上的, 并未应 用到具体实践中（波奇斯（Berchicci），2005）。此外, 可持续创新过程中以及 机构环境下较高的不确定性, 也对创新过程以及其管理机制产生了消极的影响。有 必要加强这些实践与当前机构和创业理论之间的联系。因此, 本章主要解释了为什 么“设计为导向实施方式” 是一种创业背景下产品开发和产品服务系统创新的适用 方法。尽管尚未对设计融入践行活动展开全面的研究, 但本章通过一个实际案例, 对首个以设计为导向的践行模型进行分析。除了以目标为导向的产品和产品服务系 统的方法论之外, 该践行模型为可持续产品和服务的开发提供了一种可选方案。

\section{参考文献}

Archer, B.L. (1971) Technological Innovation: A Methodology (London: Inforlink).

Berchicci, L. (2005) The Green Entrepeneur's Challenge: The Influence of Environmental Ambition in New Product Development. Doctoral dissertation. Delft University of Technology, Delft.

Brezet, J.C., Bijma, A., Ehrenfeld, J. and Silvester, S. (2001) The design of eco-efficient services. Design for Sustainability Program. Delft University of Technology, Delft.

Buijs, J. (2003) 'Modelling Product Innovation Processes: from Linear Logic to Circular Chaos', Creativity and Innovation Management 12 (2): 766-93.

Buijs, J. and Valkenburg R. (2000) Integrale Productontwikkeling (Utrecht: Lemma).

Burns, T. and Stalker, G.M. (1961) The Management of Innovation (London: Tavistock).

Cooper, R.G., Edgett, S.J. and Kleinschmidt, E.J. (2002) 'Optimizing the stage-gate process: What best practice companies are doing' Research Technology Management 45(5).

Dorst, K. (1997) Describing Design: A comparison of paradigms. Doctoral dissertation. Delft University of Technology, Delft.

Garud, R. and Van de Ven, A.H. (1992) 'An empirical evaluation of the internal corporate venturing process', Strategic Management Journal 13: 93-109.

Hellman, H. (2007) Probing Applications: How Firms Manage the Commercialisation of Fuel Cell Technology. Doctoral dissertation. Delft University of Technology, Delft.

Knight, F.H. (1921) Risk, uncertainty and profit (1933 edn) (New York: Houghton Mifflin).

Lee, F., Edmondson, A.C., Thomke, S.H. and Worline, M. (2004) 'The mixed effects of inconsistency on experimentation in organizations', Organization Science 15(3): 310-326.

Lynn, G.S., Morone, J.G. and Paulson A.S. (1996) 'Marketing and discontinuous innovation: the probe and learn process', California Management Review 38(3): 8-37.

Roozenburg, N.F.M. and Eekels, J. (1995) Product Design: Fundamentals and Methods (New York: Wiley).

Sarasvathy, S.D. (2001) 'What makes entrepreneurs entrepreneurial?' http://www.entreprnr. net/assets/WhatMakesEntrepreneurs.pdf, accessed 24 June 2013.

Sarasvathy, S.D. (2008) Effectuation: elements of entrepreneurial expertise. New Horizons in Entrepreneurship (Cheltenham, UK; Northampton, MA: Edward Elgar Publishing).

Schön, D.A. (1967) Technology and Change: The New Heraclitus (New York: Delacorte Press).

Silberzahn, P. (2011) 'Flexibility and Commitment in the Management of Uncertainty in Nascent Markets', Academy of Management Annual Meeting, San Antonio, Texas. 


\section{4 可持续产品服务系统设计}

Thomke, S.H, von Hippel, E. and Franke, R. (1998) 'Modes of Experimentation: An Innovation Process - and Competitive-Variable', Research Policy 27(3): 315-332.

Van De Ven, A.H., D.E. Polley, R. Garud and S. Venkataraman (1999) The Innovation Journey (Oxford: Oxford University Press).

York, J.G. and Venkataraman, S. (2010) 'The Entrepreneurship-Environment Nexus: Uncertainty, Innovation and Allocation', Journal of Business Venturing 25(5): 449-463. 
的知识, 也了解它潜在的双赢特点, 但这些对于这个概念的应用还是十分有限。其 中一个很重要的原因在于 ${ }^{2}$, 大多数情况下的生态效益型产品服务系统都属于根本 性创新, 因此在采用这种经营策略的时候会遭遇来自企业、文化和管制方面的阻碍 （山士恩 (Ceschin) 2012b)。

舒特 (Schot) 和吉尔斯 (Geels) (2008) 认为, 根本性创新在初入市场的时 候一般都很不成熟, 往往会受到来自社会和技术环境的排斥（及其完善稳定的规则 和参与者网络）。生态效益型产品服务系统创新, 在大多数情况下(塔克（Tukker） 和 蒂什纳（Tischner）（2006a），将对现有的体系、消费者的习惯和生活方式、公 司的组织结构以及监管架构造成冲击, 所以，被称为是根本性创新型模式。因此， 它们极有可能被主流市场拒之门外。所以, 那些把产品服务系统创新作为企业未来 发展战略方向的公司仍然面临重大挑战, 不仅要推进产品服务系统理念的进一步发 展, 还要在现实环境中寻求最好的策略和发展途径使其得以利用和推广。

因此, 本章的主题就是生态效益型产品服务系统的应用和推广。尤其要解决以 下关键问题:

- 在此系统应用和推广的过程中, 有利因素和不利因素分别是什么? 在引进和 推广过程中如何进行有效地管理?

- 在支持和指导过程中, 战略设计的作用是什么?

要解答这些问题, 我们建议学习创新研究领域的知识, 尤其是转型研究领域。这些 领域的近期研究（尤其是战略利基管理研究和转型管理方法研究）把重点都集中在 社会技术转型以及如何促进根本性创新设计在现实生活中的使用和推广上。根据这 些理论, 推进根本性创新, 要求对部分社会技术实验进行保护, 使其免受主流市场 选择环境的影响, 使其能够孵化并渐渐成熟。本章讨论了这些理论在指导生态效益 型产品服务系统的应用和推广方面的作用, 以及在此过程中战略设计的重大作用。

\section{2 转型研究}

转型理论将系统创新或根本性创新视为社会生活各个方面, 如交通、通信、食宿等 方面所进行的重大变革。系统创新是复杂而长期的过程, 涉及社会、经济、技术和 政策领域。通过对历史上社会技术发展的案例研究, 转型研究人员分析总结出了 系统创新的过程, 并精心制做了一个模型, 称为 “产品转型的多层次视角(吉尔斯

(Sheate) 和范 ·德 - 霍斯特 (van der Vorst) 2006); 技术型产品服务系统的模块化设计 (奥瑞克 (Aurich)，福克斯 (Fuchs) 和韦卓肯特 (Wagenknecht) 2006)、MSDS, 可持 续系统设计方法 (维佐里 (Vezzoli), 山士恩 (Ceschin) 和科尔泰西 (Cortesi) 2009; 维佐里 (Vezzoli) 2010), 参照第1部分第4章。

2 在此必须说明的是, 并非所有的生态效益型产品服务系统都是激进的创新行为。产品服务 系统提供的支持平台和最终结果（特别是在企业对消费者的电子商务行业中）通常被认为 是激进的创新。 
(Geels) 2002)模型”，该模型描述了对这些复杂而长期的过程进行调控的情况。 通过多层次的视角, 对三个概念进行了区分(吉尔斯 (Geels) 2002), 即:

- 社会技术体制：这个概念可以被定义为创新、生产、分配和消费等环节所采 取的主要方式。它是指与具体领域（如交通或能源）相关的文化、实践和机 制等的动态稳定的集合(罗特曼斯 (Rotmans) 等2001)。相对而言, 体制是 稳定而不易变化的, 因为其习惯做法、规章和各种机制将阻碍体制内的参与 主体对原有的体制进行变革。

- 利基市场：是一个被保护的空间, 它被“隔绝”在主导体制之外, 在这里可 以对根本性创新进行测试和培育, 使其逐步走向成熟, 并为了对整个现有体 制和体系提出挑战，甚至对现有体制进行变革。

- 宏观环境: 指相对稳定的社会、经济和政治环境, 在这个环境中各参与方展 开互动, 各种机制和利基市场不断发展壮大。它是各种机制和利基市场的发 展环境。它不仅包括社会经济、人口、政治和国际的结构性发展, 也包括如 战争或自然灾害等天灾人祸。这种背景会影响整个体制, 但是利基市场不会 受到影响（至少短期内不会）。

这三个层次的区别只是从分析角度进行的, 而非一种实际的区分; 换句话说, 这几 个层次有利于对社会技术变革更好地进行分类和理解, 而不是有这三个层次的实 体 “存在”（瑞文 (Raven) 等人2010）。值得强调的是：转型是通过所有这三个 层面的相互之间积极互动的情况发生的(瑞普 (Rip) 和肯普 (Kemp) 1998; 吉尔斯

(Geels) 2002), 即当体制以充分开放的姿态来迎接根本性创新; 当整体形势迫使 我们进行变革; 当在利基市场展开了根本性创新, 而这种创新被用于探索变革的机 会时(瑞文 (Raven) 等人2010)。

因此, 利基市场是转型的必要条件, 但不是充分条件。而且, 尽管利基市场具 有良好的发展前景, 但短期内它们无法达到预期效果, 因为在初入市场的时候还不 成熟, 并且它们与社会的组织形式存在冲突。在这个意义上讲, 如果马上参与市场 竞争, 它很有可能被市场淘汰。综上所述, 有必要创建一个保护空间, 来保证实验 的持续进行, 让创新逐步地走向成熟(舒特 (Schot) 和胡戈玛 (Hoogma) 1996)。 而利基市场可作为根本性创新的 “孵化器” (吉尔斯 (Geels) 2002), 可以在这个餒 化器中进行实验和学习。

在引入根本性创新的过程中, 开展一些社会技术实验并使其免受外界影响是一 个重要的前提(肯普 (Kemp) 等 1998, 胡戈玛 (Hoogma) 等 2002; 范·德 ·拉 克 (Van der Laak) 等2007; 布朗 (Brown) 和维格雷特 (Vergragt) 2008; 瑞文 (Raven) 等 2010; 范·登·波什 (Van den Bosch) 2010)。这些受到保护的实验 通过对流行文化、组织和监管规定（当前的社会技术体制）进行部分屏蔽, 推动根 本性社会技术创新的孵化并逐渐成熟。社会技术实验的结果可以作为一个战略舞台 被用于实验、学习、形成规划并建立社会网络, 以便进行推广, 同时挑战并改变当 前的旧体制(瑞文 (Raven) 2005)。

实验的运用在创新管理研究中扮演着重要的角色。拉劳德 (Laredo) 等人认 为, 根本性创新项目开发并不是按部就班的顺序过程（如概念形成、实验项目、原 
型创建和工业化开发），而是一个反复实验的过程。在此过程中，可以对创新特点 进行逐步测试。拉托尔（Latour，2000）把这种实验定义为集体性实验或社会技术 示范, 而被用来评估创新的技术、社会、政治和经济环境状况。布朗 (Brown) 等人 （2003）也强调小规模社会技术实验的重要性, 而里恩 (Lynn) 等人提出了“探索 式学习” 策略, 即利用早期的原型去进行市场实验, 将其作为一种在实际生活中学 习新技术的媒介, 并随后对技术设计和市场营销手段进行调整。（早期原型的面世 将会影响潜在用户和其他利益相关方的预期、需求和行为。)

总之, 社会技术实验为转型的开展和深化提供了一次重要的战略机会。这些 实验成功推动根本性创新的普及, 这一问题在战略利基管理 (SNM) 领域得到了 更加深入的研究, 其中包括三个内部流程（肯普 (Kemp) 等1998; 2001; 胡戈玛 (Hoogma) 2000; 胡戈玛 (Hoogma) 等 2002)。

第一个流程是推动一个广泛的社会经济网的建立和发展。广泛的网络, 它不仅 包含着直接与创新相关的主体（如公司、合作伙伴和用户），也包括其他与科学、 政策和社会领域相关的主体（例如：研究中心、政府机构、非政府组织和特殊利益 集团） 3 (瑞文（Raven）2005)。换句话说，它应是一个涉及科学、社会、经济、政 治和文化等领域的多样化网络, 这些参与方包括:

- 能调动知识以及金融和管理资源来开发这种创新的机构（如外部公司）(范德 波罗 (Van de Poel) 2000)

- 能引入新型设计、标准、方法和概念的机构和人员 (如科学家、研究中心和 大学）(范德波罗（Van de Poel） 2000)

- 能确保实验合法性和稳定性的机构 (如政府机构)

- 有权并愿意直接影响主流文化、实践和体制的主体（如各政府部门、决策制 定者和政客) (范·登·波什（Van den Bosch) 2010)

- 那些社会中能够从可持续实践中获得利益并能够对体制产生直接影响的 实体（如非政府组织、游说团体和消费者群体）(范•登•波什（Van den Bosch) 2010)

- 传播创新信息的机构（如媒体、舆论领袖和非政府组织）

- 可能支持创新推广的主体（如潜在的行业合作伙伴、行业协会或联盟）

第二个流程很关键, 那就是将各参与方的预期汇聚成一种长期的共同愿景。正如 前文所述, 社会中那些融入了根本性创新的实验过程需要不同领域多方参与者 的参与, 而每个参与者可能对某一项特定的创新有着各自的预期。因此, 最根

3 这与一些激进创新型学者的理论相符, 如凯伦(Callon, 1991), 他提出 “不同参与者之间 协调的重要性, 像实验室、技术研究中心、金融机构、客户和公共机构等。经过协调重 组, 他们都可参与到创新的研发与推广中来。通过众多互动, 将研究与市场之间建立联 系”。凯伦(Callon, 1991), 凯伦 (Callon) 等人 (1992) 和拉劳德 (Laredo) 和曼斯特 尔 (Mustar)，1996）将上述异质性因素成为“技术经济网络” 
本的是将各个参与方的不同预期进行管理, 通过沟通与协调, 最终达成一致(瑞 文 (Raven) 等 2008)。这种融合为创新过程提供战略方向及其合理性（肯普 (Kemp) 等1998; 瑞文 (Raven) 2005), 同时也有助于引入新的参与方和资源 (瑞文（Raven）2005）。创造一个共同的项目愿景有助于明确预期效果、制定 议程和行动方案, 在协调各参与方的策略上也能起到积极作用 (肯普 (Kemp) 和罗特曼斯 (Rotmans) 2004)。实际上, 对未来的憧憬和愿景对于参与方的决心 和行动都至关重要(德拉特（De Laat）1996; 安奎科（Akrich）1992; 波克浩特

(Berkhout) 2006; 奎斯特 (Quist) 等 2006)。然而, 必须要强调的是参与方的 预期不是一成不变的(范伦特（Van Lente）1993; 胡戈玛（Hoogma）2000；瑞文 (Raven) 2005), 也就是说, 在与其他参与方进行协商过程中, 或在经历外部环境 的变化之后, 参与方会改变他们的看法和预期。因此, 不断地重新设定项目愿景, 使之不断完善, 这个过程非常重要（即灵活的愿景, 可以对其进行调整）。

第三个关键流程是可参与方的有效学习过程。个体吸收新的知识并将其应用到 之后的行动过程中（霍尔（Hall）1993）。因此, 要在使用和推广根本性创新的过程 中减少不确定性, 学习过程很关键, 这需要形成新的基本信念, 确立行为规范和准 则(范·德・克雷霍夫 (Van de Kerkhof) 和威佐克 (Wieczorek) 2005)。适当的学习 过程至关重要, 因为它使得对创新进行调整成为可能, 并提升了创新推广的成功率 (瑞文 (Raven) 等2010)。适当有效的学习过程应当:

- 广博（韦伯（Weber）等 1999; 瑞文（Raven）2005），涉及多个层面的 问题：除了技术和经济领域的创新之外，还包括文化层面（社会信仰、价值 观和习惯）、管制层面（政府政策和法规框架）, 以及制度层面（规则和标 准) 的革新。

- 反思（胡戈玛（Hoogma）, 舒特 (Schot) 2001; 瑞文 (Raven) 2005）, 意味着学习过程分为两个步骤, 第一和第二阶段的学习。第一阶段的学习 是对特定问题进行更正和解答（如：技术问题）。第二阶段的学习（霍尔

(Hall）1993）涉及方式转变, 即问题定义、基本假设、标准、价值观、 实验可以融入到市场利基中, 影响并改变现有体制, 或使其成为一个可行的方案选 项。

\section{3 实施和推广生态效益型产品服务系统（PSS）的理 论框架}

尽管转型研究学派使用的是偏向社会学的研究方法 (关注参与者、消费者预期等因 素），经常是从技术层面开始，将社会发展看作是技术创新的衍生物进行研究（海 格 (Hegger) 等, 2007)。生态效益型产品服务系统并非技术创新, 当然也可以包含 技术层面的东西, 但创新性因素主要都是与社会层面有关。事实上, 与其把它看作 是新技术产品, 倒不如将其视为是一种社会组织的新模式。因此, 此处的关键问题 
在于：转型研究对生态效益型产品服务系统的意义是什么? 它能否既被应用到技术 创新的引入和推广中, 也可以应用到生态效益型产品服务创新的引入和推广中?

一项研究案例对6家公司在它们将生态效益型产品服务概念引入市场所走过的创 新历程做了调查, 该研究对上述假设进行了验证（山士恩 (Ceschin) 2012a，b）。 基于上述案例研究所得出的结论, 我们可以构建出生态效益型产品服务系统在实施 和推广过程中的概念框架（引入和推广）。（参见图4.1）。总之, 生态效益型产品 服务系统创新的切入点则是项目愿景 (I) : 提出这一概念或理念的目的是为了应对 来自社会/环境/商业的挑战。这一项目愿景为社会参与过程指明了方向。(II)：广 泛的参与者网络可通过这个过程来体验和学习如何实现项目的愿景。（III）：社会参 与过程是基于一个体制中的小型社会技术实验的实施, 利基市场的开发和授权, 产 品服务系统创新的推广（还包括与其相关的系列文化、实践和组织的构建）。这一 过程具有动态适应性的特点：参与方通过所学到的知识不断对项目的愿景、过渡路 径和参与者网络本身进行调整 (IV)。

换句话说，生态效益型产品服务系统创新的引入和推广过程是一个集设计、开 发、实验和实施等一系列活动为一体的过程。从这个意义上说, 该过程所采用的是 一种边干边学的方式。

\section{图4.1 生态效益型产品服务系统引进和推广的概念框架}

来源：山士恩 (Ceschin) 2012a

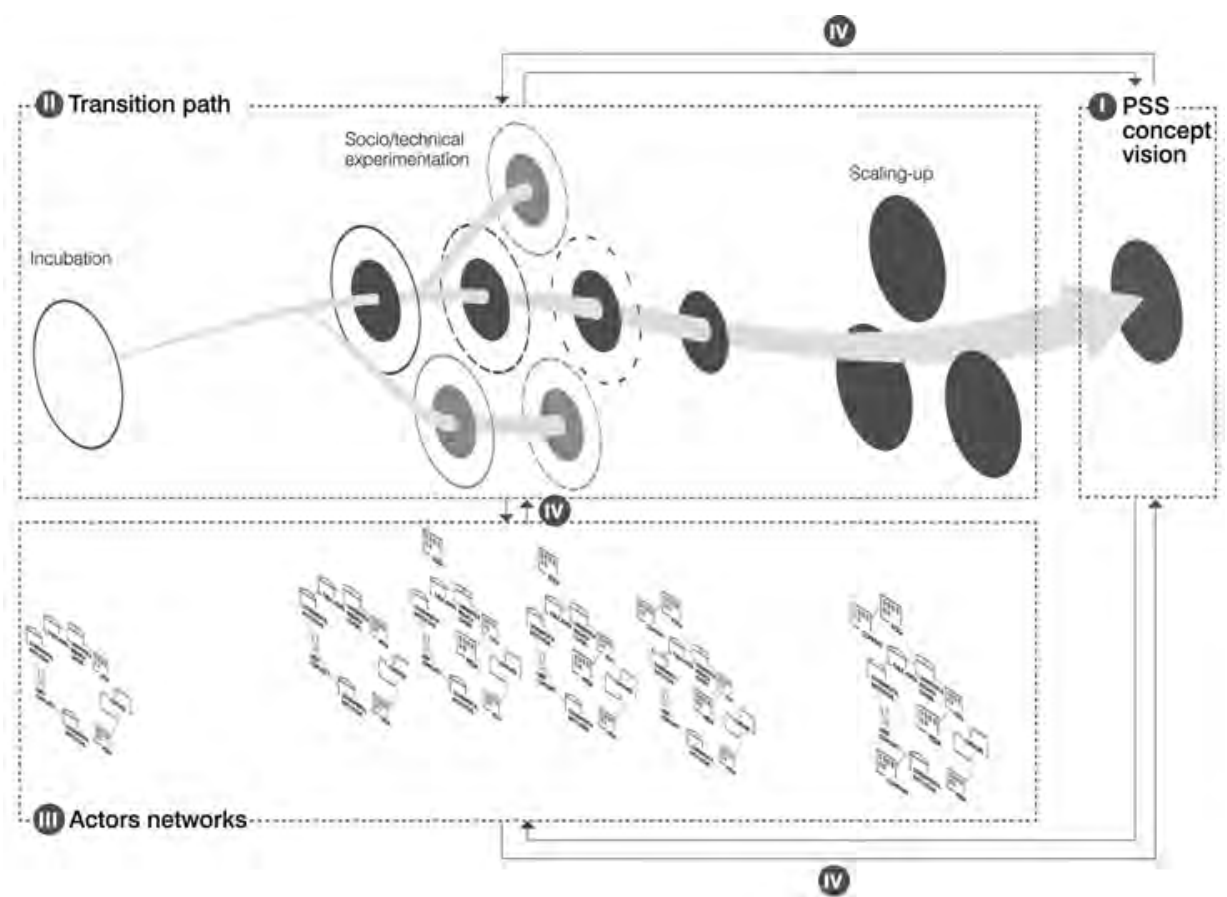


在这一过程中, 开展了一系列社会技术实验, 通过这些实验支持、推动并引导 根本性创新的孵化、测试并逐渐成熟。也就是说, 生态效益型产品服务系统的引进 和推广过程应被看作是一条转变发展路径的过程, 其主要特点是:

- 在孵化阶段, 应对推进社会参与所需的条件进行充分了解 (参与方的参与和 认可；讨论和协商，就产品服务系统概念可行性战略达成共识）。

- 在社会技术实验阶段, 开展一系列实验, 旨在学习和探索如何提升产品服务 系统创新, 如何推进其社会参与程度。

- 在推广阶段, 产品服务系统创新（及其相关的新实践、行为和组织）可促进 并影响社会技术体制的发展（即最初独特的产品服务系统创新已日益成为满 足社会需求/需要的重要方式）。

在这一转换过程中, 适当的参与者网络的建设和发展起到了至关重要的作用: 这种动态广阔的网络可以更好地推进、支持并促进创新的开展。这一广泛网络不仅 应涵盖产品服务系统价值链中的参与方（如：生产商、合作伙伴和供应商, 及消费 者/用户），还应包括其他参与方，比如：大学和研究中心（可以提供技术支持）, 各类机构和公共行政部门（有助于推进创新的进行并提供相应的政治支撑），非政 府组织（可以成为项目的合伙人），还有媒体（可对创新的结果进行宣传报道）。 该网络的推动力值得一说: 随着时间的推移, 各参与方的构成和角色也不断演变。 比如: 一些参与方在初期阶段还彼此关联, 而在后期彼此之间的作用就消失了

（如：公共管理部门只会参与前期的工作，为创新提供激励和保障机制）。

构建一个所有项目参与方长期共同愿景是十分必要的。共同项目愿景可以为社 会参与过程指明方向, 并因此为利益相关方的行动指明方向。所以, 项目愿景既可 作为参考以便制定各种战略, 还可以用于吸引、引导更多的潜在合伙人和利益相关 方加入到这一项目中来。

最后, 重要的是要为广泛的知识学习（学习有关产品服务系统创新和引进创新 的背景的不同层面知识) 和反思性学习 (了解参与方参考框架、信念、行为和实践 等的变化）创造空间。学习过程与实验的设计和管理密切相关。实验不仅关注技术 层面的探索和实验, 而且还与可用性、政策、法规、社会认可等相关, 这将有助于 推动广泛学习过程的因素。反思性学习对于了解参与方的既定设想和日常行为, 促 进文化、实践和组织变化都具有十分重要的意义。

必须要强调的是, 这一方法不应该被看做是 “成功的秘诀”。实践的推广需要 有利的条件和环境（如：需要承受来自环境的巨大压力, 体制应足够开放, 并愿意 接受根本性创新等）。公司或是小型的参与方网络或许不能直接（或间接）地对上 述所提及的条件和环境造成影响。这一过程从孵化到推广, 所面临的不确定性因素 日益增多, 管理难度也将加大, 会越来越容易受到项目之外的因素和事件的影响而 出现变数。然而, 采取实验型、学习型和网络型的管理模式则有利于提升成功的概 率（即加快并增加能够使得创新商业化的市场利基）。在这一过程中，社会技术实 验扮演了具有战略意义的重要角色, 对于根本性创新项目起到了激发和催化作用。 由于其重要性, 澄清社会技术实验的概念及其对转型的贡献是十分有益的。 


\subsection{1 社会技术实验及其在触发转型过程中的重要性}

社会技术实验可以被定义为一种局部受保护的环境, 一个广泛的参与者网络可在这 个环境中进行学习和探索: (1)如何孕育和促进根本性创新的发展; (2)如何促进社会 参与。这些实验能够为可持续产品服务系统等高风险创新的带来战略机遇, 不会受 到来自主流市场选择环境的直接压力。然而, 社会技术实验不只是一个简单的试点 项目或示范项目 4 。社会技术实验具有以下主要特点:

- 第一, 实验具备根本性创新特点, 需要在各种不同层面（社会文化、技术、 规范和制度等方面）进行重大变革的创新。并非所有产品服务系统都是根本 性创新, 因此, 不是所有的产品服务系统都需要采用这种社会技术实验策 略。

- 第二, 这些实验并不只是在公司实验室中进行的简单测试, 而是在真实环境 中进行的。这就是说, 只有这种实验室之外的经验, 才能够真正对根本性创 新进行测试和完善。此外, 这些实验只在小范围内进行, 但却能带来较大规 模的变化。

- 第三, 这些实验不仅仅包括与创新紧密相关的参与方（如生产商、合作伙伴 和供货商等主体）。而且还包括广泛的参与者, 其中包括用户、决策者、当 地政府、非政府组织、消费者群体、行业协会、研究中心等。换句话说, 我 们的目标是重新打造一个小规模的社会技术环境。从这个意义上讲, 这些实 验的特点是参与者的广泛参与: 即多种参与者都参与到创新过程的讨论、协 商、共同创造和开发。

- 第四, 这种实验是在一个受保护的空间中进行, 它不受主流选择环境的影 响。这种想法的主要目的是对创新提供暂时的保护, 防止其受到选择压力等 因素的影响（包括市场和体制因素），以打造一个可替代的选择环境。这些 保护的形式不尽相同：财政保护（如公司的战略性投资、免税和投资补助） 和社会制度保护（如实施单行条例）。实行保护措施的困难在于如何实现培 育创新和应对市场环境压力之间的平衡（韦伯（Weber）等1999）。

- 这些实验的目的是为了从多个层面了解并改进创新, 不仅仅涉及技术、经 济、市场需求和实用性等方面, 也包括政策、管制、环境、文化和社会等领 域。从这个角度看, 为了持续地进行调整和改善, 就必须保持创新。一般而 言, 通过实验, 我们能够识别一些在未来的实施和推广过程中可能会出现的 各种阻力和障碍, 并找出解决方案。

4 这里的社会技术试验中的概念, 也因其具体的环境不同而有所不同。“存在于真实世界中 的生活实验室是由用户主导的, 通过与研究机构、公司和公共民事部门合作, 旨在开发新 产品和服务”。(比恩根索尼 (Björgvinsson)，爱恩 (Ehn) 和惠勒根 (Hillgren) 2010)。 与生活实验室相比, 社会技术试验的概念范畴可要广的多。比如, 怎样在真实的场景中设 定一个参与的方式来开发信息的解决方案; 如何提供保护空间促进创新和研发, 怎样致力 于激发社会技术环境中的变革。这些都是社会技术试验所要探讨的问题。 
- 这是一个很关键的方面, 社会技术实验不仅能够对创新进行检验和改进, 而 且还能够促进社会技术环境的改变, 由此为产品服务系统创新创建最有利的 条件。换言之, 从战略上讲, 实验就是用于影响环境条件, 从而加快社会参 与过程（例如：引导当地政府制定有利于创新的政策措施或促使潜在用户改 变他们的行为和习惯）。

这个框架包括三个主要机制, 而技术实验正是通过这些机制促进转型（范·登・波什 (Van den Bosch)，罗特曼斯（Rotmans）2008; 范•登•波什（Van den Bosch） 2010) (图 4.2)) :

- 深化, 即在一个特定环境中尽可能多地了解创新。深化能够让参与者了解 当地文化上的变化（思维方式、价值观、参考框架等）、习俗上的变化（习 惯、做事方式等）和制度上的变化（标准和制度等）。深化最终将催生并完 善一系列与产品服务系统创新有关的新文化、新习俗和新制度。

- 拓展, 即在不同的环境中重复实验并将其与其他项目及举措结合起来。因为 从单个实验中学到的东西很有限, 因此, 应该将实验放在各种环境中反复进 行, 以便在不同的背景下学到不同的设计方法。拓展是指同时开展的不同实 验相互相互依赖, 相互促进（瑞文 (Raven) 2005; 吉尔斯 (Geels) 和瑞 文（Raven）2006）。而且, 加强与当地其他类似项目及方案的合作也非常 重要。通过拓展过程, 新生的文化、习俗和制度, 将 (1) 得到检验并拓展至 各种不同环境中; (2) 与其他项目和举措建立联系。

- 推广, 是指针对思维方式、处事方式和组织方式所开展的创新。这就意味将 创新（及其初步的社会技术实践）从局部的实验层面拓展到全局层面。范・ 登・波什（Van den Bosch, 2010) 强调, 与其说推广针对的是产品、服务或 用户, 不如说其针对的是观念、思维方式、习惯、立法、制度等。

基于上述情况, 社会技术实验除了促进转型过程之外, 还应当具备以下功能：(山士 恩 (Ceschin) 2010, 2012a; 山士恩 (Ceschin) 等, 2011)（图4.2）

- 实验室, 主要是对产品服务系统创新的诸多方面进行检验、学习和改善（技 术、适用性、管制、政治、经济和社会文化等方面），并拓展至不同的环境 中（了解不同背景环境下产品服务系统的不同构成）。

- 窗口, 提升创新项目和相关参与方的兴趣, 推广创新成果, 与现有项目/方案 建立协同，吸引并招募新的参与方加入（例如新用户或潜在合作伙伴）。

- 变革的动力, 用来改变环境条件, 以促进社会参与过程。实验旨在向社区引 入新创意和新知识, 并促使各社会团体（用户、事业单位、公司等）改变他 们的观念、信仰和生活方式。实际上, 实验应成为参与者改变其行为和思维 方式的催化剂（如：刺激用户改变他们的习惯或促使政府机关采取适当的政 策措施来支持产品服务系统创新）。 
图4.2 社会技术实验通过三种主要机制有利地推动了转型(深化、拓展和推广), 充当了实验室、窗口和变革催化剂的角色

来源：作者，范·登・波什（Van den Bosch）和罗特曼斯（Rotmans, 2008)

[

实验作为变革的催化剂

从实验层次到主流层次

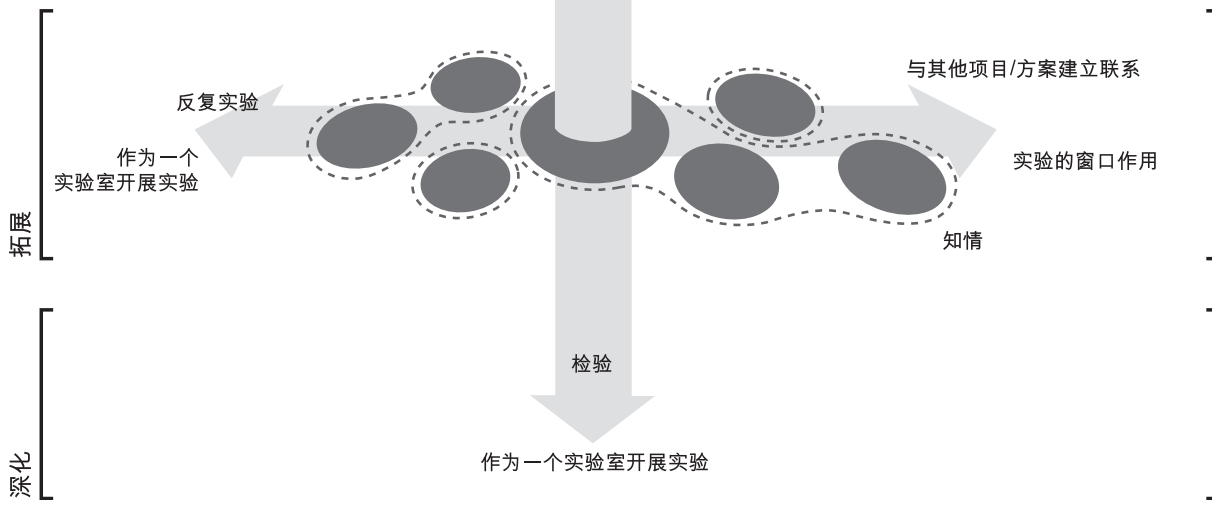

\section{4 设计的含义: 战略设计在可持续发展中扮演的全 新角色}

如果一种基于实验、学习和网络的管理方式，是成功孕育、检验、开发、完善生态 效益型产品服务系统的有效策略，那么对设计层面又具有什么意义呢? 战略设计在 这其中又扮演了怎样的角色呢?

我们知道, 采取一些特定的方法并使用一系列工具将有助于设计师形成生态 效益型产品服务系统的概念。然而, 如果设计师想成为创新的有力推动者, 他们必 须了解相关机制及其演变过程, 以及它们在此类创新的实施和推广过程中所发挥 的协调作用, 并对这些创新过程进行引导。简言之, 如果设计师们想在可持续的 转型过程中发挥更加积极的作用, 他们就不能仅限于提出生态效益型产品服务系 统理念, 他们应该为此类根本性创新的实施和推广指明道路。换句话说, 可持续 的战略设计在该领域转型过程中扮演重要角色, 并对这些概念的引进和推广提供支 持和帮助。（维佐里 (Vezzoli), 山士恩 (Ceschin) 和肯普 (Kemp) ; 山士恩

(Ceschin) 2010，2012a）。所以, 设计师应当在将生态效益型产品服务概念引入 
社会的过程中对公司、机构或参与者网络提供支持和指导。为了做到这一点, 需要 开发一种新型的设计方法, 并要求设计师们具备一种全新的设计能力。

\subsection{1 新型战略设计方法}

在此新方法中, 设计师首先应当着眼于更为广泛的设计范围, 并将可持续的产品服 务系统创意与适当转型路径的设计相结合。特别是设计范围应拓展至:

- 战略设计的一系列步骤可逐步促进/推动产品服务系统创新的开展, 并推进其 参与社会进程（孵化、社会技术实验、利基市场的开拓）。

- 识别那些能够在转换过程的各个环境对社会参与过程提供支持的参与方。 （即确定参与方以及相关角色）。

因此, 转型路径要求设计态度的多元化。这种多元化要求设计师们须同时关注：

- 项目长期目标: 可持续产品服务系统创新在将来满足社会过程中所需要取得 的成果（项目愿景）。

- 短期和中期计划, 推动社会参与进程, 实现长期目标。

第二, 需要更为广泛的战略设计态度。这意味着战略设计师们不仅应关注于产品服 务系统创新, 还应当关注有利于或不利于社会参与进程的环境条件。因此, 战略设 计师们应促进社会技术条件向有利于产品服务系统的实施的方向发展。若要实现这 一目标, 必须使那些直接或间接地对体制产生影响的参与者参与其中, 并促进他们 行为和实践方面的转型。由此, 转型路径不仅应着眼于测试并促进产品服务系统创 新走向成熟, 还应关注社会技术层面, 以便更好地促进该系统的社会参与过程。

第三, 更为广泛的战略设计态度需要构建一个范围更大的利益相关方系统。从 事产品服务系统工作的战略设计师应善于使用系统设计方法。这便意味着他们的设 计活动所关注的不应仅仅是产品服务系统本身（产品和服务的整合），而应关注参 与到产品服务系统中的社会经济利益相关方们以及他们之间的相互关系（即产品服 务系统的价值链或网络）。从这个角度来说, 战略设计师不仅应着眼于产品服务系 统的价值链, 还应关注产品服务系统的社会技术环境状况。这意味着纳入考虑范围 内的参与方不仅包括那些直接与创新相关的人群, 还包括其他科学、政策和社会领 域的相关参与方, 即一个融科学、社会、经济、政治和文化为一体的综合网络。建 立并开发这样一个范围广、多元化的社会经济网络, 事实上对根本性创新的保护、 支持和推进能起到极其重要的作用。总之, 将不同的圈内和圈外人, 现有或新的参 与方融入其中是十分重要的, 有助于在网络中、网络间和网络外围都构建更加丰富 的联系。

第四, 需要有实验和学习态度。我们研究的既然是高度负责、存在不确定性的 创新活动, 就不能局限于采用原先预想的固有方案。因此, 社会参与过程应当被看 做是一个基于探索、搜寻和学习的过程。从这个角度可以清楚地看出, 战略设计师 所扮演的一个重要角色便是从事一系列社会技术实验的设计（如实验室、窗口和变 革的动力），这些均能够推进产品服务系统创新的社会参与进程。 
最后, 实验型和学习型方法的实施需要富于弹性的动态管理。项目愿景并不是 一个有待完成的静态指标, 而应根据在社会参与过程中参与方的学习成果进行适时 和持续的调整（尤其是在社会技术实验的过程中）。因此, 既然转型战略的着眼点 在于实现项目愿景, 那么在调整项目愿景的同时, 转型战略也该进行相应的变更。 甚至可以说, 社会参与过程中的参与方、网络也是动态的：其组成部分及各参与方 的任务都应随着时间的变化而进行调整, 其原因在于, 转型过程中的不同阶段所需 的网络构成有所不同。比如：当地社会技术实验中的网络构建过程就与网络推广过 程有所不同。换句话说, 我们所应对的是富于弹性的动态的过程, 其特点是长期愿 景、转型路径和参与方网络之间的相互协调（相互协调是这个学习过程的结果）。 因此, 重要的是战略设计师应采用一种灵活且动态的方法来管理这个持续的挑战和 再定位过程。

\subsection{2 新设计能力要求}

根据上述分析, 这种新设计方法要求具备以下所述的创新设计技能。

- 将产品服务系统的概念、愿景应用到转型战略中: 战略设计师必须学会分步 骤对产品服务系统理念、愿景进行诠释, 以便对其实施和推广提供支持。换 句话说, 他们必须学会设计转型路径、产品服务系统从无到有的一系列步骤 的实施。在转型过程中, 社会技术实验所扮演的角色十分重要。因此, 战略 设计师们必须懂得如何设计这些实验, 特别是要学会如何将这一系列实验按 顺序进行设计和实施, 以便学习和探索如何改进并提高产品服务系统创新的 实现及如何促进其社会参与过程。应将产品服务系统理念的设计融入到各项 实施步骤的设计过程中, 以促进创新发展实现其愿景。

- 设计能够推进社会参与进程的参与方网络配置: 战略设计师必须确定在该进 程的各个阶段所涉及的各参与方: 设计一个参与方动态网络, 其中各种组件 和参与方在该网络中持续不断的进行互动。另外, 战略设计师要能够应用综 合的系统方法, 不仅思考产品服务系统价值链（生产者、合伙人、供应商、用 户等），还应考虑到那些有能力、有意愿、能直接影响主导体制（如：各政 府部门、政策制定者、政治家、相关组织) 的参与方, 以及那些将对主导体 制产生间接影响的参与方（如：非政府组织、社会群体和媒体）。因此, 战 略设计师应既能够充当网络沟通者（成为各参与方之间沟通的桥梁）, 又能 够扮演谈判者/促进者（能协调管理网络内部出现的争议和分歧）的角色。

- 推进项目愿景的设定和行动计划的制定: 战略设计师必须学会推动项目参与 方之间的战略对话, 以便制定统一的项目愿景和行动计划（适时进行调整）。 因此, 战略设计师们应有能力改善参与方式, 并将众多利益相关方召集在一 起, 共同讨论、协商、开发备选方案。因此, 具备管理复杂信息的能力对于 战略设计师来说十分重要, 有利于实现信息交换, 推进利益相关方之间展开 有效沟通; 鼓励并引导各参与方参与到战略对话中来, 管理各种不同预期, 协调商谈和合作等事宜。因此, 基本技能包括: 充当沟通者（能对复杂信息 
进行有效诠释, 如项目愿景和行动计划）和协调者（实现对个体参与方预期 有效管理）。

- 社会参与过程中动态适应管理：战略设计师应该学会如何对项目愿景、转型 路径和参与方网络进行不断评估和调整。项目愿景不是一个静态指标, 转型 战略也不是一个僵化的路线图, 参与方网络中的各个组成部分也不是预先设 定好的: 随着参与者不断学习, 这些要素也不断的丰富和发展。因此, 能够 对项目愿景、转型战略和参与方网络之间互动实现动态管理对战略设计师来 说是十分重要的, 不应将这个过程视为一个具有固定结果的项目, 而应将其 看作是开放的搜索和学习过程。所以, 将设计与实施这两者进行区别对待是 十分必要的: 设计、开发和实施应同时进行并确保它们之间的持续互动。

该战略性设计理念近期已应用于若干研究项目中, 由意大利米兰理工大学可持续 设计与体系创新 (DIS) 项目实验室协调进行。其中一项被称为 “开普敦可持续交 通项目”, 是我们与南非开普半岛科技大学 (the South African Cape Peninsula University of Technology) 合作完成的。下一节将简要描述该项目的设计和实施过程 及主要成果。

\subsection{3 设计经验: 开普敦可持续交通项目}

背景

该项目的主要参与方包括: Shonaquip (南非一家为残疾人生产轮椅和轮式移动设备 的小公司），BEN Bikes（当地一家致力于可持续交通项目宣传推广的组织），开普 半岛科技大学 (Cape Peninsula University of Technology)，意大利米兰理工大学 (Politecnico di Milano (Polimi)) 。该项目旨在向开普敦城郊的残疾人及老年人介绍 并推广一种可持续交通产品服务系统。

尤其值得一提的是, 该系统将为残疾人及老年人提供更多的出行服务, 使他 们能方便地从其住所到达邻近的公交车站或者前往学校、医院等地。就技术层面而 言, 该交通系统的设计灵感来自那些依靠太阳能、电力和人力发电的轻型汽车5。 该车的原型是由意大利米兰理工大学 (Politecnico di Milano (Polimi)) 的IPSIA A. Ferrari Maranello于2006年设计的。该交通系统的设计是为了给更多像开普敦城郊这 样的地区带来便利, 这些地区因为缺少优质的公共交通服务而普遍存在各种出行问 题。产品服务系统的初始概念来自海泽 · 居米什 (Hazal Gumus) 2009年的硕士学 位论文, 该论文是在一个米兰理工大学 (Politecnico di Milano (Polimi)) 与开普半岛 科技大学 (Cape Peninsula University of Technology) 的合作项目下完成的。该论 文设计项目引起了Shonaquip公司的兴趣。2009年7月, 一项以产品服务系统创新为 特征的社会参与项目正式启动。

5 由法布里齐奥 · 山士恩 (Fabrizio Ceschin) (作者)设计, 用于他于2006年在米兰理工大学 (Politecnico di Milano (Polimi)) 设计学院的硕士学位毕业论文。 
孵化

项目的第一步便是确立项目愿景, 愿景是在米兰理工大学 (Politecnico di Milano (Polimi)）、南非一家轮椅及代步工具制造商（Shonaquip）和开普半岛科技大学

(Cape Peninsula University of Technology) 共同提出的产品服务系统初始概念的 基础上形成的。其目的是为了将项目理念转化为可视化的人工制品, 使其能清晰有 效地向各参与方展现产品服务系统的创新特质及其潜在效益。该项目使用了一系列 工具6：1）产品服务图表：展现产品服务系统满足了哪方面的客户需求；2）互动图 表：标明产品服务系统是如何提供服务并满足客户需求的；3）系统图表：对价值链 的架构进行可视化表达；4）可持续性图表：诠释环境、社会道德及经济效益。

下一步是拟定行动计划, 识别当前状态与实施产品服务系统后的未来状态 之间的主要步骤。该项活动由米兰理工大学 (Politecnico di Milano (Polimi)), Shonaquip和开普半岛科技大学（Cape Peninsula University of Technology）共同 合作完成。下一步需要确定参加战略性讨论的参与方。首先, 应当包括有限的参与 方（他们对产品服务系统概念和行动方案的讨论及推动起着至关重要的作用），接 下来应该扩大参与方范围，例如邀请开普敦相关市政当局、当地的公交运输公司及 地方媒体的参与。最初的参与方主要包括潜在用户、当地居民、开普半岛科技大学

(Cape Peninsula University of Technology) 的科技专家和两家当地的非政府组 织：DWDE（一家向残障人士提供就业机会的组织）和教改小组（一个旨在帮助吸 毒者和罪犯重新融入社会的组织)。

随后, 一个为期两天的研讨会于2009年9月召开。第一天集中讨论和调整了项目 愿景, 第二天则讨论了行动计划。研讨会调整了产品服务系统的概念和转型路径, 分析了实施过程中会遇到的障碍, 介绍了新的参与人员并就参与人员的工作任务达 成了共识。

在第二阶段, 设计并实施社会技术实验。

第一次实验与教改小组在阿思隆区（布里奇顿）合作进行，其目的是就产品服 务系统创新的技术性和可用性进行测试和完善。一辆现有的人力车被用于测试社区 老年人出行服务, 以找寻它的不足之处并使之更加完善。该人力车的模型完成后将 通过一系列技术对其进行检测和试验（图4.3）。

图4.3 首个社会技术实验：汽车技术实验过程中拍摄的照片（2011年8月） 来源：山士恩 (Ceschin) 2012a

6 请参阅第1部分, 第四章, 此卷中对这些工具有着详尽的解释。 


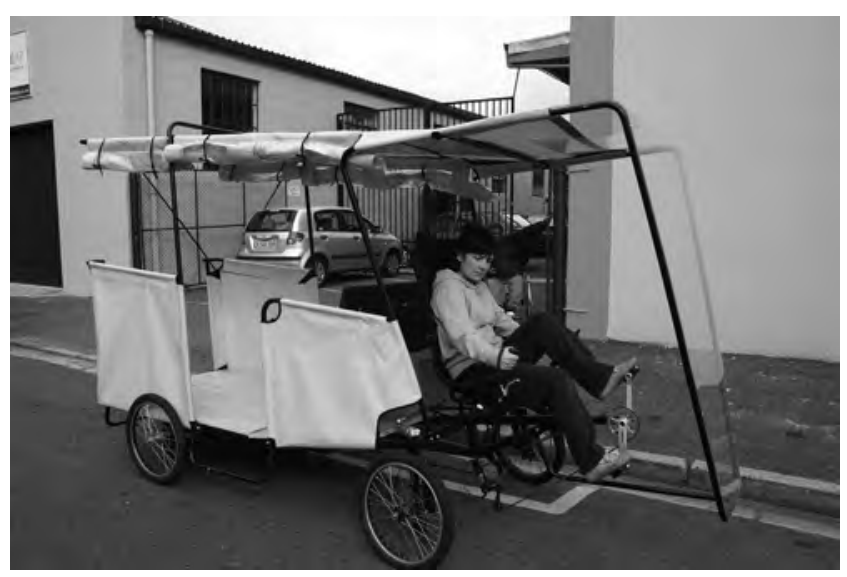

在解决了汽车的技术性问题并收集了首次服务回馈之后, 第二次实验（更为关 键的）与BEN Bikes 公司合作进行。该实验始于2011年10月, 至今仍在进行。设计 该实验的目的是为了说明创新实验的三方面功能：实验室、窗口和变革动力。以下 我们将分别分析这三方面的 “功能”。

该实验的第一个目的是对产品服务系统创新（实验室功能）进行测试和改进。 将老弱病残者从住处转送到拉瓦德山 (Lavender Hill) 社区附近的地方（如医院、教 堂或者邮局）的交通服务已经投入运营。BEN Bikes中心主要负责对该运输服务进行 管理并提供车辆维修、保养服务。该实验如今主要用于：车辆的调试和改进; 服务 质量的测试和提升（采用调查问卷和访谈的方式进行）；产品服务系统结构的测试 和改建（利益相关方价值链和商业模型）; 障碍的识别（包括社会文化、监管等多 层面的障碍）。对于后者, 为了找出潜在的障碍, 应听取不同参与方（当地居民、 政府部门和非政府组织）的意见与建议。需要强调的是, 所用方法要有助于各参与 方在设计选择过程中的广泛参与。所有参与方（从潜在用户到当地居民再到当地机 构）不仅要对项目本身进行评价和反馈，还应尝试提供改进意见及其他可选方案。

该实验也旨在提高人们对于创新性项目的兴趣, 吸引并招揽潜在用户以及其他 相关的参与方（窗口功能）。为此, 一直被视为 “露天走廊” 的BEN Bikes中心向游 客提供了参观、接触和咨询该项计划的机会。感兴趣的人可以免费参观，更直观地 了解该项目的各种特征及其带来的环境、道德和经济效益。这种参观模式也对参与 方（例如潜在用户、潜在合作伙伴和当地组织等）开放。为了更有效地向不同类型 的参与方介绍项目内容和潜在优势, BEN BIKES中心的全体工作人员都经过了专门 培训。项目发起人认为这点至关重要, 因为, 这不仅要对项目本身进行宣传, 还需 要对项目参与方的行为和日常活动产生影响（例如鼓励潜在用户重新思考他们的出 行习惯, 重新考虑该项目可以给他们带来的益处)。很显然, 这与实验的第三项功 能有关：变革的动力。

该实验旨在促进项目参与方的行为和习惯的转变, 并为产品服务系统的引入和 推广创造有利条件。因此, 我们在 2011 年10月举办了一个与相关项目参与方有关的 活动。该活动的目的是正式启动该项实验, 展示未来发展趋势, 与受邀项目参与方 
一起讨论应如何为项目的实施推广提供支持。该活动在拉瓦德山 (Lavender Hill) 的 BEN BIKES中心举行。

受邀参加该活动的项目参与方包括开普敦市政当局（尤其是交通部和环境资源 管理部），因为该项目与这些机构存在利益关系，并且对当地运输管制机制产生直 接影响; 对穆洛 (MULO) 汽车运输服务感兴趣的当地参与方（特别是当地学校和当 地诊所）以及当地媒体。该活动产生了如下积极的影响：首先，当地项目参与方认 为该项目对当地社区十分有益, 因为它带来了切实的经济、环境和社会伦理效益。 第二, 当地一家诊所, 作为参与方之一, 表示对此项目有兴趣, 认为这有利于及时 且迅速地转送病人。第三, 开普敦交通部门有意加强产品服务系统与城郊公交线路 之间的协作。另外, 交通部门称, 他们将制定议程, 安排会议讨论并制定相关政策 措施, 以支持并建立产品服务系统所需的特定汽车类型。

因为第二项社会技术实验还在进行中, 所以现在不可能对整个可持续交通项目 得出最后结论。然而, 可以说, 整个过程加强了利益相关方网络, 有助于产品服务 系统概念的提升和改进, 同时为将来的发展创造了重要的机遇。

\section{5 设计与实施生态高效产品服务系统的新方法}

基于我们假设的战略设计方法, 并参照开普敦可持续交通项目实施的中期结果, 我 们为生态效益型产品服务系统的引进和推广提出了第一个试验性设计实施方案。

图4.4 对整个过程进行了综述（山士恩 (Ceschin) 和瑞文 (Raven) 2011；山 士恩 (Ceschin) 2012a) 战略设计师、项目经理和顾问们都可以将这一方案（或小 型参与方网络）应用到生态效益型产品服务系统创新的社会参与的管理和改进过程 中。特别值得一提的是, 该方法促进了实验型、学习型和基于网络型设计和管理理 念的应用, 能够更好地实现生态效益型产品服务系统的引进和推广。整个过程包含 五个活动集群和三个阶段。活动集群包括以下几个种类:

- 愿景构建和期望形成（项目网络所要实现的目标）：制定行动计划（项目愿 景如何实现）将愿景转变为实际的行动步骤的活动, 支持产品服务系统概念 的社会参与过程。

- 参与方网络的确立和发展（项目参与方）：即项目网络的建立、管理和发 展。

- 行动方案的实施（按计划实施）：实施战略计划中确定的相关的活动。

- 监控、评估和学习 (从中活动中吸取经验)：转型过程监控、评估和调整相 关的活动。

三个阶段包括：孵化、社会技术实验和利基市场的开发与推广，具体内容将在 以下章节中分别论述。（山士恩 (Ceschin) 和瑞文 (Raven) 2011; 山士恩

(Ceschin) 2012a)。 


\section{图4.4 生态效益型产品服务系统社会参与的辅助过程}

来源: 作者

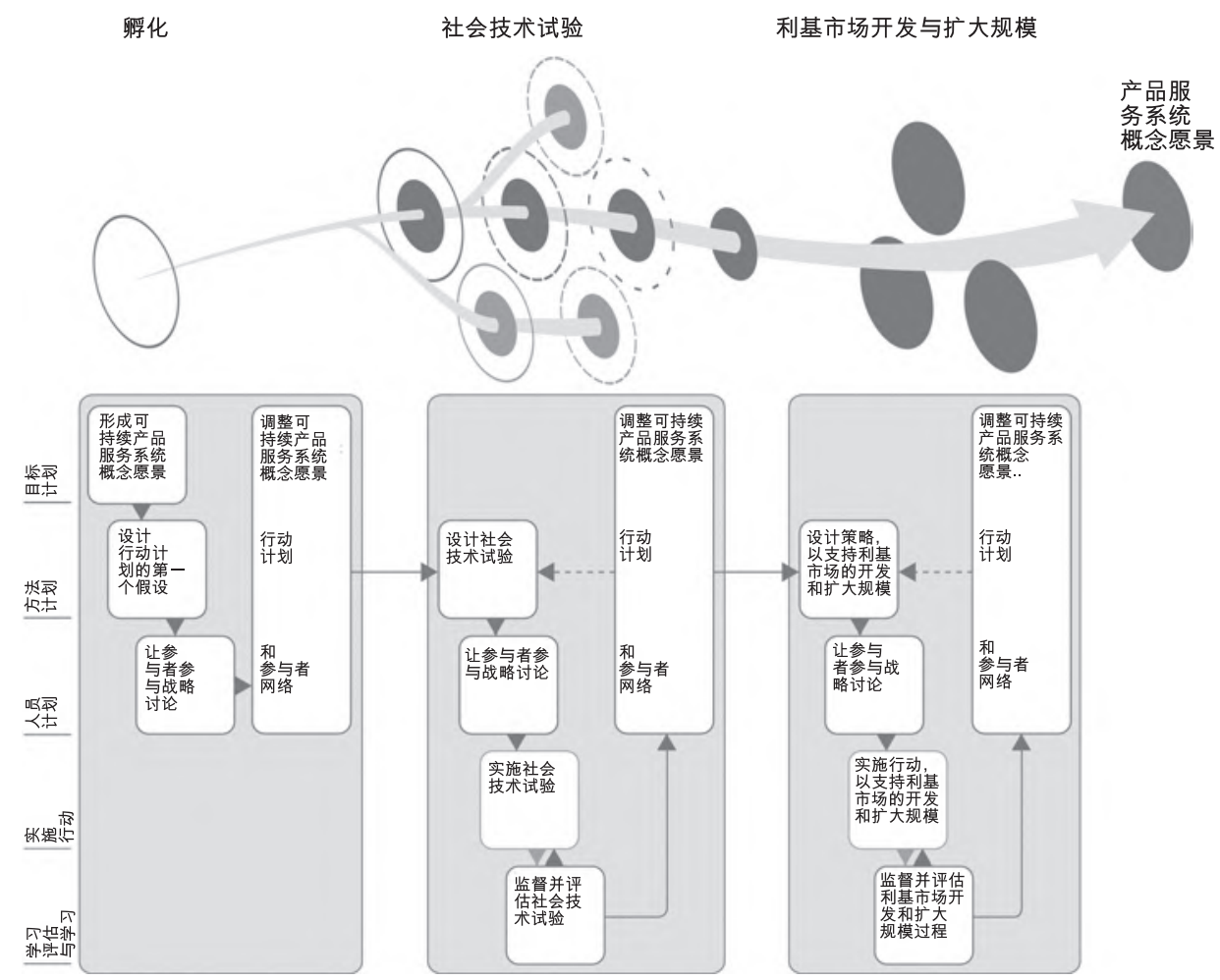

\subsection{1 第一阶段：孵化}

孵化阶段为社会参与过程创造了条件。生态效益型产品服务系统的最初理念是由一 个或多个PSS倡导者提出的。第一步是确定项目愿景, 并就项目的目的、产品服务 系统创新的主要特点及其潜在效益（环境、经济和/或社会伦理方面）进行清晰和有 效的沟通。

下一步是探讨如何将此理念更好地融入社会。这就需要将实施产品服务系统前 的状态与将来该系统实施后的状态进行对比。重要的是要从战略角度进行分析, 确 定短、中期的行动计划, 以创造最有利的运行环境。识别那些对此理念感兴趣的参 与者, 以及能够对创新提供保护和支持的参与方。在这一步骤中需要拟定初步的行 动计划草案（确定行动步骤、参与者及其角色）。

第三步是确定利益相关方参与到战略讨论中: 在这一阶段, 召开参与方会议并 举办研讨会。这些活动的目的是比较各不同参与方的期望, 讨论并调整项目愿景和 行动计划, 统一思想, 达成共识。 
上述这些会议和研讨会还需要对项目愿景、行动计划和参与方网络进行调整。 这个阶段的具体工作包括：构建项目网络，确立项目愿景和行动计划。

\subsection{2 第二阶段：社会技术实验}

在这一阶段, 小型社会技术实验正式开始实施, 这个阶段学习和研讨的目的在于如 何推进产品服务系统的创新以及如何促进社会参与度。

这一阶段的第一步工作就是对实验进行设计, 使其不会受到市场竞争环境的 影响, 并发挥其实验室、窗口和变革催化剂的作用。实验设计包括：实施区域的选 定, 适当的金融和社会体制保障，产品服务系统的技术要素，以及保护并支持创新 的社会经济组织（确定参与方及其角色）的确定。

在实验过程中, 监控和评估活动也随之展开。内容包括实验（技术与实用性、 参与项目的各社会团体对生产服务系统的接受程度, 实施和推广中遇到的困难）; 直接和间接参与方（他们的角色、行为、期望、冲突与融合）; 共同的项目愿景和 行动计划（演变和即时调整）。

之后评估结果可有助于新行动的开展。通过边做边学的方式, 对实验、行动计 划和项目愿景进行及时调整, 同时还可以提升对环境改变和实现方式的理解。

在这一进程之后, 可以从不同的角度开展不同的实验, 并对新功能进行测试。

\subsection{3 第三阶段：利基市场的开发与推广}

这一阶段的目的在于推进产品服务系统创新（及相关的新实践、行为和制度）并对 社会技术体制产生影响。创新将日益成为满足社会需要的主要手段。

首先, 确定恰当的行为方式, 改进实验方法和手段。深入开展产品服务系统创 新, 扩大影响。关键问题包括:

- 在各种背景下反复进行实验, 在类似的项目和方案中发挥协同效应。其目的 在于实现经验的共享, 推进并扩大网络的建设规模（如：在一个部门, 或全 国范围内推广）。

- 在全国范围发布信息/项目成果, 吸引媒体关注。

- 从战略层面鼓励参与方在社会技术环境中发挥作用, 以便为产品服务系统创 新的推广创造最有利的条件。

总的来说, 目的是与相关的政治、行业和社会参与方建立更深层次的联系：包括那 些能够直接对主流文化、习俗和体系产生影响的参与方 ${ }^{7}$, 能够直接或间接对体制产 生影响的参与方; 有兴趣致力于新型可持续理念的推广的参与方; 能够促进产品服 务系统创新的信息传播参与方; 以及可以辅助创新推广的参与方, 如潜在的行业合 伙人、行业协会或联盟。

7 由范·登·波什（Van den Bosch）提出（2010）。 
在这一过程中, 需要持续进行监控和评估活动。评估对象包括利基市场发展 和推广进程（如：与其他实验之间的联系、新参与方加入、项目成果宣传、与体制 参与方联系、在利基市场中引入产品服务系统创新）、参与方、项目愿景和行动计 划。在评估过程中将调整相应的行动方案, 以便更好地促进利基市场的发展和推 广, 同时, 根据不同情况, 还会对项目愿景进行重新定位, 调整参与方网络和行动 计划。

\section{6 结论}

生态效益型产品服务系统创新代表了一种可用于提升公司竞争力并能够带来环境效 益的重要概念。然而, 这类创新在大多数情况下都是激进的, 其引进和推广通常会 遭到现行文化、企业和管制方面的阻力。因此，如果将其迅速投入到主流市场环境 中, 它们大多都无法生存下去。所以, 最大的挑战不仅是同时形成可持续产品服务 系统概念和理解引入的环境条件, 而是找到那些将这些概念融入社会的发展路径。 基于对转型的深入研究, 本章提出了生态效益型产品服务系统引进与推广的概念性 框架。在这其中, 社会技术实验扮演了重要的角色, 由于不会受到来自市场环境的 直接压力, 社会技术实验为参与方网络创新的孕育、试验、开发和成型创造了空 间。理论和实验结果都验证了这一观点的正确性, 为了更好地推进转型过程, 社会 技术实验充当实验室、窗口和变革驱动力等角色。

所以, 战略设计不应只是推进生态效益型产品服务理念的产生, 而是应在设计 转型路径的过程中对概念本身的引进和推广起到辅助和促进作用。本章还讨论了新 的设计方法和当代设计师所应具备的能力。

\section{参考文献}

Akrich, M. (1992) 'The Description of Technological Objects', in W. Bijker and J. Law (eds.) Shaping Technology/Building Society: Studies in Socio-Technical Change (Cambridge, USA: MIT Press).

Aurich, J.C., Fuchs, C., and C. Wagenknecht (2006) 'Life cycle oriented design of technical Product-Service Systems', Journal of Cleaner Production 14.17: 1480-1494.

Berkhout, F. (2006) 'Normative expectations in systems innovation'. Technology Analysis \& Strategic Management 18.3: 299-311

Björgvinsson, E., Ehn, P. and P.A. Hillgren (2010) 'Participatory design and "democratizing innovation"', in: Proceedings of the Participatory Design Conference (PDC), Sydney, Australia 29 November - 3 December 2010.

Brezet, H., Bijma, A.S., Ehrenfeld, J., and S. Silvester (2001) The design of eco-efficient services: Methods, tools and review of the case study based 'Designing eco-efficient Services' project, report for Dutch Ministries of Environment (VROM).

Brown, H.S., and P.J. Vergragt (2008) 'Bounded socio-technical experiments as agents of systemic change: The case of a zero-energy residential building', Technological Forecasting \& Social Change $75:$ 107-130. 
Brown, H.S., Vergragt, P.J., Green, K., and L. Berchicci (2003) 'Learning for Sustainability Transition Through Bounded Socio-Technical Experiments in Personal Mobility', Technology Analysis \& Strategic Management 13.3: 298-315.

Callon, M. (1991) 'The Dynamics of Techno-Economic Networks', in R. Coombs, P. Saviotti and V. Walsh (eds.) Technical Change and Company Strategies (London, UK: Academic Press).

Callon, M., Laredo, P., and V. Rabeharisoa (1992) 'The Management and Evaluation of Technological Programmes and the Dynamics of Techno-Economic Networks', Research Policy 21.3: $215-236$.

Ceschin, F. (2010) 'How to facilitate the implementation and diffusion of sustainable ProductService Systems? Looking for synergies between strategic design and innovation sciences', in Ceschin, F., Vezzoli, C. and Zhang, J. (eds.), Sustainability in design: now! Challenges and opportunities for design research, education and practice in the XXI century. Proceedings of the Learning Network on Sustainability (LeNS) conference (vol. 1), Bangalore, India, 29 September - 1 October 2010 (Sheffield, UK: Greenleaf Publishing).

Ceschin, F. (2012a) The introduction and scaling up of sustainable Product-Service Systems: A new role for strategic design for sustainability. PhD thesis (Milan, Italy: Politecnico di Milano).

Ceschin, F. (2012b) 'Critical Factors for Managing the Implementation and Diffusion of EcoEfficient Product-Service Systems: Insights from Innovation Sciences and Companies' Experiences', Journal of Cleaner Production doi:10.1016/j.jclepro.2012.05.034.

Ceschin, F. and R.P.J.M. Raven (2011) 'Managing the introduction and scaling-up of sustainable Product-Service Systems: Towards a system innovation approach for practitioners', working paper.

Ceschin, F., and C. Vezzoli (2010) 'The Role of Public Policy in Stimulating Radical Environmental Impact Reduction in the Automotive Sector: The Need to Focus on Product-Service System Innovation', Int. J. Automotive Technology and Management 10.2/3: 321-341.

Ceschin, F., Vezzoli, C., and P. Vergragt (2011) 'Small Scale Socio-Technical Experiments as Stepping Stones for Eco-Efficient Product-Service Systems Diffusion: a New Role for Strategic Design for Sustainability', in: J. Hesselbach, and C. Herrmann (eds.) Functional Thinking for Value Creation. Proceedings of the 3rd CIRP International Conference on Industrial Product Service Systems, Technische Universität Braunschweig, Braunschweig, Germany, 5-6 May 2011 (Berlin Heidelberg: Springer): 111-116.

De Laat, B. (1996) Script for the Future: Technology Foresight, Strategic Analysis and SocioTechnical Networks: the Confrontation of Script Based Scenarios. PhD Thesis, University of Amsterdam.

Geels, F. (2002) 'Technological Transitions as Evolutionary Reconfiguration Processes: a Multilevel Perspective and a Case-Study', Research Policy 31.8/9: 1257-1274.

Geels, F.W., and R.P.J.M. Raven (2006) 'Non-linearity and expectations in niche-development trajectories: Ups and downs in Dutch biogas development (1973-2003)', Technology Analysis \& Strategic Management 18: 375-392.

Gumus, H. (2009) Kanga: a sustainable system design for the transportation of learners with disabilities in Cape Town-South Africa, Master's degree thesis, Politecnico di Milano, Faculty of Design.

Hall, P. (1993) 'Policy Paradigms, Social Learning and the State: The Case of Economic Policymaking in Britain', Comp. Polit. 25.3: 275-96.

Hegger, D.L.T., van Vliet, J., and B.J.M. van Vliet (2007) 'Niche Management and its Contribution to Regime Change: The Case of Innovation in Sanitation', Technology Analysis \& Strategic Management 19: 729-746.

Hoogma, R. (2000) Exploiting Technological Niches: Strategies for Experimental Introduction of Electric Vehicles, PhD Thesis (Enschede, NL: Twente University Press). 
Hoogma, R., and J.W. Schot (2001) 'How innovative are users? A critique of learningby-doing and-using', in: R. Coombs, K. Green, A. Richards and V. Walsh (eds.), Technology and the Market (Cheltenham/Massachusetts: Edward Elgar): 216-233.

Hoogma, R., Kemp, R., Schot, J., and B. Truffer (2002) Experimenting for Sustainable Transport: The Approach of Strategic Niche Management (London/New York: Spon Press).

Kemp, R., and J. Rotmans (2004) 'Managing the Transition to Sustainable Mobility', in B. Elzen, W. Geels, and K. Green (eds.), System Innovation and the Transition to Sustainability: Theory, Evidence and Policy (Cheltenham, UK, Northampton, USA: Edward Elgar Publishing).

Kemp, R., Schot, J., and R. Hoogma (1998) 'Regime Shifts to Sustainability Through Processes of Niche Formation: the Approach of Strategic Niche Management', Technology Analysis \& Strategic Management 10.2: 175-195.

Kemp, R., A. Rip and J. Schot (2001) 'Constructing Transition Paths Through the Management of Niches', in R. Garud and P. Karnøe (eds.), Path Dependence and Creation (London, UK: Lawrence Erlbaum).

Laredo, P., and P. Mustar (1996) 'The Techno-Economic Network, a Socio-Economic Approach to State Intervention in Innovation', in R. Coombs, A. Richard, P. Saviotti, and V. Walsh (eds.), Technological Collaboration (Cheltenham: Edward Elgar).

Laredo, P., Jolivet, E., Shove, E., Raman, S., Rip, A., Moors, E., Poti, B., Shaeffer, G.J., Penan, H., and C.E. Garcia (2002) Management tools and management framework for assessing the potential long term S\&T options to become embedded in society. Socrobust Final report.

Latour, B. (2000) 'PROTEE Principles: Theoretical Background', in M. Duret et al. (eds.), Final report of the PROTEE project (Paris, France).

Luiten, H., Knot, M., and T. van der Horst (2001) 'Sustainable product service-systems: the Kathalys method' paper presented at the Second International Symposium On Environmentally Conscious Design And Inverse Manufacturing, 2001.

Lynn, G.S., Morone, J.G., and A.S. Paulson (1996) 'Marketing and Discontinuous Innovation: the Probe and Learn Process', California Management Review 38: 8-37.

Manzini, E., Collina, L., and S. Evans (eds.) (2004) Solution oriented partnership (Cranfield, UK: Cranfield University).

Maxwell, D., Sheate, W., and R. van der Vorst (2006) 'Functional and systems aspects of the sustainable product and service development approach for industry', Journal of Cleaner Production 14.17: 1466-1479.

Quist, J., Rammelt, C., Overschie, M. and G. de Werk (2006) 'Backcasting for Sustainability in Engineering Education: the case of Delft University of Technology', Journal of Cleaner Production 14.9/11: 868-876.

Raven, R.P.J.M. (2005) Strategic Niche Management for Biomass, PhD thesis (Eindhoven: Technische Universiteit Eindhoven).

Raven, R.P.J.M., Heiskanen, E., Lovio, R., Hodson, M., and B. Brohmann (2008) 'The contribution of local experiments and negotiation processes to field-level learning in emerging (niche) technologies', Bulletin of Science, Technology and Society 28.6: 464-477.

Raven, R.P.J.M., van den Bosch, S., and R. Waterings (2010) 'Transition and strategic niche management: towards a competence kit for practitioners', International Journal of Technology Management 51.1: 57-74.

Rip, A., and R. Kemp (1998) 'Technological Change', in S. Rayner and E.L. Malone (eds.), Human Choice and Climate Change, Vol. 2 (Columbus: Batelle Press): 327-399.

Rotmans, J., Kemp, R., and M.B.A. Asselt (2001) 'More evolution than revolution: transition management in public policy', Foresight 3: 15-32.

Schot, J.A., and R. Hoogma (1996) De Invoering van Duurzame Technologies: Strategisch Niche Management als Beleidsinstrument, DTO Programme (Delft: Delft University of Technology). 
Schot, J., and F. Geels (2008) 'Strategic Niche Management and Sustainable Innovation Journeys: Theory, Findings, Research Agenda, and Policy', Technology Analysis \& Strategic Management 20.5: 537-554.

Tukker, A., and U. Tischner (2006a) 'Product-Services as a Research Field: Past, Present and Future: Reflections from a Decade of Research', Journal of Cleaner Production 14.17: $1552-1556$.

Tukker, A., and U. Tischner (2006b) 'A practical guide for PSS development', in A. Tukker and U. Tischner (eds.), New Business for Old Europe: Product Services, Sustainability and Competitiveness (Sheffield, UK: Greenleaf Publishing).

Tukker, A., and C. van Halen (2003) Innovation scan product service combination: manual (Delft: TNO-STB).

Van de Kerkhof, M., and A. Wieczorek (2005) 'Learning and Stakeholder Participation in Transition Processes Towards Sustainability: Methodological Considerations' Technological Forecasting \& Social Change 72: 733-747.

Van de Poel, I. (2000) 'On the role of outsiders in technical development', Technology Analysis and Strategic Management 12.3: 383-397.

Van den Bosch, S. (2010) Transition Experiments. Exploring societal changes towards sustainability, PhD thesis (Rotterdam: Erasmus Universiteit Rotterdam).

Van den Bosch, S., and J. Rotmans (2008) Deepening, Broadening, and Scaling up: towards a Conceptual Framework for Transition Experiments (Delft, The Netherlands: Knowledge Centre for Sustainable System Innovations and Transitions, KCT).

Van der Laak, W.W.M., Raven, R.P.J.M., and G.P.J. Verbong (2007) 'Strategic niche management for biofuels: Analysing past experiments for developing new biofuel policies', Energy Policy 35: 3213-3225.

Van Halen, C., Vezzoli, C., and R. Wimmer (eds.) (2005) Methodology for Product Service System: How to develop clean, clever and competitive strategies in companies (Assen, The Netherlands: Van Gorcum).

Van Lente, H. (1993) 'Chapter 6: construction by expectations', in: van Lente, H. (ed.), Promising Technology: The dynamics of Expectations in Technological Developments (Twente: Twente University): 177-204.

Vezzoli, C. (2010) System design for sustainability: Theory, methods and tools for a sustainable 'satisfaction-system' design, 2nd edn (Milan, IT: Maggioli editore).

Vezzoli, C., Ceschin, F., and R. Kemp (2008) 'Designing transition paths for the diffusion of sustainable system innovations: A new potential role for design in transition management?', in C. Cipolla and P.P. Peruccio (eds.), Changing the change. Design, visions, proposals and tools, Changing the change conference, Turin, Italy, 10-12 July 2008 (Turin, Italy: Umberto Allemandi).

Vezzoli, C., Ceschin, F., and S. Cortesi (2009) Metodi e strumenti per il life cycle design. Come progettare prodotti a basso impatto ambientale (Rimini, Italy: Maggioli).

Weber, M., Hoogma, R., Lane, B., and J. Schot (1999) Experimenting with Sustainable Transport Innovations: A Workbook for Strategic Niche Management (Twente: Universiteit Twente). 


\section{我们的共同性}

\section{系统设计中的“道德职能”及其作 用对社会和环境可持续发展的影响}

哈森・因多维拉 (Hussain Indorewala)

卡姆拉维迪阿尼迪建筑与环境研究学院 (Kamla Raheja Vidyanidhi Institute of Architecture and Environmental Studies), 印度孟买 (Vidyanidhi Marg,Juhu Scheme)

卡洛·维佐里 (Carlo Vezzoli)

米兰理工大学设计学院,可持续设计与可持续系统创新 (DIS) 项目,意大利

(Politecnico di Milano,DESIGN Department,Design and system Innovation for Sustainability (DIS), Italy)

\section{1 我们共同的末来}

1996年,联合国粮食与农业组织（FAO）召开峰会,185个国家的首脑作出各项承诺,其 中之一便是要彻底解决全球的饥饿问题。在2000年的联合国千禧年全球峰会上,191 个成员国签署了《禧宣言》,重申了这些目标,宣言内容如下：1）1995年至2015 年, 将极度贫困人口的数量减少一半；2）保障包括妇女和青年人在内的所有人能够 获得体面的工作机会。然而,10年之后,联合国粮农组织总干事杰克.戴欧夫 (Jacques Diouf), 在该组织的会议上做年度报告时指出：世界饥饿人口每年都在以 4 百万的数 量递增。世界上 $1 / 3$ 人口的粮食安全供给未能得到保障, 而超过 $1 / 6$ 的人口（约十亿两 千万人）生活在饥饿状态,创出历史新高（联合国粮农组织（FAO）2009）。

从其他的一些社会指标中也能看出我们这个世界所面临的悲惨境遇：最富有的 人, 仅占总人口的 $2 \%$, 却掌握着全球近一半的家庭财富, 而处于社会底层的人口占到总 人口的 $50 \%$,却只拥有不到全球家庭财富的1\%（奥茨伊维茨（Oziewicz）2006）。 
世界上 $1 / 3$ 的城市人口住在贫民区, 居住条件甚至差到令人难以置信的程度, 并且这 部分人口在 2030 年的时候将可能增至 20 亿之多。(联合国人类住区规划署 (UNHSP) 2003）。如今气候变化导致每年30万人死亡, 影响着300万人的健康, 而这个人数预 计在 2030 年将达到50万（维戴尔 (Vidal) 2009)。现在地球上物种灭绝速率是人 类出现之前的100到1000倍。而哈佛大学生物学家E . O - 威尔逊 (E.O.Wilson) 表 示,2030年的物种灭绝速率将是之前的10000倍。（乔威特 (Jowit) 2010)

如果从外太空通过星际显微镜观察地球,我们会惊讶地发现, 人类正在不断 地破坏自己原有的生存方式, 这种方式造成了巨大的浪费, 可以视为一种毁灭式的 生存方式。令人不可思议的是, 我们中的许多人却对此麻木不仁, 而这仅是冰山一 角。长期以来, 人们一直认为, 就像人类创造了语言并自然而然地形成不同的发音和 语法结构一样,我们与生俱来就赋有一种“道德能力”, 因成长环境和教育程度的 不同,自然就孕育出了不同的道德系统。郝瑟 (Hauser 2006b）将这种“道德能 力” 与语言能力进行了类比, 并且把这样的一种能力称为 “我们的普遍道德法则”。 这样一种能力对于所有社会性动物而言都是必要的, 不仅限于人类, 因为如果没有它, 我们就都是孤立的个体,任何形式的社交活动都不可能存在。事实上,那些大脑的前额 叶区域受到损伤的人没有感情,没有同情心,并且在做出判断的时候会显得 “异常功利 化” (寇恩宁斯（Koenigs）2007)。仔细观察一下, 我们会发现,各种情绪,比如同情、 羞耻、内疚、愤怒和厌恶都是一些用于加强社会合作、惩罚破坏合作行为的机制。 但是, 我们的与众不同不仅仅是由于我们具备 “道德能力”, 也因为我们能够制定行为 准则, 并在此基础上逐步建立社会体制, 并将人类划分成不同的民族、宗教或语言群体, 而这些群体内部成员之间并不一定具备血缘或是亲戚关系。（鲍尔斯（Bowles）和 金提斯 (Gintis) 2003)

可持续发展的概念是在联合国报告《我们共同的未来》中被首次提出来的（联 合国 1987）。报告把 “可持续发展” 定义为 “一种既满足当代人的需求,同时不牺 牲后代满足他们自身需求的发展模式。”报告中也明确提出要保障世界贫困人口的 “本质需求”并强调 “技术现状” 和 “社会组织”所允许的最大环境承载限度。其 同时也提到了公平原则, 也就是每个人都有权公平地使用全球自然资源或者环境空 间。我们认为应该将其含义进行延展, 每个人不仅有权得到和使用物质资源, 也有权通 过使用这些物质资源来满足自己的需求。

为了实现 “我们共同的未来”, 我们需要更好地理解 “我们共有的本质”, 建立 并实施各种体制和战略（并且与之共存）。这里的一个基本假设是, 即使社会经济的 可持续发展已经作为理性的发展目标为公众所认可, 人类定义的体制和战略却并没有 完全与这种 “道德职能” 保持一致。更直白地说, 制定新的更为有效的体制和策略能 够帮助我们实现期待已久的可持续发展目标（例如：千年发展目标 (the Millennium Development Goals）中要彻底消除贫困的目标）并缓解我们当前迫在眉睫的社会问 题。首先, 这个问题需要我们在对道德理解的历史进行广泛回顾基础上展开讨论。然 后,我们将简要讨论这个领域中一些最新的研究成果。最后,我们会以这些最新的发现 为基础, 展望未来,继续扩展可持续系统设计研究的范围,并且在与各利益相关方进行创 新性交流的过程中充分发挥设计的作用。 


\section{2 道德史节选}

17世纪,托马斯 - 豪伯斯（Thomas Hobbes）在他的著作中对 “人性” 做出了著名的 解释, 然而, 他对人类的评价是负面的。人与人之间的关系是 “狼” 与 “狼” 的关系, 他 们本能地喜欢 “相互伤害”, 而且在进入社会之前,他们的“自然状态” 是 “与所有人 争斗,对抗所有人”（豪伯斯（Hobbes）1651：17)。因此,要想在社会上生存下来,人 类必须定下一个社会 “契约”, 就是所有人都要臣服于一位绝对统治者,对他的命令无 条件服从,而这位统治者将保护他们的生命和财产。

托马斯 - 玛尔萨斯 (Malthus) 在他的《人口论》中解释道: 人口往往增速过快, 致使地球无法保障新增人口的基本生活, 而这种不受控制的人口增长终将产生惨痛的 代价一一贫穷和饥荒。贫穷是自然规律, 人类的体制改革根本无法消除不平等现象。 因为“人类的本性中存在着不可避免的弱点”, 他说, 因此 “就一定有人因为欲望而 痛苦。那些人之所以痛苦是因为他们想靠运气过上理想的生活,结果却一无所获。”

(玛尔萨斯 (Malthus) 1798：71) 玛尔萨斯 (Malthus) 之前曾预测到“不可避免 的” 大饥荒的到来,如今,世界人口较以往增加了6倍,食物产量和消费量更是达到了前 所未有的程度（森（Sen）,1994）。许多著名的书籍最近都集中关注这一主题,其中 最有名的是保罗・伊利克 (Paul Ehrlich) 写的《人口爆炸》,他警示世人：“人口无 限制增长”已成为这个世界的 “绝症”, 人们需要果断决绝地做出决定来拯救我们自 己。美国社会生物学家嘉利特・哈汀 (Garrett Hardin) 发表了一篇名为《平民百姓的 悲剧》的著名论文, 文中指出人类是理性的, 他们追求利益的最大化, 而在这个资源缺乏 的世界, 将毁掉他们赖以生存的那部分资源。这种 “悲剧”, 会导致人在自由社会中, 不 顾一切地索求个人最大利益, 并将把人类推向自我毁灭的深渊。哈汀 (Hardin)当时做 出了精辟的总结：平民的自由将给所有人带来灾难（哈汀（Hardin）1968）。彼得・ 莱恩勃 (Peter Linebaugh) 评论道,哈汀 (Hardin) 接受的是新古典主义经济理论 和“绝对利已主义”理论,却没有注意到几千年来人类之间的亲密关系的存在,也忽视 了沟通与妥协的作用。哈汀的理论, 实际上是将地球及其所有资源的毁灭归处于受害 者（帕特尔（Patel）2009：93）, 而这种理论未能就造成这种毁灭的深层次原因进行 探讨。

伊曼努尔 ·康德 (Immanuel Kant) 因强调人类道德中的 “纯粹理性” 的作用 而闻名。他希望建立起一种基于理性的道德规范,完全不同于那些基于直觉或者功利 因素的道德规范。应该把每个人看成是纯粹的个人, 而不是达到任何目的的工具。康 德认为, 道德行为只是指那些遵守道德法则的行为, 而不是出于自身利益的考虑或者 出于仁慈的行为（拉塞尔 (Russell) 1975: 683)。而另一方面, 功利主义者（边沁

(Bentham), 詹姆斯 · 米尔 (James Mill) 认为道德行为一定离不开功利性,或者说 道德行为一定会使社会幸福感增加,而非消失（边沁（Bentham）2000：89）。

玛尔萨斯 (Malthus) 的学说是达尔文1859年出版的《物种起源》的灵感来源, 书中提到了“生存竞争” 原则, 达尔文解释说他在文中用的是它的 “宽泛的比喻意 义”。然而, 达尔文也尝试着从进化的角度来理解道德良知。他发现, 道德行为源于一 种 “社会本能”, 这种本能让动物与自己的同伴分享快乐, 对同伴的痛苦产生同情, 并为 同伴提供各种服务。而“同情心” 恰好是这种社会本能的 “基石”。他认为, 即使是 
像“人类的祖先猿类那般未开化的人”,一旦拥有这种社会本能,也能“激发出最善良 的一面”（达尔文1871：86,95; 克鲁鲍特金 (Kroptokin) 1902）。

不久,达尔文的学生托马斯 · 赫胥黎 (Thomas Huxley) 继承了他的学说, 首次 把 “生存竞争” 原则解释成了众所周知的“适者生存” 原则。1888年,在一篇论文 中,赫胥黎跟一位道德家提到了这个原则, 也就是说动物的世界就像是“生死角逐的战 场, 只有那些最强壮、最迅捷、最狡猾者能够存活下来”。赫胥黎表示, 在远古人类时 期, “最懦弱、最愚蚌的人都被淘汰, 活下来的都是最强壮的和最精明的。”所谓文明, 其实是人类为了摆脱豪伯斯 (Hobbes) 哲学中提到的 “有史以来” 就存在的 “人与 人之间相互对抗” 这样一种自然状态所做出的努力（赫胥黎 (Huxley) 1888: 204)。 1893年,他做了一次题为《天演论》的演讲,他强调说: 虽然人类 “残酷的一意孤 行, 弃之不顾, 压迫蹂路” 等本性是存在的, 但是人类社会建立起了各种法律和道德规 范来控制这些破坏性本能（赫胥黎1888 (81-82)。而今,查理德·道金斯 (Richard Dawkins）在他的著作《自私基因》中给出了相似的观点,如他所说：“成功的基因 具有的最主要的特点便是绝对的自私, 而这通常会导致个人行为上的自私。”因此,我 们要尝试着教导人们学会慷慨大方, 奉行利他主义, 因为我们生来就是自私的（道金斯

(Dawkins) 1989: 2-3)。

亚当·斯密 (Adam Smith) 是自由市场经济的倡导者,他在其著作《道德情操 论》中阐述了他所认为的引发人类道德行为的内在动力。他把这样一种动力称为 同情心”，我们对同胞的悲惨境遇感同身受的那种心情也就来源于此。也正是由于“ 这种心情的存在”, 人们才会因为同伴的幸福而感到快乐。他在文中写道,当我们 “把 个人利益置于多数人的利益之上” 时, 我们就成为了别人 “鄙视和泄愤的对象”（斯 密 1759）。他的《国富论》内容平实, 立场公正, 而他倡导自由市场仅仅是因为他相信 这是建立 “绝对公正、自由和平等” 的社会 “再简单不过的捷径” 了。今天,他的追随 者只是盲从他的理论,却完全忽视了他的这些理由（威亨 (Werhane) 1989,1991）。

克鲁鲍特金 (Peter Kropotkin) 在他的重要著作《互助》中写道: 1902年写的 《互助的进化观》这本书, 详尽地描述了同一物种内部的合作、互助及团结,并给出 了许多的范例。有些时候, 不同物种之间甚至会为了繁衍生息而进行互助合作。他认 为: “能够互帮互助的动物无疑是最具竞争力的, 他们的智力水平和身体组织都是最 发达的。”克鲁鲍特金 (Kropotkin) 觉得,卢梭的乐观人性论- - “高贵的野蛮人” 和赫胥黎的悲观人性论- - “生死角逐” 都不对, 都没能反映真实的自然世界。对他 来说, 人性是一种 “深度隐藏的本能”, 它随着人类的进化而逐步形成, 而人们也是在此 基础上萌生了道德的观念（克鲁鲍特金（Kropotkin）1902）。他指出，“美德”和“ 邪恶” 都是生物本性,并不是人们臆想出来的（克鲁鲍特金（1902）。

\section{3 人类道德与经济学理论}

1776年,亚当 ·斯密完成了他的《国富论》,他认为,社会利益和个人利益是统一的, 如果建立一个体系,激励每个人都理性地去追求自身的利益,那么理想社会可能就会 出现。18世纪的政治经济学不仅与经济学有关, 也涉及人类的伦理观和价值观, 然而, 
在最近的两个世纪, 经济学变成了纯抽象的 “科学”, 不涉及任何道德考量（威翰尼 (Werhane) 2006)。新古典主义经济学家认为人类是完全理性的。为使自己的抽 象模型得到认可,他们提出了经济人的说法,认为人类就是以实现自身利益最大化为目 标的生物, 不顾道德廉耻, 只在乎自身利益, 也不考虑自身所作所为对社会造成的影响。 这样的观点与斯密的看法不尽相同,他认为 “人性的完美源于对自私的控制和对仁爱 的宣扬。”在斯密看来, 每个人都在追求自身利益,这将对社会带来有利的结果; 在现 实世界里,每个人都必须是自私的,这样才能更好地发展经济。

经济制度是规范社会中的商品生产、分配、消费及服务等经济活动的制度,其 中当下社会最看重的方面是市场、私有财产权、雇佣劳动、小型和大型企业等。当 代企业在很大程度上如同寻求椎取最大利益的自私怪物, 因为作为一种机制, 他们缺 少任何形式的人性 “道德” 和对他人的同情。他们是彻头彻尾的经济人（帕特尔

(Patel) 2009: 48) 。而在这些机构工作的员工必须按照他们的要求行事, 否则就会 被辞退或者被他人取代。此外,当整个社会都相信 “市场是衡量价值的标准和快乐的 源泉,积累个人财富是最崇高的目标” 时,那种“市场利益高于所有人际关系和态度” 的观点就不足为奇了。很明显, 我们建立的主要体制都是多余的, 不公平的, 其目标和使 用对象都是错误的。因此, 要改革现有体制, 我们不仅要改变最初建立它们的目标, 也要 更好地理解我们共有的 “本性”。

然而,即使用非经济手段来解决社会问题,其成效也极其有限。同时,需要注意的 是, 在资本主义制度中, 非经济体系和经济体系之间的区别微乎其微, 甚至不存在。所 以, 错误并不在于解决方案的实施不利, 而在于对问题的理解。人类社会在前 20 万年 中一直处于 “无国家” 的状态, 人们以自治社区为单位组织起来以满足自身的需求和 物质需求。这些自治组织的出现不是规划师和政治家为了有效地进行管理而规划出 来的,而是种族繁衍生息的本能需要。一些机构及其设定的目标,例如联合国消除贫困 和饥饿的目标（千年发展目标（the Millennium Development Goals））, 虽然目标 宏伟,但如果没有各个国家积极参与并履行承诺,便无法实现。而像“国家”这种中 央集权制的官僚机构, 即使是出于良好的意愿并进行了精心规划, 也存在通病：一种 忽视了关键的当地知识、习惯和条件的对人类社会运作高度计划性的看法（斯科特

(Scott) 1998：6）。我们还必须强调, 这种计划性将人类及其需求进行了系统量化, 以便更好地了解人类需求, 从而着手满足这些需求。由此引出了一个重要的问题, 这 个问题需要更深入地进行探讨：如果我们已经很好地理解了我们的共性, 也就是所谓 的 “道德职能”,那么在解决涉及道德因素的社会问题时,我们需要怎么做呢? 这个问 题将在以下部分进行讨论。

\section{4 深化对 “道德职能” 的理解}

在当代,生物学家如马克 · 郝瑟 (Marc Hauser) 、约翰 · 米哈伊尔 (John Mikhail) 等人认为, 人类天生就具有一种隐性的 “道德器官”, 是一种天赋, 与我们的语言能 力相似。他们还提出了 “通用道德规则” 理论, 其中涵盖了与道德相关的一些原 则和参数, 为 “可能道德体系的建立提供了工具”。“道德体系”的发展显然会 
受到环境、文化及教育的影响, 在个体发展的早期, 就已经选定了特定参数（郝瑟 (Hauser) 2006a,b; 米哈伊尔 (Mikhail) 2007)。

实验由来自全球各地具有不同文化背景的跨学科研究人员组成的小组实施, 主要 以游戏的方式进行。该实验主要针对人类经济和社会偏好, 收集了大量的数据并得出 了相当有趣的结果。其中有个叫做 “最后通牒” 的游戏,需要两个人参与,一个 “提问 者”, 一个 “回答者”, 游戏中双方不能看见彼此, 且游戏在两人间只进行一次。进行游 戏时,他们会收到一笔钱（假设是10欧元）,然后由提问者提出 “赠送” 回答者其中的 一部分钱,后者可以选择 “接受” 或者 “拒绝”。如果回答者接受了那部分钱, 那部分 钱就是他的, 剩下的就是提问者的, 如果是拒绝了, 那么双方都将空手而归。如果参与双 方都是 “很理智的利己主义者”, 那么最有可能出现的结果会是: 赠送的那部分钱往 往是最少的（假设是1欧元）, 然而回答者往往会接受（因为1欧元比0欧元要好）。可 是, 研究者发现, “这种利已主义结果, 并没有出现, 甚至与真实结果大相径庭。”事实 上,根据各种不同社会体系情况不同,最后的实验结果有很大的不同, 那些来自对相互合 作奖励最多的社会的参与者赠送的钱是最多的。（金提斯（Gintis）等.2003)

另一个实验称为 “公共物品博弯”, 这个游戏需要很多人参与, 而且可以进行很多 轮。每个玩家都会得到一些硬币或 “点数”，(假设是10欧元）,每一轮, 玩家都可以 选择把一些硬币 “投资” 到一个 “共同账户”里,然后把剩余的部分收到他们的“私 人账户”里。在每轮的最后, 公共账户里的钱会被公布出来, 不管玩家们各自投了多少 钱进去, 每个人最后都会得到相等的一笔钱,这笔钱是按固定比例从公共账户里折算出 来的（假设是 $40 \%$ ）。而他们私人账户里的钱还是他们自己的。比如说,如果4个玩 家参与进来, 每个人都把自己的10欧元放到共同账户里, 那么最后他们每人可以得到16 欧元。但是,如果只有两个玩家投入了10欧元, 而另外两个人没有任何投入,那么一轮 最后,投了钱的两人将每人得到 8 欧元, 而没捐钱的两人就会每人得到 $8+10=18$ 欧元。 因此,当每个人都把自己所有的钱投到公共账户中去时,他们最后总共得到的钱是最多 的, 但是就个人而言, 每个人都希望别人倾囊相赠, 而自己一毛不拔。假设参与者都是利 己主义者,那么所有的玩家都不会把自己的钱投到公共账户中去; 然而, 实验证明：大 部分玩家一开始就投了他们所有钱的大约一半,随着游戏一轮一轮地进行, 他们每次投 入的钱在逐渐减少。玩家们后来抱怨说,其他人捐的钱太少,这使得他们很生气, 因此, 他们投进去的钱也相应地越来越少了。更有趣的是, 当游戏规则发生改变时, 其他人可 以惩罚那些捐钱很少的人（让他们交 “罚款”, 玩家们有权决定是否 “罚” 那些人的 钱）以保证在接下来的游戏中各个玩家之间正常合作, 情况就没有像先前那样变得越 来越糟糕,甚至有几轮各玩家之间表现出了高度的合作精神（金提斯（Gintis）等 2006: 25-18)。

大量的实验结果证明,生物和经济模型都质疑利己主义这一观点, 而且人类行 为更适合用 “强互惠性” 这个概念来解释, 也就是说 “一种积极与他人合作,并惩罚 （如果有必要的话,个人付出代价）那些违反合作规则的人的倾向。而且, 实验还 表明, 人类既非完全利己主义, 也非完全利他主义; 通常来说, 当他人愿意合作时, 他 是 “有条件的合作者”, 而当他人在合作中的行为有失公允时, 他们就会按照通行 的合作标准以“无私的制裁者” 的身份去处罚那些人（金提斯（Gintis）2006: 6-8）。这些研究结果对我们有下列启示: 
- 在经济活动中,人们不仅关心自身的利益,也关心利益实现的具体过程。也就 是说,公平与否,公正与否,自愿与否,这些都是评价互动的重要指标（金提斯

(Gintis) 等 2006: 6)。

- 人们不仅关心行为产生的后果,也关心行为背后的动机（法尔克 (Falk) 2008)。

- 在某些情况下,当人们将来自外部的干预视为外部控制时,他们对这种外部控 制产生本能的抵触情绪就会减少。换句话说, 人们更愿意参加那些自己更易掌 控的活动。相反, 当人们将外部干预看作一种有益的活动并且他们觉得拥有更 宽松的行动自由时,他们参与这类活动的积极性也增加。例如：尼泊尔曾对其 灌溉系统的管理策略进行了研究, 研究表明,与由外部机构（这里指政府）管 理的系统相比, “农民自主管理系统”的农业产出更高,水资源分配更加公平, 且灌溉系统维护得更好。在一些研究案例中, 由于高效的社区资源节约监管 系统的崩溃,那些引入罚款和补助机制来倡导节约的地方, 资源消耗的更快。

(奥斯特罗姆 (Ostrom) Ostrom)，金提斯 (Gintis) Gintis) 等引用 2006: 260-268) 。

- 不同文化背景的人的行为也极其不同（例如：上述 “最后通牒游戏” 中的参 与者的行为就大相径庭）,这种不同很大程度上是由于他们各自经历的经济结 构和体制（生产、分配）所造成的。换言之,那些积极主动参与社会合作的人 （以制度性安排的形式）,在实验性游戏中,更愿意与他人合作并分享经验 (金提斯 (Gintis) 等 2006: 27-28)。

- 只要一方愿意合作,人们一般都具有与之合作的倾向,而提供物质刺激往往违背 了他们的合作初衰。也就是说,比起物质上的激励（特别是在物质提供方不被 信任的情况下）,信任和互助更有助于调动人们的积极性（金提斯（Gintis） 等 2006：28）。有一个很好的例子可以证明这一点：在海法（Haifa）,六家 幼儿日托机构强制性地对那些未能够及时接走孩子的父母们处以名义上的罚 款。而事实上,正是由于这个名义上的罚款, 那些父母平均的迟到时间延长了一 倍, 而且, 令人费解的是, 即使在这个罚款制度被取消以后, 他们平均的迟到时间 也没有减少。以前,父母亲的道德责任感迫使他们尽快地去接孩子,而在实行罚 款制度之后, 这种责任被一种“商品”取代了, 这种“商品”就是父母可以买到 的 “时间”。这种责任感的消逝,表明物质激励有些时候可能会阻碍合作的进 行（鲍尔斯 (Bowles) 2008)。

有史以来, 人类的生活几乎都是以相对独立的游牧社群为单位进行的群居生活, 而我们 的“道德职能” 也就是在那段时间内逐步形成的。直到最近, 随着科学技术的进步, 人 口高度集中于小城镇中心, 世界人口也在迅速集中融合。这可能是因为我们的本性还 不能适应当代复杂而又紧密互动的生活,但是这个结论似乎下得有点仓促, 因为我们还 没有更好地理解所谓的 “本性” ,对它的理解还只是表面性的。另一方面,根据不同的 职业、思想、地域、语言、文化、宗教,人类建立了各种跨越亲属关系的团体和组织, 这些不同组织中每个人的参与度、责任感和忠诚度都不同。除非我们承认人类 “同 
情” 的天性在其中的作用, 否则我们不能简单地认为那些超越狭隘利益的社会组织和 附属机构都是个人与团体为了实现天下一统而努力的结果; 尽管人们对 “同情” 的 定义尚不十分清晰,但它确实能够让人们感觉到与他人休戚与共的关系,并在实现上述 目标的过程中起到非常重要的作用。

\section{5 相关案例研究}

并不是我们所有的社会关系都是以市场为中介, 事实上, 我们在日常生活中也经常相互 交流和合作。通常情况下,我们会无意识地对人类,包括自己或他人的特征和行为进行 评估, 这种评估结果并非通过对盈利和亏损的精打细算统计出来的。可以很直观地看 出,算计盈亏的做法不仅有损人际关系的构建,也基本无益于社会福利的进步。人们普 遍认为,经济援助项目,救助灾区或人道主义援助等都在致力于解决社会问题和消除社 会弊端,而这些作用都不是市场机制能够做到的。也有一些如联合国设立的大型专业 机构, 虽然它们相互独立, 但都是以联合国宪章为宗旨。从微观上看, 赞助和个人捐赠是 常见的人帮人的方法, 而帮助的对象往往是那些素不相识的人。很多组织和机构都依 赖这种同情和团结倾向, 但是我们的任务是如何把这种倾向转变成为一种制度化的机 制。在以下部分,我们将通过几个这方面的例子来说明这一问题。

\subsection{1 参与式规划 ${ }^{1}$}

印度第73次宪法修正案的目标是要在农村地区实行参与式民主制和分散规划制, 虽然 这一举措在全国范围内并未得以有效实施。其中一个实行该法案的地区是印度的喀 拉拉邦（Kerala）,在1996年,这里启动了人民计划活动（PPC）, 该计划把整个邦发 展预算中的 $35 \%$ 分配给了各社区,让它们计划和实施自己的方案。据说这个试验项目 极大地改善了当地公共服务的质量,促进了种姓和名族之间的平等,更极大提高了妇女 在公共生活中的地位并改善了民主状况（弗兰奇（Franke）2007）。这些社区自创 并实施了很多创新且实用的项目, 例如, 呼声最高的是与当地科学家合作开展的生物防 治蚊子项目, 还有为整治徇私腐败开展的社会审计活动, 为应对失业问题而开展的创新 型 “劳动力银行” 项目, 以及使行人和自行车出行更加便利的桥梁项目, 甚至, 还有自杀 预防方案。过去,这些问题一直都被当局忽视（弗兰克（Franke）2007）。

2000年到2001年在喀拉拉邦启动的一个新项目叫做 “马拉利库兰实验”

(Mararikulam experiment)，该项目一共有1500个邻里组织 (NHGs: Neighbourhood Groups）参与,每个组织都包括20至40个妇女。该地区的八个村庄和两个小镇的人口 总数达 272,000 人。这个项目一方面要把这些邻里组织 (NHGs) 都转变为归工人集 体所有, 并由他们自主经营合作社, 另一方面要求利用当地原料进行生产, 并供应当地 市场。为了获得更多的资金开办更多的合作社,这些邻里组织 (NHGs) 每周举行会

1 本章基于弗兰奇 (Franke) 2005,2007的研究。另见: 贝隆 (Veron) 2001; 邦迪昂帕蒂 约恩 (Bandyopadhyay) 1997; 弗兰奇 (Franke) 与哈辛 (Chasin) 1998。 
议,并且发起了一项叫做“节俭募捐” 的活动,即把一周或者一个月募捐得来的钱贷给 组织成员。募捐活动成功地筹到了开创小型企业所需的资金,提供这笔启动资金的机 构后来成为当地合作银行。这些银行采用格莱珉银行 (Grameen Bank) 的小额贷款 模式,并且他们更进一步地突破了原模式中必须由外部官僚机构进行管理的严重局限 性。

为组建一个生产肥皇的合作社,一些志愿者顾问帮忙从村寨里选出了16个邻里组 织 (NHGs) , 每村2个。肥皇生产对整个项目来说是个非常好的选择, 因为所需原料当 地几乎都有（大约 $90 \%$ 是楖子油）, 而且喀拉拉邦是印度人均肥㿝消费最高的地区,肥 皇的需求量很大。根本也没必要为产品打广告或者设计吸引眼球的包装, 因为当地教 育和人们的参与使社区活动人所共知, 并为之提供了可靠的市场和相互信任。此外,由 于所有的原料产自当地,消费市场也在当地,因此资金只会在当地流通; 而且合作社是 工人集体所有, 比起私人企业, 这些合作社的利润, 哪怕极其微薄, 也都会有助于当地财 富的积累。在这个项目的第二阶段, 其他的用品如笔记本、书包、雨伞也开始由当地 合作社进行生产; 在第三阶段,合作社开始规划粮食生产和垃圾处理工作。

然而,这次实验项目最重要的收获不是促进生产或者提高就业率,而在于人们参与 其中、相互合作和相互帮助的感觉。这个项目提高了妇女的地位, 减轻了贫困, 保护了 当地生态环境,这些不是依靠执行政府条例或规定而实现的,而是社区人民保护当地资 源环境的本能行为。雨水收集、垃圾循环利用和养鱼等项目也是用来保护当地资源 环境的方法。

\subsection{2 工人自我管理 ${ }^{2}$}

2000年至2001年,阿根廷发生经济危机,正当很多公司倒闭关门,成千上万的员工面 临失业之时,许多企业最后都转让给了员工并被重组成了工人合作社。而其中一个 最大的被工人接管的工厂是扎农陶瓷厂 (Zanon), 该厂拥有470名雇员,位于阿根 廷最南端的内乌肯省 (Patagonian province of Neuquén) 境内。2001年,扎农陶 瓷厂的雇主路易斯 · 扎农 (Luis Zanon) 把因抗议裁员和拖欠工资而参与罢工的 员工都锁在门外。同年10月,工人们决定接管该工厂,他们在工厂外扎营数月,最终与 雇主达成协议恢复生产。工人们还积极为自己经营的合作社努力争取法律上的认 可, 定名为FASINPAT: 无老板工厂运作模式 (Factory Without a Boss)。需要强 调的是, 工人接管工厂的行为很大程度上是出于生存需要, 而不是某种政治意识, 而大 范围失业的经济状况是导致工人采取这种极端做法的一个主要原因。在经济危机 最严重的时候, 失业人口占全国人口的 $20 \%$, 半失业人口达 $40 \%$ 。2 001 年至 2002 年 期间,全国 $53 \%$ 的人的生活处于极其贫困状态。阿根廷有 180 家工厂在工人自己的 管理下起死回生,为全国提供了约一万个工作岗位（斯班诺斯（Spannos）2008: 157)。

2 本章基于：玛丽・齐格纳（Marie Trigona）“Fasinpat（无老板工厂）自我管理在阿根廷的 一次尝试”（斯班诺斯 (Spannos) 2008: 155-168). 
当工厂由雇主自己经营的时候, 为了追求利益的最大化,支付给工人微薄的工资, 减 少安全防护支出, 并尽可能地减少雇佣工人。工厂内事故频发, 令人震惊, 每个月都会有 20 到 30 起事故发生, 而且平均每年出现一次重大死亡事故。工人们还强制性地被要求 遵守工厂“纪律”, 不同的生产线工人必须穿戴不同颜色的服饰, 而且不准他们之间进 行交流。无论在餐厅还是在休息的时候, 都不允许工人自由交谈。甚至, 在工厂内来回 走动和出入洗手间都不那么自由。然而自从工厂由工人自己管理经营以来, 他们废除 了管理和组织的等级制度, 并引入了新式的工厂管理经营方法, 从而大大改善了工作环 境。自此, 事故引发的死亡人数也降至零,小事故的发生率大大降低。每个员工的工资 都设定在同一水平, 只是根据个人经验和资历,工资会略有不同。在工厂被接管之后, 工 人委员会一共新雇佣了230名员工, 其中很多是之前被雇主解雇的老员工。新组织中设 置了一个协调系统, 每条生产线上的所有员工组成一个委员会, 然后每个委员会选出一 个协调人并定期轮换。所有的协调人要集聚一起召开会议, 报告各部门工作的进展情 况。工人们每周举行一次协调人会议, 全体工人会议每个月会举行一次。公司每个月 都会公开账目, 每个部门的协调人将对公司的账目支出明细作详细说明。工人大会有 权分配企业利润并对其它重要事情做出决策,包括雇佣新员工。工人们与其他专家如 律师、会计师一起共事,但是专家们只负责提供意见建议,最终的决定权还是交由工人 大会。以前,工厂的产品全部销售到外地, 采用新型管理模式之后, 产品则主要提供给当 地市场。

工人们也会轮换工作岗位,每个人脑力劳动和体力劳动的工作量基本相等。他们 甚至还创办了一些新的项目, 如各种教育项目。在扎农工厂内部设立了图书馆,开设与 大学及学校合作的培训课程, 设立妇女委员会, 讨论职业女性如何应对在无雇主企业工 作时所出现的问题。工人们不断地尝试改善他们的工作环境, 不断地学习新的知识, 而 不是像原来那样, 只关心他们的工资和在工厂的地位。工厂也积极参与各种社区服务 项目, 如为其他工薪家庭建房, 开展学生实地考察项目, 并向公共事业部门捐赠陶瓷品。 此外, 工厂还组织各种活动如摇滚演唱会, 戏剧, 并与各类艺术家, 活动积极分子和其他 工人开展合作。

由于社区服务项目得以整合,扎农陶瓷厂得到了广大社区民众的信赖和支持,社区 居民还帮助确保工人的权益免于遭到右翼激进组织的侵害。除此之外, 扎农已经开始 与其他一些由工人直接管理的企业进行合作并成立了一个广泛联盟—-国家企业调 整运动（National Movement of Recuperated Enterprises,MNER), 该联盟共由40个成 员组成,包括酒店、印刷厂、食品厂等企业。甚至他们的这些做法获得了来自国际的 支持,在他们的启发下,其他企业争相效仿。2004年,娜欧米·克莱恩 (Naomi Klein) 拍摄的一部纪录片《工人当家》就是以扎农陶瓷厂的故事为创作原型, 这部片子使 得全世界的人们都了解到他们所做的抗争。一个工人在总结 “扎农” 的成功历程时 说: “扎农”的成功代表着整个工人阶级的成功,也代表着社会组织另一种存在方式, 即在没有雇主和别人的压迫下工作的一种社会形式; 以前, 雇主强迫工人劳动, 自己赚 取所有利润,工人却始终一贫如洗（斯班诺斯（Spannos）2008：166）。

在阿根廷,最近新成立的工人合作社越来越多,而这样的举措已经被英国、美国、 爱尔兰、法国、波兰和加拿大等国家（克莱恩（Klein）2009）所仿效。 


\section{6 可持续设计 “道德职能” 的深层含义及其潜在作用}

在过去的20年中, 可持续设计学的学科范围及应用领域不断得到扩展。（维佐里

(Vezzoli) 和曼齐尼 (Manzini) 2008) 从材料和能源低消耗选择扩展到产品的生命 周期设计（或生态设计）,到注重生态效益的（产品一一服务）系统设计,再到促进社 会公平和社会凝聚力（系统）的设计, 设计过程可以直接应对社会公平和社会凝聚力 问题。由于这种发展变化, 人们对设计的作用有了新的认识, 人们认为随着社会经济等 方面的转型, 设计的（潜在）作用正在被重新定义, 包括：服务导向、相互联络, 以及全 球化与本土化相结合（全球本土化）。

当前,设计师的一个重要角色是建立一种能够促进经济职能和社会互动的机制 （如联合国机构、企业单位、委员会、工会等）。这需要设计师们掌握多方面的技 能,既包括生产、分配和消费等方面（规划、产品和结构说明、信息设计）的具体技 能, 又包括在组织管理方面的能力（如何做决定、如何执行方案、如何对收益进行再 分配）。为了达成这些目标, 设计师不仅要知道如何设计既有效又符合道德准则的组 织, 而且要懂得如何实施这些设计, 如通过鼓励进行合作与创新等。已有实例证明, 合作 性质的机构在实践中更有利于社会和环境的可持续发展, 我们也已经掌握了那些能够 用于促进或设计此类机构的构成要素。以下我们将对这些要素进行简明的阐述。其 中的有些要素是过去和当今 “社区管理” 体系中的规范（例如：上文提到的农民自 主管理系统（Farmer Managed Systems）），其他一些是有待验证的假设：

- 自我管理。如今,大多数公司和机构都有着严格的层级管理体制,一小部分人做 决定,其他人执行命令。自我管理提高了工人的内在动机; 自我管理就是一个 团队中的所有人员共同制定计划、确立目标、管理资源、做出决策、执行已 商定的任务,并选出他们的代表,最重要的是,共同决定最合适的管理方式。

- 所有权。资源、工具、厂房和收益都归大家共同所有,这样一来,所有参与者 都会有一个共同的目标。所有权分配不均势必导致不平等现象的产生,引发利 润分配的不平等。

- 信息/知识。一般来说,自我管理团队的团队成员有权查阅与团队及活动相关的 所有信息,比如交易和账目。但这些信息也应当对社区所有人公开,这样才能保 证公司经营的透明性和经营的责任。

- 创新活动。人们往往享受那些具有创新性又能给人带来成就感的工作, 而厌恶 那些单调乏味的工作。这就要求彻底改变我们现在的一些做法, 即剥夺工人的 创造性和控制权,并让他们单纯从事那些单调而又之味工作的做法。

- 可获得性。可获得性不仅包括开放知识和技术成果, 而且还包括开放这些知识 和技术本身。对某些方法和商业秘密的垄断,造成了各个不同群体之间的权力 结构的不均衡和资源 (优势) 的不均衡。这样的 “知识共有” 的优势 (帕特 尔 (Patel) 2009: 154) 在软件领域最为常见,除非来自既得利益的阻力,在 现实中没有理由解释为什么不对它们进行复制。 
- 收益分配/报酬。一直以来, 最理想的方式是: “各尽所能, 各取所需”。根据 不同的组织类型、不同的工作内容、内外部约束条件等因素, 可以对收益做出 不同的安排。但这个决定必须在组织内达成共识。

- 确定需求。谁来决定生产什么? 生产多少? 在当前的系统中,存在这种现象, 即 人类的需求屈从于某些个人利益。这种现象无法保证公平地分配收益, 并掩盖 或忽视了其负面结果。理想的情况是,社区应该根据对生产能力、资源可获得 性、工作积极性、可能的负面影响等方面的评估来确定需求。制定规划和预 算时,必须经过集体协商,不能独断专行。

- 休闲活动。如果工人做工只是为了满足生活需要, 而非追求利益最大化, 那么大 家将会有充裕的时间来丰富自己的生活并乐在其中。

\section{7 结论}

值得一提的是, 尽管这些最新的研究还并不完善, 但在某些方面, 它们能够为其他领域的 应用奠定基础。本章为设计师界定了一个可能的研究领域, 并简述了几个人们非常关 注的问题。在这个关键的历史时期, 我们可能需要提出一些最基本的问题,并希望获得 对这些问题的深刻解答。或许我们对自己了解得还不够, 但是有了一些线索和零碎的 知识,我们就可以以这些线索和零碎的知识为出发点进行探索。当今社会,无数的人在 充实自己的同时也在丰富着他人的生活, 我们需要确定从他们那里学习到最重要的东 西。几个世纪以来, 哲学家和道德学家都说仁慈、同情和合作是确保全人类幸福的唯 一途径; 而要获得这些理想品质不是不可能, 它们很大程度上是 “我们共同的本性” 的一部分, 而且一直存在。我们所要做的就是建立起一套机制, 培养这些理想品质, 消除 其他恶习,这才是我们这个复杂交织却又前景严峻的时代所面临的紧迫任务。设计一 种让利益相关方都积极参与,且有利于社会和环境可持续发展的方法, 就是设计界肩负 的重大责任。

\section{参考文献}

Bandyopadhyay, D. (1997) 'People's Participation in Planning: Kerala Experiment', Economic and Political Weekly 32 (39): 2450-2454.

Bentham, J. (2000) Selected Writings on Utilitarianism (Wordsworth Editions Ltd).

Bowles, S. (2008) 'Policies Designed for Self-Interested Citizens May Undermine "The Moral Sentiments": Evidence from Economic Experiments', Science 320 (5883): 1605-1609.

Bowles, S. and Gintis, H. (2003) The Origins of Human Cooperation (Cambridge, MA: MIT Press).

Darwin, C. (1871) The Descent of Man (Forgotten Books, 2007).

Darwin, C. (1859) Origin of Species (Wilder Publications, 2008).

Dawkins, R. (1989) The selfish gene (Oxford: Oxford University Press). 
Falk, A., Fehr, E. and Urs Fischbacher (2008) 'Testing theories of fairness: Intentions matter', Games and Economic Behavior 62 (1): 287-303.

FAO (2009) 1.02 Billion People Hungry, Food and Agriculture Organization.

Franke, R.W. (2005) 'The Mararikulam Experiment: Women-Owned Cooperatives in Kerala, India A People's Alternative to Corporate Dominated Globalization', World Prout Assembly.

Franke, R.W. (2007) 'Local Planning: The Kerala Experiment' (http://chss.montclair.edu/ anthro/frankepaperskerala.htm).

Franke, R.W. and Chasin, B. (1998) 'Power to the (Malayalee) People: Democracy in Kerala State', Economic and Political Weekly 32(48): 3061-68.

Gintis, H., S. Bowles, R. Boyd, and E. Fehr (2003) 'Explaining Altruistic Behavior in Humans', Evolution and Human Behavior 24 (3) (May 2003): 153-172. http://linkinghub.elsevier. com/retrieve/pii/S1090513802001575.

Gintis, H., S. Bowles, R.T. Boyd, and E. Fehr (2006) Moral Sentiments and Material Interests: The Foundations of Cooperation in Economic Life (Cambridge, MA: The MIT Press).

Hardin, G. (1968) 'The Tragedy of the Commons', Science 162 (3859) (December 13, 1968): 1243-1248.

Hauser, M. (2006a) Moral Minds: How Nature Designed Our Universal Sense of Right and Wrong (1st edn, Ecco).

Hauser, M.D. (2006b) 'The liver and the moral organ', Soc. Cogn. Affect. Neurosci. 1 (3): 214-220.

Hobbes, T. (1651) De Cive (Kessinger Publishing, 2004).

Huxley, T. (1888) Evolution and ethics, and other essays (MacMillan and Co, 1894).

Jowit, J. (2010) 'Humans driving extinction faster than species can evolve, say experts', The Guardian (7 March 2010).

Klein, N. (2009) 'Fire the Boss!: the cure for layoffs', Znet (20 May 2009).

Koenigs, M., L. Young, R. Adolphs, D. Tranel, F. Cushman, M. Hauser, and A. Damasio (2007) 'Damage to the Prefrontal Cortex Increases Utilitarian Moral Judgements', Nature 446 (7138): 908-911.

Kropotkin, P. (1902) Mutual Aid: A Factor of Evolution (Forgotten Books).

Linebaugh, P. (2008) The Magna Carta Manifesto: Liberties and Commons for All (University of California Press).

Malthus, T.R. (1798) Population: the first essay (University of Michigan Press, 1959).

Mikhail, J. (2007) 'Universal moral grammar: theory, evidence and the future', Trends in Cognitive Sciences 11 (4): 143-152.

Oziewicz, E. (2006) 'The rich really do own the world' Globe and Mail (12 May 2006).

Patel, R. (2009) The Value of Nothing: How to Reshape Market Society and Redefine Democracy (Portobello).

Russell, B. (1975) A History Of Western Philosophy (2nd edn, George Allen \& Unwin).

Scott, James C. (1998) Seeing Like a State: How Certain Schemes to Improve the Human Condition Have Failed (Yale University Press).

Sen, A. (1994) 'Population: Delusion and Reality', New York Review of Books 41 (15).

Smith, A. (1759) The Theory of Moral Sentiments (Martino Fine Books, 2009 edn).

Spannos, C. (2008) Real Utopia: Participatory Society for the 21st Century (AK Press).

UN (1987) 'Our Common Future' (http://www.un-documents.net/a42r187.htm).

UNHSP (2003) The Challenge of Slums, UN.

Veron, R. (2001) 'The New Kerala Model: Lessons for Sustainable Development', World Development 29 (4): 601-617.

Vezzoli, C. (2010) System design for sustainability: Theory, methods and tools for a sustainable 'satisfaction-system' design, 2nd edn (Milan, IT: Maggioli editore). 
Vezzoli, C. and Manzini, E. (2008) 'Review: design for sustainable consumption and production systems', in Vezzoli, C. Tukker, A., Charter, M., Stø, E. and Anderson, M.M. (eds.), System Innovation for sustainability I. Perspectives on Radical Changes to Sustainable Consumption and Production (Sheffield, UK: Greenleaf Publishing).

Vidal, J. (2009) 'Global warming causes 300,000 deaths a year, says Kofi Annan thinktank', The Guardian (29 May 2009).

Werhane, P.H. (1989) 'The Role of Self-Interest in Adam Smith's Wealth of Nations', The Journal of Philosophy 86 (11): 669-680.

Werhane, P.H. (1991) Adam Smith and His Legacy for Modern Capitalism (Oxford University Press, USA).

Werhane, P.H. (2006) 'Adam Smith's Legacy for Ethics and Economics', Review of Business and Economics. 


\section{第二篇 \\ 在低收入和新兴经济体背景下审视产品 服务系统 (PSS) 的新视角}




\section{垃圾处理行业中的产品服务系 统：印度非正式经济的经验教训}

安穆利特·斯里尼瓦桑 (Amrit Srinivasan)

印度德里理工学院人文社会科学院

(Department of Humanities and Social Sciences, IIT Delhi, India)

\section{1 引言}

众所周知, 尽管目前印度的人均环境影响增长显著, 但仍远远低于工业化国家的水 平。这主要与印度在垃圾循环再利用方面所固有的习俗有关（印度政府（GOI）, 2007年），长期以来，这方面的工作都由生活在社会最底层的群体来完成的。因 此, 印度固体垃圾管理这一非正式部门为产品服务系统 (PSS) 提供了一个十分重 要的测试案例。产品服务系统 (PSS) 是一种致力于满足所有利益相关者多样化需 求的设计创新模式。如果想从社会传统本身范围内实现联合国环境规划署 (UNEP) 于2002年提出的产品服务系统 (PSS) 设计, 那么我们不仅要满足工业部门的需 求, 而且要满足家庭、商人、市民、穷人, 乃至被边缘化的垃圾处理工人的需求。

由于有非正式部门的参与, 印度垃圾处理可持续实践并未像西方国家那样, 产生较高的人力、社会和交易成本（鲍维（Power）和蒙特（Mont），2010）。 长期以来, 印度的城市贫民一直为社会提供着 “隐性” 廉价的垃圾回收服务。就此 而言, 其所耗费的人力成本其实并不算小。然而, 这项工作虽有大量人员参与, 但 印度的消费习惯并没有提升到富裕的工业化国家水平。如今, 印度被视为主要的污 染排放国。长期以来, 可持续设计理论与实践所普遍持有的看法是, “贫穷导致污 染”，而这一观点并不符合印度的实际情况。认为印度缺乏大规模垃圾处理技术 和工具的看法也是片面的。事实上，非正式的固体垃圾管理机制及其所有相关活 
动-一收集、分类、运输、储存、回收、营销甚至制造, 均对该国的发展做出了巨 大的历史贡献。但因社会对印度垃圾处理工人的歧视导致公众对固体垃圾管理机制

(SWM) 产生根深蒂固的偏见，从而低估了这一机制所做出的贡献。这种对固体垃 圾管理机制的长期的漠视, 甚至蔓延到了专业设计领域, 这也正说明了垃圾处理工 作在印度所受到的歧视。

印度国立设计学院（National Institute of Design）成立于上世纪60年代。该校 直属于印度工业部（Ministry of Industry），而不受任何大学体制的束缚。一直以 来, 该校引领着印度设计教育的发展方向, 并为工业发展提供服务。鉴于印度土布 (手纺纱和手织布) 在昔日该国自由运动历史中的重要地位, 以及大量致力于乡村 发展的机构的存在, 印度非正式手工业部门一直以来受到特别关注。但由于不具备 多学科教育环境, 导致大学中的设计课程普遍缺少相应方法论, 因此无法为社会和 经济发展提供有力的理论支撑。

相反，在工业化国家，只有当普通市民都能够清醒地认识到垃圾处理不当会对 人们的健康和环境造成危害, 并在此基础上, 将城市固体垃圾 “问题” 列为教育和 政策重点时, 其设计方案才能够得到真正的改进。印度却完全不同, 该国垃圾处理 的社会文化传统和沿袭已久的简单易行的垃圾处理方法影响了该领域的正规教育和 政治参与。因此, 近期回收再利用方面所做的努力基本上没有受到来自设计专家们 的指导。这些专家都接受过专门培训, 他们了解当地情况, 会激励那些已经认识到 垃圾处理不当会带来不良效应的人们行动起来。当然, 由于印度垃圾材料的密度、 含水量、大小分布各有不同, 需要培训大量工程师和设计师, 应用西方国家开发的 工业化技术并结合印度自身的条件, 来解决这一问题。但在垃圾回收再利用这个重 要的社会环节, 如, 进行有计划地收集、分离和财存, 对于产品服务系统理念十分 重要, 但这些方面却往往被忽视了。

如今, 无论是官方记录还是国家推行的经济福利政策, 都几乎没有涉及到 非正式经济, 但它已经逐渐被人们所了解。另外, 印度也正在努力填补有关非 正式经济这个印度经济的重要组成部分的资料及研究数据方面的缺口（森古达

(Sengupta）2009）。就设计方法论而言, 产品服务系统创新不仅包括了产品生命 周期对环境影响的评估, 而且还包括了对社会和经济影响的评估。这也完全符合其 宏大的目标-一改变人类的消费习惯, 而不只局限于工业生产。显然, 为实现产品 服务系统目标, 在处理印度城市固体垃圾问题时, 社会学和经济学将会扮演更为重 要的角色。

如今, 在全世界都认为垃圾已经 “变成金子” 的情况下，与印度国立设计学院 创立时相比, 印度的设计情境已经大相径庭。最具商业头脑的人们高度关注如何在 提升垃圾价值的同时减少它的长期环境成本。作为企业的解决方案, 这一理念主要 建立在技术、工业和产品的基础上。非政府组织和市民团体参与到城市固体垃圾处 理工作中, 他们一方面关注垃圾处理的工作环境, 另一方面关注如何改变人们的消 费行为和消费态度。然而, 非政府组织和市民团体都无法发挥专业设计和产品服务 系统 (PSS) 设计的作用。事实上, 这两项设计能够凭借人们对垃圾行业非正式经 济的重视, 把这两个关注点结合起来。 


\section{2 垃圾金字塔}

显然，在实现产品服务系统的社会公平设计目标的过程中，不能忽视印度金字塔式 的、高度结构化的非正式垃圾回收体系和其现存运营机制的影响。尽管官方否认, 但是在垃圾处理过程中, 非正式部门的参与绝不是辅助或次要的, 它在垃圾收集、 隔离、运输、储存、回收和销售等所有活动中与市政当局已结成了长期合作关系。 案例研究证明了这种合作关系的广泛性, 以及非正式部门技术与服务的多样性。这 些多样性能够适应多样化的工作安排一一从保障最低生活标准到获得丰厚的商业利 益（吉尔（Gill）2010, 查克梅因）（Chikermane），戴斯潘德 (Deshpande)， 纳瑞安 (Narayan) 2001, 斯诺 (Snel) 1999, 加罗威（Galloway）1993）。大规 模独立的垃圾运输和处理工作仍然只能在市政府的安排下进行。

印度德里非政府组织蔡坦（Chintan）的一个早期研究显示, 一个拾荒者平均每 天的垃圾收集量大约在 25 至 30 公斤之间。单单在德里市的两个区里, 拾荒者总共收 集并贩卖了约125,000至130,000公斤的垃圾。这种非正规垃圾回收方式每年就为 整个城市创造多达2至2.6亿卢比的经济效益（察坦（Chintan）2003，2007）。但是 它一直是 “隐形的”：不仅未被显示在官方统计数据上, 得不到政策扶持, 而且还 被主流的设计实践和教学所忽视。

当高速的城市化进程和资源衰竭削弱了各个市政机构的管理职能时，产品服务 系统便开始在提高非正式经济认可度中扮演重要角色。它使人们意识到在处理垃圾 的过程中, 非正式经济是物力和人力资本的重要来源。众所周知, 在市区肆意扩展 所带来的压力之下, 官方机构仅能为社会提供 $30 \%$ 的垃圾处理服务（联合国人类居 住中心 (UNCHS) 1994）。在德里, 市政机构无法清理首都地区产生的全部垃圾。 于2001年创立的印度污染控制中心（IPCA）是一家非政府组织, 由参与德里印度理 工学院（IIT Delhi）“校园回收项目”的学生和项目策划人员创建。该中心的发言人 坦言：由德里市政机构处理的城市垃圾只达到 $62 \%$ 。剩下的垃圾处理工作由拾荒者 完成, 他们免费收集、分类并运送垃圾。拾荒者作为非正式垃圾行业的主力军, 每 天都能给政府省下一大笔开销。印度 “住房和城市扶贫部” 发言人在 2004 年一场由 蔡坦 (Chintan) 在德里组织的听证会中承认, 现在印度 $90 \%$ 的人口都从事正式部门 以外的工作，其中 $59 \%$ 的人从事垃圾收集与回收工作。

与其他新兴经济体类似, 在国际劳工组织 (ILO) 和世界银行 (World Bank) 的大力提倡下, 印度的垃圾处理工作通过消除对非正式部门的歧视, 实现正式和 非正式部门之间的互补。事实上, 在1992年里约热内卢联合国环境与发展大会

(UNCED) 后出台的 “21世纪议程”，涉及的问题包括减少垃圾排放、垃圾回收再 利用、生态可持续的垃圾处理和处置, 以及扩大垃圾处理服务范围等。除环境问题 外，该议程还关注社区居民的非正式参与和民生问题。

考虑到内部关系和交易过程中的复杂性, 产品服务系统 (PSS) 设计对垃圾处 理过程进行干预时应保证非正式部门内部各组成部分的不同利益。比如当今的私有 化严重威胁着处在非正式部门最底层的拾荒者的生存状态。值得注意的是, 产品服 务系统的 “最佳实践” 虽然鼓励城市居民参与到垃圾分类与回收中, 但最终也对垃 圾处理行业造成了严重的损害，因为它打破了拾荒者对家庭垃圾处理的垄断局面。 
于是，官方的偏狭、公民的忽视和冷漠在不经意间双重打击了这个极易受到疾 病侵袭和警察压制的弱势群体。由于非正式的垃圾回收行业缺乏组织管理, 各种不同 的人都加入进来, 其中就包括被社会边缘化的居民和外来移民。他们不考虑社会地 位, 只求能够迈进底层经济行业的最低门槛。这也使他们极易成为政府压迫的对象。

家庭能够直接参与到垃圾捡拾工作中, 这使该工作对金字塔底部人群或穷人产 生了吸引力, 因为它甚至可以为妇女和孩子提供微薄的收入。金字塔的倒数第二层, 是走街串巷的垃圾收购者, 他们中既有男性也有女性, 专门收购和销售各种垃圾, 他 们的生活质量因此有所改善。倒数第三层包括废品零售商、小型批发商和大型批发 商。很多中产阶级都参与到这一行业中, 相比之下, 他们从中获得的利润更多。

金字塔的顶端由废品再加工企业和废品注册经销商组成。尽管他们通常都拥 有执照并且是正式部门的一部分，但是很少承认后者的责任和监管义务。他们公然 违反包括1948年出台的《商店和企业或工厂法案》在内的各类法律法规（阿南德 Anand 2001）。印度缺少完善的机构信贷机制，小规模或家族企业在某些行业占据 主导地位, 社会地位低下的印度妇女通常只能成为雇佣工人, 很少能成为企业家。 贸易行业的门槛很高。拾荒者或零售商永远不可能升级为经销商和再加工企业。

尽管上述每一层级通过非正式垃圾处理服务而获得的利润有天壤之别, 并且长 期以来这个行业一直被视为是 “脏活” , 但对许多人而言这仍不失为是一种谋生手 段。能获取高额利润的高端职业, 对那些领取固定薪水的职业人士, 如管理人员, 银行从业人员, 甚至股票经纪人, 往往都很具吸引力。事实上, 从产品服务系统的 角度来看, 垃圾处理和定期上门收购 (kabari) 通常被视为双赢服务, 可以满足每个 业界参与者的需要。居民能够处理掉他们的废品, 并且可以用更低廉的价格购进可 回收材料制作的商品。拾荒者、废品收购商和零售商以此谋生（每月收入从几百卢 比到20000卢比不等, 甚至更多)。垃圾回收行业将继续为新人和移民开放, 并为他 们提供生存的空间。工厂用低价购进原材料, 国家也无需进口木浆和塑料树脂, 既 节省了外汇储备又能够从中获益（加罗威（Galloway）1993）。

\section{3 垃圾处理产品服务系统设计中的社会公平问题}

为了提升产品服务系统在设计行业中的声誉, 城市固体垃圾方面的研究必须综合所 有能满足 “利益相关者” 和主要利益集团需求的各种要素。例如, 政府出台了以整 顿拾荒市场、提高拾荒者的生活水平为目的的一系列措施，包括为他们制作合法的 身份证件, 提供社会保障等; 但这并未能满足拾荒者的意愿, 因为政府始终未把他 们的“回收” 纳入到市政规章认可的经济行为中。同样, 如果是由市政当局与技术 专家和企业领导层共同制定的垃圾处理方案, 没能考虑到实际运营中非正式经济的 因素, 那么这个方案就是不完整的。

市政当局一方面与企业合作，另一方面也与非正式部门合作。然而，当前这种 仅依靠理论层面的正式一一非正式合作模式已不再可行。而产品服务系统 (PSS) 设计也不可能等到城市固体垃圾处理获得广泛社会共识, 或相关的法律出台之后, 再开始寻找解决的措施, 履行其承担社会责任的义务。毫不夸张地讲, 在进行专业 
化干预之前, 从事垃圾回收工作的底层人民的生活情况和生活空间急需被深入地了 解和观察。在这方面, 社会学以及人种学, 尤其是参与者的观察, 能为产品服务系 统 (PSS) 设计提供教学和实践依据。科学技术和管理经济学一直支撑着设计教育 的规范工作, 但这二者都没有针对垃圾问题提出一个整体的解决方案。从方法论层 面上讲, 社会学关注的是：1）家庭和社区日常的具体活动；2）周围的文化大环境; 3) 记录市民的实际态度、行为和活动将有助于产品服务系统 (PSS) 设计者在寻求 垃圾解决方案的过程中确立社会责任感和公平性目标。这也能检验已成型的、正式 与非正式经济之间、企业与市政当局之间合作关系的可行性。

\section{4 产品服务系统和私有化问题}

印度城市固体垃圾管理的进一步“私有化”计划, 目前只是在垃圾处理服务行业的 公司层面实施, 并不包括家庭和非正式部门。非正式部门具有灵活性高、生存能力 强、涉及范围广和自给自足等特点, 却未能得到官方认可。德里市政公司 (MCD) 把处理废品和与废品相关的工作都移交给私营承包商, 这在很大程度上抑制了非正 式部门发展。由于私营部门不顾一切地保护自己的经营领地, 现在拾荒者在私人承 包商管辖范围内拾荒必须付出代价，他们不得不付给私人承包商一定的费用。同 样，市政特许的相关活动仅包括：由市政工作人员从事的垃圾 “清扫”工作，在政 府所建的垃圾桶 (dhalaos) 或者仓储附近区域从事的垃圾 “收集”工作, 市政卡车 进行的废品 “运输”工作和在政府批准的场所从事的垃圾 “掩埋”工作。其中并不 包括垃圾的“回收”和 “交易”活动。这已经自然而然地将印度街头随处可见的拾 荒者的经济活动排除在外了。

现今的印度, 只有政府负责大型的垃圾运输和处理工作。而且, 从本质上讲, 印度政府颁布的《城市固体垃圾（管理和处理）条例》（印度政府（GOI）2000) 是把私人和公共区域, 把未经授权的贫民窟和官方领地, 把衣衫褴褛的拾荒者与市 政工作人员（safai karamcharis），把家庭住宅与商业设施区分开来。这种概念化的 划分是与现实情况相背离的。实际上, 正式和非正式的部门早已通过多种方式融为 一体了。垃圾回收点 (dhalao) 不断增加, 占用了原本 “属于”拾荒者们分拣垃圾 的街区。当拾荒者的居住地被政府用作垃圾收集回收区域时, 贫民窟则变成了与其 相对应的非正式 “垃圾回收区”。市政当局担心这种“非法”和危险的回收行为在 城市区域内滋生䒤延, 却并未按照现行的条例规定, 给拾荒者划定活动区域。事实 上, 如果拾荒者能够分配到属于自己的一方区域, 他们能够就此承担更大的社会责 任。出于类似的原因, 在城市固体垃圾处理方面, 市政当局仅与企业, 而非社会部 门展开协作, 这些社会部门被视为城市治理的寄生虫和附属品。以满足各方利益为 核心的产品服务系统 (PSS) 设计旨在重新调整官方的规划, 将回收行业现已存在 的城市家庭和非正式服务纳入考虑范围。 


\section{5 产品服务系统与垃圾回收和再利用中的政治经济学}

产品服务系统 (PSS) 设计致力于在城市固体垃圾处理过程中, 把正式和非正式的 行动整合起来。这种系统设计不应忽视回收和再利用过程, 因为它们不仅能够提供 微观社会层面, 如家庭和社区的满意度, 而且能够获得宏观方面, 如经济与环境的 良好收益。从人力资源角度而言, 垃圾回收能为城市贫民创造更多的就业机会。为 了提高效益, 所有的回收项目都要考虑从垃圾的源头, 即从每个家庭开始, 对其进 行分类, 从而降低总体垃圾的数量和处理量。最理想的情况是, 我们不仅要提高资 源回收的数量和质量, 而且要改善拾荒者的工作环境, 提高他们的社会地位, 并保 护他们的自尊心。然而现实中, 由于印度根深蒂固的文化习惯和对 “处理”垃圾的 偏见, 垃圾分类的办法在社区和家庭当中成效甚微。同样, 如果有一天垃圾的价值 得到了提高, 人们也绝对不会将其利益转移到那些卑微的拾荒者身上。因为城市家 庭和私营公司早在拾荒者之前就争相把垃圾中的价值榨取干净了。

受到传统观念的影响, 印度社会把垃圾分拣及其相关处理工作视为社会地位 低下的行业, 这导致了人们对这一行业产生偏见和鄙视, 这种态度甚至反映在家庭 成员处理自己的厨房垃圾时。人们认为处理垃圾的工作应该交给全职或兼职的佣 人来完成。在公共场所、街道和市区里, 处理垃圾的都是被称作贱民的达利特人

(Dalits)（在印度传统社会中, 上等种姓人称他们是 “不可接触者”，无论是身体 上还是精神上, 印度社会认为他们是危险的, 不可靠近的人群）。事实上, 在印度 殖民统治时期, 在种姓制度的压迫下, 当局把城市清扫工作全部分配给“不可接触 者”（现在给他们支付薪水），而同时剥夺他们通过贩卖垃圾谋取商业利益的权利。

即使是在印度独立之后, 由于种姓制度并没有被彻底废除, 清理垃圾的工作依 然受制于这种传统的政治强制性。正是在这种制度之下, 负责分配社会利益的中间 人对达利特人恶劣的生存环境和工作条件不闻不问, 一味从中谋取暴利。这种将社 会地位卑贱的工作全部分配给特定群体的观念严重地阻碍了垃圾处理工作的多元化 发展。然而, 被压迫的达利特人却强烈反对现今非正式部门参与到社区垃圾回收和 垃圾源头分拣行动中。他们想要保住自己的谋生手段, 不希望那些被他们视作 “外 行人”的中产阶级和城市贫民抢走自己的饭碗。即使在市政层面, 被视为有官方保 障的垃圾处理工作也吸引了很多高等种姓的人们。为了争取好的工作机会, 他们把 传统的歧视态度都抛到脑后。这也威胁到了政府工作人员（safai karamcharis）。事 实上, 由于通过非法偷窃和贩卖市政垃圾所获得的收益不断提高, 抵制外部人员加 入该行业的行为愈加强烈。

\section{6 产品服务系统的提升和垃圾处理的文化感知}

印度对垃圾的两种对立和等级化的文化感知是一个需要被打破的恶性循环, 为此, 许多垃圾处理领域内的非政府组织和非政府项目都在实施意识提升项目。这两种文 化感知, 一个是城市中产阶级的普遍想法：垃圾处理与我无关。第二个是被压迫阶 
层普遍认为垃圾处理是他们的工作, 千百年来都是如此。若要改变这种根深蒂固的 偏见和习惯, 需要非政府部门做出巨大努力（苏米特里（Soumitri）2002, 普瑞赛德

(Prasad）1998）。设计界当然也需要做出适当的贡献, 因为出于历史原因, 长期 以来, 印度的设计界仅仅为工业发展提供解决方案。

在文明社会中, 各利益相关方之间总是存在着各种文化与历史冲突, 而对这种 冲突背后的各种活动进行认真考察是非常有益的, 它有助于加深人们对在印度实施 产品服务设计系统潜力的认识。

\subsection{1 垃圾的收集}

收集是指从不同的收集点收集垃圾，这些收集点包括垃圾桶、私宅、社区垃圾回收 箱（dhalaos）（露天垃圾桶）以及露天垃圾场。在印度, 乱丢垃圾的行为是被禁止 的, 而印度的垃圾制造者有责任确保来自住户、商业企业、工业部门和酒店的垃圾 得到及时收集并进行处置。在印度, 去各家各户上门收集垃圾的工作, 主要由非正 式部门来完成。而捡垃圾者, 他们更希望被称为拾荒者, 这些人则在经济活动金字 塔的最底层。他们中的大多数, 无论男女, 都属于种姓制度中较低阶层的人群, 是 被这个社会边缘化的群体。这些人甚至做起了将垃圾送往当地社区收集点并进行分 类的工作。有时市政当局或居民福利协会（RWAs）会提供一些手推车或其他小型 车辆供其用于垃圾的运输和分拣。

流动的废品收购者（kabari-wallahs或-wallas）通过从家庭和其他垃圾制造 者手中收购垃圾, 在一定程度上也有助于垃圾的收集和分拣。废品收购者的数量 明显少于拾荒者, 他们多为男性, 以自行车作为交通工具在城市中活动。与通常 留给公众的印象相反, 拾荒者和废品收购者的工作时间非常有规律, 就像警察一 样。他们将垃圾桶、垃圾堆放点进行 “权属”划分。因侵犯“权利”而引发口 角争执是家常便饭, 但该行业还是对外开放的（纳瑞安 (Narayan) 和查克梅因 (Chikarmane) 2000）。印度人口稠密城市的固体垃圾收集工作每天或每两天进 行一次, 因为城市里气温很高, 垃圾储存空间有限（家庭或街道），而且垃圾极易 腐烂。然而, 印度城市固体垃圾的平均粒度比工业化国家小得多, 导致工业化国家 研发的高新技术, 在印度均无用武之地。由于印度已经采用了非正式的垃圾收集 手段, 所以没有必要再用能耗和原料成本巨大的高科技手段。私人和企业部门的 活动范围虽然现在还很小, 但却在垃圾收集方面的参与程度越来越高了。非常遗 憾的是, 印度并未选择采用产品服务系统 (PSS) 的方法, 而是采用平行劳动力

(parallel workforce) 的方法来组织垃圾收集工作。

\subsection{2 垃圾分拣}

印度的城市固体垃圾被分成几大类, 常见分类如下:

- 玻璃和瓷器 玻璃瓶（完整的和破碎的）, 门窗玻璃、瓷陶器和碎玻璃

- 纸张和纸制品 报纸、杂志、书本、书写用纸张、纸板和纸箱 
- 塑料制品 油箱、卫生间用品和化妆品; 塑料袋; 塑料板; 管材; 马桶座圈和 水泥包装袋

- 金属制品 钢铁、铝、铜和锡质容器（完整的和破损的）

- 纺织品 窗帘, 衣服和挂建以及纺织厂垃圾

- 橡胶和皮革制品 轮胎和鞋

- 骨骼动物尸体, 屠宰场垃圾以及酒店和餐馆垃圾

-木材破损家具和花园垃圾

- 其他有机垃圾 厨余垃圾, 蔬菜垃圾和花园修剪垃圾

- 建筑垃圾 砖块和水泥碎石, 铁制品和木块（联合国人居中心 (UNCHS) 1994) 3-6)

对有机垃圾和可回收垃圾的分拣主要在四个层面进行：垃圾产生的源头、公共垃圾 回收箱、垃圾运输车辆和垃圾堆放点。要使垃圾管理计划取得成效, 理应从家庭单 元开始对垃圾进行分拣, 然而因为上述种种原因, 这项措施目前仍然不能被大多数 印度人接受。因此, 挨家挨户收集垃圾的效果并不是很好。此外, 拾荒者/捡垃圾者 的工作环境十分恶劣。他们每天花费数个小时在社区垃圾桶内翻找垃圾, 身体健康 受到严重威胁。许多市政工人从政府垃圾储存区和垃圾运输车上“偷窃”垃圾, 并 通过不法手段出售垃圾以贴补他们微薄的工资。市政工人和警察甚至直接从拾荒者 们手中抢夺垃圾。在运输和工作期间, 这种非法活动导致垃圾的大量丢失, 造成了 政府收入的严重损失，这些损失甚至超过了这些资源本身的价值。

流动的垃圾买家和定期上门的垃圾收购者也为垃圾分拣工作做出了积极贡献。 通常情况下, 他们收集的垃圾产品的市场价值比拾荒者收集的更高。这些垃圾按重 量销售给零售商, 通常零售商在贫民区都有固定的回收点。这些回收点都不归相关 组织部门管理。垃圾在不同的贸易渠道中经过层层分拣和分类, 最终到达再加工者 或最终用户手中。在每次交易中, 垃圾的价值也得到了相应的提升。

\section{6 .3 储存}

由于文化禁忌和各种垃圾所含市场价值不等的原因, 印度家庭很少会储存垃圾。流 动收购者会定期上门收购垃圾, 对其进行分拣, 然后卖给批发商和零售商。许多未 经政府批准的区域和 “贫民窟”变成了垃圾非正式分类和储存的地点。印度的废品 交易没有受到任何管制。废品交易商店通过侵占贫民区的空间而进行经营, 其中只 有个别极具规模的垃圾交易公司是根据《商店与商业机构法案》获得经营许可的。 然而, 废品收集者之间的交易没有任何收据, 这些交易是否纳税也不得而知。价格 的季节性波动, 倾倒废料和从工业化国家进口垃圾等情况, 都会对印度的废品交易 市场造成影响。大型贸易商通常直接从工厂、大型机构和商业机构那里购进废品。

严格来讲, 所有存放在市政垃圾点的、具有价值的废品都归政府所有, 严禁破 坏。然而实际情况是, 非正式的和违法的回收活动已经 “淘” 走了其中大多数具有 
商业价值的废品, 而剩余在回收中心和填埋场的废品也极有可能被社会等级最低的 拾荒者 “顺走”。从市政垃圾储存区中运出的只是那些生物可降解的和 “不值钱” 的垃圾（普通居民垃圾）。事实上, 正是由于这些原因, 市政当局承担了把垃圾从 垃圾桶运输到特定储存区、并对它们进行处理的整个工作。

没有人愿意清理这些垃圾, 政府只能花钱雇佣清洁工完成垃圾清理的工作。印 度人口众多, 能为垃圾清理工作提供丰富的人力资源。肮脏的街道和垃圾桶成为官员 阶层给当地政府和公众施压的有效手段。他们虽然处在相对受人尊敬的生活的边缘, 但也受到某些政治“保护”。因为监管者和高层官员基本都是来自受过良好教育的、 属于高等种姓的中产阶级，市政当局通常把工作交给那些来自同一个阶层的劳动力。 由于垃圾清理设施投用之初没有综合考虑该区域垃圾产量、人口密度和交通方面的影 响，致使垃圾储存区得不到及时清理，其周围也经常被倾倒的垃圾所包围。

\section{7 结论}

本章所讨论的与产品服务系统相关的非正式部门的固体垃圾回收工作已经在印度多 数城市展开。然而, 国家和地方政府以及社区并未充分利用垃圾回收和再利用所带 来的所有益处。造成这种情况的主要原因包括以下几点:

- 在亚洲的新兴国家, 垃圾管理服务的收费很低, 这使得家庭对垃圾分拣工作 缺乏相应动力。非正式经济以及印度社区对垃圾分拣工作责任心低下也是造 成上述情况的原因之一。同时, 文化因素也制约了在源头分拣垃圾的效果, 这导致可回收垃圾无法做到完全回收利用。

- 市政机构不愿与非正式部门合作进行固体垃圾回收工作（当局普遍认为拾荒 者的活动传播垃圾, 带来扰人的恶臭, 并且影响了政府的工作, 所以他们认 为应该取缔非正式部门。）

- 当地政府和居民福利协会（Resident Welfare Associations）对改善拾荒者和 流动垃圾收购者的工作条件的支持力度不够。对垃圾处理工作者还存有传统 的歧视, 导致了固体垃圾管理 (SWM) 过程中公众参与的不足。

- 设计教育活动得到了许多非政府组织的支持, 然而来自政府或是公众的支持 则很少, 甚至几乎没有。

- 这些制约因素和矛盾的存在使得产品服务系统的效益无法完全发挥出来。因此 必须将那些有助于解决固体垃圾管理问题的可持续性设计项目纳入考虑范围。

\section{参考文献}

Anand, S.H. (2001) Nature of the Informal Economy \& Three Sectoral Studies (Geneva: ILO). Chikarmane, P., M. Deshpande and L. Narayan (2001) Study of Scrap Collectors, Scrap Traders and Recycling Enterprises in Pune (Geneva: UNDP \& ILO). 
Chintan (2003) Space for Waste: Planning for the Informal Recycling Sector (Delhi).

Chintan (2007) Wasting Our Local Resources: The Need for Inclusive Waste Management Policy in India (Delhi).

Galloway, L.N. (1993) Recycling: A Natural Response to India's Solid Waste Problems (Delhi: Development Alternatives).

Gill, K. (2010) Of Poverty and Plastic: Scavenging and Scrap Trading Entrepreneurs in India's Urban Informal Economy (Delhi: Oxford University Press).

GOI (Government of India) (2000) 'Waste (Handling \& Management) Rules 2000', Gazette of India Notification No. 648 (Delhi: MOEF-GOI).

GOI (2007) India: Addressing Energy Security \& Climate Change (Delhi: MOEF, Ministry of Power, Bureau of Energy Efficiency).

ILO (2001) 'Global Employment Trends', World Employment Report (Geneva: ILO).

Narayan, L. and P. Chikarmane (2000) 'Formalising Livelihood', EPW XXXV (41).

Power, K. and O. Mont (2010) 'The Role of Formal and Informal Forces in Shaping Consumption and Implications for Sustainable Society: Part II', Sustainability 2: 2573-92.

Prasad, V. (1998) Untouchable Freedom (Delhi: OUP).

Sengupta, A.K. (2009) Report of NCEUS: the National Commission for Enterprises in the Unorganised Sector. Government of India (Delhi: Academic Foundation).

Snel, M. (1999) 'Integration of the formal and informal sector waste disposal in Hyderabad, India', Waterlines 17 (3) (I February).

Soumitri, G.V. (2002) Report on IITD Campus Recycling Project (Delhi: IITD).

UNCHS (United Nations Centre for Human Settlements) (1994) A Reference Handbook for Trainers on Promotion of Solid Waste Management in the Developing Countries of Asia (Nairobi: UNCHS).

UNEP (2002) Product-Service Systems and Sustainability: Opportunities for Sustainable Solutions (Paris: United Nations Environment Programme, Division of Technology, Industry and Economics, Production and Consumption Branch).

World Bank (1999) What A Waste: Solid Waste Management in Asia (Washington, DC: World Bank). 


\section{贫困城市背景下非正式经济中的 可持续产品服务系统}

\section{印度及德里服装护理行业尉衣工 的案例}

帕温・普努 (Parveen Pannu)

印度德里大学家政学院 (Institute of Home Economics, University of Delhi, India)

\section{1 印度城市化和贫困化的问题加剧}

城市化是当今时代最主要的社会转型进程。城市是非农业生产活动的中心地带, 它 不断吸收农村地区的剩余人口。20世纪, 城市人口激增: 大批农村人口前所未有地 涌入了中心城市。在今后几十年中, 亚非大陆新兴国家的城市人口仍会大规模增长。

根据萨因（Sarin）和扎因（Jain）（2009）的观点, 印度是一个城市化发展进 程较快国家, 到2020年, 预计将有超过5亿的人口生活在城镇。印度的城市人口增 长率甚至高于其总人口增长率。与其他新兴国家一样, 面对大量涌入城市的农村人 口, 印度并未做好各方面的准备。《2009年印度城市贫困报告》显示, 目前, 印度 有 2.86 亿人口居住在城市, 占其总人口的 $28 \%$ 。到 2030 年, 印度将会有 5.57 亿人居 住在城镇, 占总人口的 $41 \%$ 。这需要印度意识到, 城市贫困问题并不只在于农村贫 困人口的过度涌入的, 其需要为城镇发展制定更为包容的规划, 进一步出台解决城 市贫困问题的国家战略。印度的城市化进程正在不断加快。伴随着这样快速的增长 步伐，城镇为印度创造了 $62 \%$ 的GDP，但同时也带来了城市贫困和贫民窟等问题。 艾瑞（Aiyar 2009）指出：在印度，有五个州的城市人口超过全州人口的50\%, 德里 是其中之一。 


\section{1 .1 城市贫民的微型企业}

大多数城市贫民都在微型企业中工作。微型企业为贫民和他们的家庭成员提供工作 岗位。绝大多数城市贫民只能通过非正式职业谋生。微型企业最多只有五名员工, 贫民依靠在微型企业工作来养活自己的家庭。这类企业是新兴国家经济的一个重要 组成部分。大多数微型企业都是个体经营, 为了生计艰难度日, 永远也没有发展为 大企业的可能（米德（Mead）和里德霍姆 (Leidholm)，1998）。

印度城市的经济活动中有很大一部分是非正式部门的活动。其中衣物慰浈服务 是非正式部门中多数微型企业的主要业务形式。衣物慰烫是劳动密集型的服务性行 业, 也就是一个为顾客提供基本服务的行业。

\section{图7.1 慰衣工在用沉重的木岸慰斗慰衣服}

来源: 作者

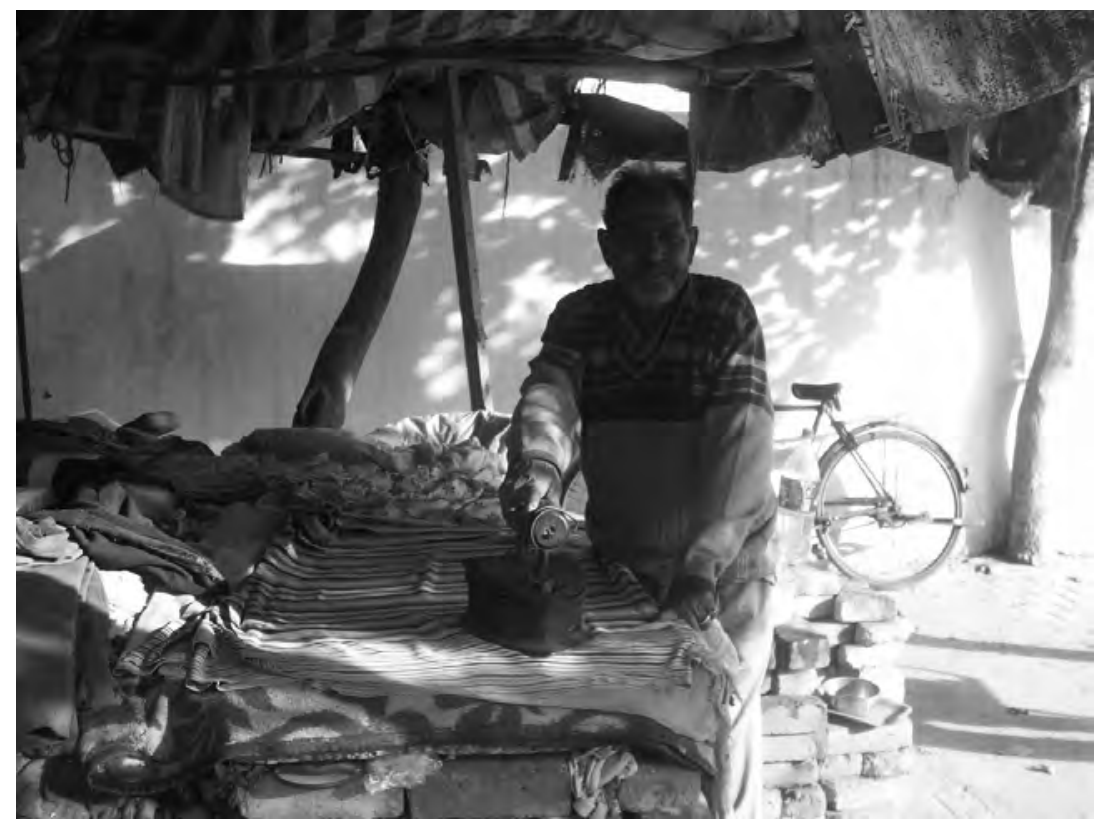

慰衣服务有很广阔的市场需求，遍布德里大街小巷的众多慰衣工就是最好的证 明。慰衣工作是基于种姓制度的一个传统家族职业，无论男女老少都可从事。

长期以来, 洗衣工和慰衣工（通常被称为presswallas）一直是印度城市经济重 要的组成部分。对于普通居民来说, 城市生活离不开洗衣工和慰衣工。在德里郊区 的街头巷尾都能见到慰衣工的身影。他们通常在桌前拿着木炭加热的慰斗, 等候着 客户上门。很显然, 由于家务琐事的巨大负担, 印度的中产阶级非常欢迎衣物慰烫 服务。再者, 也因为忙碌的工作和复杂的天气状况, 中等收入群体需要购置很多衣 服。因此，对慰衣服务的需求成为印度文化习俗的一个重要组成部分。 
衣物慰淴生意很大程度上需要依靠良好的人际关系和良好的商业信誉。马宗达 (Majumdar) 和拉尔（Lall）（1992）的研究表明，对于经营微型企业的企业家们 来说, 他们的创业精神是难能可贵的, 他们没有受过专业教育, 在大都市竞争激烈 的市场中凭借一己之力开创了自己的事业。市场有着自动调节机制, 只有那些财务 上有生存能力的公司才能够生存下来。如果这些企业在不利的环境中都能够得以生 存, 那么, 在有利的经济环境中他们就会发展的更快更好。一些有事业心的洗衣工 进而建立了他们自己的现代化洗衣店和干洗店。在这些店里客户可以自主使用这些 设备（NIUA 1991）。这些慰衣店都是创业者们通过辛苦打拼创建起来的，在激烈的 竞争中, 凭借独特的优势生存下来。

属于城市非正式部门的慰衣企业的经营也反映出了挣扎在社会边缘的群体的 生存状况。随着新型、高技术家电产品比如洗衣机的出现, 传统的洗衣行业受到冲 击, 大部分业务已经被机器取代了。因此他们不得不努力改变自己以适应快速变化 的形势（NIUA 1991）。

德里, 这个为人们提供了无数谋生机会的城市, 也为我们提供了一个研究德里 慰衣工的社会和经济生活、评估慰衣服务的微型企业发展前景的机会。本章集中关 注那些在慰衣服务微型企业中, （同时作为业主）慰衣工的角色, 以及产品服务系 统中的产品（如手机）所起的作用。尽管有很多坊间证据证明手机的使用可以提高 贫民的社会和经济地位, 却很少有系统化的证据证明手机确实为这一群体带来了利 益。非正式部门从业者在努力增加收入, 改善工作环境, 获取社会保障福利和扩大 就业机会的过程中, 也促进了社会公正和经济发展。在这个过程中, 我们仍需要对 非正式部门从业者以及作为信息通信技术工具的手机所面临的问题形成更深刻的理 解, 促进问题的解决。

\section{2 德里慰衣工概况}

在低收入地区, 产品服务系统的发展提供了能够增加利润、改善环境并提高社会效 益的双赢解决方案（联合国环境规划署（UNEP） 2002）。产品服务系统策略的成 功实施依赖于目前的科技发展水平和社会文化背景; 因此, 本节通过描述慰衣工的 生存现状来阐述可持续设计系统在促进微型企业发展方面的战略意义。

本节的内容是根据一项对分布在德里不同地区的从事慰衣服务的200个家庭型微 型企业的实证研究展开论述的。该研究的数据收集渠道包括调查、采访、观察和讨 论, 数据的收集工作于 2009 年完成。研究的目的在于深入了解尉衣工的经济活动历 史、工作模式、企业管理、家庭内部关系（包括女性和孩子的角色）和从事经营慰 衣业务的微型企业家庭的生活质量。

\subsection{1 慰衣工简况}

\section{工作概况}

（家庭）微型企业为城市中的广大中等收入群体提供衣物慰资服务。除了衣物慰 菏, 其服务内容还包括上门收取衣物、慰烫和把慰好的衣物送回顾客家中，均按固 
定价格收取费用。这项工作是以手工方式完成的, 在德里48摄氏度的酷热夏天里, 这项工作既乏味又辛苦。尤其是在街头露天工作, 这个问题尤为突出。

\section{迁移和居住}

大多数慰衣工都是迁移到德里的, 从北方的北方邦、哈里亚纳邦、喜马偕尔邦和拉贾斯 坦邦迁移过来的居多。每个家庭迁移的原因各不相同, 但都与社会经济有关。他们迁移 的动机是为了寻求更高的收入和更好的工作机会, 也是为了摆脱传统社会环境的束缚。

慰衣工迁移的原因包括:

- 收入低和家庭贫困（38.7\%）;

- 全国性的灾害和社会弊病（比如公共暴力） (4.2\%);

- 城市就业机会 $(28.2 \%)$;

- 受早期移民的影响 (19.8\%) ;

- 对该城市的向往 $(4.9 \%)$;

- 其他原因 $(4.2 \%)$ 。

在德里, $29 \%$ 的家庭, 其全部成员自出生便居住在德里; 这意味着他们是在德 里土生土长的居民。剩下的 $71 \%$ 的家庭是迁移到德里来的, 居住时间从不足一年到 15年以上不等。

\section{工作时长}

慰衣工（全家）每天的工作时间长达8-10小时。

\section{设备}

慰衣工通常使用两种慰斗：木炭慰斗和工业电慰斗（功率为900-1200瓦特）。木 炭尉斗重约6公斤, 工业电尉斗约7-8公斤。沉重的木炭尉斗使尉衣工作变得十分辛 苦。他们还需要掌握一些所慰浈衣物布料的相关知识。

\section{住所类型及可用的基本福利设施}

在被调查的样本家庭中， $66 \%$ 的家庭居住在称为jhuggis 的茅草房里； $9 \%$ 的家庭居住在 专门为经济弱势群体提供的公寓中； $10 \%$ 的家庭居住在单间出租屋里； $21 \%$ 的家庭居 住在房东免费提供的处所里。很大一部分家庭没有生活基础配套设施, 如饮用水、照 明、适用的卧室和独立卫生间，他们中的大多数人只能在露天场所解决大小便问题。

\section{店面位置}

这些店面主要位于居民区。由于这种类型的业务经常需要上门服务, 因此店面的选 址便具有重要的战略意义。 


\section{图7.2 慰衣工的工作环境}

来源: 作者
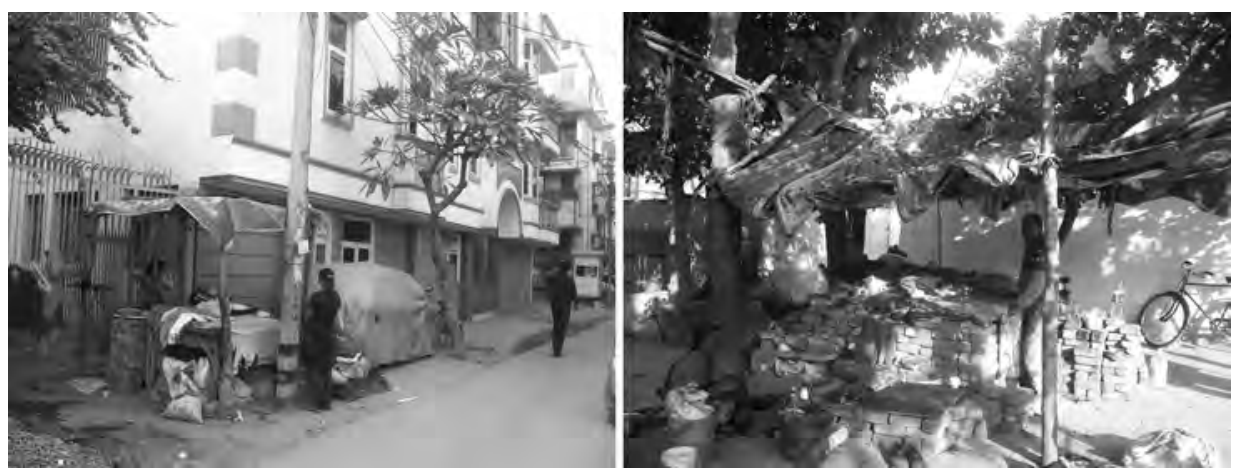

种姓制度

调查发现, 所有的慰衣工都是受种姓制度的影响而成为慰衣工的 1 。在现代印度, 由于政府采取的各项举措（如推行定额分配制、贫困生免费上学和其他社会改革制 度），种姓歧视在近几十年已经得到了扼制。宪法也明确规定种姓歧视是违法行 为。种姓制度带来的障碍在大城市已经基本被消除，然而在居住人口占 $72 \%$ 的农村 地区, 种姓制度根深蒂固的影响无处不在。

家庭构成、教育和培训

在被调查的从事微型企业慰衣服务的200个家庭中，33\%是成年人，47\%是青少 年, $20 \%$ 是儿童; 总共有 $52 \%$ 是男性， $48 \%$ 是女性。他们中的 $82 \%$ 属于核心家庭

(小家庭），15\%是扩大式家庭（包括两对及以上夫妻或是核心家庭加上夫妻一方 的成年亲戚），还有3\%是亚核家庭（家庭中没有已婚夫妻，例如，遗孀、鱝夫，离 婚的男女; 或是未婚的兄弟姐妹; 或是亲属、朋友及同乡）。这些家庭成员中, 大 多数都是文盲。女性文盲的数量多于男性。由于这是一种以传统的种姓制度为基础 的职业, 他们一直以来都是接受 “在职”培训。

1 种姓制度在印度是非常复杂的, 并且拥有很悠久的历史。在印度教中形成一个不同社会阶 层的混合社会结构。主要包括四种种姓：婆罗门 (Brahman) (教师、学者、牧师), 刹帝利

(Kshatriya) (勇士), 吠舍 (Vaishya) (农业和商业从业者) 和首陀罗 (Shudra) (服务提 供者和艺人), 以及达利人（Dalits）( “贱民”)。每种主要种姓都有数百个分支种姓。洗衣 工Dhobis属于达利人 (Dalits) 的上层至中性。达利人（Dalits）或 “贱民”属于最底层种 姓。他们处于社会的最底层, 在不良环境和被污染的环境中从事那些有害健康的工作。他 们受到极端的歧视, 被隔离, 贫困交加。 


\section{女性和孩子的职责}

女性工人有三重职责：照顾家庭成员（作为妻子和家庭主妇）和孩子（作为母亲）, 同时还要作为慰衣工在单位工作。约有 $60 \%$ 的女性为慰衣工, 除了从事辛苦的体力 工作, 还要独自操持家务, 没有其他家庭成员分担她们的重负。她们中的 $2 / 5$ 的人甚 至还要独自出门采购生活必需品。

这些情况清楚地反映出她们自己及其家庭低劣的生活状况。两个或两个以上家 庭成员在一起工作, 每个人付出的劳动通常是不一样的, 因此, 女性工人在家庭企 业中对收入的贡献是无法用钱来衡量的。

由于慰涊工作是带有家庭性质的职业, 所有的家族成员聚在一起工作, 所以几 乎不存在对婴幼儿照管不周的问题。

\section{第二职业}

慰衣工作通常是第一职业, 有些家庭成员还兼职从事一些与慰涊相关或完全不相关 的第二职业。大多数家庭 $(70.5 \%)$ 只从事慰沕服务这一项工作。其余约 $20 \%$ 的家庭 还兼营其它相关工作, 如上浆。调查还发现：这些工作都是由家庭中的男性成员完 成的, 女性成员只从事尉涊衣物这一项工作。8\%的家庭还从事衣物清洗工作, 在被 调查的家庭中, 这项工作多数由女性成员完成。

\section{2 .2 尉㳷企业的主要活动}

慰渴企业起步和发展阶段的主要活动包括以下几项:

慰沕企业起步阶段：

- 寻找投资资金来源；

- 企业选址;

- 市场调查;

- 市场规模;

- 市场潜力;

- 服务定价;

- 市场维护;

- 充足的服务供应;

- 高质量的服务;

- 应对市场竞争;

慰渴企业发展阶段:

- 慰涊衣物;

- 上门收取和送还衣物; 
- 购买木炭尉斗所需的煤、煤油、火柴等;

- 电慰斗的维护保养;

- 与顾客、亲属以及工会保持良好的关系。

\section{记账和启动资金}

调查发现, 大多数家庭企业没有设置账薄, 业务往来只凭大脑记忆, 利用银行进行 融资的意识也相对欠缺。调查还发现，启动资金一般都来自家庭自有资金。

\section{融资周期}

慰资企业的融资周期是一个循序渐进的过程。最初，创业者有了开办企业的构想， 然后便开始对各种资源进行投资。创业者运用家庭储蓄和外借的资金，购置设备， 负担经营费用。他们通过为客户提供尉淴服务获取利润。

融资周期包括以下几部分:

- 创业者一一慰烫公司的慰衣工;

- 他/她的创业构想一一建立一家慰渏企业

- 投资一一店面位置、慰斗、慰衣架等慰衣设备的选择等;

- 企业资金筹集;

- 借入资金;

- 资产;

- 费用;

- 服务销售情况；

- 利润

\subsection{3 商品和运输工具的可用性}

调查发现，87\%的家庭有收音机，42\%的家庭有黑白电视机，40\%的家庭有电风扇 （台式和吊顶式），37\%的家庭有高压锅（尽管通常被当做普通锅使用），7\%的家 庭有窗口式冷风机, 甚至有 $3.5 \%$ 的家庭拥有彩色电视机。这些数字说明开办慰烫企 业是可行的。

绝大部分家庭, 也就是 $93 \%$ 的被调查家庭都拥有自行车。他们把自行车作为运 输工具； $1 \%$ 的家庭拥有两轮小摩托车； $0.5 \%$ 的家庭有三轮摩托车, 并把其用作商业 用途; 还有 $5.5 \%$ 的家庭没有自行车, 也因此没有运输工具。

共计 $67.5 \%$ 的家庭拥有电话（27个家庭拥有两部或两部以上的电话），32.5\%的 家庭没有电话（家里没有手机）。 


\subsection{4 慰涊企业及其工作环境}

慰菏企业内部有多个子系统：家庭成员通常也是企业的工人，个体慰淴户通常提供 衣物尉淴服务, 他们的客户端是需要他们提供尉淴服务的客户。

个体经营部门是一个有用的概念, 它帮助个人和机构创造就业, 并对制约该过 程的政策环境展开分析。慰烫企业的地位是由大环境所决定的：包括自然环境、政 策环境和社会文化环境。这些因素影响了慰烫业当前的发展策略和未来的生存环境。

- 自然环境包括气候、季节、温度和基础设施

- 政策/制度环境 包括政府规章制度、政策、法律和政策框架, 研究与推广, 以 及相关支持服务。

- 社会文化环境 包括种姓、社区、宗教、文化、价值观和传统

\section{2 .5 慰衣工面临的挑战和他们的期望}

慰衣工面临的挑战反映出他们所在的微型企业承受着来自以下方面的压力:

- 令人难以忍受的（尤其在6、7月份）酷热;

- 工作地点缺乏配套的基础设施;

- 同行间的不正当竞争;

- 缺少顾客 (少数情况)

- 在街头做服装慰渏生意是违法的, 这给慰衣工造成了很大的困扰, 为了避免 被抓住, 他们只能四处躲鼌或者采取贿赂的手段以求生存。

对未来、对自己、对孩子，这些家庭都寄予了很高的期望。

- 大多数家庭 $(72.5 \%)$ 表示他们在德里的经济地位得到了提高; $63 \%$ 的受调 查家庭感到生活条件有了改善（比如能够得到类似水、住房和食物等方面的 基本生活条件）。

- 有关的职业选择调查问卷显示： $54.5 \%$ 的人打算继续从事自营慰恣个体经 营, 而 $22 \%$ 的人则向往得到政府部门等正式部门的工作。另外 $16 \%$ 的人希望 从事其他行业，如干洗服务。

\section{对子女未来的期望}

他们希望自己的子女能拥有更好的工作机会。当问及他们对于子女未来生活的展望 时, 我们发现:

- 他们中的大多数 $(42.5 \%)$ 的人希望子女可以继续从事尉资企业的经营, 因 为这是被调查家庭的传统谋生方式。他们认为慰渴企业为子女提供了足够大 的发展空间。 
- 很大比例 $(32 \%)$ 的家庭希望自己的子女以后可以在正式部门工作, 能够在 政府部门找到稳定的工作。因此，他们都把自己的子女送进学校接受教育。

- $10 \%$ 的家庭希望子女能够从事与慰烫相关的工作如干洗生意。

- $4.5 \%$ 的家庭希望子女能够转行, 从事其他技术性工作。

- $11 \%$ 的家庭表示没有考虑过这个问题。

\section{3 产品服务系统的可持续性}

企业必须具备产品服务体系所要求的三个重要因素。这三个因素分别是：外部影响 (环境要素)，利润（经济要素）和人（社会要素）。

企业就是一个由家庭、种姓和利益共同导向的服务机构，原因在于：

- 低廉的创建和运营成本;

- 工具（包括尉斗、木炭、电器设备、慰衣板、自行车等）维修成本低, 对产 品（慰涊衣物），工作材料和工作进展，以及亲属/家庭成员的工作所需承担 的责任小。

- 有时用自行车运送客户的服装。

- 为客户提供慰淴服务的费用是：每件衣服2.00-5.00卢比（0.035-0.89欧元）。

- 每月收入为 6,435 卢比 2

企业的可持续性包括以下几个方面:

企业在运营过程中不产生垃圾

- 慰斗非常坚固耐用, 慰衣工在使用慰斗时力求效率的最大化（比如当慰斗温度 很高时，工人慰菏棉质衣物；当温度适中时，工人慰烫混合纤维质衣物）。慰 㳷服装工作不会因为燃料而产生垃圾, 并且尉衣工对于垃圾管理非常敏感。

- 尉渏服务是一个生态高效的系统, 交付衣物的过程中不需要大量运输工作; 这是因为尉㳷企业大多都是在同一个街区或只为邻近的居民提供服务, 店面 通常就在居民区附近。因此, 慰浈企业不需要消耗汽油。他们通常采取步行 或骑自行车的方式上门收取和送还客户的衣服。收取或送还服务的方式都被 设计的非常方便。所以运送衣物过程不存在运输成本。

- 企业宣传通过口口相传的方式完成：无需印制宣传册进行广告宣传。

2 根据2010年5月17日的汇率计算, 约为 114 欧元。 


\section{满意至上的客户服务关系}

慰沕是服务型工作, 目标是让顾客满意。每个家庭都需要一位手艺精湛的可靠慰衣 工提供衣物护理服务。

- 熨衣工尽心尽力为客户服务, 也因此会拥有很多忠实的老客户。

- 他/她得到了客户的信任和很高的服务满意度。

- 这主要得益于他们精准无误的服务、合理的价格和准时的递送系统。

- 他/她们稳重、有条不紊、对人友善; 他们的态度恭敬有礼, 令客户满意。

- 慰渴企业现在都用手机联系新老客户, 以保证稳定的客户量以及保持良好的 客户关系。

\section{通过移动通信优化资源并提升价值}

移动通讯给企业提供了一个方便的网络结构, 使它们能够将业务集中在很小的区域 范围, 拥有可承受的工作和业务量, 因而可以获得合理的利润来维持其可持续经营。 越来越多的慰衣工出于工作原因, 或社交原因使用手机。他们也通过手机娱 乐、玩游戏、听广播; 把手机作为获取信息、新闻的工具; 用手机联系医生、补习 教师和护士等等; 他们还用手机参与广播电视竞赛, 甚至还用手机照相。调查发 现, 慰衣工使用手机, 主要是为了联系家人和朋友, 联系业务倒在其次。熨衣工认 为手机有很多优点, 可以存储工作和生活中重要人物的联系方式, 比如医生、护 士、补习教师或者是警察。这在突发情况中能发挥巨大作用。

慰沕服务的管理和运营是经过系统化设计的，它为居民提供便捷优质的衣物慰 渴服务, 高效且守时。慰渴企业能够应对突发情况和特殊场合, 比如婚礼和长途旅 行都要准备很多衣物, 这个时候就是那些未经过正式培训但是经验丰富的熟练慰衣 工大显身手的时候。

\section{企业反映了印度文化和印度人的特点}

提供衣物慰淴服务而获得收入, 属于传统型的微型企业。

- 慰㳷服务推动了棉质衣物的广泛应用。棉织物在印度批量生产, 物美价廉, 也非常适合印度的天气环境。

- 因此, 衣物慰沕服务成为印度文化的重要组成部分。

- 作为一种产品服务系统, 慰汮行业为印度广大非正式部门的贫困移民家庭带 来了可持续发展的机遇。它为众多的文盲和无专业技能的家庭提供了赚钱的 机会, 使他们能够通过合法的渠道养家糊口。

- 所有家庭成员在一起工作, 这使他们之间得以建立起一种互相照顾的亲密关 系。 
- 由于所有慰衣工人都是工会成员, 慰烫行业为他们的领导力提供了锻炼的机 会。

- 慰衣工和他们的客户之间建立起了相互支持的关系。他们的客户中可能有受 过高等教育的专业人士、生活富裕的小康家庭等。

\section{4 结论与未来产品服务系统的介入}

显然, 慰衣工可以作为可持续性产品服务系统的一个典型案例。尽管产品服务系统 的思想和可持续产品服务系统（PSS）设计有助于进一步改善尉烫企业的核心经营 活动和结构。从理论上讲, 产品服务系统干预还有助于将本案例和许多例子纳入到 正式教育的课程设置中。因此，产品服务系统可以被纳入到以下领域：

- 可以对两种类型的尉斗进行改进, 使其成为更具生态效益、价格更加低廉、 更轻便、更节能高效的慰烫工具。

- 需要考虑到服装储存和组织方面的设计。

- 政府要保障尉衣工在街头工作时不被骚扰, 并且要承认他们是非正式部门的 一个组成部分。

- 必须意识到：城市贫困问题并不单纯是由于农村贫困人口的过度涌入造成 的, 同时也需要为城镇发展制定更为包容的规划, 进一步出台解决城市贫困 问题的国家战略。

- 这对逾越数字鸿沟, 缩小城乡差距、解决人口迁移和城市贫困问题都是至关 重要的。与此同时, 手机已经对慰衣工的社会和经济生活, 以及他们企业的 收入产生了越来越大的影响。

\section{参考文献}

Aiyar, S. (2009, September 28) 'India's Best \& Worst States', India Today 44.

Majumdar, N.A. and V.D. Lall (1992) Satellite Banking and Micro Business Development Corporation for Financing the Informal Sector (Society for Development Studies, New Delhi).

Mead, D.C. and C. Leidholm (1998) 'The dynamics of micro and small enterprises in developing countries', World Development 26(1): 61-74.

Ministry of Housing and Urban Poverty Alleviation (2009) India: Urban Poverty Report 2009 (Government of India, with support of UNDP, http://www.undp.org.in/index. php?option=com_content\&view=article\&id=538\&ltemid=568, accessed 18 August 2009).

National Institute of Urban Affairs (NIUA) (1991, December) Women in the Urban Informal Sector, Research Study Series (49) (New Delhi): 65, 323, 324. 
Sarin, A. and R. Jain (2009) 'Effect of Mobiles on Socio-economic Life of Urban Poor', www.esocialsciences.com/data/articles/Document1275200950.4425165.pdf (accessed 9 January 2013).

Sharma, U. (1986) Women's Work, Class, and the Urban Household-A study of Shimla, North India (London and New York: Tavistock Publications).

UNEP (2002) 'Product-Service Systems and Sustainability Opportunities for Sustainable Solutions', http://www.unep.fr/scp/design/pdf/pss-imp-7.pdf (accessed 13 October 2012). 


\section{可持续工作, 可持续生活 城市园艺项目对印度贫困儿童的 影响}

基诺斯纳 ·白利阿帕（Jyothsna Belliappa），艾莉森·伯恩（Alison Byrnes） 和普莱拉斯 ·埃比纳夫 (Prayas Abhinav) 印度斯瑞施蒂艺术、设计与科技学院 (Sristhi School of Art, Design and Technology, India)

\section{1 引言}

城市Spinning项目指的是一个印度都市园艺实验, 目前它已经在两个印度城市创建了 社区网络。它是一个典型的低成本、资源节约型项目, 它把所有权和消费分离- 这是有效可持续性产品服务系统的一个基本标准。斯里尼瓦桑（Srinivasan）和瓦拉 达拉雅（Varadarajan） (2003) 认为, 产品服务系统在印度、中国、巴西等新兴 经济体中是利用传统非正式服务关系获得的财富, 而非不加鉴别地从现代工业制造 模式中擢取财富。城市Spinning计划并非建立在传统非正式企业服务关系（例如中 产阶级家庭和街头小贩的关系）的基础之上。该计划认为, 这种非货币化的非正式 交换模式可以帮助城市社区中的穷人和富人可持续地保证基本需求（食物）的自给 自足, 因此, 这个项目被作为一个可持续性产品服务系统的案例。其中贯穿了食品 安全、就业机会和社会凝聚力等内容。通过对此案例进行分析, 我们推荐一个更加 有趣、更加艺术化的产品服务系统 (PSS) 设计。这项设计能够充分发挥人类的潜 能, 并鼓励边缘人群在分享和管理资源方面共同承担责任。通过采用玛莎 - 努斯鲍 姆 (Martha Nussbaum) 的能力方法对这一项目的效果进行评估, 我们尝试证明从 发展经济学和政治哲学中衍生出的能力方法和可持续产品服务系统的设计方法从理 论上说是可行的。 
我们需要从印度当代社会经济史的角度, 对城市Spinning项目进行更深一步的 解读 (项目以此命名的原因在于它提倡一种能使城市中不同群体相互联系, 形成互 惠关系的发展方式）。在20世纪早期印度争取民族独立的运动中, 领袖们对于印度 (未来) 的经济发展设计了各种不同的模式。第一种模式的灵感来自甘地的哲学思 想。它支持小型、低成本技术, 强调加强乡镇的经济发展和自给自足的能力, 同时 限制消费和支出。这一模式反对大规模工业化建设、消费和对进口的依赖（然而应 该注意的是, 甘地并非像人们所认为的那样完全反对所有形式的工业化或机械化, 甘地思想的详细内容请参见《印度自治》[Gandhi 1910]）。

第二种模式, 是尼赫鲁 (Nehru) 模式, 主张在发展重工业的同时发展社会主义 经济。在经济发展过程中, 国家始终控制着国民经济重要行业和关键领域。印度独 立后, 社会主义模式一直沿用了 30 多年。政府建立并管理着大型的公共部门, 并通 过许可机制和进口限制等一系列措施实现对私人企业的控制。然而, 在 20 世纪 90 年 代初, 伴随着新自由主义改革, 上述许多限制都被取消, 政府也从一些主要部门退 出, 这为私营企业的发展注入了动力。其中, 人们对消费态度的转变更为明显。帕 凡. 瓦尔玛 (Pavan Varma) (1998) 认为, 甘地的紧缩政策和尼赫鲁的社会主义 政策都为同一种观念让路。这种观念认为：高水平的消费能促进国家经济的发展。 从那之后, 印度经济迎来了大繁荣, 并且与其它新兴经济体如中国和巴西一道成为 全球重要的市场。地位不断上升的印度中产阶级经常从所谓的“发达”国家（有着 完善的工业化资本主义经济的国家）的消费习惯中获得启示。这些发达国家的生活 方式通过媒介的宣传和外国特许经营的方式被不断地引进印度。

根据主流的经济学观点（倾向于公司和股东的利益），较高的消费能力已经成 为经济发展的标志, 也成为人们追求的目标, 消费能力低下则被认为是贫穷和 “欠 发达”。为了向 “发达” 经济体看齐, 这些新兴经济体试图达到更高的消费水平。 然而, 具有讽刺意味的是, 这种努力却造成了负面的后果。他们所仿效的经济发展 模式, 越来越被认为是不利于环境可持续发展, 并可能导致社会和经济方面的不平 等。目前, 为了追赶发达经济体, 班加罗尔、德里和上海等城市都在不断完善自己 的基础设施、服务行业、交通和通讯。然而, 盲目地追赶很可能会导致未来环境不 稳定、社会两级分化等负面效果。

在这一背景下，一个包括社区建设、园艺及重建“废弃空间”等一系列实验活 动的城市Spinning项目应运而生。这是一个公共艺术项目, 2008至2009年间在印度 的两座城市: 班加罗尔和德里开展。在本章中, 我们主要关注城市Spinning项目的核 心实验 “Pett Puja”（印度语中“填饱肚子”的意思）活动。本章会涉及到由本章 作者之一普莱拉斯 ·埃比纳夫 (Prayas Abhinav) 最初设计的一款产品。该款产品是 一个竹制的顶棚。那些无家可归的“街头” 流浪儿可在竹棚下玩耍, 或栽种蔬菜, 而成人则把它当作茶馆, 还有些人把这里当作一个表演的场所。可能该项目表面上 收获的只是一些由孩子们栽种的蔬菜所做成的食物, 但实际上, 社区居民的联系的 加强和利益相关者自主意识的提高才是该项目最重要的收获。作为一个产品服务系 统 (PSS) 项目, 城市Spinning项目促进了产品和服务的整合。尽管该系统在给服务 提供者和接受者双方都带来益处, 但并不能产生直接的经济利益。不仅如此, 这个 项目具有多重的社会、生态、经济和政治影响。我们运用玛莎·努斯鲍姆 (Martha Nussbaum) 的能力方法 (capabilities approach) 对这些影响进行了详细的研究。 
我们认为, 扶持并培养个人和团队的能力, 能够使他们在社会和经济事务中发挥更 大的作用。因此，在讨论项目结果之前，我们首先简述一下努斯鲍姆 (Nussbaum) 能力方法的基本原则。

\section{2 通过 “能力方法” (capabilities approach) 来了 解人类需求}

能力方法 (capabilities approach) 是由阿玛蒂亚·森 (Amartya Sen) 和玛莎 · 努 斯鲍姆 (Martha Nussbaum) 提出的 (1993)。能力方法 (capabilities approach) 是一种衡量社会发展的另一种方法, 它与占主导地位的把GDP和家庭收入作为衡量 社会发展指标的方法有所不同。森（Sen）反对把资源、收入和商品（产品）效用 作为衡量人类发展的指标。他认为，应该从特定人口的个体状态和行为中寻找更有 意义的衡量指标, 例如, 健康、教育、自由流动、政治参与、远离暴力和饥饿等。 能力方法也被称为是人类发展方法, 这种方法很受发展倡导者的欢迎, 因为它引出 了关于分配公平的问题（根据需要和情境因素, 如社会伦理的可持续发展维度等进 行的资源分配），并且强调了非金钱方面的福祉的重要性。能力方法认为，如果有 来自外部适当的支持, 个人就能够创造自己的未来。能力方法的提出摒弃了对产品 所有权的重视, 转而将关注点放在如何通过对社会参与者进行授权（赋予某种能 力）来使他们获得满足, 这也非常符合当代产品服务系统的观念（曼齐尼 (Manzini) 2006 2010; 纳拉亚南 (Narayanan) 2010; 山士恩 (Ceschin), 维佐里 (Vezzoli) 和金吉尔 (Zingale) 2010)。

森 (Sen) 并没有对一系列的能力进行定义, 而只是对能力提出了一个框架。 在这个框架中, 只有根据具体的背景才能对相关能力下定义(参见森 (Sen) 和努斯 鲍姆 (Nussbaum) 1993)。相反, 努斯鲍姆 (Nussbaum 2007) 则对一系列能力进 行了明确的定义。努斯鲍姆认为, 可以基于这些能力, 制定公正的宪法原则, 确保 社会公正。这些能力包括生命权; 健康和身体不受侵害的权利; 感官和想象力; 情 感; 娱乐; 实践理性或判断是非的能力, 以及规划人生的能力; 掌握自身政治和物 质环境的能力, 以及处理与他人关系的能力ー一包括集会自由, 言论自由, 关心和 支持别人的自由, 以及被人尊重, 不受歧视的权利。努斯鲍姆 (Nussbaum) 把她的 理论用于观察边缘群体（如印度贫困的女性）进行斗争和争取胜利的过程。她的著 作被批评为过于程式化和普救主义- - 她反驳说, 她的理论只是建议性的, 每个国 家可以根据他们的社会文化环境和历史传统, 把能力方法融入到各自的社会体制中

(努斯鲍姆 (Nussbaum) 2007)。

在本章的下面两节中, 我们将运用城市spinning计划所支持的能力方法的观点对 其进行研究。这里提及的能力方法的框架是贯穿在社会伦理（人民）可持续维度中 的（曼齐尼(Manzini ) 2006)。它不仅试图帮助城市贫穷的儿童满足他们的营养需 求, 而且还致力于达到一定程度的社会公平, 同时让被边缘化的社会群体能够与社 区成员进行交流互动，而社区成员可以为他们提供一些东西（例如汤）。 


\section{3 城市Spinning}

城市Spinning行动的第一个活动是Pett Puja项目。“Pett Puja” (字面的意思是印 度语中的 “民以食为天”，比喻填饱肚子）的目的是使边缘化群体和德里城市中受 歧视的 “街头流浪儿童” 更能适应德里城区的生活。这一项目由就读于斯瑞施蒂艺 术、设计与科技学院 (Srishti School of Art, Design and Technology) 的研究生埃 比纳夫 (Abhinav) 提出。最初, 这是一个关于艺术介入社区的实验项目（属于学历 课程要求完成的内容），然而这个项目越做越大，现在已经远远超越了其最初的设 想。它还激发了在班加罗尔和德里开展了一系列其他相关实验。Pett Puja项目的灵 感来自埃比纳夫（Abhinav）自己在城市中生活的孤立感，这使他开始思考如何在不 同的城市社区之间展开互动。通过Pett Puja项目, 孩子们学会种植蔬菜, 也愿意与 团体中的伙伴们分享自己的劳动成果。菠菜和其他蔬菜都种在垂挂在竹棚上的篮子 里（详见图8.1）。这些竹制棚屋从2008年12月12日至21日被搭建在德里繁华的贾玛 清真寺 (Jama Masijid) 的停车场中。当孩子们收获了足够多的菠菜时, 便为街道商 店的老板和行人举办 “热汤聚会”。这样他们可以深入社区, 照看菜园, 并结交到 更多的朋友。这种街道聚会使人们能够在社区内相互分享食物。它的灵感实际上来 源于锡克教的langar（社区厨房）概念, 它能够在加强社区凝聚力的同时有助于保障 弱势个人和团体的食品安全。Pett Puja项目借鉴的是一个根植于当地文化遗产的模 式（而不是在局促环境中的各个分散的文化背景下，重新构造的模式）。这是产品 服务系统在新兴经济中获得成功的一个关键因素（斯里尼瓦桑 (Srinivasan) 和瓦拉 达拉雅（Varadarajan）2003; 皮宁 (Penin) 和维佐里 (Vezzoli) 2004)。

\section{图8.1 “Pett Puja” 结构}

来源: 作者
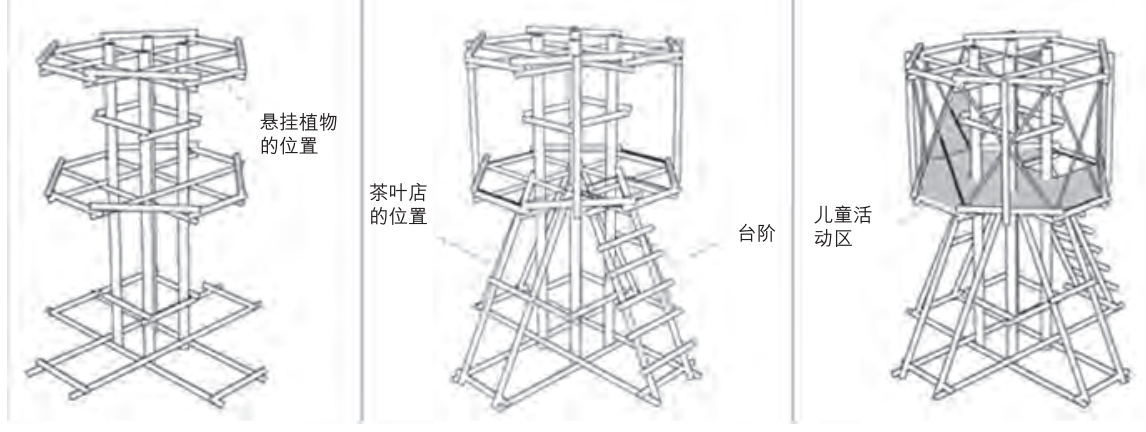

该项目还带来了一些埃比纳夫意料之外的益处。竹制棚屋还吸引了附近学校的学 生, 他们也参与到种养植物的活动中。因此, 花园不仅得到来自多方面的 “照料” , 它也成为附近中产阶级和下层中产阶级家庭的子女共享的游乐场地。没有这个竹制 棚屋之前, 这两个群体之间没有任何交流互动。棚屋下面开了一间茶馆, 由于地理 
位置优越, 它吸引了很多顾客的光顾, 这也给店主（一个失业青年）带来了收入。 店主说他愿意照料花园和棚屋并照顾在这里玩要的孩子们。其他街上的商贩也开始 偶尔在棚屋下摆摊。棚屋也成了当地艺术家表演的场所, 这既为茶馆招徕了生意, 同时也为那些之前没法欣赏艺术表演的流浪者群体提供了观看表演的机会。因此这 个项目扩大了成年参与者的谋生的机会。然而它真正的价值还是体现在流浪儿身 上。在这个把他们遗弃的城市环境中, 竹棚为儿童们提供了一个安全的空间。

作为一项毕业设计, Pett Puja项目虽然受到项目时间的限制, 但它可以很容易 地被应用到不同的城市场景中。该项目还触发了一系列相关项目: 班加罗尔举办了 一个交流活动, 在这项活动中, 孩子们通过讲故事, 换取食物和其他物品。他们的 故事被记录下来并且被重新编辑, 用于教学和艺术表演等。在班加罗尔的一个国际 性赛事活动中, 艺术家设计了一些与上述竹棚相似的场所, 为班加罗尔城市空间提 供了一些临时的流动文化场所。德里的街头流浪儿参与了一项绘图活动, 即在图上 标出与他们相关的资源（用以遮风挡雨的树木、玩要场所和水果等）的位置。那些 历史留下来的能够对社会融合提供支持的资源现在又重新引起了人们的重视。一个 位于班加罗尔的废弃旧建筑工地, 被重新改造成孩子们的玩耍场所。在这里, 来自 不同社会经济背景的孩子们可以一起玩耍聊天。

\section{4 该项目的社会与生态效益}

任何儿童都需要有一个安全的玩夏空间, 需要与其他市民一起参与社交活动、培养 他们作为社会公民应具备的能力（例如责任感、合作意识和自我表现的能力）。在 大多数印度城市, 儿童的娱乐空间都被限制在设有边界和围栏的操场和公园。由于 不可预测的交通情况和担心交通事故的发生, 家长都不允许孩子在家门外的小巷里 玩耍。公园在建设过程中, 政府通常没有考虑到孩子们玩耍的需求。这些公园尽管 被法律规定为 “公共场所”，但只有中产阶级或上流社会的孩子会在家人、保姆或 者年长的兄弟姐妹陪伴下进入。公园和操场几乎不允许街头流浪儿童进入。

通过建立一个无人监管、制度宽松的娱乐空间, Pett Puja项目能够激发孩子 的创造力, 并使他们能有机会观看并参与到艺术表演中。该项目提高了儿童的活动 能力、情感表达能力、感知和想象力, 以及处理人际关系的能力（见8.2节中关于 努斯鲍姆 (Nussbaum) 的内容)。尽管开展的时间有限, 但该项目仍然为街头流 浪儿童提供了一个玩耍空间。尽管这个项目不能完全满足他们所有的社会和娱乐需 求, 但也确实为孩子们找回了一种归属感。不仅是棚屋本身, 而且棚屋下这块小 小的地盘, 成为这些孩子们所熟悉并对他们有亲切感的地方。为了找到使产品服 务系统变得更有吸引力的方法, 山士恩 (Ceschin), 维佐里 (Vezzoli) 和金吉尔

(Zingale) (2010) 主张通过产品服务系统 (PSS) 设计, 创造娱乐、社交和加强 社会联系的机会。Pett Puja项目正好具备了这样的功能, 除此之外它还有另外的作 用, 即培养年轻参与者的能力。

因此, 这个项目鼓励被边缘化和疏远化的人群（通常是指那些乞讨、青少年犯 罪和行为不端, 及欺负盘剥他人等行为有关的人群）中重新建立起一种可持续并对 
社会有益的生活方式。这些脆弱的城市贫民并没有被视为国家福利或者中产阶级慈 善事业的 “受益者”，他们已经成为所在社区变革的促变因素。我们可以通过树状 映射图来认识他们所具备的资源和能力, 这将促使城市、环境资源, 及其与贫困儿 童关系进行重组, 这也有助于加强他们的自我价值意识, 因为他们对于这个城市的 认识和理解对城市的发展也起着重要作用。

Pett Puja项目通过鼓励儿童与社区居民分享自己的成果, 缩小了城市贫民和中 产阶级之间的距离。该项目鼓励这两个团体以不同于以往的、一种更加平等的姿态 去相互交流, （过去这两个群体之间的互动仅限于中产阶级在非正式部门为城市贫 民提供就业岗位）。另外，通过让孩子们共同参加游戏和照看花园，该项目也促进 了中产阶级和贫穷儿童之间的互动。流浪的贫困儿童可以和那些家境优越又备受呵 护的中产阶级儿童分享那些他们所不熟悉的技能和资源。这样的互动强烈地冲击了 深深根植于人们头脑中的关于阶级、收入、生活方式，及（正规）教育的等级观念。

这个项目也加强了成人与儿童之间的互惠关系, 这种关系使儿童不再只是成年 人关怀怜悯 (或烦恼) 的对象, 而是进一步成为有能力积极参与社会事务的群体。 成年人与儿童群体的划分一直是存在争议且具有不确定性。有的时候儿童所能够 获得的知识、理解和资源成年人未必能得到（瓦伦丁 (Valentine) 1997）。瓦伦丁 (Valentine) (1997) 认为, 就像成年人有时会做出一些 “幼稚” 的举动一样, 儿 童有时也会像个成年人一样表现得沉稳老练（如展示理性、有自我意识和成熟）。 通过了解儿童的知识、资源和想法, 该项目对成人和儿童群体重新进行了分类。

与环境科学中的主流教育课程相比, 城市Spinning项目在倡导年轻市民参与具有 生态效益的社会活动（食品安全和社会凝聚力）方面获得了更大的成功。印度的学 校教育一贯提醒学生关注环境问题（比如全球变暖、水资源短缺、水污染和全球能 源危机）。学校会通过一个 “告知、教育和警告” 模式来教育学生, 帮助改变他们 的行为方式。从长期效果来看, 与那些具有良好生态效益的, 旨在提高个人满意度 和加强社会联系的方法（如不同社会经济群体共同治理公园,并且共同分享因此带来 的良好效益）相比, 这些方法的效果并不理想。但不经意之间, 这个项目培养了儿 童无私的品德和有利于环境可持续发展的生活行为。

在生态学方面, 城市Spinning项目利用城市的闲置空间种植作物, 缩短了生产和 消费二者之间的距离。食品安全问题这一城市贫民社区的头等难题也得到了有效改 善。城市Spinning项目可以补充孩子的饮食需要, 这减少了他们在食物方面的开支, 可以将省下来的钱用于购买其它的生活必需品。尽管该项目没有完全解决孩子们的 营养需求, 但至少这些远离化肥和农药的纯天然绿色蔬菜, 给他们提供了身体成长 所必须的营养。

城市Spinning项目还促进了闲置的不美观的空间（如停车场和废弃的建筑工地） 的创造性再利用。它向人们展示了城市空间再利用无需依靠昂贵的, 不可持续的资 源密集型新项目的建设。这一项目为如何促进低消耗（即无需建设俱乐部会所和娱 乐中心）的社区互动提供了一个很好的例证。约翰·萨拉卡（John Thackara 2010: 31) 认为, 街头的热汤聚会有利于居民共享食物、技能和地方性知识, 这是“可持 续性设计的核心任务”。因此, 它使两种经济能够共生: 茶馆的商品经济和邻里间 食品交换的非商品经济。 
埃齐奥 ·曼吉尼 (Ezio Manzini) 认为, 可持续解决方案与目前占主导地位的 各种方式有所不同, 它减轻了环境影响, 同时支持一种新的更有利于加强社会联系 的方式（2010：14）。Pett Puja项目中使用的棚屋利用的是当地材料（竹子和麻 绳）制作的廉价的临时性建筑。设计过程依靠本土技术，建造和拆卸也都非常方 便。装配和运输过程不需要投入大量的劳动力, 也不需要熟练的工程技术人员。该 建筑非常简单, 本身造价也不高, 却是环境可持续技术的一个典范。然而, 作为社 区园艺、娱乐和表演中心, 其附加的社会和文化含义对周围社区更是产生了无形的 影响。它重组了社区内和社区间的关系, 并且对公共空间进行了再利用, 使其能够 满足个人和社会互动的需要。通过将情感（非商业性的）、交换活动和艺术表演三 者相互融合的方式, 在不同社会群体之间建立联系, 有助于促进城市社区的和谐发 展。在这个人与人相互疏远、庸俗和丑陃的环境中, 人们通过自身的劳动创造愉 悦、友爱和快乐, 这使市民在这个公共空间中重新融入社会, 找到归属感。公共环 境逐渐被个性化, 其危害性也因此降低了。

这一项目对当代社会生活中僵化的二分法提出了挑战：工作和娱乐间的二分 法, 商业的和非商业间的二分法, 艺术和实用间的二分法。它对一些与城市生活相 关的，且被大众认为理所当然的观念提出了质疑：一个人必须通过工作赚钱来购买 食品的观念, 儿童在公共场所玩要不安全的观念, 以及不允许 “与陌生人说话” 的 观念。这一项目对公共空间进行重新定义, 使其成为各年龄段市民都能开展互动, 共同创造有意义的社会、经济和文化交流关系的地方。通过对停车场或建筑工地创 造性地再利用和改造, 该项目创造了一个可以享受惊喜、快乐和友情的体验空间。

\section{5 设计中关注人类的需求和能力}

城市Spinning计划对努斯鲍姆（Nussbaum，2007）所提出的部分基本能力提供支 持: 身体健康, 娱乐和社交能力。同时, 它也使其他能力得到发展, 比如健康, 对 环境的控制, 建立友好人际关系以及保持良好的情绪。通过参与这个项目, 无家可 归的孩子能以更多不同的方式设计他们的未来和生活, 理解他们能够为社区做出贡 献的价值, 并且培养他们的自尊和自我价值观。该项目并没有解决孩子们所需的所 有生活需求, 如基本营养（非补充性营养）、洁净饮用水、足够的医疗保障和（正 规）教育。但是该项目在提高孩子们上述能力方面产生了重要的影响, 使他们能认 识到他们也是对社会有有益的群体。

根据努斯鲍姆 (Nussbaum, 2007) 的能力方法论, 玛丽 · 克拉克 (Mary Clark, 1994）阐述了在 “人类需求” 框架内的可持续性问题。克拉克（Clark, 1994）强 调了与他人分享世界观以获得安全感的重要性。群体归属感是十分重要的, 因此, 当自己的群体面临威胁时, 个人就会产生强烈的恐惧感, 甚至会产生暴力行为。与 群体归属感一样, 个人自主性也是一项需要被满足的基本人类需要。因此, 个人自 由和群体的整体协同并不是相互对立的, 二者共同构成了社会稳定的基础（克拉克

(Clark) 1994：181）。在可持续性的框架之中, 克拉克（Clark）认为, 如果以 
上条件得不到满足, 人类社会将倒退, 并且会存在“与周围环境格格不入的社会行 为，从而导致环境破坏”（克拉克（Clark）1994：182）。

争夺资源而引发的冲突往往是造成这些与社会环境不相适应行为的原因。而克 拉克（Clark 1994）认为, 南部新兴经济体中, 日益活跃的当代新自由主义社会的个 人主义正是这种冲突的具体表现。正是这种个人主义加剧了对资源的竞争。对于街 头流浪儿童, 这种资源竞争可能表现为偷窃或其它反社会行为。当个人被社区疏远 时，他们就会想尽办法获取稀缺资源。如果个人不把 “他人”当作自己的同类，也 就是说, 不与他人发生任何社会联系, 那么这样的人就容易为了获取资源而违反社 会规范。相反的, 如果视他人为自己的同类, 这样的人往往会表现得相对更无私一 些。

Pett Puja项目充分利用这种人类的固有特性, 鼓励个人与他人分享经验。参与 到这个项目中的儿童第一次与普莱拉斯 (Prayas) 进行互动。在互动中, 普莱拉斯 (Prayas) 得以了解他们, 并决定把棚屋赠送给他们。后来, 通过在花园里共同劳 动、耕种作物以及制作和分发热汤等活动，他们进一步拓展了他们自己的小社区。 近邻的中产阶级的孩子们看到了这个围绕植物种植展开活动的多功能社区, 也自发 地参与其中。因为人与人之间这样有意义的互动（无论是基于建设性的或破坏性的 互动）无疑都具有非凡的吸引力。茶馆老板和街头表演艺人也因此有机会加入到这 个社区之中。

正如努斯鲍姆 (Nussbaum) 和克拉克 (Clark) 所提倡的那样, 从发展的角度 来关注人类的能力和需求是十分重要的, 因此从设计角度来看, 一直以来都特别强 调这些价值。理查德 - 步凯纳 (Richard Buchanan) 对设计的功能更是大加赞赏, 认为 “当人们在不同社会的经济、政治和文化环境中展现自己的生活时，设计“支 撑并加强了人类的尊严” (2000)。他指出, 设计应该以人为本, 而非以用户为 本。这两个概念间细微的差距在于关注人类的生活, 而非仅仅以设计来迎合终端用 户的需求。从这个角度看, Pett Puja项目中的棚屋可谓是以人为本设计理念的一 个典型代表。尽管项目时间有限, 但是棚屋设计极大地提高了人们的生活质量（以 及邻近社区居民的生活），远远不只是为儿童提供了娱乐的空间。伊尔斯 · 欧斯特 拉肯 (Ilse Oosterlaken) (2009) 做出了与步凯纳 (Buchanan) 相似的论断：为 发展中国家设计发展方案时, 运用以能力为中心的方法是至关重要的。欧斯特拉肯

(Oosterlaken) 倡导参与式的设计方法。他认为这种方法考虑到了会影响人类幸福 生活的多个不同方面的需求、能力和环境。本章主要讨论能力方法是如何促进设计 实践的。我们已经讨论了能力方法被用于进行回顾性评估。另外, 它也可以用来作 为整个设计过程的指导方针。设计伊始, 设计师需要思考, 如何使他们的设计能够 支持人类能力的发展, 并在设计过程中不断继续思考该问题。然而, 不应该让这种 做法限制设计过程。我们应当牢记, 设计经常会产生出乎设计师预料的结果。

\section{6 结论：产品服务系统经验教训}

有这样一个问题产生了: 产品服务系统 (PSS) 设计从城市Spinning项目中获得了什 么经验教训? 为了回答这一问题, 首先我们应当要问: 这一项目是否获得了成功。 
这个项目周期短而且资金不足，许多结果只造成短期影响。项目结束后，街头流浪 儿童也许不会再对园艺感兴趣, 重新开始乞讨甚至偷窃食物, 中产阶级的儿童很有 可能重新回到他们所属的社区, 茶馆主人和其他摊贩则有可能受到街头罪犯和警察 的持续威胁, 继续过着不安定的生活。然而, 实验的成功和人们热情的参与表明, 如果这个项目能长期进行下去, 一定能获得成功。

当该项目能继续开展时, 面临的主要挑战在于如何寻找种子资金。埃比纳夫 (Abhinav) 相信筹集资金的最好途径是通过给街头摊贩群体或是代表儿童利益的非 盈利团体提供小额信贷。只要资金到位, 项目的运营就可以自行维持下去。另一个 挑战可能来自当地政府官员，他们总是对街头摆摊持怀疑态度; 应当说服政府给项 目提供充足的空间并减少对这些项目的干预。政府认可和融资也会有其局限性, 可 能会呈现等级化、官僚化以及僵硬化等缺陷。我们要努力确保项目的有机性、直观 性, 并使其充满情趣。

在较短的项目运营周期内, 该项目成功地为居民的娱乐、合作和谋生提供了空 间, 但我们不可以凭借如此短的周期来评估其长期影响。不仅如此, 这一成功也应 归功于埃比纳夫 (Abhinav) 对该活动的热忱和初期他与儿童建立联系的能力。这一 项目的成功也受到他个人性格的影响。因此, 在能够对项目的效果进行评估之前, 由不同发起人开展这些项目是非常有必要的。除此之外, 产品服务系统 (PSS) 设 计项目也积累了一些有用的经验教训。

作为一个可持续项目, 城市Spinning项目的成功源于以下许多因素。该项目规模 小, 成本低, 充分利用了现有资源。项目由当地人进行管理, 而那些拥有归属感的 人也都可以加入这一项目。因此它符合曼齐尼（Manzini，2010）所定义的当代可持 续发展计划的四项重要特征中的三项。这四项特征是：规模小、公开、本地化和具 有联系性。由于时间和资源的限制, 埃比纳夫 (Abhinav) 没有能够实现在整个城市 范围内创建一个相互联系的, 能够用于交换食品、商品和其他技能的Pett Puja棚屋 网络; 因此尽管项目确实创建了不同社区和团组之间的联系, 但具有联系性这一特 点并没有完全实现。

该项目的优点在于它具有娱乐性、趣味性和直观性等特点。与以往可持续发展 计划的常用方法不同，该项目没有为了达到预期目的而列举事实和数据使人们对未 来担忧, 也没有营造消费的负罪感。相反, 它运用一些对儿童来说相对简单易行和 轻松的方法来改变人们的行为。这些方法包括游戏、社会互动、讲故事和体育活动 等。能够敏锐觉察到年轻参与者的各种需求也是项目成功的关键因素。

通过这一实验收获的最重要的经验可能就是, 在没有严格遵循常规设计流程 的情况下, 产品服务系统项目如何保证其效果。埃比纳夫（Abhinav）运用的这一 套有机的、直观的以及结构相对松散的方法使项目超越了最初的设计, 展现了自身 鲜明的特点。这套方法对最终结果没有做预先设想和期待, 旨在促进各种关系顺其 自然地得到发展。在棚屋项目中, 利益相关方收获了出乎设计师意料的成果。在参 与过程中（凭直觉地而非有意识地参与），这种平等的参与方式很快地就使利益相 关者和用户都因为棚屋这个空间而产生了主人翁意识, 而这种意识跨越了参与者年 龄、阶层和生活方式的差距。尽管产品与最初设想基本相同, 但是随着时间的流逝 和系统的自然发展, 项目所能提供的多层次服务也发生了变化。这种情况在一定程 度上是有可能发生的, 因为没有投资者, 非政府组织或政府会在项目背后控制或影 
响其进程。因此, 在这一实验中, 产品服务系统 (PSS) 设计得到的另一个经验教 训是, 要重视终端用户对项目结果产生影响, 而不能仅仅关注设计项目资助方的影 响。自上而下的政府法令并不鼓励那些没有受到监督的活动。因此有信仰是很重要 的, 正如萨姆尔·赫斯 (Samuel Hess, 1998: 291) 所言：“一些公益事业也可以 在没有政府干预的情况下开展”。

\section{参考文献}

Buchanan, R. (2000) 'Human Dignity and Human Rights: Toward a Human-Centered Framework for Design', keynote presented at Design Education Forum of Southern Africa, Cape Town, February 2000.

Ceschin, F., Vezzoli, C., and Zingale, S. (2010) 'An aesthetic for sustainable interactions in Product-Service System?' In Ceschin, F., Vezzoli, C., and Jun, Z. (eds.) Proceedings of LeNS Conference Sustainability in Design: now! Challenges and opportunities for design research, education and practice in the XXI Century (Sheffield: Greenleaf Publishing).

Clark, M.E. (1994) 'Integrating Human Needs into our Vision of Sustainability', Futures 26 (2): 180-184.

Gandhi, M.K. (1910) Hind Swaraj, available from: http://www.soilandhealth.org/03sov/0303critic/ hind\%20swaraj.pdf, accessed 7 December 2012.

Hess, S. (1998) 'Individual Behaviour and Collective Action towards the Environment: An Economic Framework Based on the Social Customs Approach', Rationality and Society 10: 203-211.

Manzini, E. (2006) 'Design Ethics and Sustainability Guidelines for a Transition Phase' in Cumulus Working Papers, http://www.designmattersatartcenter.org/wp-content/content/ pdf/NantesWorkingPaper.pdf\#page=9, accessed 12 December 2012.

Manzini, E. (2010) 'Small, local, open, connected: design research topics in the age of networks and sustainability', in F. Ceschin, C. Vezzoli and J. Zhang (eds.) Sustainability in design: now! Challenges and opportunities for design research, education and practice in the XXI century. Proceedings of the Learning Network on Sustainability (LeNS) conference, Bangalore, India, 29 September - 1 October 2010 (Sheffield, UK: Greenleaf Publishing): 14-18.

Narayanan, G. (2010) 'Enactive Design: The imagination challenge for Indian design 2010', in F. Ceschin, C. Vezzoli and J. Zhang (eds.) Sustainability in design: now! Challenges and opportunities for design research, education and practice in the XXI century. Proceedings of the Learning Network on Sustainability (LeNS) conference, Bangalore, India, 29 September - 1 October 2010 (Sheffield, UK: Greenleaf Publishing): 19-24.

Nussbaum, M. (2007) 'Human Rights and Human Capabilities', Harvard Human Rights Journal 20, http://www.law.harvard.edu/students/orgs/hrj/iss20/nussbaum.pdf, accessed 22 November 2010.

Oosterlaken, I. (2009) ‘Design for Development: A Capability Approach', Design Issues 30 (4): 91-102.

Penin, L. and Vezzoli, C. (2004) 'Sustainable PSS Design in Emerging Contexts' in SusProNet Conference Information Product Service Systems, http://www.gv-ss.com/js/plugins/ filemanager/files/SusProNet_June_2004.pdf\#page=48, accessed 9 December 2012.

Sen, A. and Nussbaum, M. (eds.) (1993) The Quality of Life (Oxford: Oxford University Press).

Srinivasan, A. and Varadarajan S. (2003) 'Sustainable Development: An Indian Perspective' in Second International Workshop on Sustainable Consumption Proceedings, Tokyo, December 2003. 


\section{4 可持续产品服务系统设计}

Thackara, J. (2010) 'The pretending phase is over', in F. Ceschin, C. Vezzoli and J. Zhang (eds.) Sustainability in design: now! Challenges and opportunities for design research, education and practice in the XXI century. Proceedings of the Learning Network on Sustainability (LeNS) conference, Bangalore, India, 29 September - 1 October 2010 (Sheffield, UK: Greenleaf Publishing): 28-32.

Valentine, G. (1997) "'Oh yes I can." "Oh no you can't": Children's and Parents' Understanding of Kids' Competence to Negotiate Public Space Safely', Antipode 29 (1): 65-89.

Varma, P.K. (1998) The Great Indian Middle Class (New Delhi: Penguin). 
第三篇 推进社会可持续性创新的新方法 


\section{中国社会创新设计}

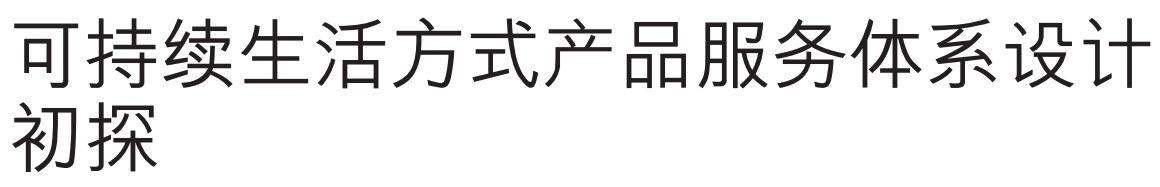

巩水森

中国江南大学设计学院

\section{1 中国的社会创新一一营造可持续的和谐社会}

中国正在把工作重心从经济发展逐步转移到可持续发展上来, 这是一个新的转变。 与此同时, 政府又做出一个新的决策一一创建和谐社会。面对这些紧迫的问题（环 境和社会），我们也期待美好的社会发展愿景（和谐社会），对于促进中国的可持 续设计研究和行动议程而言, 这是一个合适的时机。为实现可持续生活方式而进行 的社会创新是打开可持续和谐社会大门的钥匙之一。它通过自上而下和自下而上 的方式来体现。2006年10月16日、17日在北京举办的“国际社会创新会议” 具有 重要的里程碑意义。这是有史以来该行业第一次由英国文化协会 (British Council 2007) 、杨式基金会（Young Foundation）和中央编译局比较政治与经济研究中心 (CCCPE) 共同举办的重大会议。在此之后, 社会创新的发展获得政府机构的大力 支持。

此外, 自下而上的创新举措在中国层出不穷, 日新月异。很多有发展前 景的基层社会创新案例被广泛收集和研究, 作为创新社区CCSL项目（梅罗尼

(Meroni) 2007年），如社区支持农业（Community Supporting Agriculture），拼 车、团购、合作居住、老年互助服务、邻里互助、时间银行和重振自行车交通等。 
此种类型的案例不断涌现, 并扩散到许多不同地区, 融入到城市的日常生活中。

同时, 随着社会创新的不断开展, 一些新的现象, 如拼车（Car Sharing）、拼客

(Pinke)，团购（Group Purchase）、社区支持农业（CSA）也在中国蓬勃发展起 来。这些有良好的发展前景并富有创意的可持续生活方式在人们的日常生活中自发 地涌现出来。

以拼车为例, 这一服务体系把上班同路的有车一族和无车一族联系在一起。 它在服务参与者之间产生了一个共同的价值, 既改善车辆交通又减少了经济开 支。因此, 这一体系降低了交通的生态足迹并增加了社会参与性。比较一下中国 (CCSL, 2007) 与欧洲 (EMUDE, 2006) 的生活方式, 就会发现两国其实有许多 相同的服务理念, 只不过形成的背景各异。比如, 在中国 “拼车” 的人们主要考虑 的是经济因素而非环境问题。但是, 通过这些例子, 我们可以洞悉中国可持续生活 方式的发展（巩水栤等 2008）。因此, 提出更有前途的案例和举措, 可能会使中国 创建可持续社会向前迈进一大步。

\section{2 基层社会创新的设计实践}

为了更好地了解设计在促进基层社会创新（尤其是协作服务）方面的作用, 在过去 的几年里, 江南大学设计学院与米兰理工大学设计部门共同协作, 开展了一系列的 行动和研究项目。它们是以设计工坊的形式进行的, 其中, 中国学生同时与来自两 所大学以及其他合作团体的教授及研究人员共同开展协作。他们专注于特定的主 题, 每个项目团队针对中国可持续生活方式的具体服务体系提出一些新的建议。通 过这些尝试性的设计实践, 探讨设计师在产品服务系统设计中所扮演的角色, 以及 他们是如何开展工作的。

\subsubsection{Chita08：协作服务和移动通信}

CHITA08项目是意大利和中国两所设计学院教学和研究的合作项目。重点研究如何 在以产品服务系统设计方法的基础上推动社会创新和可持续的生活方式, 以及这些 项目如何借助移动通信技术得以实施。相比欧洲的实践, 这是在中国背景下对社会 创新所进行的试验。在江南大学, 27 名学生和 9 个拥有多元文化和多学科背景的教师 共同参与了该项目的工作坊活动。

开始, 各组学生被要求做实地调研, 确定在当地要开展的项目主题。然后, 根 据实地调研, 确定该产品服务系统 (PSS) 项目的思路。最后, 利用产品服务系统 设计工具, 例如: 故事板、系统图和视频模拟等, 产生了6个以无锡为背景的产品服 务系统设计方案。他们分别是食品网络、交通服务、医疗保健、场景故事、外来务 工人员和户外运动。这些产品服务系统 (PSS) 设计侧重于概念上的设计。相比于 问题的解决方案, 它更注重交流与沟通。这次工作坊针对中国的可持续生活方式, 提出了更多前沿的服务方案, 而非后台系统。 


\section{图9.1 创意形成和设计情境}

来源: Chita08

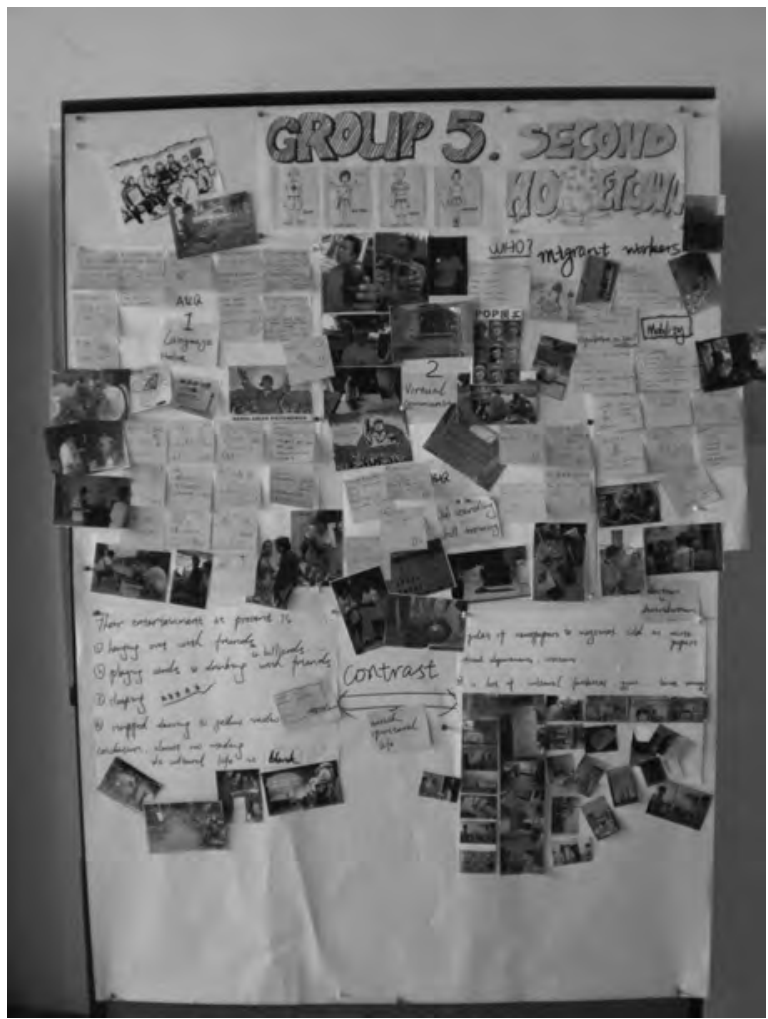

\subsubsection{Desis09-JU: 社会的创新与社区服务}

DESIS09是米兰理工大学（Polimi）与DESIS中国的创始成员之间的协作项目。这是 一个以设计为导向的教学与研究项目, 旨在观察和探索中国社会创新设计。在江南 大学设计学院, 共有7组28名学生参加了该项目。

在工作坊期间, 他们以无锡本地情况为重点进行调研, 确定了7个受社会关注的 案例, 其中包括拾荒者、老年股民、封海时闲暇的渔民、志愿献血者、素食主义运 动者、报刊亭销售商、广场舞者。通过这些调研，他们收集了自己的目标“用户” 的数据并进行了分析, 确定了各自的设计理念。此外, 还组织了一些短期的小练 习: 用户游戏工作坊, 气球模拟工作坊, 行为工具工作坊, 以进一步发展完善设计 理念。最后, 工作坊的成员们生动地描绘了在无锡居住的各类人群, 并通过设计来 改善他们的生活。 


\section{图9.2 用户游戏}

来源: 张宪

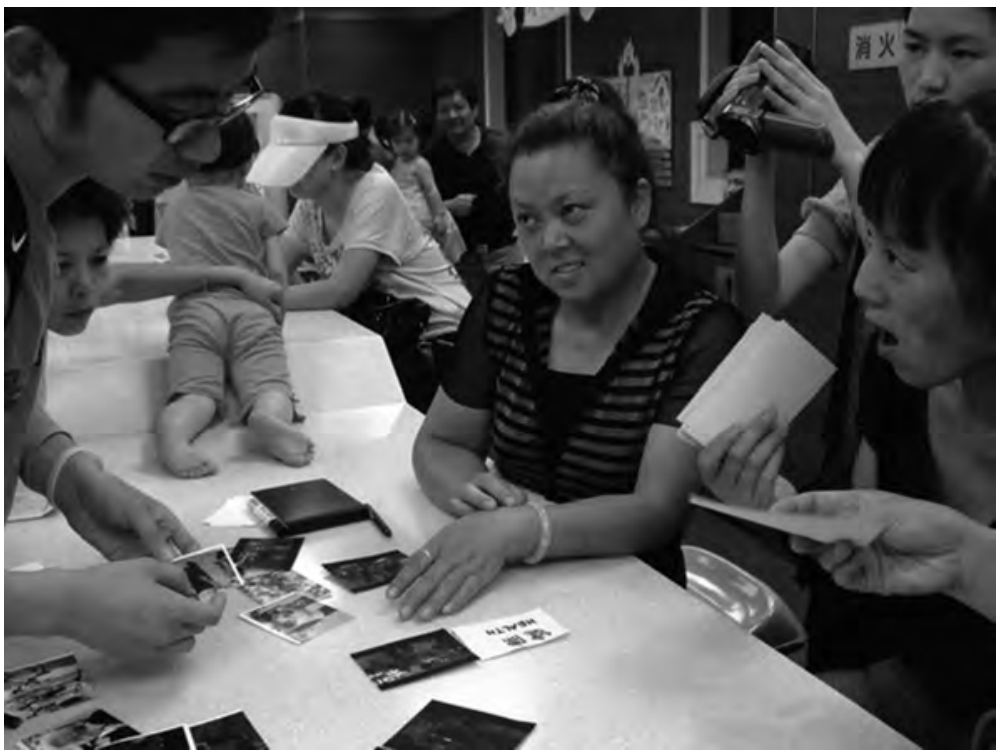

\subsubsection{DESIS10@Wuxi: 生态农业与健康饮食}

DESIS10@Wuxi是江南大学与米兰理工大学的另一个合作项目。它是以食品网络为 特定主题的产品服务体系设计工作坊, 主要针对无锡当地的城市农业和社区支持农 业 (CSA) 。这个项目一方面是探索新的问题解决方案的可能性; 另一方面, 它旨 在从根本上改变主流食品加工行业和消费模式, 而这种消费模式已被广泛的认为是 不可持续的。通过一系列系统化设计, 该项目还考察了城市与农村地区之间的富有 活力的新型关系。28名大四学生和研究生在6位来自不同学校、具有多元化背景的 导师团队的带领下, 参加了本次的工作坊。最后, 根据当地的实际情况, 提出了 5 个设计方案：隔壁蔬菜（Next-Door Veges），快乐种植（Happy planting），生长 (Grow)，共同种植（Co-planting）和有偿教育（Feeducation）。这些提议为解 决农业和食品问题提供了不同的途径。 


\section{图9.3 在生态农场实地调研}

来源：作者

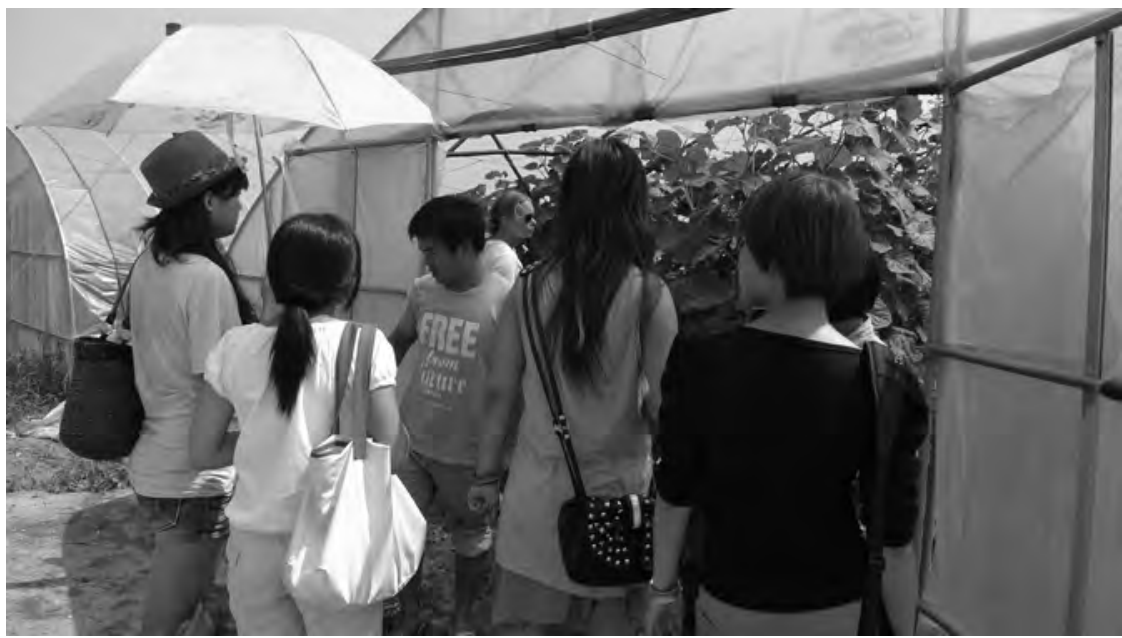

\section{3 中国可持续生活方式的设计情境}

设计工坊构建一系列的设计情境, 提出并开发了许多概念和方案。他们为未来可持 续发展提供了新的可能性范例。作为设计练习, 这些提议大多仍然处在设计过程 中, 尚未实施。其中有些观点可能会被认为是幼稚的, 或者是因为太复杂、不易实 现而被否决。然而, 它们不完全是乌托邦, 因为所有的方案都是基于实地调查和问 题分析而制定的, 以当地实际情况为基础。

这些实验性的设计理念为新的商业模式和中国可持续生活方式的实践提供了 崭新的创意、广阔的视野和有趣的提议。它们从不同角度探索了社会创新设计的应 用：关注技术应用和移动通信如何促进协作服务的问题；关注某些处于社会边缘 的特殊群体, 以及我们如何以一种可持续的方式去提高他们的生活质量; 关注生 态农业, 并重建城市与农村的关系。这些方案从日常生活的不同方面展示了许多 有关中国可持续生活方式的愿景, 比如重新组织移动服务 ( “出租车拼车” (Taxi Pooling））、分享个人旅游经历( “旅行足迹” (Footprints))、加强移民的社会凝聚 力( “自豪馆” (Pride House) )、实现多方交流（“怀孕母亲交流平台” (Mom's Talk）），构建食品网络(“寻找新鲜食品”(Finding the Fresh)，“共同种植” (Co-planting) 和 “养育” (Feeducation))、实现社区支持农业( “邻家蔬菜”

(Next-Door Veges), 生长 (Grow) 和“共同种植” (Planting Together))以及 完善社会的基础设施( “昨日重现” (Yesterday Once More))。总而言之, 它们是 参与式的协作服务, 可以作为社会创新被进一步发展和提升。这些设计过程和结果 将在接下来的章节中进行初步的讨论。 


\subsection{1 本土背景下的设计}

这些工作坊的研究结果体现了产品服务系统设计与清晰界定系统语境之间的关系。 基层群众的社会创新是通过自下而上的自发性事物和自上而下的干预实验发展起来 的。换句话说，它是在具体的、有创意的场所（弗兰奎利拉（Franqueira）2009） 由协作社区的那些有创意的成员（梅罗尼（Meroni）2007)共同协作产生的。这是 为什么实地调查和其他的调查工具是产品服务系统设计过程所必备的基本要素, 尤 其是在创意生成和问题设定阶段。在以上的设计实践中, 团队工作将从实地调查和 人类学研究开始, 由此来说明真正的问题和机遇, 而非仅仅依靠假设。然而, 在大 多数的提议中, 产品服务系统的创意都能够很好地适应本土语境。比如, “昨日重 现” (Yesterday Once More) 是一个数码平台, 人们可以把对某个地方的记忆保存 在那里, 并通过当地专门的移动服务, 与大家分享他们过去的故事。当代中国大规 模的城市化建设, 改变了城市社区的原有的基础设施, 这个创意才得以应运而生。 它以当代中国大规模都市化为背景, 而这种城市发展模式破坏了原有社会结构。

“合作种植”（Co-planting）主要是针对当地社区支持农业项目所面临的问题, 参与者们发现他们很难定期参与所要求的活动, 因此, 需要依靠共同承租人和合伙 人来照看他们种植的植物。同时, 设计干预所面临的一个挑战就是当地环境的可达 性, 而这是一般的设计过程和方法无法达到的。

\subsection{2 为特定目标设计}

这些服务系统的设计过程对 “谁是服务的使用者” 这一问题进行了激烈的讨论。讨 论结果表明, 这些情境的目标人群是非常特殊的。这里的所谓“特殊” 并非指人口 统计学的群体或者市场细分, 因为这些方案不能够被普通人的观念所接受。比如, 对于那些想要保护自己不受陌生人打扰的孕妇来说, 就很难参与到“怀孕母亲交 流平台” (Mom's Talk) 中, 因为该项目正是旨在促进孕妇和新妈妈与医生的交 流。在很多情况下, 这些服务并非适合所有人群, 而只针对一些特定的、有合作意 愿的以及符合主题情境的人群。因此, 设计师要精确定义目标人群, 这个特定的人 群需要通过仔细探究来选择而不是草草决定。这就是为什么这些有前景的创意和提 议最初都主要以特定的情境和人群为背景而设定的, 因为大环境并不是项目的理想 环境。设计师一定要寻找及定义那些社会创新的先驱者。由于种种原因, 这些先驱 者有足够的动机和知识储备去践行一种新的生活和生存方式。一旦协作服务开始运 作, 并成为这些特定人群的日常生活惯例的时候, 就可以在更大的范围内进行推广 和传播。

\subsection{3 共同创造的设计}

创新设计是个复杂的交互过程, 各方面人员在这个过程中自发协作。创意设 计由设计师、终端用户和利益相关者共同创造(考特姆 (Cottam) 和莱德彼特

(Leadbeater) 2004)。在工作坊中, 设定的终端用户不仅参与到设计过程的初始阶 段和定义问题的实地考察阶段, 而且还参与到创意和解决方案的制定阶段。例如, 
在构建食品网络的（“寻找新鲜食品” (Finding the Fresh)）或者实现社区支持农业 的（“邻家蔬菜”（Next-Door Veges））提议中，除了在实地调查阶段设计师需要 参观农场和访问农民之外, 他们还需要参与到整个设计过程中。一方面, 设计师与 农民之间进行对话和交流推进了设计进程，创造了新的成果。他们自发地参与共同 创造的过程。在这个过程中, 传统的设计师不仅要做设计, 而且需要整合系统中不 同的参与者：耐心地与他们交流并努力理解他们的想法。另一方面，系统中其他的 参与者也是 “业余” 设计师。通过营造友好的设计氛围和提供得心应手的工具, 鼓 励他们参与到设计过程中来, 这都是很有必要的。由于相比于传统的设计过程, 这 个过程更加复杂, 合作创造的过程很大程度上丰富了设计师的经验、知识和方法。 在传统的设计中, 跨学科的合作往往意味着要与市场、技术方面的人一起工作, 只 是, 用户仍然是用户, 并没有参与到设计过程中。在这点上, 共同创造过程却显示 出不同之处：它不仅仅是跨学科的, 而且其创造过程不只包括不同的参与者, 还包 括了最终用户。

\subsection{4 为重建信任而设计}

合作关系需要建立在一个相对较高层次的信任和良好关系的基础上。这是在服务系 统设计实践中面临的最大挑战。在过去几十年中, 由于社会城市化和个体独立化的 快速发展，人与人之间的信任感逐渐降低，关系日渐淡漠。面对这种信任危机，重 建并加强参与者之间的相互信任和友好关系, 成为产品服务系统设计的重要原则。 一方面, 产品服务系统设计来源于已有的概念, 并非是什么新生事物, 所以它本身 就存在相互信任的基础。另一方面, 这个系统为信任重建提供了机会。比如, 在

“独乐乐, 不如种乐乐” 的案例中, 参与者来自同一个社区, 所以他们能很好地了 解对方。在 “邻家蔬菜” (Next-Door Veges) 案例中, 小规模农户提供的有机食物 并未经过认证。我们可以相信这种形式的农产品是健康的, 因为它们是小规模生产 的, 特别是与那些生产流程很长且不可见的连锁超市相比, 这种优势更加明显。

\subsection{5 新商业模式的设计}

商业模式是产品服务系统设计项目的重要组成部分，它从商业的视角提出服务理念 和概念。然而, 在协作型服务的设计中, 我们需要一种新的商业模式。尽管项目中 这些被定义的问题或举措通常被传统商业部门忽视, 但是我们仍然可以发现这些服 务理念是以社会利益而不是经济利益为前提的。此外, 这些服务很少是以商业为导 向的，如事业单位。它们涉及到政府、公共服务部门，以及非政府组织或公民社 会组织部门。从经济学的角度看, 短时间内产品服务系统设计不能带来利润, 但 是这并不意味着它们不能在未来创造价值, 这里需要有一种全新的商业模式。无 论如何, 设计项目需要为新的提议定义新的商业模式, 例如, “自豪馆” (Pride House）的解决方案能够增强社区对外来务工人员的凝聚力, 培育外来务工人员的认 同感和归属感。新商业模式设计的利益主体包括那些积极参与到其中的当地政府、 移民工人协会、当地社区、技术开发者和移动通信供应商。 


\section{4 结论}

文中所说的这些研究并不是为社会创新和可持续产品服务系统设计做一个综述和概 括, 也不是为了给某些具体问题做出可靠的结论。相反的, 本章旨在提供在江南大 学设计学院这一特定的环境下有关这个课题的前沿探索的相关信息。江南大学是国 内最大、最早创办设计学院的一流设计院校之一。基于这个条件, 社会创新以及为 社会创新而进行的设计不管是在学术界还是在设计领域都是一个很新的课题。更有 意思的是, 这些研究和实践又可以引发新的讨论和研究。时至今日, 这些研究取得 了一些初步成果。首先, 通过引进产品服务系统的设计方法, 社会创新成为传统设 计院校的一个新的设计课题。老师和学生开始意识到这是个新的设计领域和新的设 计教育方式。其次, 设计干预必须深深地扎根于中国本土的设计语境, 这与欧洲及 其他地区在文化、社会和政治领域三个维度上都是截然不同的, 就技术这个维度中 国与其他国家和地区几乎是一样的, 但总体而言, 中国的公民社会背景相对薄弱, 重建信任是解决问题的关键。这给我们的设计带来了新的挑战和机遇。有些具体课 题可以在今后的研究中进行进一步的探讨。而且, 众所周知, 设计院校可以作为一 个专门的机构, 在推动社会创新和可持续方面扮演相当重要的角色。设计院校不仅 是培养未来设计师的摇篮, 也是可持续创新的孵化器。在这个研究中, 此观点得到 了充分的肯定。

\section{参考文献}

British Council (2007) Social Innovation: Working paper of social innovation conference (Beijing: Cultural and Education Section British Embassy).

CCSL (2007) Creative Communities for Sustainable Lifestyles, Task Force on Sustainable Lifestyle, Internal document, DIS-DESIGN.

Cottam, H. and Leadbeater, C. (2004) Health: Co-creating Services (Design Council - RED unit, London, UK).

EMUDE (2006) Emerging User Demands for Sustainable Solutions, 6th Framework Programme (priority 3-NMP), European Community, internal document.

Franqueira, T. (2009) Creative Places for Collaborative Cities, PhD thesis, Politecnico di Milano.

Gong, M., Feng, S., and Assawaboonyalert, C. (2008) 'Collaborative service and Mobile network: Observation of social innovation and anticipation of sustainable lifestyle in China', paper presented at Changing the Change Conference, 10-12 July 2008, Turin, Italy.

Manzini, E. (2010) 'DESIS statement', Creation and Design 2010.8(4).

Manzini, E. and Jegou, F. (2003) Sustainable Everyday: Scenarios of Urban Life (Milan: Edizioni Ambiente).

Meroni, A. (2007) Creative Communities: People inventing sustainable ways of living (Milan: Poli.design). 


\section{0 \\ 设计与社会创新 网络与社区的设计实践和方法}

季铁, 杨秋月和王伟

湖南大学设计艺术学院

\section{1 引言}

中国作为世界上近30年发展最快的国家, 遇到了经济与文化发展严重失衡问题。 表面上, 以区域经济为中心的辐射扩张取得了显著成效, 在如基础建设、GDP发 展、房地产业、城市化和时装产业等方面的成果显而易见。但是，在“人”的生活 方式、公共福利、文化传承与发展、伦理道德与信仰等方面的发展则相对滞后。迅 猛的城市化已经破坏了许多地区文化和传统社区。无论是农村社区还是城市社区, 人地关系的急剧变化及城市化进程中的旧城改造和新区建设累积了许多问题和矛 盾, 而这些急需解决的问题都集中在基层社区。宏观社会经济的变迁引发了城市基 层社会的动荡, 在 “工作单位” 体制和 “街道居委会” 体制无能为力的情况下 1 , 如 何重新整合 “原子化” 的个人以及逐渐 “支离破碎” 的社会单元, 成为迫切需要解 决的重大问题2。在这种情形下, 无论是作为国家治理的需要, 还是公民社会意识的 需要, “国家一一社会一一社区”的分析框架成为国内学者讨论的热点。“社区矛 盾”也成为社会矛盾的一个焦点。

1 “原子化” 这一概念源自社会学理论的概念, 原子说, 该理论认为个人在分析社会生活时 被看作是最基本的分析单元。“原子化” 在此是指中国人口, 他们正趋向于成为自我为中 心、平等和理性化的社会单元, 这些单元形成了以自我为中心的聚合社会。

2 “工作单位”体制和“街道居委会”体制是中国政府城市管理的基层管理体系。随着市场 经济的建立, 传统单元体系受到了根本性的影响, 而社区系统发生了上述两种情况。 
设计领域在过去十年中也经历了许多挑战。设计的重心已经从“物” 的设计 转向服务设计、信息设计、商业模式设计、系统设计等 “非物” 层面的思考 (桑德 斯 (Sanders) 2006; 伯恩斯 (Burns) 考特姆 (Cottam) 凡斯敦 (Vanstone) 和 温浩 (Winhall) 2006; 桑德斯 (Sanders) 和斯塔普斯 (Stappers) 2008; 麦格 (Mager) 2009; 曼齐尼 (Manzini) 2009b。一方面, 设计总是想用新的科技手段 无休止的满足和刺激 “人”的欲望和想象力, 另一方面, “人”的社会属性在这些 产品的影响下被重构、从而滋生很多新的社会问题。在这个过程中, 设计师作为一 个重要的构想者和实施者, 到底该如何平衡 “个人的物质需要”与 “社会的公共属 性”。这个问题需要从人类学和社会学的层面进行深刻反省。

设计的基本研究方法是 “以人为中心” 的设计方法。在一般的用户研究里,

“人” 往往被作为 “个体消费者” 来研究。但实质上 “消费情境中的人” 只是“人 的一种瞬间的状态”：大多数情况下人是处于其他的社会情境中。因此, 本文的研 究目标是尝试将 “人” 置于不同的“社区” 中, 探索以 “社区” 和“社区中的人” 为中心的设计研究方法。探索设计应该如何参与社会创新并创造更大的社会价值? 设计者可以成功解决什么样的人与社会之间的问题? 各种不同特点的设计师应该以 什么样的方式协同设计?

\section{2 设计目标与方法}

文献显示, 传统农村社区出现的问题与现代都市社区出现的问题大不相同。下面的 章节中将讨论这些问题及其相关实践。

\subsection{1 传统社区与城市社区的目标}

基于地域、血缘、信仰、地方文化的连结, 传统社区原本就存在较强的社区认同 感。其社会实践的主要目标包括（刘新 2008）：

- 维护原有的社会资本, 这些社会资本正因为传统社区人口减少而受到威胁

- 鉴于来自农业的收入不断下降, 应适时促进农村产业多元化, 刺激当地经济 发展

- 在当地居民的共同参与下, 对公共场所和基础设施进行改造, 加强社区意识

- 鼓励可持续发展类型的社会实践, 以促进传统文化遗产的保护与自然资源的 合理利用 3

3 据报道, 中国有些拥有非常好的环境和文化资源的地方在寻求通过旅游业来发展经济, 但 最终却造成了污染和生态破坏。针对这种问题, 我们提出了一个关键的目标, 这就是“理 性地使用环境和自然资源”。 
日本学者宫崎清的社区营造方法在东南亚国家和台湾地区激发了大量的相关创新, 并产生了广泛的影响（铃木（Suzuki）和宫崎（Miyazaki）2008）。这些实践来源 于早期的社区身份和当地知识。

多元化的城市社区的社会需求截然不同。城市社区异质的人口结构、高流动 性、多元化、开放性的特征使得城市社区中的社会关系远不如传统社区那么紧密。 相对传统社区而言, 城市社区处于更为广泛的系统联系中, 人们应该从整个城市 的角度研究, 而不仅仅从有限的、狭窄的物理角度研究, 那样会忽略了外部环境 的影响。针对城市社区的社会实践主要关注以下目标（刘新（Liu）2008; 兰德里 (Landry) 2000; 勃兹 (Bolz) 等2005) :

- 解决快速城市化带来的社区空间和公共设施不足的问题

- 缓解城市社区空间阶层化问题、兼顾社会公平、避免社会阶层对立

- 建立城市社区的独特性, 以减轻全球化倾向对个体独特性所带来的负面影响

- 提高社区服务质量与居民生活质量

- 探索城市可持续发展的生活方式, 应对全球气候和环境的挑战

- 通过建立特色社区创建城市品牌, 在知识和体验经济主导的时代能够吸引更 多资金和人才

巴塞罗那城市重振社区的规划方法; 曼齐尼（Manzini）等学者对都市可持续生活 情境的构建; 多特（Dott），艾迪欧（IDEO），生活|工作（Live|work）等设计 机构和参与者通过服务设计方法所进行的社区建设; 普华永道 (Pricewaterhouse Coopers) 在“未来城市 (cities of the future)”, 以及查尔斯·兰德里 (Charles Landry）在“创意城市” 中对未来城市的思考, 都是城市社区社会实践的典型 代表（曼齐尼 (Manzini) 和耶由 (Jegou) 2003; 耶由 (Jegou) 和曼齐尼 (Manzini) 2008; 勃兹 (Bolz) 等人2005; 兰德里（Landry）2000）。

从传统社区到城市社区的变迁是一个差异化消失的过程。知识结构上逐渐从地 方性知识主导转变为全球化知识主导。同时, 地域、血缘、信仰、地方文化等传统 社区的社会连结因素作用减弱, 而教育、社会地位、职业、爱好等连结因素作用增 强。生活形式的多元化和个人化是未来城市社区的特征（兰德里 (Landry) 2000; 弗罗里达（Florida）2002）。新兴社区的利益将维系在 “弱关系（weak ties）”和 偶然承诺上。多元化与个性化风格的社会对以地域为连结、强调以参与构建社区认 同的方式提出了挑战。然而，全球网络基础构架的传播为信息和社会网络提供了工 具, 为重新连接那些松散化的个体提供了新的可能性。虚拟社区和移动社区未来可 以成为把有创意的市民联系起来的神奇空间。

\subsection{2 设计网络和社会创新}

根据皮埃尔・布迪厄（Pierre Bourdieu）的社会实践理论（social praxeology）、 米歇尔 · 福柯 (Michel Foucault) 的权力理论、以及克利福德 - 格尔兹 (Clifford 
Greetz）的 “地方性知识” 的论述，设计可以被认为是一种社会实践或者有创造性 的行动, 需要有一种结构形式（权力）的结合才可以执行。虽然“设计”在这个年 代已经被社会和與论推到了“时尚”的风口浪尖，一些设计精英也似乎开始热衷于 参与一些公众性的讨论。“中国创造、国家创新体系、低碳设计”等概念的热炒在 某种层面上反应了国家治理者的战略思考, 但本质上, 设计师在参与社区改造的过 程中所起的作用是随机的。在错综复杂的关系中, 设计者最多是处于一种社会力量 的位置和一种服务者的角色。换言之, 一方面设计师往往是作为一种 “外来者” 参 与设计。在社区中的各种不平衡的 “权力” 和 “资本” 运动的对抗中, 无法获得一 种实质的结构形式参与。另一方面在基于社区的设计过程中, 设计师如何获得 “地 方性知识”，以文化持有者内部眼界（the native point of view）创造性地推动社会 创新? 我们相信, 设计师参与社区的社会实践可以更有效地构建多学科的设计网络。

通过回顾现有的社区实践, 我们发现, 设计师都习惯运用自己的学科来认识和 解决问题。设计实践者们往往以自己的领域和角度去解读问题, 例如建筑、规划、 工业设计、信息设计或者视觉设计。这些实践者之间的设计活动往往分割开来，几 乎没有一种可以协同参与的方法。而事实上社会是一个复杂的系统, 所有的问题和 需求是相互关联的。单一的设计不能全面的解决社区的问题。目前, 设计学科的变 化, 不管是转化设计还是战略设计其特征都强调了系统性和多学科的结合 (伯恩 斯Burns），考特姆（Cottam），凡斯敦 (Vanstone) 和温浩 (Winhall) 2006; 梅罗尼 (Meroni) 2008)。此外, “信息时代”或 “网络社会”（科斯特

(Castells) 2000) 展现了组织网络的重要性：未来基于网络的“虚拟智能社区”。 在这个过程中, 以社区为基础的设计实践和社会创新、知识平台建设与组织设计因 此可能成为让设计师参与其中的可行方法。这也要求我们重新审视我们的基本工作 方法。

强调地方性知识解决了设计师的角色问题, 知识平台的构建回答了如何获取地 方性知识的疑问, 而组织设计则提供了不同利益相关者和多学科合作伙伴的参与方 式。这种设计方式将使设计拥有更具张力的结构形式4与社会认同（通过创新网络、 设计网络、社会网络等）去参与社会创新, 促进网络的使用和可持续发展的和谐社 区建设。

\section{3 案例分析：传统社区中的社会创新举措}

通道侗族自治县位于湖南、广西、贵州三省交界处。全县人口 22.5 万人, 其中侗族人 口占 $78.4 \%$ 。境内生态环境极为秀美, 民族文化保存完好, 被誉为“侗族文化圣地”。 虽然通道物产丰富, 森林覆盖率达 $74 \%$, 年产商品材 17 万立方米, 但经济形式单 一, 至今仍然是全国贫困县, 2008 年农民人均纯收入1756元。

4 物理学中的张力是指弹性物体拉长时产生的应力。它有助于保持物体的原来状态。这里 的“张力结构形式” 是指通过这些网络, 克服社区创新过程中存在的阻力, 从而使得创新 成果更具可持续性。 
在“新通道设计与社会创新” 项目中, 我们希望整合不同专业和学科团队的优 势, 通过合理的村镇规划、生态旅游开发、信息与物流网络建设、产品与服务系统 整合、非物质文化遗产保护等综合举措, 建立一个国际化的设计创新联盟和基于网 络的信息平台。在保持当地居民和谐生活形态的前提下，通过设计使得这些地区能 够凭借自身的文化优势和资源特点获得发展机遇, 并促进当地居民的文化自主意识 和产业创新。

为了深入理解通道所面临的问题, 诺基亚研究中心 (NRC北京) 5 与湖南大学设 计学院 (HNU) 6合办了一个研讨会, 做了为期20天的实地考察, 对当地居民的生 活有了深入了解, 这为设计提供了有利支持。整个团队被划分为了 5 个小组: 社会学 研究小组、互动设计小组、环境和工业设计小组、影像设计小组和视觉设计小组。 团队采用了实地考察中的直接观察、参与式观察、非结构性访谈、乡村快速评估

(PRA) 、社会影响分析 (SIA) 等方法。当地4个村庄的 25 户以上的家庭参与了本 项目。28名当地村民接受了正式的访谈。

\subsection{1 关键概念}

以下术语是一些重要的概念, 因此本节将对它们进行详细阐述。

\section{本土的}

项目设计中应当首先考虑当地人的因素。文化多样性与自然的多样性一样重要。它 有利于整个社会和生态系统的和谐发展。关注不同文化背景中个性化的体验与需 求, 关注根植于不同文化群体中文化的适应力与变迁。我们应该和当地人一起寻找 他们自己认为满意的生活方式。

\section{连接的}

项目将经济边缘化地区与全球网络相连接。当下, 在全球网络的影响下, 文化交 流、生活方式、生产方式和消费行为发生了根本性的变化。对于经济落后地区而 言, 它们已经失去了工业化时代所带来的发展机会。如何凭借其仅存的文化优势和 资源特点, 以最小的成本融入全球化的商业与社会关系网络? 如何发展生态旅游、 有机农业、林业深加工等有地域特征的产业? 如何建立基于网络的交易与传播平 台、增加就业机会?

5 一个包括16位高级研究人员组成的小组, 包括来自法国、英国、美国和芬兰的专家。

$6 \mathrm{HNU}$ 小组拥有 50 为成员, 由教授、医生, 以及来自工业设计、建筑、景观、城市规划、环 境保护、信息, 及视频艺术等行业的毕业生组成。 


\section{可持续的}

项目通过产品服务系统设计的本地化来打造可持续发展社区。可持续的范围已经从 环境保护和资源节约等基础建设领域延伸到生活形态与消费方式的可持续设计, 从 产品的环保设计延伸到社区的服务设计与创新。

\subsection{2 社会需求}

杨氏基金会（Young Foundation）将社会创新定义为“为了满足社会需求并改善人 民的生活而产生的创意”（周若刚（Mulgan）2006）。对社会需求内容的定义是农 村地区社会创新的起点。波 (Pol) 和维尔 (Ville) (2009) 认为, 社会创新应该惠 及广大人民, 他们的主张成为我们篮选社会需求的主要标准之一。我们将通道地区 主要的社会需求总结为两大类。

\subsubsection{1 生活、生产与消费方式}

原始的古村落是传统生活方式的载体，也是通道最重要的文化遗产与视觉特征。当 传统的小农经济无法实现他们发展需要的时候, 一切都需要改变。人地关系的变化 促成了变卖资源、商业与旅游发展、外出务工等新的经济形式的出现。农民辛苦十 年的积蓄变成了古建筑群中新建的瓷砖房。如何在满足村民重建需求的同时, 保护 古村落景观? 如何利用传统的文化与手工艺技艺提升家居生活品质? 农民们是无法 独立解决这些问题的。我们应该积极的与原住民一起来共同探讨这些问题:

- 景观：保护原始村落景观和发展适应现代生活需求的建筑样式

- 家居：利用当地的材料和手工艺提升当地居民的家居生活品质

- 利用当地的文化遗产和自然资源发展经济, 增加居民收入

\subsubsection{2 交流方式}

大量青壮年外出务工, 留守儿童、妇女以及老年人成为村里的主要成员。与此同时 大量新的通讯与信息交流方式涌向他们，铺天盖地的广告中承诺的服务真的可以让 他们维系原来的和谐交流方式吗? 新的社交网络服务可能已转向了这些有着新兴的 生产观念和生活方式的青年人。在这个过程中, 建筑教育、社会知识学习与通讯平 台建设需要当地知识和沟通系统的支持。因此, 本土社区、个人交流方式等用户研 究和虚拟社区构建方法是我们本次研究的另一个重要目标。

- 家庭：当地青壮年常年在外, 他们如何与留守家中的父母、妻子和子女进行 情感联系?

- 经济: 在全球化的今天, 如何让通道重新融入全球化的商业与社会关系网络 中以获得发展机会?

- 文化：如何利用当地传统延续当地和谐的文化生态? 


\subsection{3 知识平台与组织设计}

正如之前提到的, 为社区和社会创新时, 建设 “知识平台” 与 “组织设计” 要优先 于实际设计。

知识平台主要由两大部分构成：当地情境(local context)和本地知识(local knowledge); 另一部分来自于跨领域和跨学科知识团队的知识背景。本地知识包括 当地各种形式的资本，三种主要的类型为文化资源、自然资源和行为资源。地方性 知识通过对当地政府、居民及其他组织的访谈、实地观察，以及阅读当地的书籍、 历史、故事而获取。多元化团队的知识背景提供了多样化的观察与解读的视角, 跨 领域的合作还为系统性社会创新创造了条件。多学科团队合作的关键是保持思想开 放并进行相互交流。交流可以采用报告和小组讨论等方法。知识平台的建立是一个 获得设计能力的过程, 也是吸引其他利益相关者参与并实现跨学科交流合作的基础。

研究组织设计这个问题, 我们必须要弄明白：谁来扮演社会创新的角色?

罗宾·默里 (Roblin Murray) 在《危险与机遇》 (Danger and Opportunity) 文中指出, 新的社会经济将分为国家 (state)、市场 (market)、慈善 (the grant economy)和家庭经济（the household）这四大领域, 并且越来越多的创新来自跨 领域的合作（默里（Murrary）2009）。埃齐奥·曼齐尼（Ezio Manzini）将社会创 新描述为一个变化的过程。在这个过程中, 新的创意在参与解决问题的各参与方中 不断涌现：终端用户、草根技术专家、企业家、本地机构和市民社会组织（曼齐尼

(Manzini) 2009b）。以上学者的论述对关于中国农村社会创新主体的思考不无启 发。本文将主要的创新角色概括为政府（state）、慈善经济（thegranteconomy）、 企业（market）、农民和其他社会团体(the household)。根据对这些角色的设定和了 解, 我们构建了本次项目的联合创新组织。

\section{图10.1 “新通道” 组织设计}

来源: 作者

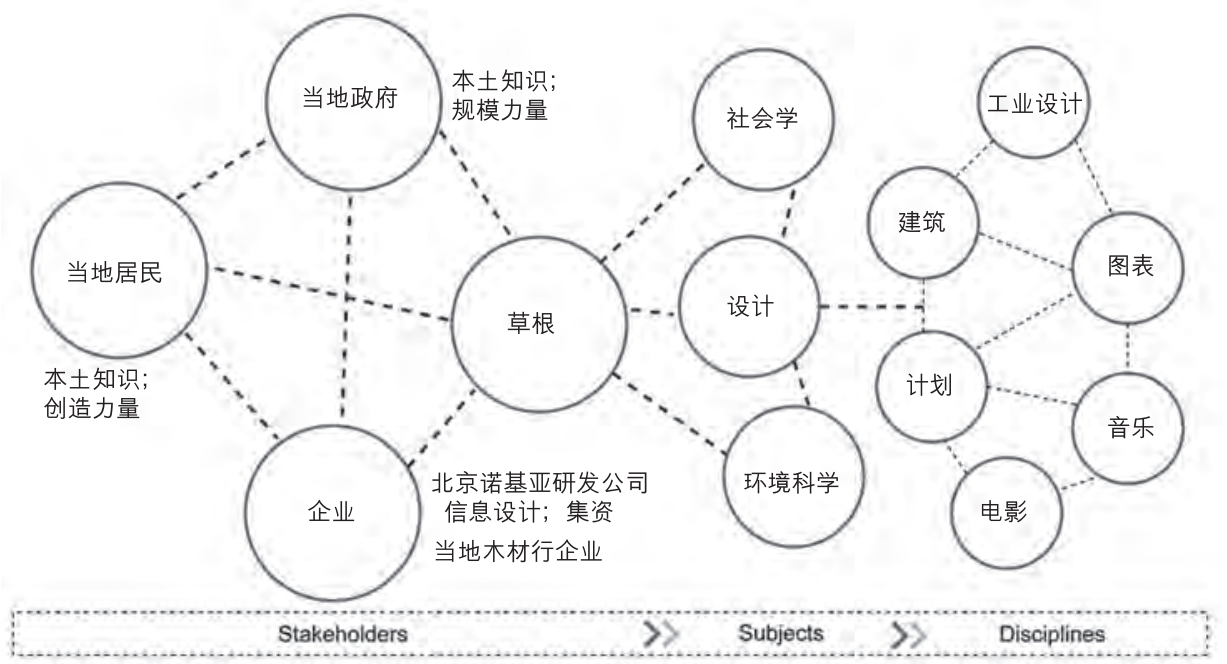




\subsection{4 设计内容}

克雷兹曼 (Kretzmann) 和麦克奈特 (McKnight) 提出了以资本为本的社区发展模 式 (Asset-Based Community Development)，并提出只有以资本为本的社区发展 模式才能帮助我们摆脱 “需求驱动的死胡同” (the needs-driven dead end）。波伊 尔 (Boyle)，斯雷 (Slay) 和斯蒂芬斯 (Stephens) 也曾多次强调了“从人们已有 的能力出发 (building on people' s existing capabilities) ”的观点。设计机会潜藏 在资产的整合和社会需求当中。他们的发现是基于设计团队对于当地环境和知识的 解释的。

\section{表10.1 设计机会}

来源: 作者

\section{设计机会}

\begin{tabular}{llll}
\hline 智慧+社会资本 & 有利条件 & 不利条件 & 振兴经济 \\
文化资本 & 几 & $\Omega$ & 社会资本的保留 \\
自然资本 & 社区资产 & 社会需求 & 基础设施改造 \\
行为资本 & & & 文化遗产 \\
$\ldots \ldots . .$. & & $\ldots \ldots$ \\
\hline
\end{tabular}

在新通道社会实践中，我们尝试联合“规划与建筑设计、工业设计以及信息服 务设计”建立协同的社会创新参与方法。社会学研究小组针对目标村落进行有关人 口结构、生产方式、消费方式与社会组织等问题的基础研究和调查; 环境和工业设 计小组将社会需求划分为 “生活形态、生产与消费方式” 的社会需求; 交互设计小 组针对 “交流方式” 的社会需求做出相应设计; 所有团队并不是完全相互独立的, 他们也合作进行一些设计工作。通过这个设计过程, 该项目取得了卓有成效的设计 结果, 其中一些成果将呈现在下面的章节中。

\section{图10.2 参与创新}

来源: 作者

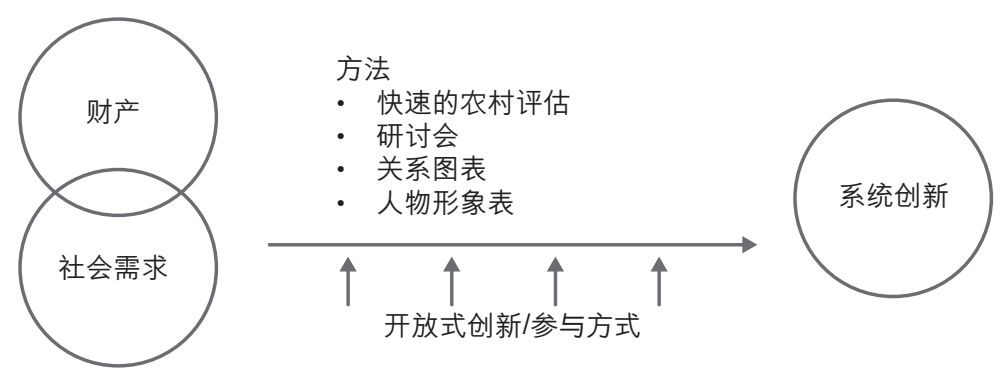

规划与建筑

通道侗族拥有独特的建筑风格。清华大学陈志华教授 (2008) 在《乡土建筑保护论 纲》一文中写道, “聚落是一个有机的系统, 其历史文化意义和功能大于它所有的 
各个单栋建筑的简单总和。乡土建筑的保护应该以村、镇整体保护为主要方式”。 虽然通道侗族的公共建筑受到法律的保护, 但更令人担忧的是当地住宅建筑的保 留。2006年到2009年, 我们目睹了当地景观的破坏过程。这使我们得出这样的结 论：村民们不承认他们的景观价值; 他们积蓄多年, 把他们的木屋改造成贴着瓷砖 的水泥房，但这些房子在我们眼中，既不美观又与周边环境格格不入。我们保护景 观的目标和村民们的意愿和选择发生了冲突。此外, 该地区大多数的侗寨位于平潭 河沿岸。我们发现, 有越来越多的固体垃圾和污水被直接倾倒入平潭河, 造成环境 污染。

在“新通道社会创新实践”项目中, 我们的目标是从不同的角度来解决这些问 题。环境和工业组调查了当地的村庄、景观和资源, 起草了《古村落保护指南》和 《污染控制指南》, 这些都被提交给当地政府作为决策参考。该指南包括对古建筑 的鉴定、修复和改造古建筑物的方法、对于材料和风格的要求、对新建成的建筑物 的保护和旅游开发、利益相关者的权利和责任，以及提高公众意识与当地居民对建 筑物尊重的方法。《污染控制指南》以高团村为例, 讨论了处理日常生活垃圾和污 水的方法, 还探讨了如何减少农业污染，以及可行的生态农业模式。在报告中还简 要提出了一个卫生监管方案。

从建筑的角度来看, 为了帮助村民找到新房建设和保护古村落之间的合理平 衡, 我们设计了新的民俗屋模型, 这些民俗房屋既能满足当地居民的需求, 又与现 有景观兼容。新设计的民居样板房, 它形式美观, 与原有的景观协调一致, 尽量采 用当地材料, 从而降低成本, 并且从通风、防潮、防火、隔音、加固、卫生和功能 分区上对传统住房进行改造，使其更加舒适宜居; 这些优势可以吸引当地居民自愿 选择我们推荐的房屋样式，从而达到间接保护景观的目的。

激发村民自觉保护景观行动的另一个重要做法是使他们从直接的景观保护中受 益。因此, 我们还制定了当地的旅游规划, 促进横岭村文化资源的利用率。这也与 当地政府的未来经济发展规划相一致, 可以促进当地的旅游经济发展。我们在村里 调查后选择了合适的地点, 在那里规划了服务区、分销区, 以及相应的旅游线路。

\section{图10.3 侗寨鼓楼；侗寨民居； 民居原型设计}

\section{来源: 作者}

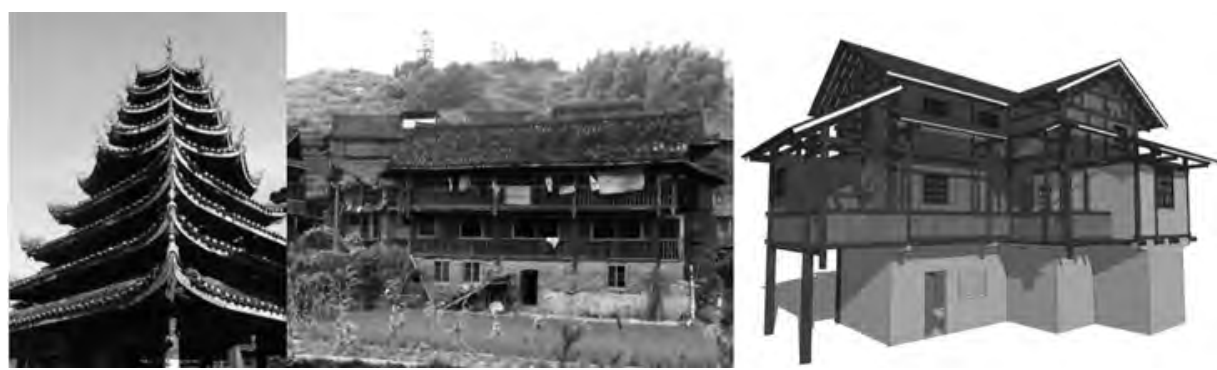




\section{工业设计}

我们调查发现, 通道县拥有丰富优质的森林资源, 但许多林产品只经过初级加工, 便以低附加值廉价出售。通道还拥有精湛的木工技术, 从当地的公共建筑和家具中 就可以看出来。然而, 本地需求下降, 木工的收入变得不稳定, 手艺涃熟的木匠们 更倾向于去外地工作以寻求更好的发展机会。从长远来看, 这是一项传统技艺的流 失。

我们还发现，当地家具市场具有巨大的发展潜力。然而，目前现有的家具消费 模式包括当地的家具、从大城市进口的家具和自制家具, 居民们很难从这些家具的 价格、质量、功能和美学之间找到一个平衡点。此外, 当地政府出台了多项扶贫举 措, 如支持当地企业、在职培训, 以及给予农民一定补贴, 以推动市场需求。通过 分析项目服务的生态环境, 有可能会找到新角色加入到生态当中的机会, 形成新的 角色关系。最终，可持续的服务生态取决于参与者交换价值的方式，随着时间的推 移, 生态中的各角色互惠互利（生活|工作（Live|work）2008）。面对上述问题和机 遇, 我们新设计了一个本地家具产品服务体系。该项服务以系统的方式重新组织了 农民、本地木工、政府机构、林业部门、家具生产企业、本地林场和其他社会组织 之间的关系。系统图（图10.4）是服务技术组织的可视化展现：不同参与方参与进 来, 它们之间相互联系在一起, 而各种材料、能源、信息和金钱等要素的在系统中 不断流动（默里丽（Morelli）和托莱斯查普 (Tollestrup) 2007)。

在该新系统中, 政府帮助当地小工厂购买木材加工设备, 改善他们的产品组 合。小工厂购买当地森林中的木材, 将它们处理成各种规格的木板, 使其成为可以 直接用于建造房屋和制作家具。当地木匠加入当地协会。当地居民购买到标准化木 板, 并与当地木工协会联系, 得到装配和定制服务。产品服务系统 (PSS)有三个 特别创新, 或者可以说成是新颖的特质: 第一, 设计机构参与政府在农村地区的项 目; 第二, 当地木匠在特殊训练的帮助下, 创造设计解决方案; 第三, 与当地设计 学校的合作计划。作为家具设计创新的一个例子, 根据低成本、高质量准则, 我们 希望我们的家具和装饰的设计理念能够与上述民俗屋模型相匹配。

新产品服务系统 (PSS) 弥补了原来的三个家具交易模式的缺陷。该服务满足了 在经济、环境和社会三方面的可持续要求 (2010年《经济师》)。

- 经济：当地居民可以享受到低价格、高品质、使用功能齐全、美观大方的家 具。该服务和政府在扶贫和经济发展方面共同努力, 形成了投资和收入的良 性循环。它可以刺激消费, 拉动当地家具企业和林业的繁荣, 并确保新的家 具与从前的文化传统具有一致性。

- 环境：此服务减少了外销到其他省份的木材数量, 可以大大降低运输需求。

- 社会: 木匠协会是这项服务的一个重要组成部分, 协会提供装修服务, 加强 了木匠们的生计能力, 使当地的建筑和木工技术可以传承下去。

事实上, 这种地方协会启用的产品服务系统 (PSS)模型也同样适用于当地手工纺织 业和畜牧养殖业。 
图片10.4 本地家具服务设计 来源: 作者
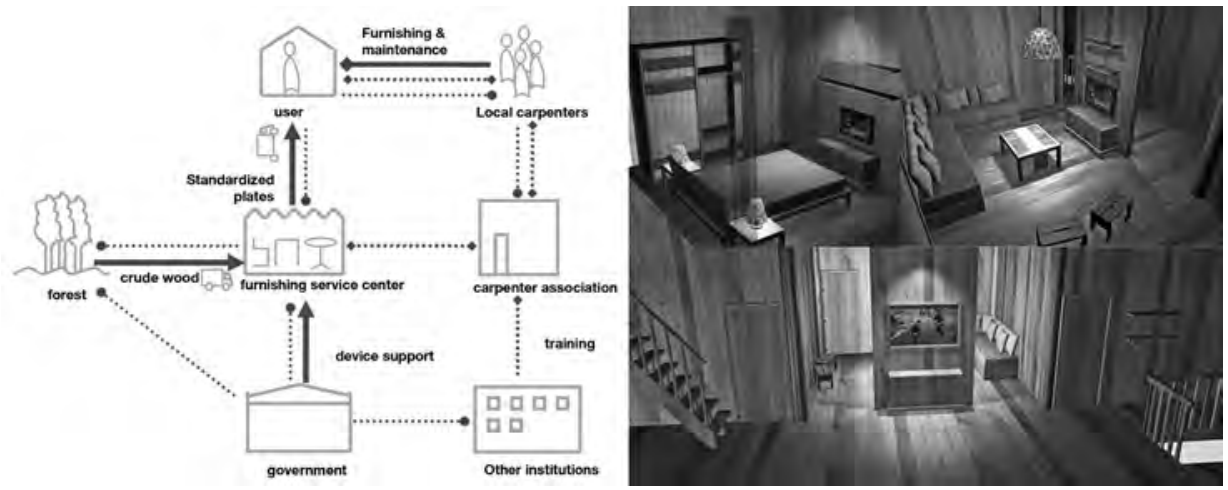

产品和视觉设计

\section{为当地居民进行设计}

当地妇女受教育程度很低, 除了干农活外, 她们没有其他经济来源, 但她们中的大 多数却掌握多种技能，如织物制作、布艺饰品制作、制作侗族织锦工艺品。我们还 发现, 只有少量纪念品是销售给游客的, 它们多数来自中国沿海地区, 都是大规模 生产出来的, 并没有什么特点。项目组对当地织物侗锦在图案和产品上进行了再设 计。一批符合现代家庭需求同时能够手工加工的产品被设计出来。留守的妇女可在 农闲时间手工制作这些产品, 在赚取额外收入的同时还能增加当地旅游纪念品的特 色。

此外, 我们还为当地的特产, 例如侗王酒、杨梅酒、土特产、小吃等, 制作了 酒瓶、包装、海报等商业化的设计, 让它们更富有吸引力。

\section{为外来旁观者的设计}

该系列包含三个主题。首先是有形的当地建筑，可以呈现给游客最有价值的文化底 蕴和当地景色。第二是我们研究过的侗锦（当地传统的织物）, 目的对其注入现代 化内容。第三是运用平面设计打造有特色的地方织品, 进行有地方特色的交流。

\section{信息服务设计}

在农村地区，手机已经相当普及，并已成为通信和娱乐的重要工具。我们对农村 信息需求进行了深入的研究, 并挖掘出值得深入设计的机会点。例如, 通过对村 民寻找打工机会的模式和习惯的研究，交互设计小组设计了基于手机的求职 (Job hunting）服务概念。此外, 在大多数农村地区, 大量青壮年在大城市工作, 留在老 家的是许多儿童与老人。家庭成员因此长时间分离: 手机成为了他们保持联系的重 要工具。他们因为经济原因很少相互打电话, 每周一次甚至每月才联系一次。在遥 
远的城市生活的农民工希望听到更多他们家乡变化的消息，但手机能带来的信息是 有限的。大多数进城务工的年轻人有使用互联网的经验：他们可以上QQ、汶览网 页, 还是高级论坛的用户。然而, 留在农村地区的儿童和老人很少有机会使用计算 机, 他们的能力还不足以使用计算机。他们不能处理复杂的注册过程, 也没有用过 在线QQ或Skype ${ }^{7}$ 等视频聊天功能。尽管计算机和互联网的使用并不常见，居民可以 在每个村的“地方文化中心”上网。仔细考虑了这些特点后, 我们设计出一个尽可 能简单的本地网络工具。农民工可以通过该网站获得他们家乡的新闻，儿童和老人 经过简单的培训后, 便可以轻松地使用视频聊天功能。

\subsection{5 传播}

参与式视频传播的方法成为本次影像设计工作的一个重要组成部分。夏令营期间, 影像工作组将每日采集的内容播放给当地村民观看, 并通过这种互动的方式发现社 区中最值得记录的人、特别的仪式、当地最具特色的音乐等内容。这种讨论也会让 社区的居民重新发现家乡最为珍贵的财富, 增进他们的对本地文化的自豪感, 增强 社区凝聚力。这些影片和音乐实现了对当地非物质文化的影像保护, 同时也真实的 再现了当地的社会问题。他们将作为连接和沟通通道与外部世界的媒介, 用优秀的 文化传统吸引社会资源, 解决当地问题。

\section{4 结论}

设计师如果仅以社会力量的形式开展 “设计服务” ，将无法在社区改造中获得一种 实质性的结构形式。而 “知识平台” 的构建和 “组织设计” 可能成为设计师参与的 一种可行的方法。在本次实践中, 我们通过参与式方法确定了该地区社会创新的需 求。从本地人的角度 (the native point of view) , 我们试图构建符合本地需求的 地方性知识平台”，建立了由当地政府、外部企业、当地居民和跨学科设计团队组 成的组织网络。通过这些方式, 我们将传统的、以用户为中心的设计方法（其中设 计师经常以一种不确定、并以个体和企业为主导的方式提供服务）转变为一种将各 种设计资源整合为一个强大网络的新方法, 并推动基于满足共同 “社会需求” 的 社会创新。

7 一种在线软件, 能够通过视频或音频使注册用户能够相互联系。 


\section{图10.5 社会创新平台}

来源：作者

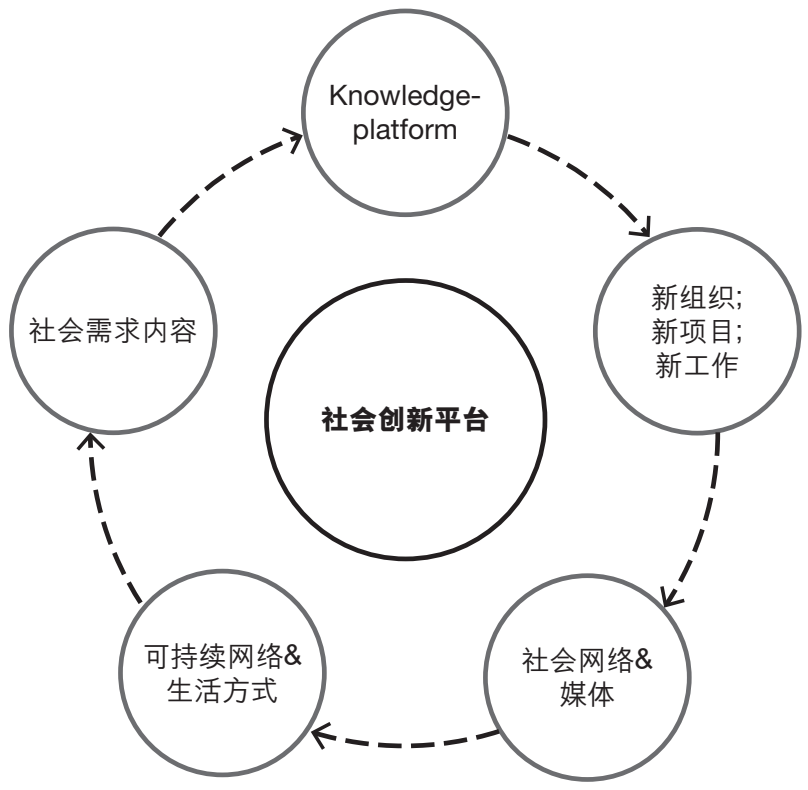

基于网络和社区的设计可能成为社会创新的一种新的范式。在社会创新过程 中, 知识平台、组织设计与社会传习（social learning）等环节都依赖于网络平台的 构建和跨学科的协同设计。网络和虚拟社区将使得设计以一种更有张力的结构形式 和社会认同力量（创新网络、设计网络、社会网络等）参与到各种社区的社会创新 中, 使得基于网络的可持续的和谐社区成为可能。

\section{参考文献}

Bolz, U., Ford, A., Gourley, M., Magee, C., Castilla, M., Rakel, J., Radovanovic, D., Sieverdink, A., Sivertsen, T., Sturesson, J., Teunisse, P., and Toussing, J-L. (2005) 'Cities of the future: Global competition, local leadership' (PricewaterhouseCoopers; http://www. pwc.com/gx/en/government-public-services/issues-trends/index.jhtml, accessed 29 June 2010).

Boyle, D., Slay, J., and Stephens, L. (2010) 'Public Services Inside Out: Putting co-production into practice' (NESTA; www.nesta.org.uk/library/documents/public-services-inside-out.pdf, accessed 25 May 2010).

Burns, C., Cottam, H., Vanstone, C. and Winhall, J. (2006) 'Transformation Design' (Design Council; www.designcouncil.info/mt/RED/transformationdesign/TransformationDesignFinalDraft.pdf, accessed 15 March 2010).

Castells, M. (2000) The Rise of the Network Society (West Sussex: Wiley-Blackwell).

Chen, Z. (2008) 'Outline of Local Architecture Conservation', in Lu Y. and Yang X. (eds.), Local Architecture Study and Conservation (Shanghai: Tongji University Press). 
Economist (2009) 'Triple bottom line' (http://www.economist.com/node/14301663, accessed 14 April 2010).

Florida, R. (2002) The Rise of the Creative Class: And How It's Transforming Work, Leisure, Community and Everyday Life (New York: Basic Books).

Jegou, F. and Manzini, E. (2008) Collaborative Service: Social innovation and design for sustainability (Milan, IT: Edizioni POLI.design).

Kretzmann, J. and J. McKnight (1997) Building Communities from the Inside Out: A Path Toward Finding and Mobilizing a Community's Assets (Chicago: ACTA Publications).

Landry, C. (2000) The Creative City: A Toolkit for Urban Innovators (London: Earthscan).

Liu, L. (2008) 'Reflections on Community Empowerment: Consideration of Urban-rural Differences, Perspectives of Urban Development, and Exploration of the Bottom-up Concept', Journal of City and Planning 35(4), 313-338.

Live|work (2008) 'Service Ecology' (http://www.servicedesign.org, Accessed 1 May 2009).

Mager, B. (2009) 'Service design as an emerging field', In S. Miettinen and M. Koivisto (eds.), Designing services with innovative methods (Helsinki: TAIK): 28-43.

Manzini, E. (2009a) 'DESIS-International: A network on Design for Social Innovation and Sustainability' (Internal document. Dis-Design, Politecnico di Milano).

Manzini, E. (2009b) 'Next design: Design for social innovation and sustainability' (Changsha: Presentation on 2008 Summit Forum of Hunan International Industrial Design).

Manzini, E. and F. Jegou (2003) Sustainable Everyday: Scenarios of Urban Life (Milan, IT: Edizioni Ambiente).

Meroni, A. (2008) 'Strategic Design to take care of the territory: Networking Creative Communities to link people and places in a scenario of sustainable development', In Anais P\&D - $8^{\circ}$ Congresso Brasileiro de Pesquisa e Desenvolvimento em Design.

Morelli, N. and C. Tollestrup (2007) 'New Representation Techniques for Designing in a Systemic Perspective' (paper presented at Design Inquires, Stockholm).

Mulgan, G. (2006) Social Innovation: What it is, why it matters, how it can be accelerated (London: Basingstoke Press).

Murray, R. (2009) 'Danger and opportunity: Crisis and the New Social Economy' (NESTA) (http://www.nesta.org.uk/library/documents/Danger_and_Opportunityv2.pdf, Accessed 14 April 2010).

Pol, E. and S. Ville (2009) 'Social innovation: Buzz word or enduring term', The Journal of Socio-Economics 38: 878-885.

Sanders, E. (2006) 'Design research in 2006', Design research quarterly 1(1): 4-8.

Sanders, E. and P. Stappers (2008) 'Co-creation and the New Landscapes of Design', CoDesign: International Journal of CoCreation in Design and the Arts 4 (1): 5-18.

Suzuki, N. and K. Miyazaki (2008) 'Flowering of the Total Person: A Practical Design Philosophy for Indigenous-Led Regional Development', Bulletin of Japanese Society for Science of Design 55 (1): 37-46. 


\section{1}

\section{促进社会资源的可持续发展 社会创新与社区设计}

埃齐奥 · 曼齐尼 (Ezio Manzini)

可持续设计与社会创新设计网络协调员

安娜 · 梅罗尼 (Anna Meroni)

意大利米兰理工大学设计学院

\section{1 社会创新}

社会创新是由社会需求驱动的创新形式, 而决非市场或科学技术自发研究的成果, 它并不只是某几个科研人员的专利, 各种社会力量都可参与其中, 为社会创新出 力。从上述这个初步定义中, 我们不难发现, 社会创新其实会在任何一个社会的发 展过程中出现。然而, 尽管社会创新始终存在, 但我们出于两大原因必须重视这个 问题。首先, 为了应对可持续发展所面临的挑战, 社会创新举措层出不穷, 而在不 远的将来会变得更为常见。第二, 随着当代社会的不断发展变化, 社会创新的本质 也在发生变化, 呈现出日新月异的局面, 并产生了一些出乎人们预料的现象。

仔细回顾历史, 我们发现, 当社会的发展进程中同时存在以下两个条件时, 社会 创新会呈现出繁荣发展的趋势: 当社会正面临着难题, 并且当广泛使用新技术, 且其 潜力尚未充分挖掘时。而当今社会明显符合这些条件（周若刚（Mulgan）2006）。

事实上, 无论是从问题出现的数量还是程度看, 当前的经济危机足以使我们预 测出社会创新在未来的角色（默里 (Murray) 2009)。此外, 其他棘手的老问题和 不断出现的新问题, 都会触发社会创新的出现: 如今数以百万计的人口（那些主动地 或被动地从农村走进城市的人们）的生存环境迫使他们创造出一种新型的生活和生产 方式。与此同时, 人们已逐渐意识到地球资源的有限性, 人们开始从不同的角度（经 
济和健康相关）来看待这一问题，并开始寻找一种更加节省资源的新系统了。同时， 一系列 “大问题” 的出现也决定社会创新的发展必将持续 (温佐丽 (Vezzoli) 和曼 齐尼 (Manzini) 2008; 克林 (Kling) 和舒尔茨 (Schulz) 2009)。

与此同时, 很显然, 第二个条件也是满足的。无论从数量上还是从质量上看, 科技成果应用的广泛程度已超乎了我们的想象（科斯特（Castells）1996, 班克勒

(Benkler) 2006)。近几十年来, 从全球范围来看, 我们的社会已经受到了几次技 术创新浪潮的冲击。从分布式计算, 到互联网, 再到手机。这些技术已经迅速地融 入我们的日常生活（例如, 现在没有人把使用手机视为可炫耀的先进技术），而且 开发潜力巨大, 用户总是喜欢花样翻新, 将其功能升级换代。新网络导致了新的组 织形式、商业模式和经济形式的出现, 人们也可由此找出相应可行的解决方法（鲍 温斯 (Bauwens) 2006; 塔普斯科特 (Tapscott) 和威廉姆斯 (Williams) 2007, 莱德彼特 (Leadbeater) 2008)。

由于当今社会满足上述两个条件, 我们可以合理地预测, 解决新老问题的新方 案也将会出现（周若刚（Mulgan）2006; Green 2009）。

\section{1 .1 社会创新路线图}

社会创新可以简单地定义为: “能够满足社会目标的新创意”（周若刚

(Mulgan) 2006)。以下是对这个定义的具体阐释：社会创新是一个变化的过程, 是现有资产 (从社会资本到历史遗产, 从传统工艺到先进技术) 有创意的重新组 合, 目的是用一种新的方法实现社会认可的目标。这样的定义表明, 社会创新的范 围非常广泛。我们可以分门别类地制定一个明确的创新路线图, 但是这个内容不在 本章所讨论的范围之内。基于第一稿的概述, 这里我们将对这一内容进行一个大致 的讨论。

第一种是渐进式创新与激进式创新之间的对立。这里我们运用了技术创新领 域的形容词: “渐进的” 和 “激进的”：它们指在现有的思考和行为范围内（渐进 式创新）和超出现有思考与行为方式范围（激进式创新）之间的变化。具体来说, 若我们要促进可持续变化的产生, 我们要考虑的创新应是“激进式”的（温佐丽 (Vezzoli) 和曼齐尼（Manzini）2008）。即目标本身和实现目标的方式必须是与当 前的主流方式有所不同。

第二种是“自上而下”与“自下而上”两种不同方式之间的对立。这涉及到 两个问题: 变化从哪里开始? 变化的发起者是谁? 如果发起者是专家、决策者或政 治活动家, 创新将主要采取自上而下的模式。如果（主要）是公众和社区直接参与 的, 那么这将（主要）采取自下向上模式。在本文中, 我们将主要考虑自下而上 的创新形式, 或更确切地说, 是由那些我们称之为新社区成员的积极参与者和协作 者策划、实施和管理的创新（伯纳德 (Bernard) 1973; 班克勒 (Benkler) 2006) 。因此, 我们把这些自下而上的创新称为社区创新。事实上, 人们的态度和能力 随着创造性、创业精神和设计方法的广泛传播在不断发生变化（雷（Ray）和安德 森 (Anderson) 2000; 兰德里 (Landry) 2000; 梅罗尼 (Meroni) 2007)，人 们还在不断思考互联网组织如何为这些变化提供支持（威尔曼（Wellman），哈泽 (Haase)，维特 (Witte) 和汉普顿 (Hampton) 2001; 周若刚 (Mulgan)，斯坦 
伯格（Steinberg）和塞伦（Salem）2005；莱德彼特（Leadbeater）2008），这些 社区为导向的创新具有高效推广可持续变化的潜力。

\section{1 .2 社会问题与可持续变革}

第三则是社会问题与可持续变革之间的对立。“社会的”这个形容词具有两层不 同含义。到现在为止，“社会的” 往往被用来表示由极端贫困引起的急迫而严重 的问题, 尤其是指饱受疾病困扰、脆弱的社会群体所产生的问题（如缺水的棚户 区; 缺乏医疗护理的偏远村庄; 或缺少就业岗位的边缘化年轻人)。在这种情况 下, 创新的动机是什么? 这是亟需解决的问题。为了解决这些问题, 各种形式的 创新都是可能的，一定会受到公众的认同：技术的与社会的、渐进和激进的、自上 而下和自下而上的，等等。通常，触发并支持这些创新的设计过程被称为社会设 计：一种不是由市场需求而是由应对这类社会公认问题所导致的设计活动(玛高琳

(Margolin) 2003; 布朗 (Brown) 怀亚特 (Wyatt) 2010。然而, 形容词 “社会 的”也具有其他含义, 可以用于其他用途：这些可持续变化与整个社会的主要发展 趋势密切相关: 人口演变、城市化、人与人之间联系的加强, 以及更为宏观的概 念, 如向可持续社会的过渡（食品网络和新型城市/农村关系; 合作居住和协作服 务; 替代出行方式, 合租汽车和自行车以及拼车等）。在这些情况下, 创新的动机 既是对解决短期问题和长期问题方法的探索，也是对新机会的探索。这意味着，不 同的参与者都可以推动社会创新：包括地方、国家或国际公共组织、基金会和非营 利组织, 但也可以是各类不同的创新企业; 贫困和边缘化的人, 还可以是新兴国家 的中产阶级。这一领域的设计流程被定义为 “可持续变革设计”。由于这些设计活 动（主要）是由那些对社会与经济可持续的关注所触发, 因此, 所提出的解决方 案和商业理念定能实现对主流生产生活模式的彻底变革(曼齐尼 (Manzini) 和耶由 (Jégou）2003)。

还需要说明一点, 尽管这两个创新领域已经在不同的动机和背景下进行了讨 论, 然而最近这两者出现了趋同的现象。事实上, 一方面, 我们越来越清晰地发 现，大多数社会问题只有在更大的可持续变化的框架下才能够得到解决。另一方 面, 当面临危机, 需要将生活方式朝着更加可持续的方向转变时, 日益壮大的中产 阶级却固守成规，他们甚至依赖社会贫困群体的发明而仍然生活在前现代化时期的 固有传统中。

在讨论可持续社会创新潜力的过程中, 本章主要讨论了可持续变革; 重点描述 了一种特定的社会创新形式：促进可持续变革的以社区为导向的创新。

\subsection{3 以社区为导向的创新}

大家可以通过我们当今现实生活中的种种创新举措, 具体了解以社区为导向的创 新。例如, “零公里食品”（zero-mile food）项目中不仅仅创造了一种新的饮食方 式, 还建立了生产和消费之间、城市和农村之间的新型关系。这是一种将老人自发 组织起来互相帮助, 同时开拓通向福利的新思路。更多的例子还包括, 能够提高城 
市质量和社会结构, 由居民自己建立并管理的花园，以及那些承担一些公共服务以 减少经济和环境支出, 同时也想创造新的邻里形式的家庭所建立并管理的花园。

一旦我们开始观察社会并寻找这类举措, 就会发现很多其他有趣的案例: 新 形式的社会交流和互助（如当地的外汇交易系统和时间银行）；一些替代个人汽车 的交通系统（从汽车共享、拼车, 到重新发现自行车的潜力）; 当地资源和技术为 基础的连接到全球互联网的生产活动（当地特产, 在全球在生产者和消费者之间建 立的公平和直接贸易网络）。这样的例子还很多, 涉及日常生活的各个领域, 并发 生在世界各地（阅读更多关于它们的信息，见 “可持续日常项目” (Sustainable Everyday Project) 1)。

通过观察这些案例, 我们发现, 社会创新突破了传统的行为模式, 而采用新 的、不同以往的更可持续的方法行事。当然, 我们应该分析社会创新案例的每一个 细节（以便更准确地评估其环境和社会可持续效果）。然而, 乍一看, 我们发现, 可持续设计与社会创新发展在根本指导方针具有一致性。

首先, 许多创新方案具有前所未有的作用, 可以充分协调个人、社会和环境三 方面的利益（例如创新的副作用之一就是加强社会结构）并产生新的、更可持续的 关于福祉方面创意, 这种创意更大的价值是可以提升社会和自然环境的质量, 如提 供社会关怀、慢节奏的生活、协作行动、新形式的社区和当地发展的新思路（曼齐 尼 (Manzini) 和耶由 (Jégou) 2003)。此外, 实现这些社会创新方案, 也就顺应 了环境可持续发展的指导方针, 如: 用积极的态度共享空间和物品; 提倡食用有机 的、当地的, 以及当季的食物; 本地网络的重建; 最重要的是, 采用可以减少交通 流量、更能够整合可再生能源和高效生态系统的经济模式(维佐里 (Vezzoli) 和曼齐 尼 (Manzini) 2008)。

由于这些创新案例将个人利益与社会、环境利益相协调, 因此它们应当在今后 广泛推行。凭借这些由于不同原因并以不同方式产生的举措, 人们能够将他们的期 望和个人行为向更加可持续的生产和生活方式转变。

\section{1 .4 创新社区}

这些具有发展前景的案例的背后, 都有一支负责策划、开发和管理的团队。这些团 队有一些共同的基本特征：他们都能够合作发明、改进和管理那些创新型解决方 案, 以打造新的生活方式。他们在系统（经济、机构、大型基础设施等方面）没有 发生根本改变之前, 对已经存在的事物进行改造重组。出于这个原因, 这些人群可 以被定义为创新社区: 他们协作发明、改进和管理那些创新型解决方案, 以打造新 的生活方式。(梅罗尼（Meroni）2007)。

这些案例的第二个共同特征是, 它们都是为了应对当前日常生活中出现的问题 而产生的, 如: 我们如何摆脱由于个人主义日益盛行所导致的孤独感? 如果家庭和 邻里失去了传统上所能够提供的支持功能, 那么我们如何组织我们的日常生活? 生 
活在一个国际化大都市里的我们, 如何满足天然食品的需求, 并获得健康生活的条 件呢? 如何才能保护本地生产, 使之免于遭受全球贸易的巨大压力而造成破坏?

创新社区能够解决所有这些问题: 我们日常生活中面临许多迫切需要解决的问 题。那些占主导地位的生产和消费系统, 尽管它们有巨大的能力提供产品和服务, 却无法解决我们面临的问题, 或者更准确地说, 无法以可持续的方式解决我们所面 临的问题。总之, 我们可以说, 创新社区运用它们的创造力, 打破了主流思维和行 为模式。由此, 它们自觉或不自觉地造成了前文提到过的根本性变革。

第三个共同点是, 创新社区是需求与机遇共同创造的结果, 这些需求总是为了 应对当前日常生活出现的问题而产生，而机遇来自两个基本要素的不同组合：即传 统的存在（或关于传统的记忆）和（以适当方式）现有技术（以产品、服务和基础 设施的形式) 使用的可能性的组合。

关于最后一点, 我们可以观察到创新社区和社会网络（以及其他形式的网络组 织）之间的融合。即使它们在不同环境背景下出现，产生的动机也不尽相同，创新 社区和社交网络却有着有趣的相似之处：它们的产生多数都源于使用者的需求, 而 不是在实验室里闭门造车的结果; 在这两种情况下, 开发者和使用者的角色界限是 模糊的, 从而产生了新的社会角色, 即他们既是生产者也是消费者。最后, 也是最 重要的是, 我们发现两者具有互补性：创新社区活动的社交网络可以把自身与日常 生活联系起来。而另一方面, 创新社区在社交网络中发现它们需要的工具, 使社区 向更有效、持久、可复制的组织形式发展（格兰诺维特 (Granovetter) 1983; 贝克

(Baek）2010）。在此基础上，可以说，以社区为导向的创新（创新社区）和基于 互联网的创新（社交网络）的融合是一个持续的趋势：这个强大的趋势大力支持现 有的社会创新，同时，生成新的、前所未有的创新形式（瑞金（Rheingold）1993, 2002)。

在结束这个创新社区的特点的简短概述前, 我们可以尝试给以社区为导向的创 新（对比其他形式的社会创新的背景）下一个定义:

以社区为导向的创新是众多角色（最终用户、基层技术人员和企业家、当 地机构和民间社会组织）共同参与的设计过程，他们为一个共同问题寻求 一个共享的解决方案。

\subsection{5 协作组织}

创新社区是与时俱进的有机体。经过深入的观察我们发现, 它们开发出来的这些案 例可以被看成是处在不同发展阶段的组织。事实上, 当它们合并为成熟的组织时, 创新社区成为了一种新组织：在实际应用中, 它们可以成为能够提供社会服务、负 责任的企业或用户协会那样的组织（耶由（Jégou）和曼齐尼（Manzini）2008）。

所谓协作服务就是社会服务, 在此, 最终用户们积极参与其中, 他们不仅作为 用户，同时还共同承担着设计师和生产者的角色。一些例子包括：在一个资源共享 的社区里, 生活着不同年龄段的老人, 他们按照各自的生活方式, 享受多样化的服 务; 在老人和年轻人的家庭共享式服务中, 学生们既可以找到经济的、有家庭氛围 的宿舍, 同时也为寂寞孤独的老人提供帮助、陪伴和经济支持; 自发组织起来的托 
幼机构为社区的婴幼儿提供服务, 这样既发挥了家长的能力（社会资源）又利用了 闲置的房屋（物质资源）等, 这是现有资源的最佳整合利用。

协作企业是创业型生产和服务企业，通过与用户和消费者建立联系并使他们成 为协作生产者, 创立以当地活动为主的新模式。例如：农户帮助客户体验食物链中 生物多样性的价值; 本地企业教人们如何重新使用旧的二手材料; 体育用品商店里 人们交换二手运动器材; 房地产公司返修房屋, 改善人们的共同生活环境。

合作协会（Collaborative associations）是由一些协作解决问题、寻找新机会的 人员组成（他们再一次成为合作生产者）。这类例子包括：居民们将闲置的土地开 辟成景色秀美的街心花园; 热爱烹饪的人们, 在一个成员的家里聚餐, 共享美食盛 宴, 交流烹饪技巧; 一群人相互帮助交换彼此的时间和技能; 一群老年人和教师为 小学生搭建蔬菜园地。

\section{1 .6 自下而上, 自上而下, 对等互动}

创新社区和协作组织的创新活动采取的是自下而上的方式：“从基层” 开始行动, 逐渐形成有前景的社会创新项目。然而, 仔细观察这些社会创新的演变过程, 从最 初的设想, 发展成为具有成熟的组织形式。这一过程, 表明了其具有长期存在的可 能性。它们往往从开始就依赖复杂的机制, 因此受到了相关人群的关注（自下而上 的互动），创新活动往往能与其他类似的组织进行信息交流（对等互动），并受到 不同类型的机构、民间组织或公司的干预（自上而下的互动）。

例如, 一个小型幼儿园, 在家长的积极参与的支持下得以生存、发展。然而, 它从开始就借鉴其它团体的经验（最终与其中一些团体进行互动），并受到自上而 下的各种政策和工具的支持, 例如: 按照指导手册, 循序渐进地进行设立和管理; 并得到地方当局评估认证方面的支持（以保证其符合既定标准）; 或来自公共服务 的支持（解决那些无法在幼儿园内部解决的医疗问题）。许多类似的例子告诉我 们: 创新社区和合作服务被视为自下而上的举措, 这不是因为所有的一切都来自基 层, 而是因为它们存在的前提是, 对它们感兴趣的人们的积极参与。

因此，它们的创立、日常生活管理和不断完善通常是以复杂的自下而上、自上 而下、对等互动等形式通过各方相互作用而展开的（每个案例的情况有所不同）。 正是在此基础上, 我们认为：即使创意活动和协作行为（每个创新社区和协作组织 的建立必不可少的组成部分）无法于事先进行规划, 但它们还是有很大的存在和发 展的可能性。

\section{2 社区为导向的设计}

创新社区与可能由其产生的协作组织对我们是很重要的, 这不仅仅是由于它们引人 关注的社会学意义（尽管它们只能反映当代社会的一个重要方面），或是由于它们 能够为新企业提供潜在利润丰厚的利基市场（虽然这个机会确实能够也应该被我们 利用）(德雷顿 (Drayton) 和布迪尼克 (Budinich) 2010; 汤姆森 (Thomson) 和 
麦克米伦 (MacMillan) 2010)。更重要的是因为它们是可持续生活方式的 “原型” , 是解决现今许多紧迫问题的可行方案。因此, 它们很有可能被广泛应用, 来为广大 人群的可持续生活方式提供支持。

在本节中, 我们将讨论这种情况是如何发生的：也就是说, 创新社区和协作组 织如何在设计活动（即社区为导向的设计）的支持下得以扩展? 而当代设计师可以 在这方面发挥什么作用?

\subsection{1 日常生活背景下的非正式设计师}

创新社区是 “专家社区”：他们非常熟悉他们所开展的活动。他们创造、设计、测 试、塑造并评估这些活动, 而他们的专业水平无人匹敌; 他们信守承诺并具有很强 的内在动力, 受到明确的价值观和思想意识的驱动。他们既代表生产者也代表用 户, 因为他们体验过这两种不同的角色。它们就像找到了适当栖息地的生态系统, 这个栖息地能够使它们生生不息, 甚至蓬勃发展。

作为设计师, 他们将在实践中获益良多。社区的价值是独一无二的, 无论我 们打算为社区工作, 还是想要从中学习到知识, 都需要对它们有深刻的理解。我 们建议专注于 “以社区为导向的设计” (梅罗尼 (Meroni) 2008b), 而设计师的职 责就是要理解其中的价值和行为, 与最活跃的社区合作共同制定解决方案(欧盖维

(Ogilvy) 2002; 耶由 (Jégou) 和曼齐尼 (Manzini) 2008)。“以社区为导向的设 计”也指在 “以用户为中心” 基础上发展起来的一种综合方法和工具的, 它能够在 复杂的社区背景中理解人们的行为、需求和关系网络。

“以社区为导向的设计”需要两种能力：一是获得与社区和他们所生活的栖息 地的相关知识的能力; 另一个是与非设计师进行创造性合作的能力。前者可以使得 设计师能够融入到环境中, 能够在特定环境中获得直接经验, 获得与社区居民相同 的感受。后者需要设计师将其创造力以各种不同的方式展现出来。

深入一个创新社区的目的是为了深刻理解人们的行为和关键网络的价值, 以 及影响社区结构的关系, 从而在随后的设计活动中, 实现这些价值, 并使其以实 体的形式展现出来。这种看待社区的方式与步凯纳（Buchanan）（2001），定义 的 “以人为中心的设计” 存在密切的关系, 这意味着我们要尊重那些通过产品、服 务和解决方案传达的人类文化和尊严。此外, 深入社区能让设计师们深入了解那些 能够真正带来根本性创新的创新行为、机遇和人们的潜在需求。最后, 深入社区是 最有效的促进人们 “移情作用” 的方式：移情作用设计是一种能够让设计师进入真 实情境的设计方法, 它能够使得项目受益于用户和设计师的情感作用。（莱纳德

(Leonard) 和雷波特 (Rayport) 1997)。

在我们 “以社区为中心设计” 的直接经验中, 移情作用不仅是一个深受欢迎且 可以丰富项目内容的设计方式, 它还是唯一能使设计师能够深刻理解创新社区, 并 学习如何激励人们采取行动, 并与他人合作。

那么, 我们再来讨论一下前面提到的第二种能力: 如果设计师干预的目的是 为了产生一个有创造性的成果, 那么他们与社区的关系将有别于与通常的专业人 士一一客户关系。事实上, 已经有了非正式的创新社区, 但他们之中的设计师肯定 被认为是专业设计师。因此, 设计师很有可能通过以下两种主要方式参与设计: 
- 与社区协作, 改善或解决社区活动中出现的问题。这就要求设计师既具备管 理协作流程的能力, 又拥有跨学科的才干, 能够回归到 “设计创作者” 的角 色, 并以一种正确的态度与那些非专业人士（他们的设计思维在某些方面可 能比专家更为出色) 进行互动。(莱德彼特 (Leadbeater) 2008; 冯・希派尔

(von Hippel) 2004)。这种关系是基于高度协作的体验而建立起来的, 以推 动社区创新活动的展开。它要求设计师积极参与, 共享价值观和愿景。这种 关系不仅带来渐进的创新, 甚至能够带来根本性的创新。

- 运用专业技能解决各类问题, 为社区做出贡献。为解决一些明显的问题, 这 种情况很可能发生, 但从我们的经验来看, 这不会影响到社区活动的核心, 因为社区既有能力又期望为自身设计出这样的系统。设计一个社区的另一种 方式是旨在“复制”或“放大”未来最有发展前途的活动（耶由（Jégou） 和曼齐尼 (Manzini) 2008)。当设计师以系统为出发点, 运用洞察力, “设计”出一个新的解决方案, 以诠释、再现原始想法, 使其在更大的目标 上变得更加可行。即便是根本性创新也能够来自这种“解释”，但这里的关 键问题是能致力于创造未来的“创新社区”。

在接下来的章节中，我们将讨论这两种选项，并对原来 “应用支持平台” 的创意提 出质疑, 揭开新举措的序幕。

\subsection{2 服务、协作、自我设计}

根据蒂姆·布朗 (Tim Brown) 的观点, 我们可以重新阐释这些不同方式的设计, 从“为了社区设计”到“与社区一起设计”，最终进入到“让社区自己设计”的阶 段（布朗（Brown）2009）。

为了进一步朝这个方向发展, 我们必须做出明确的区分：一个现成的但需要一 些设计干预的社区与围绕一个创意和一项活动今后要建立的社区之间存在很大的区 别。其实, 创新社区的 “英雄们” ，他们作为设计师，为这个社区带来了愿景和前 进的力量。它们无法进行复制, 而如果他们不存在, 为了一个新设计的开始, 它们 必须以某种方式被 “取代”。这是当代设计师可能扮演的角色吗?

我们退一步讲。

产生一个新创意、创造性地适应并管理一个现有的社区, 或者直接参与一个新 的项目需要大量时间付出和人员投入。尽管这些英雄式的举动非常吸引人, 但其长 期存在, 以及被其它社区所复制或进行推广将受到客观因素的限制。因此, 这似乎 是协作组织得到广泛应用的主要障碍：只有少数人有能力也愿意跨越出这个障碍, 成为其中的倡导者或甚至是积极的参与者。事实上, 布庸质疑, 对很多人来说这些 举措非常有吸引力, 但大多数这类活动需要花费太多的精力和时间, 也就是说, 需 要投入巨大的资源, 而这些资源在当今被认为是最稀缺的。

社区的英雄并不一定非设计师莫属, 专业设计师（尤其是服务、战略和产品 服务系统 (PSS)设计师) 应该有能力为社区构建方案, 这意味着设计师必须深入 团组和社区中开展互动。这将有助于开展协作设计, 促进日常生活层面系统变化 方面的对话, 实现实际生活方式的重大转变, 同时促建商业机会的出现（梅罗尼 
(Meroni) 和桑吉欧尔盖 (Sangiorgi) 2011)。如前面所述, 为了使得这些情境 有机会寻求适合的土壤, 并形成今后的解决方案(欧盖维 (Ogilvy) 2002; 布朗

(Brown）2009), 它们必须对特定的生态系统有越来越深刻的理解。

必须承认, 设计师的战略角色在于建立特定的产品服务体系, 这个系统可以成 为更复杂的解决方案的组成部分, 业余设计师和 “普通人” 也可以设计和建立自己 的解决方案。我们讲的是通信和生产工具、数字化平台、可转换的对象和空间、物 流和信息服务：各种工艺品和半成品的组件，都可以显著影响社会的自己动手能力。

但是, 如果我们的目标是启动一个新活动、新社区，但社会居民都不愿意成为 社区革新中的 “英雄” , 这些设计师纵有天大的本事, 也无能为力。换句话说, 在没 有创造性、没有胆识的用户面前, 再富有挑战性的方案和智能组件, 也没有用武之 地。

我们目前正在进行各种背景下的研究项目（其中包括一个在米兰都市圈的宏 大计划, 该计划旨在创建一个本地食品系统）。这个项目给予我们的一个重大启示 是: 只有通过项目设计师个人的积极参与, 社会创新才能真正展开。这意味着设计 师的参与度远远超出了专业顾问, 并且他们的动机和价值观也融入到群组之中。换 句话说, 为了启动一个新的社区项目, 设计师必须扮演英雄的角色。在这种情况 下, “为了社区” 还是 “与社区一起” 设计的界限变得模糊, 而设计一个 “退出战 略” 的问题出现了。这实际上成为一个战略设计问题，因为重点落在寻找合适的利 益相关者, 让他们为这项活动也出一份力(梅罗尼 (Meroni) 2008b)。

对于第一个结论, 我们要指出的是: 如果设计活动的目的是在全社会范围内启 动与传播社会创新, “使能平台” 必须有具备下列能力的设计师参与其中:

- 关注创意, 发掘潜在的利益相关者

- 选择那些使社区能够自行管理和创新的组件

- 激励并鞭策参与者们相互支持, 相互协作, 从而创造一个良好的合作环境

- 实施有效的退出策略, 促使团队成功合作

换句话说，我们建议，设计师作为一个 “临时英雄”，要支持新合作社区项目的启 动和发展。 
图11.1 该图片描绘的是大型社区的研究项目, 该项目是关于米兰当地的一个食 物链系统。项目标题为 “供应米兰”，这是一个由大型程序开发出来的 服务网络, 它通过各种产品和服务将城郊的农民和城区的市民直接联系 起来。该图显示了各不同利益相关者的协作设计互动。

来源: 米兰理工大学
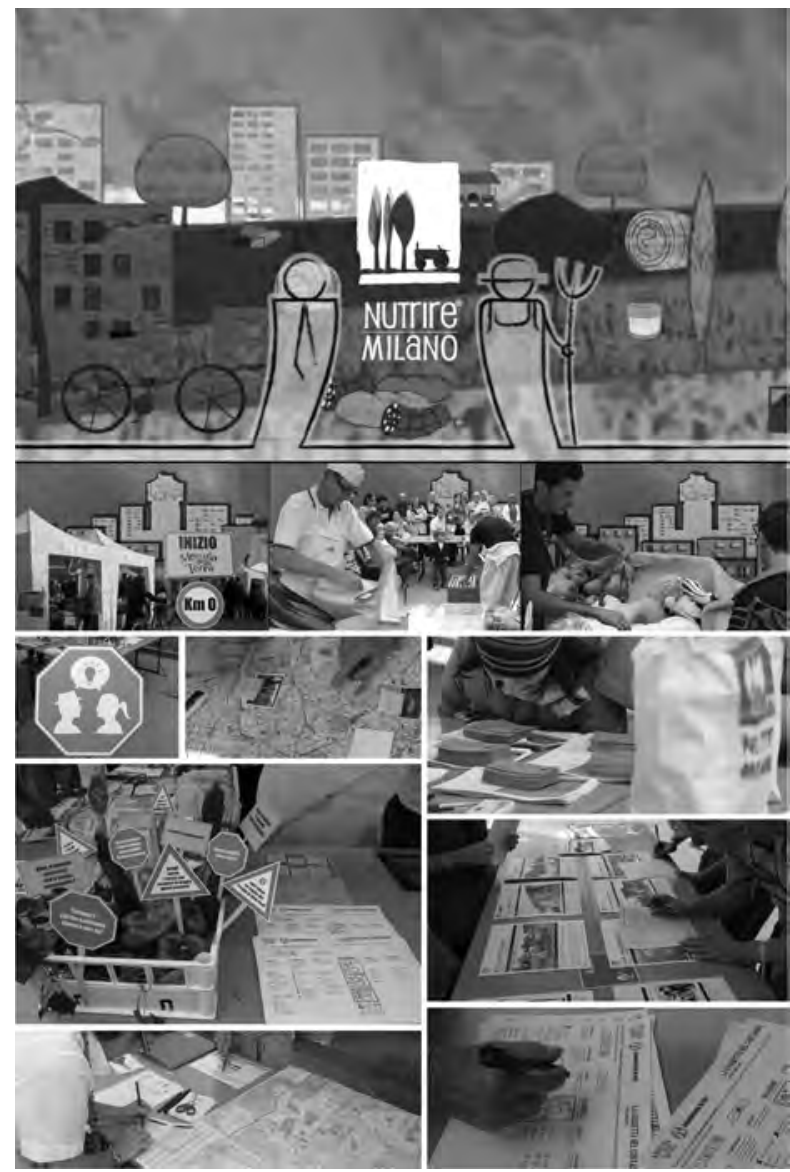

\subsection{3 网络和协同作用}

复制一项优秀的创新方案或开启一项新创新活动并不是鼓励社会创新的唯一方式。 就其本质而言, 其实, 这些创新活动在经济和技术方面十分脆弱且不稳定, 为了使 其得到蓬勃发展, 我们必须找到一种方法, 来改善这种状况。

“协同作用” 的意思是把局部范围内的创新活动联系起来，实现资源和能源共 享, 这将会产生事半功倍的效果。这需要给它们设计一个共同的“框架”, 这是个 包含若干具体方案的大规模项目, 这些方案对区域发展有着类似的愿景并遵循类似 的原则。我们可以把这个框架当作一个情境。 
这些大型项目（如城市再生项目、区域食品网络、以社区为基础的开发和 福利方案）形式多样, 背景各异。然而, 它们呈现出一种相似的体系结构: 它们 通过一个清晰的框架项目进行推动和协调这些当地的自立项目的多样性, 该项目 能够给它们提供一个愿景（为它们指明方向）、一些策略（帮助它们实施愿景） 和一套具体的配套活动（使本地项目具体化、促进项目展开, 并进行整体项目的 交流）。这种活动方式的结果是大型项目，同时，这些项目具有集中性（由于它 们的框架项目），灵活性和适应性（由于它们本质上是小型自立项目的特性）

(梅罗尼 (Meroni) 2008a; 梅罗尼 (Meroni), 西蒙尼 (Simeone) 和特拉帕尼 (Trapani) 2009)。

不同项目（已经存在的或新的）间协同作用的创新可以使它们持续蓬勃发展, 这主要是由于以下两个原因造成的。

可能需要创新社区和企业网络作为其社会基础, 旨在加强各参与方在相关社区 中的参与度, 社区中每个人（《当地的 “变革者”》; 德雷顿 (Drayton) 和布迪尼 克 (Budinich) 2010) 都为集体的成功做出了很大贡献。当共同的愿景赋予具有认 同感和价值观的网络, 建立信任感, 明确动机、展开切实行动并具有一定策略时, 将对创新活动具有促进作用(范·欧斯汀 (Van Alstyne) 1997)。这就是这个框架所 发挥的实际作用。

为了节省时间和资金，必须借助网络的基本功能，分享或补充各种不同资源， 或分享不同方案的运行经验。因此, 我们所说的 “协同作用” 有以下三种主要类型:

- 类似活动之间的协同作用。经济规模和范围类似的解决方案的协同作用, 可 以从共享运营和基础设施, 创造群聚效应中获得益处。

- 互补活动之间的协同作用。经济规模和范围不同的解决方案, 虽然创造不一 样的产品和服务, 却因为一个活动的产出成为另一个活动的投入, 它们之间 有着很多共同的组成部分。

- 兼容的活动之间的协同作用。方案之间形成规模经济可以产生良性互助, 节 约资源并促进解决方案之间的合作。

总之, 发挥协同作用是在同一地点建立创新活动网络的有效方式, 这些活动有 着共同的愿景, 并以协作活动的方式开展。

当今的设计师是否有能力掌控这项工作?

- 我们相信, 设计学校当前的一些项目正在提出一项可以培养这些技能的研究 和培训路径, 这些能力包括:

- 设定情境和框架项目, 帮助利益相关者和创新活动找到共同的发展目标, 以 便让他们更有效地开展工作

- 在不同的主题、相关能力和共同利益背景下的协作设计

- 拥有全方位的教学方法, 使他们能够管理产品服务体系

- 应用设计思维和战略思维, 可以使他们提出整体上的具有可持续发展潜力的 创意：在社会、经济、技术和环境等各个方面 


\subsection{4 当代设计师的视角和角色}

我们已经了解到, 当下正是在设计教育和实践中采取新视角的最好时机。

我们从一些学者那里了解到, 当今的设计师必须有能力为人们创造条件, 使人 们能够发挥自己的创造性去进行创新; 如此一来, 专业的设计师必须能够认识并理 解创新解决方案的背景环境、开发工具和工作方法(艾迪欧公司 (IDEO) 2009)。他 们必须运用专业的设计技能和敏感性, 引导其他参与者, 使他们成为与自己一样优 秀的设计师(萨拉卡 (Thackara) 2005; 默里 (Murray)，凯利尔格莱斯 (CaulierGrice), 和周若刚 (Mulgan) 2008)。总之: “现在是支持人们行动或与别人开展 合作的时候了” (梅罗尼 (Meroni) 和特拉帕尼 (Trapani) 2010)。这两种行动是紧 密联系的, 很大程度上有所重叠; 这是一种合作设计的能力, 并结合专业技能和各 种工具, 将这种能力在实践中发挥出来。这都需要人们用积极的态度进行设计, 系 统地开展能力建设, 并调动人们的积极性。最重要的是, 这要求将设计思维融入到 人们的日常行动中, 成为人们生活中自然而然的一部分。

设计界的各种举措似乎为非设计师熟悉设计思想提供了很好的机会, 同时, 这 些举措也能够支持设计师的创新活动并鼓励他们与他人展开合作。特别是, 一些著 名的设计顾问设计了大量的英语手册和工具包，他们通过这种方式支持自下而上的 创新, 并且通过网站为公众提供了详尽的创新常识 2 。最终, 这些资料和问题设置 与设计工具组合起来, 应用到当地组织或直接应用到开展创新活动的社区中。除了 这种类型的材料之外，使用者可通过互联网享受免费开源的“工具包”、“入门提 示” 以及循序渐进的“教学材料” 3 。

这些材料旨在帮助形成一种工作“方法”（设计思维方式）, 产生新创意, 并结合适当的产品服务体系，而具体的实施的效果将取决于 “设计师”（专业或业 余）的技能和本地的多元化资源情况。我们相信, 这种专业能力（设计知识）可 以由受过培训的设计师带给社区, 这些设计师将会成为社会创新的推动者(曼齐尼

(Manzini) 2009b)。他们的作用不仅仅是促进创新的进程, 而是提出一个愿景并通 过具体的解决方案来实现这一愿景, 激励人们加入, 甚至带领整个社区开展创新活 动。他们将成为社区的 “临时英雄” ，这是我们所说的 “以社区为中心的创新” 非 常核心的一点。这意味我们看重的并不是设计师的专业资历, 而是凭借其独特的敏 感性和与社区的关系, 掌握设计思想和知识的能力。

正如本章所述, 设计师多变的角色并不能构成一个新学科, 但可以结合他们服 务、策略和产品服务体系设计等方面的技能, 形成一个横向的方法, 这种新方法如 今被全世界越来越多的设计项目所采用。

2 只是提供几个例子, 如IDEO, 曾出版过 “HCD以人为本的设计：2009工具包” ; 引擎服 务设计, 曾发布“服务设计: 服务和制造企业”, 以及斯坦福大学哈索 - 普拉特纳设计学 院 (Hasso Plattner Institute of Design) 出版的 “D-School Bootcamp Bootleg”，以上两 部作品均在2010年出版。

3 www.instructables.com, www.makingpolicypublic.net, www.wallacecenter.org/our-work/ Resource-Library/wallace-publications/handbooks/Farmer11-1_Sc.pdf/view. 


\section{3 开放的、分布式设计机构}

如上所述，社会创新是以设计为主导的过程，有其自身的特征：“设计”者们是那些 自觉或不自觉地采用各种形式的“设计思维”和 “设计知识” 的各类社会参与者(布伦 斯 (Bruns)，考特姆 (Cottam)，凡斯敦 (Vanstone) 和温浩 (Winhall) 2006)。

因此, 我们此处所说的“社会创新设计”这一概念的涵盖范围非常广泛。在实 践中, 它是一个 “伞状概念” , 包括 “任何可以启发并支持的社会创新的设计” (曼 齐尼 (Manzini) 2009a)。同样, 我们可以说, 社会创新的设计者是所有积极参与社 会创新的构思和开发的人: “设计专家” 不仅仅是那些已经受过培训的设计师, 也 包括所有自觉或不自觉地应用设计方法并有设计能力的人。

在实际应用中，设计专家在启发并支持社会创新的工作中，主要的贡献可以归 纳为以下四个方面:

- 就项目情境和提议, 在不同社会层面展开对话: 从微观层面（具体的当地问 题）到宏观层面（旨在打造共同愿景）

- 通过与创新社区合作, 促进现有社会创新活动。由于采用了专用工具和专门 设计的产品和服务, 创新社区持续的时间更长, 实施更有效, 参与更方便, 过程更愉悦

- 作为社会创新的践行者（“临时英雄”)，设计者们要借鉴好的创意并不断 提出新创意, 运用设计思维和知识, 在新的社区开展创新工作

- 促进大规模系统性变革, 发挥地方的协同效应, 特别要注重专门策划的“框 架策略”的重要作用

这四个方面的工作需要贯穿到具体的实践活动中, 并且要求掌握那些通过学习 和培训所获得的具体设计知识。凭借学生的积极性和教师的经验, 设计学校至少可 以成为解决复杂问题的实验室, 可以产生新的愿景, 测试并定义新工具。很可惜, 设计学校的这种潜力一直被低估（甚至根本被忽视了）。但是, 如果给予学校一个 适当的框架和支撑平台, 这些潜在的资源可以得到充分的利用, 而学校之间也可以 共享成果并展开交流。换句话说, 所有这些学校, 至少是其中的一部分, 可以成为 能够公开、自由地创造有意义成果的设计实验室。反之, 通过将这些设计实验室整 合起来，我们便有可能建立一个大型分布式设计机构：社会创新项目可以在一个开 放式的设计机构中启动并获得本地支持, 还可以在地方、区域甚至全球范围分享和 讨论经验。也正是本着这种原则和目的, 我们已经在国际上推出这种可持续设计与 社会创新 (DESIS) 网络。

DESIS表示 “社会创新与可持续设计”。它是一个建立在设计学校（或者其他 设计类大学）中的设计实验室网络, 旨在推动可持续的社会创新 ${ }^{4}$ 。这些可持续设计 与社会创新 (DESIS) 实验室团队的教授、研究人员和学生的教学内容和研究方向 有着明确的导向, 以开展和促进社会创新进程为目标。每个实验室都在当地开展项 
目和研究, 但同时它们作为一个更大的类似实验室网络的节点, DESIS网络使各个 实验室之间能够相互交流经验，合作开发更大规模的设计和研究项目。

因此, 可持续设计与社会创新 (DESIS) 网络是一个高度创新型的设计机制: 在这个开放的机制中, 可以解决复杂的相关问题, 建立情境并寻找解决方案, 使其 为社会的对话与交流做出贡献。它是一个分布式机制, 其中许多设计团队平行开展 工作，他们之间相互沟通，对文化、社会和经济的多元化问题保持敏感。

总之, 可持续设计与社会创新 (DESIS) 网络本身可以被看作是社会创新的一 个例子：一个独创的、分布式的组织能够促进现有的社会资源-一学生的热情和教 师的经验（一直以来被低估）的充分利用-一组织中不断产生的创意和解决方案、 概念框架和实用工具, 都将成为可持续发展的催化剂。

\section{参考文献}

Baek, J.S. (2010) A socio-technical framework for collaborative services, Doctoral dissertation, Politecnico di Milano.

Bauwens, M. (2006) The Political Economy of Peer Production. Post-autistic economics review. Benkler, Y. (2006) The wealth of networks: How social production transforms markets and freedom (New Haven and London: Yale University Press).

Bernard, J. (1973) The Sociology of Community (Glenview, IL: Scott Foresman).

Brown, T. (2009) Change by Design (New York: Harper Business).

Brown, T. and Wyatt, J. (2010) 'Design Thinking for Social Innovation', Stanford Social Innovation Review, Winter, 2010.

Bruns, C., Cottam, H., Vanstone, C., and Winhall, J (2006) Transformation Design, RED Paper 02, Design Council, London.

Buchanan, R. (2001) 'Human Dignity and Human Rights: Thoughts on the Principles of HumanCentered Design', Design Issues 17(3): 35-39.

Castells, M. (1996) The Rise of the Network Society, The Information Age: Economy, Society and Culture Vol. I. (Oxford, UK: Blackwell).

Drayton, B. and Budinich, V. (2010) 'A New Alliance for Global Change', Harvard Business Review, September 2010.

Granovetter, M. (1983) 'The strength of weak ties: A network theory revisited', Sociological Theory 1.

Green, J. (2009) Democratizing the future: Towards a new era of creativity and growth (Eindhoven: Philips).

IDEO (2009) HCD Human Centered Design, Toolkit. Retrieved from: www.ideo.com/work/ featured/human-centered-design-toolkit.

Jégou, F. and Manzini, E. (2008) Collaborative services: Social Innovation and design for sustainability (Milan: Polidesign).

Kling, A. and Schulz, N. (2009) From Poverty to Prosperity (New York: Encounter Books).

Landry, C. (2000) The Creative City: A toolkit for Urban Innovators (London: Earthscan Publications).

Leadbeater, C. (2008) We-Think (London: Profile Books).

Leonard, D. and Rayport, J. (1997) 'Spark Innovation Through Empathic Design', Harvard Business Review, November-December: 102-113.

Manzini, E. (2009a) 'DESIS-International: A network on Design for Social Innovation and Sustainability' (Internal document. Dis-Design, Politecnico di Milano).

Manzini, E. (2009b) 'New Design Knowledge', Design Studies 301. 
Manzini, E. and Jégou, F. (2003) Sustainable Everyday (Milan: Edizioni Ambiente).

Margolin, V. (2003) Healing the World: a Challenge for designers (New York: Archeworks).

Meroni A. (2007) Creative communities: People inventing sustainable ways of living (Milan: Polidesign).

Meroni, A. (2008a) 'Strategic Design to take care of the territory. Networking Creative Communities to link people and places in a scenario of sustainable development', Paper presented at the P\&D Design 2008, São Paulo, Brazil.

Meroni, A. (2008b) 'Strategic design: where are we now? Reflection around the foundations of a recent discipline', Strategic Design Research Journal 1(1): 31-38 [available at: www. unisinos.br/sdrj/].

Meroni, A. (2010) 'Design for services and place development. Interactions and relations as ways of thinking about places: the case of periurban areas', Paper presented at the CUMULUS conference, Shanghai 2010, 7-10 September.

Meroni, A. and Sangiorgi, D. (2011) Design for Services (Aldershot, UK: Gower Publishing).

Meroni, A. and Trapani, P. (2010) 'Public spaces as common good. The role of creative communities and collaborative networks', Paper presented at the CUMULUS conference, Shanghai 2010, -10 September.

Meroni, A., Simeone, G. and Trapani P. (2009) 'Servizi per le reti agroalimentari. II Design dei Servizi come contributo alla progettazione delle aree agricole periurbane', In Ferraresi, G. (ed.), Produrre e scambiare valore territoriale: dalla città diffusa allo scenario di forma urbis et agri (Firenze: Alinea Editrice).

Mulgan, J. (2006) Social innovation: What it is, why it matters, how it can be accelerated (London: Basingstoke Press).

Mulgan, G., Steinberg, T. and Salem, O. (2005) 'Wide Open: Open source methods and their future potential', Demos (Ed.). London.

Murray, R. (2009) Danger and opportunity: Crisis and the social economy, NESTA Provocation 09, London.

Murray, R., Mulgan, G. and Caulier-Grice, J. (2008) How to Innovate: The Tools for Social Innovation. Working paper (London: SIX Social Innovation Exchange).

Ogilvy, J. (2002) Creating better futures: Scenario Planning As a Tool for A Better Tomorrow (New York: Oxford University Press).

Ray, P.H. and Anderson, S.R. (2000) The Cultural Creatives: How 50 Million People Are Changing the World (New York: Three Rivers Press).

Rheingold, H. (1993) The Virtual Community: Homesteading on the Electronic Frontier (Reading, MA: Addison-Wesley).

Rheingold, H. (2002) Smart Mobs: The Next Social Revolution (New York: Basic Books).

Tapscott, D. and Williams, A.D. (2007) Wikinomics: How Mass Collaboration Changes Everything (New York: Portfolio).

Thackara, J. (2005) In the Bubble: Designing in a complex world (London: MIT Press).

Thomson, J.D. and MacMillan, J.C. (2010) 'Making Social Venture Work', Harvard Business Review, September 2010.

Van Alstyne, M. (1997) 'The State of Network Organization: A Survey in Three Frameworks', Journal of Organizational Computing and Electronic Commerce 7 (2 \& 3): 83-151.

Vezzoli, C. and Manzini, E. (2008) Design for Environmental Sustainability (London: Springer). von Hippel, E. (2004) The Democratization of Innovation (Cambridge, MA: MIT Press).

Wellman, B., Haase, A.Q., Witte, J. and Hampton, K. (2001) 'Does the Internet Increase, Decrease, or Supplement Social Capital?: Social Networks, Participation, and Community Commitment', American Behavioral Scientist 45 (436). 


\section{第四篇 适度设计新方法}




\section{2 \\ 充足经济理论简介}

萨姆皮特 · 莫伊 ·福萨克勒（Sompit Moi Fusakul）

泰国先皇技术学院, 建筑学院

\section{1 充足经济理论的起源}

充足经济理论 (SEP)是由泰国国王普密蓬·阿杜德 (Bhumibol Adulyadej) 提出 的。普密蓬国王在位65年, 在保障人民福祉上多有建树, 充足经济学及其哲学思想 就是他为促进人类发展、消除贫困、保护环境所做出的贡献之一1。

1974年7月18日, 充足经济理论（SEP）－词首次出现在泰国农业大学 （Kasetsart University）毕业典礼的皇家演讲中。

经济发展必须循序渐进。首先, 应该巩固经济基础, 解决大多数人民的温 饱问题。当取得一定进步后, 才能进入下一阶段, 即追求更高水平的经济 发展。如果只注重经济发展的速度, 而忽略人民需求和国情, 那么将不可 避免地出现各种不均衡现象, 重蹈某些国家的覆辙, 必以失败或危机告 终。

自那次开创性的演讲之后, 充足经济理论就成为该国社会生活的指导方针, 并成为 适当商业行为的指南。

1997年的亚洲经济危机之后, 充足经济理论再次受到重视, 成为应对全球化和 快速变革的一个解决方案。1997年, 普密蓬国王重申了充足经济理论的重要性; 不 久之后, 国家经济与社会发展委员会, 经国王授权，对SEP这一泰国提出的非正式译 法进行了完整诠释(萨希拉坦(Sathirathai)和皮波斯拉威优特(Piboolsravut) 2004：9)。

1 详见第一章, 3.5.2部分。 


\begin{abstract}
“充足经济”提倡的是一种中庸思想, 是各层次人群应树立的行为准 则...... “自足”意为适度、合理, 或是一种自卫的免疫机制, 能够抵御内 在或外界的变化对自身产生的消极影响。为了达到这一要求, 应明确该理 论须经过深思熟虑后才能加以应用。同时, 也要重视提升国家道德建设, 只有这样, 每个人, 特别是各级公务员、学者和商人, 才会重视并坚持诚 信原则。
\end{abstract}

从实质上讲, 充足经济理论是一个整体性概念, 是指在生产和消费过程中实现一种 适可而止的状态，人与人之间、人与自然之间应保持一种相互依存的关系。它涉及 经济增长、可持续性、人权和安全、平等和政治参与等方面的问题。充足经济理论 与联合国议程中的理念不谋而合, 把人类的发展放在第一位, 让人们能够过上健 康、有知识和创造性的生活。2006年5月26日, 联合国秘书长科菲·安南将史上第 一个人类发展终身成就奖 (Human Development Lifetime Achievement Award) 颁给了泰国国王普密蓬·阿杜德陛下, 以表彰他为人类发展做出的贡献。安南称赞 道, “在这个全球化快速发展的时代，充足经济理论与全球每一个角落都息息相 关。该理论中的 “中庸道路” 强调了联合国的主张, 即要走以人为本、可持续发展 的道路”（联合国2006）。

\title{
12.2 充足经济理论的实质
}

2001年，泰国成立了一个工作小组，以进一步研究充足经济理论，使其能够被 普通公众理解并将其应用到实际行动中。该小组由国家经济与社会发展委员会

(NESDB) 、泰国王室财产局(CPB)和最近成立的充足经济研究小组(SEWG)构成, 其目标是在充足经济理论的基础上构建一个经济学框架。

在充足经济理论官方定义的基础之上, 充足经济研究小组 (SEWG) 使用演绎 法开展研究工作, 从语义和语法学两个角度对这个定义进行分析。研究小组得出了 以下结论（皮波斯拉威优特（Piboolsravut）2009）：

\subsection{1 形式和功能:}

- 在议程中, 充足经济学将中庸路线诠释为 “经济生活的指导性原则”, 即对 现实世界的规范化表述，而非对某种宗教信仰的解读。

- 在实施过程中, 充足经济具有可延展性, 同时具有 “普通适用性”。应用范 围包括: 个人、家庭、社区、项目、企业、管理层、机构、政策、社会、国 家、宗教、人类以及生物圈。

- 充足经济理论作为经济框架的基础, 具有完整的结构, 范围涉及从动机

（实用性、驱动力等）到标准（目标、目的等），从行为（生产、消费、投 资等），到体制（集合性、连通性等）等方面。可以说，充足经济理论能够 解决在动态环境中出现的任何问题。 


\subsection{2 相关背景:}

- 充足经济在相当长的一段时期内都在发挥作用, 但它绝不只是亚洲经济危机 的产物。经济危机后, 充足经济理论作为全球化和快速变革的一种解决方案 再次受到重视。

- 在未来的发展进程中, 这种中间道路依然至关重要, 尤其是在当前为了跟上 全球化的步伐, 实现经济社会发展的这个阶段。在将来, 充足经济能确保为 材料、社会、环境、文化等领域的广泛而深刻的变化做好准备, 并保持各方 平衡。

\subsection{3 工作定义:}

- “自足”由三个部分组成:

一适度，即“足够的”，既不多也不少，处在自给自足与过分节俭之间。

- 合理, 也就是一一对所有行动的原因进行评估，并知晓其全部后果。

- 系统对自身免疫力的要求一一能抵御内在或外界的变化造成的冲击。

- 这两个基本条件是达到“自足”所必需的。

- 知识, 即智慧, 用细致和审慎的态度深刻理解信息的含义, 在理解的基础 上实现对信息的积累。

- 道德, 即一一当人们在生活中不解、无私、慷慨地追求他们的生活目标 时, 他们身上所展现出来的诚信品质。

图12.1显示了一个充足经济的架构。三个相互环扣的圆表示三大组成部分，即合理、 适度和自身免疫系统。该图中三者之间是相互关联、相互依存的关系。为了使这三 个组件之间彼此达到适度水平, 个人必须掌握足够的知识, 以提升自身的道德修 养, 使生活变得更加安定, 增进自然与社会和谐。因此, 充足经济理论有助于个人 和团体在应对突发情况时做好准备, 并保持平衡性; 当遭遇不可预测的冲击时, 能 够使自身获得免疫。如：材料、社会、环境、文化、科技和其他不同类型的影响。 


\section{图12.1 充足经济理论架构}

来源: 作者

\section{充足经济理论：中庸道路}

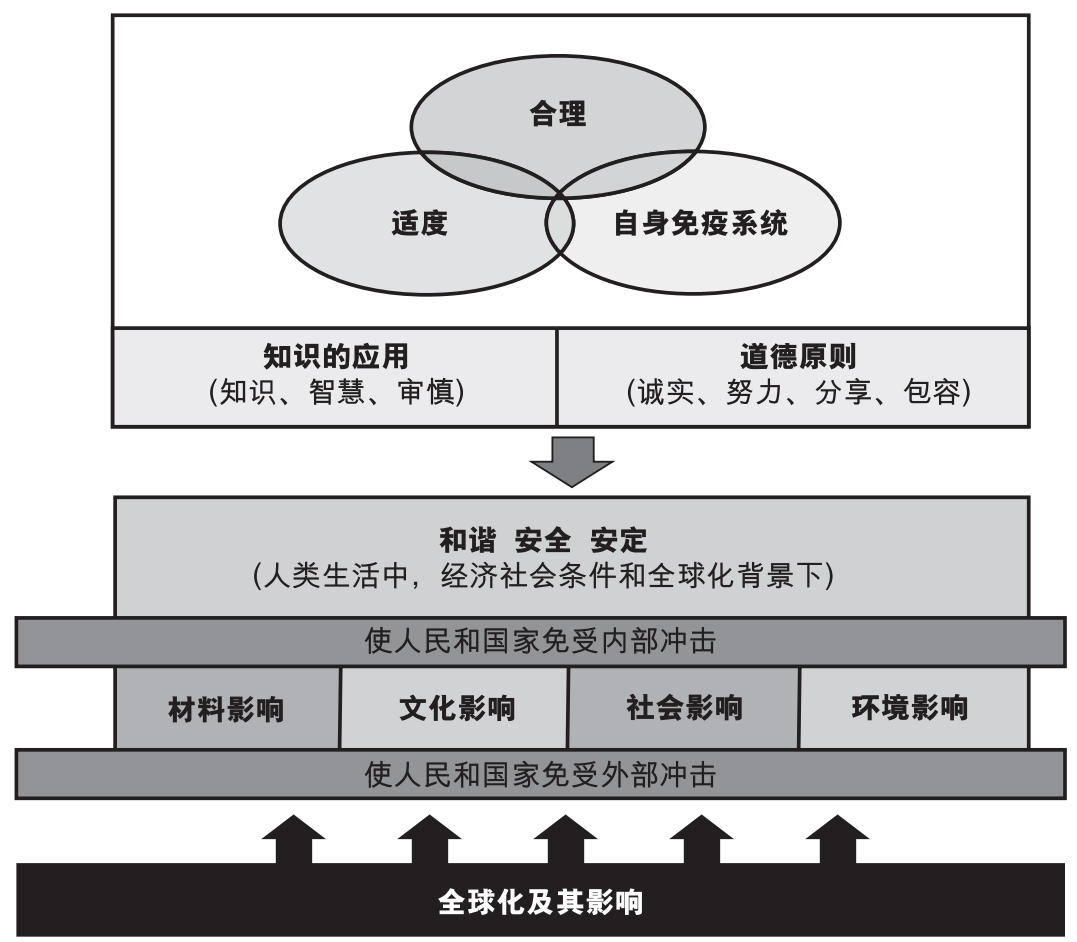

\section{3 充足经济理论的应用}

在众多的应用并解释充足经济理论的项目中，国王在迟塔拉达宫开展的“皇家迟塔 拉达农业项目” 是其中最有价值的实验，该实验通过对知识进行积累和整合，促成 了“新理论农业”的出现和“皇家发展学习中心”(RDSC)的建立。

半个多世纪以来, “皇家迟塔拉达农业项目”一直开展着广泛的农业试验和 示范活动。该项目从一个小鱼塘开始, 随着项目的逐步开展, 渐渐扩展到更多不同 的领域, 其中包括稻田、菜地、小树林、家畜围场、大米加工厂、乳品厂、小型工 厂、林地、植物研究和生物柴油等项目。 
图12.2 迟塔拉达宫的可持续循环项目

来源: 作者

\section{Sustainable Cycle at Chitralada Villa}

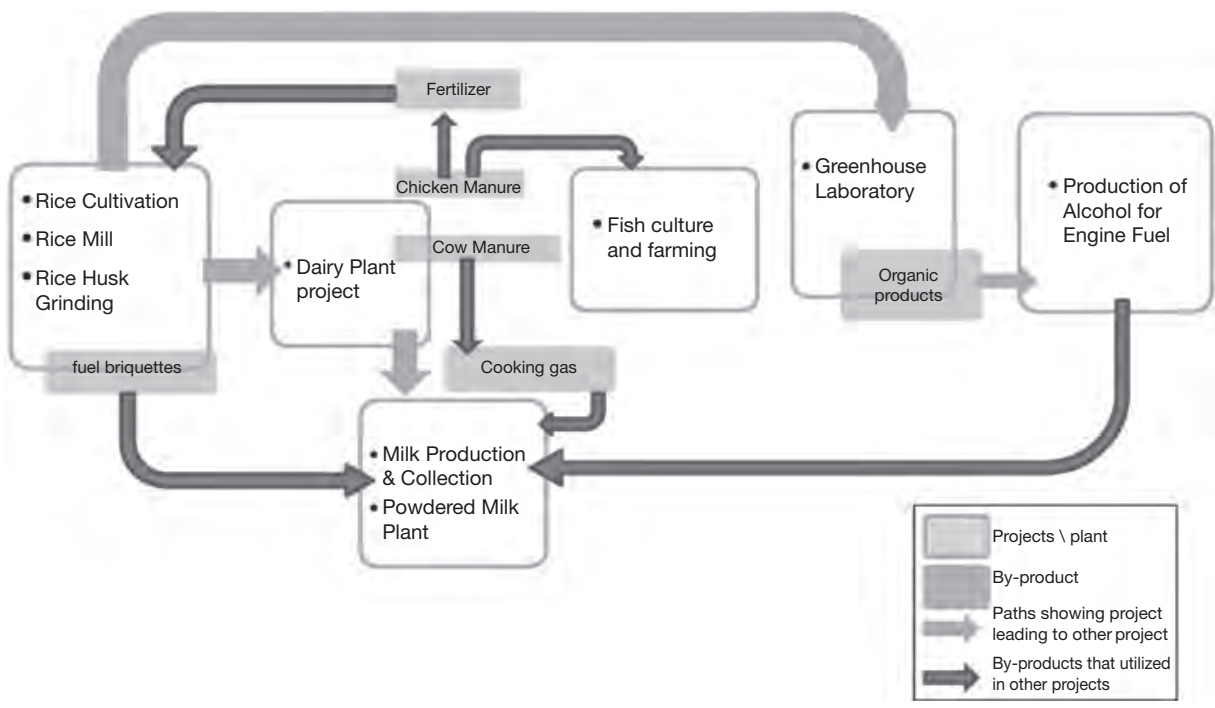

经过数十年的试验, 该项目向农民及当地的社区传授并推广了综合农业知识。 迟塔拉达宫是最初的试验场地，现在变成了一个巨大的“教室”，提供可持续农业 科技知识和自给自足的生活方式的示范课程。所有对这一项目有兴趣的人, 包括外 国人, 均获准到这个 “教室” 中参观一天。游客从观摩活动中掌握了相关知识, 并 对其进行加工整理, 将来可以更好地应用在他们自己的生活和企业环境的改善上。 这些项目不仅旨在展示几个合理利用农业资源的易于理解的模式，更在于促进一种 全新使用方式的推广, 即实现资源更经济、更可持续并更充分地利用。

尤其值得一提的是, 大多数项目是相互关联和自给自足的, 因为一个项目可能 会直接影响其他相关项目的开展, 而一个项目的副产品可以用于其他项目。这种相 互关系说明了综合农业系统可以实现最高效的可持续循环（见图12.2）。

该项目证明, 人类可以在满足个人需求的同时保持生态的可持续性。

\subsection{1 促进个人发展}

农民占泰国人口的绝大多数, 他们生活贫困且缺乏基本的日常生活必需品, 因此泰 国制定了农业综合体系指导方针，该方针通常亦被称为“新理论农业”。这一理论 旨在改善农村家庭的生活和工作条件, 鼓励更多自力更生的社会与经济生活方式的 产生, 使他们能够与当地的自然和社会环境和谐共处。根据国家经济社会发展局

(NESDB) 的数据（皮波斯拉威优特（Piboolsravut）2000：5）新理论农业包括三 个阶段：家庭、社区、国家的自给自足。 
第一阶段是政府通过制定家庭土地管理指导方针, 有效地为家庭提供居住用 地、充足的洁净水、营养丰富的食品, 保障他们最基本的生活需要, 从而实现家庭 的自给自足, 并通过在当地推广草药种植来提高人民的福祉。应用可持续农业技术 必须经过仔细的选择。例如, 害虫与除草之间相互关系的利用; 有效微生物制剂技 术在肥料中的应用; 季节性轮作, 以及整个农业体系。

第二阶段是通过合作和过剩资源的分享, 使社区实现自给自足。通过降低生活 成本和创造收入, 使社区达到更高层次的自足状态并改善社区成员的生活。小屋活 动、储蓄小组、社区企业和医疗中心等形式的活动, 在形成了规模经济和范围经济 的同时, 也构建了社区安全网络。

第三阶段是实现国家的自给自足。当社区能够获得外部资源, 能将其活动范围 扩展到不同的组织层次（例如集资建立一个社区碾米厂或银行），便可以达到这三 个阶段中的最高阶段。在这个阶段中, 机构（包括民营企业和政府机构）以协作方 式, 通过制度安排, 加强各参与者之间的互信, 从而在社区中树立社会责任感。

\section{图12.3 由家庭主妇组织成立的纺织企业, 为国内、国际市场生产纺织品。} 来源: 作者

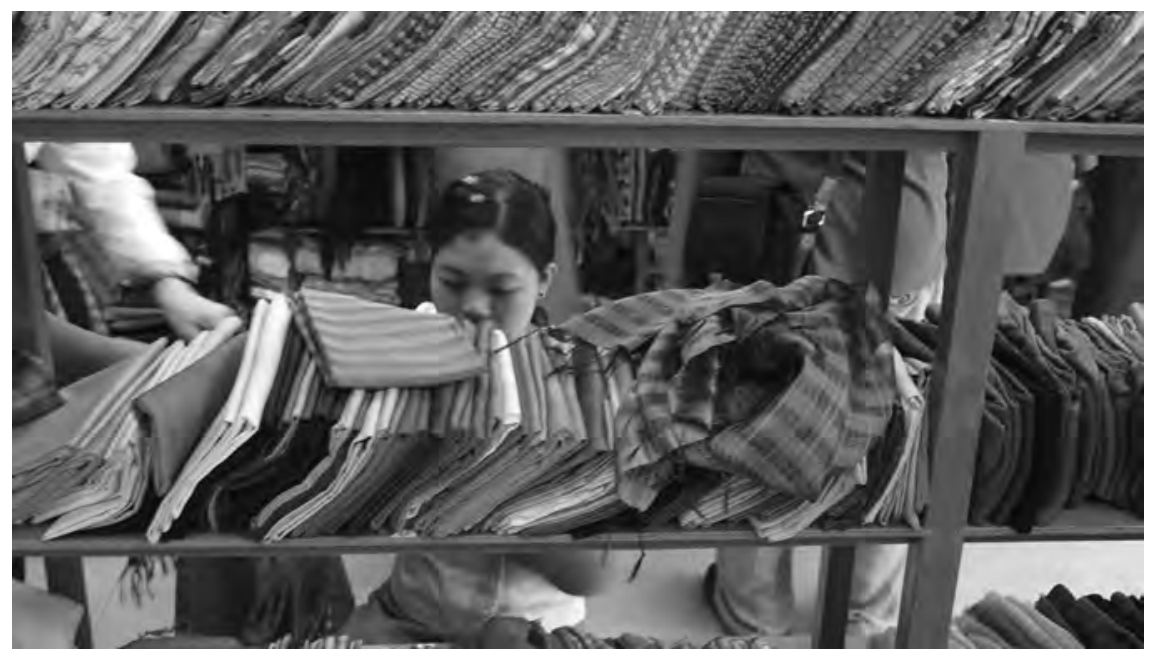

\subsection{2 加强社区建设}

新理论农业的第二和第三阶段为推进泰国的社区建设奠定了坚实的基础。然而, 新 理论农业仅仅是适合农村建设指导方针的一个范本。各专业领域希望能够利用充足 经济理论来制定他们自己的指导方针或计划。国家经济与社会发展局提出了“社区 发展计划” 的五个筹备阶段, 旨在加强公众参与并提升那些已实现家庭自给自足成 员的社区管理能力。这些都为社区成员提供了指导方针, 使他们能够理解并分析社 区当前的情况, 形成共同的愿景和相关工作计划, 彼此之间相互学习, 找到适合自 身的解决方法（皮波斯拉威优特（Piboolsravut）2000：6）。指导愿景的范围包 括: 通过在村寨中种植更多的农作物或蔬菜以降低食物方面的成本支出, 进一步提 
升自给自足水平; 在村寨内部建立一个储蓄基金, 方便村民有需要时随时借款。通 过这五个阶段的实施, 加深了社区成员间彼此的学习和了解, 而作为协调者或促进 者, 政府机构帮助社区制定并实施其计划。在三个财政年度中（即2003至2006年）, 超过三千个社区准备开展社区发展计划（CDP），国家经济社会发展局则是实施这 一计划的主要协调机构。

\subsection{3 推进商业部门的发展}

在日常生活和商业活动中, 充足经济理论逐渐得到了发展, 而私营企业和组织应当 在实践中应用充足经济理论以实现可持续盈利。敦促企业在商业活动中的每一个环 节都要守道德、讲诚信, 承担社会责任, 关注环境保护问题; 注意平衡各利益相 关方，如消费者、员工、企业合伙人及股东之间的利益分配; 确立良好的公司治 理模式; 谨慎处理风险管理问题（充足经济活动小组委员会 (Sufficiency Economy Movement Sub-committee) 2007: 1)。

那些遭受1997年亚洲经济危机, 但依然生存下来的许多公司, 很好地证明了充足 经济理论在增强企业活力和自身免疫力方面的巨大作用, 这些公司因此免遭全球性经 济危机的影响（联合国开发计划署 2007：70）70)。这些企业包括：春蓬卡巴那酒店

(Chumphon Cabana Resort) 、暹罗水泥集团（Siam Cement Group）、泰国国家石 油公司 (PTT)、泰国东芝 (Toshiba Thailand)、泰国庞达珠宝 (Pranda Jewelry) 和泰国邦乍石油公司（Bangchak Petroleum）。这些企业获得了2010年充足经济竞赛 的一等奖（First Prize Winner of the Sufficiency Economy Contest in 2010）。

2010年3月, 泰国朱拉隆功大学Sasin商学院 (Sasin Graduate Institute of Business Administration of Chulalongkorn University) 出版了一本题为《充足经 济理论影响下的公司可持续性》的书。在公司可持续性这一广泛议题的基础之上, 这本书从商业和管理这两个方面解读并深化了充足经济理论, 并形成了理论框架。 这本书采用了一系列案例, 如公司洗手间设计、春蓬卡巴那酒店、泰国Nithi食品公 司、泰国Nopadol Panich陶瓷公司和泰国美巴侬牌调味品公司等, 分析充足经济理 论与企业之间的相关性，以及泰国各行业企业在其运营过程中如何采用并体现公司 可持续性 (Corporate Sustainability) 的原则(SGIBA 2010：14-22)。这本书也对充 足经济理论中其它术语的使用提出了自己的意见, 包括充足经济理论原始内涵: 充 足经济理论的合理性与公司治理、适度性与可持续性、自身免疫力与风险管理等概 念一起使用。

\section{4 充足经济理论的普遍适用性}

根据《充足经济的意义与应用》一书所述, 充足经济理论能够被所有层次（即 家庭、社区和国家）和不同“团体”的人群所应用（充足经济活动委员会分会

(Sufficiency Economy Movement Sub-committee) 2007：12-31)。这些人群分别 是农民、商人、政治家、公务员和教育工作者。关于教育, 这本书提出, 一个教师 或讲师应该在生活中践行充足经济理论, 成为学生的行为榜样, 这样他们能够以身 
作则, 通过课堂教学和实践活动, 引导学生更好地理解充足经济理论（充足经济活 动委员会分会 2007: 29-30)

许多例子都表明了充足经济理论的成功应用, 因此, 泰国人民越来越接受这个 概念并认识到它的重要性。充足经济理论设计在可持续系统设计和可持续产品服务 系统设计中扮演着重要的角色。

\section{参考文献}

Piboolsravut, P. (2000) 'Sufficiency Economy: Introductory note: 10th UNCTAD', Office of National Economic and Social Development Board, Bangkok (Thailand), http://www. sufficiencyeconomy.org/mfiles/1073646388/Research $\% 20$ Note $\% 20$ on $\% 20$ Sufficiency $\% 20$ Economy.pdf [accessed 28 June 2013].

Piboolsravut, P. (2009) 'Thoughts on Sufficiency Economy: Interview with Dr. Priyanut Piboolsravut', Sufficiency Economy Research Project, http://www.aseanaffairs.com/interview_ dr_priyanut_piboolsravut [accessed 28 June 2013].

Sathirathai, S. and Piboolsravut, P. (2004) Sufficiency Economy And A Healthy Community, For 3rd IUCN World Conservation Congress Bangkok, Thailand, 17-25 November 2004, http://pikul.lib.ku.ac.th/FullText_SE/SE010224.pdf [accessed 28 June 2013].

SGIBA (Sasin Graduate Institute of Business Administration of Chulalongkorn University) (2010) Corporate Sustainability Under Sufficiency Economy Philosophy, Chulalongkorn University, Bangkok, Thailand, http://brainbank.nesdb.go.th/Portals/4/know_pdf/Corporate $\% 20$ Sustainability $\% 20$ under $\% 20$ the $\% 20$ Sufficiency $\% 20$ Economy $\% 20$ Philosophy.pdf [accessed 28 June 2013].

Sufficiency Economy Movement Sub-committee (2007) Sufficiency Economy Implications and Applications, Office of the National Economic and Social Development Board, Thailand (September 2007), http://www.nesdb.go.th/Md/book/booksuffwork_eng.pdf [accessed 28 June 2013].

UN (2006) 'Thai King's development agenda, visionary thinking inspiration to people everywhere, says Secretary-General to Bangkok panel', UN Secretary-General Kofi Annan address to panel 26 May 2006 (New York: UN Department of Public Information), http:// www.un.org/News/Press/docs/2006/sgsm10478.doc.htm [accessed 30 November 2012].

UNDP (United Nations Development Programme) (2007) Thailand Human Development Report 2007: Sufficiency Economy and Human Development, UNDP, Bangkok, Thailand, http://hdr.undp.org/en/reports/nationalreports/asiathepacific/thailand/name,3418,en.html [accessed 28 June 2013].

For more on the Sufficiency Economy:

Isarangkun, C. and Pootrakool, K. (2005) 'Sustainable Economic Development through the Sufficiency Economy Philosophy', www.sufficiencyeconomy.org/old/en/files/3.pdf [accessed 28 June 2013].

Mongsawad, P. (2010) 'The Philosophy Of The Sufficiency Economy: A Contribution To The Theory of Development', Asia-Pacific Development Journal 17 (1), http://www.unescap. org/pdd/publications/apdj_17_1/5_Mongsawad.pdf [accessed 28 June 2013].

Office of the Royal Development Projects Board (2004) 'The Royal Development Study Centres and the Philosophy of Sufficiency Economy', http://www.sufficiencyeconomy.org/old/ en/files/14.pdf [accessed 28 June 2013].

Senanarong. A. (8 November 2004) 'His Majesty's Philosophy of Sufficiency Economy and the Royal Development Study Centres', PowerPoint document presented at the Ministry of Foreign Affairs, Bangkok, Thailand, http://www.sufficiencyeconomy.org/old/en/files/16.pdf [accessed 28 June 2013]. 


\section{3 \\ “自力更生”原则在充足经济设 计中的应用}

帕瑞恩纽治・斯瑞迪治（Praoranuj Siridej）

泰国先皇技术学院, 建筑学院 (Faculty of Architecture, King Mongkut' s Institute of Technology Ladkrabang, Thailand)

\section{1 自力更生的必要性}

1997年亚洲经济危机的严重程度超出了每个人的想象。这场危机给泰国的社会经 济造成了巨大的影响, 资本、收入分配不均, 发展不平衡导致了自然资源和环境的 退化, 甚至对道德水平和文化价值观都产生了消极的影响。泰国人民和社区都遭受 了巨大的损失。受危机影响最大的是那些一无所有的人一一失业者、贫民、小型企 业主及社会地位低下的广大农民（提苏拉诺达（Tinsulanonda）2001）。1997年 危机期间, 为促进经济稳定发展和快速恢复, 充足经济理论再次受到人们的关注 (UNESCAP 2006)。

这种理论对昔日那些只关注经济发展的理念提出质疑, 倡导一种以人为本的新 型发展模式，使每个人都实现自力更生，并保证各方彼此之间的平衡（亚洲生产力 组织 2008)。这个方法要求人们暂时停下来进行反思一一根据现实需求以及当地的 具体条件和环境, 集思广益, 采用相应的技术来解决问题。充足经济理论提倡的自 力更生指的是用智慧和知识评估优势与不足, 形成相应工具, 使个人、社会和国家 能从容应对各种内部和外部的变化。

然而, 自给自足并不意味着要彻底与他人隔离、“闭关锁国”：即一个国家或 社会单位完全依靠自己, 本国人民或社会成员独立生产所有必需品, 无需他人的丝 毫帮助。而该理论所提倡村庄与城区应实现的是相对自给自足, 本地生产的剩余产 
品可以销售到其他地区。一些人把充足经济理论视作另一种“甘地的经济理论”： 即主张的一种建立在家庭和小型企业基础之上的传统经济模式。当时恰逢20世纪 中期, 印度因其技术水平有限, 这种经济学恰好符合当时印度的国情。但现在这种 做法显然是不合时宜的, 放眼如今开放的世界, 现代化和现代科技的应用无处不 在（克朗克伍（Krongkaew）2003）。因此充足经济理论认为, 全球各地之间的 相互依赖不断加强, 人们对自然环境的依赖可通过适度消费体现出来（萨希拉坦

(Sathirathai) 和皮波斯拉威优特 (Piboolsravut) 2004)。通过践行充足经济理论 的三项原则（适度性、合理性和自身免疫力）和两个基础条件（知识和道德），人 们能够在可持续的社会、环境中自力更生, 和谐生活。

为了贯彻自力更生的方针, 充足经济理论建议在以下五个方面实现绝对平衡 (联合国亚太经社理事会(UNESCAP) 2006)。

- 心理状态。一个人应该具备这些素质：坚强、自食其力、富有同情心、适应 性强; 应该具有良好的道德品质, 并且能够将公众利益放在个人利益之上。

- 社会事务。人们应该互相帮助, 加强社区建设, 维护团结并且构建一个学习 机制。

- 自然资源与环境管理。有效利用国家资源, 创造可持续效益, 并维护国家资 源的安全稳定。

- 科技。充分发挥当地村民的聪明才智, 推进新技术的研发。

- 经济事务。一个人应该增加收入, 减少支出, 追求体面的生活。

\section{2 自力更生的应用}

\subsection{1 农业和社区发展中的自力更生：新理论}

为了实现个人的自食其力（尤其是泰国的农民，他们收入低，生活基本需求都难以 保证），泰国决定推行一种全新的可持续的农业系统，这就是泰国众所周知的 “新 理论农业”。由于利润丰厚, 许多泰国的农民一般都选择种植单一品种的农作物或 者经济作物。然而, 这种农作物很大程度上受到市场价格的影响, 因此, 农民在面 对外部价格冲击时变得非常脆弱。产品的供过于求使价格大幅走低, 迫使农民不得 不借钱以实现再生产。最坏的情况是：在经济作物青黄不接而家无存粮的时候，农 民又不得不借钱购买食物。此外, 为了增产增收而大量使用化肥和杀虫剂的做法会 对环境造成破坏。从长远看, 这种做法是不可持续的。根据新理论, 家庭应该将经 济模式从种植单一农作物或经济作物, 调整为发展综合农业。通过这一做法, 农民 个人和家庭都能够实现自给自足。通过对土地进行综合管理，他们能够实现“衣食 无忧”，与自然和社会和谐相处。以下对“新理论农业”如何在不同层面帮助泰国 农民实现自力更生进行了讨论。 


\section{个人和家庭的自力更生}

家庭的目标是: 使每个家庭都实现自力更生, 在劳动成果满足其基本需求的情况 下, 出售多余的农作物和产品, 获取足够的收入, 而无需再依赖于他人。这将使农 民获得基本的免疫能力。

新理论虽然主要针对泰国平均拥有大约10-15莱（rai）（2.4公顷）土地的家 庭, 但是它也适用于那些拥有更多土地的农民家庭。通常, 土地按30：30：30：10 的比例被划分为几个部分, 并规定好其不同的用途（即30\%用于水稻栽培; $30 \%$ 用 做水池, 如建造鱼塘或者蓄水池; $30 \%$ 用于综合农业和园艺作物种植, 如水果、蔬 菜以及牲畜饲养; 剩下的10\%作为住宅用地和其他用途。）由于水稻是泰国家庭的 主要的种植作物, 新理论估计, 每个家庭按照这个比例种植水稻, 他们可以获得全 家一年所需的口粮, 这样既保障了食品安全, 又省下了高价购买水稻所需的不必要 花费（皮波斯拉威优特(Piboolasravut) 2000：3）。

\section{社区的自力更生}

社区的自力更生是以个人和家庭自给自足的完成为前提的，虽然这些个人和家庭都 已经实现了自力更生, 但是他们都在为更高的目标而奋斗。下一个层面就是要使社 区中的居民们团结起来，以小组或合作的形式来经营他们所共有的资源。这样社区 成员可以减少他们对外部的依赖, 同时他们在资产购置和产品销售方面能获得更多 的话语权。通过规模经济, 他们还可以节省运输和营销成本。可以为了共同利益而 制定社区的生产规划。社区的自给自足有几种表现形式，比如成立社区企业或者进 行合作生产; 用当地产品代替进口产品; 雇佣当地专家而非外地专家; 运用当地智 慧实现创收, 而不是应用不熟悉的新型技术; 组建社区储蓄小组; 不从社区外部借 款, 而是依赖社区内部的资金资源; 实现社区自治, 不依靠外部支持; 自己动手, 丰衣足食, 推行自我管理, 而非等待政府援助; 在发展经济建设的同时, 也对社会 基础设施的建设进行完善。以上这些举措改善了社区的生活环境, 并提高了社区 自力更生的能力。然而, 为了实现整个国家的自力更生, 必须要逐渐推进一些充足 经济之外其他一些方面的发展, 如促进地区之间, 各省之间和国家之间的交流与合 作。

万姆旺村 (Ban Moung Wan) 和奥克山里诺村 (Koak Chareon) (国家经济 与社会发展局 2005) 是实现社区自力更生的优秀案例。这两个社区都实施了储蓄 项目, 在降低开支和债务的同时, 成功地增加了社区的储蓄。微型储蓄项目伊始, 只有10位参与者。每个成员每周需要存入小数目的资金。后来小组成员的数量渐渐 上升到667人, 而他们的储蓄额也达到了 750 万泰铢。现在村民们更愿意从社区储蓄 账户里借款, 而不是到社区外的银行。此举为社区创造了收益。实施该举措获得的 收益分为两部分：一部分全额退还给成员，另一部分是用于其它社区活动的资金。 这个做法展现出了充足经济理论提升免疫力的作用, 凭借这一特点, 就能够使社区 免于遭受外部冲击, 这是实现自力更生的基础。社区活动成功开展的另一个例子可 从这两个村成立的社区商店和碾米厂, 以及汽车服务店等项目中体现出来。这些项 
目获得的部分利润被用做了社区的福利基金，用于将来社区活动的举办和孤儿、贫 民、孤寡老人的赡养费用。

\subsection{2 商业部门的自力更生}

充足经济原则逐渐被运用到各级商业活动中。成功应用充足经济理论获利的企业包 括：春蓬卡巴那酒店（Chumphon Cabana Resort）、暹罗水泥集团（Siam Cement Group)、泰国邦乍石油公司(Bangchak Petroleum plc)、True Corporation，以及 SE-Education集团。以下叙述的是春蓬卡巴那酒店（Chumphon Cabana Resort）的 例子。

\section{春蓬卡巴那酒店和潜水中心（The Chumphon Cabana Resort \& Diving Centre)}

春蓬卡巴那酒店建于1982年, 坐落于泰国的童瓦兰海滩（Thung Wua Laen Beach） 。酒店决定通过银行贷款拓展其业务, 并建成三家新酒店。不幸的是, 与许多其他 企业一样, 酒店遭遇了亚洲经济危机, 经济上举步维艰。为了挽救企业, 酒店决定 最后一搏, 酒店业主把充足经济理论方法作为酒店管理和规划的指导方针。按照充 足经济理论的自力更生原则, 酒店业主开始在酒店区域内种植水稻、蔬菜、花卉和 水果, 供酒店自己使用: 即为客人和员工提供食物。酒店业主重视环境保护问题, 尝试使用有机肥料（酒店泔水和其他材料等）来改善沙地的土质, 节省购买化肥的 开支。后来, 成立了一家碾米厂, 将果壳加工成肥料和牲畜的饲料。

后来, 酒店从其土地上的收获所得不足以满足其需要, 酒店业主便转移目标, 寻求与员工和村民开展合作, 这些员工和村民多数都是农民, 他们可以供应酒店所 短缺的物品, 酒店还对他们进行培训, 教授他们制作肥料以及其他与有机农业相关 的技能。员工因此除了从事他们的主业之外，在业余时间还可以通过为他人提供服 务来增加收入。充足经济理论的理念渐渐地在社区周围被广泛接受。

当地产品的范围逐渐扩大, 除了食品以外还包括多种利用当地资源、知识、 技术制作的清洁材料。随着产量的不断增加，这些产品也被提供给该地区的其他酒 店。酒店从低成本的生产和有保障的供应中获益。由于没有中间商, 产品的价格也 颇有竞争力, 附近的农民能够为这个市场提供保障。通过成功的经营, 酒店赢得了 良好的声誉。社会各方如其他的酒店业主、农民、非政府组织和政府机构希望从它 的成功运作中学习经验。最终，在农业基础和充足经济制度的支持下，一个名为“ 寓玩于学” (Plearn) 的学习中心落成, 并向公众开放。大量游客前来参观、学习, 酒店员工们因此产生了极大的成就感。从该酒店业主发起的一些其他项目也能够看 出他对旁人、经济状况以及环境的重视。如“巴挑水稻回家”（“Pathiu rice returns home'）活动旨在保护并促进巴挑黄水稻粒有机生长。巴挑黄水稻曾经是泰国普及 率最高的稻粒品种, 其发源地便是在春蓬。然而, 由于现在该地区大多数农民种植 单一品种的农作物, 巴挑黄水稻的种植量一度下降, 在泰国近乎绝迹。在“人在林 在” (People live, forest alive) 项目中, 参与者学习人类与自然和谐相处之道, 如何 
给人类自身带来利益。最后, 一个名为 “大洋” (The great ocean) 的项目关注潜 水运动。春蓬卡巴那酒店开设的跳水课程, 既教授入水的一系列动作, 同时又体现 出了对水资源和教学规律的关注。因此春蓬卡巴那酒店成为中型企业应用充足经济 理论的典范。它向世人展示打造自力更生经济的每一步过程, 在个人自力更生的坚 实基础之上进行逐步发展, 上升为社区和国家的自力更生。

\subsection{3 国家的自力更生}

实现国家的自力更生, 政府和社区领导的作用至关重要。迄今为止, 泰国政府在设 计制定政策时一直沿用充足经济理论（联合国开发计划署2007），特别是那些用于 扶贫和加强社区建设, 鼓励自力更生的相关政策。以下描述的是泰国实现自力更生 的例子。

\section{泰国黎敦山区扶贫开发计划(Doi Tung Development Project)}

泰国黎敦山区扶贫开发计划（DTDP）是由泰国皇太后基金会（MFLF）负责的著名 项目。皇太后基金会是一个非营利性的发展基金会, 旨在提高泰国少数民族人民的 生活质量, 并为他们提供合法稳定的生活保障 1 。众所周知的 “可持续民生发展项 目”（SALD）中的以人为本发展模型就源于这个项目。“可持续民生发展项目”主 要关注三个问题：健康、民生和教育。

泰国北部偏远的黎敦山区是少数民族聚居地, 大约有 1.1 万人生活在 29 个村寨 中。大多数人的谋生方式是种植鸦片、拐卖人口和贩卖武器, 他们的农业生产仍然 沿袭刀耕火种的古老方式。通过长达30年的规划和发展, 泰国黎敦山区扶贫开发计 划 (DTDP) 提供的医疗志愿者, 解决了这里的医疗卫生问题。关注民生的行动从人 工造林入手, 将鸦片种植农和以农业为生的自给工人变成了林业工作者。工人的工 资当天结算, 从短期看, 可以产生积极的影响, 获得当地社区的信任, 而长期效益 则是不可估量（狄思库（Diskul）2010）。教育为长期发展奠定基础, 并将促进可持 续发展, 消除贫困。

16年后, 人工造林项目获得成功, 极大地改善了当地环境。鸦片种植已被咖啡 和澳洲坚果种植所取代。“可持续民生发展项目” (SALD) 成功的一个关键因素是 提高了当地群众的生活质量和生产力, 培养了当地社区的主人翁意识。黎敦扶贫开 发项目允许当地人租借咖啡树, 租金为每年每棵树 0.5 泰铢（约合 0.01 美金）。农民 和他们的家庭十分愿意照料植物, 因为他们培育的咖啡质量越好, 他们获得的利润 就越多。另外, 为了把单纯依赖单个企业的风险降到最低, 该项目还组建了其他一 些商业机构, 包括从事组织培养, 园艺, 编织和桑皮纸、陶瓷、地毯生产和加工的 一系列商业企业。

从2001年起, 黎敦扶贫开发项目在经济上已经实现了自力更生。到2017年, 当 黎敦已经证明具有经济可行性而且当地人有能力自我管理时, 皇太后基金会（Mae Fah Luang Foundation）会把项目完全移交给本地社区负责。 


\section{3 结论}

为了给可持续发展打下一个坚实的基础, 允许并鼓励人们创造他们自己的目标, 培 养自力更生所需的技能、知识和资源至关重要。因为能够凭借自己的知识和道德力 量, 通过适当的方法谋生的个人、社区、企业和国家有能力为实现更高水平的发展 做出贡献, 也有具备独自应对外界不确定性的能力。

本章中的例子表明：充足经济理论提倡的自力更生并不等于完全孤立; 而是 个人、社区和企业都不应过度依赖彼此之间的相互作用。充足经济设计师必须评估 用户 (个人、社区、企业或国家) 的优势和不足, 并分析他们的生存能力和管理能 力。然后根据他们的特殊需要、当地条件和环境状况, 制定出相应的产品服务系统 设计战略，以促进自力更生的实现，从而有利于人类和地球的长远发展。

\section{参考文献}

APO (Asian Productivity Association) (2008) 'Thailand's philosophy of the sufficiency economy for sustainable enterprises', APO News 35 (5): 8, http://www.apo-tokyo.org/00apo_ news/2008/APO_News_05_2008E.pdf [accessed 28 June 2013].

Diskul, S. (2010) 'The Mae Fah Luang Foundation from bare feet to big brand: design in development', in F. Ceschin, C. Vezzoli and J. Zhang (eds.), Proceedings of LeNS Conference Sustainability in Design NOW!: Challenges and Opportunities for Design Research, Education and Practice in the XXI Century (1).

Krongkaew, M. (2003) 'The Philosophy of Sufficiency Economy', http://kyotoreview.cseas. kyoto-u.ac.jp/issue/issue3/article_292.html [accessed 28 June 2013].

NESDB (National Economic and Social Development Board) (2005) 'An Introductory Note: Sufficiency Economy', http://www.sufficiencyeconomy.org/old/en/files/4.pdf [accessed 28 June 2013].

Piboolsravut, P. (2000) 'Sufficiency Economy: Introductory note: 10th UNCTAD', Office of National Economic and Social Development Board, Bangkok (Thailand), http://www. sufficiencyeconomy.org/mfiles/1073646388/Research $\% 20$ Note $\% 20$ on $\% 20$ Sufficiency $\% 20$ Economy.pdf [accessed 28 June 2013].

Sathirathai, S. and Piboolsravut, P. (2004) 'Sufficiency Economy and Healthy Community', in Proceedings of the Third IUCN World Conservation Congress, Bangkok, Thailand, 17-25 November 2004: 1-24.

Tinsulanonda, P. (2001) 'Sufficiency Economy: His Majesty's philosophy for development. Bangkok, Thailand', http://www.generalprem.com/Speech5.html [accessed 28 June 2013].

UNDP (United Nations Development Programme) (2007) Thailand Human Development Report 2007: Sufficiency Economy and Human Development (Bangkok: UNDP).

UNESCAP (United Nations Economic and Social Commission for Asia and the Pacific) (2006) 'Self Sufficiency Economy in Thailand'. 


\section{4}

\section{事理学}

\section{中国的可持续设计思维方法 ${ }^{*}$}

柳冠中 刘新

中国 清华大学美术学院

\section{1 引言}

中国目前所面对的社会与当初工业设计诞生之时所面对的西方工业社会迥然不同。 历史和时代不允许我们去重蹈西方国家的发展道路, 而必须学会总结西方发展过程 中的经验和教训。站在人类文明成果这个巨人肩膀上, 应该看得比这个巨人更远。 因此, 我们必须在借鉴中华文化精髓和中国古人智慧的基础上, 探索自己可持续发 展的理论、方法和实践。

中国总理温家宝提出要 “高度重视工业设计” , 这是中国领导层首次肯定设 计在经济发展中的重要地位, 也预示着可持续设计的研究与实践有望得到社会的广 泛认同和重视。如何建构当代中国语境下的可持续设计理论, 并有效指导设计创新 活动, 是设计、研究与培养下一代生存理念和智慧的重点课题。以人类可持续发展 为指导思想; 以创造人类合理、健康的生存方式、与自然和谐的生存环境为目标; 以高科技为手段来调节市场机制的异化; 并保护人类文化遗产, 为人类大多数谋利 益, 创造更丰富多彩的生活方式。中国目前所处的国内外社会态势和发展需要正是 工业设计的本体论、认识论和方法论提高到 “事理学”- - MATTEROLOGY高度 的“设计学” 新生的机遇与社会基础, 使我们有可能把工业设计作为我国可持续发 展、构建和谐社会、创造自己的知识经济新文化的国策。

* 本研究项目已获得国家社科基金的部分支持（授权号：11BH064） 


\section{2 工业设计在当代社会中的意义}

人类的生存与发展, 除了衣、食、住、行、用物质享有以外, 还有额上的汗、手上 的茧, 人与人的接触、沟通、谅解, 与大自然的互动、共生, 与他人一起参与、合 作、改造、创造时产生的行动节奏、思想谐调统一的乐趣、情感、情操, 以及对自 然和一切存在事物的尊重。社会的任何进步, 首先是品行道德、社会风俗、政治制 度的进步, 这都属于科学的发展和文化的进步。这就是目前中国社会发展现实的反 思, 也是工业设计所面临的现实。

首先, 认识任何人为事物都必须从三个层次入手：“物质层”、“组织层”和 “观念层”（图14.1）。同一事物, 由于观察者的立场、角度、层次等不同, 或着 眼的动机、过程、结果、观念、方法、技术、工具、影响等等不同, 其结论完全不 同。语言包括这些层次：中国的汉字是世界上唯一自古至今以 “象形” 又 “会意” 的方式记录和传达了人在认识客观世界的基础上, 把主观的想象和意念也整合到文 字中的符号系统。中国传统思想一贯主张整体、综合地对待世界上的一切事物。

\section{图14.1 设计的关系和机制}

来源：作者

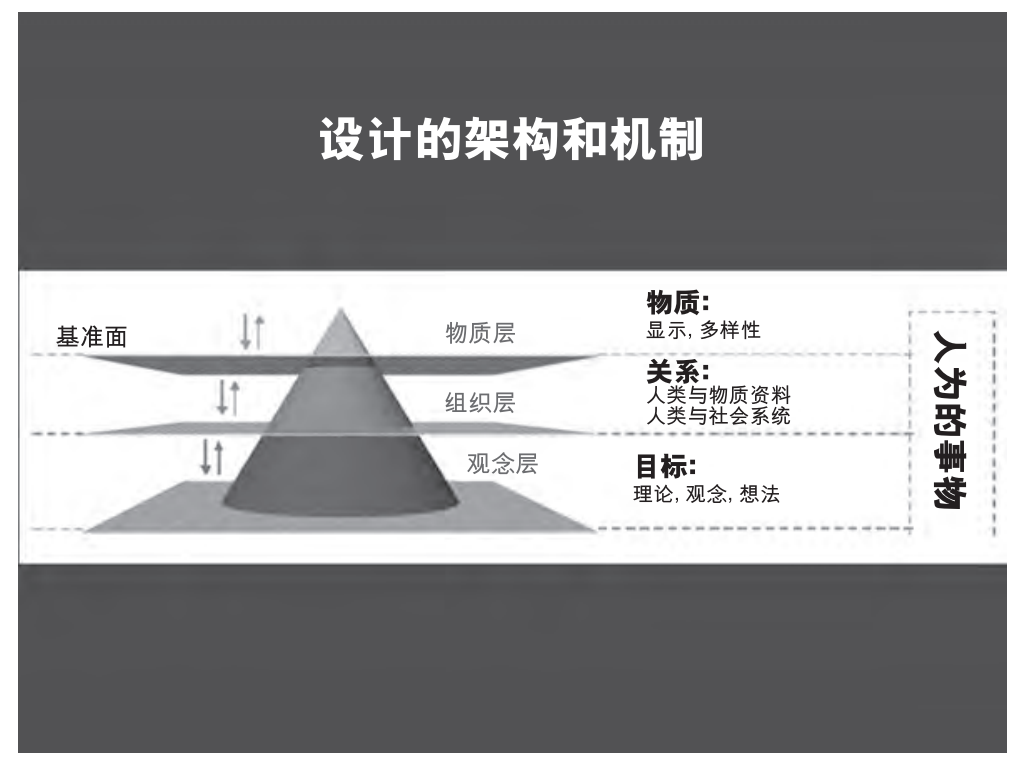

概念是随着时代社会背景和社会关系的变化而不断演化着的。“工业设计” 诞生于 “手工业经济” 向 “产业化经济”演变的过程中。德国是“工业设计”发 源地, 工业设计是基于产业革命的“大生产分工” 经济基础上的“社会结构” 这 个 “上层建筑”的产物。以“政府作为背景”的“德意志制造同盟” (Deutsche 
Werkbund）的建立标志着德国经济机制的“组织工业化”。设计这个工业革命的新 生事物从一开始就是为了解决小生产方式不适应大生产方式而被催生出来的一种“生 产关系”。因此, 设计是自发产生的一种以横向的思维逻辑指导、用系统整合的方 法、体现在创意、计划、流程、效果的统一上的工作方式。其目的天生就是为了协 调社会各工种、各专业、各利益集团的矛盾。这才是工业设计（或称产业设计）的 目的、本质。由于工业设计初期的工作对象主要是产品, 这就极容易被狭义地解释 为 “工业产品的设计”; 或由于工业革命以来, 出现了大批新事物, 其外观造型与 手工业时代的工艺美术品大相庭径, 因此被表面地认为是对产品外观造型的美化。 而淡化了对其本质的理解- - “工业时代设计活动的理念、方法”。

因此, 当今 “可持续设计” 的本质应是 “重组知识结构、产业链, 以整合资 源, 创新产业机制, 引导人类社会健康、合理的、可持续生存发展的需求”（见柳 冠中2009a, b) 。

\subsection{1 设计的 “元” 与 “本”}

此物与彼物的抽象意义是一致的。

- “搓板、洗衣机、自助洗衣站”;

- “算盘、计算机、计算中心” ;

- “扫帚、吸尘器、保洁服务”

- “房屋、建筑、小区、城市”。

它们有共同的 “目的”：或为了干净的衣服; 或为了数字计算; 或为了除尘卫生; 或为了居住生活。这就是设计的不变内容- - “元”与“本”。“设计”总是不 断的求新, 总是向人们展现出最大的变化性, 但是我们不该忘记它永恒不变的内 核: “人类有目的的, 针对未来的, 创造性的社会活动”。

设计是 “以人为主体有目的活动的社会全过程”- - 人类为了生存在适应和改 造自然、创造和借助工具、在实践中把 “梦想”变为 “理想”过程的“思考”和“ 创造”- - “在改造自然的过程中改造人类自己, 并创造与自然和谐的人类社会” 。设计是一种创造行为, 是 “创造一种更为合理的生存(使用)方式”。这个提法似乎 有点 “抽象”：不像搞技术的专家所希望的那样具体, 例如某某产品设计, 某某造 型设计。而设计一旦被圊于一种物的设计的话, 就已经被这个物的概念和现象束缚 了设计师的创造力。

工业设计是人类总体文化对工业文明的思想和修正。是从设计 “物” 到设计 “事”的升华。因此，工业设计的范畴也已经可以是 “谋事”- - 全新的社会系统 的 “设计”：如工作、学习、饮食、娱乐、休息、交流等生活方式的概念创造、策 划、开发。 


\section{3 从设计 “物” 到设计 “事” 的转变}

大千世界这个自然系统之所以生机勃勃, 皆因为万物在适应大自然这个外部因素的 运动过程中不断变异, 以调整自己的内部因素得以繁衍。我们称之谓 “适者生存”、 “各得其所”。在大自然中任何事物都不可能脱离它所存在的外部环境和食物链系 统上的其它物种而单独存在。自然界与万物的存在是处于一个整体系统结构之中 的。每一个体的 “物” 都与它所存在的外部因素和其他物有千丝万缕的联系。这个 千真万确的真理正是我们任何学科研究的起点和基础。

人类区别于其他生物之最重要的特点是能改造自然, 创造 “人为事物”这个第 二自然一一即 “人类的社会系统”。然而，人类社会物质文明的每一发明、发展、 进步无不寓于当时人类社会这个大背景之中，不同民族、不同地域、不同气候、 不同时代的人类物质文明依然遵循“适者生存”、“各得其所”的规律。人类的发 明、创造不可能违背这个规律, 这也是我们常说的“师法造化”的道理。

\section{图14.2 人类的社会系统}

来源: 作者

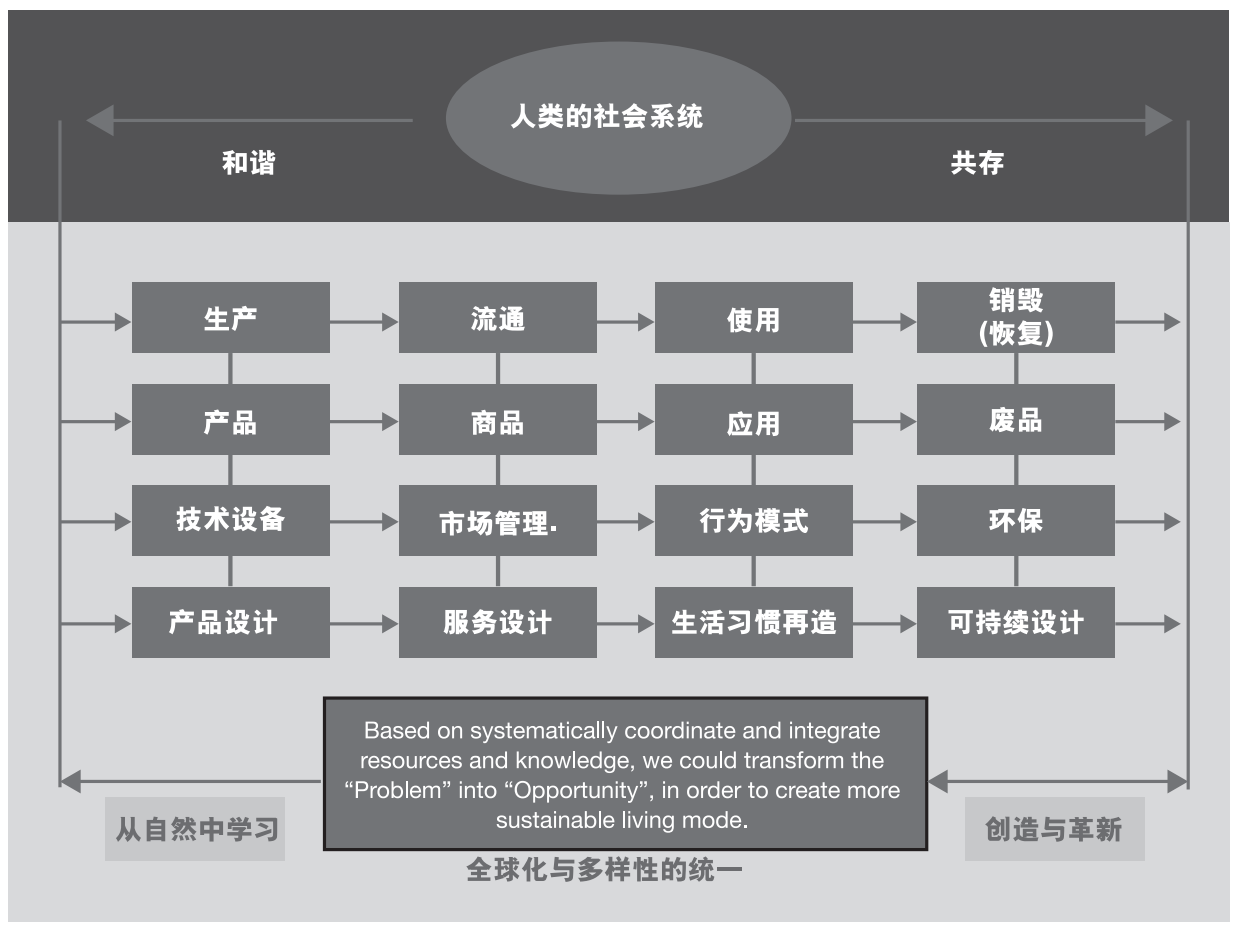

设计是为人类 “创造更合理的生存方式”，其最显著的特点是要不断“创新” 。而“新”不是“无病呻吟”地添加高技术、“画蛇添足”地美化、装饰。人类社 
会的可持续发展和地球资源的有限和全人类共同发展的理想对无限膨胀的“个性” 的制约，逼迫我们要深刻理解 “新”的评价标准是“适当”、“适度”、“适合” 即中国古代的哲理-—“适可而止”。在这个评价平台上去“创” 新, 意味着我们 要学会从 “人为事物” 的全过程中去发现问题、分析问题、判断问题、解决问题、 评价问题，这就是“设计事理学”系统方法论的本质。

\section{4 “设计事理学” 是知识经济时代设计的方法论}

\subsection{1 “事理学” - - 设计方法论}

设计事理学就是搜寻需求目标的限制因素以确立目标系统一一实 “事”; 然后再选 择造 “物” 的原理、材料、工艺、设备、形态、色彩等内因一一求 “是” 的研究

(图14.3)。

图14.3 事理学和目标系统

来源: 作者

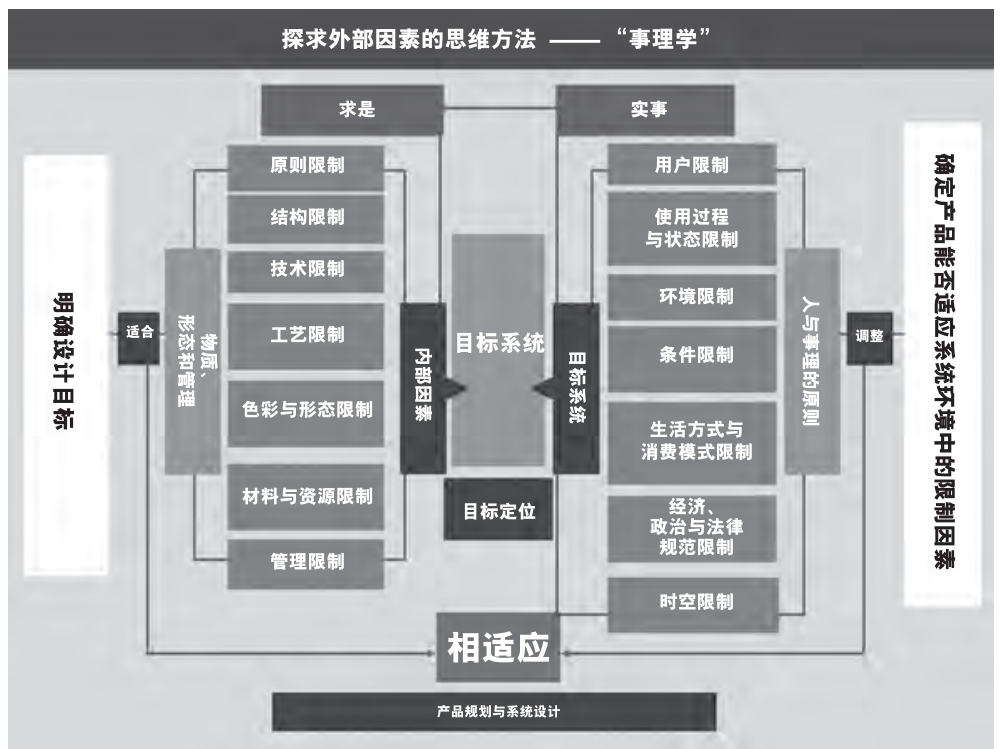

“事理学”的思维方法实际上是围绕着 “问题” 来展开的。所谓 “问题” 是指 设计各要素交织在一起时, 所产生的关系或矛盾。研究 “问题” 的方法通常是通过 一整套解决问题的模式来构筑的。如果对制约设计 “目标系统” 的“外部因素” 研 究不明确, 设计就失去了方向。盲目的“试错法” 效率低下。因此, 设计需要发展 自己的一套方法体系, 去探求外部因素, 明确设计目标。 
“事”特指在某一特定时空下，人与人或物之间发生的行为互动或信息交换。 在此过程中，人的意识中有一定的“意义”生成，因而物发生了状态、属性的“变 化”。事里包含着人与物、也有 “背景”、还体现了三者之间的关系（行为互动与 信息交换），反映了时间与空间的 “情境”。通过事可以看到事背后人的动机、目 的、情感、价值等。因此, 事是一个更大的系统。在具体的事里, 动态的反映了 人、物、环境之间的“显性关系”与“隐藏的逻辑”。“事”是一个“关系场”， 可以看到“物”存在合理性的关系脉络。

“事” 是塑造、限定、制约 “物” 的外部因素的总和, 因此, 首先要研究不同 的人(或同一人)在不同环境、条件、时间等因素下的需求，从人的使用状态、使用过 程中确立设计的目的，这一过程叫做实 “事”; 然后选择造“物”的原理、材料、 工艺、设备、形态、色彩等内部因素, 这一过程叫做求 “是”。实事是发现问题 和定义问题, 求是解决问题; 实事是望闻问切, 求是对症下药, 然后再把设计放回 到 “事” 里去检验, 看是否合乎特定的人的特定的目的性, 是否合乎人的行为习惯 与信息的认知逻辑, 是否合乎环境, 是否合乎人之“情” , 是否合乎人之“价值” 标准。设计表面上看起来是在造物, 其实是在祈使, 在讲理, 也是在抒情。

事理研究可以粗略的分为两个层次：微观、宏观。微观研究即在 “具体” 的情 境内去把握 “事” 的各元素间关系, 去理解人是如何感知外部世界的, 如何与外部 世界互动, 又是如何被外部世界所影响: 从中发现问题, 为细节设计提供依据。宏 观层次的事理研究即对生活形态的研究。类型化的人群、一件件微观的事被有结构 的组织在一起, 就成为了宏观的“生活方式”。这样的研究可以了解人们是怎样生 活的, 什么是可以接受的, 他们的希望与梦想是什么。设计创造的其实是人类的生 存的方式。事理学可以启示人再去创造新知识; 或者说可以启示人去开拓新的创新 的方向，乃至重组知识结构、重组资源与知识结构之间作 “事” 的系统，以满足人 类健康发展潜在的需求。因此, 工业社会的“以技术引导需求的模式”在知识经济 中正好要倒过来, 会由适合人类理想的 “需求” 来引导科学技术发展的方向;

将 “设计”视作一门科学的、系统的、完整的体系, 即研究 “事理学”- - “ 人为事物科学的方法论”，在当今这一历史关键时刻是具有革命性意义的。尤其对 于发展中国家来说, 与其仅仅关注原材料与新技术的革命中寻找经济持续发展之 路, 还不如与此同时转变观念, 寻找新增长点, 更有效的创新知识结构系统。

\subsection{2 “设计事理学” 的核心理念与思维方法}

“设计事理学”- - MATTEROLOGY, 正是将中国传统的思维观与现代设计理念 相融合, 并着力于面对当下中国问题的设计理论。不仅暗合于可持续设计的精神与 内涵, 而且更为中国文化圈所接受。研究这个在 “物”之外因素限制的过程, 即是

“做事”的“目标系统” 定位, 也是评价、选择、整合原理、材料、技术、结构、 造型、产品等 “内部因素” 的依据, 乃至是引导这些内部因素创新的动力, 以创 造 “新”物种, “服务系统” 和产品服务系统的创新。对解决问题的外部因素的认 识是对人类已有的产品或服务系统 “目标系统” 的修正或 “革命”。“设计事理 学”对创新的评价标准就是来源于中国古代的哲理：“持而不有观”、“适可而 止”，即“适当”、“适度”、“适合”，而非对欲望和最优解的无限追求。 


\subsection{3 案例研究}

本部分描述了作者参与的两个项目, 以供参考。这部分着重对设计事理学的过程和 方法进行介绍, 而不仅仅是对设计结果加以描述。

\section{筷子项目和烹饪吧}

筷子项目 ${ }^{1}$ 是对不同文化中的消费者在准备食物和家庭消费的日常习惯和行为进行 研究的, 因而对跨文化的交流与研究有着很强的借鉴意义。因此, 通过对事 “人主 导自然”的分析来发现问题, 寻找设计机会, 并最终提出一个创新型系统的解决方 案。该项目以部分亚洲国家和地区（中国大陆，香港，日本和韩国）的中产阶级家 庭为研究对象。分成两步进行实施: 先是初期的用户研究 (对外部因素进行调查和 分析），然后是后期的概念设计（对内部因素进行整合和创新）。在用户研究阶 段, 项目组通过撰写文献综述, 对大量饮食数据进行搜集和整理, 以便找出每种饮 食文化的特点、发展趋势、烹饪方法和现代社会人们的行为举止。在对北京的中产 阶级家庭进行定位研究后, 项目组挑选出10个样本家庭, 并运用社会学和人类学方 法进行了用户研究, 例如问卷调查、图片日记、观察报告、影像故事和深度访谈等 等。通过对背景资料的广泛搜集和分析, 以及对消费者生活方式的深入研究, 最终 构建出了北京中产阶级家庭饮食需求系统。对此, 研究小组提出了一些重要见解, 并确定了与设计相关的一些机会，为后期的概念设计奠定了基础。

烹饪吧是清华大学美术学院提出的五个解决方案之一。概念设计阶段, 其目 的是为了构建一个新型自供伙食系统, 除满足对象成员的需求外, 还可以实现对中 国传统中健康节俭的饮食习惯的继承和发扬。烹饪吧旨在解决以下几个问题：快节 奏的生活方式造成快餐文化的流行。反过来, 过度食用快餐会给人的身心健康带来 不利影响。烹饪食物对大多数中国中产阶级来说是一件非常耗时的事情。“下馆 子” 成为城市白领的首选, 但是多数餐馆却不能提供绿色环保健康的食品, 用餐价 格昂贵且浪费现象严重。在对这些问题进行深入研究并就 “事” 的约束条件进行分 析之后, 研究组便提出了烹饪吧食品服务系统计划, 鼓励顾客自己动手烹饪并享受 美食。人们从烹饪中国菜的过程中得到乐趣, 并通过与家人、邻居和朋友分享厨艺 来增进彼此的亲密关系。另外, 它还可以保证人们吃到健康、美味且数量充足的食 物。这个新型系统鼓励用户使用先进的数码/管理系统来实现从采购、食材准备、烹 饪和品尝菜看等一系列步骤。这一系统能够自主完成例如清洁等繁琐的工作。这个 系统还能够提供诸如烹饪培训、协助和营养咨询等服务。它与传统超市和餐馆所提 供的服务显然大不相同。

1 该项目由香港理工大学和香港设计中心共同发起, 北京地区负责人为清华大学美术学院柳冠 中教授。这一项目的最终成果已于2004年香港设计营商周上公布, 参见兰姆(Lam), 2006。 


\section{青年一代的交流 (Young Generation Contact) 和拼车（EASY-RIDE）}

该课题取自清华大学美术学院和诺基亚北京研究院的合作课题 “Young Generation Contract” (青年一代的交流) ${ }^{2}$, 围绕中国都市年轻人交流反映出的生活方式特征、需 求以及设计机会进行研究, 并有针对性地提出具有前瞻性和可持续性的设计创新方 案。EASY-RIDE方案 3 是六个新型系统设计概念中的一个。

项目研究分为三个主要步骤。前两个步骤涉及对目标系统外部因素开展的深入 研究。第一步首先是对课题的概念、研究范围、内容进行明确定义。而后, 从横向 (不同年龄段) 与纵向（不同年代）两个维度, 对青年人交流的特征进行对比研究。 基于上述研究成果, 项目组进一步明确了当代青年人的核心特征, 并将主题确定 为 “移动虚拟交流” (Mobile Virtual Contact)。第二步采用文献综述的形式对 “移动虚拟交流” 的特点、主要方式、相应技术、行为过程进行分析, 以此制定下 一步 “用户研究” 的具体访谈内容和提纲。项目组精心篮选了14个目标用户进行深 入访谈。用户研究主要是通过照片日记、访谈与观察的形式进行。最终, 项目工作 组有了许多重要发现。一种正在显现并呈不断发酵趋势的“拼”与“晒”现象获得 人们的关注。由此, 设计的机会也随之浮现出来

“拼”（分享）作为一种社会行为由来已久，近些年再度流行并备受关注。这 种现象可以追溯到私家车主间的非法 “拼车”（或 “拼客”）（合用小汽车）等现 象。“拼”指的是群体集中在一起共同完成一个事件或从事一个活动，通过集体利 益或意志的实现达到个体利益或意志的实现。其参与主体既可以是熟人朋友, 也可 以是陌生人。目的是分摊成本、共享优惠、享受快乐、共享经验、彰显自我、扩展 和巩固社交范围。“晒” 不仅有英文的分享 (share) 和展示 (show) 的意思, 也有 中文 “晒太阳”的悠闲自得、非功利主义，以及将真相曝光的意思。如果说 “拼” 更多是经济上的考虑，“晒”则更追求精神上的满足感。

项目组在进行了充分调查、分析后, 利用 “社会创新” 理念, 选取了多个方 向进行创意设计与系统完善。其根本目标是保证新型的 “产品服务系统” 的可持续 性, 即在确保目标人群需求的同时, 使系统运作更有效率, 更有助于实现资源的节 约、促进环境的保护，并重点思考如何采用恰当的盈利模式，吸引相关企业加入其 中。EasyRide 服务系统针对的是都市年轻上班族的日常出行和通勤问题。概念的初 衷源于以下几个问题: 首先, 中国某些地区的公共交通系统不够完善。对于年轻白 领来说, 上下班乘坐地铁或公共汽车并不方便。第二, 尽管私家车可以保证舒适, 但是它们造成了严重的交通拥堵和空气污染。燃油费极速攀升给使用者造成了越来 越重的经济负担。最值得关注的是, 在北京, 每天约有300万辆汽车上路行驶, 而其 中的240万辆只乘坐了一个人; 针对上述问题, 在中国的某些区域出现了民间的“拼

2 这一项目是清华大学美术学院和诺基亚研发中心的几个少数长期合作研究项目之一。项 目由蔡军教授、刘吉昆教授和刘新负责, 诺基亚研发中心的研究员王伟参与。这一项目从 2009年一直持续到2010年。

3 EASY-RIDE产品服务系统概念的设计师是清华大学的学生刘青、李建、韩威、李白和王玉 （以上均为音译）。见刘新 2010. 
车”现象, 尽管极具发展潜力, 但缺乏有效的管理和相应的硬件与软件系统配置, 加上公平价格体系与信用机制的缺乏，因而极易引发事端。

EasyRide的创意就是深入发掘“拼车”可能给未来都市交通发展带来 的机遇，并利用现代通讯与网络技术，重新构建一种新型的产品服务系统。 同时, 通过 “晒”的理念完善公共监督机制。该系统的第一个步骤是首先构 建一个 “拼车” 服务网络平台。有意愿提供搭载服务的司机与愿意搭乘他人 车辆的乘客都可以注册成为会员。服务系统对会员的身份进行认定, 并提供 手机端的应用软件, 以保证会员可以及时、方便地使用服务。EasyRide平 台将为会员提供出行信息与搭乘偏好的设置、检索、出行线路快速定位、匹 配、手机支付、安全监控、专题论坛、信用评级、开具发票、纳税等服务。 服务平台在每次 “拼车” 成功后, 从乘客在线支付的费用中取得一定服务 费; 乘客将花费比乘坐出租车更便宜的价格达到目的地, 并有可能结识更多 同路的年轻朋友; 并有效降低空驶率。该系统将带来显著的环境效益（降低 污染、减少拥堵）、社会效益（鼓励分享使用而不拥有的新道德风尚和消费观念）。 可见, EasyRide新型产品服务系统的设计, 在充分满足了使用者需求的同时, 也保 证了环境、社会和经济的效益, 并实现了不同利益主体之间的互利与共赢。

\section{5 结论}

“工欲善其事, 必先利其器”。“物” 是有力的工具, 是达到“目的”的保障, 技 术、造型都是实现 “目的” 的手段, 是被选择的; 而“目的”则是做 “事”。 事” 是“物”和 “技术” 存在合理性的关系脉络。因此, “设计” 的本质是在“ 事” 的 “关系脉络” 里去研究、发现、理解, 才能创造出合情合理的“物”。

设计科学可转化为两个侧面: “目标系统的确定”与 “重组解决问题的办法”, 可进一步化约为：“目的-一手段”。信息时代、知识经济下的 “设计” 将重点探 索“物品、过程、服务” 中的“方式创新”- - 谋 “事”, 其研究具有广泛性和纵 深性两个维度上的意义。“设计”将更多以“整合性”的概念加以定义。

“文脉” 是意义的承接, 技术与形式只能作为手段。而当我们过多的关注于手 段时, 手段也就成为了目的。“人们往往停留在通向最终价值的桥上却忘却了最终 价值。”这是手段对目的的殖民。当文化存在的 “语境” 已改变时, 我们便需要设 计师去创造新的“可持续设计”的文化了。

\section{参考文献}

Guanzhong, L. (2009a) "Urgent need to re-understand the "origin" and "primacy": reflection from industry chain'.

Guanzhong, L. (2009b) 'Original design and creation of industrial design “industry chain"', Art Journal. 
Lam, Y. (2006) Chopsticks: An Asian Life-style Study in Domestic Culinary Habits for Design (Hong Kong: School of Design, The Hong Kong Polytechnic University).

Xin, L. (2010) 'Current Situation and Practice of Design for Sustainability in China', in Ceschin, F., Vezzoli, C. and Zhang, J. (eds.), Sustainability in design: now! Challenges and opportunities for design research, education and practice in the XXI century. Proceedings of the Learning Network on Sustainability (LeNS) conference. Bangalore, India, 29 September 1 October 2010 (Sheffield, UK: Greenleaf Publishing): 540-549. 


\section{5 \\ 中国传统的生态文明观与现代服 务设计系统}

郑曙旸

中国 清华大学美术学院

清华大学艺术与科学研究中心可持续设计研究所

\section{1 世界设计文化观的趋向}

人与自然和谐共享的观念贯通于东方文化的历史, 并影响其设计文化观的形成。在 中国传统的哲学体系中, 人与自然的关系是一个根本的问题, 即所谓 “天人之际” 这里的“天”指的是广大的客观世界, 亦指自然界。中国古代关于人与自然的学说 都不把人与自然的关系看作是相待相成的，以天人的完全和谐为最高理想。战国荀 子《天论》（荀子关于天人关系的理论）首先明确提出 “明于天人之分, 则可谓之 人矣。”认为自然界有自己的运行规律, 不会因为人而存亡, 与人类社会的贫病灾 祸没有必然联系, 不能主宰人的命运。道家学派的创始人老子提出“天之道损有余 而补不足; 人之道则不然。损不足以奉有余”，提出人应当顺从自然。

天人合一说最早由子思、孟子提出 ${ }^{1}$, 他们认为, 人与天相通, 人的善性天赋, 尽心知性便能知天, 达到 “上下与天同流”。庄子认为 “天地与我并生, 而万物与 我为一”。人与天本来合一, 只是人的主观区分才破坏了统一。主张消除一切差 别, 天人混一。宋以后思想家则多发挥孟子与《中庸》的观点, 从“理”“性”“ “ 命” 等方面来论证天人关系的合一。明清之际王夫之说 “为其理本一原, 故人心即 天”（《张子正蒙注·太和篇》）, 但强调 “相天”“造命”, “以人道率天道”。

1 说明: 在本章节中, 中文中的“人”被译成了“man”，而并未使用“human” 或 “humanity” 的译法。此举只为更忠实地传达出古语的内涵, 绝无性别歧视之意。 
天人合一各说, 力图追索天与人的相通之处, 以求天人协调、和谐一致（舒新 城 1999: 1486) 。以这样的哲学作为基础的设计文化观, 及在这种观念的孕育下建 筑、园林、城市规划体现了文化内涵所赋予的特质: 建筑结合自然环境互为映衬相 辅相成, 园林以其自然的山水形态体现出深奧的意境。

人作为大自然主宰的观念贯通于西方文化的历史, 同样影响其设计文化观的形 成。在西方文化的传统观念中：人处于万物之灵的地位, 或宇宙中心的地位; 别的 一切都是为了人的利益而安排, 都得服从人的需要, 听从人的摆布。柏拉图（前427 一前347) 在《泰阿泰德》中说: “人, 是衡量一切的尺度, 是衡量现有的一切的存 在价值的尺度, 也是衡量现在所没有的一切的不存在的理由的尺度。”亚里士多德

（前384-前322）在《政治学》中说: “如果说大自然所创造的一切没有哪一样是 不完善的, 也没有哪一样是无用的, 那么推断的结论必须是: 大自然已经创造的一 切动物都是为了人。”培根 $(1561-1626)$ 在《古人的智慧 · 普罗米修斯》中说: 人可被视为世界的中心。如果把人从世界除开, 其余的一切都将茫然无所适从, 失 去了目标或主旨, 正如习语所说, 恰似一把拆散了的旧扫帚, 不成体统。这是因 为, 整个世界万物都在协调一致地为人效劳, 人不能使用又不能从中获得成果的东 西是根本就不存在的。

康德 (1724-1804) 在《目的论批判》中说：“人就是世界上创造的终极目 的, 这是因为人是这个世界上唯一能够从物的总体中有意识地形成目的概念的活 物, 还能够凭借自己的智慧建立一套目的系统。”

当世界进入 21 世纪- - 因为 “我们这一代人是在以西方为导向的历史背景下成 长起来的, 我们自然也生活在一个由西方居支配地位的世界中。”以市场经济为主 导的全球化社会运行模式, 导致设计文化的取向全面倒向西方世界, 包括影响环境 绝不低碳的西方发达国家设计标准。然而, 如果中国再这样走下去, “不仅会影响 世界和谐, 还会造成内部不和谐。”（廖晓义 2010：3。）因此, 摒弃人类中心主 义, 弘扬 “天人合一” 的东方传统文化观, 具有世界向生态文明转型的普世价值。

\section{2 传统文化中精华与糟粕的取舍}

东方传统文化背景下的环境观孕育了农耕文明, 西方传统文化背景下的环境观引发 了工业文明。由于中国近现代历史所呈现的波澜壮阔的跨越式发展, 我们直接从农 耕文明的社会形态跨入了后工业文明的信息时代。旧有的具有糟粕性质的传统观念 尚未彻底打破, 新的符合可持续发展战略的观念未能及时建立。同时, 旧有的具有 精华性质的传统观念却被我们轻易地丢弃, 而不加选择地迅速接受了西方文化所造 就的价值观，导致今天实施可持续设计面临重重障碍。

当代中国处于发展的十字路口, 我们需要在重新审视西方工业文明和自身传统 文明精华的抉择中, 实现可持续的和谐发展。中国的国家发展战略, 是要在本世纪 中叶达到中等发达国家的水平。中国共产党十七大报告中历史性地提出“建设生态 文明”，依靠科学发展的道路全面建成小康社会。所谓 “小康” 就是在满足人的基 本温饱的基础上, 生活的各个方面略有盈余。换句话说, 这是一种介于贫穷和富裕 
之间的中间状态, 也还不是国际公认的中产水平, 当然更不能以所谓“有房有车” 的物质标准来衡量, 因为这不符合中国的国情。如果让每个中国人都来做“美国梦” , 按照美国中产阶级的生活方式作为小康的标准, 以中国的人口与自然条件, 是一个 难以达到的目标。所以说这个核心标准的定位必须适度。

“度”在汉语中表达了：分寸、节制、礼数、平衡、和谐的含义。“度”在 哲学上指一定事物保持自己质的数量界限。在这个界限内, 量的增减不改变事物的 质, 超过这个界限, 就要引起质变。从传统文化的概念出发, “度” 是东方生态智 慧的凝练表达。凡事适度, 在中国传统的文化教育中世世相传。适度的概念为“ 俭”，恰恰是中国传统文化的精华部分；过度的概念为 “奢”，恰恰是中国传统文 化的糟粕部分。两者都能从“天人合一” 的观念中找到注解。

消费主义和物质主义的泛滥, 成为经济主义在当代社会与文化运行中的具体 表现。在经济主义的指导下，人类采取了“大量生产一大量消费一大量抛弃”的生 产、生活方式, 就是这种生产、生活方式引起了全球性的生态危机。问题是, 在市 场经济的条件下, 生产经营者以赢利最大化为目的, 存在着无限掠夺自然资源、破 坏生态和环境的自发倾向, 并因此危害着社会公众的利益。这种情况下, 创新旗帜 下产品的设计将会变成违背可持续发展的同谋。这种设计理念显然与最大限度地合 理配置资源和能源的可持续发展原则背道而驰。

可持续发展思想的核心，在于正确规范两大基本关系：一是 “人与自然”之间 的关系; 二是 “人与人”之间的关系。要求人类以最高的智力水准与道义上的责任 感, 去规范自己的行为, 创造一个和谐的世界（可持续发展研究组2000：12）。

可持续发展思想的本质, 就是要以生态环境良性循环的原则, 去创建人类社会 未来发展的生态文明。面向生态文明的可持续设计, 则需要从“人与人”、“人与 物”、“人与环境”三个方面去规范, 以期达到理想的三种境界。

第一种境界是: “人与人”仁爱相待, 人际平等的沟通原则; 第二种境界是: “人与物”珍惜物品, 物尽其用的价值目标; 第三种境界是: “人与环境” 尊重自 然, 和谐相处的建设定位。

\section{3 “天人合一” 观念二元特征的内涵}

“天人合一”的观念, 属于农耕文明的传统生态, 符合中国封建社会政治的法 则。“修身、齐家、治国、平天下”既体现出天人完全和谐的最高理想, 也成为个 人完善的最高境界。这种观念的文化传承, 对于当代中国来讲, 显然有一个凝练精 华和扬弃糟粕的篮选过程。然而, 在这个问题上, 今天的国人却采用出世的态度看 待 “人与自然” 的关系, 用入世的态度看待 “人与社会” 的关系。于是, 自然的环 境保护只是抽象的概念, 社会的经济运行才是具象的实际。

关于这一点, 可以在传统与当代建筑营造的对比中得到充分的印证。北京故宫 （紫禁城）是以封建皇权的概念来宣示“天人合一”世界观的建筑典型。紫禁城作 为明清两代的皇宫, 南起永定门北到钟楼的北京城中轴线, 纵贯紫禁城。从紫禁城 前庭大明门起始, 经千步廊, 过金水桥, 入承天门过端门, 再入紫禁城午门过太和 
门, 穿过太和、中和、保和三大殿, 再经乾清门、乾清宫、交泰殿、坤宁宫、坤宁 门、钦安殿、最终洞穿神武门北上（从大明门到神武门全长2200余米）。无比壮观 严整对称的纵横双向扩展组合, 形成前殿后鼏的整体格局。这条中轴线的核心, 无 疑是太和殿上显示皇权的宝座。所有的时空铺垫无不以这个坐标而展开。从大明门 到达此点的距离, 是从此点到神武门的一倍。帝王的权势, 天子的威仪, 以君临天 下的气势，通过建筑的空间序列得以充分的诠释（郑曙昒 2008：12）。

今天, 遍布中华大地的无数行政办公大楼, 几乎都在尽力模仿紫禁城的时空序 列。宽大正面具有宏大尺度内庭的建筑, 坐落在占地可观、中轴线布局、空旷无比 的广场之上。然而, “为人民服务” 的政府机构, 完全不需要百姓顶礼膜拜的空间 铺陈。于是在实际的社会运行中, 不少建筑的大门终日紧闭, 而旁门左道则成为人 流如织的出入口。土地和建筑空间的浪费令人瞠目, 完全背离了国家可持续发展的 战略定位。

\section{4 环境选择的学问：风水学}

风水, 亦称 “堪與”。按《辞海》（舒新城 1999）的解释：“这是中国的一种 迷信。认为住宅基地或坟地周围的风向水流等形式, 能招致住者或葬者一家的祸 福。”“在中国数千年的文明历程中, 风水一直是中国人追求理想环境的代名词”

（刘沛林 1995）。至少风水是一门 “环境选择”的学问, 就是说 “人类只有选择合 适的自然环境, 才有利于自身的生存和发展。”（刘沛林 1995）中国传统的风水学 实际上就是哲学理论与建筑实践的结合, 它蕴含了环境设计的理念。它注重人与环 境相互作用的关系, 而这种关系在 “人文地理学”、“行为地理学”、“环境心理 学”中有着同样的论述。

中国的风水思想强调人与自然的和谐相处, 强调人与大地同处于一个有机的整 体之中。英国剑桥达尔文学院的唐通 (Tong B.Tang) 在《中国的科学和技术》一书 中指出: 中国的传统是整体论的和人文主义的, 不允许科学同伦理学和美学分离。 理性不应与善和美分离（唐通1984）。风水的思想文化是以中国古代的阴阳学说 为指导的。阴阳是天地万物的根源, 以人类乃至动物的两性交感繁衍后代的普遍现 象推演至自然界的变化。认为万物的变化都是在阴阳两种势力的对立中形成的, 而 变化的形式则是通过交感。以交感的观点来观察事物的动静变化成为阴阳理论的基 础。建立在中国古典哲学阴阳思想基础之上的风水学, 正是以这样的根本观点来认 识大地、认识地形的。风水“气论” 思想是其重要的理论支柱。在以阴阳为前提、 以气为指导思想而展开的风水理论中, 气的概念运用的最为普遍。所谓 “气” 是风 水中一种无形而连续性的物质。气论认定的：天生于气、地生于气、人生于气、万 物皆生于气的观点, 反映出中国古代关于大地有生命的有机自然观。既然天地人都 是气所生成, 那么它们之间必然有着某种共性, 同时也可彼此感应。这种天、地、 人的自然感应观, 必然导致大地有机论的产生。风水学发展的价值正是建立在“大 地有机” 自然观的前提下。实际上现代科学研究的结果, 已经证明地球生态系统是 一个环环相扣的有机链, 一旦某个环节出现问题, 受到影响的必定是整个机体。 
风水所追求的目标, 是选择对人的生产与生活发展有利的环境。按照风水的理 论所寻求的理想风水宝地, 展现出一种 “藏风得水” 的环境模式。这是一个山环水 抱的理想居所, 群山环抱, 流水环绕, 草木繁茂。《阳宅十书》中提到: “人之居 所, 宜以大地山河为主。”“背山面水”的居所选址成为中国古代民居典型的环境 模式。在中国古代 “宅为人之根本” 的观念指导下, 民居的宅内形, 讲究坐势、朝 案。在住宅的建筑上讲究开门法则、天井功能、排水法则。总之, 风水的目标就是 今天环境设计所追求的最高境界, 两者之间异曲同工。因此, 风水的环境选择理论 涉及生态、景观、安全、行为、心理等诸多因素的考虑。

\section{5 风水学与现代服务设计}

随着日渐严峻的全球环境问题, 各国不同行业的专家学者, 不约而同将眼光转向东 方。一方面是基于中国传统文化中的风水学研究; 另一方面是源自设计本身的内容 与方法研究, 其中尤以服务设计的概念受到广泛关注。前者, 虽然是东方世界关于 环境选择的传统，但其“人与自然”和“人与社会”设计本质深层次内容的体现， 对于走向生态文明的可持续设计具有明显的启示意义。后者, 因为打破工业文明所 催生的现代设计-一单一的产品观, 逐步进入面向用户全方位的服务系统设计- 综合的环境观，使得两者（即风水和可持续设计）具备了相互借鉴的可能性。

与传统的设计学科比较, 服务的设计采用了整体的办法, 来评估需求、产品和 战略, 以多种渠道提供服务。服务设计在最大限度地提供方便和满意度的同时, 还 着眼于增加价值, 改善用户和供应商的关系。风水学是一门东方古老的综合设计系 统; 服务设计是一门西方新兴的综合设计系统。面向人类未来的生态文明, 它们共 同具有不可替代的环境生态学理论基础, 因此也就具备了明显的可持续设计向度。 通过结合传统与当代的设计理念优势, 形成对可持续设计理论与实践的有力支撑。

今天的人类需要在思想意识的层面实现彻底的变革, 从而使社会的经济、政 治、技术、教育向着生态文明的道路转进。因为, 工业文明已经走入了死路。“现 代工业文明的基本准则是...... 与生态匮乏不相容的。从启蒙运动中发展起来的整个 现代思想, 尤其是像个人主义之类的核心原则, 可能不再是有效的。”（沃斯特 1999: 412) 设计同样需要面对生态文明的挑战, 需要调动人类全部的智慧与能力去 应对。设计的运行只有建立在环境生态学的理论基础上：如何使用更少的能源和资 源, 去获得更多的社会财富; 如何实现材料应用的循环, 产品产出回收的循环; 如 何变工业文明的实物型经济为生态文明的知识型经济。总之, 就是要运用人类思想 的所有财富, 通过科学的设计最大限度地合理配置资源和能源。

建立生态文明, 如果仅用工业文明的思维定式, 单靠科学技术手段去修补环 境, 不可能从根本上解决问题: 我们必须使人与自然的关系由工业文明的对立走向 生态文明的和谐。解决这样的问题显然需要回到人文科学的层面, 在与科学技术的 通力合作中找到一条出路。从艺术与科学的角度出发, 立足于环境保护观念的设 计, 正是可持续发展战略诸多战术层面的一条可供选择的道路- - 这就是可持续设 计。 


\section{参考文献}

Peilin, L. (1995) Feng Shui: The environmental concept of Chinese (Shanghai: Shanghai Joint Publishing).

Shuyang, Z. (2008) 'Thinking About "Housing"', Decoration 3.

Sustainable Development Research Group (2000) China Sustainable Development Strategy Report 2000 (Chinese Academy of Sciences, Science Press).

Tang, T.B. (1984) Science and Technology in China (London: Longman).

Worster, D. (1999) Nature's Economy: A History of Ecological Ideas (Cambridge: Cambridge University Press).

Xiaoyi, L. (2010) Look Around: Liao Xiaoyi Chats with Chinese and Foreign Philosophizers about Green Prescriptions (Beijing: Sunchime Film Library Audiovisual Press).

Xincheng, S. (1999) Cihai (Shanghai Lexicographical Publishing House). 


\section{第五篇 新的教育方式}




\section{6 \\ 新的教育方式 展示经验*}

吉谭雅力•萨克戴夫 (Geetanjali Sachdev)

印度斯瑞施蒂艺术、设计与科技学院 (Sristhi School of Art, Design and Technology, India)

\section{1 引言}

本章回顾了一种特殊教学法的形成过程, 目前, 本人正尝试在自己的教学过程中采 用这一方法。这种教学方法为公共行动、审美形式的抗议与话语权的出现提供了空 间。这种方法是在某种教学实践经验的基础上形成的。而这些经验对课程的设计至 关重要。本章是基于这样一种假设而形成的, 即我们经验的本质内涵能够影响并引 导我们思想的外在物质表现。随着可持续成果以产品服务系统和全新的系统概念的 形式展现在人们面前时, 新的教育方式也必须同时重视创造这些过程和结果的人们 的个体体验。

本章提出了五种类型的人类体验：主观体验、客观体验、参与式体验、竞争性 体验以及反思性体验。在为设计教育制定革新型教学方案时, 必须将这五种体验类 型纳入考虑范围。纳拉亚南（Narayanan）（2010）指出，若使教育为未来可持续 发展做贡献, 就必须有能够为争取话语权和公共行动提供空间的革新型教学方案。 她对传统可持续教育的出发点提出了质疑, 并在制定设计教学法之初, 就提出了一 种将知与行相结合的综合方法, 以培养学生了解、感知和观察世界的能力。这种教

* 我在此对艾薇・瓦格西（Avy Varghese）、科林・戴维斯（Colin Davies）、吉塔・纳拉亚南 （Geetha Narayanan）、拉塔·玛尼（Lata Mani）和亚沙思·舍提 (Yashas Shetty) 表 示感谢, 他们极大地影响了我形成现有的思想。 
学法将社会与生态公平作为其可持续教育的基石。革新型教育方案不再单纯教授产 品和人工制品的制作方法, 取而代之的是让学生获得动手实践、沟通和执行的能 力, 并将其作为可持续设计教育的核心。这也体现了我们对与我们生活密切相关的 人的关心。

本章所用案例均来自我的教学实践, 用于说明该教学法的形成过程。这里所描 述的每一种教学法都旨在为学生提供进行上述五种类型体验的机会。每种方法都能够 帮助学生形成关于行动、互动和理解新模型的想法和概念。这种方法可以引导学生开 展自主性的和参与式的活动, 同时也鼓励学生以实际行动或是以言语交流的方式, 参 与到公共及社会活动中。这种方法允许设计构思超越手工制品、产品或服务层面, 进 而上升到一个关注个体与个体之间, 个体与环境之间关系的更为宽广的层面。

我们相继开展了4次教学探索, 我们将按顺序逐一对其进行分析。这项研究基 于我的教学经验, 所以每一次的探索都可以形成一个 “范本”。我利用理论来解释 所观察到的一些现象, 因此, 这五种类型的体验是进行设计教育时需要考虑的相关 因素。然而, 需要长期的系统研究来对这些体验带来的影响进行分析, 才能使其更 具说服力。本章的最后总结认为, 将上述五种体验进行综合运用会产生一种审美体 验, 对学习者产生延伸效应。本章的最后部分再次对杜威（Dewey）关于艺术、美 学和学习的观点进行了讨论, 并提出把教学法作为延伸的概念。

而且, 把教学法作为延伸这一概念, 与系统思维设计方式有相似之处。构思 的复杂性是所有设计活动的核心特征。系统思维提供了一种处理复杂问题的方法, 该方法注重理解构成整体的各成分之间的关系, 这些关系构成了所有产品服务系统 或利益相关方互动设计过程中的关键组成部分。系统是指具有整体性特征的任何实 体。在大环境背景下, 系统思维主要关注的是事物的整体属性。系统思维提供了解 决问题（发现问题）的整体方法。这种方法具有相关性的特征, 并能在应对复杂环 境时, 综合考虑多种因素, 以便理解行动和干预的依据。延伸教学法概念的运用正 是艺术和设计专业学生发展的切入点: 因为延伸教学法是一个具有深远意义的教学 方法, 能够使学生更多地参与和接受挑战, 并帮助其解决棘手的问题。

\section{2 印度艺术与设计专业本科学生的认识论信念}

我的第一个提议-一学生的主客观体验作为教学设计的关键组成部分一一这个概念 源自于本人的硕士论文：“关于艺术与设计专业本科学生的认识论信念, 及其对艺 术与设计教育的看法”。

在研究过程中, 我产生了一种想法, 就是将上述各种类型的经验植入到教学应 用中。

认识论是哲学的一个组成部分, 研究人类知识的起源、本质以及合理性, 并关注人们对真理的认识过程。人们曾用不同的术语表述认识论, 但对知识产生 和发展规律的探究始终是关注的重点。研究个体的认识论价值系统主要就是研究 个体如何形成知识或认知的概念, 以及是如何使用这些概念去了解世界的（霍弗 (Hofer) 2002)。 
我对于知识和认知信念本质的好奇心来源于我对实践判断的兴趣。这种兴趣产 生于我对学生作品进行美学价值判断的过程, 也产生于与此过程相关的各种知识。 哪些知识是客观的, 是让师生去共同理解的? 哪些知识是主观的或者个人的, 被认 为是无效或不相关的, 是需要进一步阐释的? 如何将这两种知识结合在一起? 如果 无法将二者结合起来, 那为什么客观知识通常比那些学生从他们亲身经历所得出的 主观知识更有价值?

这一研究基于马莱娜 · 肖沫 (Marlene Schommer) (1990, 1994) 的理论 体系。该体系认为, 认识论信念是各种关于知识认知过程的基本性质 “相对独立的 信念”的集合。肖沫 (Schommer) (1998) 认为, 特定的核心信念会影响学生的 学习态度。她设计了调查问卷来评估其中占主导地位的认识论信念。她将认识论信 念系统划分为至少五个维度：结构、确定性、知识来源、知识掌控能力和习得知识 的速度。这五种信念维度又可以分成两大主要领域：知识的本质及认知的过程。认 知的本质涉及知识的确定性和知识的结构, 知识来源涉及认知的过程, 即某一个体 逐渐认识客观事物的过程。她解释说, 认知速度和对认知过程的控制与多种因素相 关, 比如学习的毅力和动机等 (Schommer-Aikins 2002)。她举例解释: 在课堂 上, 有的学生认为自己是积极的听众, 这是因为他们认为知识是广为人所知的; 而 有的学生认为他们只是被动的听众, 这是因为他们认为只有权威才应该拥有知识。

只有当这些调查问卷在各种文化环境中均适用并有效的情况下, 我的研究结果 才是有意义的。样本大小、学生性别、学生背景、场景数量都会影响调查结果的普 遍适用性。本研究对于经验的本质及认知的影响都形成了许多深刻见解。

\subsection{1 该研究通过观察得出的结论}

通过分析调查问卷收集来的数据, 在这个案例中, 知识的组织和呈现方式, 都是固 定的、具有权威性的、不可挑战的。这将影响学生对于知识特点的看法。学生对于 知识特点的看法决定他们对认知过程的看法, 而不是相反。印度学生的认识论信念 较大程度上受到以往殖民历史及本土教育观念的影响, 却很少受到印度教思维方式 的影响。

分析、研究数据后得出三个主要结论, 对我们的实践有所启发。第一, 认识论 信念会承载特定的文化特征：本案例的实验样本是斯瑞施蒂 (Srishti) 学校的本科 生, 他们的认识论信念体系认为, 所有的知识, 无论是图像或文本的, 都具有权威 性。第二, 知识来源会对知识本质产生影响, 进而影响认知过程。第三, 认识论信 念受到许多相同或不同因素的影响，但是在不同程度上，都受到文化因素的影响。 教育系统对儿童的训练具有重大影响, 因为知识习得主要发生在正式的教育环境 中。

\subsection{2 对于教育实践的启示}

在设计教学过程中, 学生对于知识和认知本质的看法进行评价将有助于制定认知策 略。霍弗 (Hofer) (2004) 对大学一年级学生从认识论的角度解释教学实践的方法 进行了研究。有的学生认为, 知识是许多分散事实的简单集合, 持此相对简单看法 
的学生会认为开放式问题很难解决。日常教学只采用简单的教学方法, 然而, 在测 验中学生却需要处理复杂和综合性的问题, 这加重了学生的认知负担。当学生的成 长环境不鼓励他们提出不同观点, 或当学生趋向于躲避复杂问题时, 他们需要的是 那种强调个人观点、具有挑战性的、能够提供多种答案的开放式的教学方法。霍弗

(Hofer) 的发现表明, 学生所获得知识的来源, 也就是其权威性来源, 更多地来自 外部, 而非内部。学生对于权威的信仰可能来自于老师、宗教、课本、媒体或者家 庭。如果他们相信真知来自于权威, 那就可以解释为什么在一些课程或者项目中, 当需要创新型设计方案时, 这些学生给出的总是千篇一律、毫无创意的答案。在教 学规划过程中, 教师通常要求学生从大众新闻、媒体以及专家, 而非他们自己独特 的个人经验中获取知识。贝尔 (Bell) 和林 (Lin) (2002：342) 总结道, “分析争 论的倾向源于教学指导”。他们引用林 (Lin) 和希斯 (His) (2000) 的陈述, 在 教学实践中有两个重要的设计原则: 教学应该充分利用学生的经验与认知知识, 教 学还应该让学生在自然的学习环境中重新审视自己的想法。

\section{3 经验的角色}

\subsection{1 经验作为一个分析单元}

基于约翰・杜威（John Dewey）的经验哲学以及他关于艺术、美学和教育的观点, 我 们认为, 设计教育的教学可以根据对经验本质的理解进行设计。

杜威 (Dewey) 提出, 研究人类活动应该把经验单元作为整体进行分析, 而 不是拆分成小的部分, 如认知、情感或者行为。正是通过总结与世界交流之后所收 获的经验, 我们逐渐与环境建立了联系, 并且能够继续生存其中。经验是个体与世 界的互动, 在二者之间寻求统一和稳定, 这一切都是彼此能够继续存在的前提（杜 威 (Dewey) 1938)。但是, 经验并不会自发引起学习认知, 认知过程需要对经 验进行有机整合; 一个中介过程帮助学习者充分理解经验。在此过程中, 中介资源 能帮助学习者批判性地评价、审视和反思他们的经验, 最后从中学习到有效的知 识。杜威 (Dewey) 认为, 学习经验与其它经验有所不同, 其它经验会阻止或妨碍 未来经验的积累。他认为, 在这些经验中, 个体对外部环境所做的变化能反映出个 体本身的内部变化（杜威 (Dewey) 1916)。杜威 (Dewey) 也认为, 经验之所以 能够独立于欲望或意向而存在, 是因为其有能力在后续经验中继续发挥作用（杜威

(Dewey)，1938）。他认为, 经验是学习的基础, 并且同时也考虑到了经验两个 方面的属性, 即经验的适用程度, 以及对后续经验的影响。这二者的结合决定了所 有教育经验的重要性和价值。经验过程与教育过程是密切相关的, 另外, 我们也需 要承认社会因素在个人经验形成中所发挥的作用, 因为人们的经验总是来自外部, 而且所有这些经验来源都是有效的（杜威 (Dewey) 1938)。

\subsection{2 经验的主观性}

这种方式的学习完全是对过去经验的总结, 以便今后能够利用这些经验来指导行动。 
为了有效地学习这些知识, 必须将这些学习对象 (知识) 带给人们的心理反应 进行分析, 或将其重新转换为直接的个人体验, 因为知识都是从这些个人的直接体 验中所汲取或习得的：这就为学习认知提供了动力（杜威（Dewey）1938）。在斯 瑞施蒂 (Srishti) 学生的案例中, 他们获取教育经验的途径属于遗产传递型 (legacy transmission model), 这一模型强调的只是机械性地学习客观知识, 并不太重视将 学生的个人经验作为内在的知识来源。为了避免受到之前所受教育的影响, 知识的 展示不应该仅来源于权威著作或者权威人士, 学生知识的内在来源也同样有效, 但 仅仅利用学生的个人知识, 寄希望于增强学习动机, 引入客观主题等是不够的。为 学生提供机会发挥他们的主观能动性, 并且把他们的个人经验作为学习的基础, 这 两点同样也很重要。这就是为什么将经验的主观性提出来作为教学的第一要素。学 生的主观能动性是个人个性的来源, 也是该学生经验特殊性的来源。这种特殊性的 经验有别于那些一般性的经验: 在艺术和设计教育的教学大纲中, 应该把培养想象 力和创造力作为教育的目标, 这是不容忽视的。

\subsection{3 经验的客观性}

公共教学研究主要是以不同于学校教学的方式进行探索, 这些教学方法要求重新审 视教学的重要组成部分和必要的教育过程（桑德林（Sandlin）, 舒茨 (Schultz), 柏迪科（Burdick），2010）。作为理论建构, 这一概念被公众认为是一支重要的教 学力量, 无论在校内还是校外, 它都为理解教育实践活动提供了一种新方法。教学 过程需要从课堂之外寻求其它知识来源, 因此, 经验的客观性作为第二要素被提了 出来。教育方法首先需要辨别和认可这些来源, 并加以利用, 对从这些经验来源所 传递出的思想和价值观进行验证、质疑或者重塑。

每个个体构建属于自己的世界, 但是, 这个世界是在一个意义共享的社会环境 中构建出来的。这些意义是由我们的日常所见所感而产生的想法和概念, 以及用科 学方法引导出的概念而组成的; 这些意义的存在, 借助的是彼此之间的关系, 而非 直接经验。以来自不同学科和专业团队的价值观和判断作为知识的来源是广为接受 的, 而理论和实践的学科知识使学生能够有机会接触一些专业团队。

客观知识经验提供学习的机会, 这样, 就可以对知识体系进行认可、接受、批 判、质疑和重塑。如果设计教育要探索可持续生活方式的发展前景, 重塑和进一步 发挥想象力是很必要的。

在接下来的四个章节中, 我将对教学尝试进行详细的讨论, 主要关注了教学设 计中的竞争性、参与性及反思性体验。

\section{4 第一次教学法尝试：公共环境中的恐惧与性别}

“公共环境中的恐惧与性别”项目是斯瑞施蒂学院中期学期课程的一部分。该项目 通过带领学生参与改善社会、文化和生态居住环境等活动, 探索、学习和体验其本 
质。该项目为期五周, 通过与该市建筑界和社区的设计师展开互动, 探索艺术实践 对理论研究所起的作用，以期达到影响市民关注社会热点问题的目的。1

在项目前半程的两周中, 参与项目的六名艺术家带领学生们参加了表演、广播 及其它媒体形式的活动。在班加罗尔 (Bangalore) 的一系列创新活动中, 学生置 身于各种使他们感到恐惧的环境, 通过这种方式探索这种体验与性别之间的关系。 所有学生均为女性。这些活动包括: 临时将公园里一个 “可怕的” 同性恋活动区改 造成一个适宜晚上聊天的场所, 把女生们都组织起来, 进行她们擅长的编发活动, 尝试扭转由男性占据该场所的局面, 并让学生们邀请公园里散步的人们在一幅班加 罗尔刺绣地图上缝上几针, 在学生们曾感受过幸福和恐惧的地方举行一系列小型演 出, 挑战男女之间的互动模式。

还有一项活动, 是以步行的方式进行公开抗议。一个极端右翼政治组织在印度 城市芒格洛尔的一个酒吧和班加罗尔的几个露天酒吧袭击女性, 此举造成了巨大的 社会恐慌, 学生举行抗议活动以示声援, 他们认为该组织的 “西化” 行为是对印度 价值观的不尊重。这些学生声称, 作为印度女性, 她们拥有多重身份。她们提出的 口号是 “说我是 (Say I Am) ”, 她们设计了能够穿戴在身上的标签和横幅, 还利用 各种媒体的力量号召人们参与抗议游行。大约有 200 人以和平游行的方式参加了抗议 活动, 导致班加罗尔政治局势一度相当紧张。

在项目后半程, 学生决定以班加罗尔市民关注的社会热点问题为活动的主题。 这些项目反映了以下社会艺术原则: 与社区互动; 与他人交流, 参与社区活动, 改 变或创造人与工作之间的新型互动关系, 帮助人们在工作中建立一种新型同事关 系。通过三周的实践, 他们共完成了4个项目: 第一, 把具有恐怖效果的声音, 播放 给街上的行人听; 第二, 与小学生举行研讨会, 讨论他们在公共场所遭遇的恐怖经 历, 并将这些经历用书面形式表达出来; 第三, 收集能够提升女性魅力的、适合女 性在公共场所穿着的服装; 第四, 参加一系列家庭研讨会, 并开展一系列活动, 针 对社会各阶层的女性学生都容易产生的公共场所恐惧症的问题进行讨论。

\subsection{1 反思与思考: 竞争性、参与性及反思性体验}

“恐惧与性别” 项目提供了一个机会, 让我们理解怎样进行设计教学才能吸引和推 动社会力量参与公共行动和抗议活动。感兴趣的程度、公共抗议的计划和执行力度

1 本课程包含两部分。第一部分是在班加罗尔举行的为期两周的研讨会, 包括一系列对表 演、视觉和声音艺术的探索及相关教学干预。早前, 瑞典大地当代艺术实践艺术馆 (LAND Contemporary Art Practices) 馆长、艺术家茜茜·韦斯特伯格（Sissi Westerberg）和维 拉尼卡 · 维曼 (Veronica Wiman) 二人在哥伦比亚、瑞典和南非曾开展过相同主题的研 讨会。这次研讨属于与它们的合作项目, 受到它们的启发。本次与会的艺术家有利兹 · 科内克 (Liz Kueneke)、卡罗琳· H. 拉森 (Karoline H. Larsen)、安娜·宝拉·阿 尔贝 (Ana Paula Albé)、理查德·韦德伯格 (Richard Widerberg)、维纳亚克·达斯

(Vinayak Das)、贾汀·韦德雅蒂 (Jatin Vidyarthi) 、曼格拉·阿内波马斯 (Mangala Anebermath) 和维拉·曼德 (Vera Maeder)。兹纳斯·哈桑 (Zeenath Hasan), 他们 协作将该项目引进到班加罗尔。第二部分中, 在斯瑞施蒂学院教师拉德哈 ·昌德拉谢克哈 兰（Radha Chandrashekharan）的协助下, 学生独立完成自选的个人或小组项目。 
以及学生在完成个人项目时表现出的持续参与的兴趣, 都对设计教学法有一定的启 示作用。课程结束时, 学生参与项目的结果显示, 艺术实践在引导公众关注社会问 题这方面确实可以发挥重要作用。

在符合艺术家定义的社会艺术原则方面, 有两个常见的思路贯穿所有的这些 活动过程。一个是重塑个人的经验, 另一个是通过参与过程与公众形成更广泛的互 动。这两条思路不仅使个人的观点更容易为公众所了解, 而且可以提高公众的参与 度并见证这些观点。然而, 学生在反思了自己的主观立场并理解了问题产生的大环 境之后, 才会决定如何作为。在对自己的反应、情感和感觉进行了大量反思, 并且 在预测了自己的行为及表达的后果之后, 学生才会行动。通过采用争论、参与和反 思等策略, 促使学生行动起来。这一过程具有美感, 而且由于学生考虑的范围更广 泛, 这种美体现在具体行动中。

美感体现在超越了物质形式的行动和参与活动中, 体现在大众的相互关系和人 们在进行抗议游行时所感受到的快乐中, 体现在挖掘公众心目中的 “真相” 和验证真 相的过程中, 体现在社会行为动机的来源中。同时, 这些美感还体现在与艺术家表达 方式之外的其它不同认识世界的方式中，人们通过这些不同的方式来认识世界。路易 斯 (Lewis) (1990, 1992年帕亚雷斯 (Pajares) 引用) 描述了认知方式如何作为 选择价值观的方式, 以及所有知识的来源如何存在于信仰体系中。人们利用自己的感 官、直觉、逻辑或者自然法则开始认识外部世界。他认为, 个体用六种方式来认识外 部世界：相信权威、演绎逻辑、感官体验、是非判断、合理直觉以及个人对科学方法 的使用。他认为其中的一种模式会成为个人价值观形成和发展的主导模式。但是, 即 使其中一种模式成为个体认知的主要模式, 人类仍然可以通过所有这六种方式获得知 识。克莱克斯顿（Claxton）（2000）则描述了三种认知方式，其中之一便是直觉。 他对直觉认知、分析认知和反思认知三种方式进行了比较。这三种认知方式代表老师 的三种思考方式: 直觉思维是人们从以往经验中无意识地提取出的思维模式和对事物 的整体解释; 分析思维是逻辑和推理; 反思性思维则是指对问题进行反复的深思。积 累经验对于学生来说是必须的, 因为经验能够帮助学生找到各种各样的获取不同类型 知识的方法。如果认知方式影响认识论信念（帕亚雷斯（Pajares）1992），那么教 学策略需要有所调整, 考虑是否把所有方法都传授给学生。

\section{5 第二步教学法尝试：公共场所和教学法}

2009年7月，持续八周的 “公共场所和教学法” 课程采取开放式、项目化的问询方 式, 探索了如何发挥公共场所的教学作用, 帮助个体学习、构建知识脉络、价值观 和身份认同。在课程结束之际, 学生必须对这些知识体系提出质疑并对其进行重 塑, 同时, 把他们自己的观点作为一种教学法的尝试回馈给公众。该课程包含不同 类型的教学指导, 包括各种各样的艺术、活动和视觉表现方式 2 。

2 设置公共场所和教学法课程的目的是可以让学生对不同的访学教师采用不同的询问模式: 表演艺术家和媒体从业者迪帕克 ·斯里尼瓦桑（Deepak Srinivasan）、摄影师安娜 - 福 
这个项目借用亨利·吉鲁（Henry Giroux）关于公共教学概念著作中的概念，把 市场作为公共教学场所, 检验其作为学习场所的运作情况。吉鲁 (Giroux) 使用的 “ 公共教学” 这一术语包含了文化全球化过程中的政治和教育影响, 还包括通过数码 和媒体技术等新形式表现的认知和学习。吉鲁 (Giroux) 说, 处于主导地位的新自由 主义公司文化为公共领域的教学提供了新场所。这些教学法在各类机构中以多种方 式开展教学, 并不断生成、传播和宣传在这种强大教育影响下出现的创意。这些教 学法的目标是培养具有竞争力、自我本位的学生, 他们追求自身的物质和精神双丰 收。

在这些不同的方式和体验中, 课程内容源于学生的需求和实际的参与空间。 和“恐惧与性别”的方法类似, 在本课程后半段, 学生利用前六周所收获的一系列 经验设计并整合出自己的项目。这些项目包括: “均衡 (Equilibrium)”，在公园里 的互动项目中, 游客受邀反思自己的性别偏见以及他们形成（或者没有）性别等级 观念的过程; “换装项目 (Nayi Dastaan)”，把衣物看作是可视的性别标志。在该 项目中, 学生制作出科幻电影海报, 上面是用纱丽（印度妇女用整块布料裹住肩膀 和头的服饰）装扮的英雄人物, 他们在街上展览这些海报, 以此激发人们讨论对于 穿异性服装的态度; 还有“这不是我的原因” (I Never Ask for It) 项目, 学生在虚 拟的公共场所, 以街头性骚扰为主题, 讨论女性在公共场所面临的安全问题。

\subsection{1 反思和理解：争论的本质}

“公共场所和教学法” (PSP) 项目内容积极向上, 形式上却更偏向艺术 ${ }^{3}$ 。学生们 认为, 这些项目开发了新的行为和互动模式, 成为了解周围环境的新方法。大部分 项目都是在不同程度上以抗议为表现形式, 表现出人们对于某些意识形态或强加规 则的不满或者反抗。

公共教学法......是嵌入到集体行为中的行动主义, 不仅存在于制度化结构中, 还存在于非制度化结构体系中，包括基层组织、社区项目、艺术团体以及镇民大会 上一一凡是能够为民众提供表达同情、愤慨、幽默和行动的场所都包括在其中。这 种教学法避免了教学过程中的不公平现象, 为复杂的、有争议的、来自底层的观点 的表达提供了机会（布拉迪（Brady）2006: 58, 奥马利 (O' Malley) 和罗斯波罗 (Roseboro) 2010年引用)。

本课程提出了这样一个观点, 公共教学法既能够用于研究, 也能够指导设计专 业学生开展各种形式的活动。采用一系列的形式, 如视觉表达、具体行动和效果展 示等形式, 将那些不满和反抗的情绪表现出来。

克斯（Anna Fox）、历史学家和文化批评家拉塔·玛尼博士（Dr Lata Mani）、图表和 标准设计师马林达 ·帕特尔 (Mahindra Patel) 、艺术家和社会活动家贾思曼 · 帕特加 (Jasmeen Patheja) 及学者和哲学家孙达尔 - 萨鲁开博士（Dr Sundar Sarrukai）。本课 程由斯姆里提 ·梅拉 (Smriti Mehra) 、莱文德恩·古他 (Ravindra Gutta) 及阿伊莎·亚 伯拉罕 (Ayisha Abraham) 协助完成。

3 在2010年10月的谈话中提到在现存的多种认知方式中广泛存在的“等级制度”。 


\subsection{2 其它发现: 审美形式与互动}

从学生的积极性和参与程度看, “公共场所和教学” (PSP) 课程受到学生的高度 重视。一些项目极具吸引力一一激发了学生的兴趣和他们情感表达的愿望; 但是, 项目的阻力往往不是来自参与这些项目的学生, 而是来自外界。就像设计师用情感 化设计吸引消费者的注意力一样, 这些项目通常涉及的是有感召力的话题, 使人们 产生一种有别于自身体验的感受，这种感受完全是受到他人影响而形成的。

这些项目表明, 艺术方法可以用于美化一种社会形态, 或反对这种社会形态, 甚至是产生新的社会理解、行为和互动的方式。这些新社会形态的性质及其影响可 以看作是一种美学抗议。这些观察和思考引发了对美学作用的质疑。利用美学吸引 眼球仅能够激发短暂的快乐感, 而非持久的快乐。提出这些问题导致了另外两个课 程的设立, 以下两个部分将会对它们进行简要的介绍。

\section{6 第三步教学法尝试：抗议美学}

本课程探讨了抗议的性质和内容, 并深入研究了其不同的表达形式。艺术家和设计 师在努力重塑、想象并设置不同的现实选项时, 尤其是在交流中用情感吸引更为广 泛的观众时, 会结合使用抗议这一概念 4 。学生们也追求美的理想, 作为公众的一 员，他们也通过各种媒介和其它渠道享受这种美。在最近一个由当红影星代言的“ 白晳可爱 (Fair and Lovely) ”美白霜广告期间, 他们的讨论受到了重视。他们质 疑白和美的关系以及把白作为理想的美进行推销的过程。接着, 他们在公共场所进 行了一系列活动, 表明他们对于这一话题的立场。本课程以街头示威游行的方式结 束, 学生把这次游行称之为对把白强加给理想美的 “美学抗议” , 称之为 “黑俏可 爱 (Dark and Lovely) ”。学生与公众开展对话, 他们在自己脸上喷上深棕色和 白色颜料, 还为此事制作了海报。他们把抗议声明写满街头巷尾, 制作了称为“白 晳尺”的手带, 在这种尺上标了等级, 用数字表示和比较人的肤色深浅。他们把这 些“白晳尺”发给在脸谱网（Facebook）上及街头接受他们访谈的人。

\subsection{1 反思和理解: 体验顺序, 表现化}

这一步教学法尝试展示了在抗议行动中, 审美体验如何引发图像和视觉创建形式之 外的其它考量。它还可以扩展到抗议的互动性及其对参与者和旁观者的后续和残余 效应。本课程强调, 当通过具体行动和表现, 并以身体作为主要表达媒介时, 个体 及周围公众的观点可以引发更为积极的响应和交流。

为了对相关问题展开深入探讨并进行相关的设计, 该教学法首先需要着手找 出那些能够触发某些政治、社会或客观现象的个性化或主观概念（理念）, 而这正 是这种教学法所要达到的目标。而传统教学法首先关注客体, 然后找出它们与学生

4 斯瑞施蒂学院的莱文卓 · 古他 (Ravindra Gutta) 和阿里森·库德拉 (Allison Kudla) 也参 与帮助了本课程。 
之间联系, 以此来激励他们。但是, 引入的顺序是相关的：主体需要将自己在客体 中进行定位; 个体首先需要找到自己在人群之中的位置, 然后决定自己该如何成为 整体的一个部分。明确自己在公众中的定位, 可以显示个人在整个人类经验中的位 置。需要一个反思过程来指导人们进入一个辩证过程, 为其争取空间和发言权, 然 后再重新进行反思。

\section{7 第四步教学法尝试: 经验美学}

当试图在广大公众面前使学生的争论清晰明朗时, 当不知道交流信息如何被接收 时, 就会又一次产生兴奋感, 这种意识在这时得到加强。似乎美感藏在参与的兴奋 感和结果的不可预测性中, 学生走在街上想方设法让人们注意到他们时就体会到了 这一点。杜威 (Dewey) 提到美学经验时指出, 风险体验也可能是一种审美体验, 因为这种经历需要我们全神贯注的投入其中。人类经验可能存在一些共同维度, 这 些维度可能会在我们共有的情感、感受和认知中找到, 可能会跨越阶级、社会地 位、性别以及其它差异, 而不像我们应用在形式判断上的视觉美学限制。这种判断 把我们观察和学习到的判断事物美丑的标准作为前提条件。

这些观察和思考将我们引入了“经验美学” (Aesthetics of Experience) 的课 程, 来探索认知和经验的美学维度及其对设计教学法的意义。我们把 “经验美学”

(Aesthetics of Experience) 课程作为另外两个课程的小模块开展 5 。第一个课程的 名称是 “形式问题” (Matters of Form) : 经验美学 (Aesthetics of Experience) 研 究的是人类的感知方式, 这一理论的核心理念是, 对艺术和科学进行整合必须建立 在对一系列共享的技能和具体实践的认识的基础上。

第二门课程 “班加罗尔的骄傲” (Bengaluru Pride) 的根本目标是, 在那些能 够鼓励公众参与的体验设计中与大型社区合作开展创作。

烹饪和饮食体验是其中一个重要的情形, 其中探索的是这样一个概念, 即有一 些方面能让人留下一段难忘的回忆, 这些方面的某些特点对经历者的影响比其它一 些特点更加强烈。另一种情形是电影体验和参与式的丝网印刷聚会活动, 学生在那 里打印自己设计的T恤衫, 并穿着这些T恤衫在大型社区中游行展示。这些内容都被 整合到这两门课程中。“经验美学” (Aesthetics of Experience) 课程试图揭示那些 能够给参与者带来快乐感, 并促进艺术家和设计师就这些方面潜在的相关性展开对 话。课程包括学生蒙住眼睛参加晚宴等活动。他们还设计并举行了三次聚餐。在三 次聚餐中, 最后一次教师参与的人数最少, 但是也有 200 多人参加。在 2010 年 11 月 举办的LeNS会议晚宴上, 学生们体验了从购买食材到为来宾服务的全过程。

5 第一项课程由斯里史蒂学院教师拉梅什 ·卡尔库 (Ramesh Kalkur) 和认知科学家拉杰 什 · 卡斯图里兰根博士 ( $\mathrm{Dr}$ Rajesh Kasturirangan) 协作完成。第二项课程由拉梅什 · 卡 尔库 (Ramesh Kalkur) 和莱文德恩·古他（Ravindra Gutta）协作完成。 


\subsection{1 思考与反思：对话}

帕特里克 ·派瑞斯（Patrick Parrish）（2008）在其博士论文 “把学习当作审美经 验” (Learning as Aesthetic Experience) 中引用了杜威 (Dewey) 的理论, 在论 文中, 他认为有效的学习模式应该包括一个审美场所。派瑞斯 (Parrish) 对个人经 验中情感与认知的整合过程进行了探讨, 认为审美经验对这一整合至关重要。杜威

（Dewey）的审美经验的概念超越了审美是对美好和鼓舞人心的事物有所反应而产 生情感这一概念。他认为广义的艺术是把多元化的自然和人类活动统一起来的审美 经验, 是各种类型经验的统一体。恰恰是一个人参与的深度和强度以及达到的成就 赋予了艺术美学特点（杜威（Dewey）1934/1989）。审美经验和其它经验的区别在 于审美经验具有整体性, 因为审美经验可以达到圆满的境界, 实现内在的统一。

我能够再次观察到我称之为美学的这种参与的兴奋感, 因为它要求深度参与到 这种具有参与性、合作性、动态的人与人之间的交互活动中，人们在这个活动中有 着共同目标。这里的共同目标包括 “恐惧与性别” (Fear and Gender) 项目中的 抗议游行、“公共场所和教学法” (Public Space and Pedagogy) 项目及 “抗议美 学” (Aesthetics of Protest) 项目中的一些教学内容, 哈兹拉 (Hazra) (2010: 6) 在描述一个虚构的参与性声音艺术事件时也提到了“参与性美学兴奋感” 这一概 念。

\subsection{2 其它发现：共同创造体验，延伸效应}

在“恐惧与性别 (Fear and Gender)” 课程上与学生一起穿街走巷时, 除了感 受到作为公众一员的兴奋感，还可以感受到人群的密集和人与人之间身体的近距 离接触, 接触到陌生人, 感受到团体在表达和行动中的共同目标, 还能感受到 把个人立场上升为政治和公共宣言时的相关风险。在“经验美学 (Aesthetics

Experience）”课程中, 当聚餐的人群达到高潮时也可以感受相似的兴奋感，这种 兴奋感不在于竞争的激烈场面, 而在于自己成为事件的参与者而非旁观者, 在于大 家向着一个共同的目标努力。艾利亚斯 ·柯乃提 (Elias Canetti) 在《人群与权力》

(Crowds \& Power) (1962) 一书中提出, 人群是一个普遍、玄妙的现象。他认为 在接触未知时产生的恐惧是人类所面临的最大恐惧, 只有在人群中, 人们才不会害 怕这种恐惧, 也只有在这种情形下, 恐惧感才会转化为相反的感受。在这里, 没有 任何区别, 即使是不同性别, 都是平等的。麦克卢汉 (McLuhan) (1964) 认为, 数字是我们触觉的延伸, 人们的服装品牌是人与他人的关系的延伸。身处人群之中 可能会令人倍感舒适和愉悦, 设计教学法在探索究竟是什么因素能够使人们在经历 难以忘怀时可以借用这种思路。众生皆平等, 人们不再在乎谁挤压着谁。人群中的 无差异性构成了作为其中一员的美感。也有可能当人们身处人群中时, 他们所感受 到强烈情感体验构成了这一美感：柯乃提（Canetti）认为意外事件所导致的恐慌强 度和其它类型的恐惧不同。

“经验美学” (Aesthetics of Experience) 课程中的最后一次聚餐有200人参 加。这是一次难忘的聚会, 给我们留下了很多思考空间。也许行动和互动的残留影 响类似于生产过程的残留影响, 未来的设计师应该认识到这一点。意识到这一点 
后, 设计任何拟定活动都会对活动的影响和后续结果有更为清醒的了解。在一个共 同创作体验中, 展示个体在群体中的位置是很有必要的, 就好像每个人做的菜看放 在一起构成整桌美食所产生的美感一样, 这些细节都可以让我们看到个体如何组成 整体。这样, 每个人都能清楚地意识到他们的个人经验对于更为庞大的人类经验整 体所做出的贡献。

\section{8 结论}

\subsection{1 艺术实践、设计教学法和设想一个可持续发展的未来}

设计行业的教育工作者采用各种工具, 让学生熟悉自己的设计作品将要传播和产生 后续影响的环境。通过阅读材料、文章、观看电影和其它媒介, 我们能够让学生了 解看待一个环境的各种视角, 传授他们在设计过程中必须要考虑到的问题。这些都 是外部知识来源: 这些来源于学生本人之外, 学生通过客观来源或者其他人的讲解 学习这些知识。然而, 任何环境中和环境周围所包含的问题除了来自外部, 也可以 通过我们内部的个人经验和主观性获得。同时, 我们还有必要了解那些客观的、外 部的、与我们疏远的来源, 因为, 从中我们可以了解到, 作为社会的一份子, 我们 与其他人以及这个世界的相互关系。艺术实践运用那些鼓励对环境进行主观探索的 表达方式。主客观知识有必要结合在一起, 要想实现这一点, 可以利用艺术表达方 式, 并通过运用理论对问题进行批判性地理解, 或邀请权威的加入来处理需要解决 的问题。我们建议教学设计采用前两种经验, 即主观经验和客观经验, 前提是通过 主客观来源的平衡, 学习并了解环境的复杂性, 这种主客观来源的平衡有助于对环 境的复杂性有更加深刻的理解。

我们可以向学生提供得益于设计干预的世界观, 当这些考虑符合学生自身利益 时, 他们的行动会有个人动机在其中。这通常从认识到不公平和不合理的社会安排 开始, 反对这种社会安排, 并通过社会理解、行动以及互动形式倡导新模式。认知 和表达的艺术方式也可以作为一种方式, 让人们讨论现有社会安排的性质, 构想出 更新颖、更可持续的社会安排。它们还向我们提供了方法, 通过我们的想象, 展现 出可能实现的未来王国, 然后希望有朝一日能够实现它。其它三种体验, 竞争性、 参与性和反思性体验, 作为教学设计所需考虑内容。新的实践和行为模式可以依据 这些体验开展想象一一并且这些体验也引入了新概念, 未来的实践可以从中得到发 展。

\subsection{2 把能动行为 (enactive design) 作为审美行为}

纳拉亚南（Narayanan）（2010）表示, 印度设计专业教育所面临的挑战在于能 动教学法的设计、演说空间的提供、美学抗议以及能动行为。这些挑战引起了我 们的关注, 而我们需要在更广泛的领域开展工作。她总结了欧文 ·拉斯洛 (Ervin Laszlo) 和罗伊·阿斯科特 (Roy Ascott) 的理论著作和斯瑞施蒂学院在文化、环境 和教育领域的教学法和项目, 并将其作为案例进行研究。她提出把基于自主性、经 
验和主动性的意识的整体发展作为设计思维新形式的核心。本章所述课程让学生参 与到不同类型的演说和公共行动中: 审美抗议、能动行为 (enactive action)、关于 强加身份的争论、价值观、意识形态、新的创意、社会安排和社会现实。学生展现 出自主性、积极性和主动性。纳拉亚南（Narayanan）（2010）认为这些品质能够 推动能动行为 (enactive action) 和审美抗议的进一步发展。

设计专业教育的新方式必须注重实践, 实践表现出我们对其他人, 即那些与 我们同在一个星球上的人类的关注（瓦雷拉（Varela）等人（1993），纳拉亚南 2010年引用)。当拥有不同种类的丰富经验时, 我们就有动力采取行动, 改造我 们的环境和世界。杜威 (Dewey) 认为, “经验为学习之基础”, 提出 “经验的 持续性和互动性” 这两项原则, 并将其作为区别不同经验内在价值的标准（杜威

(Dewey）1938）。这两项原则代表了经验的横向和纵向两个方面, 他认为, 两项原则的结合决定了教育经验的重要性和价值。以经验为基础的教育会要求选 择那些持续连贯、可以和未来经验有效结合的经验; 这就会唤起对连贯一致的相 似经验的渴望。第二个原则, 即互动原则, 意味着客观因素和个体的内在条件都 会影响经验的形成。杜威 (Dewey) 指出, 审美经验始于强烈的无法控制的参 与欲望。它从一个坚定的需求开始, 不断开展行动, 直到需求实现, 否则这个需 求会一直发挥作用。在这一过程中, 我们对最终目标充满了期待, 并始终坚持那 些能够实现期望目标的行动。我们也关心那些与我们预期目标相关的条件（杜威

(Dewey) 1934/1989)。

\subsection{3 延伸教学法}

当我们产生主观感情和情绪时, 当这些感情和情绪借助外部方式持续地表现出来 时, 当我们的内在冲动与既具有一致性又具有连续性的社会领域发生联系并结合起 来时, 当我们为了共同目标加入到更大的团体而成为其中一份子并为这一团体做出 自己的贡献时, 当我们分辨出哪些是强加给我们的东西并且我们可以向这些东西发 起挑战时, 当我们有机会重塑我们的生活经验时, 当我们反思并关注我们自身的成 长时-一所有这些经验都有助于提高学习经验的质量, 并且赋予它美学特征。为了 自己和他人而有所作为的冲动是互相联系的：它们都是连续统一体的一部分, 是相 同渴望的一种极端表现形式。能动行为 (enactive action) 在一个更广泛环境下定位 个人行为, 而这个环境也受到该行为的影响。能动行为 (enactive action) 通过外部 世界发生作用并通过精神和物质的两个方面影响世界, 因而它要求有自我意识。

在我最近的教学实践中, 我试图了解人们是否能把审美经验和经验美学这两个 概念区别开。在本章末尾, 我提出的观点是经验美学也许是该经验的影响给人们留 下的延伸效应, 而它鼓励人们追求类似经验, 或者寻求同样经验的延伸。五种经验 要素: 主观性、客观性、参与性、竞争性和反思性性, 试图说明一种延伸教学法。 这种方法主要是针对教学设计问题, 要求我们考虑到我们的行为作为整体中的重要 组成部分所具有的残留影响。 


\subsection{4 延伸教学法, 可持续教学和系统思维}

当我们教授 “可持续设计” 时, 我们关注的问题是创造出来的东西与那些保留和传 承下来的东西能够拥有相同的质量。可以采用鼓励学生对结果进行反思的教学策 略, 把系统方法融入设计思维和行动中。五种经验要素: 主观性、客观性、参与 性、竞争性和反思性。经验包含规划延伸教学法的因素, 它们旨在打造能动行为

(enactive action) 的能力, 这种能力把个人的行为置于更加广阔的环境中, 而这种 环境反过来受到能动行为 (enactive action) 的影响。该教学法要求我们将我们行动 的延伸效应作为整体中的关键部分，提出了我们如何在一个较大的动态环境及其相 互影响中展开互动。在设计可持续教育的大环境中, 延伸教学法提供了一种方法, 把系统思维方式融合到设计思维和行动中。

\section{参考文献}

Bell, P. and Lin, M.C. (2002) 'Beliefs about science: How does science instruction contribute?' in B.K. Hofer and P.R. Pintrich (eds.), Personal epistemology: The psychology of beliefs about knowledge and knowing (Mahwah, NJ: Erlbaum): 321-363.

Canetti, E. (1962) Crowds \& Power (New York: Farrar, Strauss and Giroux).

Claxton, G. (2000) 'The anatomy of intuition', in Atkinson, T. and Claxton, G. (eds.), The intuitive practitioner: on the value of not always knowing what one is doing (Buckingham: Open University Press): 32-52.

Dewey, J. (1916) Democracy and education (New York: The Free Press).

Dewey, J. (1934/1989) Art as experience (Vol. 10) (Carbondale: Southern Illinois University Press).

Dewey, J. (1938/1997) Experience and education (New York: Simon \& Schuster).

Giroux, H. (2010) 'Neoliberalism as Public Pedagogy', in Sandlin, J., Schultz B., and Burdick, J. (eds.), Handbook of Public Pedagogy (London: Routledge).

Hazra, A. (2010) Excerpts from the IDAF Annual Report: SHM Dials-a-Logician on a Mobius Strip Joint.

Hofer, B.K. (2002) 'Personal epistemology as a psychological construct and educational construct: An introduction', in B.K. Hofer and P.R. Pintrich (eds.), Personal epistemology: The psychology of beliefs about knowledge and knowing (Mahwah, NJ: Erlbaum): 3-14.

Hofer, B. (2004) 'Exploring the dimensions of personal epistemology in differing classroom contexts: Student interpretations during the first year of college', Contemporary Educational Psychology 29: 129-163.

McLuhan, M. (1964) Understanding Media: The Extensions of Man (Cambridge, MA: MIT Press).

Narayanan, G. (2010) 'Enactive Design: The Imagination Challenge for Indian Design 2010', in F. Ceschin, C. Vezzoli and J. Zhang (eds.), Sustainability in design: now! Challenges and opportunities for design research, education and practice in the XXI century. Proceedings of the Learning Network on Sustainability (LeNS) conference, Bangalore, India, 29 September - 1 October 2010 (Sheffield, UK: Greenleaf Publishing).

O'Malley, M. and Roseboro, D. (2010) 'Public Pedagogy as Critical Educational and Community Leadership: Implications from East St Louis School District Governance', in Sandlin, J., Schultz B., and Burdick, J. (eds.), Handbook of Public Pedagogy (London: Routledge). 


\section{0 可持续产品服务系统设计}

Pajares, M. (1992) 'Teachers' beliefs and educational research: Cleaning up a messy construct', Review of Educational Research 62: 307-332.

Parrish, P. (2008) 'Learning as Aesthetic Experience: John Dewey's Integration of Art, Inquiry, and Education', in Designing Compelling Learning Experiences, PhD dissertation, University of Colorado Denver.

Sandlin, J., Schultz B., and Burdick, J. (2010) 'Understanding, Mapping and Exploring the Terrain of Public Pedagogy', in Sandlin, J., Schultz B., and Burdick, J. (eds.), Handbook of Public Pedagogy (London: Routledge).

Schommer, M. (1990) 'Effects of beliefs about the nature of knowledge on comprehension', Journal of Educational Psychology 82(3): 498-504.

Schommer, M. (1994) 'An emerging conceptualization of epistemological beliefs and their role in learning', in K.A. Feldman and M.B. Paulsen (eds.), Teaching and learning in the college classroom (2nd edn) (Needham Heights, NJ: Simon and Schuster): 173-183.

Schommer, M. (1998) 'Dimensions of tacit epistemology and comprehension', Paper presented at the Annual Conference of the American Educational Research Association, New Orleans, LA, April 1998.

Schommer-Aikins, M. (2002) 'An evolving theoretical framework for an epistemological belief system', in B.K. Hofer and P.R. Pintrich (eds.), Personal epistemology: The psychology of beliefs about knowledge and knowing (Mahwah, NJ: Erlbaum): 103-118. 


\section{7 \\ 创新可持续性 （设计）教育的任务}

海伦娜·许沃宁（Helena Hyvönen）、佩卡·萨莱拉（Pekka Saarela）和塔 图·马蒂拉 (Tatu Marttila)

芬兰阿尔托大学艺术、设计与建筑学院 (Aalto University School of Arts, Design and Architecture)

\section{1 创新可持续性 1}

本章选用此标题是有特殊原因的。它是2010年在芬兰设置的新的跨学科硕士课程, 该课程是在三所大学或学院合并成阿尔托大学 (Aalto University) 2 后, 为该校学 生所开设的课程。该课程把商业、技术以及艺术与设计领域各专业的学生聚集在一 起。这个标题正好也代表着一种思维方式: 我们的目标是利用设计师或艺术家的专 业特长实现世界的可持续发展, “创造性”是实现这一目标的出发点。

作为一个国家, 芬兰本身就是一个成功的故事。约150年前, 芬兰粮食欠收, 很多人饿死。经历上世纪中期前的战争之后, 芬兰国弱民穷。老一辈芬兰人厉行节 约, 粫帚自珍。家家户户都是将哥哥姐姐穿过的衣服再传给弟弟妹妹们穿, 反复使

1 涅米宁E. Niemi (E. Nieminen, 2008) 同名著作, E · 涅米宁是一项与书同名的硕士项目 的发起人之一。

2 阿尔托大学 (Aalto University) 是芬兰国内的一个项目, 由三个在学术研究方面相互独立 的大学组成: 赫尔辛基艺术与设计学院 (The University of Art and Design Helsinki) 、 赫尔辛基经济学院 (The Helsinki School of Economics) 和赫尔辛基理工大学 (Helsinki University of Technology）。这所新学校成立于2010年初。 
用, 直到最后编织成破布垫。人们出门除了步行就是骑车。如今, 芬兰却被国际杂 志《新闻周刊》（2010）（Newsweek 2010）3评为世界最佳国家。

教育的发展是这个国家能够被评为最佳国家的主要因素。由于芬兰在“教育培训、 科研、高科技及其应用、可信赖的公共部门以及芬兰人的价值观和态度” 等方面的 积极发展, 其综合竞争力位列世界前列 (教育部 (Ministry of Education) 2003b: 6）。芬兰拥有世界上最好的基础教育, 而且社会效率很高, 这不仅仅是芬兰人的骄 傲, 而且是带动整个国家发展的工具。因此, 在本章中, 我们得出这样的结论: 在 分析高等教育机构的教育, 尤其是可持续设计教育, 能够且应该努力达到什么水平 时, 可以将芬兰作为可行的研究对象。

本章探讨了学术界的新任务, 以及教育和社会创造知识的新方式。本章的目的 是通过学习芬兰阿尔托大学 (Aalto University) 的实例, 研究现代设计和艺术教育范 例, 决定应该采取什么行动来实现上述目标。本章介绍了政府在支持艺术与设计方 面的政策和举措。本章还试图识别艺术与设计教育的未来走向, 提出展开跨学科教 育活动, 以便将产品服务系统 (PSS) 融入教学大纲, 从而更好地实现未来社会的 可持续设计教育。

\section{2 学术界新角色}

过去十年里, 学术界的角色逐渐发生了变化。虽然芬兰和欧盟采取更为积极的举措 为社会和经济创造新知识, 全球气候变化的现实让人们越来越关注可持续教育 4 。传 统上, 大学的两个主要任务是学术研究和高等教育。21世纪初, 芬兰就立法为高校 增添第三个任务这一方案展开了讨论, 并且也采取了一些实际行动：这第三项任务 就是创造实用知识 ${ }^{5}$, 并将之服务于社会。知识在规划和生产过程中扮演着越来越重 要的角色, 知识密集型产业对科技人才的需求日益增长（教育部2003b：5）。从高 校的角度看, 这第三项任务通常被认为是社会协作、服务活动, 或从更为狭义的角 度看, 是与商业相关的活动。

竞争的全球化和市场的日新月异要求国家的应对措施既能保持其未来的活力, 又 “强调创新作为高等教育的主打产品的重要性”，这也是阿尔托大学 (Aalto University）建立的初衰（评估小组（Evaluation Panel）2009：48）。然而, 除了国内的环境要求之外, 高校还需要担负起国际及全球责任。就可持续性而 言, 转型过程中必要的创新不仅仅与技术有关, 还与社会文化息息相关（维佐里

(Vezzoli) 2005)。此外, 欧盟把跨学科教育能力作为评估 “杰出高校”的三个先 决条件之一（欧洲委员会（European Commission）2003：17）。因此，高校必须

3 在线参考http://www.newsweek.com/2010/08/15/interactive-infographic-of-the-worlds-bestcountries.html的统计数据。

4 在线参考http://www.newsweek.com/2010/08/15/interactive-infographic-of-the-worlds-bestcountries.html的统计数据。

5 联合国指定2005年到2014年是“联合国可持续发展教育的十年”。另见本卷第一篇第一章。 
走跨学科发展道路, 在科研、教学及现实生活中都要把商业和技术、艺术和设计结 合起来。

\section{3 可持续社会的设计与艺术}

纵观历史, 芬兰重视设计由来已久, 在国际设计领域, “芬兰设计”也享有盛誉。 这种盛誉是二战后的一代设计师创立起来的, 他们在国际展会上的出色表现受到世 人的关注和赞赏。20世纪 90 年代, 为了改变公众对设计能力的认识, 政府制定了 新的设计发展规划。该规划的主要内容包括工商业的竞争力、技能的提升和多样 化、加强开展科研工作, 并创造设计机会。芬兰政府的 “设计政策”（后来成为 2005! 设计规划 (Design 2005! programme) ) 中的“决策原则” (Decision-inPrinciple）6, 强调设计在 “促进创新体系发展” 中的作用（教育部2000）。成功的 产品开发无一例外都是 “多专业协作” 的结果, 因此, 政策目标建议将设计融入到 商业和技术领域的管理项目和本科课程中（教育部2000）。

以解决问题为导向的设计实践创造实用知识, 以用户为目标, 采用参与式设计 等方法, 把越来越多的利益相关方纳入到设计过程中, 因而这些设计实践更具系统 性。除了这些改变和政府政策上的完善之外, 设计界也越来越注重它在可持续发展 中的作用。(维佐里 (Vezzoli) 2007)。设计涉及文化、政策和技术等诸多领域, 与消费者和环境这两者之间的关系更是密不可分。因此, 在设计领域, 社会政治和 经济的价值观与技术现实必须融会贯通。艺术则遵循并促进这一过程的发展。艺术 不仅是一种技能, 还具有反映社会與论并影响社会與论的作用。艺术和设计把不同 知识领域的价值观融合起来, 同时又为它们所涉及的社会实践设定价值观。对于设 计、协作设计和研究及艺术过程的反思可以为上述过程提供支持。

\subsection{1 推进可持续性}

艺术和设计是阿尔托大学 (Aalto University) 的两大优势学科（克劳斯 (Krause) 等, 2009)，艺术、设计与建筑学院 (School of Arts, Design and Architecture)

（原来是赫尔辛基艺术和设计大学（University of Art and Design Helsinki））长期以 来非常重视可持续方面的研究和开发。显而易见, 艺术、设计和建筑在 “高质量、 无障碍和高审美标准的环境” 的建设中扮演重要角色（教育部2003a：9）。此外, 由于能够 “在消费者文化领域和产品生产之间架起一座桥梁”，设计师在可持续框 架中发挥着重要作用(维佐里 (Vezzoli) 2003: 2)。

艺术有能力把可持续发展方面的问题、愿景和未来计划以形象化的形式展示给 公众。因此, 艺术是引导人们讨论环境改变及其对人们生活的影响、激发人们情感的 一个很好的工具, 同时它还具有参与性和能动性: 艺术使创造性的自我表达、情感发

6 本章作者之一佩卡·萨莱拉 (Pekka Saarela) 全面参与了“2005! 设计项目” (Design 2005 ! programme) 的策划工作 
展和自我实现成为可能, 通过这些方法, 个体可以 “分析现实” , 而社区可以创造出

“富有创造力的社会、文化和经济资本”（教育部2003a：6）。艺术活动还可以利 用不同意义体系中的 “转移创意” 推动 “可持续设计 (Design for Sustainability)” 过程, 并反映出 “认知参考和价值”（维佐里 (Vezzoli) 2005: 4)。

\subsection{2 设计与艺术的研究}

“设计创新的目的是推动社会可持续发展”，当代社会的相互联系和文化多元性 为 “设计创新的发展” 提供了一个 “特殊的机会” (维佐里 (Vezzoli) 2005：2）。 换句话说，如果我们认为可持续创新以 “完善、合理、与各种现代环境相契合” 这 样的理念而被传播, (维佐里 (Vezzoli) 2007: 27) ”，那么艺术和设计就是这个 过程的基础。对阿尔托大学（Aalto University）研究项目的正式评估体现了艺术和 设计研究的重要作用: 艺术和设计工作者整合信息, 统筹规划, 利用可视化表达方 式，推动文化产业的发展。同时对基础性社会软件提供支持，并促进协作性知识的 构建（克劳斯（Krause）等, 2009）。因此, 创新性的知识探究和艺术工作, 不仅 不会互相冲突（评估小组（Evaluation Panel）2009），反而会向同一个目标努力。 芬兰设计研究环境的特点是民主化、非物质化、数字化、片段式、政治化、策 略化, 且综合性强。同样, 艺术研究 “脱离了传统知识形式”, “对所有参与者” 构成了“挑战”（评估小组（Evaluation Panel）2009：50）。生产性创造要求重视 研究、文化和志愿活动的多样性和自由化（教育部 (Ministry of Education) 2003b: 7) 。艺术和设计领域的争论越来越倾向于针对那些 “能最好地服务于艺术及设计领 域” 的研究方法（评估小组（Evaluation Panel）2009：22），即能够促成行业与社 会中跨学科互动的方法。

\section{4 （设计）教育的跨学科方法}

在芬兰, 一些国家层面的研究项目已经涉及了更多的跨学科研究方法, 乃至开展了 教育和社会方面的跨学科研究 (如芬兰科学院 (The Academy of Finland) 的项目, 参看布云 (Bruun) 等, 2005) 。这些方法的发展及其创新潜力, 都被认为是阿尔托 大学 (Aalto University) （阿尔托大学 (Aalto University) 2010: 4) 未来的发展机 遇, 通过多学科研究及教育的形式表现出来。

\subsection{1 学科新方法}

学科新方法方面的一个开山之举是启动了创造性可持续发展项目 (Creative Sustainability (CS项目)) , 这是一个新的多学科硕士课程, 综合了设计与建筑、 工商业管理、企业管理和房地产等多种专业。创造性可持续发展 (CS) 项目提倡系 统方法, 在不同层面加强战略性思维, 以促进未来的可持续发展: 这些领域包括从 复杂的生态系统、城市及工业基础设施、技术和商业, 到个体选择。研修可持续设 
计课程的学生来自于CS项目涉及的所有专业, 无论他们是否接受过传统的设计基础 培训, 都体验了产品服务系统 (PSS) 解决方案的设计和为复杂世界开发创新策略 的实际过程。各学科核心课程仍然得以保留, 因为学生毕业时会拿到与自己所在院 系和专业课程相关的学位。

创造性可持续发展（CS）课程把三个学院的专业技术知识汇集到一个有影响 力的主题之下, 这个主题就是可持续发展。该课程以个体分析为出发点, 个体的消 费习惯和行为方式是未来能否实现可持续发展的决定性因素。社会和基础设施以及 工业和生产方法也都是关键因素, 另外, 还包括社会结构、建筑及环境的规划和建 设。最后一个重要因素是万物赖以生存的的生态系统（参看图17.1）。

\section{图17.1 有关个体及生态环境的创造性规划}

\section{来源：涅米宁 (Nieminen) (2008: 39)}

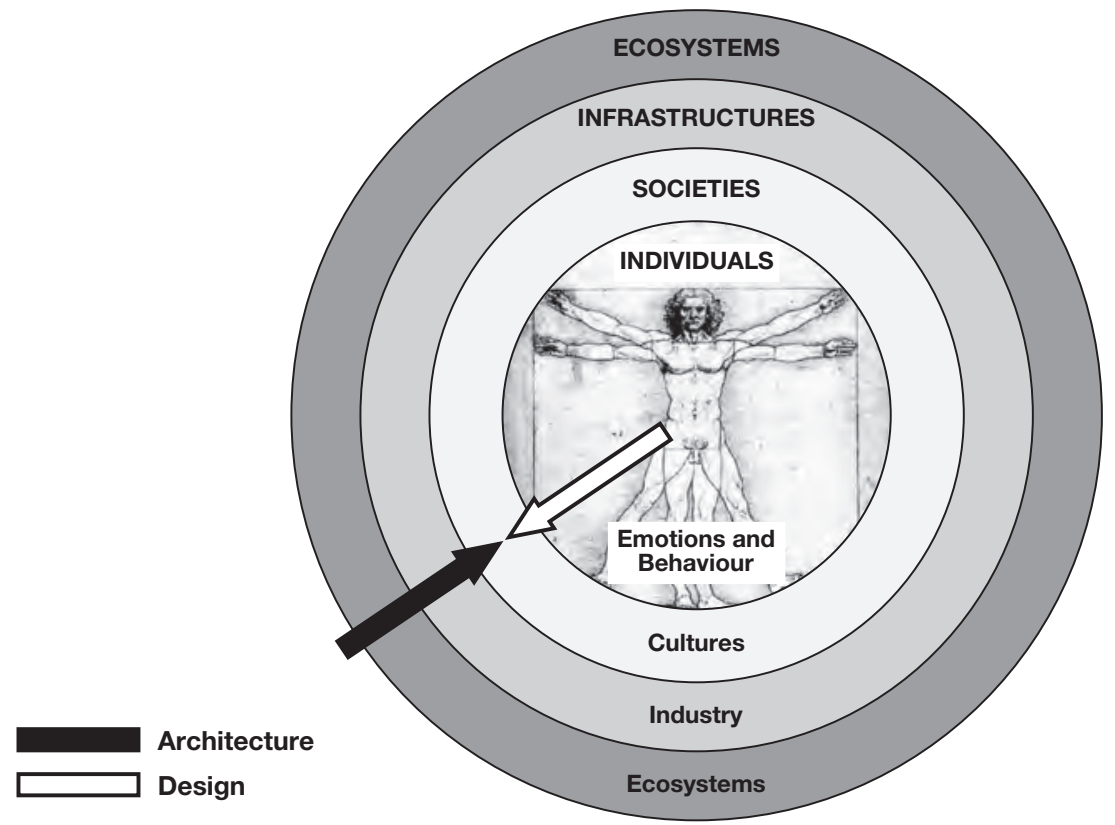

创造性可持续发展（CS）项目致力于全方位培养思路开阔、跨学科、富有创造 性、有解决问题能力的专业人士, 目的是建设一个更适宜居住和工作的世界。此项 目的目标是通过制定共同愿景和道德标准, 把可持续发展作为一种思维定势进行强 化, 更进一步地将多学科方法推向跨学科的方向发展 (参看马蒂拉 (Marttila) 和科 塔拉（Kohtala）2010）。在操作层面，该项目通过学生案例和不同科系、课程模块 及课程之间的合作, 帮助阿尔托大学 (Aalto University) 把可持续发展的观点完美地 融入到其研究和日常活动中。 


\subsection{2 对知识创造的启示}

科学知识至少在三个方面具有影响：知识的相关性、知识的转移以及接受者使用知识 的可能性（涅米宁（Nieminen）（2004））。这就意味着需要建立一个机制把知识 和社会现实生活实例结合起来, 把很多学科领域知识集合起来, 同时设计一个适合在 各种不同利益相关方之间使用并传播这些共享知识的方式。在这个过程中信息是分布 式的、当地化的、基于实例并且呈网状结构, 现实生活中的利益相关方及企业将在系 统创新中发挥关键作用, 这对于可持续的消费和生产模式的创新则尤为关键（如维佐 里 (Vezzoli) 2007)。在阿尔托大学 (Aalto University), 此类实例与利益相关方 之间的新型互动可以创造出丰富的成果, 不同专业领域和专业知识的结合可以带来大 胆创新, 使艺术和设计与商业、技术和科学水乳交融, 产生积极的影响。

为了打造最具创新型研究和设计的环境, 就必须确保获得服务或知识的平等权 利。我们创造的教育和研究框架必须要支持信息在社会和各个学科之间的流动。知 识的有效性问题不仅仅是知识的传播问题, 更关系到诸如大学、公司、政府机构和 民间团体等几个部门活动的价值观和最终目标（涅米宁（Nieminen）2004）。这些 价值观将促进社会的可持续发展和知识的传播。

\section{5 编后记：经验}

未来设计的一大挑战, 就是完善生态、经济和社会三者之间的可持续发展方案。其 中一个主要问题是，如何让消费者选择对可持续发展有利的服务和产品。在可持续 产品服务系统 (PSS) 的设计过程中, 不仅需要消费者的参与, 也需要各利益相关 方和知识主体的加入。作为设计师和艺术家, 这在我们的实践中也意指对 “可持续 美学” 的个别定义 (the aesthetics of sustainability) (维佐里 (Vezzoli) 2007: 43 , 亦可参看第二部分, 第一章）。这些美感来自多个方面, 源自于不同的价值观 和生活环境（维佐里（Vezzoli）2007) 。总而言之, 随着全球性挑战的加剧, 利益 相关方、专业人士和知识界之间需要加强联系。与此同时, 我们还必须兼顾环境责 任、社会公平、经济健康发展和文化活力7

此外, 国际间的交流和跨文化的合作也十分重要。作为设计行业的教育工作者 和研究人员, 我们应该以开放的姿态展开合作, 实现知识管理最佳实践分享。就像 不同学科甚至不同国家之间的互动一样, 设计和艺术之间的相互影响也可以创造文 化对话, 推动产生新的创新成果。LeNS项目把 “跨文化” 对话作为目标 (维佐里

(Vezzoli) 2005：5）。未来的设计教育也应该呼吁各国家文化、工作文化以及思 维文化之间的相互交流和融合。

21 世纪伊始, 芬兰实行的针对设计的政治方案, 以及设计教育整体情况, 现在 都需要进行更新。无论是方案的更新和教育的发展, 其出发点都应该是系统和服务

7 这些方面在美国专业设计协会 (AIGA) 为设计师提出的框架性目标中也有论述。该协会2009 年构思出了 “设计的生存理念” (The Living Principles for Design, http://www.livingprinciples. $\mathrm{org} /$ ) , 并将其在2009年10月9日的AIGA设计会议（AIGA Design Conference）上正式公布。 
的设计, 重点是以人为本, 面向大众, 以跨学科的方式, 追求可持续发展的目标。 阿尔托大学 (Aalto University) 的宏伟目标是: 通过高质量的跨学科研究、领先的教 育、持续更新以及通过大胆逾越传统界限来推动上述变革。如果能够把 “真正的跨 学科知识合并” 坚持到底, 把阿尔托大学 (Aalto University) 各学科的专业知识融会 贯通，那么阿尔托大学 (Aalto University) 就有可能成为 “真正适应21世纪” 的教 学机构（评估小组 (Evaluation Panel) 2009：29）。

\section{参考文献}

Aalto University (2010) 'Strategia (FI-II-01)' (Helsinki, FI: Aalto University; http://www.aalto.fi/fi/ about/strategy/AALTO_strategia_FI-II-01_korjattu.pdf, accessed 28 June 2013).

Bruun, H., Hukkinen, J., Huutoniemi, K. and J.T. Klein (2005) Promoting Interdisciplinary Research: The Case of the Academy of Finland (Helsinki, Fl: Edita).

European Commission (2003) 'The role of the universities in the Europe of knowledge' (Brussels, Belgium: European Commission; http://eur-lex.europa.eu/LexUriServ/Lex UriServ.do?uri=COM:2003:0058:FIN:EN:PDF, accessed 28 June 2013).

Evaluation Panel (2009) Research in Art and Design in Finnish Universities. Publications of the Academy of Finland (4/09) (Helsinki, Fl: Edita).

Krause, O., Saaristo, A., Sivenius, P. and K. Lehtovaara (eds.) (2009) Striving for Excellence: Aalto University Research Assessment Exercise 2009 and Bibliometric Analysis 20032007 Project Report (Helsinki, FI: Aalto University; http://www.aalto.fi/fi/research/strengths/ striving_for_excellence-aalto_university_research_assessment_exercise_2009_and_biblio metric_analysis_2003-2007.pdf, accessed 11 July 2013).

Marttila, T. and C. Kohtala (2010) 'Towards Transdisciplinarity: Understanding Current Multidisciplinarity in Designing Sustainable Urban Solutions', in Ceschin, F., Vezzoli, C. and Zhang, J. (eds.), Sustainability in Design: Now! Challenges and opportunities for design research, education and practice in the XXI century. Proceedings of the Learning Network on Sustainability (LeNS) conference (vol. 1). Bangalore, India, 29 September - 1 October 2010 (Sheffield, UK: Greenleaf Publishing).

Ministry of Education (2000) 'Government's Decision-in-Principle on Design Policy', (http://npa. ktpmalta.com/resources/Finnish_Design_Policy.doc, accessed 28 June 2013).

Ministry of Education (2003a) 'Government decision-in-principle on arts and artist policy', Publications of the Ministry of Education, Finland 23 (2003:23).

Ministry of Education (2003b) 'Ministry of Education Strategy 2015', Publications of the Ministry of Education, Finland 35 (2003:35).

Nieminen, E. (2008) Creative Sustainability (Helsinki, FI: Designium).

Nieminen, M. (2004) 'Lähtökohtia yliopistojen kolmannen tehtävän tarkastelulle', in Kankaala, K., Kaukonen, E., Kutinlahti, P., Lemola, T., Nieminen, M. and J. Välimaa (eds.), Yliopistojen kolmas tehtävä? (Helsinki, Fl: Edita): 15-42.

Vezzoli, C. (2003) 'A new generation of designers: perspectives for education and training in the field of sustainable design. Experiences and projects at the Politecnico di Milano University', Journal of Cleaner Production 11: 1-9.

Vezzoli, C. (2005) 'A migrant design creative-thought: Fostering necessary discontinuity for sustainability', In Proceedings of Research In and Through the Arts Conference, ELIA (European League of Institutes of Arts) Conference and Universitat der Kunste Berlin, 13-15 October 2005.

Vezzoli, C. (2007) System Design for Sustainability (Milan, IT: Maggioli Editore). 


\section{8 \\ 跨学科学习平台 \\ 教授设计专业学生可持续知识}

塔图·马蒂拉（Tatu Marttila）和辛迪 ·科塔拉（Cindy Kohtala）

芬兰阿尔托大学艺术、设计和建筑学院 (Aalto University School of Arts, Design and Architecture)

\section{1 引言}

2009年, 芬兰科学院 (Academy of Finland) 对芬兰的艺术和设计院校进行了 一次全面的评估。本章作者所在的设计系展开的这项研究被确定为主要的应用研 究, 主要针对一系列问题和案例进行分析, 其中 10\%的研究为 “临床研究 (clinical research) ”。因为这些研究 “是针对某个具体的案例或者客户——很像医生诊治 病人”（评估小组（Evaluation Panel）2009：29）。在可持续性设计的大背景下 来处理社会和环境问题时, 就必然具有临床特性：即必须对具体“症状”进行具体 分析。但是, 很明显, 要找出这些“症状”，甚至“流行病”背后的原因, 所采用 的系统方法则要求必须有专门的科学知识来支持。如果要实现本书第一卷第一章所 提出的根本性变革, 我们还需要在学习、鉴别问题和解决问题的时候使用全新的方 法。这种方法跨越学科界限, 不仅能够创造出新的知识和技能, 同时, 还能够帮助 学生在跨学科环境中设计出具有创新性的产品服务系统 (PSS) 新方案。本章利用 阿尔托大学 (Aalto University) 的案例以及正在进行的研究, 梳理了用跨学科知识构 建和设计的现有研究成果, 并将其应用于设计专业的教学中。 


\section{2 跨学科：是什么与为什么?}

首先, 有必要弄清楚跨专业协作的各种术语, 如多学科合作、各学科间合作和跨学 科合作之间的区别 ${ }^{1}$, 因为术语很容易被误解和误用, 以致在科学争论上产生一些理 解上的偏差。

\subsection{1 定义}

在多学科研究中, 各学科的视角是并列的, 每一种视角都有其自主性。多学科研究 的目标是知识的集成, 即用更多的信息来源、方法和理论来扩展知识库, 而不是针 对所研究领域生成一个整体的观点（哈凯奈 (Hukkinen) 2008, 布云 (Bruun) 等, 2005) 。所有学科之间并不会因为相互影响而发生根本性变化, 而且采用多学 科方法的目标也不在于实现各学科之间的协同（波尔 (Pohl) 等, 2008)。

20 世纪70年代 2 , 学术界开始有一种普遍认知, 即学科专门化有其风险性, 主要 在于它考虑不到潜在的负面影响和长远影响, 也不能大范围地满足全社会的需求。 因此, 便产生了越来越多的、冠以交叉学科研究或跨学科研究之名的综合研究方法

（赫斯 ·黑顿（Hirsch Hadorn）等, 2008; 克莱恩 (Klein) 2008; 布云 (Bruun) 等, 2005)。实际上, 交叉学科研究的目标是更加全面统一地理解问题, 并要求 各学科的词汇、框架、方法和思维模型适合全方位的共享和融合。这对认知过程、 教学机构和知识库的分级以及具有共同目标的各学科知识领域之间的互动有着重 要意义。

目前, 由于对跨学科研究的需求不断增加, 学术界也发生了转型, 研究的内 容从和社会相关的科学转变成了为社会服务、与社会协作的科学 (斯考兹 (Scholz) 马克斯 (Marks) 和布云 (Bruun) 等2005：31)。根据我们所给出的定义, 跨学 科研究尤其是可持续领域的跨学科研究, 需要延伸到社会中, 把诸如政界和除学 术界以外社会其它领域都囊括其中（哈凯奈 (Hukkinen) 2008, 布云 (Bruun) 等, 2005) 。跨学科研究 “除了关注问题的解决方案, 还关注问题的选择” (克莱 恩 (Klein) 2004: 518), 因此, 相对于传统科学的研究过程而言, 跨学科的研究 过程要更加规范、更加对社会负责。

\subsection{2 责任和承诺}

虽然一些人觉得多学科研究从根本上没有对 “现状提出质疑” (布云 (Bruun) 等, 2005: 27), 然而, 跨学科研究涉及对现状的研究与改进, 这一过程受到各利 益相关方和各学科不同利益及投入实际情况的影响（波尔（Pohl）2005）。因此, 参与跨学科研究的动力是社会责任感, 即为社会公共利益而开展研究工作。（波尔

1 这里的术语 “跨专业合作” (inter-professional collaboration) 只是被用来描述不同专业及 不同专业人才之间的合作。

2 1970年, 经济合作与发展组织 (OECD) 在巴黎组织了第一次国际交叉学科会议。这是该 领域的一个开创性事件。 
(Pohl) 2005)。任何企图改变现状的行动势必面临来自机构和个人等各方面的阻 力, 这也成为开展跨行业研究、设计和实施过程所面临的主要障碍之一。然而, 在 管理良好的项目中, 规范性程序通过强调尽责和参与来推动协商过程, 而且这在一 定程度上减小了跨学科研究的难度。对专业技术的研究表明, 当专家们全力以赴投 入工作的时候, 他们就会发挥出最高的专业水平。（哈凯奈（Hukkinen）2008）。 在此, 本人再次以临床和医学作比喻, 跨学科研究方法注重的“不再是孤立分析, 而是致力于综合的诊断”（哈凯奈 (Hukkinen) 2008: 67)。

我们在与非专业人士展开合作时, 这个承诺的特点也适用, 这里的非专业人士 是指那些会受到环境决策重大影响的利益相关方。使他们在一定程度上参与决策, 可以确保在实施及后续过程中更好地承担义务（萨布鲁（Thabrew）等，2009）。 另外, 这种做法有利于对系统内部的不同要素以及各要素间的信息流、资金流和物 质流进行更全面系统的评估。在一个复杂且内部相互关联的系统中, 以丰富、广阔 的知识为背景出台的 “兼容并包的决策” 可以作为一个指南, 引导系统获得一个更 可持续的结果（沃尔 (Wahl) 和巴克斯特 (Baxter) 2008：76)。因此, 在问题解 决过程中, 外行的利益相关方不再只是 “听众” , 他们变得更加专业, 成为了“积 极的分析师和解决问题的专家” (哈凯奈 (Hukkinen) 2008: 67)。这就说明, 在 对可持续产品服务系统 (PSS) 进行设计的各个方面, 从提出问题、设立目标, 甚 至到规划活动等方面，都必须考虑到与利益相关方加强协作的问题。

\subsection{3 新机构和新平台}

当今社会错综复杂, 创造知识、传授知识是大学和研究机构的主要责任, 其中一些领 先的研究机构堪称知识传播的 “捍卫者和旗手” (杜德斯达 (Duderstadt) 2000: 48-49）。其实, 各个大学也在不断地试图将自己定位为 “第三个角色”, 力求在一 个不断趋向于以知识为导向的社会中的政治及经济结构中发挥自己更大的作用 ${ }^{3}$ (涅 米宁 (Nieminen) 2004：22）。这样的一个角色要求大学应当针对当前的社会问题 展开研究, 并积累相关知识, 这就需要将研究与教育紧密联系起来。交叉学科研究 和跨学科研究绝不是是花一现, 相反, 它们将长期地 “对学术活动本身进行根本性 的改造”（杜德斯达 (Duderstadt) 2000: 121)。

另外, 仅依靠基础学科 “不能为可持续发展提供必要的可行性解决方案” （施恩 (Shin) 等, 2008: 1833) , 需要调动各利益相关方、非专业人士和各界专家们集思 广益, 群策群力, 实现可持续发展（沃尔（Wahl）和巴克斯特（Baxter）2008）。第 二, 如本文所述, 实现社会可持续发展, 必须彻底地改变现有的消费、生产模式中与 可持续不相适应的地方, 而不是简单地实行学科保守主义和保护主义来维持现状。相 反, 它需要的是更具适应性的智能化系统 4 。第三, 知识生产逐渐变得复杂起来, 并广

\section{3 参见第二卷第17章。}

4 “系统方法” (及 “系统思维” ) 已然成为可持续发展的普遍框架（波特（Porter）和寇德巴 (Córdoba) 2009)，它还可以进一步划分为不同的系统性视角，包括“功能性视角”， “说明性视角”和 “适应性视角” 等（波特（Porter）和寇德巴（Córdoba）2009）。它 们分别对教学法有实证主义和建构主义方法等方面的启示。“系统智能化” 将一种“适应 
泛“分布于社会各个领域”（布云（Bruun）2000：13）。越来越多的机构正在采用 交叉学科的做法, 私企和政府机构等也开始逐渐涉入这个领域（布云 (Bruun) 2000; 布云（Bruun）等，2005）。所以，教育也必须顺应这一发展趋势。

通过上述讨论, 我们得出的结论是, 无论是研究还是教育, 在处理涉及社会 道德和环境方面的可持续发展问题时, 交叉学科或跨学科研究是很实用的跨行业的 研究方法。同时, 对于设计一个成功的产品服务系统 (PSS) 而言, 综合、细致地 考虑各利益相关方的意见, 博采众长, 以实现社会的可持续发展, 也是有百利而无 一害的事情。因此, 我们认为, 学生通过跨专业的团队协作, “学习可持续发展理 念” 是最好的方式, 这样的团队协作能让他们在实际工作和生活中获得体验, 并能 够在实际项目和解决实际问题的过程中得到锻炼。然而, 解决这类问题的设计方向 并不很明确, 在跨专业和跨学科的新教学平台下教学生 “可持续性设计” (Design for Sustainability）的教学意义也不是很明确。

\section{3 跨学科研究: 参与者及方法}

一些交叉学科专家强调, 各学科的定义范围本身就可能是不确定的, 因为有可能 一个学科中各个细分专业之间的差异比一些学科之间的差异还大（例如, 布云 (Bruun) 2000) 。因此, 布云 (Bruun) 所指的是认知共同体, 尤其是它的“ 知识架构” (2000：29）。因为大学课程由各种学科构成, 而这些学科范围就是 根据知识内容和社会的规范化和专业化程度来确定的（迪斯普瑞斯 (Després) 等, 2004)。尽管如此, 我们还是认为某专家只属于某些特定学科。但是, 认知 方法和知识框架还是非常之重要, 因为交叉学科方法的本质是知识和框架的整体融 合。（布云 (Bruun) 等, 2000)。

反对跨专业方法的人士认为, 跨越或消除学科界限可能会导致专业化知识和技 能的退化甚至是消失（参见马蒂拉（Marttila）和科塔拉（Kohtala）2010）。然而, 据我们所知, 必要的学科融入对于一项研究是否成功至关重要, 事实上, 融入的学 科在交叉学科和跨学科研究中极有可能得到创新（威丝曼 (Wiesmann) 等, 2008), 只有学科间紧密结合, 才能做到各显神通（施恩 (Shin) 等, 2008：1834）。我 们认为, 在处理与复杂的社会生态系统有关的可持续性问题时, 因为参与者的价值 观、利益和思维模式不尽相同, 这种结合十分必要。尤其当提议的行动是基于个体 或团体的世界观的一些假设时, 参与者往往会持反对意见（卡鲁 (Carew) 和米切尔

(Mitchell) 2008)。5如果参与者能够对各学科知识融会贯通, 那么就能够充分发 挥各学科的作用（威丝曼 (Wiesmann) 等, 2008)。因此, 跨学科和交叉学科方

性的, 行动型的和感性的” 人性化视角引入到系统框架中（萨瑞娜 (Saarinen) 和哈马拉 嫰 (Hamalainen) 2010:19)。

5 在关于社交网络的研究中, “搭桥” 是一个描述信息传播的概念, 即信息从一个组（学科 领域）传播至另一个组（学科领域）。信息流的潜在规模取决于可用于信息交换的“桥” 的数量和连通性。 
法并不是要破坏 “各学科的核心”, 而是通过上述提到的整合和综合过程对某学科 知识进行 “重组”（波尔 (Pohl) 2005: 1175)，形成一个全新的形式独特的专业 学科（威丝曼 (Wiesmann) 等, 2008: 436)。正如布云 (Bruun) 所强调的, 交 叉学科方法既重视 “知其然”, 也重视 “知其所以然” : “知其所以然”包括 “区 分、比较、对比、关联、阐明、调和和综合的能力” (2000：17参见18.3.3)。

\subsection{1 知识层级}

我们尚未讨论参与跨学科研究的人选的问题。威丝曼 (Wiesmann) 等人认为, “自 然、技术、社会科学、人文科学, 以及现实中的实际研究能力的标准是无法预先定 义的” (2008: 436) 。研究过程中, 需要各利益相关方的参与, 然后再确定哪些领 域的知识需要进行整合。（威丝曼 (Wiesmann) 等, 2008)。这对于知识层级划分 有一定的启示: 各种事实和信息应当按什么样的标准进行先后顺序的排列, 以及这 些 “事实” 和相关信息的确切含义是什么。哈凯奈 (Hukkinen) 强调说, 实际上, 利益相关方从现实生活（或 “现实世界”）所带来的外行知识其实也是专业知识, 只是这些知识是在社会实践中产生的：因此，知识，从“本质”上来说，是建立在 一个稳固的社会标准之上的, 不仅非常科学可靠, 而且经过了 “公众考量” 的检验 (2008: 67)。

一旦踏上跨学科的研究之路, 就意味着, 如果希望获得相关的实用知识, 那么 就必须把科学的 “理想化环境” 抛在脑后（波尔 (Pohl) 2005：1160），而要面对 一种让学科专家没有安全感的、陌生的、至少是不舒服的环境。跨学科研究人员一 方面必须平衡好他们的职业和学科专业之间的矛盾, 另一方面, 他们也必须认识到 现实的复杂性（迪斯普瑞斯 (Després) 等, 2004)。如果不能成功解决这一矛盾, 传统知识层级将禁钿其学科范围, 束缚跨学科方法的发展, 那么就无法综合所有知 识来分析和解决问题, 导致研究与现实脱节。

\subsection{2 共享问题空间与认识论转化}

跨学科研究有多种知识来源: 自然科学、社会科学、非专业参与方以及各行各业。 知识及其构成分为三类：1)系统知识（复杂的实证问题的分析）；2）目标知识（在 制定目标以更好地解决问题时需要用到）；3)转化知识（如何活用知识）（威丝曼

(Wiesmann) 等, 2008: 436)。

如前所述, 用跨专业方法来解决复杂的环境问题时, 需要重新对知识进行共 享、整理、整合、归纳。最后形成一种新的混合知识, 或者叫 “混合” 知识, 在 性质上不同于混合前的任何一部分知识（冯·吉兹（von Ghyczy）2003，哈凯奈 (Hukkinen) 2008: 65引用; 参见图18.1) 6。简单来讲, 当一位专家遇到另一位 专家, 二人便开始寻求他们之间存在的共识。这不仅仅是理解另一方 “语言” 的语

6 跨学科合作当中体现出的知识类似于 “模式二”（吉本斯（Gibbons）等, 1994）, 远远 胜过以“学科内部分类”（诺沃提尼 (Nowotny) 等, 2003:179) 为特征的“传统科学 探究范式” (即“模式一”)。此类知识在社会上普遍存在, 以现实运用为目标, 具有 
义学过程, 还是一个必须经过的引入阶段。分享跨学科知识是一个认知过程, 一般 是通过类推或模式识别等方式来进行: 从专家角度来看, 在建设一种易于理解的人 类思维新模式的过程中, 需要采用选择性元素和关系, 也就是 “熟悉的输入空间”

(哈凯奈 (Hukkinen) 2008: 71) 。因此, 两种知识- - 两种思维模式一一相互碰 撞并融合, 生成新的知识范畴（参见哈凯奈 (Hukkinen) 2008: 71) 或 “交叉知识 领域” (参看迪斯普瑞斯 (Després) 等, 2004：475)。在早期研究中, 我们称之 为 “机会空间” (马蒂拉 (Marttila) 和科塔拉 (Kohtala) 2010：175）。在人机互 动 $(\mathrm{HCl})$ 领域, 又称为联合问题空间。

\section{图18.1 创造联合问题空间和混合知识}

来源: 作者

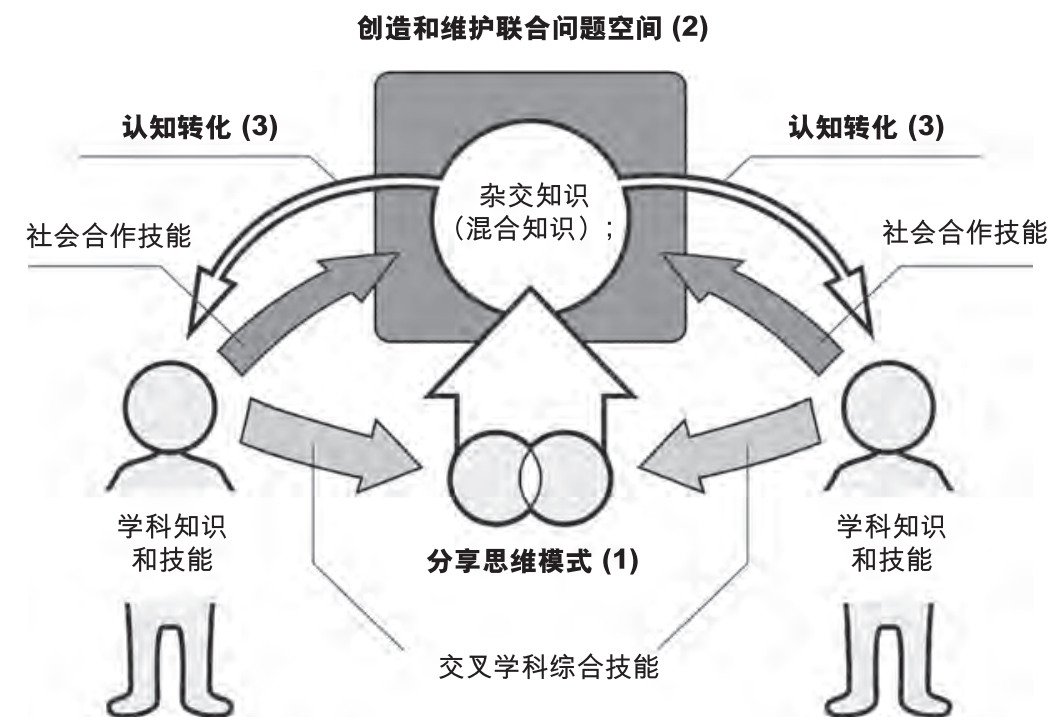

共享问题空间中到底发生了什么情况呢? 莱斯勒（Roschelle）和提斯里

(Teasley) (1995：70) 认为, 在人机互动领域, 联合问题空间是 “一个共享的 知识结构, 通过整合目标、描述问题现状、了解可行的解决方案以及与目标相关的 因素, 促进问题的解决”。解决可持续发展问题是一个互相学习的过程, 在此过程 中，参与者设定可持续发展目标、检查现状、评估方案（例如通过情形构建）、制 定策略，并制定检测和评估的指标（萨布鲁（Thabrew）等，2009）。

信任和尊重是跨学科方法的重要基石, 而学科间有效的融合旨在建立信任和尊 重。由于可持续发展是一个价值丰富的领域, 因此, 促进形成相互学习的态度一而不是在学科之间架设壁垒-一非常重要。在整个过程的所有阶段中都必须时刻意 识到价值和风险, 这需要足够的时间, 并且在推进层面需要有一个反思过程, 以打

跨学科性。它不一定直接源自己知学科, 但一定是在实践过程中创造出来的（诺沃提尼 (Nowotny) 等, 2003:186)。 
造研究人员的“价值意识”（威丝曼 (Wiesmann) 等, 2008：438）。这样一种态 度需要新的技能, 也强调认识过程中反思的重要性。（见18.3.3）。这将使得非传统 类型的知识能够进入问题空间, 它尊重并理解其它学科的认知过程和习得方式, 这 便完成了必要的第一个步骤: 定义目标。

布云（Bruun）（2000）认为, 共享问题空间的数据整合其实就是凭借数据流 通而展开的, 这个过程中一个专家可以直接使用另一个专家的数据, 甚至可以在各 学科间进行概念转换。在这种情况下专家对于所研究的内容就有了同样的认识。但 是, 在很多情况下, 数据从X领域转移到Y领域并同时承载其意义和相关性时, 就可 能需要Y领域的科学家对其进行 “转译”，因为数据的状态及其中意义都会发生变 化。因而, 在X和Y领域之间进行概念的转换时, X领域某个概念转化到Y领域中就会 变得面目全非。布云 (Bruun) 把这些改变叫做 “知识转化” (2000：32; 图18.1: [3])。例如, 环境社会学家把环境学家统计的生态或化学数据转化为社会学数据

(布云 (Bruun) 2000)。建筑师需要把自然科学或工程领域的概念转化之后, 才能 运用到城市规划项目中。现实中各外行的利益相关方提供的数据也会被转化, 以便 为相关科学家和研究人员所用。在这个过程中, 有时会转化失败, 造成困惑, 这一 点是无法避免的, 但是若没有出现失误, 知识转化将开创知识领域的新天地（布云 (Bruun)，2000)。

\subsection{3 “知其然, 知其所以然”}

总而言之, 在成功的跨学科研究过程中, 参与者不但能够熟练掌握本学科的知识技 能, 而且善于综合整理, 将不同知识融会贯通, 整合不同的思维模式, 并赋予知识 新的含义和内容（见图18.1: [1]浅灰色箭头表示）。同时, 即使是最基本的团队活 动也要求具备某些社会技巧、参与技巧和协作技能。在交叉学科方面, 利用社会技 能监测妨碍合作的活动并分析其意义, 澄清误解, 创造并维护共享问题空间（莱斯 勒 (Roschelle) 和提斯里（Teasley）1995；另见图18.1：[2]深灰色箭头）。萨尔 门托 (Sarmiento, 2009) 认为, 这两种技能与团体认知理论一致, 该理论把社会 互动和意义构建的辩证关系看做其中一个中心原则。迪斯普瑞斯（Després）等人认 为, 这是 “交际合理性” 和 “认知合理性” 在共同起作用 (2004：476)。因此, 除 了前面所提过的定义、对比、综合等必要技能- - 21世纪真正需要的技能包括：解 码那些规范理论、框架和概念的价值模式和规范性假设; 不再追求答案和解决方案 的绝对性, 而是寻求探索性和反思性的解答, 包括对认识论的反思和对学科知识的 批判（艾格尼丝（Egneus）2000），布云（Bruun）2000：46引用）。

\section{4 学科界限的设计}

研究跨专业协作中的可持续发展问题的学生必须能够重新组合自己的知识, 以 实现一个共同愿景, 解决问题并达到目标。新的理解离不开对现有知识的借 鉴和融会贯通, 而现有知识多半是源于之前的职业经历和个人经验（马蒂拉 
(Marttila) 2011b）。由于可持续发展是一个“共同演化、共同设计的过程”（沃 尔 (Wahl) 和巴克斯特 (Baxter) 2008：72），学习可持续设计 (DFS) 的学生必 须了解参与途径, 同时需要思考思想道德和价值观对所做选择的影响。如果各方在 对问题的选择愿景、情形和指标上不能达成相互理解和共识, 问题的解决和后续的 过程将无法顺利实现（马蒂拉（Marttila）和科塔拉（Kohtala）2010）。

\subsection{1 设计的混合知识}

在跨学科研究出现和发展过程中, 越来越多的企业、科研机构和政府也参与进来 （见涅米宁 (Nieminen) 2004)。在此过程中, 这些领域的价值观和知识 “相 互交织, 相互渗透, 融为一体”, 产生新的创新型科学知识和社会政策（涅米宁 (Nieminen) 2004; 参见图18.2) 7。

\section{图18.2 各领域间的融合}

来源: 涅米宁 (Nieminen) 2004

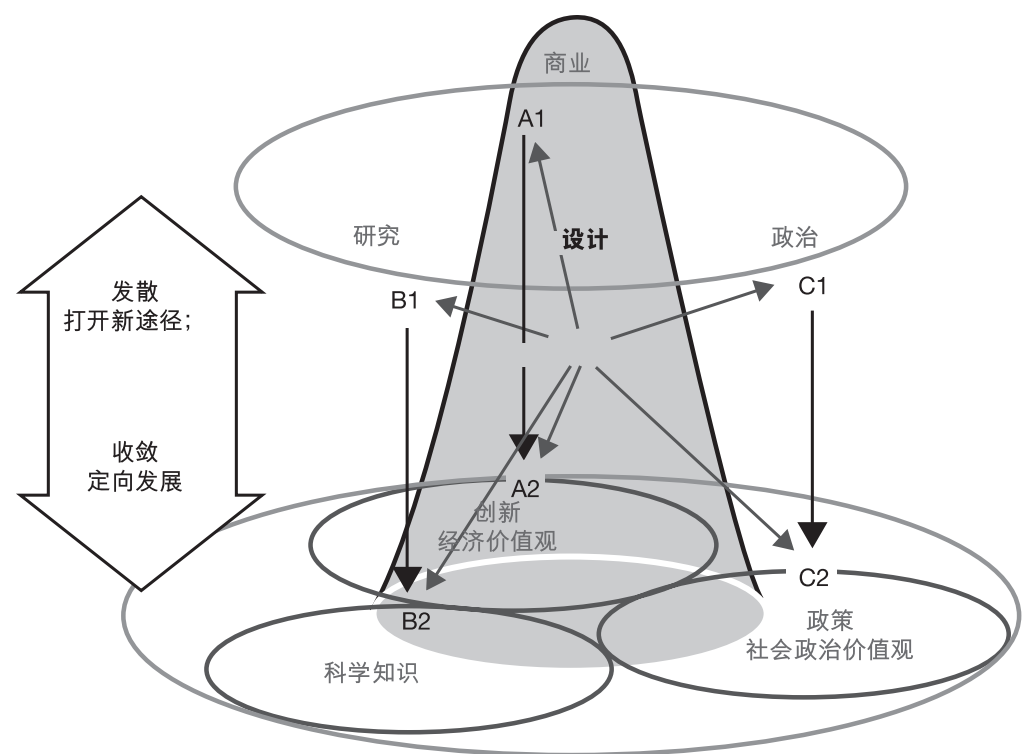

7 提里兹 (Deleuze) 和格拉特利 (Guattari) (1980) 创造了术语 “rhizome” (本义：根 茎) 和 “rhizomatic” 来描述一种知识创造理论, 这一知识创造过程在表达和阐释中存在多 个、不分层级的进入点和退出点。作为一种知识文化模型, “rhizome” 总是不断地试图挣 脱固定组织结构的束缚一一它的特点是 “不断地建立语言符号, 组织能力以及与艺术、科学 和社会斗争相关的环境之间的联系”（提里兹 (Deleuze) 和格拉特利 (Guattari) 1980)。 
在我们看来, 设计师有能力把其他领域的数据转化到设计领域, 除了需要接 受系统的培训, 当然也少不了敏锐的直觉。在设计过程中运用一定量的人类环境工 程学数据就是一个显而易见的例子, 而使用用户自己的探索性数据则更有挑战性。 我们认为, 知识作为一种实践活动在一个知识融合过程中有助于缩小概念和价值观 的差距, 因为设计过程都受到原有价值观的影响, 可持续设计更是如此。更确切地 说, 从这一角度看, 设计并没有被看做是一门学科, 而是一种认识方法, 能够用可 持续的、整体的、跨学科的设计理念, 把各利益相关方的观点进行整合。从这个意 义而言, 设计在某种程度上可以看做是一个 “知识转化机制” : 能够把各利益相关 方的价值观及学科概念和数据进行转化, 并将其应用到实际中。设计扮演着 “文化 中介” 的角色, 在各领域建立联系, 并促进知识的融合。

设计不仅是一个专业, 它还是一种社会和认知活动。在解决问题的过程中, 设 计能创造新的知识, 这种知识某些源于自然, 某些蕴含其中, 某些与之紧密相连, 某些则源于自然之外。一些研究人员建议, 用术语 “元设计” (metadesign) 来描 述设计活动非物质 “上游”过程（例如沃尔 (Wahl) 和巴克斯特 (Baxter) 2008: 74)。沃尔 (Wahl) 和巴克斯特 (Baxter) 把设计过程中的 “下游端” 定义为 “文 化产品、制度、生产模式和消费”，表现在物质方面。而 “上游” 是非物质方面, 包括我们的价值体系、世界观、愿望和自觉意识, 这些均被定义为 “物质化设计背 后的主观因素” (2008: 73) 。从大的方面来说, 作为社会内容、社会功能和社会 文化的创造者, 设计在各领域之间的边界区域发挥作用: 如用户和机器之间, 利益 相关方和系统之间，市民和政策制定者之间，以及需求和供应之间。此外，可持续 发展还要求设计在人类文化系统和自然系统之间发挥更大的作用。在评估可持续发 展时, 这样一个 “上游” 的概念非常重要, 因为不同环境中, 其具体的定义会有所 不同, 因此只有通过各利益相关方的知识、价值体系和世界观相互的融合才能确定。

\subsection{2 根本性创新}

当渐进式变革无法改变现状时, 这种系统层面的最具创新力的解决方案（例如根本 性变革）便应运而生（谢温（Sherwin）2004）, 这需要一种能够反映其价值观和 理念的创新方法。创新通常需要发散性思维, 它对设计有促进作用, 在专业领域相 关技能和现实生活环境中, 创新和设计都受益匪浅。在元层面的共享问题空间, 这 意味着可持续设计过程必须充分利用多种学科知识, 并从不同视角来考虑问题, 同 时还必须意识到 “定义每个学科观点” 的认识论和本体论的“元设计假设”（沃尔

(Wahl) 和巴克斯特（Baxter）2008：74）。因此，可持续设计（DFS）和可持续 产品服务系统 (PSS) 设计的目的不是进行预测和控制, 而是 “适当的参与、灵活 运用及不断学习”（沃尔 (Wahl) 和巴克斯特（Baxter）2008：83）。

只有首先对现实生活中的 “不可持续性” 有了适当的理解, 并且对问题进一步 进行清晰定义之后, 可持续设计才是可能的（克鲁（Clune）2009）。图18.3展示了 构建和评估问题的过程, 并且阐明了跨学科研究的各个阶段之间的关系。这里不难 看出, 在跨学科研究的所有阶段, 设计的作用可谓无处不在, 这是设计在现实生活 中得以实施和接受检验的过程（取得成果），在这一阶段设计的作用发挥得淋漓尽 致。在这些情况下, 我们建议使用上面提到的 “文化媒介” 这一说法; 举例来说, 
约翰·萨拉卡 (John Thackara) 就愿意把新的设计实践操作看成是一个过滤器: 我们拥有过多的创新, 但是都缺乏实际意义。我们面对的是观点和解决方案的对立 与不协调, 没法在实践中调动积极性”。

\section{图18.3 跨学科研究过程的三个阶段}

来源：赫斯 ·黑顿（Hirsch Hadorn）等, 2008: 35

\section{问题鉴别和建构}

设计问题时应当考虑到存在于相关学科中以及社会 上参与者方面的知识。确定问题的重要方面, 设定研究问题以及参与者。

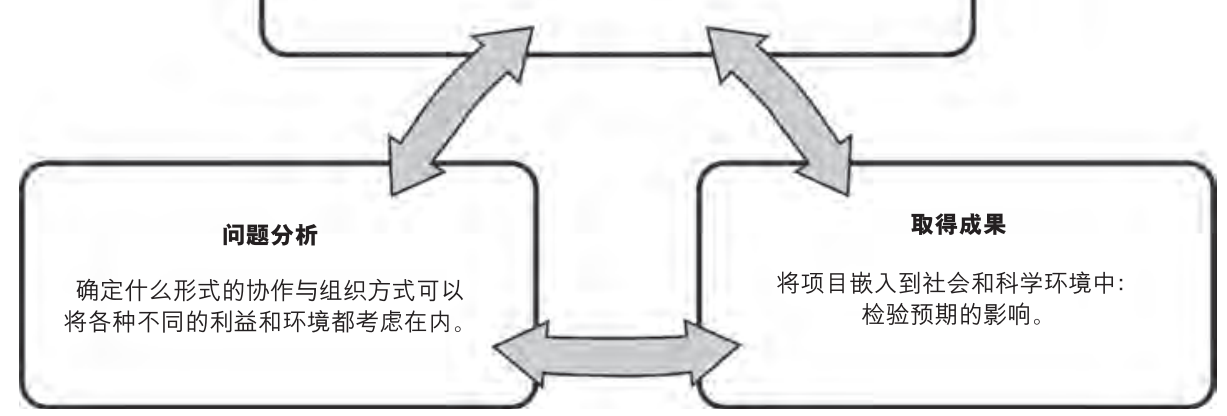

这三个阶段需要的是设计专业的知识和其他领域的知识。至于之前描述的三种 类型的跨学科知识 (见18.3.2), 设计师可以提出自己的见解, 引入相关知识[2]并将 知识进行转化[3]。说到系统知识[1], 设计师可以加强其适应性, 使之与利益相关方 的利益更协调, 以创造前面提及的 “系统智能”（萨里宁 (Saarinen) 和哈马拉嫰

(Hamalainen) 2010）。获得强大的系统知识是具有挑战性的, 因为它需要拥有一 些策略来应对不确定性：关于问题产生和发展可能性方面的不确定性，以及问题解 释和变化目标和选项等方面的不确定性。可以通过做一些 “现实生活”的试验来应 对并反映这些不确定性（赫斯 ·黑顿 (Hirsch Hadorn) 等, 2008：31-32）。诸如 快速原型、经验原型和迭代过程等策略都是典型的设计方法和工作模式, 很多作者 把它们称作 “设计思维”, 将其作为实验模式。因此, 这些设计方法在设置和评价 一些以解决方案为导向的实际实验时具有明显的作用 9 。

8 由艾迪欧公司 (IDEO) 总裁蒂姆·布朗 (Tim Brown) 推广的 “设计思维”, 可以理解 为“各种各样的人用于解决各种各样问题的一系列原则”（布朗（Brown）2009:7）。 “设计思维” 以人为中心, 采取迭代方法, 共享知识, 重点关注新观点的可视化设计 (布朗 (Brown) 2009)。

9 这种方法类似于寇斯奇嫩 (Koskinen) 等人 (2011) 主张的“构造设计法” (constructive design approach)。“构造设计法”旨在整合设计与研究, 在实际使用中, 通过原型和实 物模型, “刺激想象和思维”。 


\subsection{3 可持续设计智能}

总之, 设计作为一种认知框架，以设计问题为基础，以解决问题为导向，具体过 程包括参与策略和鼓励创新。因此, 我们提出了 “设计智能” 这一术语, 代替流 行术语 “设计思维”。弗莱 (Fry, 2008) 认为, 设计智能与纯粹的 “专业实践的 过程、产品和表达”有明显的区别（弗莱（Fry）2008：14）。设计智能对不同 创新的系统性影响进行评估, 旨在 “探索事物是如何产生并发挥作用的”（弗莱

(Fry) 2008：12）。我们所说的设计智能包括两个方面, 知识和技能, 包括认识过 程和社会过程（18.3.3中已解释）; 设计师个人、跨学科团队其他成员或者参与解决 问题的人，他们都是设计智能的一部分。通过不断的辅助和互动，设计方法（促进 设计智能）可以通过跨学科的方式来应对可持续性的挑战，不仅重视量的递增，而 且注重创新, 不断提高解决方案的水平, 以实现根本性的系统变化。这表明, 引进 新产品或进行技术修复无法实现设计实践和教育, 自我转化才是可行的办法（见弗 莱（Fry）2008），设计的目标应该上升到一个新高度，即通过 “对话和教育来改变 人们的世界观、生活目的和生活方式”（沃尔 (Wahl) 和巴克斯特 (Baxter) 2008: 80)。因此, 进行可持续设计 (DFS) 的学生应该在课程学习中特别注重学习如何 解决问题的方法, 而这一点也是至关重要: 在价值判断中学会对标准假设和框架进 行解释, 教育工作者则可以通过批判性的反思和讨论将其变得浅显易懂。

基于这些观念，我们认为，设计技能可以用来处理跨行业可持续问题，同时能 够推动多学科的协作和参与, 不断展开创新试验。因此, 一种设计方法可以培养团 队所有成员的 “设计思维”，并且作为一种 “跨学科设计对话”，跨学科设计方法 应该基于各利益相关方动态的、反复进行的实践过程，并受到一个 “整体框架” 的 支持（沃尔 (Wahl) 和巴克斯特 (Baxter) 2008：82）。此外，在为具体的现实问 题设计产品服务系统 (PSS) 解决方案时, 设计知识 (即 “元设计”) 由各个行业 或学科转化而来的相关信息组成。由于是处在一个现实的生活环境中, 也必须考虑 来自伦理道德方面的影响。以上所有这些构成了设计智能, 它是一种能力, 不仅仅 可以作为可持续产品服务系统 (PSS) 设计的目标, 更广泛意义上来讲, 它还是可 持续设计教育的目标。

\section{5 跨学科教育}

为了应对跨学科方式所带来的的挑战, 学术界应该为当代设计事业做点什么呢? 设 计教育如何培养这种精细而敏锐的能力呢?

第一个要点前面已经提到了：教育工作者在教育学生时需要先端正自己的世 界观, 消除偏见。研究显示, 教师常常把自己的假设和框架灌输给学生, 尤其是在 可持续性问题方面, 涉及如何选择行动方案并确定行动的优先顺序（例如，卡鲁

(Carew) 和米切尔 (Mitchell) 2008)；另见马蒂拉（Marttila）2011a）。定义可 持续性本身不是大问题, 关键是能在跨学科环境中定义具体的可持续发展目标。我 们非常赞同卡鲁 (Carew) 和米切尔 (Mitchell) 的观点：可持续性虽然概念朦胧， 
但它事实上是一种健康的, 甚至是必然的发展趋势, 因为它“提供了一种方式, 让 不同利益相关方有机会表达自己的观点, 以进一步发展这一概念, 并且还能在一定 环境下, 通过协商, 不断地灵活应用这些概念”（2008：106）。我们支持这些作者 的提议, 他们认为, 成功的可持续性教育要求教师的教学过程更为透明, 鼓励他们 充实教学内容, 增强其广度和深度, 拓展专家们所用的各种工作框架, 并激发学生 展开讨论。这反过来将会提高学生未来在各种各样的行业环境中工作的能力, 培养 他们成为灵活性强、富有创造力的专家 (卡鲁 (Carew) 和米切尔 (Mitchell) 2008: 114)。

第二, 文献普遍认为, 面向21世纪, 教育需要具备积极主动性、有构建性（西 格拉斯 (Segalàs) 等特征, 2010; 克莱恩 (Klein) 2008; (Leiviskä) 2001; 杜 德斯达（Duderstadt）2000）。积极主动学习包括基于具体问题的学习、案例研究 等, 而消极学习指的是更为传统的教学法: 授课、写作练习以及问题论证。积极学 习进一步分为指导性、探索性和构建性方法。指导性方法指的是知识的传授和学习 者的接受; 探索性方法鼓励有目的地搜集信息和知识并开展假设; 构建性方法强调 构建并探讨学习内容的深刻含义以及社会方面的内容（霍瓦斯（Horvath）等, 2004, 西格拉斯 (Segalàs) 等, 2010：278引用）。

第三, 过去的文献还普遍认为, 必须确定并设立学生的核心学科: 在引 进跨学科课程之前, 必须建立学科基础一一即专业学科与补充知识及专门技能 等。学生在进行跨学科学习之前, 必须有牢固的专业基础（例如, 莱维斯卡

(Leiviskä) 2001)。此外, 作为未来的研究人员或者设计师, 学生们将能够更好地 处理威丝曼 (Wiesmann) 等人 (2008) 所认为的跨学科教育和职业发展中最常见的 障碍: 例如, 不得不面对与自己的学科有冲突的参考系统, 处于跨学科研究的背景 下, 并且与社会息息相关。这种情况不仅在教育行业存在, 在研究领域和现实生活 领域也存在。在强烈的专业和学科认同感的基础上, 学生可以消除通常在跨学科团 队合作开始时会产生的成见。

阿尔托大学 (Aalto University) 正在研究跨行业教育在设计和企业管理（如莱维 斯卡 (Leivisk教) 2001) 以及可持续性相关领域（如马蒂拉（Marttila）2011a，b） 中的应用。2010年新增了一个跨行业硕士课程一一创造性可持续发展 (Creative Sustainability (CS) ) 10 , 以下章节, 我们会把现有的理解与目前对于该课程进行 的研究成果联系起来进行阐述。

\subsection{1 可持续设计 (DfS) 能力}

学习解决跨学科环境问题的设计专业的学生与跨学科研究的专家一样, 需要具备两 方面技能（参见18.3.3和图18.1）：即知识综合能力和社会协作技能, 只有这样才能

10 CS项目是阿尔托大学 (Aalto University) 多个学院联合开办的硕士项目, 学生参与共同的 概论课程和项目, 但是从各自不同的专业获得学位。该项目于2010年阿尔托大学 (Aalto University) 成立之时同时启动。参见本部分第17章 “创造性可持续发展” (Creative Sustainability (CS) ) 获得更多信息。 
够建立起共享问题空间。克莱恩 (Klein) 认为, 跨学科教育方面的文献尤其强调以 下几种技能（2002，克莱恩（Klein）2008：407中引用）：

1. 寻找和搜集相关信息并应用该信息的能力（类似于系统知识 (systems knowledge) [1], 如威丝曼 (Wiesmann) 等, 2008)

2. 对不同的方法进行比较和对比, 并将其应用于目标任务的能力 (类似于目标 知识 (target knowledge) [2])

3. 针对一个具体主题、疑问或问题进行综合整理, 生成整合性框架并形成更为 整体性的理解的能力（类似于转化知识（transformation knowledge ) [3]）

根据文献, 成功的可持续设计教育旨在传播可持续的三个方面内容, 并创造相关知 识, 形成批判式思维和系统思维, 提高人际交往能力和个人（内省）思维能力（斯 凡斯壮 (Svanström) 等, 2008)。前面提到的构建性教育方法可以很好地实现这 些能力的培养, 因为这一方法能够促进学生综合能力的发展, 并促进系统智能的形 成。此外, 西格拉斯 (Segalàs) 等人认为, 建构性学习 (constructivist learning) 强调 “分布式认知” (2010：278) , 鼓励学生在不同的协作团队中学习如何使用知 识、构建知识并做出决策（另见曼德哈凡（Madhavan）和格鲁佛 (Grover) 1998）。 我们之后对跨行业设计教育进行的研究证实了这一观点; 其中一位受访者讲述了如 下内容: 仅有可持续发展理念是不够的, 你还要了解其它内容: 首先必须了解当前 实践应用过程, 还要了解那些通过各个专业的结合而创造出来的机会空间。11

在这种教育过程中, 学生对跨学科研究过程应该怀有一个开放的心态, 培养一种 “认知灵活性”, 还要终身对自我导向学习抱有极大的热情（克莱恩 (Klein) 2004：408）。此外, 他们还应该树立与 “可持续性范例” 协调一致 的价值观和态度（西格拉斯 (Segalàs) 等, 2010; 斯凡斯壮 (Svanström) 等, 2008) 。这样一个重视价值观的方法强调建设性态度的重要性。在我们的研究 过程中, 一位受访者强调了这种心态的重要性, 它激励、统一、规范并引导着我们 的价值观: “最重要的是, 加强培养可持续发展的态度, 能让我们的学生意识到这 对我们所做的每一件事都至关重要。”所以，这是唯一的选择。12

最后, 学习可持续设计 (DfS) 的学生必须具备斯凡斯壮 (Svanström) 等人定 义的“变革推动者”技能。这些技能指的是在人际交往和自我内省过程中的沟通交 往能力和矛盾处理能力。正如上面所建议的，这些能力将逐渐在共享的可持续性 “ 价值体系” 中得到进一步提升（斯凡斯壮（Svanström）等，2008：347）。成功主 要是缘于团队成员善于向他人描述和阐明观点, 倾听他人意见并达成共识（莱维斯 卡 (Leiviskä) 2001)。我们的研究也强调这一点：“内行人把自己的体会表述出 来, 必须让那些没有这些背景的外行也能明白”，“（他们）尝试着相互交流, 然 后在某一立场上......达成共识。”13

112010 年5月17日, 受访者2。

12 2010年6月26日, 受访者 1 。

132010 年5月17日, 受访者 2 ; 加强调。 
因此, 共享问题空间的建立既是认知过程, 也是社会过程, 它伴随着混合知识 的创立, 要求有一个反馈机制, 并不断形成新知识和新提议。我们的另一位受访者 这样解释: （我们）交流技能.....建立共享问题空间......但是（这些）仍旧是不断 通过新的网络生成的新想法......把反馈带回各行业环境中, 然后......通过产生新的 知识类型而继续这一过程, 这些知识类型来源于新产生的解决方案。14

在实践中开展反思和自省活动极为困难, 这就是为什么到现在都还没有一本 关于跨学科实践的 “手册” 问世。那么, 我们怎能期望学生在学习初期就尝试应对 如此挑战呢? 根据我们自己的研究和关于可持续设计教育、跨学科研究以及创造性 的团队合作的文献, 我们为可持续的产品服务系系统 (PSS) 设计与可持续设计

(DFS) 教学提供以下指南。

\subsection{2 可持续学习平台}

首先, 正如前文所述, 跨行业的可持续教育应该设计成为一种有助于积极主动、建 构性和探究性学习的模式。如果可能的话, 学习的过程应该在一个具体环境中设置 真实或假设的“客户”, 因为在实际工作环境中去探究具体的问题, 可以加强学生 的学习积极性与学习任务的真实性 (西格拉斯 (Segalàs)等 2010)。此外, 和以个人 为导向的教学法不同, 以集体为导向的教学法建立了一个有活力的、协作性的互动 环境, 能够更好地培养可持续设计能力。让利益相关者适当参与进来, 能够引入跨 学科视角, 更有利于社区式教学的认知学习。

积极的、建构性及协作性的学习反过来又意味着一开始的团队协作训练必 不可少。阿尔托大学 (Aalto University) 设立的创造性可持续发展 (Creative Sustainability (CS) ) 项目提供了关于团队合作、心态和系统思维等入门课程, 这 是所有学生的必修课程。阿尔托大学 (Aalto University) 的第一个跨行业硕士课程项 目是国际设计企业管理（International Design Business Management，IDBM），课 程名称为 “创造性团队合作 (Creative Teamwork) ” 15。上述入门课程都遵循的是 国际设计企业管理（IDBM）已经引入的（跨学科合作）想法。“创造型团队合作” 课程让学生了解团队和集体工作过程, 以及成功交际所必备的社交技能。也许最重 要的是, 引入该课程时, 采用学生们熟悉的教学方法展开教学, 也就是说每个学生 都可以了解到其他学生学习和工作情况。对设计专业的学生而言, 学习的方式就是 动手实践, 全心投入, 专心工作; 对于商务专业的学生, 教学法则较为被动, 并且 更倾向于分析；而工程专业学生更重视整个过程（莱维斯卡（Leiviskä）2001）。在 解决实际问题前, 需要对这些不同于以往的学习和工作方式有个大概的了解, 这样 做有助于建立相互的信任和尊重, 避免矛盾冲突, 加强沟通, 可以有效地推动协作 创新工作的开展。这也可以帮助反映出在实际工作过程中会碰到的问题, 因为学科 专家会在教学过程中将他们各自机构的工作方式和研究风格带到课堂中。

14 2010年5月17日, 受访者2。

15 国际设计企业管理 (International Design Business Management, IDBM) 硕士项目 1995年面向前述三个大学的学生开放, 当时三所大学还未合并为阿尔托大学 (Aalto University)。 
第二, 以可持续性问题为主题的跨学科课程应该致力于培养擅长整合和综合知 识的专家。“T型人才” 具备的认知能力使他们能够把自己经验中的多种知识进行 整合, 能够理解其它知识与自己的学科知识如何关联及互相作用（ (Madhavan) 和格鲁佛 (Grover) 1998：3）。这些人才必须有较强的社交能力, 能够在不同的 人和观点之间搭建 “桥梁”。因此, 在本章所描述的过程中, 这些人才同样具备 进行知识转化以及在共享问题空间进行知识融合的能力。(Madhavan) 和格鲁佛

(Grover) 把混合知识称为 “嵌入知识”, 它是由问题研究小组创造出来的, 包 括隐性知识和显性知识(1998: 2)。 。 T型人才中的字母 “T” 的短横代表有效结合知 识和技能的能力, 长长的一竖则代表学科的深层知识和技能（即隐性知识和显性知 识）。加强知识和技能相结合的最佳方法是在富有创造性精神的团队合作中探索学 科之间的区别和联系, 这一探索过程尤其需要的是自我反思、方法论、抽象和理论 总结的技能（威丝曼 (Wiesmann) 等, 2008)。在实践中, 这要求进行频繁、直 接、互信的人际互动, 以便在团队中建立起紧密的联系, 增强团队中的知识构建水 平。此外, 这种互动应该是非正式的、自发的、事先未经计划的, 因为非正式的互 动意味着例行程序的变化, 以及大量的信息转化, 因此被认为是革新和创造中不可 或缺的组成要素（曼德哈凡（Madhavan）和格鲁佛（Grover）1998）。过度正规 的程序和过度的控制有可能阻碍信息流和知识流的畅通，阻碍团队效率。由此，曼 德哈凡 (Madhavan) 和格鲁佛 (Grover) 认为, 团队应该由A型人才领导。A型 人才是指同时涉足两个学科, 具备团队分享和整合知识的能力, 善于识认新的有价 值的外来信息, 吸收它并进行有效应用的人才（曼德哈凡 (Madhavan) 和格鲁佛

(Grover) 1998)。哈凯奈（Hukkinen, 2008) 则把这类人才叫做“混合型人才”。

此外, 我们建议, 应该鼓励团队在项目过程中构建不同的工作模式和个人 工作进度模块, 其目的是在创造性中鼓励必要的发散思维并尽可能避免形成 “集 体思维”。霍格 (Hoegl) 和帕波提 (Parboteeah) (2007) 指出, 合作团队 在寻求共识时会发生求同思维, 事实上这抑制了团队的创造潜力。因此, 本书作 者建议, 创作过程应当较少涉及协作元素, 各自开发自己的创意, 而在此过程 中的协作就是要求团队成员集体讨论这些创意和选项（霍格（Hoegl）和帕波提

(Parboteeah) 2007)。

第三, 为了培养系统智能一一进行设计和评价所需的一种自适应性系统方 法一一我们建议, 在跨学科教育中更应该强调社会的可持续发展, 而非环境和经济 的可持续发展（可持续发展的三维模式），这样才能确保学生真正理解可持续发展 如何影响人类的生活, 以及如何依靠技术之外的其它方法来解决问题。西格拉斯

(Segalàs) 等 (2010) 对于工程教育的研究表明, 在大多数情况下, 学生倾向于 把可持续发展与环境和经济问题联系在一起, 过分强调技术在解决不可持续问题时 的作用。这些研究人员强调需要通过改变教育的内容来解决这种不平衡问题: 教师 应该有针对性地让学生了解并认识社会制度与可持续发展相关性和技术的社会角色

(西格拉斯（Segalàs）2010：275）。

我们认为, 这种“偏见” 或者说不平衡部分是由于学科专业本身的等级造成 的, 在一些学科的教学中, 社会相关知识就没有理论知识重要。这种等级阻碍了跨 学科研究和对系统的理解, 因为在研究特定的社会环境的过程中, (由外行利益相 关方等提供的）社会相关知识至关重要。跨学科设计对话有助于把对 “全系统的 
健康、幸福、福祉、意义和生活质量” 的定性考虑引入决策和设计过程中（沃尔 (Wahl) 和巴克斯特（Baxter）2008：83）。

一种针对教育平台的解决方案其目的是确保促进对环境、经济和技术层面的可 持续性方面的理解; 同时, 也保证可持续性在社会文化和制度上得到重视。跨学科 研究应促使外行的利益相关方参与到共同设计过程中, 那些拥有共同创造经验的设 计专业学生也推动了这些研究的进展。

总之, 要使跨行业和跨学科的可持续性问题-一包括可持续产品服务系统

(PSS) 设计的理想教学平台的团队合作成为可能, 首先需要培训各团队如何进行 合作, 然后, 鼓励各团队针对具体的问题进行非正式的、直接的、频繁的互动。团 队成员也有具体分工, 他们需要根据自己的学科经验反思所接收的信息: 通过自己 反思和互相讨论探索各学科间的界限。因此, 学生应当 “保持” 并形成自己的学科 专业认同感, 但是不鼓励知识和技能的保护主义, 以此来促进学科间达成共识、培 养沟通技能。理想的情况是: 团队的领导者既善于社交, 又涉猎多种学科知识。教 师个人需要获得适应性及伦理性的系统智能, 秉持开放的心态, 并且接受跨学科研 究。他们要能够帮助学生把复杂数据转化为设计相关信息, 并培养学生在跨学科协 作中与广大参与者进行沟通的能力。

\section{参考文献}

Brown, T. (2009) Change By Design: How Design Thinking Transforms Organizations and Inspires Innovation (New York, US: HarperCollins Publishers).

Bruun, H. (2000) Epistemic Encounters: Intra- and Interdisciplinary Analyses of Human Action, Planning Practices and Technological Change, doctoral thesis (Göteborg, SE: Göteborg University).

Bruun, H., J. Hukkinen, K. Huutoniemi and J.T. Klein (2005) Promoting Interdisciplinary Research: The Case of the Academy of Finland, Academy of Finland Publication Series (8/05) (Helsinki, Fl: Edita).

Carew, A.L. and C.A. Mitchell (2008) 'Teaching sustainability as a contested concept: capitalizing on variation in engineering educators' conceptions of environmental, social and economic sustainability', Journal of Cleaner Production 16 (1): 105-115.

Clune, S. (2009) Developing Sustainable Literacy in Industrial Design Education - A three-year Action Research project enabling Industrial Design students to Design for Sustainability, doctoral thesis (Sydney, AU: University of Western Sydney).

Deleuze, G. and F. Guattari (1980; 2004 edition) A Thousand Plateaus (London, UK: Continuum).

Després, C., N. Brais and S. Avellan (2004) 'Collaborative planning for retrofitting suburbs: transdisciplinarity and intersubjectivity in action', Futures 36: 471-486.

Duderstadt, J. (2000) A University for the 21st Century (Michigan, US: The University of Michigan Press).

Egneus, H., K. Bruckmeier and M. Polk (2000) The Nature of Interdisciplinarity, report to the Inter-Faculty Committee for Thematic Studies.

Evaluation Panel (2009) Research in Art and Design in Finnish Universities, Publication of the Academy of Finland 4/09 (Evaluation Report) (Helsinki, FI: Edita Prima).

Fry, T. (2008) Design Futuring: Sustainability, Ethics and New Practice (Oxford, UK: Berg). 
Gibbons, M., C. Limoges, H. Nowotny, S. Schwartzman, P. Scott and M. Trow (1994) The New Production of Knowledge: The Dynamics of Science and Research in Contemporary Societies (London, UK: Sage).

Hirsch Hadorn, G., S. Biber-Klemm, W. Grossenbacher-Mansuy, H. Hoffmann-Riem, D. Joye, C. Pohl, U. Wiesmann and E. Zemp (2008) 'The Emergence of Transdisciplinarity as a Form of Research', in G. Hirsch Hadorn, H. Hoffmann-Riem, S. Biber-Klemm, W. Grossenbacher-Mansuy, D. Joye, C. Pohl, U. Wiesmann and E. Zemp (eds.), Handbook of Transdisciplinary Research (Dordrecht, NL: Springer): 19-39.

Hoegl, M. and K.P. Parboteeah (2007) 'Creativity in innovative projects: How teamwork matters', Journal of Engineering and Technology Management 24: 148-166.

Horvath, I., M. Wiersma, J. Duhovnik and I. Stroud (2004) 'Navigated active learning in an international academic virtual enterprise', European Journal of Engineering Education 29 (4).

Hukkinen, J. (2008) Sustainable Networks: Cognitive tools for expert collaboration in socialecological systems (London, UK / New York, US: Routledge).

Klein, J.T. (2002) 'Introduction: Interdisciplinarity Today: Who? What? and How?', in J.T. Klein (ed.), Interdisciplinary Education in K-12 and College: A Foundation for K-16 Dialogue (New York, US: The College Board): 1-17.

Klein, J.T. (2004) 'Prospects for transdisciplinarity', Futures 36: 515-526.

Klein, J.T. (2008) 'Education', in G. Hirsch Hadorn, H. Hoffmann-Riem, S. Biber-Klemm, W. Grossenbacher-Mansuy, D. Joye, C. Pohl, U. Wiesmann and E. Zemp (eds.), Handbook of Transdisciplinary Research (Dordrecht, NL: Springer): 399-410.

Koskinen, I., J. Zimmerman, T. Binder, J. Redström and S. Wensveen (2011) Design Research through Practice: From the Lab, Field, and Showroom (Waltham, US: Morgan Kaufmann).

Leiviskä, E. (2001) Creative Interdisciplinarity: Engineering, Business, and Art \& Design Students' Collaboration and Learning in the International Design Business Management (IDBM) Program, doctoral thesis (Helsinki, Fl: University of Helsinki).

Madhavan, R. and R. Grover (1998) 'From Embedded Knowledge to Embodied Knowledge: New Product Development as Knowledge Management', Journal of Marketing 62: 1-12.

Marttila, T. (2011a) 'Designing Sustainability Together - Disciplinary competences in transdisciplinary knowledge building', in H. Lakkala and J. Vehmas (eds.), Trends and Future of Sustainable Development Conference Proceedings.

Marttila, T. (2011b) 'Creating a Collaborative Action: Benefits and Barriers in Inter-Professional Design Process for Sustainability', in N. Roozenburg, L.-L. Chen and P.J. Stappers (eds.), Proceedings of IASDR2011, 4th World Conference on Design Research.

Marttila, T. and C. Kohtala (2010) 'Towards Transdisciplinarity: Understanding Current Multidisciplinarity in Design Sustainable Urban Solutions', in F. Ceschin, C. Vezzoli and J. Zhang (eds.), Proceedings of LeNS Conference Sustainability in Design NOW!: Challenges and Opportunities for Design Research, Education and Practice in the XXI Century (1): 169-177.

Nieminen, M. (2004) 'Lähtökohtia yliopistojen kolmannen tehtävän tarkastelulle', in K. Kankaala, E. Kaukonen, P. Kutinlahti, T. Lemola, M. Nieminen and J. Välimaa (eds.), Yliopistojen kolmas tehtävä? [The third role of universities?] (Helsinki, FI: Edita): 15-42.

Nowotny, H., P. Scott and M. Gibbons (2003) "'Mode 2" Revisited: The New Production of Knowledge', Minerva 41: 179-194.

Pohl, C. (2005) 'Transdisciplinary collaboration in environmental research', Futures 37: 1159-1178.

Pohl, C., L. van Kerkhoff, G. Hirsch Hadorn and G. Bammer (2008) 'Integration', in G. Hirsch Hadorn, H. Hoffmann-Riem, S. Biber-Klemm, W. Grossenbacher-Mansuy, D. Joye, C. Pohl, U. Wiesmann and E. Zemp (eds.), Handbook of Transdisciplinary Research (Dordrecht, NL: Springer): 411-424.

Porter, T. and J. Córdoba (2009) 'Three Views of Systems and their Implications for Sustainability', Journal of Management Education 33 (3): 323-347. 
Roschelle, J. and S.D. Teasley (1995) 'Construction of shared knowledge in collaborative problem solving', in C. O'Malley (ed.), Computer-supported collaborative learning (New York, US: Springer): 69-97.

Saarinen, E. and R.P. Hämäläinen (2010) 'The Originality of Systems Intelligence', in E. Saarinen and R.P. Hämäläinen (eds.), Essays on Systems Intelligence (Helsinki, Fl: Aalto University).

Sarmiento, J. (2009) 'The Sequential Co-Construction of the Joint Problem Space', in Stahl, G. (ed.), Studying Virtual Math Teams (New York, US: Springer): 83-98.

Scholz, R. and D. Marks (2001) 'Learning about Transdisciplinarity', in J.T. Klein (ed.), Transdisciplinarity: Joint problem solving among science, technology, and society - an effective way for managing complexity (Basel, CH: Birkhäuser): 236-252.

Segalàs, J., D. Ferrer-Balas and K.F. Mulder (2010) 'What do engineering students learn in sustainability courses? The effect of the pedagogical approach', Journal of Cleaner Production 18 (3): 275-284.

Sherwin, C. (2004) 'Design and sustainability', The Journal of Sustainable Product Design 4 (1): 21-31.

Shin, D., M. Curtis, D. Huisingh and G.I. Zwetsloot (2008) 'Development of a sustainability policy model for promoting cleaner production: a knowledge integration approach', Journal of Cleaner Production 16 (17): 1823-1837.

Svanström, M., F. Lozano-Garcia, and D. Rowe (2008) 'Learning outcomes for sustainable development in higher education', International Journal of Sustainability in Higher Education 9 (3): 339-351.

Thabrew, L., A. Wiek and R. Ries (2009) 'Environmental decision making in multi-stakeholder contexts: applicability of life cycle thinking in development planning and implementation', Journal of Cleaner Production 17: 67-76.

Thackara, J. (2007) 'Design and the Growth of Knowledge', in C. Brickwood, B. Ferran, D. Garcia and T. Putnam (eds.), (Un)common Ground: Creative Encounters across Sectors and Disciplines (Amsterdam, NL: BIS Publishers).

von Ghyczy, T. (2003) 'The fruitful flaws of strategy metaphors', Harvard Business Review 81: 86-94.

Wahl, D.C. and S. Baxter (2008) 'The Designer's Role in Facilitating Sustainable Solutions', Design Issues 24 (2): 72-83.

Wiesmann, U., G. Hirsch Hadorn, H. Hoffmann-Riem, S. Biber-Klemm, W. Grossenbacher, D. Joye, C. Pohl and E. Zemp (2008) 'Enhancing Transdisciplinary Research: A Synthesis in Fifteen Propositions', in G. Hirsch Hadorn, H. Hoffmann-Riem, S. Biber-Klemm, W. Grossenbacher-Mansuy, D. Joye, C. Pohl, U. Wiesmann and E. Zemp (eds.), Handbook of Transdisciplinary Research (Dordrecht, NL: Springer): 433-441. 


\section{9 \\ 学习新知识 \\ 产品可持续设计}

梁町（Benny Ding Leong）和布莱恩 $\cdot \mathrm{Y} \cdot \mathrm{H} \cdot$ 李（Brian Y.H. Lee）

中国香港, 香港理工大学设计学院亚洲生活风尚设计研究实验室

\section{1 三个过渡}

从20世纪90年代中期开始, 世界经历了三种宏观层面的过渡：向数字化互联的 过渡, 从实体互动和交流过渡到人际虚拟网络互动; 向服务经济的过渡, 从大规 模生产实体产品过渡到生产和交付高度定制化的产品和服务; 向可持续文化的过 渡, 迫切需要通过减少不环保的消费和自然资源损耗来改善生活质量。这三种转 变集中在一起, 产生了以知识、信息和服务为基础的后工业化经济和生态（梁町 (Leong) 2004; 曼齐尼（Manzini）和梁町（Leong）2001）。这种变化不仅在很 大程度上改变了全球和各地的工商业实践，还改变了人们的价值观1。21世纪早期 良心消费者” 运动开始兴起, 这些消费者, 他们追求幸福、团结和可持续生活, 目 前在世界各地, 近来特别是在中国, 持有这种观念的人, 数量已呈上升趋势（雷 (Ray) 和安德森 (Anderson) 2001; 《视点》2005; 梁町 (Leong) 2010) 2。

1 价值观可以是定量的, 强调生理和心理需求（如适量的食物、安全和财富）, 也可以是定 性的, 强调精神需求和社会心理需求（如智力培养、自我尊重、爱和团结一致）。

2 最近一项大规模研究项目 “中国生活方式” 表明, 中国城市中 $90 \%$ 以上的中产阶级家庭更 加忧虑自己所在城市的环境保护, 而非经济发展。 


\section{2 可持续设计（DfS）的兴起及在中国的发展}

为了应对上面提到的转型过渡, 十年前西方提出了一种系统变革, 旨在减少环 境资源消费, 同时维持经济增长、保障人民生活。同时, 设计界提出了可持 续设计（Design for Sustainability (DfS) ) 作为对盛行的环境设计（Design for the Environment (DfE) ) 或生态设计实践的补充, 目的是加快过渡到可 持续发展（查特 (Charter) 和蒂什纳 (Tischner) 2001; 梁町 (Leong) 和曼 齐尼 (Manzini) 2006; 塔克 (Tukker) 和蒂什纳 (Tischner) 2006; 维佐里

(Vezzoli) 2010)。本章主要作者2000年和2003年分别与埃齐奥 · 曼齐尼（Ezio Manzini) 教授、赵江洪 (Zhao J.H.) 教授 3 和卡洛. 维佐里 (Carlo Vezzoli) 进行 合作, 在香港、北京、湖南、无锡和广州等地的主要设计类大学实施试点项目, 召 开了一系列研讨会, 帮助推广可持续设计 (DfS)、可持续产品服务系统 (SPSS) 以及系统生产设计 (SpD) 4等概念。自此, 可持续设计 (DfS) 概念初步引入中国。 虽然可持续设计 (DfS) 引入伊始受到了欢迎, 但是作为一个新颖概念, 目前 还未能在中国打下良好的根基。参加可持续设计 (DfS) 或系统生产设计 (SpD) 研讨会的相当一部分学生对可持续设计 (DfS) 在中国工业中解决实际问题的实用 性提出了质疑（梁町（Leong）2008）。反馈表明，这一质疑多半是因为21世纪初 中国的实际情况和经济发展均与西方国家有明显的差异。中国经济仍旧处于工业化 的上升阶段。例如, 2003年, 中国制造业产值占国内生产总值的 $35.3 \%$ (《经济观 察》, 未标日期）。当时, 整体工业均向制造及“代工生产” OEM (即“Original Equipment Manufacturing”)倾斜。显然，中国的经济发展仍旧处于以产品为基础的 阶段, 而西方发达国家已经稳步向以服务为主的经济发展了。

\subsection{1 “反学习”的困境}

面对这样的经济现实, 中国大部份的设计院校在制订工业设计课程时, 很自然地以 产品设计和物质生产作为教学重点, 势必在 “可持续设计” (DfS)教学的推广上便造 成了一定的困难，因为“可持续设计” 本身是一套看似与传统设计相悖而又完全“ 另类” 的设计理念, 进行可持续设计 (DfS) 必须 “舍弃” 以物质设计为本的套路, 对于大多喜爱实物制作和物器设计的学生, 和久经传统工业设计观念熏陶的教职 人员而言, 都造成极大的困惑。如表19.1所示, 一个典型的设计流程列表（从创意

3 来自湖南大学的赵江洪 (Zhao J.H.) 教授与埃齐奥 - 曼齐尼 (Ezio Manzini) 教授和本章 主要作者（梁町（Benny Ding Leong））－起, 于2001年6月合作创立了名为“中国可持 续设计网络” 的组织, 这是中国首个可持续设计 (Design for Sustainability (DfS)) 组 织。成员包括香港理工大学、湖南大学、清华大学和广州美术学院。

4 系统生产设计 (System-Product Design, SpD) 是 “一种设计方法和过程, 旨在鉴定、 设计所需产品并制定战略, 使其可以在指定可持续方案产品服务系统 (PSS) 中使用”

(梁町 (Leong) 2002)。为了在中国推广系统生产设计 (SpD) 和可持续设计 (DfS) 概念, 梁町 (Leong) 和高介原创有限公司 (Kaizor Innovation Ltd) 主管伊莱恩·安女士 (Elaine Ann) 于2003年在香港、广州、湖南和无锡举办了一系列研讨会。 
孕育到设计完成阶段）, 透过DfS与传统工业设计模式的比对, 得以领会当中的种 种困惑。

表19.1 可持续设计（DfS）学习与传统工业设计学习的区别

\begin{tabular}{lll}
\hline 项目阶段 & 可持续设计 (DfS) 学习 & 工业设计学习 \\
\hline 研究 & 以人为本 (现实生活语境) & 用户为中心 (我一-以方法论为基础) \\
\hline 分析 & 社会效益主导 & 经济效益驱动 \\
\hline 构思 & 共同创造 (参与式) & 专家思维模式 \\
\hline 设计方法 & 策略性: 以系统服务为导向 & 操作性: 以物质产物为主 \\
\hline 构想发展 & 整合, 系统化思维 & 线性的, 流程化思维 \\
\hline 设计目的 & 减少物质消费 & 促进物质生产 \\
\hline 产出 (结果) & 非物质解决决方案 & 实体产品 \\
\hline
\end{tabular}

由于可持续设计 (DfS) 的独特性, 中国大多的设计院校于教学上均感到难以将 它融入本身的课程, 又或倾向把它当作课程内的一门“装饰性”选修科目来处理。 结果, 可持续设计 (DfS) 教学无法获得设计学院学生和管理者的足够重视, 故此, 在2004至2007年期间，它在中国设计教育界的推行明显地有所放缓。

具有讽刺意味的是, 一旦进入了工业生产主导经济的瓶颈-一即人民币升值 6 、 社会差距不断扩大 7 以及生态环境的迅速恶化 ${ }^{8}-$ - 中国就迫不及待地寻求移向工业 价值链的上游, 同时制定另类经济发展策略以应付其环境及社会恶化的问题。在

5 “我一一方法” 是以用户为基础的设计方法的一种基本形式, 设计师以他们自己或者朋友 为对象进行设计 (琳赛 (Lindsay) 2003)。

6 仅从2003年到 2008 年短短 5 年的时间里，人民币升值了 $21 \%$ ，但是中国制造业成本仅比 美国低 $5.5 \%$ （2003年是 $22 \%$ ）。中华人民共和国商务部表示，如果人民币再升值3\%, 就 有可能导致中国纺织业、服装业、玩具业、家具业以及家电等大多数劳动密集型行业破产

（《外汇金融人》2010引用）。

7 目前, 中国贫富群体之间收入和社会待遇差异巨大。中国社会科学院 (CASS) 2009年进 行的调查显示, 占人口 $10 \%$ 的高收入群体掌握着中国 $40 \%$ 的资产, 而同样占人口 $10 \%$ 的赤 贫群体只掌握 $2 \%$ 的资产（黑崎（Hickey）和河本（Kawamoto）2010）。中国改革基金会 国民经济研究所副所长王小鲁表示这两个群体收入相差65倍（《中国改革》2010）。收入 差距导致受教育和享受医疗保健服务机会的不平等。随着中国贫困人口积怨加深, 中央政 府下决心要在矛盾爆发前迅速解决这些问题。

8 目前, 中国超过 $40 \%$ 的地表水和 $90 \%$ 的地下水都不可用, 大约 $40 \%$ 的土地有水土流失的现 象。中国农业用地的三分之一受到酸雨侵蚀, 农业产量持续下降。中国空气中悬浮颗粒物 含量比世界卫生组织规定的“相对安全” 标准的上限还高出了一倍多。每年有 40 万人死 于空气污染。这仅在 2007 年一年就消耗了中国国内生产总值的 $8 \%$ 到 $15 \%$ (《经济学人》

(Economy and Lieberthal) 2007)。社会上, 由于环境迅速恶化, 仅在2005年一年中国 就有 5 万多次环保抗议行动。2008年一年的环保诉讼案件总数与之前 10 年的总数持平。而 且, 2009环保诉讼总数与 2008 年相比增加了 $87 \%$ 。环境问题成为中国社会动荡不安的第九 大原因。 
中国最近的“十一五”和“十二五”规划中, 有关中国的未来发展部分, 中央政 府就展示了对社会经济作出改革及全面转型的巨大决心，当中包括：把出口导向 型工业转变为内需导向型工业, 低碳经济取代高资源消耗的经济, 把侧重国家的 发展转变为以人为本及丰富他们生活素质为主的发展 (CPEIN 2010)。在这种向 可持续转变的特殊背景下, 策略性、以解决方案为基础的可持续设计 (Design for Sustainability (DfS) 和可持续性产品服务系统 (PSS) 得以卷土重来, 并在中国设 计领域内, 特别是设计教育界中再度成为闪耀的“焦点” 9

\section{3 “T型” 设计培训的神话}

与此同时, 由于中国需要寻求产业增值及经济持续的快速增长, 21 世纪伊始, 创新 就成为商业和设计界的一个流行词汇。事实上, 尤其是因为20世纪70-80年代日本 工业的崛起、20世纪 90 年代中国台湾和韩国工业实力逐渐壮大，加上20世纪末 “ 世界工厂”中国的快速发展，为了重整工业，西方国家早已产生了对创新的需求。 在《体验经济》（派恩 (Pine) 和吉尔摩 (Gilmore) 1999) 和《蓝海策略》（吉 姆 (Kim) 和 (Mauborgne) 2005) 等书出版之后, “价值创新”、“差异化策 略” 等词语便广泛、深入地在商界中流传。就工业设计而言, 由于21世纪初美国 商业迅速萎缩（麦克加特里克（McGetrick）2006），设计行业领导者艾迪欧公司

(IDEO) 通过著书立说（尤其是该公司创始人大卫 · 凯里 (David Kelly) 与总裁蒂 姆·布朗 (Tim Brown) 带头) 率先透过出版书籍和发表文章, 着力地推广设计师的 策略 (strategy) 及设计思维 (design thinking) 能力与技巧。设计（和设计思维） 本身就是一个实现愿景与预想的过程, 能够以视象化手段去满足商业创新过程中传 达策略预想的需要（布朗（Brown）2005）。布朗（Brown）在著名商业期刊《哈佛 商业评论》 (Harvard Business Review) 上发表文章表示:

设计思维......是透过人本设计精神（human-centered ethos）以贯穿整个创新 活动的一种方法。随着发达国家的经济体系由工业生产转型到知识工作及服务输送 时, 创新的领域亦不断扩展。创新的目标不再是物质产品, 而是新的流程、新的服 务、新的沟通合作的方式一一设计思维正在为这些以人为本的活动带来决定性的区 别。（布朗（Brown）2008：86）。

换句话说, 设计思维的创新与策略性价值显而易见。

9 中国近来建立起两个与可持续设计 (Design for Sustainability (DfS) 相关的网络。一个是 LeNS（可持续学习网络），2009年扩大规模LeNS-China（LeNS-中国），清华大学美术 学院、湖南大学艺术设计学院、武汉理工大学艺术与设计学院、江南大学设计学院以及香 港理工大学设计学院都参与其中。另一个网络是埃齐奥 · 曼齐尼教授提倡, 于2009年三月 创建。DESIS-China（中国社会创新与可持续网络设计），中国的六所主要的设计院校参 与其中: 同济大学设计创意学院、江南大学设计学院、香港理工大学设计学院、湖南大学 设计学院、清华大学美术学院以及广州美术学院参加。该网络是在2001年建立的合作关系 的基础上发展起来的。 


\subsection{1 “T” 型设计思考者}

布朗 (Brown) 在肯定设计思维的战略价值的同时, 还主张以聘用和提拔“T型人 才”（或者说 “设计思考者”）来推动商业创新。他认为, 所谓T型人才“T”的一 竖指的是其专业技能-一他们可能是机械工程师或工业设计师，但是他们能够把自 身的本领 “横向” 延伸至其它方面, 例如人类学, 同时还能做到应用自如。（布朗

(Brown) 2005: 3)。

事实上, 在众多设计界的领导者当中, 布朗并非唯一一个于设计领域内外强 调 “T”形设计(或 “横向” 设计思维)重要性的业界重量人物。业内领先的设计机构, 如伊利诺伊理工设计学院和斯坦福大学设计学院等, 一直以来都重视设计思维的培 训, 这种培训着重宏观(或全面的/具策略性的)视野、系统思维、综合知识（例如是商 业、社会科学、市场学等相关范畴的知识）、流程创新及共同创作的促进（图1）。

这些设计院校认为, 设计思维作为一种策略方法, 能够应用在其它很多现实世 界的问题，例如 “推进组织转型、新市场开拓、设计新体验及塑造企业策略”（班 纳吉（Banerjee）2008：20）。换句话说，一旦设计师拥有设计思维能力, 他

(她) 就可以承担多种类型的设计工作, 比如服务设计、系统设计、组织设计、商 业创新乃至社会设计。

\section{4 可持续设计与“传统” 学科混淆的风险}

\subsection{1 迅速开展T型设计培训}

自2000年开始, 涉及发展的两个核心问题成为中国国家层面首要的发展议题: 1) 从“中国制造”走向“中国创造”；2）在“环境”和“发展”中寻求平衡。因此, 中国的工业设计教育渐趋向以量及高端为发展目标, 如今设计学院平均每年招收 14000多名学生入读（1995年左右只有几百名），并且越来越多的设计学院有意从 职业培训转向着重策略性的创新“T”形培训。

有些设计院校甚至从本科生阶段, 也就是学士学位阶段就开始推行上述的教学 改革。例如, 1996年, 香港理工大学设计学院迎来了新领导, 大幅度革新其学位课 程, 重新定义设计的教授与学习, 使整个课程变得更宽广、更多层面及更具跨学科 性。主修科目及习作均以不同的主题 (themes)为基础, 而并非以学科来界定。然 而, 当时业界的响应并不积极, 上述的“实验”只维持了数年的光景, 这充满了“ 良好意愿”的课程改革最后于2002年无疾而终。

\subsection{2 关于培育“设计通才”的疑问}

从学术研讨的角度, 我们不能把一些改革设计专业教学的尝试轻率地判定为正确或 错误, 尤其是当这些尝试都是短暂而不持久的。但是, 在任何试图于今天重复类似 的改革尝试（特别是像DfS这样着重 “横” 向思维的训练）的同时，有很多方面着实 需要仔细地思量, 以下是一些关键点。 


\section{经济视角}

不管我们（作为设计师或者设计教育工作者）有多想让中国快速摘掉“世界工厂” 这顶帽子，我们都必须接受以下事实：1）目前，中国经济仍然严重倚重制造10；2） 即使中国经济能发展至更具持续性的批量生产和小规模本土贸易, 物质的产出及消 耗仍是必需的，更何况这是一个迈向低耗、可持续经济必经的“过渡阶段”。

\section{教学视角}

作为设计导师, 我们比学生更具优势, 一般都能够较先接触到新的设计概念, 如西 方先进国家的设计思维 ${ }^{11}$ 。此外, 由于对设计认知与技巧我们已掌握多年, 我们会不 自觉地视基本技巧为理所当然（与此同时, 因为我们往往会偏向从自己的角度（基 于自己的能力和美好的意愿）去设计教学大纲，这样就会很容易主观地去编排 “最 先进” 的课程及引进 “最新” 的设计理论于日常教学中 12 , 而没有考虑学生的程度或 课程的性质。由于“T”形设计是现今被认为“先进”及 “多手可热”的一种培训, 故此越来越多的设计教育工作者非常热衷地将其推广。但是, 我们或许已经忘记这 样地反思: 学生是否都应被引导成为 “ $T$ ” 形设计师, 无论他们是否具备足够的理解 能力和学习的兴趣? 究竟 “横向” 设计能力是否真的可取? 它是否真的适合中国的 国情和发展?

\section{多学科视角}

2010年7月, 在伦敦召开的美国设计管理协会 (DMI) 会议上, 社会创新方面的 知名专家周若刚（Geoff Mulgan）（杨氏基金会（Young Foundation）董事）解 释, 设计师虽然能够“进入” 社会企业的领域但却不能成功, 原因是他们“天真” 及缺乏该领域专业的知识, 以致不能有任何作为 ${ }^{13}$ 。知名设计学者丹 ·诺曼 (Don Norman）与设计从业者凯文 ·麦克莱（Kevin McCullagh）亦就以延伸“横向”设计 能力或推广设计思维作为新的设计技巧提出质疑。诺曼 Norman (2010) 并不认同设 计思维的 “独特性”和设计师 “垄断”创意能力的说法。他认为“这个可以被标签 的所谓 “设计思维” , 其实是在所有专业范畴内具有创意的人一直在做的事情” ,

“设计思维是个为美好但落伍的创意思维 (creative thinking)而设的公关术语”。麦

102009 年中国制造业占国内生产总值的 $48.9 \%$ ，而该比例在英美分别为 $25 \%$ 和 $20 \%$ （刘新 2010) 。

11 比如说, 设计教育工作者有机会参加国际设计会议, 并参观国外的先进的设计学院。

12 中国的工业设计都是在传统的艺术和工程学科的基础上发展起来的。设计在中国是一个很 新潮的学科, 中国某些没有经验的教育者和新成立的设计学院至今对一些学士学位称号或 者硕士学位称号都不是十分了解, 例如, 文学学士学位、工程学士学位、理学学士学位、 设计硕士学位、美术硕士学位、文学硕士学位、工程硕士学位、理科硕士学位, 或者哲学 硕士学位等。

13 周若刚 (Mulgan) 认为, 进入社会创新领域的设计师通常都不了解其所处新领域的背景, 仍然提出一些数年前已经失败了的想法（麦克克拉夫（McCullagh）2010）。 
克莱 (McCullagh) (2010) 认为, “如果设计师没有强大的纵向设计能力, 以应付 他们自己专业范畴的问题, 设计师就不再是设计师, 而只是随波逐流的通才队伍里 的一员。”。

其实, 在IDEO于本世纪初把 “T”形人才这个概念普及推广以前, 最先提 出 “T”培训的是管理顾问专业领域的人。因此, 这个概念目前在设计界内广泛流行, 教育业界是应当谨慎对待的。此外, 在布朗 (Brown) 于《哈佛商业评论》发表以《设 计思维》为题的文章不久, 另一篇题为《创新者的基因》 (The Innovator' $s$ DNA) 的文章亦刊登了, 当中讲述了一群商业管理教授多年来对创意的研究结果。他们提出 的方法与布朗 (Brown) 和艾迪欧公司 (IDEO) 所描述的设计思想家概念如出一辙

（戴尔（Dyer）、格雷格森（Gregersen）和克里斯滕森 (Christensen) 2009) 14。 事实上, 很多聪敏的人在 “T”形技能甚至设计思维方面, 都和设计师一样能干, 甚至 比他们更胜一筹。因此，我们应重新认真地检讨过早延伸“横向”通才能力而削弱“ 纵向”专业技巧培训的想法, 不应为了扩充更多或更新的设计领地而不断地扩大“横 向”技能的教学。

\section{5 温故而知新}

\subsection{1 重新探索设计的基本}

世纪之交，社会发展经历了三种过渡（即上文所述的向数字通信互联、服务经济和 可持续文化的过渡），它们几乎同时出现，迅速发展。此时工业设计已经不能适应 社会发展的需求, 或者说人们觉得放弃已学的设计知识而努力推行非物质化的可持 续设计 (DfS) 实践是更好的选择。我们更相信工业设计这门学科于绿色经济中的应 用潜能应再作深入探讨和发掘。

在工业及产品设计范畴内教授可持续设计（DfS）理念时, 这个专业的基本价值 及其具体的技巧亦应予以修订为推广可持续设计 (DfS) 教学的 “必要元素” 15。

我们的论断基于以下现实及愿景:

- 现实。要将“世界工厂”转型为可持续发展经济体系，过渡阶段是必需的。 在这期间，具有创意的可持续产品仍是促进今天经济体系顺利过渡并达到更 永续发展的重要元素。

14 戴尔（Dyer）提议的“五种发现技能”：关联、提问、观察、试验和网络化。格雷格 森（Gregersen）和克里斯滕森（Christensen）（2009）在他们的文章中梳理了布朗 (Brown, 2008) 提出的 “设计思考者要素”。

15 为强化减少批量生产、促进消费, 产品设计应当作为一种新学科（传统行业设计的教学） 进行改革, 这种新学科关注绿色、批量和定制化设计和生产。环境设计或生态设计的教学 也应当进行改革, 并作为这个改革课程的核心基础课展开教学。 
- 愿景。我们憧憬的永续社会, 将是非常倚赖多元化定制服务, 并配以特别 设计的耐用产品(大多是系统化操作以供分享的) 来解决人们日常的需要, 但 是, 可能再也不会大规模生产这些产品了。而现今工业设计的基础知识（如 造形美学、产品语义学、人体工学、材质物料等）和技巧将需要重新修订并 予以新的意义。

\subsection{2 “V型” 取代 “T型”}

将上述愿景和现实，与如今所提倡的T型思考者相比，我们更支持培训“ $\mathrm{V}$ 型” 设计 师。作为一个 “ $\mathrm{V}$ ” 形设计师, 需要的设计培训应从 “ $\mathrm{V}$ ” 字形最底层的专业技巧及 知识开始（并以此为根基）。学习相关技巧、知识和方法（见图19.1），并在特定、 通用（跨设计专业）及延伸的层面累积能力, 然后从长时间的训练和实习中精进 （见表19.2）。

\section{图19.1 以产品为本的V型设计培训的核心和初步框架}

来源: 作者

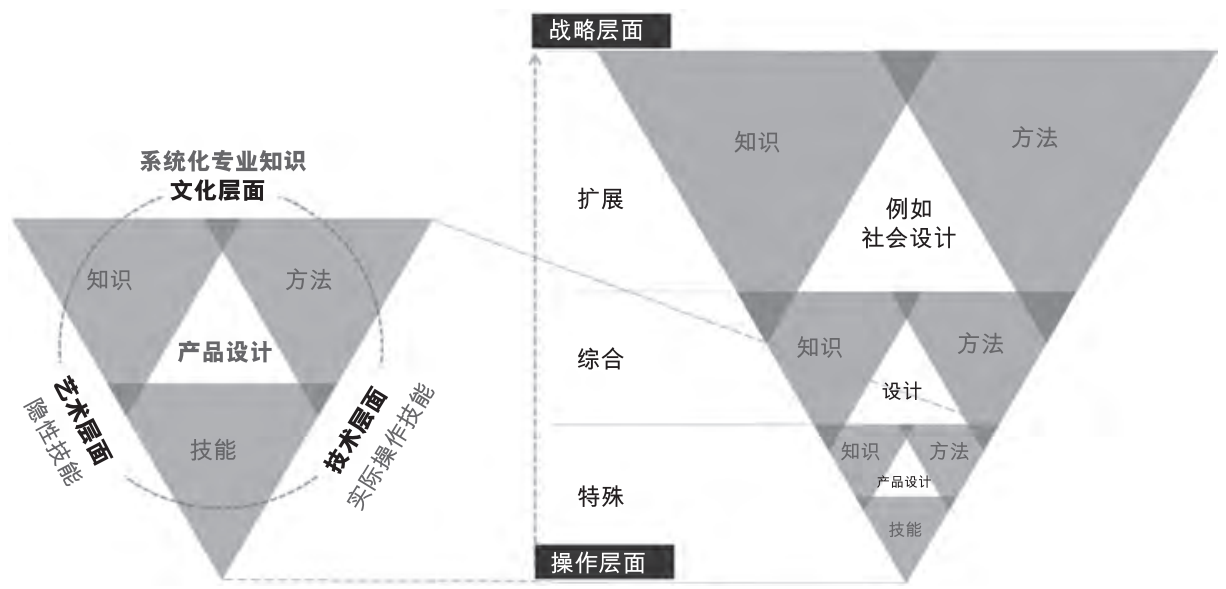


表19.2 “V”形产品设计培训所需技能、知识及方法的一些例

\begin{tabular}{|c|c|c|c|}
\hline \multicolumn{4}{|c|}{ 产品设计训练 $\leftarrow \leftarrow \rightarrow \rightarrow$ 扩展设计训练 } \\
\hline & 特定 & 通用 & 延伸 \\
\hline $\begin{array}{l}\text { 技能 } \\
\text { 隐性技能 }\end{array}$ & $\begin{array}{l}\text { - 几何面的处理 } \\
\text { - 三维视象化及绘图 } \\
\text { 换位思考 } \\
\text { - 模型的制作 } \\
\text { 等 }\end{array}$ & $\begin{array}{l}\text { - 创意 } \\
\text { - 视觉思维技巧 } \\
\text { - 问题框定与识别 } \\
\text { - 沟通技巧 } \\
\text { 等 }\end{array}$ & $\begin{array}{l}\text {-领导才能 } \\
\text {-创造机会 } \\
\text {-分析思维 } \\
\text {-协作能力 } \\
\text { （加入延伸的专业技 } \\
\text { 巧） }\end{array}$ \\
\hline $\begin{array}{l}\text { 知识 } \\
\text { 系统化专业知识 }\end{array}$ & $\begin{array}{l}\text { - 造形美学及语义学 } \\
\text { - 三维立体原则及相关 } \\
\text { 色彩理论 } \\
\text { - 物料特性 } \\
\text { - 基本机械学 } \\
\text { - 制造工艺 } \\
\text { - 制图 } \\
\text { - 人类工学/人因工学 } \\
\text { - 生态设计 (可持续设 } \\
\text { 计 (DfS)), , 等 } \\
\text { - 4DFD, PDfS, } \\
\text { 等 }\end{array}$ & $\begin{array}{l}\text { - 批判性思维、创意 } \\
\text { 思维 } \\
\text { - 表示法绘图 } \\
\text { - 视象读写能力 } \\
\text { - 计算机知识 } \\
\text { - 用户调研/用户为本 } \\
\text { 设计 } \\
\text { - 设计理论和方法 } \\
\text { - 艺术/文化欣赏 } \\
\text { - 设计历史 } \\
\text { - 可持续设计 (DfS) 等 }\end{array}$ & $\begin{array}{l}\text {-设计管理 } \\
\text {-项目规划 } \\
\text {-系统/策略思维 } \\
\text {-流程创新 } \\
\text {-跨领域促进等等 } \\
\quad \text { (加入延伸的专业知 } \\
\text { 识） }\end{array}$ \\
\hline $\begin{array}{l}\text { 方法 } \\
\text { 基于工具的技能 }\end{array}$ & $\begin{array}{l}\text { - 尺度、比例及形态 } \\
\text { 倾向 } \\
\text { - 色彩轮 } \\
\text { - 本我设计方法 } \\
\text { - CAD计算器辅助设 } \\
\text { 计/ CAID计算器辅助 } \\
\text { 工业设计 } \\
\text { - 任务分析 } \\
\text { - 生命周期评估, 原 } \\
\text { 料/能源/毒性矩阵, } \\
\text { 策略轮, 等 } \\
\text { 等 }\end{array}$ & $\begin{array}{l}\text { - 头脑风暴, 心智图 } \\
\text { 法, 等 } \\
\text { - 图表, 目标, 透视 } \\
\text { 绘图 } \\
\text { - 2D、3D、4D视觉 } \\
\text { 软件 } \\
\text { - 观察, 实地调查, 等 } \\
\text { - 故事板 (脚本), 图 } \\
\text { 标或矩阵 } \\
\text { - 等等 }\end{array}$ & $\begin{array}{l}\text { - 5Cs分析 } \\
\text { - 策略图标/ 框定 } \\
\text { - NPD、PCP、PIP } \\
\text { 等程序 } \\
\text { - 产品开发策略 } \\
\text { - 创意工坊等 } \\
\text { 情境、SOD、PSS, } \\
\text { 等 } \\
\text { (加上延伸的专门方 } \\
\text { 法) }\end{array}$ \\
\hline
\end{tabular}

“V”形设计培训的理念着重与专业的核心知识, 同时提供一个包含隐性隐性 ( 艺术）技能、系统化专业（文化）知识和实际操作（技术）技能 ${ }^{16}$ 的学习框架, 以避 免 “T”形设计培训因为向多领域扩展导致专业知识的纵向发展的弱化, 从而演变成 为 “杂而不精的通才”。

16 设计的专门知识来源于艺术技能和知识的组合, 技能和知识只能通过实践和体验获得, 而 综合的设计技术来自于文献中的系统化的知识与方法, 如文本、音频、视频。了解这些符 号的人（视觉或形式语言）都可以获得这类知识; 而设计的技术则是通过常年的培训和实 践而掌握的技术技能和方法。它可以反映在各种形式的物质形态（硬件工具）、程序、标 准过程或方法（软件工具）中。 


\subsection{3 产品可持续设计}

为了推进 “ $V$ ” 型设计训练, 促进可持续设计 (DfS) 学习, 本章重点讨论以产品 为导向的可持续设计 (DfS) (即产品可持续设计 (PDfS) )。为了完善以可持 续设计（DfS）(即系统可持续设计(SDfS））为基础的 “系统”，产品可持续设计 (PDfS) 致力于以产品为导向的解决方案, 并更倚重于设计培训中的核心操作能力 (即“V”形设计底层)。

总而言之, 产品可持续设计 (PDfS) 内容概括如下:

1. 信念和意图

- 设计的出发点是基于主体（我一一方法论）、以用户为中心的设计观 念。强 调为他人设计就像为自己设计。

- 在实现可持续的集体变革中, 个体的作用至关重要。个体看似很微小的贡 献，都能够刺激及影响周围的人及整体社会。

- 产品是推动个体 (行为或思想) 变化的关键, 让人们为其日常消费负责。

- 产品是转变社会观念及促进生产和消费可持续的媒介。

2. 潜力

产品可持续设计 (PDfS) 实践:

- 通过创造性的产品设计方案推动可持续的生活方式。

- 把策略性规划和设计的物质产品用于指定的可持续产品服务系统中。

- 通过重新焕发本土手工制品、技术或者小规模制作的活力, 促进社会边缘阶层 和富裕阶层的资金交易和知识交流。（梁町（Leong）2002；苏伊（Siu）、 潘 (Pan) 和李 (Lee) 2009)

\section{6 产品可持续设计实践案例}

根据上述信念和意图, 我们将简要介绍中国香港理工大学设计学院关于产品可持续 设计 (PDfS) 培训与实践方面的两个实例。

\subsection{1 产品可持续设计（PDfS）实践案例}

第一个案例是关于产品可持续设计 (PDfS) 的教授和学习的。“可持续产品设计 (SPD) ” 是面向香港理工大学设计学院工业及产品设计专业四年级学生的一门课 
程, 课程的教学目标是巩固学生已有的设计技巧、知识和方法, 同时向他们介绍环 境设计 (DfE) 及系统设计思维, 最重要的是引导他们以环境设计 (DfS) 的概念为 基础, 从更宏观的社会和生态环境角度进行产品的设计和开发。在此课程中, 学生 将面对指定的三个设计挑战。

\section{1. “迷你” 习作}

“迷你” 习作是课程初期为时较短的设计热身练习。例如, 2009年的项目练习就是 让学生使用废弃的聚对苯二甲酸类塑料 (PET) 瓶进行简单设计, 其要求是: 既展现 出原材料的性质特点, 又能在家里使用简单的手工工具制作完成。除了参加课程指 导老师举行的研讨会之外, 学生还可以通过实地考察和理论研究的方式, 了解香港 境内回收废弃PET塑料瓶的地点（后勤）, 以及通过测试对PET塑料瓶在物理和结构 方面的可塑性进行研究。总的来说, 鼓励及增强手作( “Hand-on”) 设计体验是迷你 习作的培训重点

\section{2. 产品可持续设计（PDfS）研习（第一阶段）}

学生面对的第二个挑战是另一个小型的设计任务, 目的是向学生介绍与可持续设计

(DfS) 理念有关的系统设计的基本概念及相关工具。在此阶段, 学生必须通过分组 合作来完成一系列的任务：对一个社会上现存（由导师预先搜集后分别指派）的消 费现象或个案进行实地调查以获取得深入的认识和理解; 利用照片、图像及文字对 其进行可视化表达, 以加强沟通效果; 分析个案（着重分析其在实用性、可取性、 社会文化背景和社会环境背景方面的薄弱环节），进行再次设计并完善案例。在项 目过程中, 学生得到的支持包括导师指导、相关讲座及样本工具（如思维模式、系 统图示和故事板等）。

\section{产品可持续设计 (PDfS) 研习（第二阶段）}

产品可持续设计 (PDfS) 研习的第二阶段是整个课程的核心。

2009年, 本阶段项目要求学生在ECOLS商店（ECOLS是利用二手材料生产售 卖可回收利用的家具、家居用品和包袋的公司）提供的废弃横幅材料及营销建议的 基础上, 与来自香港妇女劳工协会 (HKWWA) ${ }^{17}$ 的缝纫女工一起设计新产品。

1. 设计调研: 学习并分析女工的缝㧅技巧、横幅材料的特性和可用性、香港妇 女劳工协会 (HKWWA) 的组织和运行特点以及市场上潜在的竞争产品。

2. 产品设计：使用二手横幅材料, 提出有竞争力的设计创意。

17 香港妇女劳工协会(HKWWA)是1989年建立的一家非政府组织, 旨在帮助香港低收入、被 边缘化的女职工, 如上世纪80年代由于服装厂迁往大陆而导致失业的缝㧅工。在2005年至 2008, 它还发起了一系列回收项目和环保社区服务（如：利用用过的食用油做手工皇，建 立二手商店以及提供绿色清洁服务。) 
3. 设计方案可视化: 把新设计方案的运作、生产和市场推广流程的初步想法进 行可视化表达。

除了ECOLS公司、香港妇女劳工协会 (HKWWA) 和设计学院教师提供的专业知识 指导外, 学生可以充分利用在 “迷你” 习作阶段和产品可持续设计 (PDfS) 第一阶 段学到的知识, 如系统图示工具。

在课程结束时, ECOLS公司、香港妇女劳工协会 (HKWWA) 和设计学院导师 们选取了两个项目进行后续研发。最终, SDWork平台选取了两个项目中的一个进行 继续研究并将其进行商业化开发。SDWork平台是设计学院建立的独特平台, 鼓励把 优秀学生设计的项目商业化, 并鼓励学生自主创业。最后, 开发该项目的学生将该 项目命名为 “生活像素”。

“生活像素”是由废弃的塑料横幅及灯座制成的一套五颜六色的照明设备。这 一设计的创意来自于PVC (聚氯乙烯) 横幅材料（通常只有一面印有半溶性或可溶 性油墨的图文) 的半透明特性, 而这种特性是学生在经过数次材料测试、结构试验 以及完整的原型设计过程后, 与香港妇女劳工协会 (HKWWA) 经验丰富的缝㧅工一 起探索得出的。因为这一套照明设备主要是由标准的横幅像素方块和从废物站或二 手店回收的旧灯座组成, 所以它可以灵活设计, 组装成款式各异的多种造型。

通过 “生活像素” 灯饰系列, 已渐被遗忘的车衣专业技艺得以复兴（也让缝㧅 女工重拾职业自豪感）。而 “生活像素” 在网上的正式销售也见证了香港本地小规 模、可持续生产及消费模式的孕育与诞生。

\subsection{2 通过产品设计促进本土手工艺的复兴}

第二个案例是一个真实的实验项目, 通过采用产品设计技能促进香港社会的创新和 可持续发展。该项目名为 “改造木制手推车” , 是2007年年中启动的一个大型设计 研究课题中的附属项目 18 。该项目的目标是促进传统木制手推车制造工艺（正在衰 退）的复兴, 形成新设计, 并开拓生产和消费的新形式。

\section{项目背景}

“改造木制手推车” 项目由本章第二作者布莱恩 ·李（Brian Lee）领导并协调完 成, 他是一位经验丰富的家具产品设计师。项目主要针对（香港平均收入较低的地 区之一的深水埗区) 一家名为 “有记 (Yau Kee)” 的手推车店, 店老板是从事手推 车制作（图19.2）50余年的李氏夫妇。这些年来, 有记 (Yau Kee) 的手推车制作工 艺一直切实可行并且非常环保。例如, 其使用的材料虽然是废弃床板及旧轮胎, 其 成品却是一种十分便利的回收工具, 主要出售给该区的建筑工人和清洁工。

有记 (Yau Kee) 手推车店是典型的手工作坊, 占地面积小, 规模小, 独立生 产, 本地经营, 并与同一个城区附近的业务伙伴和客户有密切联系。同时, 有记

18 该设计项目由香港理工大学Siu King Chung先生发起, 命名为“寻找边缘化的智慧” (寻 找被边缘化的智慧）。该项目由香港深水埗区议会（Sham Shui Po District Council）提供 赞助。 
(Yau Kee) 作为一个手工艺店, 还担负着传承当地文化基因的使命, 它一直保留着 深水埗区的本土价值观念。但是, 随着金属手推车因大量生产和价格低廉而广受欢 迎, 有记（Yau Kee）以手工艺为基础的商业模式及技术正于激烈的竞争中被逐渐淘 汰。。

\section{图19.2 有记（Yau Kee）的店主（一对年迈夫妇）及环保的木制手推车}

来源：作者
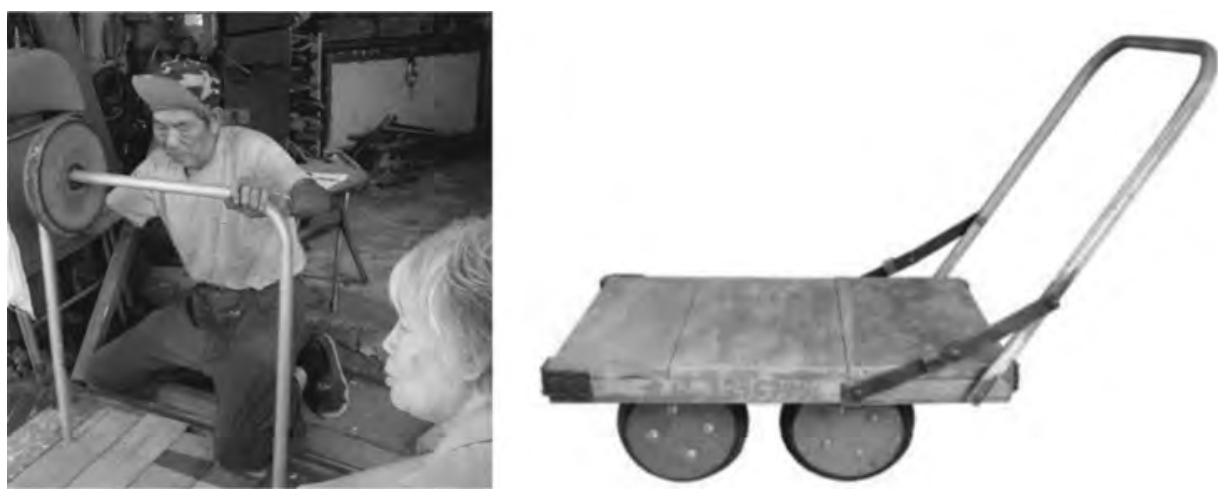

\section{手工艺改造转型}

李 (Lee) 认为, 老城区的城市手工业不仅充满活力, 而且与社会关系密切。在与 香港类似的社会环境中, 可以通过学习、复兴乃至复制的方式使这些手工艺和制作 模式获得新生。李 (Lee) 还认为, 产品设计作为一门以物理学为基础的学科, 既 要革新传统设计, 又要保护日益衰落的手工制造业的基本技术、流程和价值观, 例 如香港的木制手推车制作。为了对这一设想进行验证，制定了三项产品协同设计的 过程一一工匠为主导的过程、设计师和工匠协作的过程、以设计师为主导的过 程一一目的是把木制手推车制造技术改造为新的设计和产品方案（苏伊 (Siu) 、潘 (Pan) 和李 (Lee) 2009)。

苏伊 (Siu) 、潘 (Pan) 和李 (Lee) (2009) 提出, 上述项目还受到一个称 为 “社会问题设计运作模式” (见图19.3) 支持, 该模式概括了包括材料与人力资源 交换在内的各种活动的关系及合作类型。 

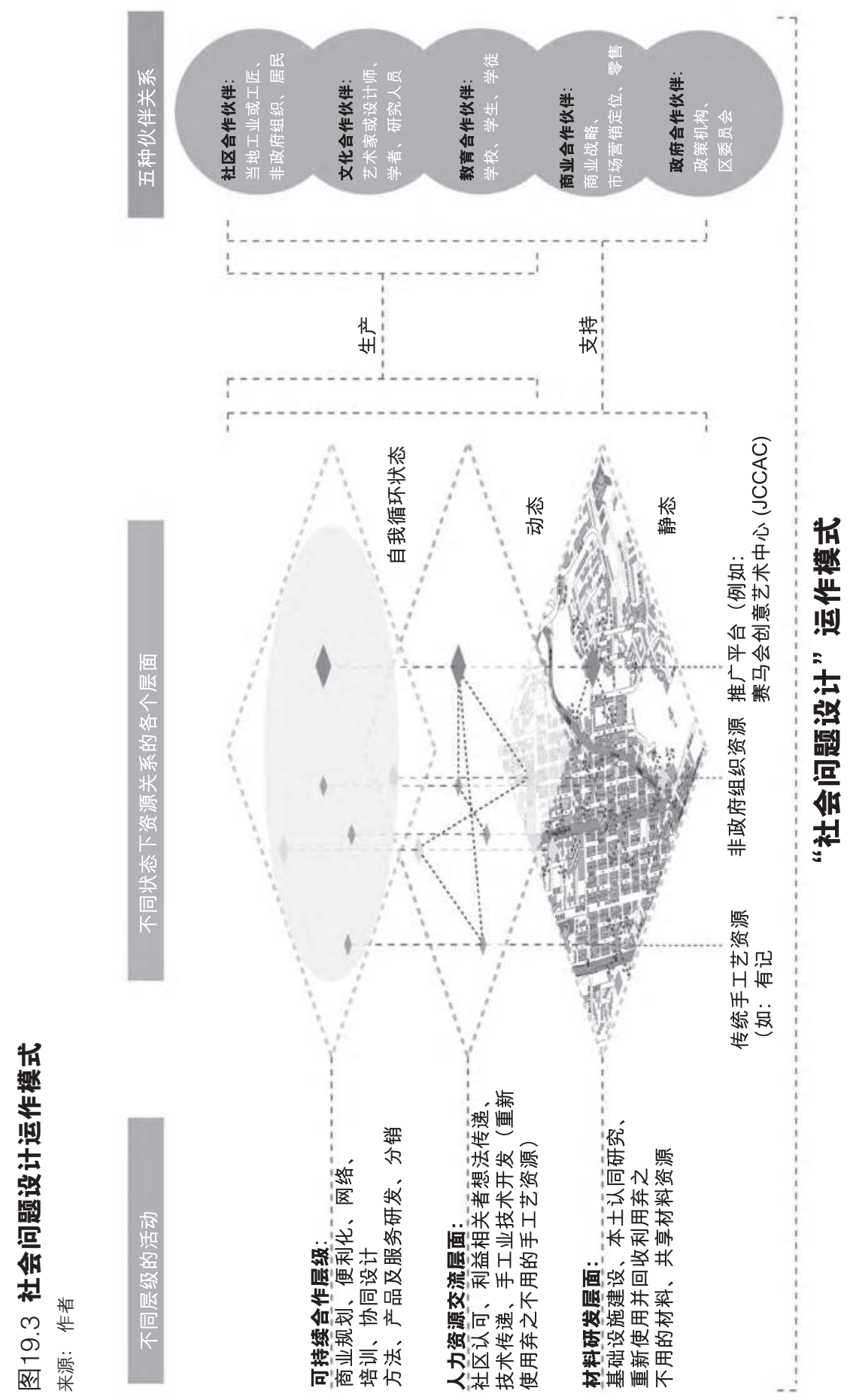


\section{7 结论}

虽然很多设计专业人士认为, 在向以服务为导向的可持续经济快速过渡的过程中, 产品设计会成为过时的“夕阳专业”，但是上述两个案例：“改造木制手推车” 和“生活像素” 都证明事实恰恰与上述看法相反：即使在（或准备）教授及学习可 持续产品服务系统 (PSS) 设计的过程中, 雄厚的产品设计能力仍然是无价之宝。

此外, 产品设计既可以用于保护本土手工艺及材料文化, 同时有助于解决社会 问题，促进可持续的商业实践，实现更美好的未来。

因此, 在我们盲目仿效西方 “自命不凡的”设计思维培训, 并确信“十”形 思维能够帮助设计摆脱形式 (form)) 与风格 (style)) 的羁绊而直接转化到所谓 更高的系统 (system)) 及策略 (strategy)) 层次之前, 我们需要重新审视这一概 念。毕竟, “没有形式 ((form)的策略 (strategy)就像是一个空中楼阁”（柯林科 (Klinker) 和亚历克斯 (Alexis) 2008：30）。为了更好地推进可持续设计（DfS） 和可持续产品服务系统 (PSS) 设计, 也为了中国的发展, 我们认为, 现在正是重 新学习那些被舍弃的设计核心内容的时候。

\section{参考文献}

Banerjee, B. (2008) 'Design, A Field in Transition', INNOVATION 27(4): 18-20.

Brown, T. (2005) 'Strategy by Design', Fast Company June (Special Issue): 2-4.

Brown, T. (2008) 'Design Thinking', Harvard Business Review 86(6): 85-92.

Charter, M. and Tischner, U. (2001) Sustainable Solutions: Developing Products \& Services for the Future (Sheffield, UK: Greenleaf Publishing).

China Political \& Economic Information Network [CPEIN] (2010, August 16) 12th Five Year Plan Seeking for Three Major Transitions.

China Reform (2010) Diagnosing China's 'Grey Income', China Reform (September 2010), 323: 58-62.

CMP (2007) 'In Search of Marginalized Wisdom: Sham Shui Po Craftspeople', Community Museum Project, Sham Shui Po District Council, http://www.hkcmp.org/craftsman_book. pdf.

Dyer, J.H., Gregersen, H.B. and Christensen C.M. (2009) 'The Innovator's DNA: Five "discovery skills" separate true innovators from the rest of us', Harvard Business Review 87(12): 61-67.

The Economist (2007) 'Clean tech in China: Green shoots', The Economist July 2007: 64-65.

Economy, E. and Lieberthal, K. (2007) 'Scorched Earth: Will Environmental Risks in China Overwhelm Its Opportunities?', Harvard Business Review, 85(6): 88-96.

Economy Watch (undated) 'Chinese Manufacturing Industry', http://www.economywatch.com/ world-industries/manufacturing/chinese.html, accessed 28 June 2013.

Forex Finance People [FFP] (2010, March 29) 'Undervalued RMB': a Misleading Myth and Today's Reality of Chinese Manufacturing Industry'.

Hickey, D.V. and Kawamoto, T. (2010, January 27) 'More Than Just Income Gap to Bridge', China Daily, http://www.chinadaily.com.cn/opinion/2010-01/27/content_9382086.htm, accessed 28 June 2013.

Kim, W.C. and R. Mauborgne (2005) Blue Ocean Strategy: How to Create Uncontested Market Space and Make Competition Irrelevant (Boston, MA: Harvard Business Press). 
Klinker, S. and Alexis, J. (2008) 'The Cranbrook-IIT Debate: Design vs Innovation (2008)', INNOVATION 27(4): 27-31.

Leong, B.D. (2002) 'How Can the Concept of "System Product Design" Revive Contemporary Eco-design Practices?', Unpublished paper presented at the International Conference on Eco-design, New Delhi, 26-28 November 2002.

Leong,B.D. (2004)'Sustainable Design as an Alternative Strategy for Product Innovation', in Leung, T.P. (ed.), Hong Kong: Better by Design (Hong Kong: School of Design, The Hong Kong Polytechnic University): 13-24.

Leong, B.D. (2008) 'Is a Radical Systemic Shift toward Sustainability Possible in China?' In Tukker, A. et al. (eds.), System Innovation for Sustainability 1 (Sheffield, UK: Greenleaf Publishing): 214-231.

Leong, B.D. (2010) 'Strategic "Green" Design: What Could we Learn from Our Ways of Living?' In unpublished proceedings, The Greenness to be Clarified: 2010 International Conference on Green Design, Zhuangshi Magazin \& Hunan University of Technology, Zhuzhou, China, May 2010: 46-66.

Leong, B.D. and E. Manzini (2006) Design Vision on the Sustainable Way of Living in China (Guangzhou, China: Lingnan Art Publishing).

Lindsay, C. (2003) 'Involving People as Co-creators', In Marzano, S. and Aarts, E. (eds.), The New Everyday: Views on Ambient Intelligence (Rotterdam, The Netherlands: 010 publishing): $39-41$.

Liu, W.H. (2010) 'The China's manufacturing and logistics review in 2009 and its projection for 2010 .

Lo, A. (2003) Navigating Design: A Voyage of Discovery (Hong Kong: Hong Kong Polytechnic University).

Manzini, E. and Leong, B.D. (2001) Strategic Design and design for Sustainability. A general overview and some consideration in the Chinese context, paper presented at the Tsinghua 2001 China International Design Forum, Beijing, June 2001.

McCullagh, K. (2010, September 24) 'Is it Time to rethink the T-shaped Designer?', http://www .core $77 . c 0 m / b l o g / c o l u m n s / i s \_i t$ time_to_rethink_the_t-shaped_designer_17426.asp, accessed 28 June 2013.

McGetrick, B. (2006) 'Fear Factory: The traumatizing effect of Chinese manufacturing on the rich', Urban China March: 107-111.

Norman, D.A. (2010, June 25) 'Design Thinking: A Useful Myth', http://www.core77.com/blog/ columns/design_thinking_a_useful_myth_16790.asp, accessed 28 June 2013.

Pine, J.B. and Gilmore, J.H. (1999) The Experience Economy: Work Is Theater \& Every Business a Stage (Boston, MA: Harvard Business School Press).

Ray, P.H. and Anderson, S.R. (2001) The Cultural Creative: How 50 Million People are Changing the World (New York: Three Rivers Press).

Siu, K.C., Pan, N.L. and Lee, Y.H. (2009) 'Adaptive Reuse From Building Conversion to Social Practice', Revitalizing Built Environments: Requalifying Old Places for New Uses, IAPSCSBE International Symposium, Istanbul, Turkey.

Tukker, A. and Tischner, U. (2006) New Business for Old Europe: Product-service Development, Competitiveness and Sustainability (Sheffield, UK: Greenleaf Publishing).

Vezzoli, C. (2010) System Design for Sustainability: Theory, Methods and Tools for a Sustainable 'Satisfaction-System' Design II edition (Milan, IT: Maggioli Editore).

Viewpoint (2005) 'The Conscience Consumer', Viewpoint: Re-Enlightenment (16): 91-103.

Yang, C.F. (2010, September) 'Who Pays for Our Environmental Pollutions and Damages?' China Reform, 323: 64-71. 


\section{0 \\ 在可持续产品服务系统（PSS） 设计过程中引入改进的生命周期 评估（LCA）}

塔图 ·马蒂拉 (Tatu Marttila)

芬兰阿尔托大学艺术、设计与建筑学院 (Aalto University School of Arts, Design and Architecture)

\section{1 引言}

在产品服务系统 (PSS) 的设计过程中, 系统中产品的各种效能, 可以通过重新设 计利益相关方的互动关系, 得到不断提高。通过对产品服务系统 (PSS) 方案进行 重新组合和优化, 使其提供更多的服务, 同时降低对环境造成的影响。生命周期设 计（LCD）方法, 重在减少产品或系统在其生命周期内对环境的负面影响。生命周 期包括获取材料、生产、分配、使用以及报废等阶段。目前, 有很多生命周期评估

(LCA) 工具和方法用于衡量产品或系统在其生命周期中对生态的影响。其中一些工 具可以在产品服务系统 (PSS) 设计过程的早期阶段使用, 用于支持那些与现有产 品系统有关的选择, 尤其是与系统的物质方面（即产品）有关的选择, 而另一些工 具则用于解决社会经济方面的问题。

本章探讨产品服务系统（PSS）设计方法与生命周期设计（LCD）方法之间的 联系, 以改善可持续设计 (DfS) 过程。本章探讨了如何展开环境影响分析, 以及从 哪些方面展开这类分析。这种分析引用了学生在LeNS项目中引入和传播可持续产品 服务系统 (PSS) 设计方法时所创立的一些概念。还提出了产品服务系统 (PSS) 方法的扩展过程模型, 并把 “简化的生命周期评估 (SLCA) ” 方法中的META矩 阵工具结合到产品服务系统 (PSS) 设计过程中。在设计初期, 这种方法有助于设 
计师定位产品服务系统 (PSS) 所要改善的领域, 加强对系统生命周期各阶段的全 面理解。

\section{2 生命周期评估与产品服务系统设计}

生命周期评估（LCA）被认为是工业生态学现行做法的基石（马修斯（Matthews） 和斯莫尔 (Small) 2000)。生命周期评估（LCA）还是ISO环境管理标准（ISO 14040及14044) 的一部分, 而且欧盟 (CEC 2001) 和联合国环境规划署 (UNEP) （2002）也都提倡这一方法。生命周期评估（LCA）的价值尤其体现在通过评估, 可以判断出一个产品在其整个生命周期中对环境的影响（路易斯（Lewis）和哲萨奇 斯（Gertsakis）2001），研究其在生产、使用及报废等各个阶段中的投入和产出。 其所提及的影响一般都与环境相关, 但是也可以扩展到社会经济领域（参见联合国环 境规划署（UNEP）提出的生命周期社会评估（Social Life Cycle Assessment））１。 作为一个分析工具, 生命周期评估（LCA）可以：1）为现有产品设定基准；2）设定 目标；3）提供 “在制品” 的评估工具；4）指导材料和组件方面的决策；5）识别产 品系统内的未知影响（路易斯（Lewis）和哲萨奇斯（Gertsakis）2001：17）。

生命周期评估 (LCA) 方法通常可以分为全面生命周期评估 (LCA) 和简化式 生命周期评估 (SLCA) 2。全面生命周期评估（LCA）实施困难，且费时费力（路 易斯 (Lewis) 和哲萨奇斯 (Gertsakis) 2001; 霍克斯寇纳 (Hochschorner) 和 (Finnveden) 2003），只适合专业人士使用（奈米拉（Niemelä）2010）。本章重 点关注后者, 即简化式生命周期评估 (SLCA) 方法, 这种方法使用简单, 省时又高 效, 设计师和设计专业学生都可以独立使用。简化式生命周期评估 (SLCA) 方法和 广义上的生命周期评估（LCA）方法一样, 一般可以用于以下两个方面：确定系统中 需要改善的领域, 或者有助于对不同的选项或概念进行比较（路易斯 (Lewis) 和哲 萨奇斯（Gertsakis）2001）。简化式生命周期评估（SLCA）所使用的方法论可以 被划分为定量型、半定量型、定性型和数据型等 (霍克斯寇纳 (Hochschorner) 和

(Finnveden) 2003)。一个通用的简化式生命周期评估（SLCA）方法是基于矩阵 的方法。

\subsection{1 基于矩阵的简化式生命周期评估（SLCA）：MET矩阵工具}

基于矩阵的简化式生命周期评估（SLCA）工具通常包括定性评估矩阵，也可能含有 定量信息, 用以解决产品（或系统）在生命周期各个阶段中对环境造成的影响。正

1 社会或社会经济寿命周期评估是联合国环境规划署在其 “社会产品生命周期评估指南”

(Guidelines for Social Life Cycle Assessment of Products) 中多次重点强调的项目。http:// www.unep.fr/shared/publications/pdf/DTIx1164xPA-guidelines_sLCA.pdf.

2 参见Lewis and Gertsakis (2001)所举的例子; 术语 “简化的” 和 “改进的” 在这里是同义 词, 与Hochschorner and Finnveden (2003)早先的出版物中所用的术语一致。 
如由布瑞吉特 (Brezet) 和赫梅尔 (Hemel) 提出的著名的MET矩阵（1997），这 种工具可以应对各种形式的影响，比如材料、能源和毒性等。

定性方法很有价值, 其作用是显示系统的新信息, 或者 “识别产品的重要方面”, 并在调整系统边界以确保合适的评估范围的同时, 能够对定量研究进行补充（霍克 斯寇纳（Hochschorner）和福因维登）2003：127）。这意味着诸如MET矩阵等 基于矩阵的定性方法适用于快速分析, 它能够给出与系统有关的更为细节的信息, 以便提供进一步的指导。MET矩阵也被认定是生态设计实践中最受欢迎的工具之一 （奈特（Knight）和詹金斯（Jenkins）2009）。对产品服务系统（PSS）构思而 言, 相似的方法可以作为有价值的评估工具, 对诸多设计选择之间的差异、服务组 件和（或）物流，以及系统内部技术的选择进行评估。

\subsection{2 社会伦理方面: META矩阵工具}

在可持续的产品服务系统 (PSS) 和系统设计中, 环境维度与社会伦理维度是相 关联的（维佐里（Vezzoli）2007 [2010]）。同样, 扩展生命周期评估的一个潜 在方法就是把评估范围从环境领域扩展到社会经济领域（杰斯瓦尼（Jeswani） 等，2010），但这也意味着在社会伦理层面和社会技术领域需要开展进一步的评 估。定性矩阵方法在META矩阵中得到进一步发展（（Niemelä）2010）。META矩 阵是MET矩阵工具的扩展版。META矩阵不仅把MET矩阵的三个方面（M、E、T) 和第四方面即代表美学的 (A) 结合起来, 同时也包含了社会、伦理、文化和经济维 度（（Niemelä）2010）。为了与以系统为主的产品服务系统 (PSS) 的设计更加匹 配, “A”可以仅仅是指包含在系统内的与社会伦理或利益相关方有关的问题及其影 响（见图20.1）。

\section{图20.1 META矩阵}

来源：源自（Niemelä）（2010）；另见马蒂拉（Marttila）（2010）。

\begin{tabular}{|c|c|c|c|c|c|}
\hline 标准 & 材料生产 & 制造 & 使用 & 处理 & 运输 \\
\hline M: 材料 & 系统选取的木 & 料以及生产对 & 环境的影响。 & & \\
\hline$E$ : 能源 & 与系统相关的 & 不同化学物质 & 和化学流程的毒 & 性 & \\
\hline T: 毒性 & 与系统相关的 & 不同化学物质 & 和化学流程的毒 & 性 & \\
\hline A: 利益相关方 & 与系统有关的 & 社会伦理维度 & (包括社会、文 & 化、伦理等） & \\
\hline
\end{tabular}

\subsection{3 把生命周期方法扩展到系统中}

许多研究结论认为, 可持续设计要求把与各个设计阶段及设计环境有关的各种方法 结合起来, 包括针对系统中不同层面的各种各样生命周期评估（LCA）工具的结合

（赫（Hur）等, 2005；杰斯瓦尼（Jeswani）等，2010）。另外，目前的生命周期 评估（LCA）工具在解决系统中利益相关方的问题上作用有限, 因此, 应当加强跨行 
业之间的相互联系和互动（萨布鲁（Thabrew）等，2009）。前面提到的战略中有 两种方法可以拓展生命周期评估（LCA）的应用，而一些文献中也提到过这些：（杰 斯瓦尼（Jeswani）等，2010：120）：1）强化系统边界、配置方法、动态方面的 指导；2）把生命周期评估（LCA）的应用向社会经济方面和新的利益相关方拓展。

系统设计有利于生态效益, 并与生命周期设计 (LCD) 的基本标准一致（维 佐里 (Vezzoli) 和曼齐尼 (Manzini) 2008)。在产品服务系统 (PSS) 设计中, 利益相关方将参与到与系统相关的一系列产品和活动中。系统得到优化后, 可以创 造更多的服务, 并降低对环境的影响。生命周期评估（LCA）方法包含了功能单元 的理念: 环境影响评估主要针对的是那些描述活动（通常是产品或流程）的单元。 在产品服务系统 (PSS) 中, 环境影响评估通常把 “满意单元” 作为参考（例如： 解决饥饿问题的满意度）（维佐里（Vezzoli）2007[2010]：34）。系统的服务价 值以 “满意单元” 为衡量标准, 而其环境价值则要通过 “供应系统中产品和活动 在生命周期的各个阶段所产生的环境影响来衡量” (维佐里 (Vezzoli) 和曼齐尼

(Manzini) 2008: 259)。

产品服务系统（PSS）方法承认 “自然（环境）与生产和消费系统之间存在 物质交换, 并通过对环境进行输入和从环境中输出这两种形式 “对环境产生影响”

(维佐里 (Vezzoli) 2007[2010]: 17) 。实质上, 输入时应该考虑保护资源, 而输 出时应该做到防止污染（维佐里 (Vezzoli) 2007[2010]）。因此, 系统生命的优化 可以“超越单个的产品生命周期” 而覆盖 “相互联系的一系列产品和服务的生命周 期” （联合国环境规划署 (UNEP) 2002: 7) 。这种优化指的是系统部件和子部件 的优化、利益相关方互动的优化以及系统内部物流的优化, 但它与传统的生命周期 原理是一致的。

\section{3 理解产品服务系统 (PSS) 中的系统}

在本书定义的产品服务系统 (PSS) 设计过程- - 可持续系统设计方法 (MSDS) 中 ${ }^{3}$, 战略分析和机会探索阶段是通过大量的系统映射和在生产和消费链中连续的影 响评估实现的（维佐里 (Vezzoli) 2007[2010]）。可持续系统设计方法 (MSDS) 的基础是生命周期思想, 它通过与利益相关方的互动, 实现对系统的理解, 并参照 满意单元, 创造出优化服务（维佐里 (Vezzoli) 2007[2010]: 34)。因此, 我们必 须把产品服务系统 (PSS) 方案作为一个系统和一项服务来进行评估, 同时应该明 确定义评估的范围。

为了说明设计的系统及其内部的互动, 欧盟资助的MEPSS (参见脚注3))和 LeNS项目引入了一套工具，包括“互动事例版”、“提供物图表”、“利益相关 方系统图”和“可持续设计定向（SDO）工具包”等，来帮助评估系统对环境、 社会伦理、经济以及对技术和文化等方面的影响。这些工具在本书第一卷有详细

3 通过产品服务系统方法(MEPSS)项目开发了系统可持续设计的方法论(MSDS; 参见第1部 分, 第4章)（详情, 请参见案例：van Halen et al. 2005; Vezzoli 2007 [2010]）。 
解释 4 。本章探索的重点是利益相关方系统图和可持续设计定向 (SDO) 工具包。利 益相关方系统图中用指定的符号来解释并讨论各种系统之间的互动。可持续设计定 向（SDO）工具包则是一个影响评估工具, 人们可以对现有系统和尚在开发的系统 的优先顺序进行排列, 并对其进行比较。

\subsection{1 系统界限和利益相关方系统图开发工具}

在评估产品服务系统 (PSS) 的影响时, 一个关键性的问题是确定系统的界限。系 统视角要求不同领域及利益相关方, 包括 “环境、金融和社会系统”，在互动时最 少也要彼此 “接纳” 对方, 最好能达到互相 “理解” ( (Shedroff) 2009: 5)。可 持续系统设计方法 (MSDS) 认为设计概念有两个边界: 产品服务系统 (PSS) 的平 台边界和产品服务系统 (PSS) 的系统边界（维佐里 (Vezzoli) 2007[2010]）。平 台边界包括系统内的功能性服务, 针对的是可轻易识别的主要利益相关方。平台边 界包括 ( “系统生命周期” 所代表的) 次要利益相关方, 主要提供系统功能或者“ 作为分包商” (维佐里 (Vezzoli) 2007[2010]），因此，该系统包含了大量的“ 次要” 服务, 超出了系统边界。利益相关方系统图是产品服务系统 (PSS) 设计 中的迭代工具, 开始时很简单, 但是随着设计的展开逐渐变得越来越复杂（维佐里

(Vezzoli) 2007[2010]）。当对平台内各功能的影响进行评估时, 很多物流和服务 流都进一步延伸到了系统层面（包括部件生产商和分包商等利益相关方）。这些参 与者都应当包括到系统图中, 这样 “系统生命周期”（上游和下游）就能变得更加 完整（维佐里 (Vezzoli) 2007[2010]: 222; 见图20.2)。而系统图－般不考虑次要 利益相关方活动创造的物流及次要利益相关方活动之间的物流。

\section{图20.2 产品服务系统（PSS）利益相关方系统图的传统生产流程 (见第一卷, 4.3.6)}

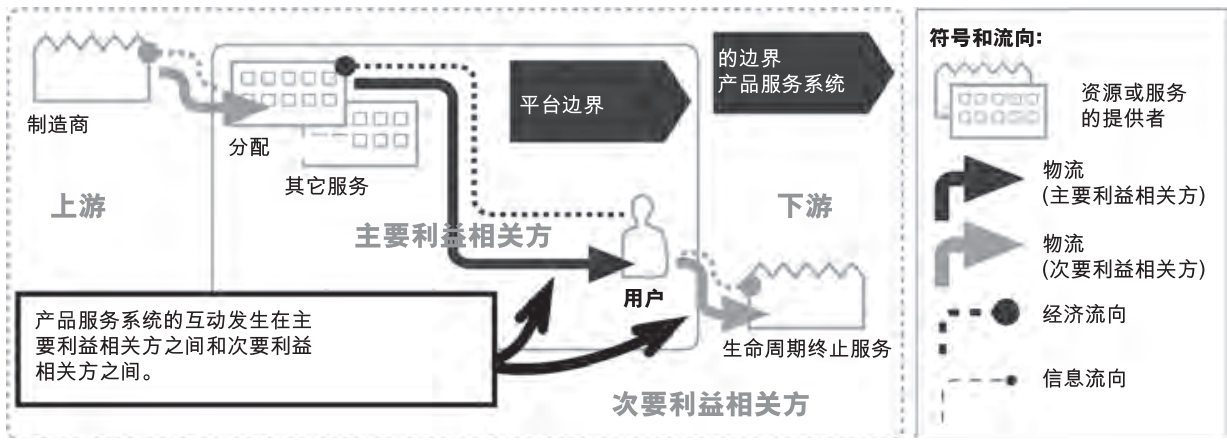

\subsection{2 可持续设计定向 (SDO) 工具包中的系统评估}

另一个产品服务系统 (PSS) 的设计工具一一可持续设计定向 (SDO) 工具包, 主 要是根据环境、社会伦理和经济维度等6项标准, 用于辅助战略分析, 确定在系统 
环境中各个阶段的系统维度和设计理念（维佐里（Vezzoli）2007[2010]）。可持续 设计定向 (SDO) 工具包将系统看作一个整体, 着重通过以上三种可持续维度进行 定性评估。该工具包有助于总结系统的潜在影响, 为几个重点领域提供设计指南。 可通过与六轴雷达图表中的现有概念进行比较, 对新概念进行测试（见本书第一卷 4.3.1)。

在可持续设计定向 (SDO) 工具包的环境标准及操作指南中都可以找到生命周 期方法, 但是这个工具不能用来评估系统部件和子部件在生命周期不同阶段所产生 的影响。系统生命要作为一个整体进行评估, 而不只是针对其部件在生命周期各个 阶段或各系统层面的参与者进行评估。虽然系统和与之相关的生产和运输均例入了 这一标准, 可持续设计定向 (SDO) 工具包并不会明确地评估次要利益相关方的活 动。这样就简化了过程, 并且就更容易将评估的重点集中在系统的核心功能及其相 关流程上。另一方面, 这也可能导致因忽视系统整体而产生巨大影响。

\subsection{LeNS项目学生设计竞赛中的生命周期}

为了掌握在实际产品服务系统 (PSS) 设计过程中, 尤其是在设计构思阶段, 如何解决生命周期问题, 我们在这里着重关注LeNS项目中学生创造出的一些概 念。LeNS项目学生设计竞赛 5 就提供了一系列很好的例子。竞赛要求参赛作品属于以 下三种类型之一：食品、交通以及医疗保健/福利项目。在注册课程中使用了可持续 系统设计方法 (MSDS) （当时为MEPSS），也或多或少用当地偏好的工具进行了 一些调整，而且该方法没有固定的流程。

分析并考察了许多参赛作品及其利益相关方系统图, 研究这些作品如何处理系 统内部生产所造成的影响。将学生的作品分成两组进行分析, 一组是比赛评委评出 的13份高分作品, 另一组则是13份随机选择的作品, 它们没有获奖或者没有获得首 肯6。将所有作品逐一进行总体分析之后, 才把获奖概念和未获奖概念分别列入到表 格中。此次评估没有参考实际竞赛评比过程中所给的分数, 只考察了生命周期方法 的使用情况。

5 LeNS学生设计大赛于2009-2010年举办, 接受来自LeNS项目的8个试点课程中包含可持续 产品服务系统设计概念的参赛作品, 以及来自全球设计学校的可持续产品服务系统课程的 参赛作品。（非LeNS教师必须注册竞赛中的课程）。在合作院校实施了8项试点课程, 他 们共享教材, 并展开跨文化教师交流项目。

6 LeNS学生设计大赛共设 20 个奖项: 分为一等奖、二等奖和三等奖, 10 个荣誉奖, 7 向 “ 最具前景” 概念奖。本书挑选了前13个奖项的获奖作品（三等奖以上和荣誉奖）作为案 例。13个案例是从这类获奖者中随机选取的, 并从评审的奖项中选取第三个案例。可以在大 赛网站上获取那些获奖的案例, 网址为: (http://emma.polimi.it/emma/events/lensconference/ images/LeNS_award-catalogue.pdf) 


\subsection{1 参赛作品的系统图如何处理系统生命周期问题?}

为了弄清系统图是如何解决具体的系统生命周期问题的, 我们分析了这些系统图。 为简单起见, 分析的重点是生命周期结束阶段。根据设计概念中系统流向的处理 方法和深度, 我们把系统影响（主要及次要影响）的评估进行了简单直观的评级

(从“-”到“++”)。

学生作品中所使用的系统图与他们处理具体产品所带来的影响的方法明显地不 一致。其中一份作品涉及了所有生产方面及相关生命周期结束时的问题, 但是没有 涉及运输方面。另一份作品提及了很多利益相关方, 但是没有涉及支持硬件或生产 方面的问题。多作品只涉及了与使用有关的生命周期终止阶段的问题（比例为 11/26） ，而几乎一半的作品都没有涉及生命周期终止阶段的问题（比例为 12/26）。

简而言之, 虽然这个分析停留在总体和定性分析的层面, 但它表明, 在这些新 兴的产品服务系统 (PSS) 概念中, 明显没有涉及到与整个系统相关的生产影响。 其中只有几份作品在系统图的使用阶段或使用活动之外涉及了生命周期终止的问 题。另外, 还有一些作品涉及从IT服务到包括太阳能电池板等在内的各种组件, 却没 有真正评估其生产所造成的影响。总之, 在如何理解并评估系统影响这个问题上, 似乎没有达成共识: 在上述产品服务系统 (PSS) 概念中, 通常只对核心功能进行 了评估, 而许多重要方面却被遗漏了。

系统生命优化与系统边界的界定有关。尽管它是生态高效的产品服务方案 (PSS) 设计的主要策略之一, 并且是制定可持续方案的一个主要因素, 但在概 念构思初期, 系统中能对环境产生影响的一些重要领域很容易被忽略。为了方便设 计师使用（包括从业者和设计专业学生），产品服务系统 (PSS) 方法更强调系 统次要部件的生命周期（即支持性设备及其生产）。换句话说，“利益相关方系统 图”这一工具不仅能把产品服务流程中的相互关系形象地展示出来, 而且它还有助 于突出系统次要部件的重要影响或其容易被忽略的生命周期影响。可持续设计定向

(SDO) 工具包还把不同部件的生命周期置于主要对象范围之外, 而不是注重一个 具体的产品服务系统 (PSS) 方案的总体状况。尽管对系统生命优化进行评估操作 起来很困难, 但还是该把它作为一个单独的概念进行评估。

\section{5 产品服务系统（PSS）方法的意义}

在对生产活动产生的影响进行确定之前, 应该进行细致科学的分析, 并且应使用生 命周期评估（LCA）等 “标准化方法”（涅米宁 (Nieminen) 2008：18）。产品 服务系统 (PSS) 的设计者确认生命周期评估 (LCA) 是评估环境影响 “最可靠的 方法”（维佐里 (Vezzoli) 2007[2010]），认为此方法有可能从所有的利益相关方 的角度出发, 提供关于环境影响的信息, 并提供 “改善环境状况的机会”（维佐里

(Vezzoli) 2007[2010]：59）。产品服务系统（PSS）设计过程如果能把生命周期 评估 (LCA) 作为核心, 那么就有助于更好地理解具体维度、系统边界和内部功能所 产生的影响。 
总之, 如果对影响评估的认识仅仅保持在系统生命层面, 而忽略了“后勤部 门”和服务供应商等组件的影响, 那么真正对环境造成影响的系统组件的问题将无 法得到解决。同时, 如果仅关注系统生命, 忽略其社会伦理影响, 简约式生命周期 评估 (SLCA) 方法在产品服务系统 (PSS) 设计中可能就不起作用。反之, 评估中 心产品的生命周期及关键利益相关方的互动的影响, 即便是在系统边界之外, 意义 也可能会更大。把整个系统融合到一个矩阵中可能不太容易实现, 但是可以把一个 系统分为很多个小的单元进行评估。

\subsection{1 在产品服务系统 (PSS) 设计中积极发挥生命周期方法 的作用}

虽然完整的生命周期评估（LCA）非常耗费时间和资源，但半定量的简约式生命 周期评估 (SLCA) 方法就比较节省时间。然而, 简约式生命周期评估 (SLCA) 方法有可能将有关系统的重要信息排除在默认的评估范围之外（霍克斯寇纳

(Hochschorner) 和福因维登 (Finnveden) 2003)。另一方面, 定性分析所产生 的问题是, 在比较不同方面的影响时缺乏定量数据（霍克斯寇纳 (Hochschorner) 和福因维登（Finnveden）2003）。因此, 所有的方法没有好坏之分（霍克斯寇纳

(Hochschorner) 和福因维登 (Finnveden) 2003; 另见赫 (Hur) 等, 2005; 杰斯瓦尼（Jeswani）等, 2010）。然而, 基于矩阵的定性简约式生命周期评估 （SLCA）方法简易、快捷, 受到大多数设计师的欢迎（奈米拉（Niemelä）2010）。

简约式生命周期评估 (SLCA) 矩阵工具适用于辨认系统的关键方面, 有助于 识别关键的利益相关方及其影响, 因为这些工具可以反复使用, 并能够关注系统的 各个部分。在有单一物流回路的简单的产品服务系统 (PSS) 图中, 重要的系统阶 段很容易被辨识出来, 方便后续评估（见图20.3）。在复杂系统中, 不同的互动仍旧 可以单独进行评估。因此, 定性的简约式生命周期评估 (SLCA) 矩阵工具可以整合 到产品服务系统 (PSS) 的设计过程中, 这样不仅能够辅助制作出对系统各部分影 响分析更为精确的系统图, 还能定位系统层面的发展区域。 
图20.3 产品（服务）系统中生命周期设计的不同目标区域：A）资源获 取；B）产品使用；C) 生命周期结束

来源：作者

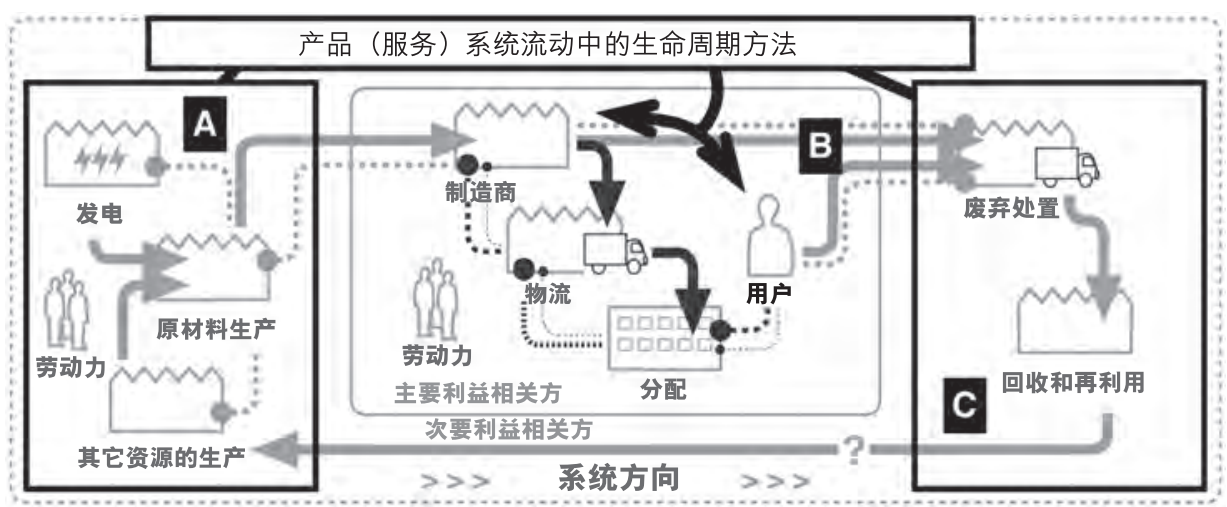

META矩阵工具是方便、快捷的简约式生命周期评估（SLCA）工具, 利用它, 可以轻松地将系统中的某些特定的子部件集中起来（见表20.1）。该工具和一份清 单分析表配套使用（奈米拉 (Niemelä) 2010：126），就这一点而言, 可持续设计 定向 (SDO) 工具包提供的清单与分析是相匹配的。在产品服务系统 (PSS) 设计 中, 利用META矩阵可识别系统及其部件中的问题所在。

\section{表20.1 在战略性系统分析阶段对比META矩阵和可持续设计定向 (SDO) 工具包}

\begin{tabular}{|c|c|c|}
\hline 标准 & META矩阵工具 & 可持续设计定向 (SDO) 工具包 \\
\hline 使用难易程度 & 简单 & 中等, 需要接受辅导 \\
\hline 持续时间 & 少于ー小时 & 数小时 \\
\hline 强调领域 & 强调使用时的资源效益 & 强调生产中的使用效果 \\
\hline $\begin{array}{l}\text { 如何管理系统? 如 } \\
\text { 何优化系统生命 } \\
\text { 周期? }\end{array}$ & $\begin{array}{l}\text { 对系统有一些定性的理解, } \\
\text { 但是在系统各部分必须重 } \\
\text { 复使用 }\end{array}$ & $\begin{array}{l}\text { 对系统的定性理解涉及生态、经济和社会 } \\
\text { 伦理维度, 但是只解决 “系统生命问题” } \\
\text { 而非分别检查系统各部分问题 }\end{array}$ \\
\hline
\end{tabular}

可以在设计产品服务系统 (PSS) 的初期阶段使用简约式生命周期评估 (LCA) 方法, 但是使用前需要先谨慎地进行计划和定位。如果在更为广阔的环境中 并且在系统边界扩大的情况下使用生命周期评估（LCA），META矩阵等定性的简约 式生命周期评估 (SLCA) 矩阵工具的时效性会更强, 其评估内容也更为广泛。由这 种工具支持的设计过程模型可用于可持续设计（Design for Sustainability (DfS) ) 和可持续产品服务系统 (PSS) 设计中, 以便：1）缩短战略分析时间；2）确定环 
境影响相对较大的系统领域及其在社会伦理方面的影响；3）更稳健地在产品服务系 统 (PSS) 设计初期运用时间和生命周期视角。

因此, 在产品服务系统 (PSS) 的设计过程中使用改进模型能够把META矩阵方 法融入到以下采样阶段:

1. 产品服务系统 (PSS) 概念及利益相关方系统的定义和构图, 还可能涉及一 些背景中的流程。

2. META矩阵评估把系统作为整体来研究, 同时也研究各子部分, 考量社会伦 理因素和利益相关方；继续使用可持续设计定向（SDO）工具包。

3. 概念搜索（倾向于）包括更为详细的可持续设计定向（SDO）工具包的 应用，甚至是在所选相关领域中使用更多的定量的简约式生命周期评估 (SLCA)

4. 用可视化的方式表现和传播概念（使用产品服务系统（PSS）工具等），并 最终进行实施。

在第1、2步的战略评估与分析之后, 传统上, 在设计过程中会继续采用产品服务系 统 (PSS) 方法或其它方法来对不同概念进行比较。其它的生命周期评估 (LCA) 方 法也可以用来支持产品服务系统 (PSS) 的设计, 因为这些方法有助于进一步评估 系统影响。例如, 一些半定量的简约式生命周期评估（SLCA）工具可以很容易地对 产品服务系统 (PSS) 中一些简单的材料或与能源相关的选择进行评估 ${ }^{77}$ 。

\subsection{2 迭代方法的例子}

为了说明迭代方法和所提及的过程模型, 我们基于LeNS竞赛的获奖作品设计了一个 例子。名为 “两代人烹饪俱乐部” 的这一创意是把当地有机农业与农民结合起来, 融入到在校园环境中的一个两代人烹饪服务系统中。除了在影响分析中所评估的食 品流向之外, 这一创意的中心是巧妙的厨房设计, 它是由外部供应商根据 “按次计 费” 的合同来提供服务。然而, 即使系统在可持续方面的改善看起来非常成功, 但 是制作效率、服务部件的使用等诸多问题仍有待解决（这些是系统的“外化”）。

表20.2展示的是构思阶段用META矩阵进行的一个模拟评估, 它反映了一些设计 选择的重要性。评估了两个主要的系统部件, 即支持性的“服务器具” 和“食品”。 此次模拟评估的目的不是为了更为全面地分析系统, 而是为了展示生命周期评估在 产品服务系统（PSS）设计过程初期所表现出的诸多作用（见表20.2）。

7 简单的评估方法参见：咨询机构 (PRé Consultants) 的生态指标99方法 (http://www.presustainability.com/download/manuals/El99_Manual.pdf). 


\section{表20.2 LeNS项目学生设计竞赛获奖创意“两代人烹纴俱乐部” 中的META矩 阵例子, 确定系统部件及其可能的影响}

\begin{tabular}{|c|c|c|c|c|c|}
\hline $\begin{array}{l}\text { 标准/生 } \\
\text { 命周期 }\end{array}$ & 物料生产 & 制造 & 使用 & 处置 & 运输 \\
\hline $\begin{array}{l}\mathrm{M}: \text { 物 } \\
\text { 料 }\end{array}$ & $\begin{array}{l}\text { 服务应用（厨房系 } \\
\text { 统）：金属、塑料 } \\
\text { 等、电力部件 } \\
\text { 食品：有机农业; } \\
\text { 连续....... }\end{array}$ & $\begin{array}{l}\text { 服务应用 } \\
\text { 模块性、高效 } \\
\text { 性、过程和 } \\
\text { 物料 } \\
\text { 食品: 有机农 } \\
\text { 业; 连续....... }\end{array}$ & $\begin{array}{l}\text { 服务应用 } \\
\text { 寿命、可用 } \\
\text { 性、维护 } \\
\text { 食品: 连 } \\
\text { 续....... }\end{array}$ & $\begin{array}{l}\text { 服务应用 } \\
\text { 可修复、可再次 } \\
\text { 使用、可循环 } \\
\text { 食品: 可循环、 } \\
\text { 可再次使用? 连 } \\
\text { 续....... }\end{array}$ & $\begin{array}{l}\text { 服务应用 } \\
\text { 制造、维护、 } \\
\text { 回收 } \\
\text { 食品: 连 } \\
\text { 续....... }\end{array}$ \\
\hline $\begin{array}{l}E: \text { 能 } \\
\text { 源 }\end{array}$ & $\begin{array}{l}\text { 服务应用 能源密 } \\
\text { 集型原材料生产? } \\
\text { 食品: } \\
\text { 使用水、电; 连 } \\
\text { 续...... }\end{array}$ & $\begin{array}{l}\text { 服务应用 } \\
\text { 能源密集型制 } \\
\text { 造? } \\
\text { 食品: 使用 } \\
\text { 水、电; 连 } \\
\text { 续....... }\end{array}$ & $\begin{array}{l}\text { 服务应用 } \\
\text { 使用和能源 } \\
\text { 高效 } \\
\text { 食品: } \\
\text { 不是问题? }\end{array}$ & $\begin{array}{l}\text { 服务应用 } \\
\text { 回收 } \\
\text { 食品: } \\
\text { 不是问题? }\end{array}$ & $\begin{array}{l}\text { 服务应用 } \\
\text { 不是问题? } \\
\text { 食品: 连 } \\
\text { 续....... }\end{array}$ \\
\hline $\begin{array}{l}\mathrm{T}: \text { 毒 } \\
\text { 性 }\end{array}$ & $\begin{array}{l}\text { 服务应用 } \\
\text { 可能有毒的物料? } \\
\text { 食品: } \\
\text { 有机农业; 不是 } \\
\text { 问题? }\end{array}$ & $\begin{array}{l}\text { 服务应用 } \\
\text { 可能有毒的流 } \\
\text { 程? } \\
\text { 食品: } \\
\text { 有机农业; 不 } \\
\text { 是问题? }\end{array}$ & $\begin{array}{l}\text { 服务应用 } \\
\text { 不是问题? } \\
\text { 食品: } \\
\text { 有机食物；不 } \\
\text { 是问题? }\end{array}$ & $\begin{array}{l}\text { 服务应用 } \\
\text { 可能有毒的部 } \\
\text { 件? } \\
\text { 食品: } \\
\text { 有机废物; 不是 } \\
\text { 问题? }\end{array}$ & $\begin{array}{l}\text { 服务应用 } \\
\text { 运输污染 } \\
\text { 食品: 运输 } \\
\text { 污染; 连 } \\
\text { 续....... }\end{array}$ \\
\hline $\begin{array}{l}\text { A: 利 } \\
\text { 益相关 } \\
\text { 方 }\end{array}$ & $\begin{array}{l}\text { 服务应用 } \\
\text { 原材料生产劳动力 } \\
\text { 食品: 当地农民; } \\
\text { 分包商 }\end{array}$ & $\begin{array}{l}\text { 服务应用 } \\
\text { 制造劳动力 } \\
\text { 食品: 当地 } \\
\text { 农民; 农场 } \\
\text { 劳力 }\end{array}$ & $\begin{array}{l}\text { 服务应用 } \\
\text { 学生和老人; } \\
\text { 服务及维护劳 } \\
\text { 动力 } \\
\text { 食品: 当地 } \\
\text { 农民和学生; } \\
\text { 服务劳动力 }\end{array}$ & $\begin{array}{l}\text { 服务应用 } \\
\text { 服务及维护劳 } \\
\text { 动力 } \\
\text { 食品: 服务劳 } \\
\text { 动力 }\end{array}$ & $\begin{array}{l}\text { 服务应用 } \\
\text { 服务劳动力 } \\
\text { 食品: 服务劳 } \\
\text { 动力 }\end{array}$ \\
\hline
\end{tabular}

表20.2中展示的便是这种练习，即便其实施的时间很短，但也是非常有益的， 因为它不仅可以对具体的设计进行指导, 还能够强调服务中的各种不同组成部分。 凭借这种简约式生命周期评估（SLCA），我们可以了解到, 系统影响的产生与那些 生命周期的开始和结束都在系统之外或在次要领域的组件息息相关; 同时还认识到 与这些设备相关的“按次计费”过程的重要性。这些要素应该与整体评估相结合, 以便对产品服务系统 (PSS) 的益处作出更为准确的估计。

这仅仅是一个例子，并不能将其应用到所有的产品服务系统 (PSS) 设计过程 中: 许多系统都由各种组件组成, 要对这些组件进行单独评估是一件非常费时费力 的事情。然而, 泛泛而言, 这种矩阵对产品服务系统 (PSS) 设计的 “模糊前端” 还是有所帮助的。而且, 在上述例子的实施阶段, 这种矩阵可以明确反映出潜在的 瓶颈: 就像协调农民、老人和学生等利益相关方之间的关系一样, 设计师必须对服 务供应商的采购流程保持高度关注（考虑到其回收策略）。 


\section{6 结论}

若要真正实现可持续发展, 产品服务系统（PSS）设计应该评估在生命周期各阶 段中各个系统部件产生的所有重要影响, 包括支持性技术及其影响。本章所提出的 可持续产品服务系统 (PSS) 设计过程和可持续设计 (DfS) 模型, 以及使用简单 的简约式生命周期评估（SLCA）工具（META矩阵工具），都是旨在把生命周期 设计 (LCD) 方法移植到产品服务系统 (PSS) 设计中, 同时也将产品服务系统 (PSS) 融入到生命周期设计 (LCD) 中。这一过程模型有助于确保在产品服务系 统 (PSS) 中环境收益不会受到其它方面的负面影响, 尤其是未来的环境不会受到 影响, 从而确保可持续的生态效益。

从可持续发展的角度出发, 设计师迫切地想创造出 “新事物” , 即便这些事物 并不比旧的好, 或是即便旧事物目前不需要被替换（谢德洛夫（Shedroff）2009）。 在营销方面, 不可否认, 新设备的未来愿景必然能够使一个概念变得更具吸引力。但 是, 在具有生态效益的产品服务系统 (PSS) 设计中, 就像学生的许多创意那样, 系 统方案的实际效能并不取决于新产品, 而是取决于使用新产品时所运用的新方法。毫 无疑问, 对过时的技术需要进行更新, 使其更加高效节能, 但是, 一个成功的产品服 务系统 (PSS) 必须接受对其系统部件的效益和影响的评估, 而这种评估必须详细而 具体, 目的是找出每个方案的环境损益平衡点。系统生命优化的要求, 则至少要对这 些因素进行粗略的评估。META矩阵等简约式生命周期评估 (SLCA) 工具可以使产 品服务系统 (PSS) 的设计过程前后连贯, 有助于评估产品服务系统 (PSS) 方案在 构思初期时的不同选择, 并有助于不断增强系统的可持续性。

\section{参考文献}

Brezet, H. and C. van Hemel (1997) Ecodesign: A Promising Approach to Sustainable Production and Consumption (Paris, FR: UNEP).

Commission of European Communities (CEC) (2001) Green Paper on Integrated Product Policy (Brussels, BE: CEC).

Hochschorner, E. and G. Finnveden (2003) 'Evaluation of two simplified Life Cycle assessment methods', The International Journal of Life Cycle Assessment 8(3): 119-128.

Hur, T., J. Lee, J. Ryu and E. Kwon (2005) 'Simplified LCA and matrix methods in identifying the environmental aspects of a product system', Journal of Environmental Management 75: 229-237.

ISO 14040 \& ISO 14044 (2006) 'Environmental Management - Life Cycle Assessment - Principles and framework' (Geneva, $\mathrm{CH}$ : International Organization for Standardization).

Jeswani, H.K., A. Azapagic, P. Schepelmann and M. Ritthoff (2010) 'Options for broadening and deepening the LCA approaches', Journal of Cleaner Production (2): 120-127.

Knight, P. and J.O. Jenkins (2009) 'Adopting and applying eco-design techniques: a practitioners' perspective', Journal of Cleaner Production (5): 549-558.

Lewis, H. and J. Gertsakis (2001) Design + Environment (Sheffield, UK: Greenleaf Publishing).

Marttila, T. (2010) 'Creating Better Tools for Sustainable Product Design: Product-Service Systems and Their Relation to Life Cycle Thinking', in 4S Summer Symposium for Sustainable Solutions, Aalto University, 15-17 June 2010, Sannäs, Finland. 


\section{4 可持续产品服务系统设计}

Matthews, S. and M. Small (2000) 'Extending the Boundaries of Life-Cycle Assessment through Environmental Economic Input-Output Models', Journal of Industrial Ecology 4(3): 7-10.

Niemelä, M. (2010) Kestävää muotoilua mallintamassa (Jyväskylä, Fl: Bookwell).

Nieminen, E. (2008) Creative Sustainability (Helsinki, FI: Designium).

Shedroff, N. (2009) Design is the Problem: the Future of Design must be Sustainable (New York, US: Rosenfeld Media).

Thabrew, L., A. Wiek and R. Ries (2009) 'Environmental decision making in multi-stakeholder contexts: applicability of life cycle thinking in development planning and implementation', Journal of Cleaner Production 17(1): 67-76.

UNEP (United Nations Environment Programme) (2002) Product-service systems and sustainability: Opportunities for sustainable solutions (Paris, FR: UNEP).

UNEP (2009) Guidelines for Social Life Cycle Assessment of Products (Paris, FR: UNEP).

van Halen, C., C. Vezzoli and R. Wimmer (eds.) (2005) Methodology for Product Service System. How to develop clean, clever and competitive strategies in companies (Assen, NL: Van Gorcum).

Vezzoli, C. (2007; 2nd edition in 2010) System Design for Sustainability (Milan, IT: Maggioli Editore).

Vezzoli, C. and E. Manzini (2008) Design for Environmental Sustainability (London, UK: Springer). 


\section{术语对照表}

\begin{tabular}{ll} 
阿里森・库德拉 & Allison Kudla \\
阿玛蒂亚・森 & Amartya Sen \\
阿南德 & Anand \\
阿帕杜莱 & Appadurai \\
阿图罗•德拉奎伊•拜拉维提斯 & Arturo Dell' acqua Bellavitis \\
阿伊莎・亚伯拉罕 & Ayisha Abraham \\
埃格纳多・多斯・桑托斯 & Aguinaldo dos Santos \\
埃伦费尔德 & Ehrenfeld \\
埃文斯 & Evans \\
艾迪欧公司 & IDEO \\
艾格尼丝 & Egneus \\
艾莉森・伯恩 & Alison Byrnes \\
艾利亚斯・柯乃提 & Elias Canetti \\
艾瑞 & Aiyar \\
安德里亚・门多萨 & Andrea Mendoza \\
安德鲁 & Andrew \\
安德森 & Andersen \\
安奎科 & Akrich \\
安穆利特•斯里尼瓦桑 & Amrit Srinivasan \\
安娜・宝拉・阿尔贝 & Ana Paula Albé \\
安娜・福克斯 & Anna Fox \\
奥比特格力 & Orbetegli \\
奥夫伊斯 & Ophuis \\
奥克山里诺村 & Koak Chareon \\
奥利弗 & Oliver \\
奥马利 & O'Malley \\
奥斯特罗姆 & Ostrom \\
巴顿・帕沃 & Baden-Powell \\
\hline
\end{tabular}


巴克斯特

巴塔哥尼亚地区内乌肯省

“巴挑水稻回家”

柏迪科

柏拉图的《泰拉泰德篇》

班加罗尔

班加罗尔的自豪

班克勒

班纳吉

邦德瑞福

保罗・伊利克

鲍尔斯

鲍维

贝恩斯

贝尔

本地人的角度

本土社区

比玛

比斯

彼得・莱恩勃

边沁

波

波尔

波尔克

波克浩特

波特

波伊尔

伯恩斯

伯纳德

伯南特

勃利诗

勃兹

布迪尼克

布拉迪

布莱恩・Y・H・李

布莱恩・李

布劳恩加特

布鲁斯・阿彻

布瑞吉特

布云

残疾人企业发展研讨会

曹明
Baxter

Patagonian province of Neuquén

Pathiu rice returns home

Burdick

Theaetetus

Bangalore

Bengaluru Pride

Benkler

Banerjee

T.M. Bondaref

Paul Ehrlich

Bowles

Power

Baines

Bell

the native point of view

local communities

Bijma

Buijs

Peter Linebaugh

Bentham

Pol

Pohl

Belk

Berkhout

Porter

Boyle

Burns

Bernard

Behrendt

Paulitsch

Bolz

Budinich

Brady

Brian Y.H. Lee

Brian Lee

Braungart

Bruce Archer

Brezet

Bruun

DWDE: Disability Workshop

Enterprise Development

Ming Cao 
查卡拉皮派特•阿苏瓦伯恩雅勒特

查克梅因

查理

查理德・道金斯

查普曼

查特

产品服务系统

产品服务系统的方法

产品可持续设计

产品生命周期设计

产品组合计划与跟踪

城市 Spinning

城市固体垃圾

充足经济

充足经济理论

充足经济设计

创新性可持续发展学

“创造性可持续发展”项目

创造性团队合作

春蓬卡巴那酒店

慈善经济

CCSL项目：可持续生活方式创新社区

$\mathrm{C} \cdot \mathrm{W} \bullet$ 莱德彼特

达利特人

大卫・凯里

大洋

代工生产

戴尔

戴斯潘德

唐纳德・诺曼

丹妮拉・桑吉欧尔盖

当地情境

当地一家致力于可持续交通项目宣传

推广的组织

德国赫斯自然公司

德拉特

德雷顿
Chakrapipat Assawaboonyalert

Chikermane

Charlie

Richard Dawkins

Chapman

Charter

Product-Service System (PSS)

Method for Product-Service System

(MEPSS)

product design for sustainability

(PDfS)

product Life Cycle Design

PPP\&T

City Spinning

MSW: municipal solid waste

Sufficiency Economy approaches

Sufficiency Economy Philosophy (SEP)

Design for Sufficiency Economy

(DSEP)

Creative Sustainability (CS)

Creative Sustainability(CS)

Creative Teamwork

Chumphon Cabana Resort

the grant economy

CCSL project: The Creative

Communities for Sustainable

Lifestyles

C.W. Leadbeater

Dalits

David Kelly

The great ocean

Original Equipment Manufacturing

Dyer

Deshpande

Don Norman

Daniela Sangiorgi

local context

BEN Bikes

the German company Hess Natur

De Laat

Drayton 
德里市政公司

德里印度理工学院

德意志制造同盟

低碳设计

狄思库

迪帕・萨迪斯

迪帕克・斯里尼瓦桑

迪斯普瑞斯

蒂姆・布朗

蒂娜・拉瑞拉

蒂什纳

侗锦

侗族文化圣地

杜德斯达

杜瑞格・凯斯肯

杜威

多斯特

二氧六环

ECOLS环保概念店

法布里齐奥・山士恩

法尔克

凡斯敦

范・德・波罗

范・德・克雷霍夫

范・德・拉克

范・德・文

范・登・波什

范・内斯

范伦特

非物质文化遗产

非政府组织

吠舍

分布式经济

芬兰阿尔托大学艺术、设计与建筑学院设计系

芬兰赫尔辛基阿尔托大学

芬兰科学院

芬兰莫鲁公司

冯・吉兹

冯・希佩尔

弗莱
MCD: Municipal Corporation of

Delhi's

IIT Delhi

Deutsche Werkbund

"low-carbon" design

Diskul

Deepta Sateesh

Deepak Srinivasan

Després

Tim Brown

Tiina Laurila

Tischner

Dongjin

Holy Land of the Dong culture

Duderstadt

Duygu Keskin

Dewey

Dorst

TCDD

ECOLS

Fabrizio Ceschin

Falk

Vanstone

Van de Poel

Van de Kerkhof

Van der Laak

Van de Ven

Van den Bosch

Van Nes

Van Lente

non-material cultural heritage

NGOs

Vaishya (agriculturists and traders)

Distributed Economies (DE)

Aalto University School of

Arts, Design and Architecture,

Department of Design, Finland

Aalto University, Helsinki, Finland

The Academy of Finland

the company Muru in Finland

von Ghyczy

von Hippel

Fry 
弗莱彻

弗兰奎利拉

弗兰奇

弗朗西斯卡・彼瑞达

弗朗西斯卡・弗欧凯

弗朗西斯卡・沃赛凯

弗罗利基

福德・路克

福因维登

伽万利

“改造木制手推车”项目

甘地

歌德库

格莱珉银行

格兰诺维特

格雷

格雷格森

格鲁德

格鲁佛

格沃斯

$\mathrm{J} \bullet \mathrm{C} \bullet$ 迪尔

$\mathrm{J} \bullet$ 克里希那穆提

隔壁蔬菜

工业部

“工作单位”体制

公共教学

公司可持续性

“公共场所和教学法” 项目

“公共环境中的恐惧与性别” 项目

“公平原则”

宫崎

巩水栤森

共同种植

固体垃圾管理机制

瓜达奴齐

国际工业环境经济学院

国际工业设计协会联合会

国际劳工组织

国际设计企业管理
Fletcher

Franqueira

Franke

Francesca Piredda

Francesca Fiocchi

Francesca Valsecchi

Forlizzi

Fuad-Luke

Finnveden

Gavelli

Transforming wooden cart

Gandhi

Goedkoop

Grameen Bank

Granovetter

Gray

Gregersen

Garud

Grover

Govers

J.C. Diehl

J.Krishnamurthy

Next-Door Veges

Ministry of Industry

"Work unit" system

public pedagogy

Corporate Sustainability

Public Space and Pedagogy (PSP)

Fear and Gender in Public Spaces equity principle

Miyazaki

Miaosen Gong

Co-planting

SWM: solid waste management

Guadagnucci

International Institute for Industrial

Environmental Economics (IIIEE)

International Council of Societies of Industrial Design (ICSID)

ILO: International Labor

Organization

International Design Business

Management (IDBM) 


\section{国家城市事务研究所}

国家创新体系

国家经济与社会发展委员会

国家企业调整运动

国家设计学院
哈卡萨尔米
哈凯奈
哈克
哈森・因多维拉
哈特
哈兹拉
海尔曼
海法
海格
海伦娜・许沃宁
海思凯恩
海希
海泽・居米什
罕・布力扎特
豪伯斯
郝奇亚
郝瑟
合作协会
荷兰代尔夫特理工大学工业设计学院

赫尔辛基艺术和设计大学

赫斯・黑顿
赫特维克
亨德森
亨利・吉鲁
亨利・吉鲁斯・布拉迪
胡戈玛
湖南大学
“怀孕母亲交流平台”
怀特
环境设计
环境行动计划
换装项目

NIUA: National Institute of Urban

Affairs

the national innovation system the National Economic and Social Development Board (NESDB) MNER: National Movement of Recuperated Enterprises National Institute of Design (NID) Härkäsalmi Hukkinen Hacker Hussain Indorewala Hart

Hazra

Hellman

Haifa

Hegger

Helena Hyvönen

Heiskanen

Hassi

Hazal Gumus

Han Brezet

Hobbes

Halkier

Hauser

Collaborative associations

Delft University of Technology,

Faculty of Industrial Design

Engineering, the Netherlands

University of Art and Design

Helsinki

Hirsch Hadorn

Hertwich

Henderson

Henry Giroux

Henry Giroux Brady

Hoogma

HNU: Hunan University

Mom's Talk

White

Design for the Environment(DfE)

Environmental Action Programme

Nayi Dastaan 
复合型人才

霍尔

霍弗

霍格

霍克茨

霍克斯寇纳

霍瓦斯

基诺斯纳•白利阿帕

吉尔

吉尔摩

吉尔斯

吉昆

吉姆

吉萨・纳拉亚南

吉谭雅力・萨克戴夫

吉耶•阿雷利

季铁

加罗威

嘉利特・哈汀

贾思曼・帕特加

贾汀・韦德亚蒂

贾瓦拉哈尔・尼赫鲁

简化的生命周期评估

建构性学习

交际合理性

教育部人文社会科学研究

“街道居委会” 体制

杰克・戴欧夫

杰斯勒夫

金吉尔

金提斯

金字塔基础(BoP)

经验美学

居民福利协会

具有生态效益的产品服务系统设计

聚丙烯腈

聚对苯二甲酸类塑料

聚氯乙烯

决策原则 hybrid expert

Hall

Hofer

Hoegl

Hockerts

Hochschorner

Horvath

Jyothsna Belliappa

Gill

Gilmore

Geels

Jikun

Kim

Geetha Narayanan

Geetanjali Sachdev

Geyer-Allely

Tie Ji

Galloway

Garrett Hardin

Jasmeen Patheja

Jatin Vidyarthi

Nehruvian

Simplified Life Cycle Assessment

(SLCA)

constructivist learning

communicative rationality

Education Ministry Humanity and

Social Science Research

"street residence" system

Jacques Diouf

Hjelmslev

Zingale

Gintis

Base of the Pyramid (BoP)

Aesthetics of Experience

RWAs: Resident Welfare

Associations

design for eco-efficient Product-

Service Systems

PAN

PET:polyethylene terephthalate

PVC

Decision-in-Principle 


\author{
“均衡” 项目 \\ 卡尔松 \\ 卡鲁 \\ 卡罗琳・H・拉森 \\ 卡洛・温邹丽 \\ 开普半岛科技大学
}

凯瑟

凯文・麦克莱

坎达查

康博斯

康德的《判断力批判》

康尼亚托

“抗议美学” 项目

考特姆

柯尔本

柯林科

科菲・安南

科利纳

科斯特

可持续产品服务系统

可持续产品设计

可持续发展教育

可持续发展战略

可持续家庭战略

可持续美学

可持续民生发展项目

可持续日常项目

可持续设计

可持续设计定向

可持续舞蹈俱乐部

可持续系统创新

可持续系统设计方法

\section{可持续系统设计方法论}

可持续消费部门（联合国设立的一个部门）
Equilibrium

Karlsson

Carew

Karoline $\mathrm{H} \bullet$ Larsen

Carlo Vezzoli

CPUT: Cape Peninsula University

of Technology

Kaiser

Kevin McCullagh

Kandachar

Combs

Critique of Judgment

Carniatto

Aesthetics of Protest

Cottam

Kilbourne

Klinker

Kofi Annan

Collina

Castells

Sustainable Product-Service

Systems (SPSS)

Sustainable Product Design (SPD)

Education for Sustainable

Development (ESD)

Sustainable Development Strategy (SDS)

SusHouse: Strategies towards the Sustainable Household

the aesthetics of sustainability

Sustainable Alternative Livelihood

Development(SALD)

Sustainable Everyday Project

design for sustainability (DfS)

SDO

SDC: Sustainable Dance Club

Sustainable System Innovation

Methodology for System Design for

Sustainability(MSDS)

MSDS: Methodology for System

Design for Sustainability

Sustainable Consumption Unit 
可持续消费与生产

可持续学习网络

克拉克

克拉默

克莱恩

克莱克斯顿

克莱默

克朗克伍

克劳斯

克雷兹曼

克里安

克里斯滕森

克鲁

克鲁鲍特金

课程编制

肯普

寇恩宁斯

库普

快乐星球指数

快乐种植

“筷子项目”

垃圾回收点

垃圾金字塔

拉德哈・昌德拉谢克哈兰

拉迪卡・罗翰

拉尔

拉杰什・卡斯图里兰根博士

拉劳德

拉梅什・卡尔库

拉纳

拉塔・玛尼博士

拉托尔

拉瓦德山

拉佐特

莱恩

莱克伯格-浩顿

莱普克

莱斯勒

莱维斯卡

莱文德恩・古他

莱文卓・古塔
Sustainable Consumption and

Production (SCP)

the Learning Network on

Sustainability (LeNS)

Clark

Kramer

Klein

Claxton

Cramer

Krongkaew

Krause

Kretzmann

Keoleian

Christensen

Clune

Peter Kropotkin

curricula development

Kemp

Koenigs

Cooper

Happy Planet Index

Happy Planting

Chopsticks Project

dhalao

the waste pyramid

Radha Chandrashekharan

Radhika Ralhan

Lall

Dr Rajesh Kasturirangan

Laredo

Ramesh Kalkur

Rana

Dr Lata Mani

Latour

Lavender Hill

Razeto

Ryan

Rochberg-Halton

Røpke

Roschelle

Leiviskä

Ravindra Gutta

Ravindra Gutta 
兰德里

劳瑞恩佐・达沃利

雷波特

类似于转化知识

李军

里德霍姆

里恩

里夫金

理查德・步凯纳

理查德・韦德伯格

理科硕士

利乐

利兹・科内克

联合国大会

联合国环境规划署

联合国环境与发展大会

联合国环境与发展委员会

联合国教科文组织

联合国经济社会事务部

联合国可持续发展会议

联合国粮食与农业组织

联合国人口活动基金会

联合国人类居住中心

联合国世界粮食计划署

“联合国可持续发展十年教育”计划（DESD）

脸谱网

LeNS项目团队

梁

梁町

“良心消费者”运动
Landry

Lorenzo Davoli

Rayport

transformation knowledge

Jun Li

Leidholm

Lynn

Rifkin

Richard Buchanan

Richard Widerberg

MSc

Tetra Pak

Liz Kueneke

United Nations General Assembly

(UNGA)

United Nations Environment

Programme (UNEP)

United Nations Conference on

Environment and Development

(UNCED)

UN World Commission on

Environment and Development

UNESCO

United Nations Department for

Economic and Social Affairs (UN

DESA)

UN Commission on Sustainable

Development

UN's Food and Agriculture

Organisation (FAO)

United Nations Population Fund

(UNFPA)

UNCHS

United Nations World Food

Programme (WFP)

United Nations Decade of

Education for Sustainable

Development (DESD)

Facebook

LeNS project team

Leong

Benny Ding Leong

conscience consumer 
列夫•托尔斯泰

邻里组织

邻里组织

林

林赫斯特

临床研究

铃木

“零公里食品” 项目

刘新

流动的现代性

卢措普

卢森伯格

路易斯

罗宾•默里

罗基

罗斯波罗

罗特曼斯

罗伊•阿斯科特

“旅行足迹”

麻吉

麻省理工学院

马埃斯

马德哈夫贾・加吉尔

马尔多纳多

马克斯

马莱娜・肖沫

马林达・帕特尔

马林达・帕特尔

“马拉利库兰实验”

马苏坦瑟・提那利

马修斯

马宗达

玛尔萨斯

玛高琳

玛丽・齐格纳

玛丽安娜・辛希亚

玛丽克拉克

玛丽莎・盖勒帕蒂

玛莎•努斯鲍姆

玛诗安妮

迈耶

麦格
Leo Tolstoy

NHGs: Neighbourhood Groups

NHGs: Neighbourhood Groups

Lin

Lindhqvist

clinical research

Suzuki

zero-mile food

Liu Xin

liquid modernity

Luttrop

Roozenburg

Lewis

Robin Murray

Rocchi

Roseboro

Rotmans

Roy Ascott

Footprints

Mugge

MIT: Massachusetts Institute of Technology

Maase

Madhav Gadgil

Maldonado

Marks

Marlene Schommer

Mahindra Patel

Mahindra Patel

Mararikulam experiment

Musstanser Tinauli

Matthews

Majumdar

Malthus

Margolin

Marie Trigona

Mariana Ciancia

Mary Clark

Marisa Galbiati

Martha Nussbaum

Marsciani

Meier

Mager 


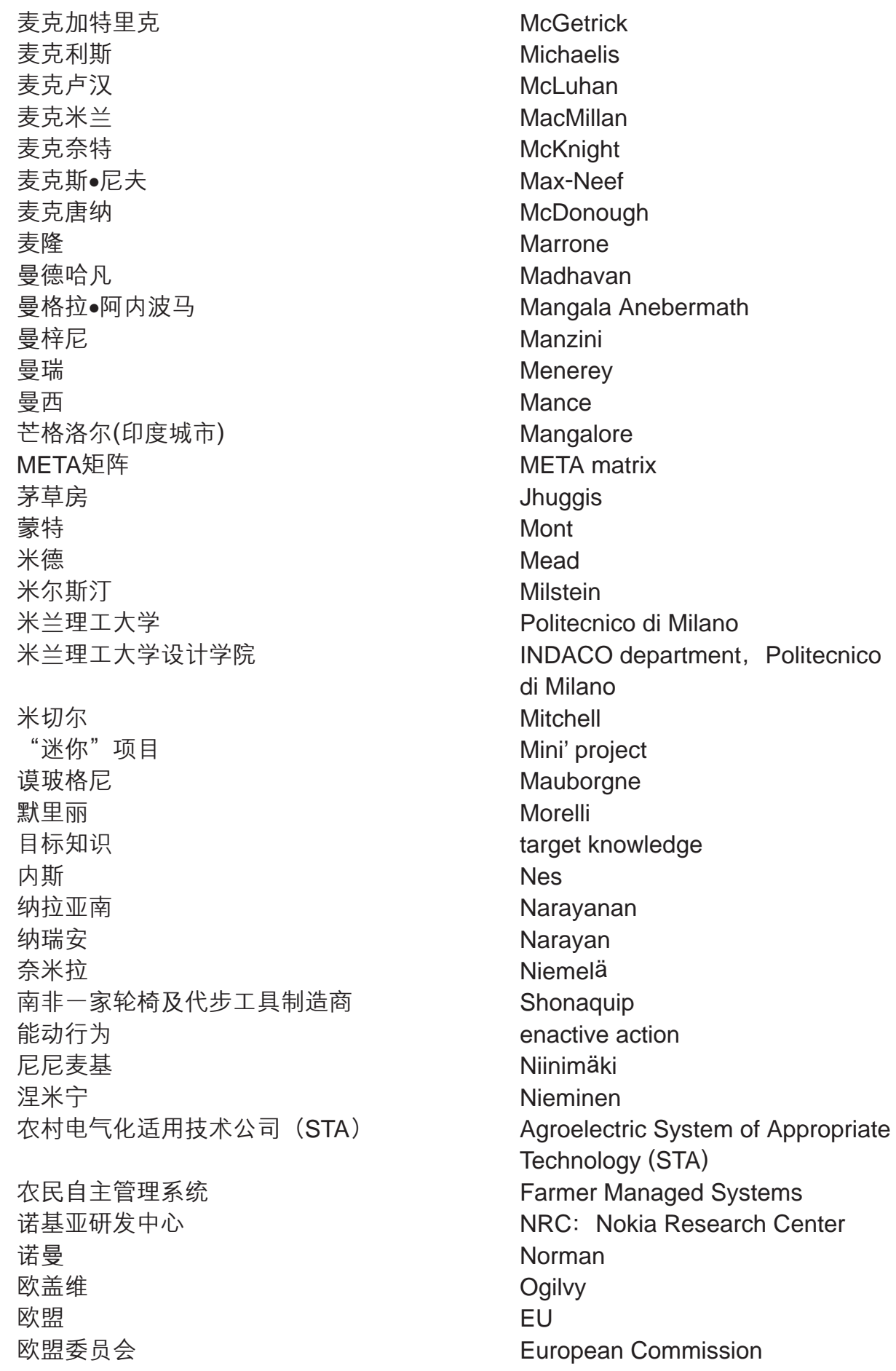


欧斯汀

欧文・拉斯洛

欧洲协调委员会

欧洲援助

帕波提

帕凡・瓦尔玛

帕帕内克

帕瑞恩纽治・安・斯瑞迪治

帕特里克・派瑞斯

帕温・普努

帕亚雷斯

派恩

派瑞斯

培根的作品《古人的智慧・普罗米修斯》

佩卡・萨莱拉

佩宁

“烹饪吧”

皮波斯拉威优特

拼车服务网络平台

拼车

平行劳动力

评估小组

婆罗门

普华永道

普莱拉斯・埃比纳夫

普莱皮斯

普瑞赛德

普温・鲁杰基埃克姆顿

齐尔希・尼恩伊玛姬

奇亚拉

企业社会责任

汽车设计峰会

千年发展目标

茜茜・韦斯特伯格

乔威特

清洁生产

“青年一代的交流”

丘吉尔
Alstyne

Ervin Laszlo

Co-ordinating European Council

(CEC)

Europe-Aid

Parboteeah

Pavan Varma

Papanek

Praoranuj Ann Siridej

Patrick Parrish

Parveen Pannu

Pajares

Pine

Peirce

Prometheus (Of the Wisdom of the Ancients)

Pekka Saarela

Penin

COOK-BAR

Piboolsravut

EASY-RIDE

PINCHE/Pinker (Chinese

Carpooling)

parallel workforce

Evaluation Panel

Brahman (teachers, scholars,

priests)

Pricewaterhouse Coopers

Prayas Abhinav

Plepys

Prasad

Pwinn Rujikietkhumjron

Kirsi Niinimäki

Chiara

corporate social responsibility (CSR)

Vehicle Design Summit

the Millennium Development Goals

Sissi Westerberg

Jowit

cleaner production

Young Generation Contact

Churchill 
人本设计精神

人类发展终生成就奖

人在林在

认识论信念

认知合理性

日本天神节纤维有限公司

瑞典攀山鼠服装公司

瑞尼・威维

瑞普

瑞文

萨布鲁

萨拉斯沃齐

萨利欧・赛伊德

萨姆尔・赫斯

萨姆皮特・莫伊・福萨克勒

萨希拉坦

萨因

桑德斯

桑塔留斯

森

森古达

沙克斯

沙玛

刹帝利

山士恩

设计思维

社会学习

社会创新与可持续设计

社会实践理论

社会影响分析

社区厨房

社区发展计划

社区研究与信息服务开发

社区支持农业

深水涉区（香港地名）

生命周期评估

生命周期设计

生态旅游 human-centered ethos

Human Development Lifetime

Achievement Award

People live, forest alive

epistemological belief

cognitive rationality

Japanese Tenjin Fibers Ltd.

the Swedish company Klättermusen

Renee Wever

Rip

Raven

Thabrew

Sarasvathy

Salil Sayed

Samuel Hess

Sompit Moi Fusakul

Sathirathai

Sarin

Sanders

Santarius

Sen

Sengupta

Sachs

Sharma

Kshatriya (warriors)

Ceschin

design thinking

social learning

DESIS: Design for Social Innovation and Sustainability

social praxeology

social impact analysis (SIA)

langar

Community Development Plan

Community Research \&

Development Information Service (CORDIS)

CSA: Community-Supported

Agriculture

Sham Shui Po

Life Cycle Assessment (LCA)

Life Cycle Design(LCD)

eco-tourism 
生态效益

“生活像素” 项目 盛杰（克雷格）

诗非斯坦

施恩

施容

时间银行

实践

世界自然保护联盟

事理学

首陀罗

舒茨

舒特

斯班诺斯

斯凡斯壮

斯考兹

斯科曼斯

斯雷

斯隆-赫斯特

斯芒齐

斯姆里提・梅拉

斯诺

斯塔

斯塔普斯

斯坦赫

斯坦尼齐普

斯涛克

斯托顿

斯瓦代希

斯旺

苏米特里

SDO工具包

孙

孙达尔・萨鲁开博士

塔哈勒

塔克

塔图・马蒂拉

泰国邦乍石油公司

泰国东芝

泰国国王普密蓬•阿杜德

泰国皇太后基金会 eco-efficiency

Living Pixels

Jie (Greg) Sheng

Schifferstein

Shin

Schön

time banks

Effectuation

the World Conservation Union

(IUCN)

Matterology

Shudra

Schultz

Schot

Spannos

Svanström

Scholz

Schoormans

Slay

Throne-Holst

Thomke

Smriti Mehra

Snel

Stø

Stappers

Stahel

Steinhilper

Stalker

Stoughton

Swadeshi

Swan

Soumitri

Sustainability Design-Orienting

toolkit (SDO)

Sun

Dr Sundar Sarrukai

Tahara

Tukker

Tatu Marttila

Bangchak Petroleum

Toshiba Thailand

King Bhumibol Adulyadej

Mae Fah Luang Foundation (MFLF) 
泰国黎敦山区扶贫开发计划

泰国美巴侬牌调味品公司

泰国农业大学

泰国庞达珠宝

泰国王室财产局

泰国先皇技术学院建筑学院设计系

泰国朱拉隆功大学萨辛商学院

泰温玛

特雷普

提斯里

提苏拉诺达

填饱肚子(印度语)

童瓦兰海滩

团购

托莱斯查普

托马斯・赫胥黎

瓦拉达拉雅

瓦雷拉

瓦伦丁

万姆旺村

王夫之的《张子正蒙注・太和篇》

\section{王伟}

网络社会

威翰尼

威亨

威丝曼

威佐克

韦伯

维戴尔

维尔

维尔库基

维格雷特

维卡塔拉曼

维克多・帕帕内克

维拉・曼德

维拉妮卡・维曼
Doi Tung Development Project

(DTDP)

Phiboonchai Mae Pranom

Kasetsart University

Pranda Jewelry

Crown Property Bureau(CPB)

King Mongkut's Institute of

Technology Ladkrabang, Faculty of

Architecture, Department of Design,

Thailand

Sasin Graduate Institute of

Business Administration of

Chulalongkorn University

Talvenmaa

Trijp

Teasley

Tinsulanonda

Pett Puja

Thung Wua Laen Beach

Group Purchase

Tollestrup

Thomas Huxley

Varadarajan

Varela

Valentine

Ban Moung Wan

Zhang-zi's Correct Discipline for

Youth•Taihe

Wei Wang

network society

Werhane

Werhane

Wiesmann

Wieczorek

Weber

Vidal

Ville

Verkuijl

Vergragt

Venkataraman

Victor Papanek

Vera Maeder

Veronica Wiman 
维默尔

维纳亚克・达斯

未来城市

魏德玛

温浩

沃尔

沃斯特

无老板工厂运作模式

“污染者付费”原则

西恩

西格拉斯

西克森特麦哈伊埃

希尔博尔赞

希迈尔

希斯

洗衣吧

洗衣工和慰衣工

系统美学

系统知识

暹罗水泥集团

乡村快速评估

香港妇女劳工协会

香港理工大学设计学院亚洲生活

风尚设计研究实验室

\author{
肖勒 \\ 谢温 \\ 心理淘汰 \\ 辛迪・科塔拉 \\ 新产品开发 \\ “新通道设计与社会创新”项目 \\ 信息时代 \\ 信息通信技术 \\ 形式问题 \\ 修普瑞兰特 \\ 需求驱动的死胡同 \\ 悬浮微粒物质 \\ 荀子的《天论》 \\ “寻找新鲜食品”
}

Wimmer

Vinayak Das

cities of the future

Weidema

Winhall

Wahl

Worster

FASINPAT: (FASINPAT: Factory

Without a Boss)

Polluter Pays Principle

Sian

Segalàs

Csikszentmihalyi

Silberzahn

Hemel

His

Wash bar

presswallas

system aesthetic

systems knowledge

Siam Cement Group

participatory rural rapid appraisal

(PRA)

HKWWA

Asian Lifestyle Design Research

Lab, School of Design, Hong Kong

Polytechnic University

Scholl

Sherwin

psychological obsolescence

Cindy Kohtala

(NPD) New Product Development

"New Channel Design \& Social

Innovation"

the information age

ICT

Matters of Form

Surprenant

the needs-driven dead end

Suspended Particulate Matter (SPM)

Tian Lun

Finding the Fresh 
雅克伯森

亚当・斯密

亚里士多德的《政治学》

亚历克斯

亚洲连接项目

杨秋月

杨氏基金会

耶由

伊尔斯・欧斯特拉肯

伊克斯

伊丽娜・玛利亚・苏图

伊曼努尔・康德

遗产传递型

以资本为本的社区发展模式

艺术、设计与建筑学院

意大利米兰理工大学设计学院设计系

印度班加罗尔斯瑞施蒂（Srishti）艺术、 设计与科技学院

印度德里大学家政学院

印度德里的贾玛清真寺

印度德里非政府组织蔡坦

印度德里理工学院

印度国立设计学院

印度理工学院

印度斯瑞施蒂（Srishti）艺术设计与技术学院

印度污染控制中心

印度新德里, 印度技术研究所

工业研究与发展院（IRD）

印度政府

（印度）定期上门收购垃圾者
Jakobson

Adam Smith

Politics

Alexis

Asia-Link Programme

Qiuyue Yang

Young Foundation

Jégou

Ilse Oosterlaken

Eekels

Irina Maria Suteu

Immanuel Kant

legacy transmission model

Asset-Based Community

Development

School of Arts, Design and

Architecture

Politecnico di Milano, Design

Department, School of Design, Italy

Srishti School of Art, Design \&

Technology

Institute of Home

Economics, University of

Delhi, India

Jama Masijid

Chintan

Indian Institute of Technology Delhi, India

NID: National Institute of Design Indian Institute of Technology

Srishti School of Art, Design and

Technology, India

IPCA: Indian Pollution Control

Association

Industrial Research \& Development (IRD), Indian Institute of Technology Delhi, India

GOI: Government of India

kabari-wallah 
英国布鲁内尔大学工程与设计学院设计系

英国环境、食品及农业部

英国文化协会

勇・生・贝克

优伊特登博格尔德

有偿教育

“有记”手推车店

预防原则

元设计

约翰・卡拉

约翰・拉斯金

约翰・萨拉卡

约克

“寓玩于学”

在践行过程中的产品服务系统（PSS）创新

扎林

扎农陶瓷厂

扎因

詹金斯

詹姆斯・米尔

战略利基管理

张娴（劳拉）

赵江洪

哲萨奇斯

哲学博士学位

诊所名称

整合性产品政策

郑曙旸

政府工作人员

中国江南大学设计学院

中国清华大学美术学院

中小型企业

中央编译局比较政治与经济研究中心
Brunel University, School

of Engineering and Design,

Department of Design, UK

Defra (Department for Environment,

Food and Rural Affairs)

British Council 2007

Joon Sang Baek

Uitdenbogerd

Feeducation

Yau Kee

precautionary principle

metadesign

John Thackara

John Ruskin

John Thackara

York

Plearn: Play+Learn

PSS innovation process in

effectuation

Zaring

Zanon

Jain

Jeswani

James Mill

SNM: Strategic Niche

Management

Xian (Laura) Zhang

Zhao J.H.

Gertsakis

PhD

Philiza Abafazi Bethu

Integrated Product Policy (IPP)

Zheng Shuyang

safai karamcharis

School of Design, Jiangnan

University, China

Tsinghua University, Academy of

Arts \& Design, China

micro Small and Medium sized

Enterprises (MSMEs)

CCCPE: China Center for

Comparative Politics and

Economics 


\author{
钟芳 \\ 周若刚 \\ 转化知识 \\ 兹纳斯・哈桑 \\ 兹瓦特克里斯-派尔格里姆 \\ 自然能源开发与可持续性研究所 \\ 自我管理与合作服务协会 \\ 自足经济活动小组委员会 \\ 自足经济竞赛的一等奖 \\ 自足经济研究小组 \\ “自豪馆” \\ 组织生态服装(公司名)
}

《2009年印度城市贫困报告》

《保护地球一一可持续生存战略》

《城市固体垃圾（管理和处理）条例》

《创新者的基因》

《古村落保护指南》

《哈佛商业评论》

《经济观察》

《可持续产品服务系统设计》

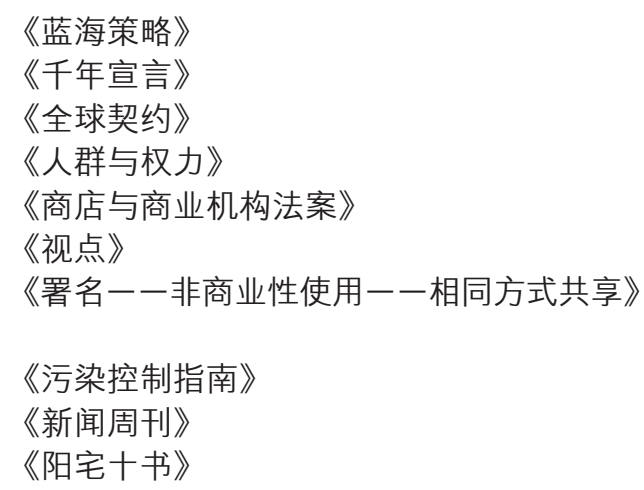

《增长的极限》

《知识共享许可协议》
Fang Zhong

Geoff Mulgan

transformation knowledge

Zeenath Hasan

Zwartkruis-Pelgrim

Institute for Development of Natural

Energy and Sustainability (IDEAAS)

Associazione Auser Como

Sufficiency Economy Movement

Sub-committee

First Prize Winner of the Sufficiency

Economy Contest

Sufficiency Economy Working

Group(SEWG)

Pride House

Ecologico Guardaroba Organizzato (EGO)

"India: Urban Poverty Report 2009"

Caring for the Earth: A Strategy for Sustainable Living Municipal Solid Waste (Managing and Handling) Rules The Innovator's DNA Ancient Village Protection Guidelines Harvard Business Review Economy Watch

Product-Service System Design for Sustainability

Blue Ocean Strategy

Millennium Declaration

Global Compact

Crowds \& Power

the Shop and Establishment Act

Viewpoint

Attribution-NonCommercial-

ShareAlike

Pollution Control Guidelines

Newsweek

Ten Books on Dwellings of the

Living

Limits to Growth

Creative Commons license 